$$
\begin{aligned}
& \text { UNIVERSIDADE DE SÃO PAULO } \\
& \text { INSTITUTO DE GEOCIÊNCIAS }
\end{aligned}
$$

\title{
OS DADOS GEOCRONOLÓGICOS DO ESCUDO SUL-RIO-GRAN- DENSE E SUAS IMPLICAÇÕES DE ORDEM GEOTECTÔNICA
}

ENIO SOLIANI JÚNIOR

Orientador: Prof. Dr. Umberto G. Cordani

TESE DE DOUTORAMENTO

Área de Concentração: Geologia Geral e de Aplicação 


\title{
UNIVERSIDADE DE SÃO PAULO \\ INSTITUTO DE GEOCIENNCIAS
}

\section{OS DADOS GEOCRONOLÓGICOS DO ESCUDO SUL-RIO-GRAN- DENSE E SUAS IMPLICAÇÕES DE ORDEM GEOTECTÔNICA}

\author{
ENIO SOLIANI JÚNIOR
}

Orientador: Prof. Dr. Umberto G. Cordani

TESE DE DOUTORAMENTO

COMISSÃO EXAMINADORA nome

ass.

$\begin{array}{ll}\text { Presidente: } & \frac{\text { Dr. K. Kawashita }}{\text { Examinadores: }} \quad \frac{\text { Dr. M.A.S.Basei }}{\frac{\text { Dr. P.L.P.Sartori }}{\text { Dr. H.Jost }}} \\ & \frac{\text { Dr.M.Bonhomme }}{}\end{array}$

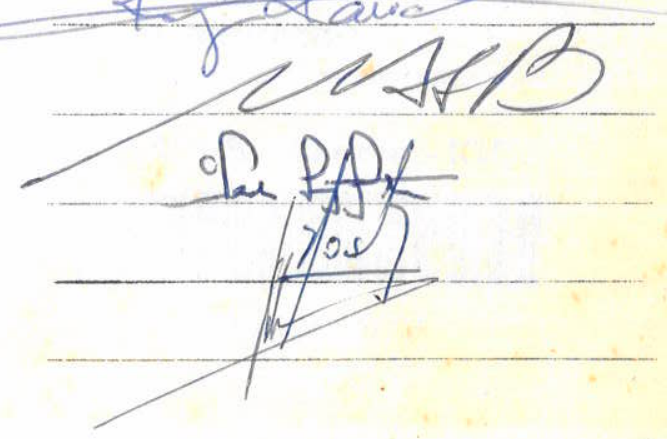

Săo Paulo 


\section{UNIVERSIDADE DE SÃO PAULO \\ INSTITUTO DE GEOCIÊNCIAS}

\section{OS DADOS GEOCRONOLÓGICOS DO ESCUDO SUL-RIO-GRAN- DENSE E SUAS IMPLICAÇÕES DE ORDEM GEOTECTÔNICA}

ENIO SOLIANI JÚNIOR

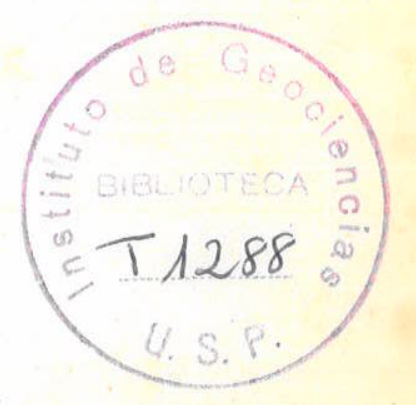

Orientador: Prof. Dr. Umberto G. Cordani

TESE DE DOUTORAMENTO

Área de Concentração: Geologia Geral e de Aplicação

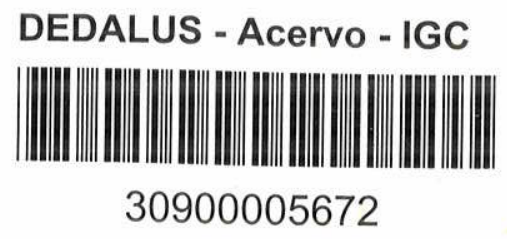

São Paulo 
"A gente pensa uma coisa, acaba escrevendo outra \& o leitor entende uma terceiracoisan n e E, enquanto se passat budo isso, a coisa propriamente dita comeca a desconfiar que näo foi propriamente ditan a"

Mário Quintana. 


\section{INDICE}

\section{ABSTRACT}

\section{SINOPSE}

\section{RESUMO}

\section{CAPITULO I}

\section{INTRODUGX̃O}

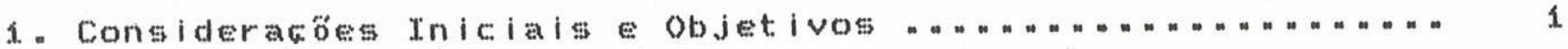

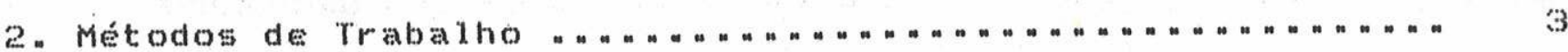

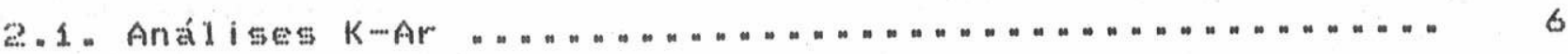

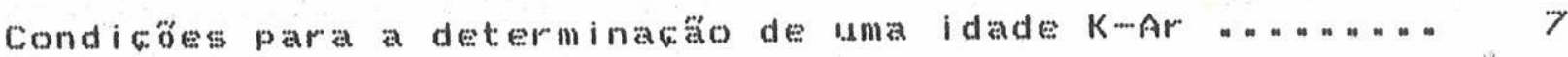

Significado beológico de uma ldade K-

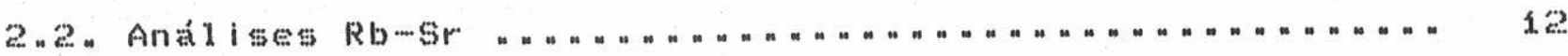

A obtentáa de idades Rb-..Sr em RTa idade convencional ... 13

A obtencăo de idades Rb-..Gr em Rra idades isocrônicas ". " 14

A interpretacta de idades Rb-Sr em RT . . . . . . . . . . . . . . . 17

A avaliacáo da qualidade dos diagramas isocrônicos " " " "

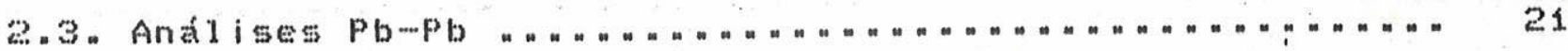

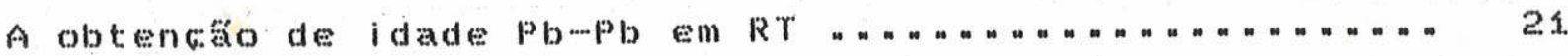

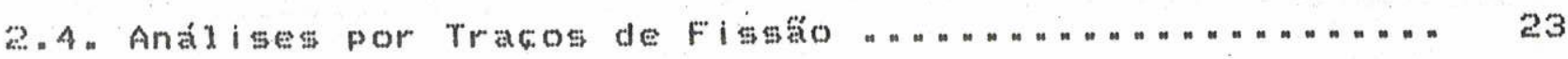

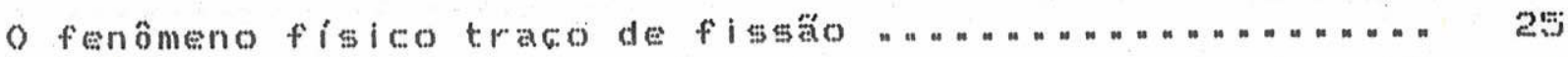

A obtencăo de uma idade por TF e seu significado . " . "... 26

\section{CAPÍTULO II}

\section{SINTESE DOS TRABALHOS GEOLÓGICOS E GEOCRONOLÓGICOS ANTERIORES}

1. Evolucako do Pensamento Geológico-ugotectônico Regional ". " 2y

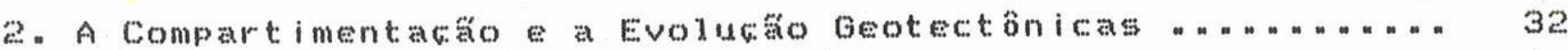

3. Enquadramento Geológico Regional do Escudo Sul-riomgran-... dense 36

3.1. O Cintura Dom Feliciano o Cráton do Rio de La Plata 36 
3.2. As Associacóes Petrotectônicas do Cinturán Dom Feli-ciano

3.3. A Compartimentacáo rectônica do Corton do Rio de La Plata

4. Consideracós sobre a Geocronologia Regional

\section{CAPÍTULO III}

\section{GEOCRONOLOGIA DA PORGÃO LESTE DO ESCUDO SUL-RIO- GRANDENSE}

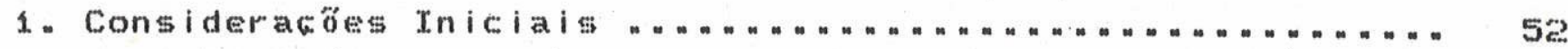

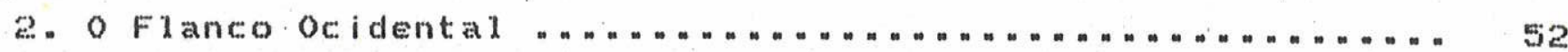

2.1. O Embasamento do Cinturăo Dom Feliciano ................ 5 .

Sintege Geológica . . . . . . . . . . . . . . . . . . . . . . . . . . . . 52

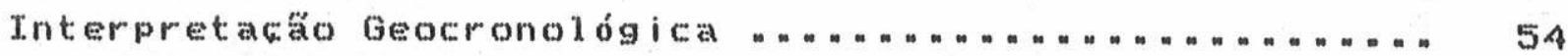

2..2. As Supracrustais Dobradas Eetamorfizadas . " . . . . . . . . 59

Sintese Geológica ... . . . . . . . . . . . . . . . . . . . . . . . . 59

Thterpretacto Geocronológita . . . . . . " . " . " . . . . . . . . . " . 60

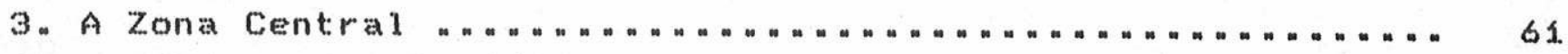

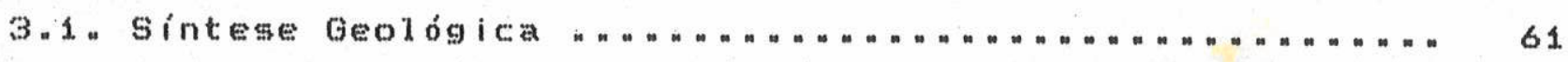

3.2. Tnterpretaca beocronológica . . . . . . . . . . " . . . . . . . . 66

Bloco Dom Feliciano . . . . . . . . . . . . . . . . . . . . . . . . . . 69

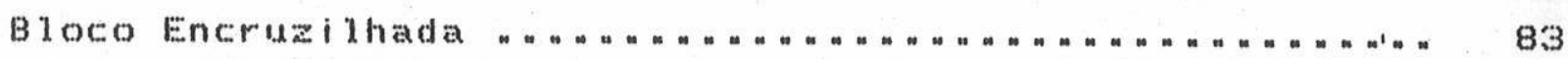

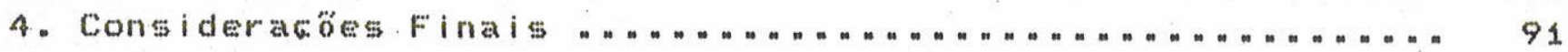

\section{CAPÍTULO IV}

\section{GEOCRONOLOGIA DO EMBASAMENTO DA PORCÃO OESTE DO ESCUDO SUL-RIO-} GRANDENSE

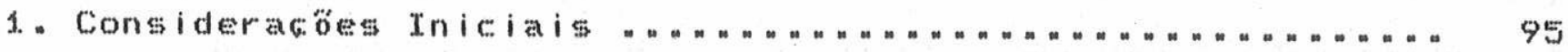

2. Bloco säo Gabriel: terrenos do tipo "granite-areenstone"

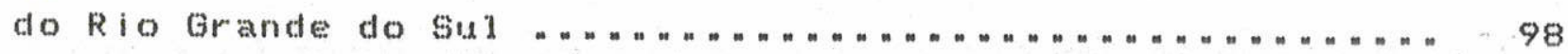

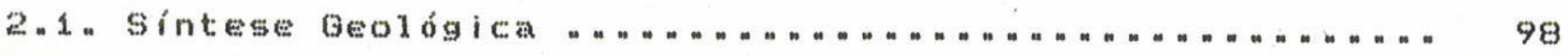


2. 2. Interpretacăo Geocronológica das Seqijencias Máfica-. ultramáficas e Vulcanomsedimentares . . " . " . " n. " . . . . . 103

2.3. Interpretacáco Gecoronológica dos Orto e Paragnais\$ese suites intrusivas associadas à unidade Cambaí ........ 1.08

3. Bloco raquarembó terrenos granuliticos do Río Grande do

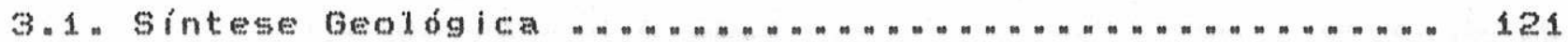

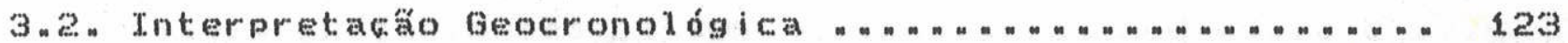

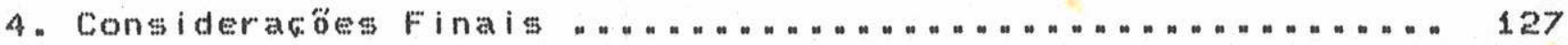

\section{CAPITULO $V$}

AS SUITES GRANITICAS INTRUSIVAS NA PORCAOO OESTE DO ESCUDO SULR IO-GRANDENSE

1. Consideracóes Iniciais " . " . . . n " n n " " . . . . . . . . . . . . . 130

2. O Compexo Granitico de Săo Sepé . . . . . . . . . . . . . . . . ... 132

3. Osi Granitos Ramada e Cerro da Cria . . . . . . . . . . . . . . . . . 135

4. O Batólico Granitico de Cagapava do sud . . . . . . . . . . ...... 137

5. O Complexo Granitico de Lavras do Sul " . . . . . . . . . . . . . . . . . 141.

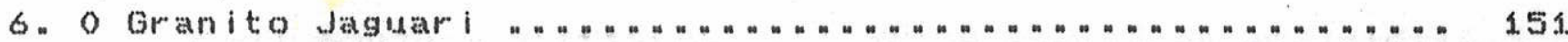

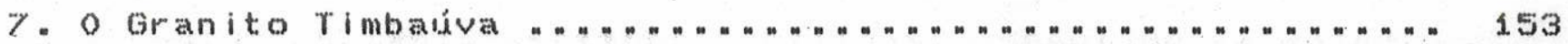

8. O Complexo Granitico Santo Afonso n " n " . " n " n " . " n " n " . " . " 154

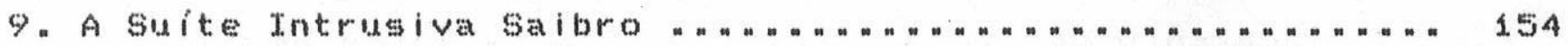

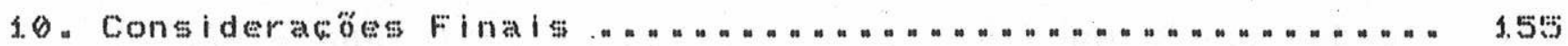

\section{CAPITULO VI}

OS DEPósITOS MOLASSICOS E VULCANITOS ASSOCIADOS DO ESCUDO SULRIO-GRANDENSE

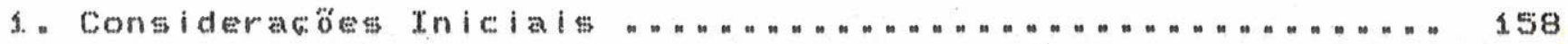

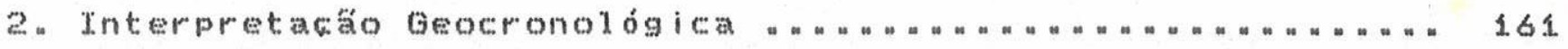

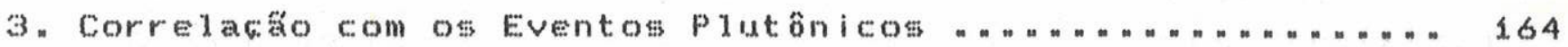




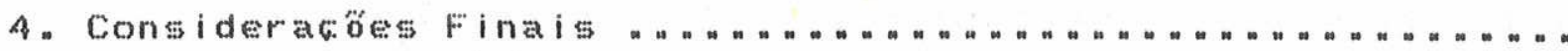

\section{CAPÍTULO VII}

\section{COMPARTIMENTACAO E MODELO DE EVOLUCXO GEOTECTÖNICA PARA O}

\section{ESCUDO SUL-RTO-GRANDENSE NO CONTEXTO GEOLÓGICO REGIONAL}

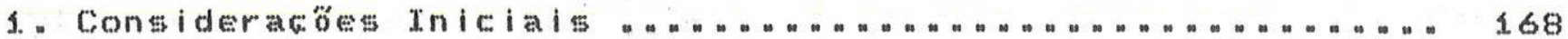

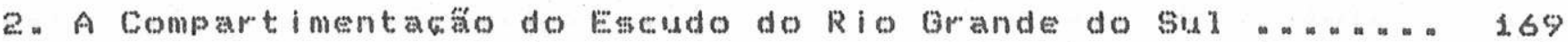

2.1. O Bloco Dom Feliciano: exposicáo principal de batóli--

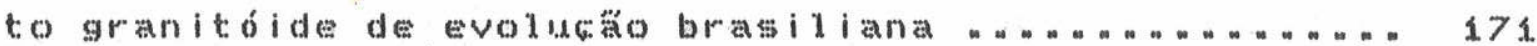

Granitóldes deformados da fase precoce. " . " . " n " " " " " " . " . 173

Granodioritos monogranito da fase principal ........ 17 A

Granitos e sienogranitos tardios . . . " . . . . . . . . . . . . 175

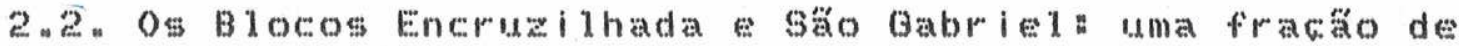

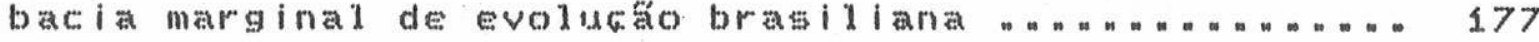

2. 3. O Bloco raquarembó uma fraco de Macico Marginal no

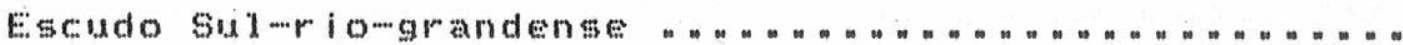

2.4. Ilhas Cristalinas de Rivera e Aceguá o prolongamento meridional do Maciso Marginal

2.5. Sistema de Falhas Dorsad de Cangugua estrutura limite entre as entidades batód ito -.. bacta marginal do cin-

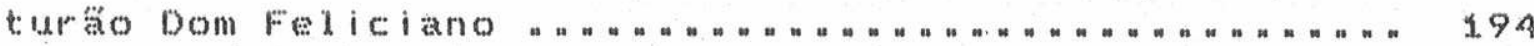

2.6. O Lineamento de Ibaré astrutura limite entre as enti... dades Bacia Marginal do Cintura Dom Feliciano e Maci...

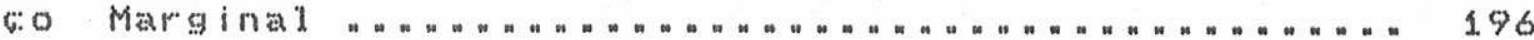

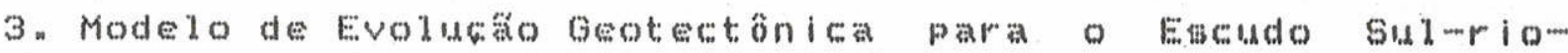
grandense

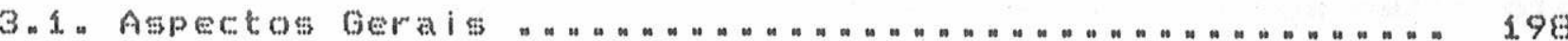

3.2. O Estabelecimento do Quadro Cronoestratigrafico .... " " 199

4. Possiveis correlacós de Entidades Geotectónicas na Porca Meridional do Escudo At lântico e ajustes com a Provincia 
5. Recomendacoos Finais.

\section{AGRADECIMENTOS}

\section{FIGURAS}

TABELAS 


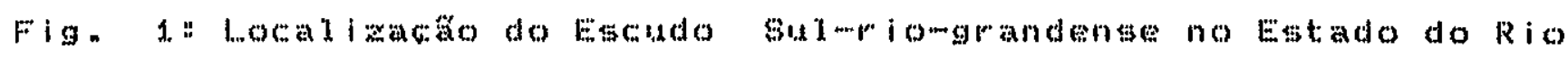
Brande do sul eprineipais vias de acesso.

Fig. 2. Esboco geologico getectonico do extremo meridionaldo Eistudo At: 1 ânt $i$ coo.

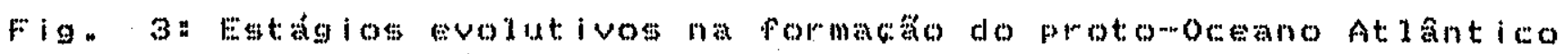
Sut, no premcambriano supertor.

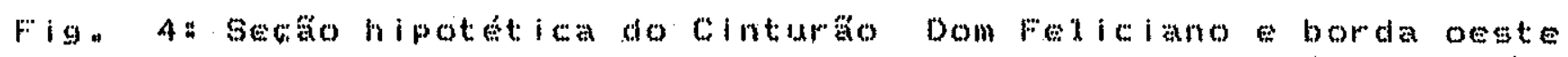

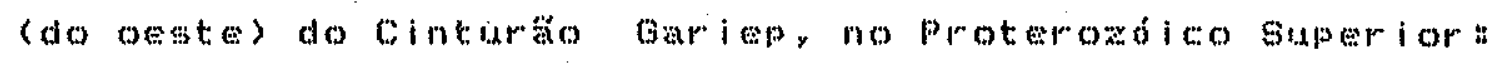
compartimentacto pal a ton ictas.

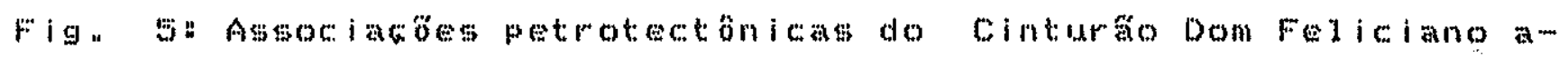

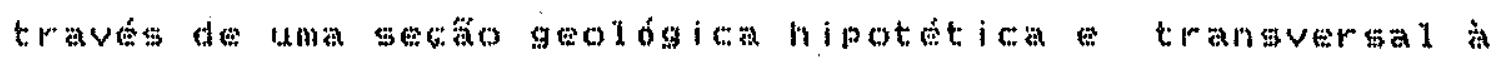
wnidacle geotectonican

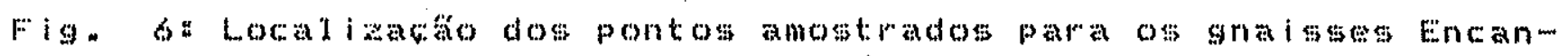

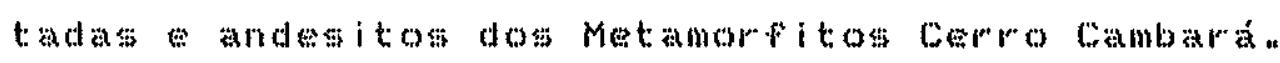

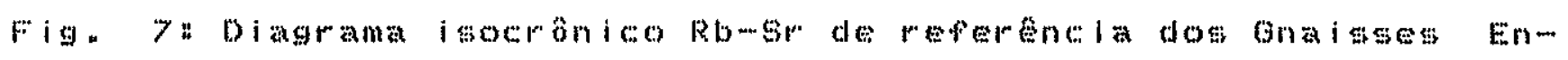
cinatiadian .

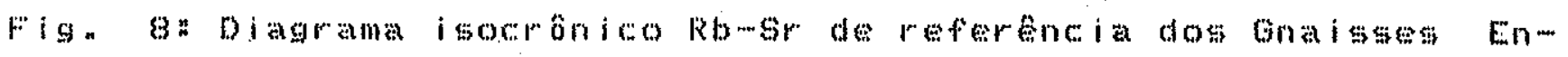

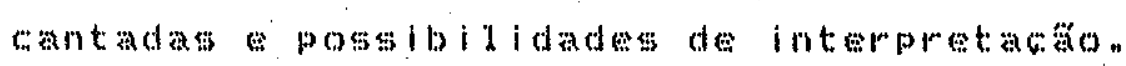

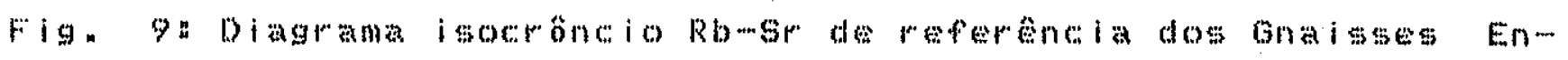
cantadas com os novos pontos analiticose possibilidades de interperetation.

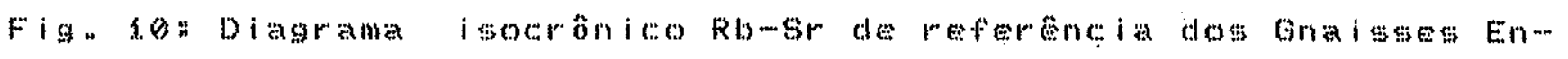

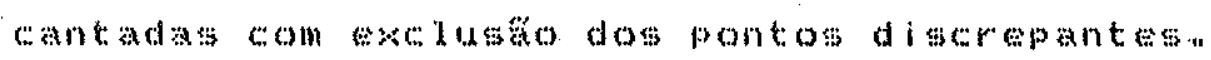

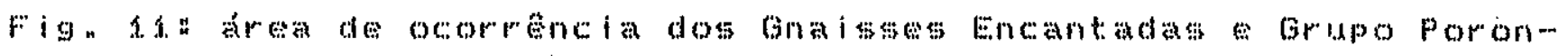
gosin no Rio Grande do but, localizata do ponto de co-

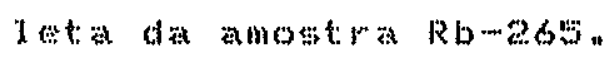




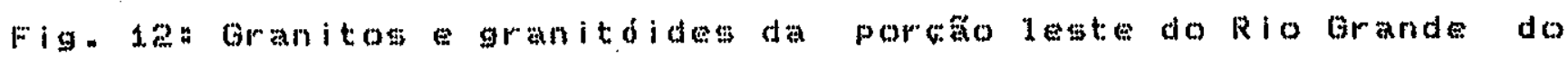
sul.

Fig. 13: Diagrama isocronico Rb-osr de reforencia de rochas grani-

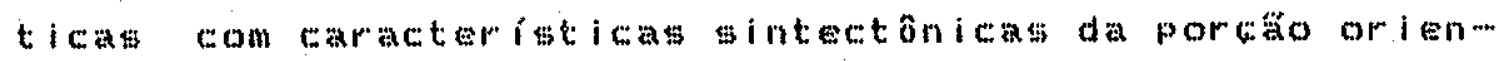

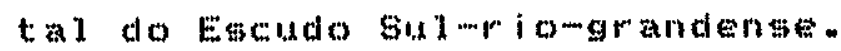

Fig. 14a Diagrama isocronico Rb-Sr de referencia de rochas grani-

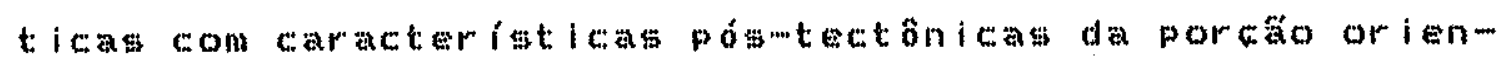
tal do Egcddo sul wriomgrandense.

Fig. 15: Diagrama isocrónteo Rb-gr de referencia de granitóldes diversos do complexo Canguta complewo oranitóde de Lesm t:

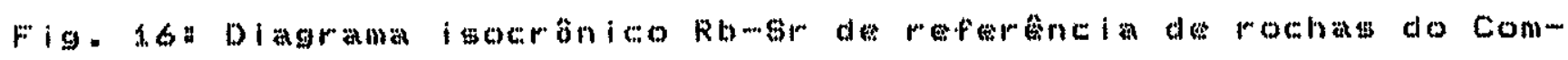
plexo Granitóide Encruzilhada do Sud.

Fig. 17: Diagrama isocronico Rb-sr de referencia de rochas da Suite Thtrusiva Arrorio dos Ladröes (Sufte Dom Feliciano).

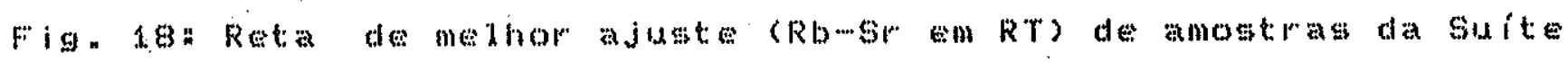
Intrusiva campinas.

Fig. 19: Mapa de localizagáo dos pontos amostrados com datąáo radiometrical nos domínios do complexo coranitóde de Leste Suite Tntrusiva D. Feliciano (Bdoco Dom Feliciano).

Fign abn Diagrama isocronico Rbome do referencia dos granito ides

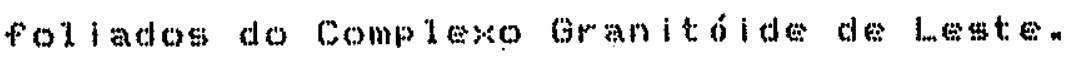

Fig. 21. Ts

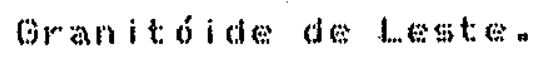

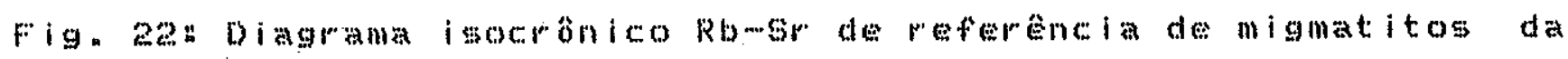
porcta stat do complexo oranitiolde de tastan

Fig. 23\% Diagrama isocrontoo Rbus de reforencia de granitódes foliados (migmatitosy gnatsses tondito) do complexo

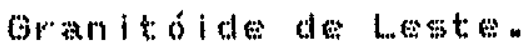

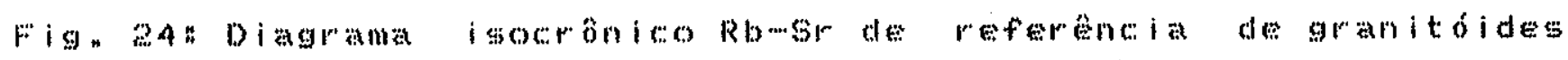


foliados coranodioritos, granitos acinowentadose, em me-

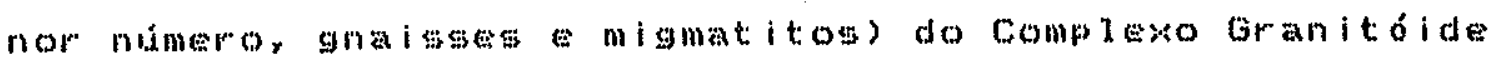
de l.test: o

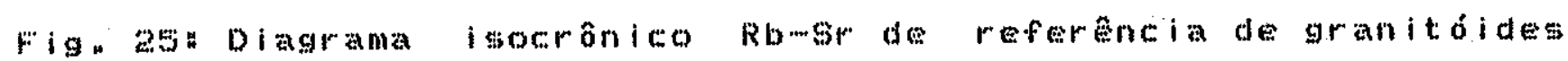

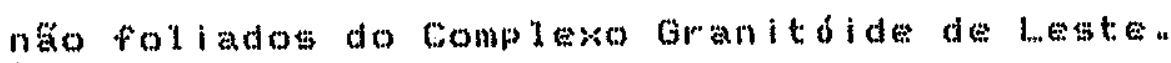

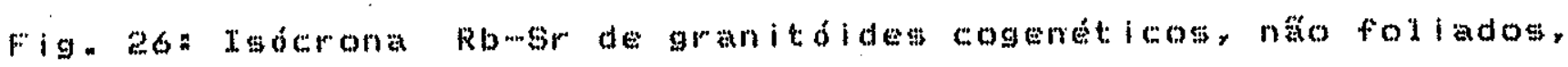

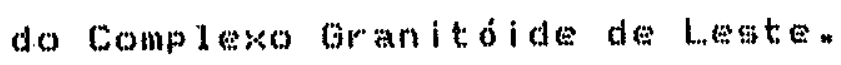

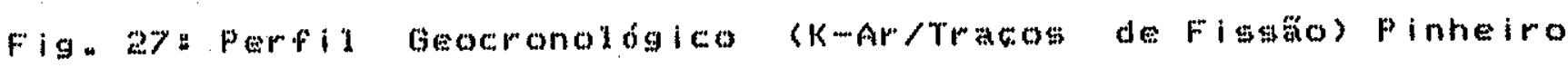
Machado-Pelotasn

Fig. 28: Diagrama isocronico Rb-sh de roferencla de rochas graniticas da sutte Dom Feliciano.

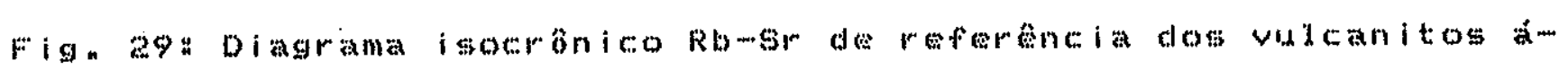
cidos da regiáo de Pinhelro Machado.

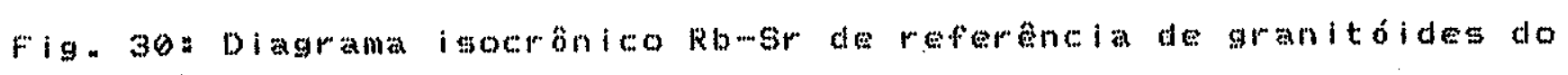
Bloco Enckenithadan

Fign 31: Mapa de localizaco dos pontos amostrados con datacăo radiometrica, nos domínios do Bloco Enerdathada.

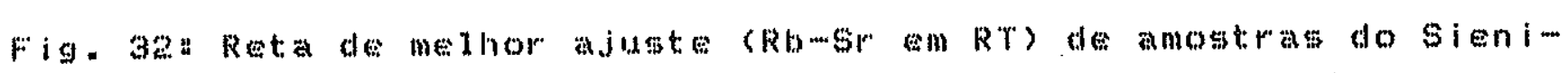
to Pialdi.

Fig. 33: Diagrama isocrontco Rb-gr do refermela de anfibolitos do

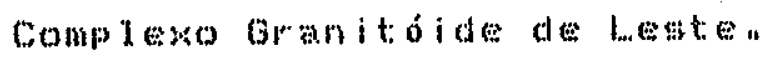

Fig. 34a Areas de ocorrencia dos terpenos "granitemgreentone"

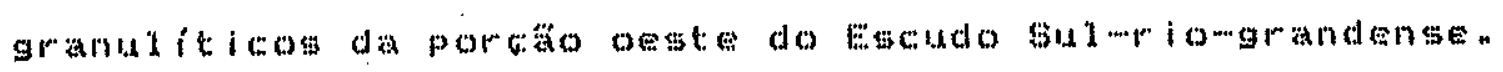

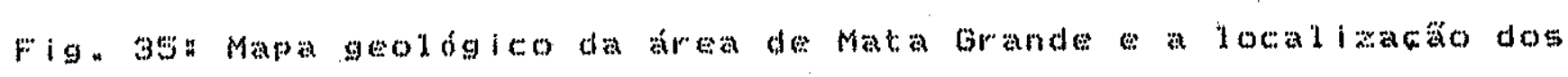
poritos amostrados.

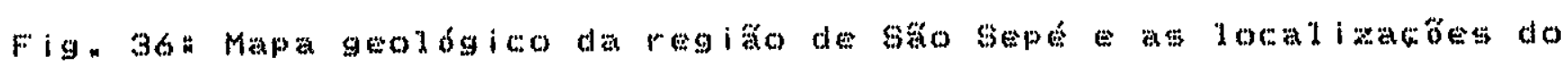

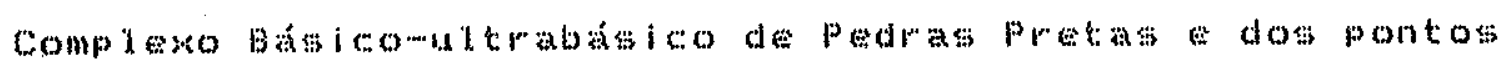
amostratom a

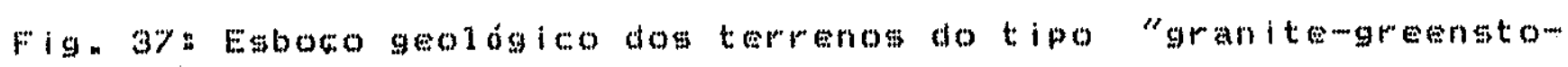

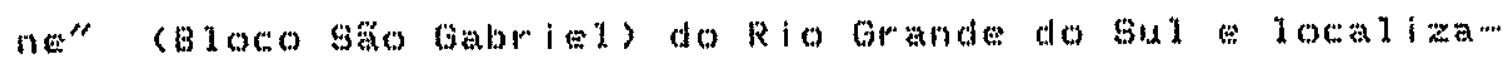


6.

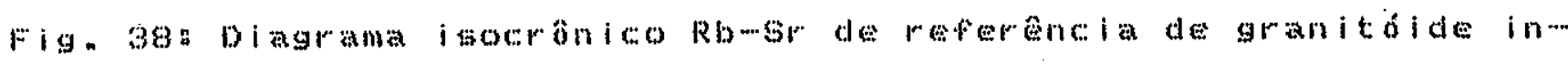
diferenciado associado à unidade Cambai na regićo central do Bloco saio babriel.

Fig. 39: Localizacto das sondagens que atingiram o embasamento da

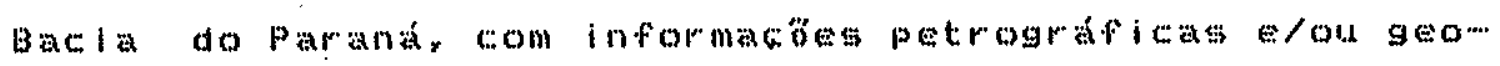
cronológicas.

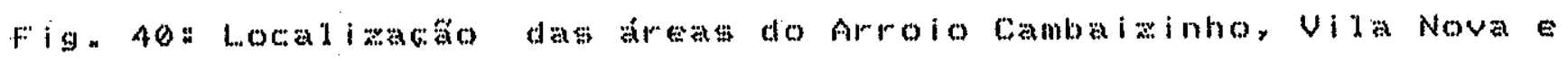

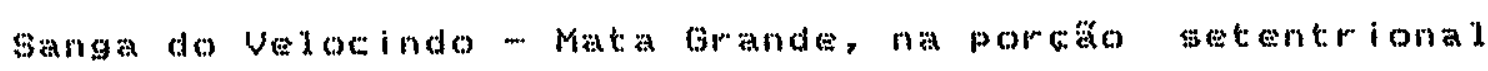

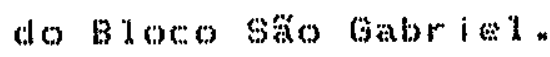

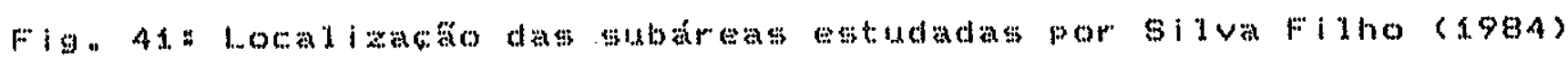
na regita de Vila Nova.

Fig 42. Diagramas igocronico Rb-sir de referencia de granitódeg diversos da área de Vila Nova.

Fign 43: Diagrama isocronico Rb-gr de referencia de granitódes da área da Ganga do Velocindo Mata Gorande.

Fig. A4a Diagrama isocronico kb-cer de referencia de granitóde da áréa do mroto cambationtron

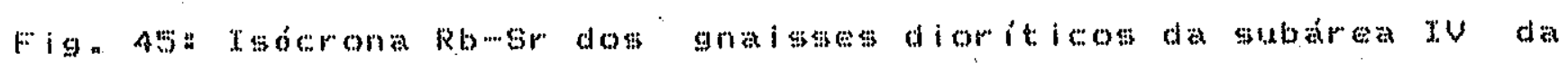
rogia de Vila Nova i

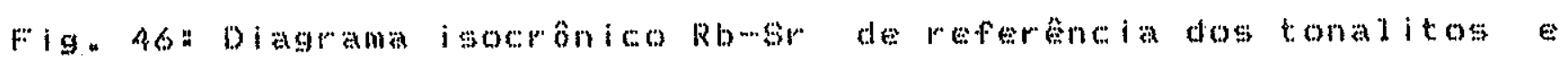
trondhjemitos da subarta IV da regiande Vila Nova.

Fig. A7n Diagrama iacononico Rb-ur do referencia dos granodioritos

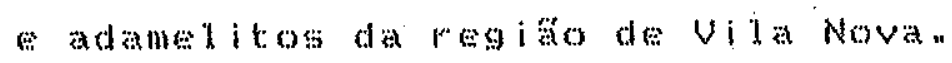

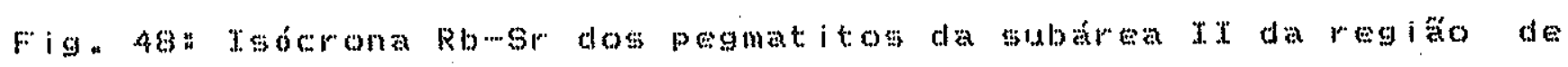
Vila Novan.

Fign 49" rendencias aterescente das idades e crescente das razos

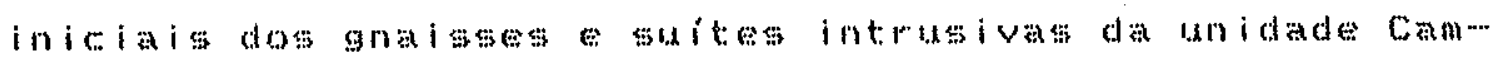
baí Ma regia de Vida Nova.

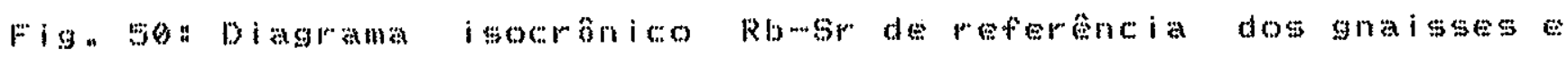


\$diteg intrugivas associadas a unidade Camba de Vila Nova.

Fig. 51. Tentativas de interpretata geoconologica dos granitó

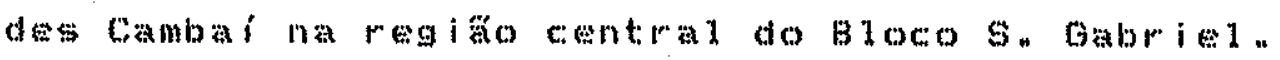

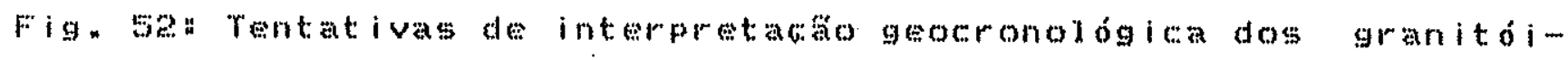
des Cambá na resiano meridional do Bloco s. Gabriel.

Fig. 53: Diagrama isocronico Rb-sr de referencia dos granitódes

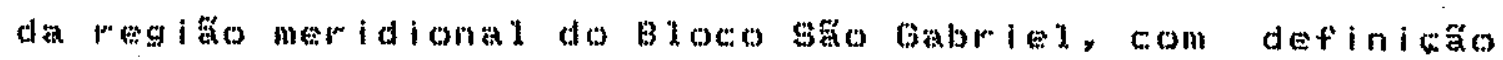
de valor temporal sem significado geológico conhecido.

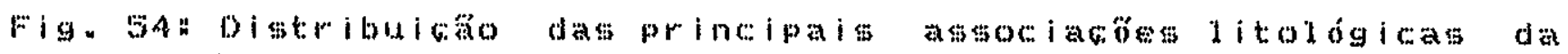

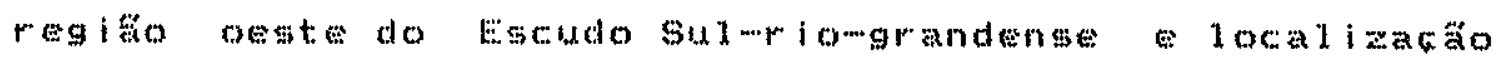

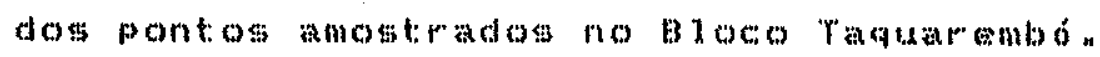

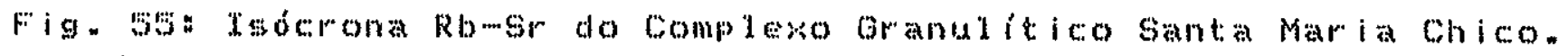
Fig.

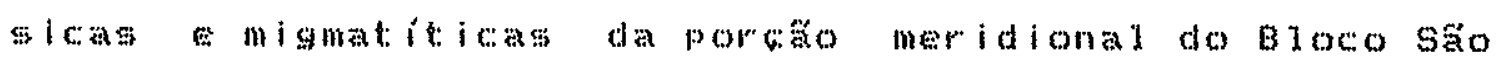
Gabriet do bloco rasuarembon.

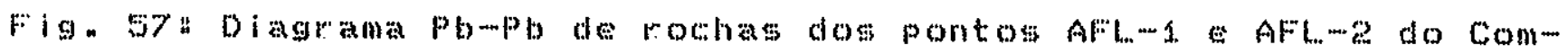
plexo toranditico Santa Maria chicon

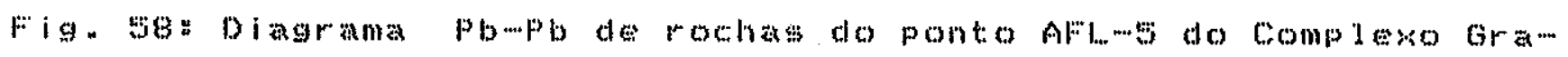
nultico santa Maria chico.

Fig. nulitico santa Maria chico.

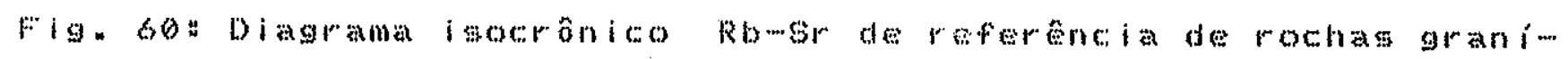

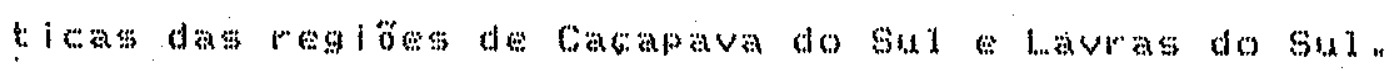

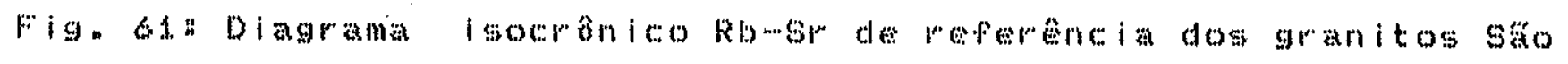
Seper Ramada riolitom Acampamento Velhon

Fign 6en Diagrama isocronito Rb-gr de referencia de amostras de rochas granitomonzoniticas da parte conteral do complexo

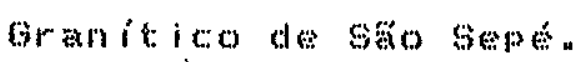

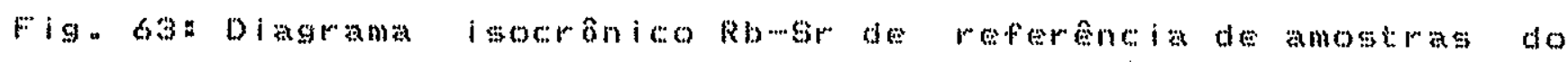




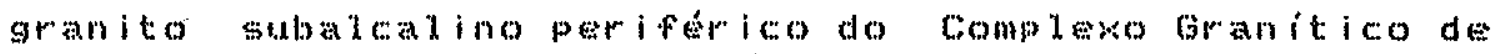
sa sepon

Fign 64y Oiagrama isocronico Rb-

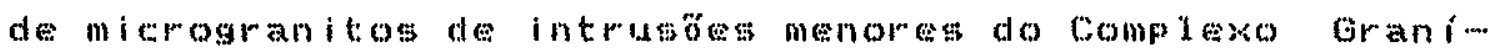

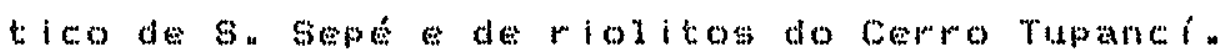

Fig.

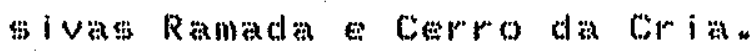

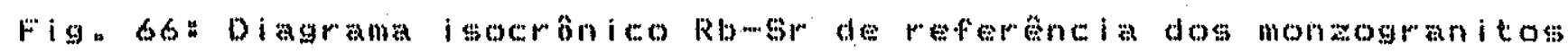

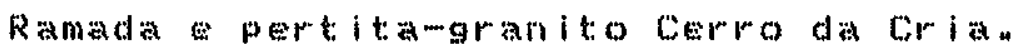

Fign o7. Mapra gológlo da regi dospontos amostratos

Fi

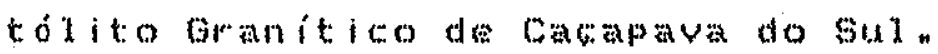

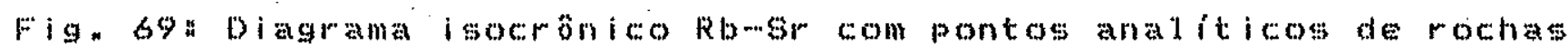

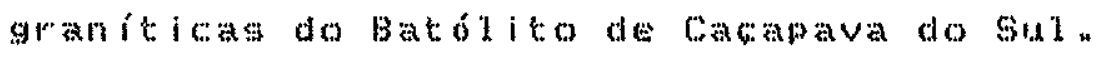

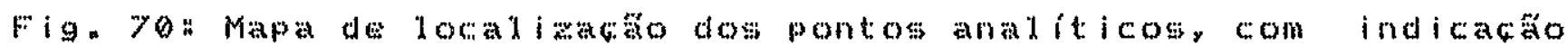

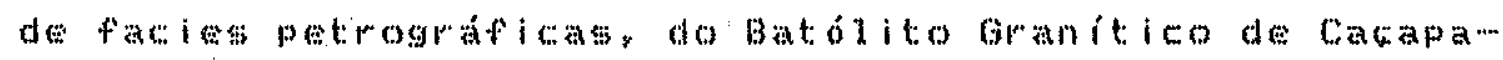
V do side

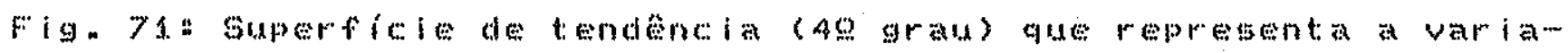

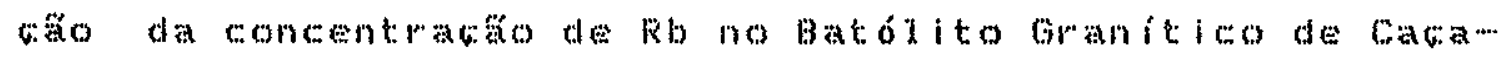
pava do sul.

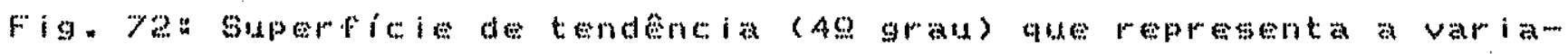
6. pavat do side

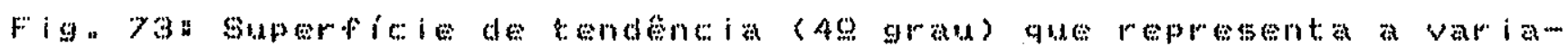

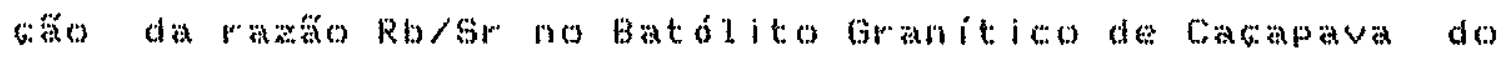
Sil.

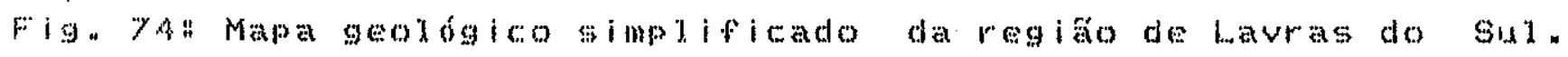
Fig. nitico de taveras do sul. 


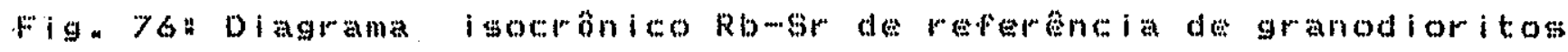
- mongogranitos da porba contral do complewo Granitico de Laveration

Fig. 77: Diagrama isocrónico Rbows de referencia de sienogranitos da faika traneicional do complexo Granitico de Lavras do $\sin 1$ *

Fig. 78: Diagrama isocronito Rb-ugr de referencla de pertita-grani-

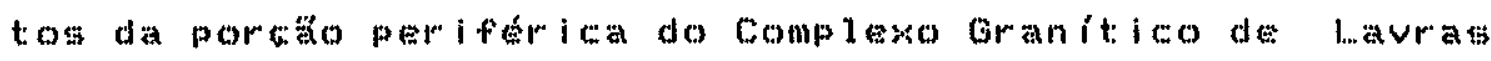
do $\sin x$.

Fig. 79: Diagrama isocrónico Rbusr do referencia para os pertita granteos da porcăo periferica do comelexo Granitico de Lavras do sul e charnogultom associados.

Fig. 80. Mapa geolóico simplificado da area dos granitog daguari e. Timbava com local iacaco dos pontos amostrados.

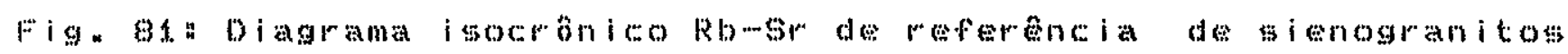
do Bat: ól it:o was dar i .

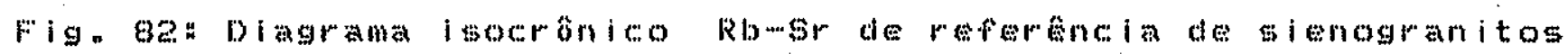

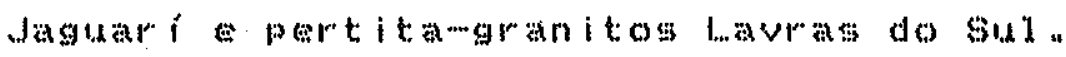

Fig. 83* Diagrama isocronico Rb-se de referencia de tonalitose granodioritos rimbativa.

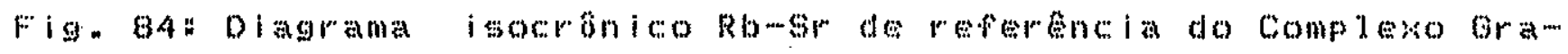
nitico santo Afongo.

Fig 85a Diagrama isocronico Rbms de referencia de riolitos da Formacia meampamento Vethon

Fig. 86. Mapa goolóico simplificado de parte dos sedimentitose

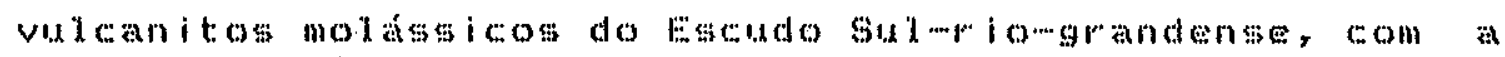
Iocal iacaso dos pontos amostrados.

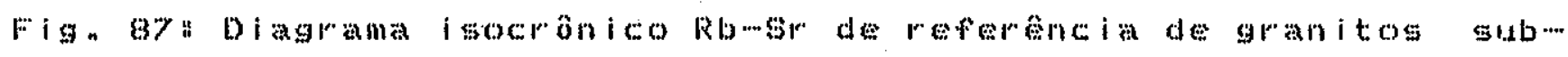
acalinos de bordo do complexo granitico de sáo sepe

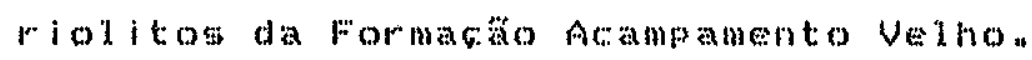


Fig. Bga Diagrama isocrónico Rb-gr de referencia de pertitamgranitos do complexo Granitico de lavras do sud e riolitos da Formacta Acampamento Va 1 ho.

Fig. 89: Diagrama imocronico Rb-sir de referencia de monzogranitos do Complamo Granitico Ramada, riolitos do Caro rupanci e microgranitos intrusivos do complexo branitico de sáo se... pén.

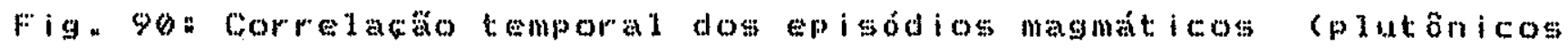

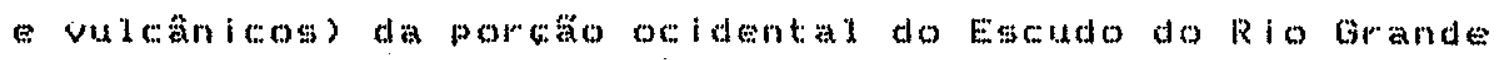
do $\sin 1$.

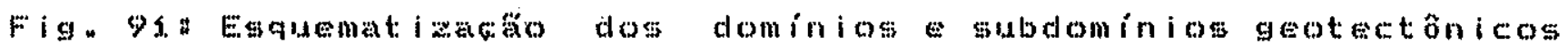
do Es:ato do Rio brande do sul.

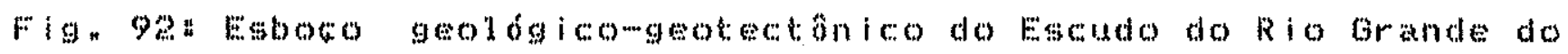
S.1.

Fign 93* Esbogo geológico do Batólito Pelotas, Bloco Fncruatiada e area de ocorrencia do brupo porongos.

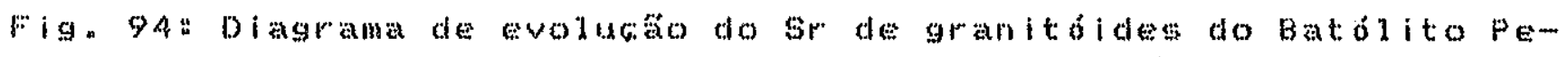
lotas.

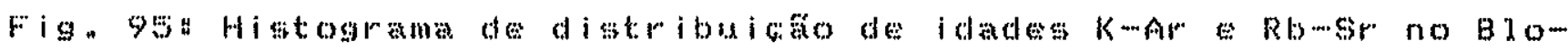
co säo Gabiel.

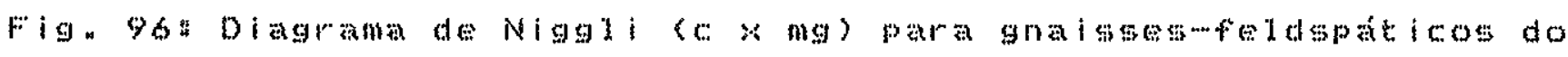
Compleso Vila Nova.

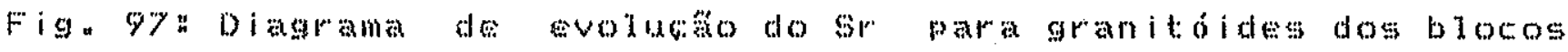
Säc Gabriel Encerarithadan

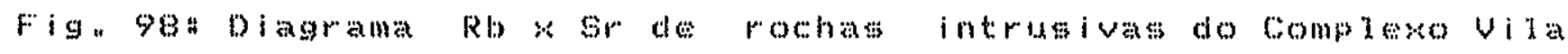
Novan.

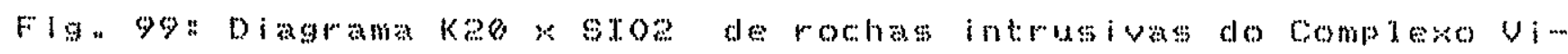
ta Nova.

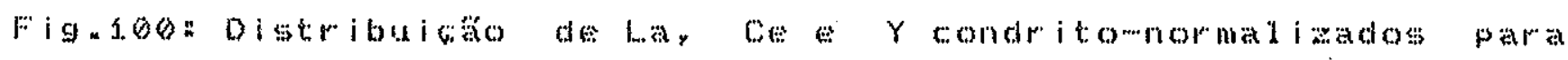
dioritos, fonalitos trondhomitos do Complexo Vila Now 
van

Fign fol. Di plexo Vita Nova.

Fig.102: Diagrama ternario normativo Qmabmor para rochas intrusiVastio domplexo Vila Nova.

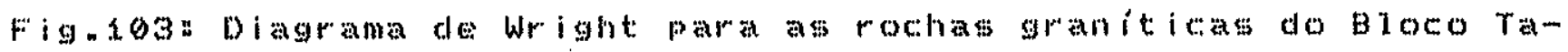
quaratón.

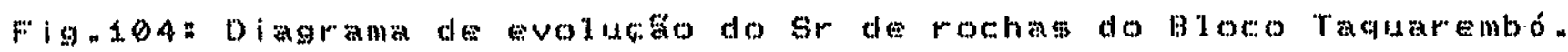

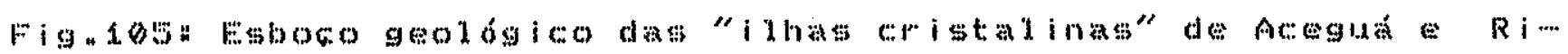

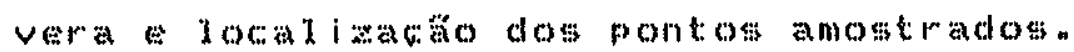

Fign

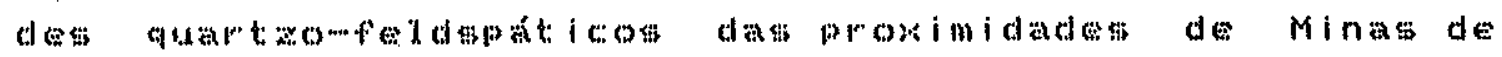

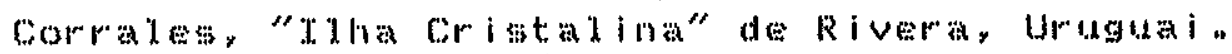

Fignforg Di porfiriticos das proximidades de vichadero co cabeceiras do Arroio Amaril to, "Tha Cotstalina" da Riveray Uruguai.

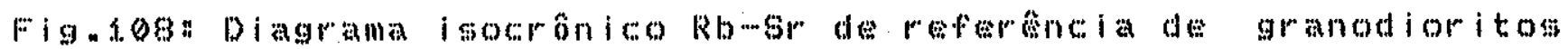

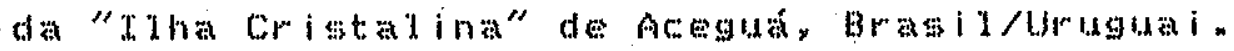

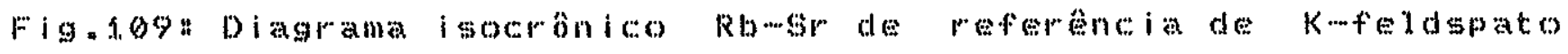

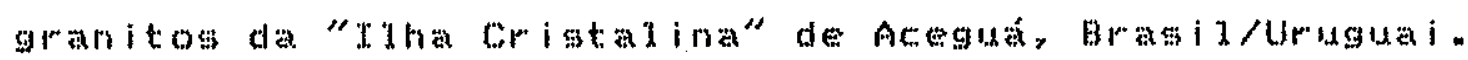

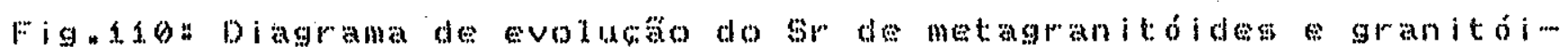

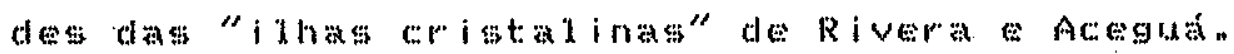

Fign A.t.

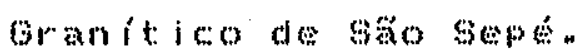

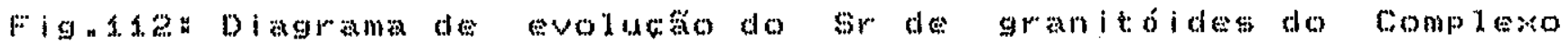

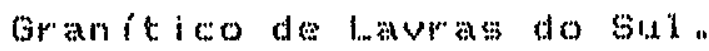

Fign f.

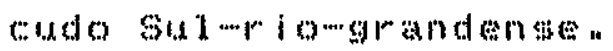

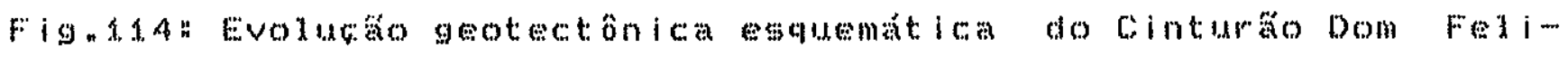
ciano no Es bado do kio grands do sul. 
Fignd

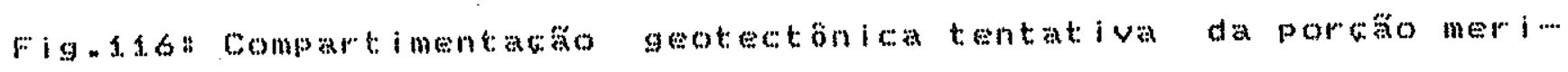
dional do Escudo At: 1 ânt ic:on

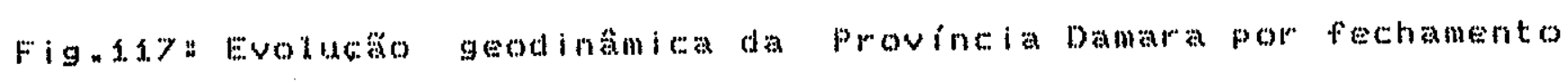
do Oceano Adamastor

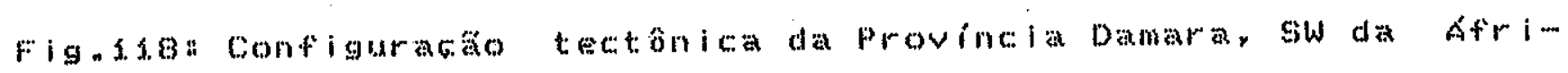
can 


\section{INNDTCE DE TABELAS}

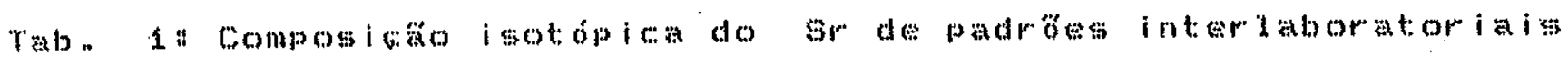

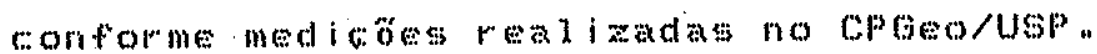

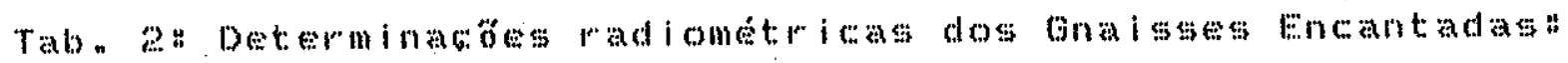

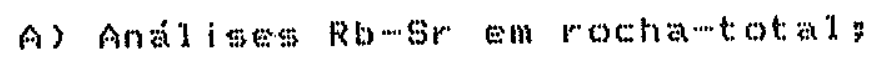

B) Anali

rabn 3\# Determinacoses ratiometricas do Grupo porongos"

A) An 1 i

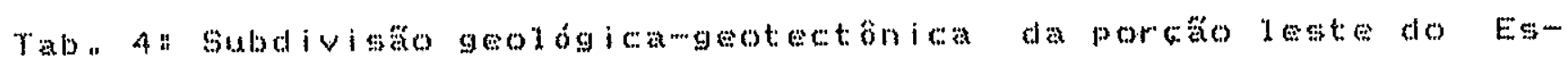

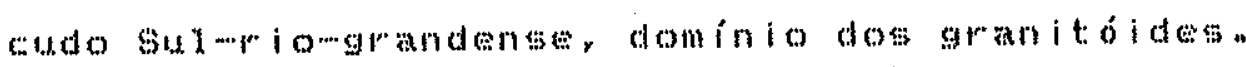

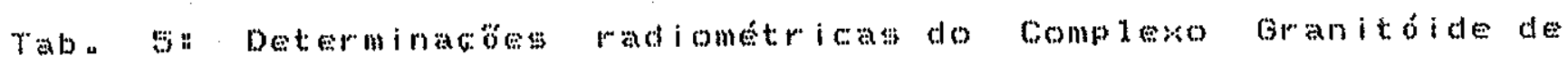
1...

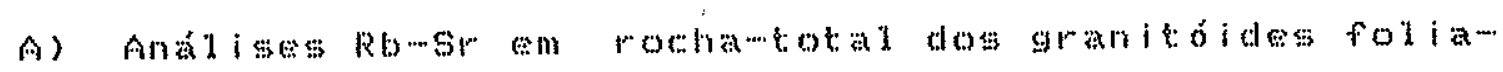
dos:

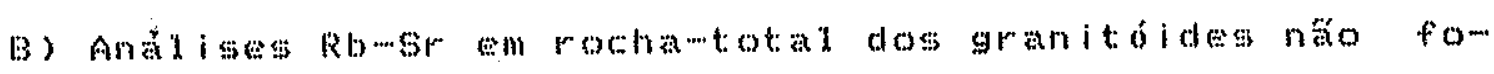

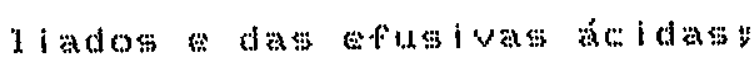

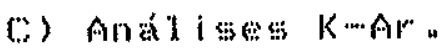

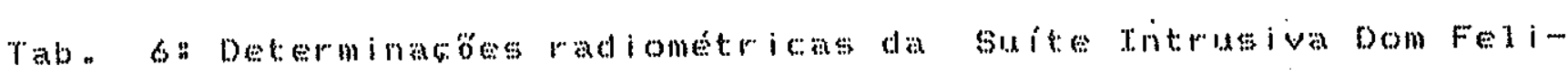
ci inot

A) And t

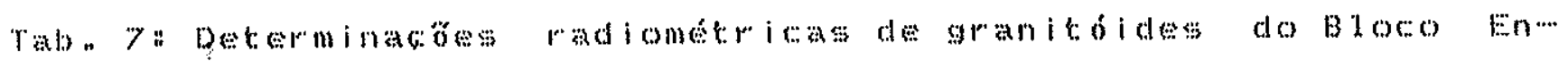

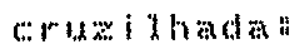

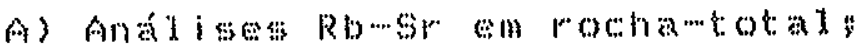

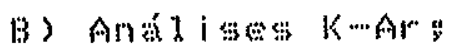
(a) Anal is

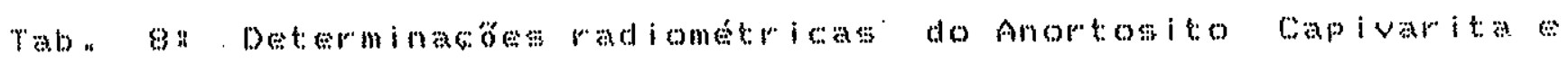

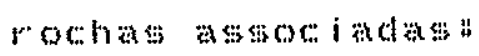

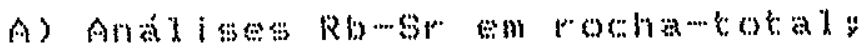

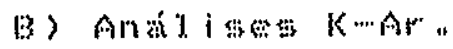


rab. 9\# Determinacoses radiometricas do sienitopiatiri e Granito Cramp inas a

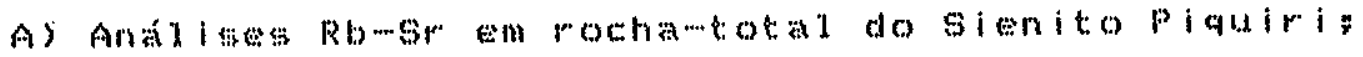
B) Anadiso Kant do Sienito Piquiri"

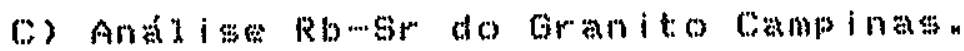

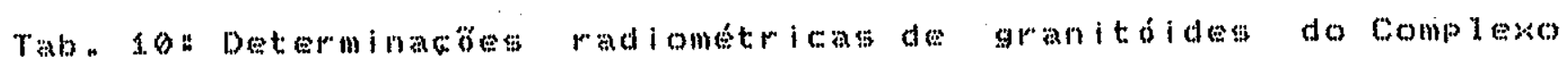

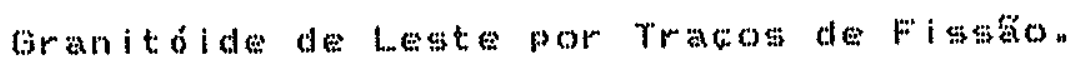

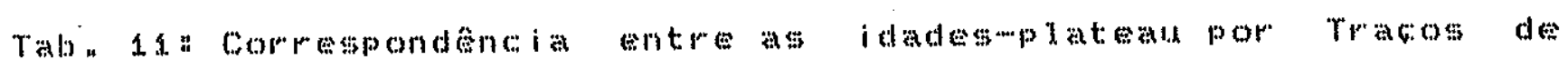

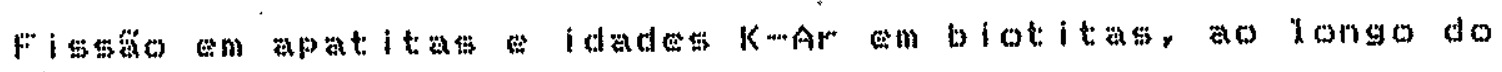

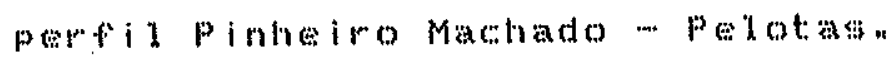

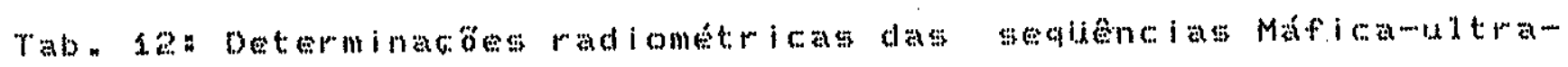

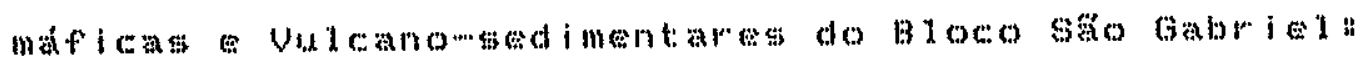

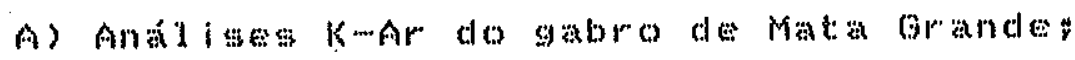

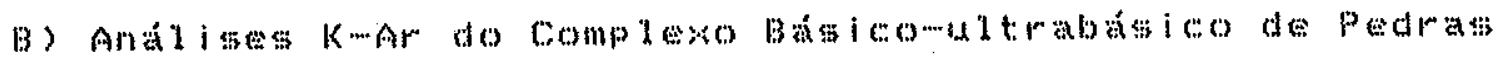 Pretasy

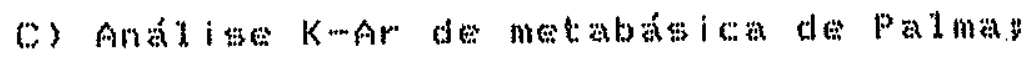

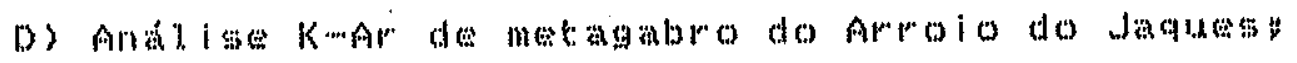
E) Aradise Kar de serpentinito do cerro Mantialdeiras

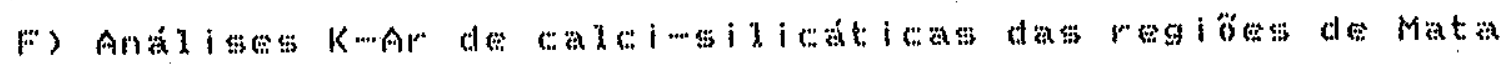 Orande palmay

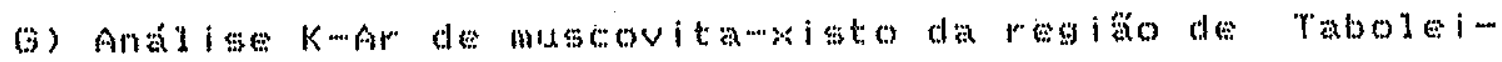 $\operatorname{rog}$

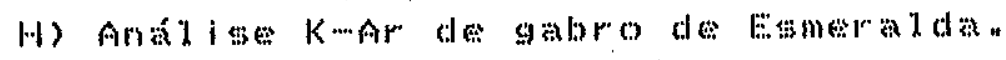

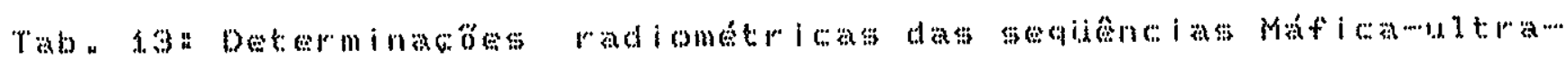

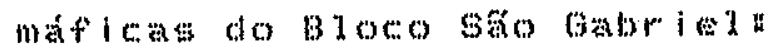

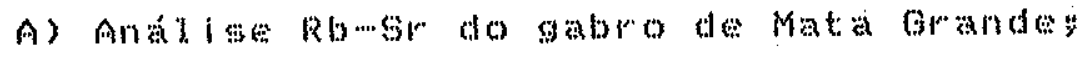

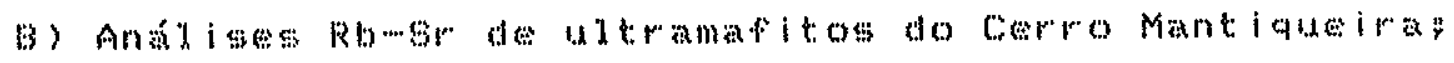

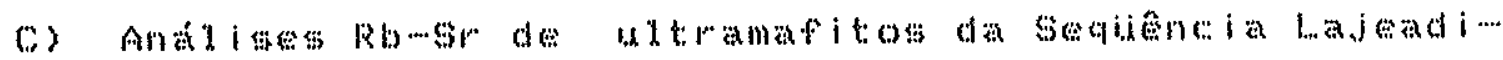 nhor compl exo Bossorocan.

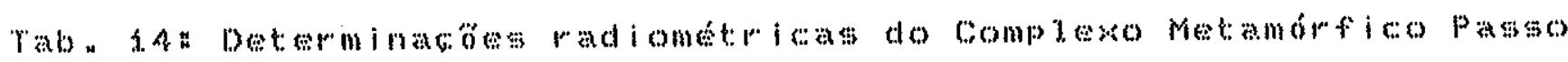




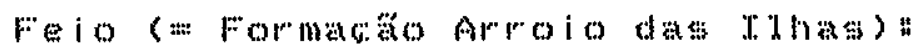
A) Análi is

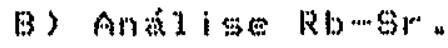

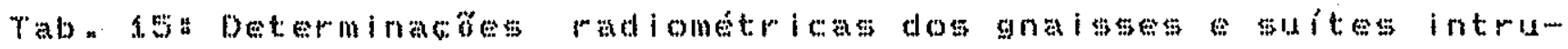
留 i Vas

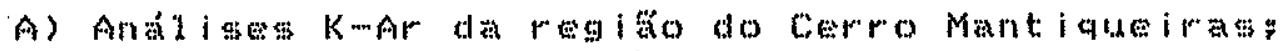

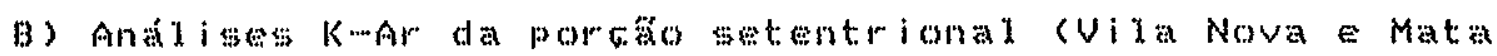 Grands?

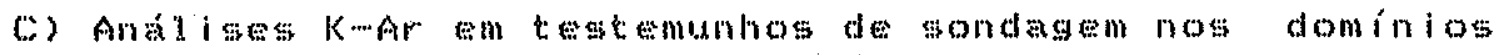

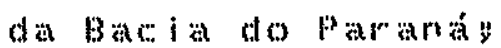
D) Outräs añ

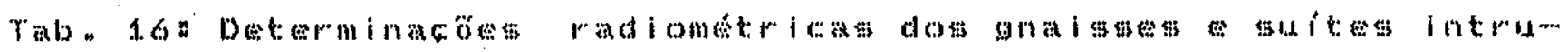

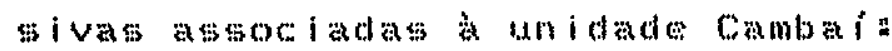

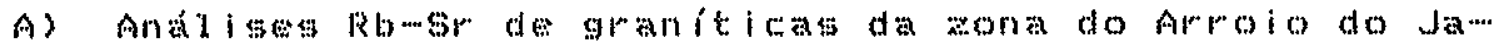

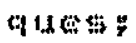

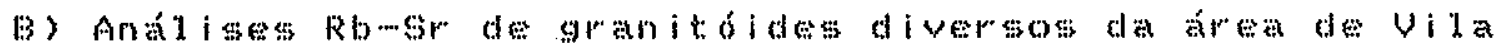
Noväy

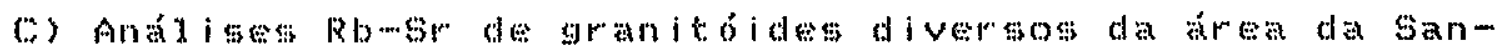
ga do Velowindo a Mat:a tomatey

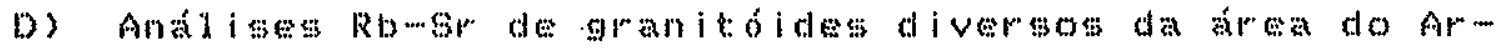

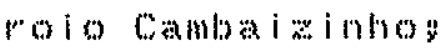

F..) An

F) Anati Novä

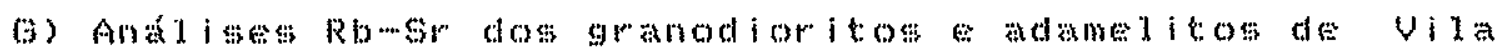
Nova;

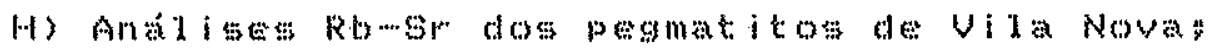

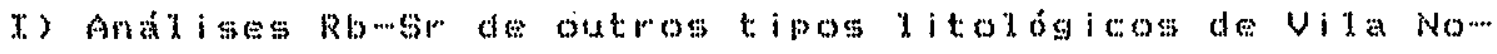
Văn

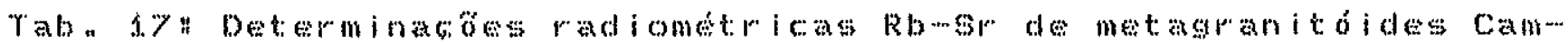




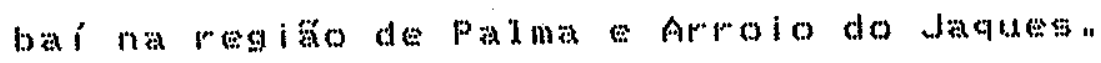

Tab. ABa Determinatöes Radiometricas Rb-sr dos metagranitódes

Cambai na regiano do corro Mantiqueirasa

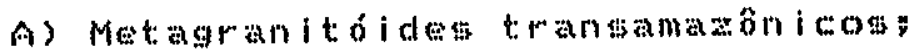

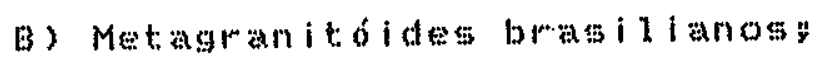

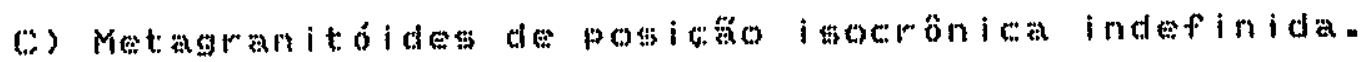

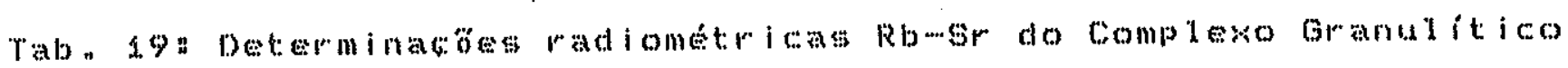
Santa Maria chico:

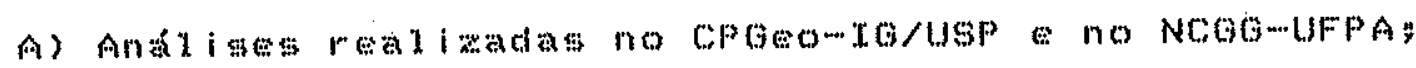

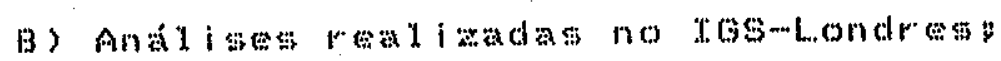

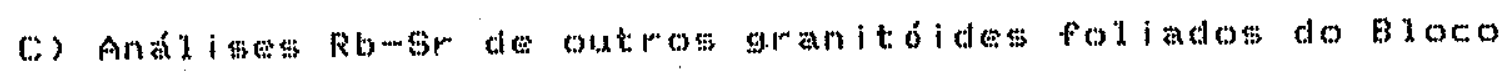
raquatembón.

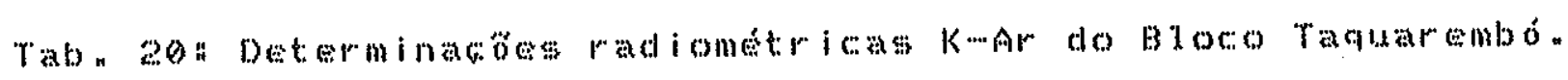

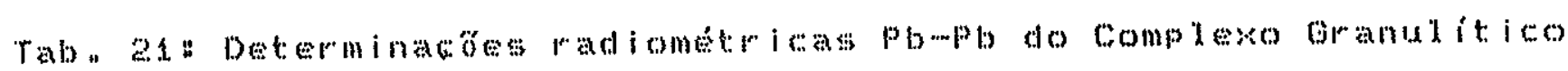
Santa Maria Chicon

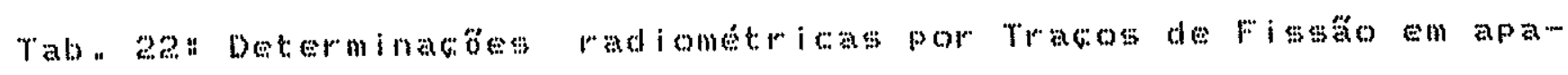
titas do complexo Granditico Santa Maria Chicon

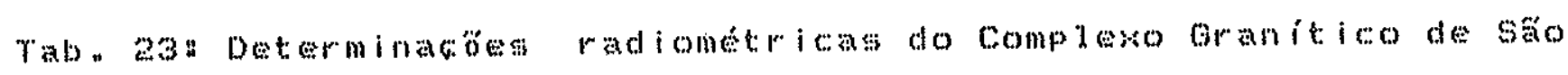
Sesp :

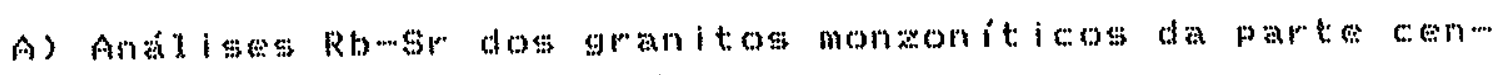
trat $a$

B) Anatises Rb-er dos grantios subatcal inosperifericos

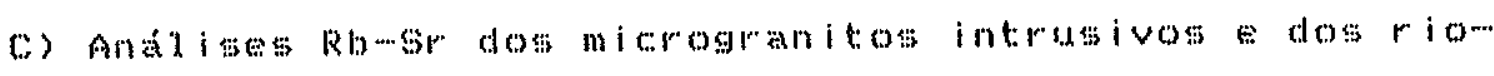

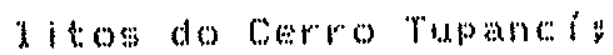

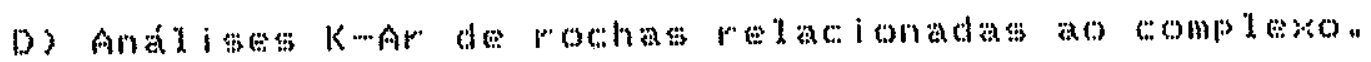

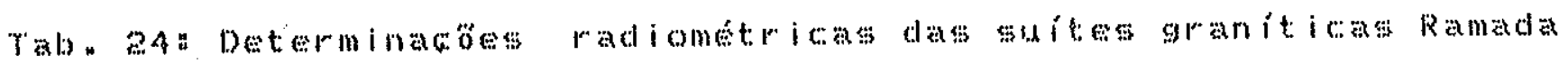
cerro da crial

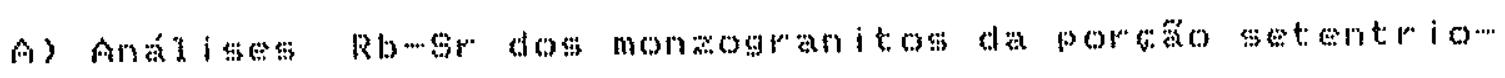

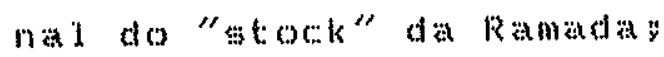

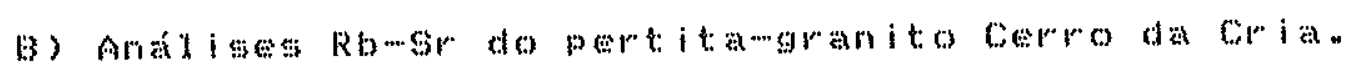




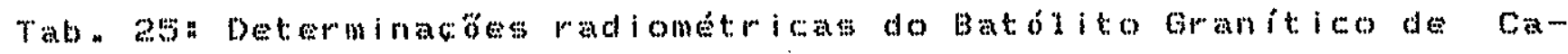
copara do sul

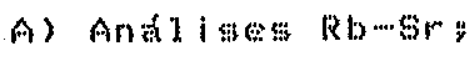

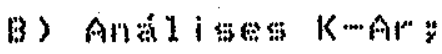

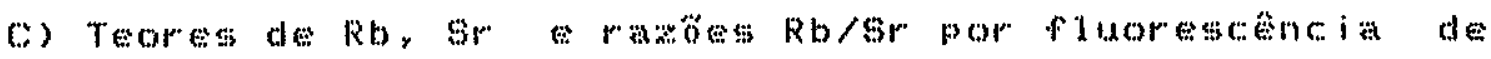

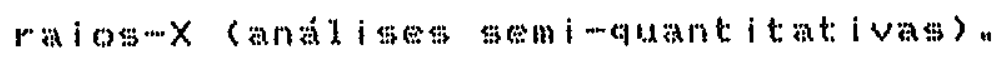

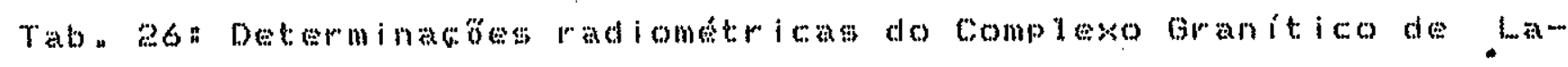
Virat do sida

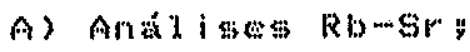
B) An

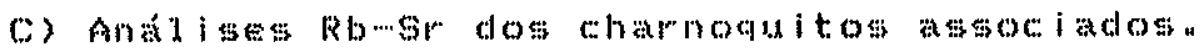

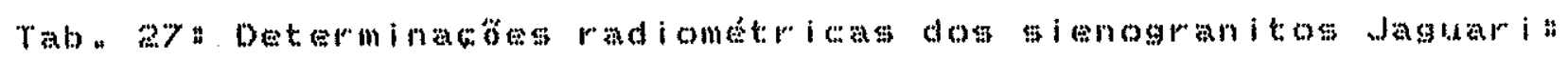

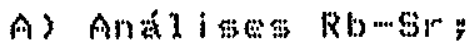

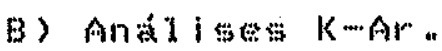

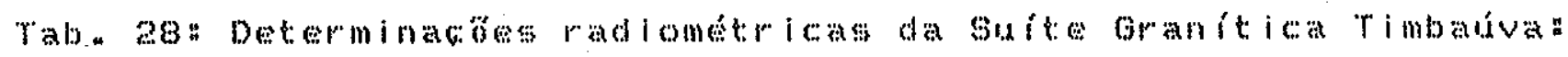
A) Anglis
Bi) An

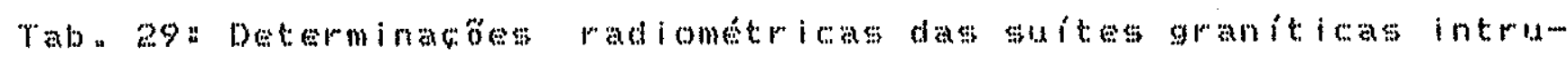

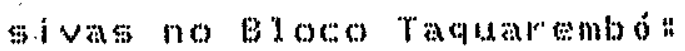

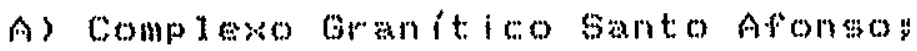

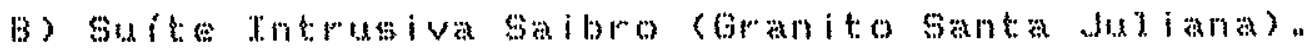

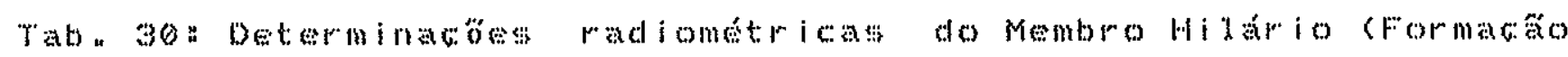
Mar.ia

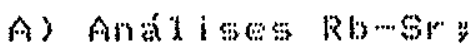

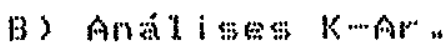

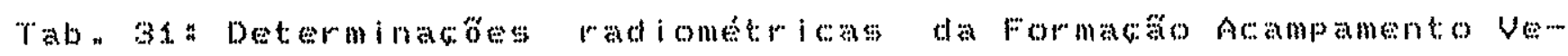
ing:
A) Andi

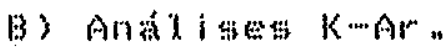

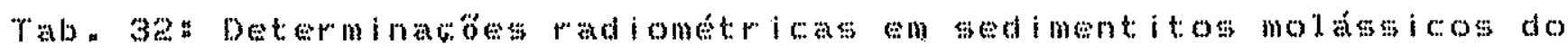


Ë:

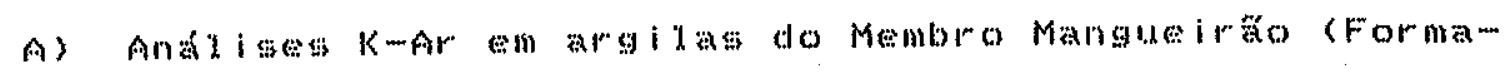 co

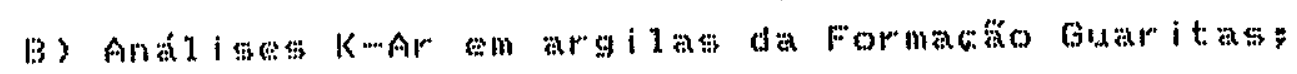

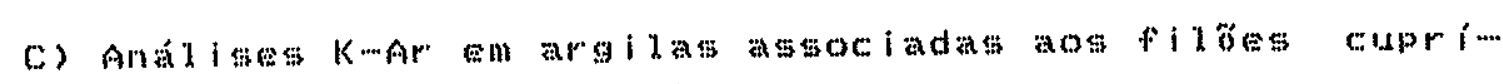 Peros da Mina Camana

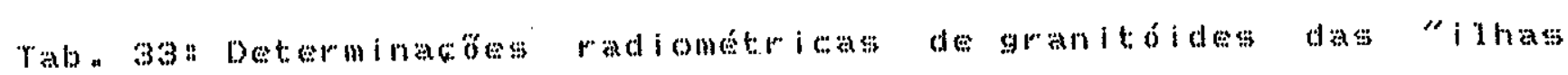

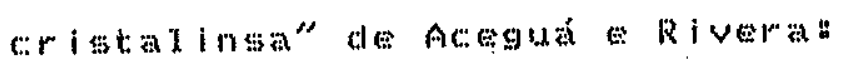

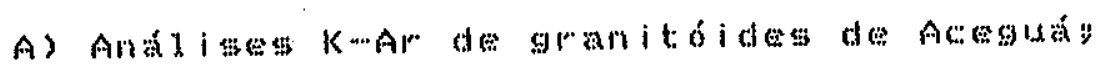

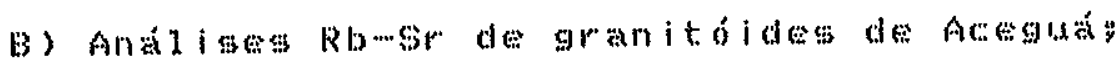

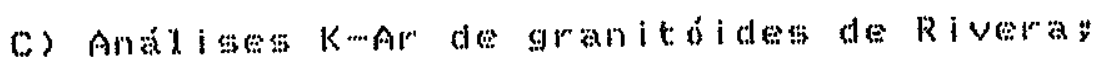

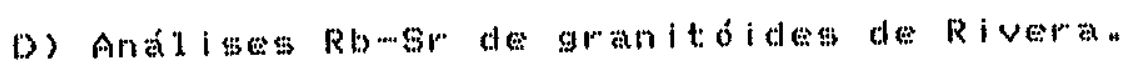

Tab. 34" Determinacos dos teores de Rb de ser por fluorescencia

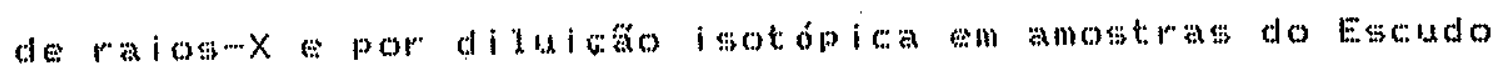
Sit 7 - iongandensen

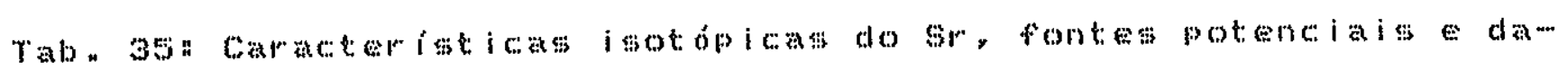

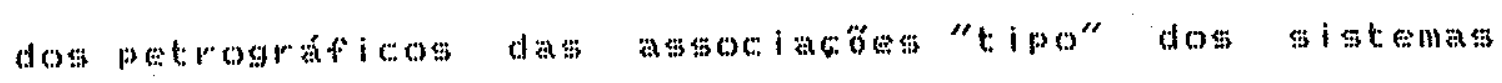

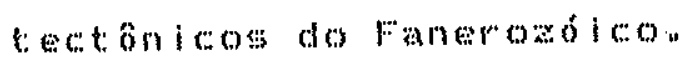

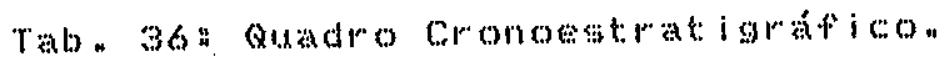

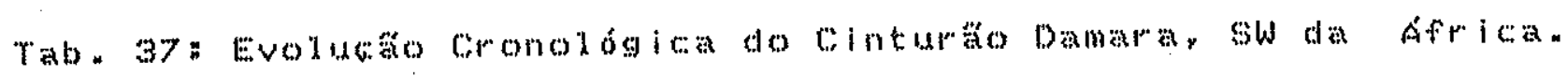


Batsed on 2so new radiometric analyses using K-Ar, Rb-..Sr, Pb... Pb and Fision Trackm methods, all of them interpreted with the ewisting geochronological data, this paper divides the Rio Granda do Sul Shield (Southern Brazil) into getectonic provinces, as well as presents the ages that seem to be of the major rock genen rator events.

It is guggested that the Brasiliano cocle (Upper Precambrian) was active during a time interval greater than has been thought: and its chronological limits could be extended from gso to sob Ma with late and local magmatic episodes reaching the 450 Ma ago. Qutcropa of Early Proterozolic or older terranes are rare. being the most areatiolated to the Late proterozoic. The a areas can be divided into two tectonic entities (1) the Pelotas Bathow 1it, a muti-intrusive and polyphase granitold body, in the eas.... tern shiedd, pointing out ages that range from 850 to 550 Ma and (2) its Marginal Basin in the west represented by suprackutal rocks such as gneisses. mafic-ultramafic and volcano-gedinentary sequences showing a complex structural pattern and green schists to amphibolite metamorphic facies. Their K-Ar and Rb-Gr ages are mainly concentrated between 760 and 640 Ma, though values of gob Ma may be found.

Poluphase granitic suites and their volcanic correspondents momet imes interbanded with molassold sedimentsy are being attribu.... ted to the $650-450$ Ma time interval.

Finally, It trles to enclobe the Rio Grande do Sul Shleld in the reglonal geologic context (Southern Brazil and Uruguas), which ia muposed to have developed in agrement with the plate rectonic: conceptis. 


\section{SINOPSE}

Em base a 250 novas analises radiometrlcas pelos métodos K-

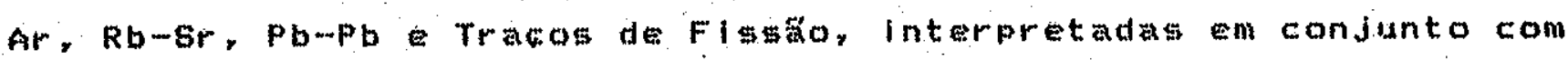
o acervo geoconológico proxisterite, este trabatho subdivide o Escudo do Rio orande do sul em províncias tectônicas e procura estabelecer o posicionamento temporal dos grandes eventos geradores de rocha.

Constata-ge que o ciclo Brabllano parece ter perdurado por un intervalo de temo ma ior do que o ate enta imaginado, tendo

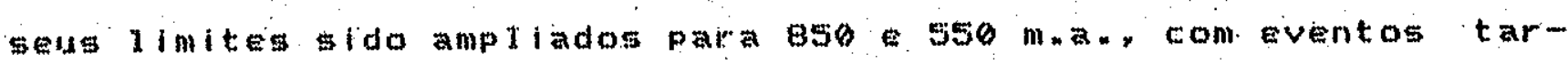
dios de ate 450 mon.

Expostabes de terrenos prébrasilianos sáo conhecluas de forma restrita nos dominios do Escudo, Eendo un expresgiva percentagen das drean atribuidas ao ciclo Bratilano. Ettas podem ser compartinentadas em dus entldades getectonicas malomes (1) o Bato lito Pelotas, muti-intrusivo polifasico, a leste, composto por suiteg granitóides com idadeg de 850 a 550 m. a. . e (2) sua Bacia Marginal, asote, representada por supracrustal dos tipos para ortogna istes, netamáf lea-ultramaficas e metaviliano-sedimentares. com idades KmAr Rb-Gr concentrada entre 760 o $640 \mathrm{mma}$. Intru-

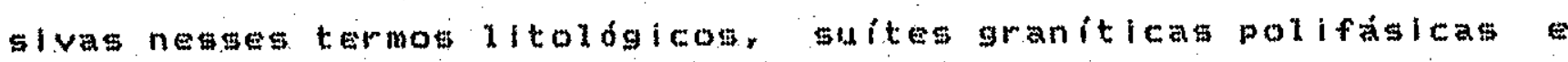
seus correspondented vuleânicos. as vezes intercalados a depósitos molassóldes, desenvolver ammse no intervalo de 650 a 460 m.

Por flin, tentame o encuadramento do Ebcudo Sul-riomgrandense no contexto geológico do Brasil Meridional e Uruguai, gendo que o estabelecimento de un quadro cromoestratigrafico permite que se vislumbre um modelo de evoluk ấ regional segundo a rectônica de Placas. 


\section{RESUMO}

A geologia do Escudo Sul-miomgrandentie, a despeito do grande. nimero de trabalhos existente, tem se mostrado controvertida permanexem en aberto mutos de seus aspectos petrograficos, geow químicos, estratigráficos, estruturaise gotectonlcos, havendo propostas diversas de compartimentacto de modelos de evolucta.

Este trabalho, com base em 2so novas analises radiometricas pelos metodos K-Ar, Rb-GE, Pbopb Tracos de Fissäo, interpretadals tem conjunto com o acervo geocronologico premexlstentevprocura estabelecer o posicionamento temporal dos grandef fenomenos gera... dores de rochas e subdividir a area de estudos en províncias de i dades como \$ubsidio à hipdtesefis evolutivas.

O primeiro fato notavel reside na constatacăo de que o ciclo Brasiliano. pelo menos no Rio Corande do Bul, perdurou por un in... tervalo de tempo maior do que o até entáno imaginado. sendo agora conhecidos corpos rochosos originados há cerca de 850 ate 4 sto ma. bosisado:

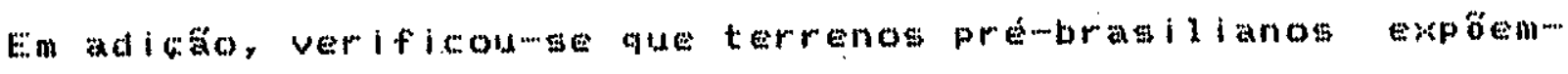
se de forma ma is ou menos continua apenati no bloco raquarembó, enn... tre as localidades de Bagé Dom Pedrito, no extremo sudoeste do Escudo (complexo Granutitico Santa Maria Chico). Litologias de ldadegt igualmente trangamazôn la no Cerro das Encantadas e na regi a de Mata Grande, interpretadas como afloramentos do embatamento em nucleos de estruturas dômicas. 
As demais áreas do Escudo gaticho Lblocos Dom Feliciano, Encruzilhada e sago Gabriel) revelaram ter evoluido nos tempos do Ciclo Brasiliano, sendo possivel agrupa-las em duas distintas entidades geotectónicas.

A primeira', coincidente com a area de afloramento dos granitóldes de leste, esta sendo interpretada como um batólito multiintrutivo polifásico (Batólitó Pelotas), con a identificacăo, de, pelo, menos, tres suites magmáticas distintag (1) wife composta por gnalases de facles petrograflca tonalitica quartzodioritica, corretpondente granitóldes do tipo I (Cordilheirano).

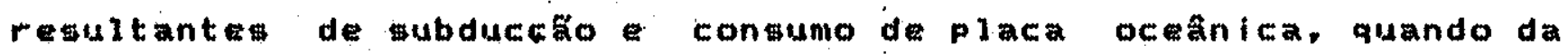
aproximacto das placas Craton Rio de la Plata e Craton do Kalahari. há cerca de $850-630 \mathrm{~m}$ - a. pamados (2) suite constituida de monzogranltos granodiorlto com tendancla calei-alcalina, que representa a magmagenese derivadáde fusto parcial da suite anterior por encurtamento espesamento crustal tardiccolisional, vistos como granitóldes do tipo I (Caledoniano) con ldade da ordem de 770 man (3) sulte representada por sienogranitose alcallfeldspato granitos, de tendencla calci-alcalina a alcalina, póstectánicosy dostipos I (Caledoniano) a A e idade de 550 m.... Magmatisno restrito velos fliós, dos tipos pegmatóldes, aplitico ou rolitico, com 450 man, corresponde tas mals jovens instrusöes de carrater anorogentico.

A segunda entidade, constituida pelas mpracrustals do centromoste, de ldades tamben orasilianas, limita-se tectônicamente com o Batólito Pelotas através da Zona de Falna da Dorsal de Cangucs, uns sutura do tipo intracontinental (subduceso A), ao longo da qual te colocaram, no periodo fin-colimional, granitódes do 
tipos (Cordilheira Augen Gnalsses Vigia).

Tais supracrustais sto interpretadas como regultantes de acumulacoes de sedimentos clasto-quimicos en bacia marginal, dobrados - netamorfizados ao longo do evento orogenico remponável pelo fechamento da entidade geotectônlea há $760-640$ m.a.. aos quais se intrudiram, en condicốtes ontectônlcas, guites igneas diversas. Deste conjunto fazem parte os para e ortognalstes da area de Vila Nova Varzea do Caplvarlta (Encruzilhada do Sul), as gequenclas mafle -ultranaficas e vulcano-sedimentares das unidades referidas no passado como orupó Pororiog ou formacôn Cerro Mantiqueiras e Vacacal. No dominio de bacia marginal, ainda sob reglme compres.' avo, intrudiramme diapiros graniticos, como as fratón de nucleo

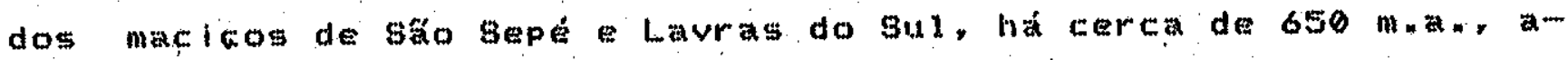
lém de fusọes vulcanicas que dinter calam com as molassas precoces em inicio de acumulacko (Formacto Marica). Ja em regimedistenivo, por volta de $550 \mathrm{mma}$. o magmatismo ge fez representar pelos granltóldes de bordo dos complexos de sáo Seper lavras do sul corpos itolados, de cvolucáo aparentemente monofasica, como o de daguari, entre outros. Desta mesma fase, mas en tempos 11 gelramente submeqienteg, há cerca de 530 man, máo os vulcanitos da Formaço Acampamento Velho, contemporancos às molassas tard lass

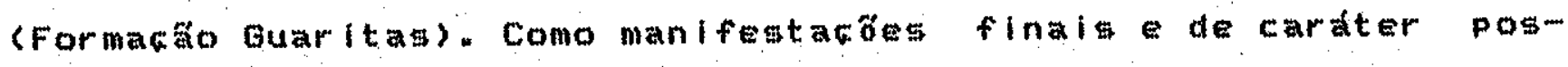
sivelmente anorogenico, relacionamos os microgranitos intrusivos do Complexo de Săo Sepé, os granitóide da Ramada os vilcanltos ácidos do cerro Tupancí, acontecidos por volta de 460 man"

A persistirem as ldeias aqui anunciadas, recomendame una rem

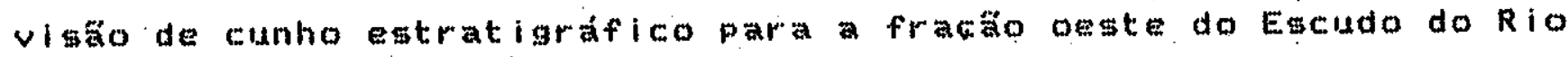
Corande do sul, incluindome os grantióldes componentes do bloco 
Encruzithada os metamorfitol Porongos, chanawe a tence para o fato de que, de agora em diante, altorame perppectiva de prospecaño de recursom minerait, una vez que, por wta nova interpretacko, Hugeremse no ocorrencia, aclatente, de litoestruturas do tipo "granlte-greenstone" de ldades arquenan ou proterom zólca inferior. 
CAP I TULO I.

\section{INTRODUCKO}

\section{Consideracbes Inleials ebjetivos}

Os terrenos prénombrianos da porca sudeste da plataforma Sul-amerleana, dos quals fazen parte lltologlas aflorantes no Escudo do Rlo orande do sul, foco prinelpal do presente trabalho, tem sido objeto de grande interesse cientifleo, sobretudo na ilt ma decada, quanda uma Ignificativa quantidade de dado petrografleos, geoquimfeos, etrutarais gocronalógos fol coleclonada. Momando-me a les mapeamentos de detalheem areas edcolhidas. Este conjunto de Informacose, representando um contideravel avanco no reconheclacito gedógleo reglonal, tem permitldo, a varlos pesqui sadoreso o vilumbranento de diferentes modelos de evolucto geotectônlea para aran.

A geologla do Pre-Cambriano sul-miomarandense pode ser melhor entendida quario Integrada a geologia da porta merldional do Es-m cudo At lántico. Uma continuldade figle de unidades litológicas ent ldades geotectonicas entre os estados de santa catarina e Rio Grande do sis 1. prolongando-se ate o Urugual, ha algum tempo,

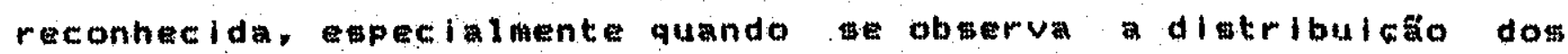
diversos conjuntos rochosos que compótem a regía. Idades radiométricas obtldas de forma olstematica, ratiflcam as tentativas de

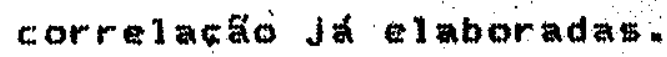

4 intencáa dest trabalino apresentar discutir todo o acervo de dados geocronoldgicos existente. ate esta data, para o 
Escudo do Rio Grande do Sul. Da mesna forma, serso comentadas, quando necestário. laades radométricas dimponivel as nos prolongamento setentrional merldlonal da regiso em pauta. Eute procedimento se valerá dos trabalho de cunho geocronológlco de Umplerre e Halpern (1971), Minioli Kawmita (1971), Imsler et al.(197.3), Cordani at a. (1974), Bartorl Rutag (1979) e Kaul Telkelra (1982), Ja de domínto público, mos quals se adiclonarto os dados obtidos nos ditimo cinco mos Junto ao Centro de Pesquisas oeocronológleas da universidade de sa Paulo ou, menor numero, en laborator los estrangelrow

Entre etew destacamos ow levantamentos madiométrico levados efeito pelo convenio RADAMBRASIL-IG/USP (Teikeira, 1982) e os studow geocronolólcos reallzados por pemquisadores que concentraram was atencóos na area enfocada, como Haiparn et al.

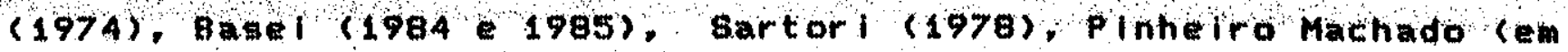
prep.), Naumann (1984), Remus (em, prep.), Nalme (em prep.), alén

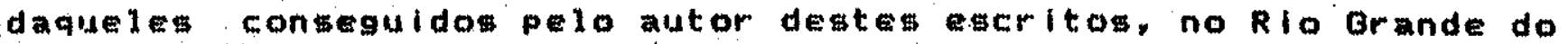
sul no Uruguai.

A rolnterpretacho de dados, sobretudo daqueles obtidos ha mals tempo, justifica-se face aos contecimentos adquirldos nos útimog anos, que fez com que a visfo sobre geologia reglonal se ateraste mubstanclalmente desde entäo. Alén dis\$o, o malor volume de Informato geocronolóicas permlte que se apur a interpreta-

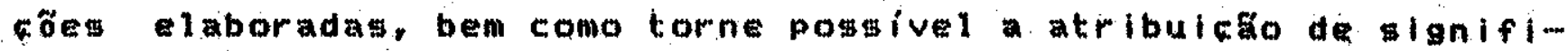

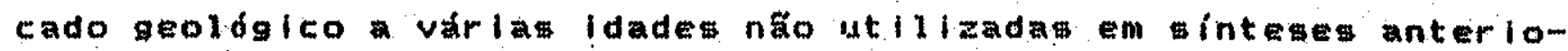
res, por aparente digcrepancia de valores, fruto de um menor entendimento geotectóntco regional. 
Por fimy pretendemos tecer comentarlos relat lvos a evolucáa crustal da regián. tendo como subsidios a geocronolosia as rew construcốt paleotectônicas decorrentes, com o intulto de testar contribuir com o aprimoramento dos modelos evolutivos ja propostosi por vários autores (Ribeiro Fantinel, 1978, Porada, 1979; Jost, 1981. Fragoso Cesar et al., 1982a, b. I\$sler, 1982; Harthady et: a $1.198 \mathrm{~g})$.

\section{Métodos de Trabalho}

O Escudo sul miomgrandense, abrangendo uma area de cerca de

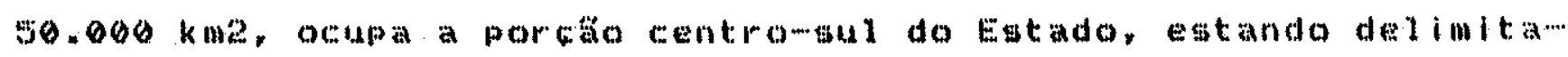
do a norte, oeste sul pelos sedimentitos gonduânicos da Bacia do Parana e, leste, pelos depósteos inconsolidados da provincia Costeira do Rio orande do Sul, de ldade cenozólea (fig. 1).

t. uma entidade geológita atravestada por varia rodovias

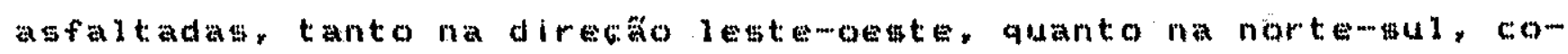

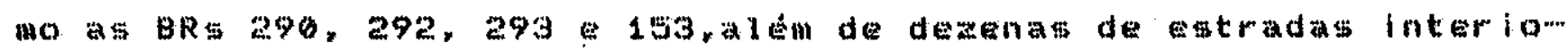
res. naco pavimentadas. mas trafaguels durante todo o ano, que permitem acesso fácil a qualquer area do Escudon

A coleta de amostra para gecoconologia obedecedaos princím plos preconizados pela ciencia, dandome preferenciar quando pos... avel, a afloramentog extensou, onde ge pudeswe recolher un con junto de rochas cogeneticas, objetivandome a obtencáco de idadest isocrônicas pelo metcodo Rb-Sr. Quando as dimeneóses ou a homogenei

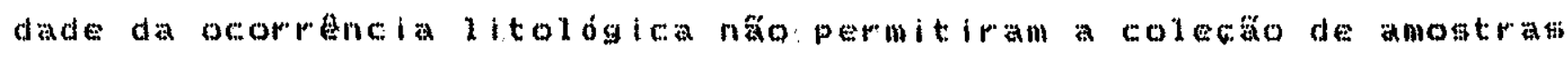
em numero suficiente, o recolhimento de rochas fol feito para de...

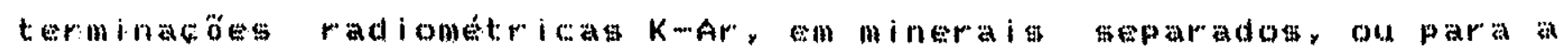




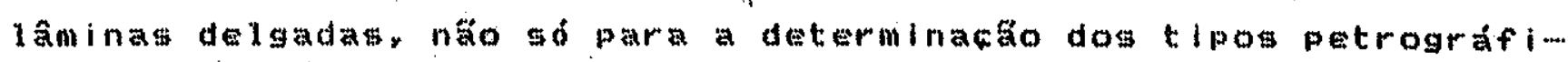

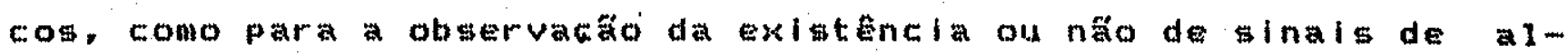

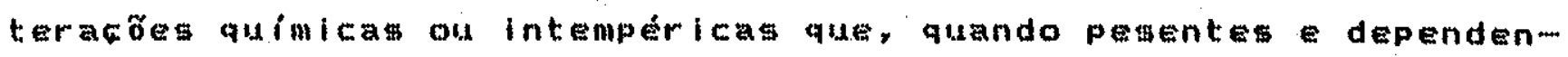
do do grau de afetacto, constituiram o criterio primeiro na selec5o das anotiras para analise geocronológlcan

A expressiva maloria das novas idades radiometricas apresentada neste trabalho fol obtida no centro de Pesquisas Geocronológicas (CPGeo) do Inttituto de Geocianclas da Univergidade de såo Paulo, ut 1 lizando-me os metodos K-Ar e Rb-Sr. Por esta razán, teceremos en moulda algumas consideracón relat lvas a obtencăo de id des pelos metodo mencionadotio bem como os procedimento que devem ger observados na tentativas de interpretacto dos resulta-

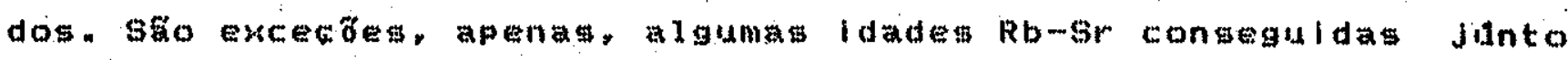
no Nucleo de ciencias Geofisicas Geológicas (NCGG) da Universidade Federal do Part, outra junto ao Laboratorio de Geocronologia da Universidade do Texas, alguns resultados Pb-Pb obtidos junto i Universidade de oxford e ldades. por tracos de fissago em apatitas. fornecidas por andises desenvolvidatio nontro Brasileiro de Pesquisag Fisicat (CBPF), no Rio de Janeiro.

A observacăo felta no pararafo anterior também pode ser estendida aos dados revelados por outros autores utilizados nesta tese. No casio. mentionanos como excludentes a alguns resultados $K-$ Ar devidos Hart (1966, apud Ferrando Fernandes, 1971) Rb-3r creditados a Umplerre Halpern (1971). para rochas cristalinas do Urugual: K-Ar en material argilosos da Bacia do Camaquá (RS), conseguldos por Bonhomme Ribeiro (1983); Rb-Sr em rochas sedimentares da Bacia do Itajai (SC), obtlososor Macedo (1982) Macedo et a $1 .(1964)$ finalmente, U-Pb em zircöe, para rochas do 
Pré- Cambriano da regiăo centromsl de Santa Catarlina, mostrados por Basei (1984).

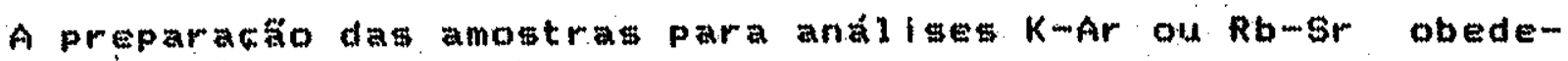
ceu rotina do Centro de Pesquisas Geocronoldgleas da USP, iniciando-ge con a britagen quarteacto da rochas coletadas e prosm seguindo com a obtencto de fracoses granulométricas selecionadas por jogos de peneiras ou pulverlzadas, dependendo do metodo utillzado.

\subsection{Análises K-Ar.}

A determinacto de idades radiometricta lo método K-Ar realizou-se gempre mineralg separados, preferencialmente anfibólos, micas plagloclatos. Oconcentrado do meamos fol obtido a partir de fractom com granulacto 60-100 mesh, por meparacán magné-

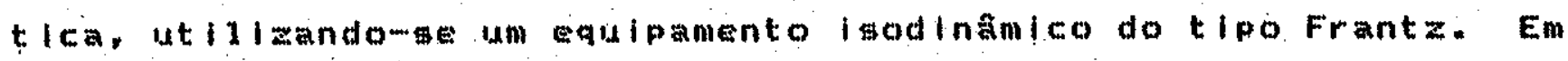
nguns casos, houve a necessidade de purfficacấo das amostras a travé do aso do bromofómio, para separacto por densidades, e de placa vibratoria. para concentracta de mineral lamelares.

A metodologia and itlea observacta foi, con algumas modificacö́s. aquela detalhadamente degerlta por Amaral et al. (1966). 0\$ teorea de potamio foram deterninadobor anallatem duplicata atraves de fotometria de chama en equipamento Micronal, modelo 8-262, com erro percentual normal da orden de $0,5 \%$.

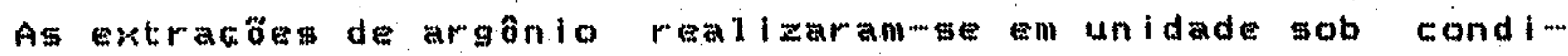

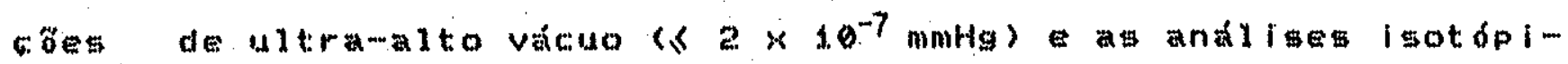

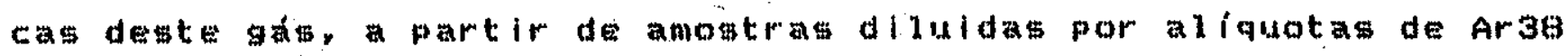


en quantidade conhecidas. for executadas em expectrónetro do masu, de forte gasosa, da marca Nuclide do tipo Regnolds. o erro do resultado geocronológito final, conseguido observando-se os criter ios andunciados, e da orden de 2 a $3 \%$, conforme atestam analises de substanciasmpadra, de uso comum entre os laboratórios, - uma consegidencia das incertezas experlmentala durante a deter-

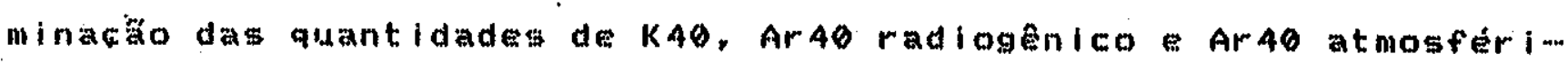
co eventualmente presente na amostra.

As constantes utilizadas no calculo das ldadeg sáo aqual as \$ugeridas por steiger Jager (1977), conforme megle"

$$
\begin{aligned}
& \lambda B=4.962 \times 10^{-10} \mathrm{ano}^{-1} \\
& \lambda K=0,581 \times 10^{-10} \text { ano-1 } \\
& (\text { Ar } 40 / \text { Ar.36) at: at } 295,5 \\
& K 40=0,01167 \% \mathrm{Ktot}
\end{aligned}
$$

\section{Condicôes para a determinaçón de uma idade K-Ar}

O conhecimento do tipos de deciaimento do K, a maior precisăo possivel na determinacăo das constantes de desintegracåo técni-

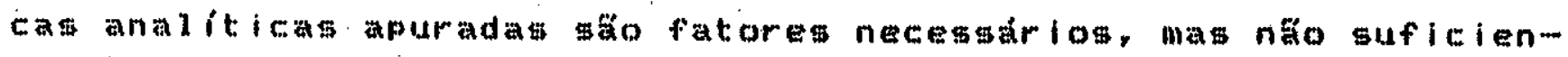
tes. na obtencäo de uma idade radiometrlca com gignificacáo geologican Alsm destes, as condicöes seguinten precisam ter observadas, conforme lembra Armstrong (1966):

n.. Eistencia de materlaim portadoret de K, gerados en algum "instante" geológico coor instante geológico entendewe um inter.valo de tempo menor do que o erro da medida feltas, apropriados

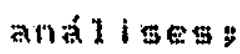

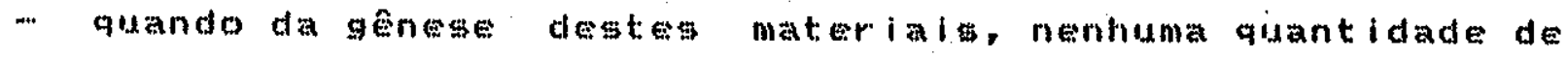
Ar radiogênlco fol a le lncorporada. ja que näo é possivel qual- 


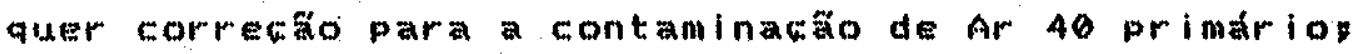

- no tempo transcorrido entre a origen a analise dos matem riais,estes devem ter permanecido como sistemat fechados para per-. das ou ganhos de $K$ e Ar. Isto implica en uma historia de baikas

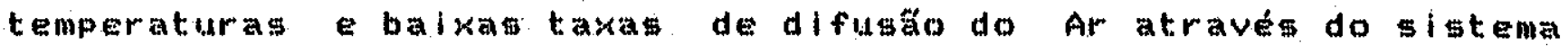
datado.

Somente no caso destas trespomiss terem sido integralmente satisfeitas, o resultado conseguldo representa a ldade real do evento geológico, no caso a ganese da rocha.

As condicoses acima mencionadas necentiam ser avaliadas em cada caso a seguir, discutiremog esteg apectom de forma sintétican

O estabelecimento de que materlais so apropriados ao método K-Ar é de fundamental Importância. De acordo con York e Farquhar (1972), entre os minerais nats comuns, que tenham experimentado una historla pós-cristalizacoúc melativamente calma, verificame que:

- as micas, alem de abundantes en un grande nimero de rochas igneas metamóficas, mpresentam estruturas cristalinas nuito favoráveis a retencăo do Ar gerado a partir de oua crigtalizaça

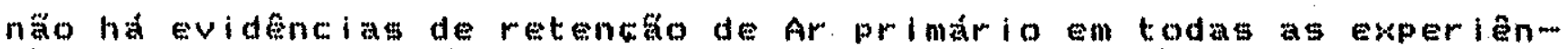
c. ias reallarada\$

- os anfibóliog postuem ba ixos teores da $K$ requeren una anal be mals culdadosa, porkm, a hornblenda, por exemplo, revela forte capacidade de retencto do Ar, o que asogura um resutado mais confiagely

- Os feldspatos potasicos os plagloclásios ádicos mosm 
tram-se inadequados. Mesmo quando orlundos de rochas náo perturbatas. revelam impreviaivel perdas de Ar. Eute comportamento parece estar relacionado problematestruturaid como a iniscibilidade de fated (pertitizacáo), o que ge renliza mesno a baikas tenperaturas. Os plagioclastos cálclcos gấo mals aproprlados as analises do que os oddicos

- og pirowentog revelam que o seu uso precima ger feito com cuidado, poliz; quando formados a grandes profundidades, mostran un ma tendencia ao fornecimento de idade anomalamente altas, o que no ocorrecom aqueles gerados prótimo superficie.

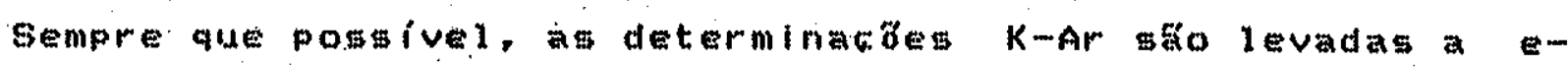
felto en minerals separados concordancia das ldades obtidag entre tipos diferentes indle a validade do método. Multas vezes, porén. conóno caso de rochas vuleanleag, a granulometrla é tăo fina que lmpogibilita uma, separactio, obrigando a uma analise en

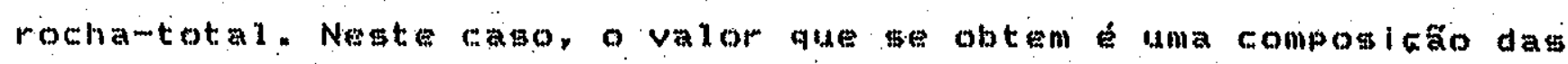
idades minerats individuait.

Os materlaik datados pelo metodo K-Ar, flm de oferecerem valores radiometrlcos interpretaveis, precisam ter retido todo o Ar radiogenico produzido apda a sua cristalizacto náto conter excosto de Ar congequente da captura do gatedurante ou apds a sua formacto. O comportamento do mineral como um tatena quimico náo fechado para o\$ lemento anal isados acarreta, na grande maioria

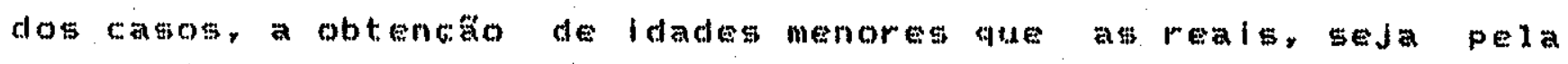
perda do Ar. o fenómeno mai comum, ja que tato gás inerte nåo forma compostos ligandomge a outrom elementos, seja pelo ganho de K, como, por exemplo, durante um evento metastomatico. A perda de K também pode ocorrer, só que, neste caso, uma fuga de maior quan- 
tidade de Ar acompanha a saida do primeiro elemento, pesultando, igualmente, em unalor radiometrleo inferior f Fure (1977) erium nera algumas cassag responsavels pela perda de Ar

- Inabilidade do reticulo crlstalino em reter o Ar, mesmo a baixas tomperaturas e pressio atmosferica

- fusăo total ou parclal de rochas segulda pela recristaliza6a de novos minerai a partir do ligido resultantey

- metamorfismo de elevadas temperatura eprestáno, implicando eim completa ou parcial perda do Ar, dependendo da temperatura e duracto do eventoy

- aumento de temperatura imposto por soterramento profiundo ou metamorfino de contator caubando perda de Ar por parte de cer... tos minerais, tem a producto de qualquer mudanca figlca ou química da rochay

- Intemperimo químico ou alteracto por fluidos aquosos, inm plicando na somente no escape do Ar, mas em variacáa no conteudo de Kos minerals

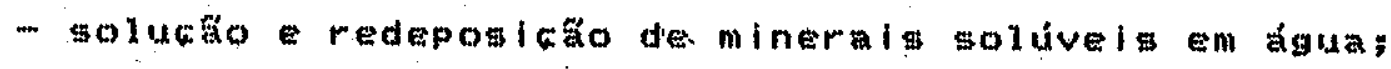

- quebra mecante dos mirierait, danos radioativos e ondas de

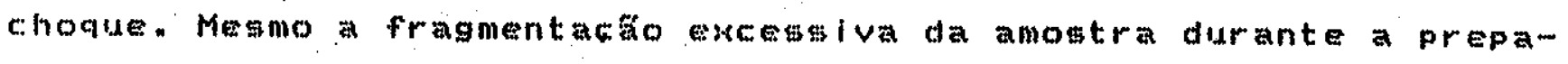
ractio pode caldor perdas de Ar.

\section{Significado geológico de uma ldade K-Ar}

Como se depreande do que acaba deser visto, a qualidade de gás nobre do Ar torna-o susceptivel a migracós interiores aos reticulos cristalinos dos minerais, pelo mecanismo da difusáno gasosa atraves de um ádido, mecaniamo mso incentivado pela excitacáo térmica imperante no materiad. A. temperaturas de 450 ou mais graus centigradosi, todo o Ar contido en um minoral migra e atinge 


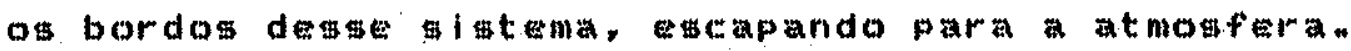

ge temperatura torna-be baixa, inferior a determinados valores empecificos para cada mineral com functo de mua estrutura crlotalinar fuga de Ar passa a ser negligenciácel. Isto se dá

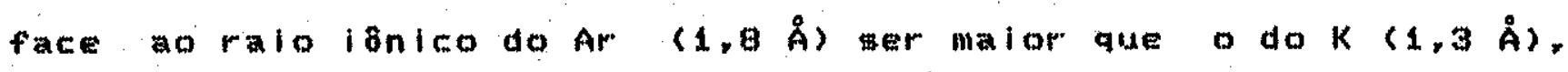
que ine dew origem, acarretando um aprigionamento do primeiro em un, local originalmente, destinado a um ion menor.

Wn dado importante, ja demonatrado, to fatode que, em

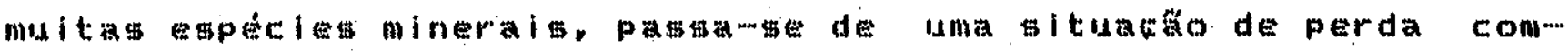
pleta do Ar. para uma de retencfo total, vartandomatapenas alguns poucos graus centigrados na tomparatura. Eute restrito intervalo tem oldoreferido na literatura como temperatura critlca oude b 109010.

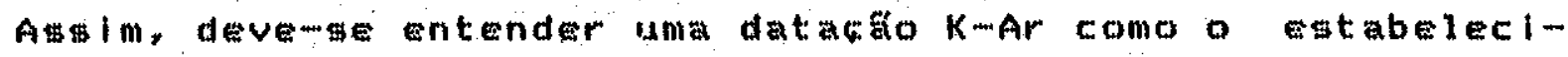
mento de un intervalo de tampo que comega a ger contado no momento em que o mineral analisado pas a a reter completamente o Ar. isto

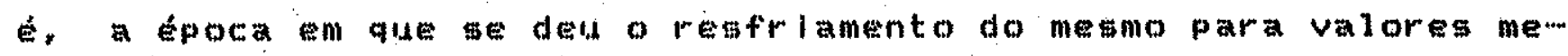
noreg do que a sua temperatura de bloquelo. As"ldadeg K-Ar, ent

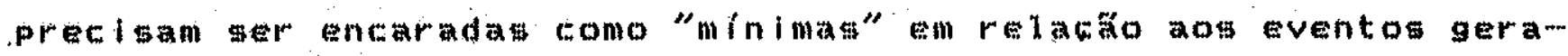

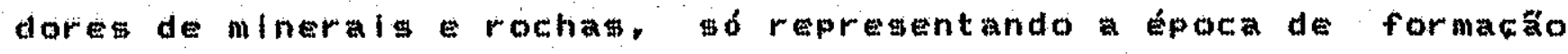

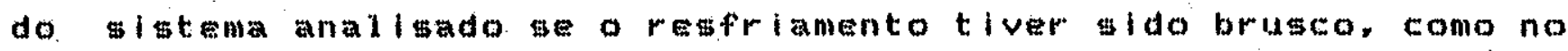
togo de rochas vule

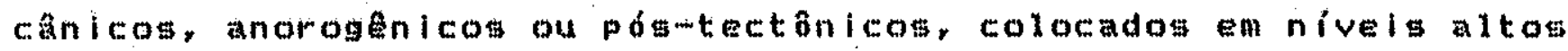

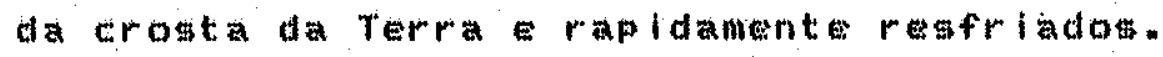

No caso de áreat com historla termica complexay onde dols ou

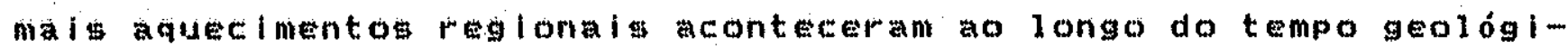


co, a Capcidade de retencto diferenciada do Ar por parte de minerais de especies distintas pode ser diagnóstica. Assim, idades con valores superiores aos comun encontrados na área devem resultar de degaseificacto incompleta, sendo frequente en minerais de alta retentividade (exy anfibolio plagioclasio) de regiós policiclicas, onde o evento térmico subsequente näo foi täo severo quanto o precedente (Cordani, 1.980).

\subsection{Análises Rb-Sr}

Para o metodo Rb-Sr, os materiais rochosos quarteados e tomados integralmente foram, de inicio. pulverizados om inimoinhos de bolase, a seguir, selecionados atraves de análses semi-quantitativas de Ro sp totals, par fluoremcencia de ralos-X, en equipamento Philips dotado de tubo de molibdenio utilizando-se os padrós BSP-1 (grandiorlto fornecido pelo united states Geological survey, com respectivos teored de Rb de Sr de 255 e 236 ppm) DTs-1 ou PCC-1 (padröes teoricamente isentos dos elementos considerados).

Ëcolnidas en functo de valores adequados da razão Sr/Rb para a constructo de diagramas inocronicos ou obtencáco de ldades convencionaisy a amostras tiveram as quantidades destes elementos determinadas com maior precistio atravess de análibes quantitativas. Para teores intermediarios entre 40 a nas dosagens de Rb Sor do corca de $2 \%$. Caso a amostra se color que fora deste intervalo, os erros analiticos crescem de maneira significativa as mantidades dos elementos considerados só podem ser obtidas por diluica lsotóplcay ut il izandowse tracadores enriquecidas en Rber e/ou Sr84, conforme demongtrado por Kawashlta 
(1972).

A malor parte das análises isotóplcas do Rb e do Sr foi demenvolvidas em espectrômetro de massa Varlan Mat, tipo TH-5, de fonte sólida, pertencente a cPGeo da Unlversidade de Sáo Paulo. com aquisicáco processamento autonatico de dado através de un microcomputador HP $9825 B$.

No Nucleo de ciencias Geofíslcas e Geológlcas da Universidade Federal do Pará, onde algumas análises ge real lzaram, o espectrómetro utilizado fol um Vom Iomass 54E, acoplado a un computador lidentico ao anterior.

As determinacoses efetivadas na Universidade de Texas, em Dallas, processaramme em espectrometro shields constrido pela Nat Ional Bureau of standard\$ (NBS).

\section{A obtenço de idades Rb-Sr em RT a idade convencional}

Apesar dos métodos radiamétricos obedecerem aos mesmos principios gerals, exigtem particularldades, inerentes a cada um, que precisam ser atentamente observadas, quando se quer obter e interpretar um resultado geocronológlco.

No caso da aplicacto do metodo Ro-Sr, como comenta Cordani (1980), oprimeiro problema que sirge reslde no fato de que o sr um elemento quimicamente ativo (ao contrario do Ar) está presente em quantidades quase sempre significativas nos materials que serven de materiampina para a geraço de rochas, isto écos magmas possuem quantidades de sr que säo fornecidas a rocha em fase de 
formacía, quantidades estas referldas como iniciais.

Em consequéncla, para obteren-se resultados con significaço geológica, uma correcto se faz necegsarla com o intuito de separarme do srg7 total, aquela quantidade ja presente no inicio, quando da eristallzaç̌o da rocha, para ser considerado apenas o Sr87 radiogênico formado a partir de entio. se é este o evento cuja idade ge quer determinar"

Qualquer que seja o tipo de rocha considerado, derivado diretanente do manto ou resultante de refutoses crustais, verifica-se que as guas razófs iniclais $(9 r 87 / 5 r 86) i$ oscilam entre os valores de 0,700 0.730, concentrandome entre 0,705 e 0.720. Assin. qualquer material rochoso que possua uma alta razäo Sr87/5r86 presente, Significativamente maior do que 0,71 ou 0,72 , o erro que introduzido na avallacăo da razăo inicial torna-se aceitável o resultado obtido pode ter valor geolóico. Neste trabalho, foram conseguldas e utilizadas alguma idades convencionais, consideradas dentro da óptica acima exposta, atribuindo-se para Ro un valor de $0,705$.

A obtença de luades Rb-Sr em RT: idades isocrônicas

A grande maiorla dos resultados $\mathrm{Rb}-\mathrm{Sr}$ aqui apresentados foi obtida atravét da congtrucko de diagramas lgocrônicos, a partir da análise de conjuntos de rochas, sempre que possivel, cogenéticas. Cabe ressaltar que, ao longo do presente texto, ser fo encontrados tres tipos de diagramas isocrônlcos, conforme as caracterigticas dos conjuntos de amostras ut lizados"

- quando todos os pontos analiticos derivarem de rochas cer- 
tamente cogeneticat, ested definimfo uma loócrona o mesultado apontado reveste-me do malor valor interpretativo

- quando as amostras forem provenlentes de corpos litológicos Imllareg próximos, porem sen continuidade fílica, podendo ocorrer uma diminuicto na precisto do valor temporal da razto inicial, estaremos nos referindo reta de melhor ajuste ou simplesmente reta de ajuste

-. compontas por amostrab de corpos rochosos imilares, mas de diversificada proveniencia, as retas de referência terăo o in tuito de revelar tendanclas de ldades regionais.

No caso de merem ut|l|zados megmentos imocrônicos prétrocados; esta caracterittica sera mencionada na figura correspondente.

A baye teórlca para o tracado de isócronas resume-se no seguinte a partir da equacăo fundamental do decaimento radioativo.

$$
N(t)=N_{0} e^{-\lambda t} \quad \text { ou } N(t) e^{\lambda t}=N_{0}
$$

onide,
$N=n g$ de átomos do lemento radioativo atualmente presente namostray

No no de átomos do elemento radioativo presente na amostra no momento de sua formacto

$\lambda$ congtante de desintegracio do elemento radioativo:

$t$ tempo transcorrido deste a formaço do bitena até o momento da analio

- base do logaritmo natural,

- Babendo-me que No a $N+F$, onde F o no de átomos radiogenicos provenientes do elemento radiativo, modeme afirmar que, para o método Rb- Sr.

$$
N=n g \text { de atomos de RbEY presente na amostrat--) (RbGT)P; }
$$


$N_{0}=(\operatorname{Rb} 87) p+(\operatorname{Srg}) \mathrm{Prad}$

Gubstituindomse, na equacăo fundanental, $N$ No pelos seus significados acima expressom, temos:

(RDE7)p $\lambda t=(R b B 7) p+(\$ r 87)$ rad

No entanto, o \$ra7 radiogencico presente na amostra pode estar associado ao sre7 incorporado no slatema durante a formacko deste ultimo, tal que, entăo,

$(8+87) r a d=(5 r 87) p-(8 r 87) 1$.

onde o indice I Indica a quantidade Inicial.

Substituindo-ge em (2) o valor de (srg7)rad fornecido pela EqRG (3), temo: que:

$(R 687) e^{\lambda t}=(R b 87) p+(5 r 87) p-(5 r 87) i$

ois

$$
(\$ r .87) p=(8 r 87) i+R b 87 p\left(e^{\lambda t}-1\right)
$$

Como os espectrómetros de masa fornecem momente relacós in sotóplcas, usams o artificio matematico de dividir todos os membros da equaço (4) por Sr86:

$(\operatorname{Srg7/Sr86)p}=(\operatorname{Srg7/5r86)i+Rb87/8ra6(e\lambda t-1)}$

SE invertemos a posicós dos menbros a direlta do sinal de igualdade, teremos:

$(8+87 / \operatorname{sr} 86) p=(2 t-1) R 687 / 8 r 86+(8 r 87 / 8 r 86) 1$

quando ve verifica, entác, a equacto da reta na forma

$y=a x+b$

A inclinacto da reta resultante dada por a , onde a c i-

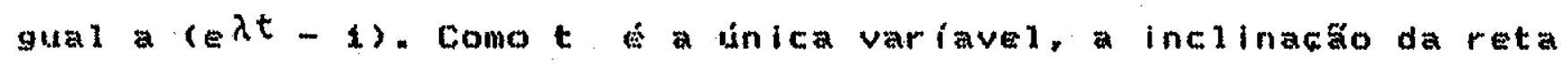


é functio do tempo (ldade).

Se $t=0, x=0$ t $y=b$, isto o valor da razáno inleial.

Assin, todos os menbros de una sult de rochas cogenéticas,

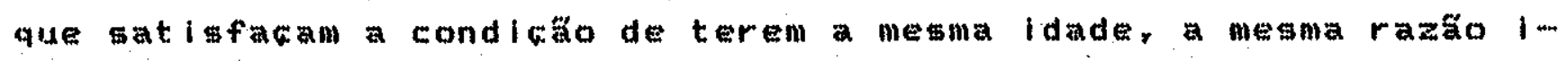
nicial e de teren permanecido como siatemas fechados para o Rb o

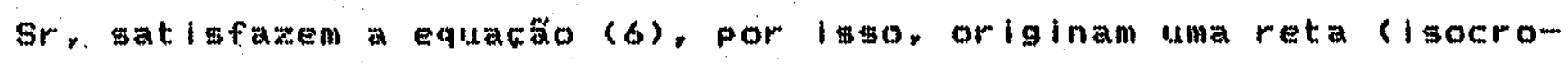
na) atravé da coordenadas $\operatorname{srg7/8r86}(y)$ Rb87/SrB6 (w).

\section{A interpretacão de idades Rb-Sr em RT}

O signiflcado geológlco de um resultado radionétrico Rb-Sr só pode ser enteridido depols que soubermos qual o comportanento geoquimico do sra7 radiogenico dentro do reticulo eristalino do mineral am que fol formado. O Srat possui un raio lônico da orden de $1,13 \AA$, valor bem menor do que a do $R b+\operatorname{orlginal}(1,48 A), 0$ que faz com que o sr apresente uma mobilidade potencialmente maior. por difusto innlea. Esta faclidida de movinentacto torna possivel - que denominamos de "homogenelazaca laotóplea" do sr, fenômeno produzido pela excitacto termica que ocorre sempre que a temperatura ultrapasm on 250 ou 300 graus centrigrados. Acima destes valores. o sr migra entre as fases minerais da rocha, influenclado pelas propriedades termodinânlcas pela disponibilidade do elemento no istema. Este proceso cespa quando ge da o resfriamento regional, sendo as ldades isocrônleas minerais relacionadas à cooca de fechamento doses sistemas cristalinow.

A nivel de rocha, as migracoses internas do sr năo significam, nectsariamente, perdas do elemento, já que, en condicöes i- 
deais, deve ter permanecido como um sistema quimicamente fechado,

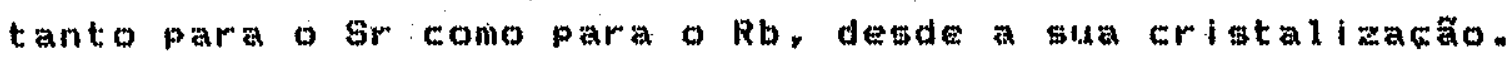

Podeme, entolo, atribuir a una ldade Rb-Sr en rocha-total, obtida geja de forma convencional, se a rocha for actequada, seja por diagrama imocrốnico, desde que og pontom analiticos revelem um

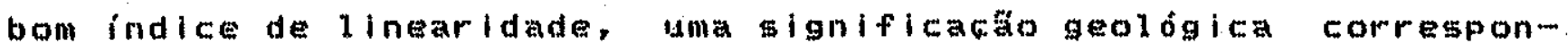

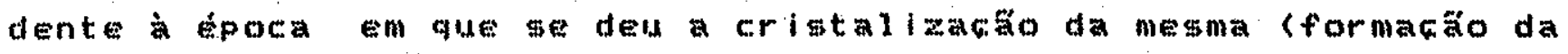
principal paraghese mineral presente na rochal, imposta por proceggos petrogenticos divereificadog como granitiatacto, anatexia, palingarese outrog similares ou relacionados aos referidos

Uma leve falta de linemrldade dos pontos analisados, obser-

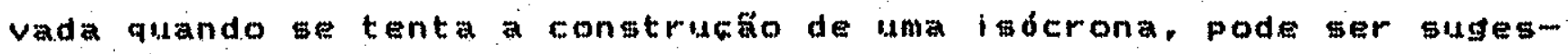
tiva de lum cogeneticldade máno rigorosa, onde as amostrag revelam razótesinicials próplas ligeiranente diferentes.

0 desalinhamento de algung pontos significa que as amostras em quest cima da reta lacoônlca, ou sto de rochag mais antigas, ou pertan-

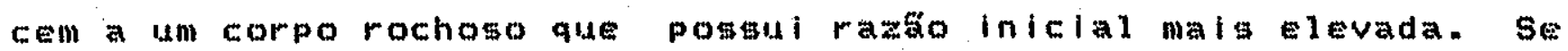
os pontos colocam-me abalioy devem corresponder a amostras mais jovens.

Una dimproso de pontos, que torna dificil o tracado do segmento de reta, metimo quando ge tem um bom controle de campo e inam gina-se que as amostra abertura do sigtema rochoso, seja por alteracós intempericas, seja por fenônenos metassomaticos ou hidrotermals. Em ambos os casos, a nä́ homogeneidade dos eventos na afetacto da rocha respon... 
gabiliza-ge pela poquena ou augente lingarldade, observando-ge, quando possivel, una importante diminulgéno no valor do resultado esperado.

Através da determinafăo da razto $5 r 87 / 5 r 86$ inicial, a partir dos diagranas igoerônicos para um dado conjunto de amostras, tem Hido postivel sugerir a proveniencia (He do manto superior, sen ou

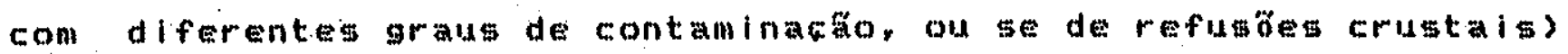
dos magnas parental das rocha igneas analisadas, segundo faure Powe 1. (1.972).

\section{A avaliafío da qualidade dos diagramas isocr 6 icos}

Com relacto ao diagramas isocrônicos apresentados neste trabalho, podemse dizer aue o grau de conflabilidade nas informacöes geocronológicas por eles fornecidas deve ser estimado em baw \$ a parametrom etatisticom calculados en cada caso, como o coeficlente de correlacto, o nivel de corte e o MSWD, lembrando, con-.. tudo, que sáo apenas valores numericos ausiliares e nádofiniti$\operatorname{vos} n$

o coeficiente de correlacăo linear uma grandeza derivada de uma formulacto que, em relaço a una reta média tracada entre pontos analiticos, leva en conta os residuos (afastanentos) dos pontos calculadom em relacto aos pontos experimentals, de tal for ma que, oe olinhamento de pontos for porfeito, seu valor numér ico Igual a f. decremendo medida qua os desajugtes forem sendo observados, at o valor o, quando náto há, entre os pontos, qualquer tendência de definicino de una reta. 
Uma grandeza mais confiaved convincente, que permite uma

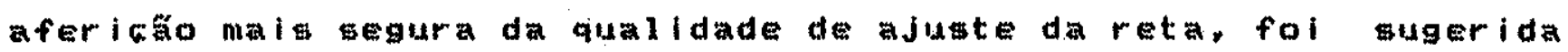
por Me Intgre et al. (1966), atraves do desvio medio quadratico ponderado (MSWD - Mean Bquare of weight deviates). Para estes autores, o limite entre uma boa ou má lgósona estarla no valor 1 para o MSWD. Há, no entanto, sugestö́s de aprimoramento do uso deste parâmetro baseadam no fato de que o valor 1, acima, é aplicável apenas not casos en que é utilizado um grande numero de pontos, cujos erros analiticos foram obtidos atraved de analises em duplicata como este procedimento näo observado na maioria dos laboratórlos, utilizame o "nivel de corte" (eut off level) para o MSWD apresentado por Grook et al. (1972). Astim, o limite entre igócronas de boa ou má qualidade cvalor máximo admissivel para o MSWD seria definido en cada diagrama isoerónico relativanente ao numero de pontos anal lsados.

Para o método Rb-Sr utilizaram-\$ os valores de Sr86/\$r88 0.194 aplicado na normalizacto dos dados lsotó.... plcos do Sr

$\lambda$ Rb\&7 $=1,42 \times 10^{-11} \mathrm{ano}^{-1}$

A aculdade das análises fsotólicas do sr desenvolvidas no CPGeo da Unlversidade de gäo Palu, através de medidas dos padröes interlaboratorials NBS-987 Elmer \& Amend, pode ser avaliada. por exemplo, pela tabe1a 1, apresentada por cordani et al. (1985).

Na Universldade do Toxas, as medidas em duplicata para as razós normalizadas de $5 r 87 / 5486$ sho concordantes, com diferencas da ordem de $0,1 \%$. O padrăto Eimer a Amend tove o valor de sua razão Sr87/8r86 normalizada definido como $0,7080+0,0006(2 \sigma)$, segundo 
Halpern et al. (1974),

No camo de idades ja ewigtentes, degde que näo obt ldas com a utilizacto dab constantes acima, as memas formm recalculadas com o intulto de realizar-me uma análise critica homogênea do conjunto radiometrico.

\subsection{Análises Pb-Pb}

Os resultadog Pb-mb apresentados negte trabaino foram obt $1-$ dos junto ao Age Laboratory da Universldade de Oxford. Inglaterra, por gentileza dos Dra. Paul N. Tawlor Stephen Moorbath, daquela Instituicton

As amostrat pulverizadas, tal como há pouco deserito, foram preparadas pelo método da eletroudeposita dupla, conforme Arden Gale (1974), e poster lormente depositadas sobre filamento linico de Rênio, com a asxilio de ácido fosforlco e silica gel.

As andises isotópicas do Pb reallaaram-se en espectrômetro de massa de fonte gólida, da marca VG-Isomass SAE, totalmente automat izado.

\section{A obtencão dè idade Pb-Pb em RT}

De acordo com Houtermans (1946, apud Köppel e Grinenfelder. 1979) Holmeg (1946, 1947 1949, aplud Köpel Gridnenfelder, op.

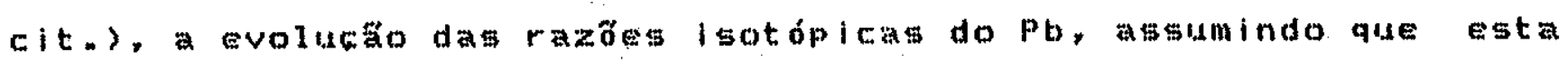
quolucão se procesuou, desde arigem da rerra até os dias de hoje, en sum sistema quimicamente fechado com diferentes razóes 
U/Pb, pode ser visualizada atraves da equacós elás lcas do deca imento radioat ivo

$$
\begin{aligned}
& P B 206 / P b 204=(P B 206 / P b 204) i+U 238 / P b 204(1238 T-1) \\
& \text { Pb207/Pb204 =(Pb207/Pb204)1 } \left.+ \text { U235/Pb204 (e } \lambda_{235 T}-1\right) \\
& \text { Pb208/PG2OA }
\end{aligned}
$$

onde as razoses acompantradas do indlce i relactonam-se aos seus valores no instante de formacto da Terra, ha $T$ anos passados $(T=$ 4,57 b. ... Tilton, 1973 Tatsumoto et al., 1973), conquanto as razóes restantas corregpondem aos seus valores no pregente.

Se náko houver fracionamento isotóplco, o chumbo extraido deste istema fechado, en un latante t qualquer, ter sua razáo $i-$ \$otopica (PbeO6/PbeQ4) definida por

$(P b 206 / P G 204) t=(P b 206 / P b 204) 1+4238 / P b 204\left(E \lambda_{238 T}-\lambda_{238 t}\right)$ (4)

Equacoses identicas podem ser construldas para as razóes $(P B 207 / P B 204) t=(P B 208 / P b 204) t$.

Se fizermos $(P b 206 / P b 204) i=a i, U 238 / P b 204=\mu i$

$$
(P B 207 / P Q 204) i=01,4235 / P Q 204=\frac{\mu 1}{137,88}
$$

e $(P b 208 / \mathrm{Pb} 204) 1=c 1, \mathrm{Th} 232 / \mathrm{Pb204}=\mathrm{W}_{\text {. }}$

$$
\begin{aligned}
& \text { sendo a } 1 \text { \% } 307 \\
& b i=10,294 \\
& c i=29.479 .
\end{aligned}
$$

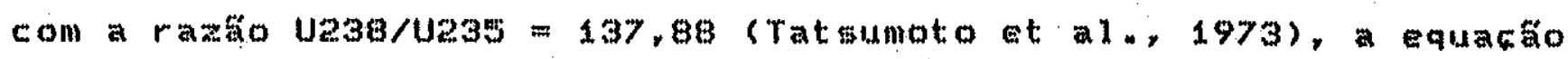


(4) suat similarem poden ser remencritas na format

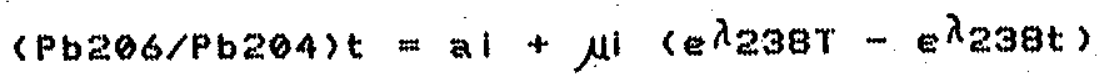

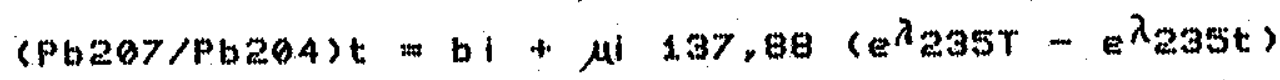

$$
\begin{aligned}
& \text { e (Pb208/Pb294)t }=c i+w\left(-\lambda_{232 T}-\lambda_{232 t}\right)
\end{aligned}
$$

Pasmando as razós iniclals al e bi para o membro a esquarda datequacto dividindo (6) por ( 5 ),

$$
\frac{(P b 207 / P b 204) t-b i}{(P b 206 / P b 204) t-a i}=\frac{1}{137.88}\left[\frac{\lambda_{235 T}-\lambda_{235 t}}{\lambda_{238 T}-\lambda_{238 t}}\right]
$$

pode-me calcular o coeficiente angular de uma reta (geócrona), para un ingtante t qualquer, atraves do membro direita da equacăo, uma vez que nesma é a equacio da reta na forma

$$
y-b=x a
$$

De igual modo. contiecido o coeficiente angular de uma isocrona, definlda por um conjunto de amostrab cogenéticas, o valor de trode ser obtido pelo uso de tabelas como apresentada por

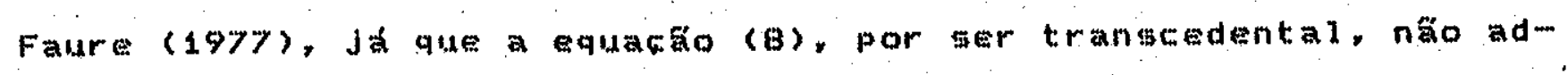
nite solutio algébrica.

Por una queqta de afinidade geoquinica, a relacăo U/Pb en geral decresce do manto muperior para a crosta, de tal modo que a ovolucăo imotóplca do pb radiogenico neste nivel es significativamente freada. Como congequencia, a semelhanca do que acontece com

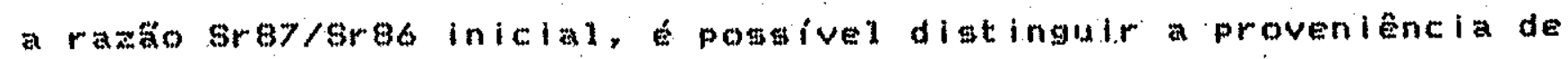
uma magna a partir do parânetro laza/pbeo4, denominado $\mu 1$, cono an cima mostrado. cujos valores situados no intervalo 7,5.- 8, 2 indicam magmag diferenciados do manto superior, enquanto resultados axternos, abaixo ou acima dos valores limites, denotam magmas rem 
sultantes de fusöes parciais da crosta terrestre.

\subsection{Anailises por Tracos de Flssão}

Datacoses por tracos de fissáo (TF) realizaran-se no centro Brasileiro de Pewquisas Físicas (CBPF), Rio de Janeiro, mobre varias populacosede apatitas oriundas de granitoides diversos do Escudo Sul-riomgrandente.

De um total de nove anostras coletadag, apenas cincose mostrairam adequadas a ste tipo de analise, mendo as restantes descartadas por nko apresentarem homogeneldade na diteribulato de urân lo nos grăos minerais.

OE cristaly de apat ita foram obtidos pelo método convencional. Apos a britagen da amostra, geparou-se en un jogo de peneiras a fraço desejada $(80-200 \mu m)$ e concentrafto de pesados se deu com o uso de bromoformio. As populaföeg de apat ltas de cada amostra, manualmente. selecionadas, foran divididas em dois conjuntos, sendo um deles aquecido soooc, por duas horat, para se apagarem os tracos de fissto espontâne prestentes e, a seguir, irradiado por neutron térmicos em reator nuclear do Instituto de Pesquisas de Energla Nuclear (IPEN) de Săo Paulo, cuja domagem neutrônica $\left(6,90+-0,13 \times 10^{-15} \mathrm{n}, \mathrm{cm}^{-2}\right)$ ge fezcom co uso de lâminas de vidro padráco preparadas pelo National Bureas of standarday Washington,

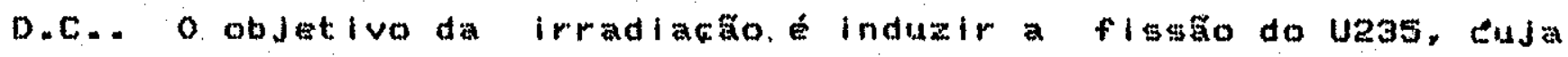
concentracáo pode ger dedazida pelo nimero de novos tracos produzidos. Como há uma relacto constante entre quantidades de u23s e U23B, o teor deste ultimo pode ger estimado. 
Em sequencia, ambos os conjuntos, Ja montados en epoxi e polidos on alumina, foram atacados por HNO3 a $5 \%$, por um tempo da ordem de 45 megundos, para a revelacádo dos tracos fósels cespontâneos) e induzidos. A contagem dos memos foi felta en microscóp lo Leintz, sob condicóge de luz trangmitida, usando-ge un aumento de $1250 x$ objetiva de imersăo de $100 x$.

Face ma particularidades demongtradas pelas apatitas, as datacoses realizaramme pelo "metodo de plateau" (Poupeau, 1981), com trea etapas de una hora de aquecimento a temperaturas de 300 , 310 e 3200c. Para cada catolo témico, as amostras foram analisadas

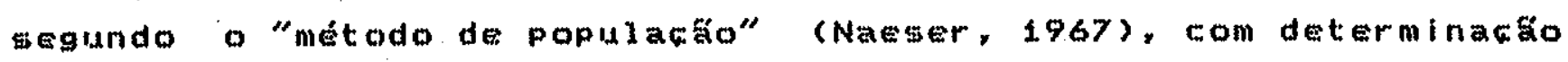
das densidades médiam de tracos fós tos de 40 cristais, na maior parte das vezes.

\section{- fenbmeno físico traco de fissão}

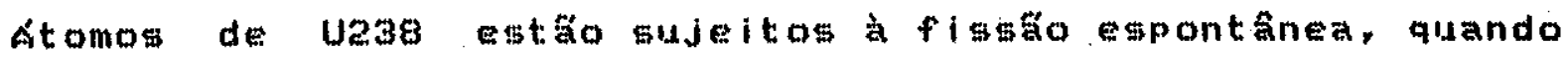

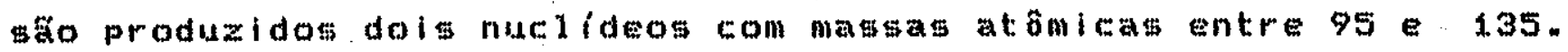
Nesta particato, ocorre una liberacto de energia da orden de zoomeV e os nuclideos resultante repelemme em difecós opostas carrem. garido uma energla cinética de 0,5 a 1 MeV/nucleon. Por serem particulas atamente ionlantes, roubam eletrons dos átomos que se pow sicionam naspoxinidades de suas trajetórias, determinando una concentraca de cargas potitivas que, ao se repeliren se afasm tarem mutumente, produzem un defeito estrutural cilindrico de comprimento variável de 10 a 20 um diametro de até 50 Á. Sáo exatamente estag perturbacós erlotalinas que se mostrarâ mais susceptiveis wos ataques quimicos, podendo, entäo, ser ampliadas ob-.. servadas, constituindo o que se denomina de traco de figstáo. 
A obtencăo de uma ldade por TF e seu sianificado

O número de tracos de fitsto obarvado en conjunto de mineraité proporcional a quantidade de uasg presente to tempo transcorrido desde o ingtante en que etas feicón comecaran a ser preservadas nos materiaim en qisegt áo. Assim, podems calcular uma idade TF atravet da equation

$t=1 / \lambda t \ln \left(1+\lambda t / \lambda f_{n} \sigma_{*} \phi_{n} I+D f / D i\right) \quad$ onde

$\lambda t$ e $\lambda f=$ conatantes de decaimento total por fissăgo do Ua38;

$\sigma$ área tranguersal ao bombardelo de neutrons térmicos para Inducto de fisso do 19235

x. $r a z$ a

$\varnothing$ = dose de neutrons:

Df e Di

A recomposica e demaparecimento dos tracos fósteis, em um dado mineral, acontecem por feito de aquecimentosn Isto pode impedir a determinaca da ldade primária do sistema, mas como os nesmos se preservam após o resfriamento, a partir de un valor próprio paracada tipo de mineral (120+m 200c para as apatitas), as idades TF precisam ser entendidas como o tempo decorrido desde que tal valor térmico foi atingido, en um epibódio de perda de calor. 
CAPITULO II

SINTESE DOS TRABALHOS GEOLÓgICOS E GEOCRONOĹ́GICOS ANTERIORES

\section{Evolucão do Pensamento Geológico-geotectônico Regional.}

oprimeiro trabalino de cunho geológico, rativo ao Ecudo do Rio Grande do 8ul, édevido Carvalho (1932), quando o autor, en base ao grau de metamorfismo, reconhectu subdividiu as rochas cristalinas e cristalofilianas do Estado em duas unidades, uma composta por rochas de alto gras metamófico, referida a Arqueano. outra constituida de litologias de balxo grau, supostamente algonqueana, denominada de serle porongos.

Na mesma oportunidade, Carvalho (op.cit., identificou ainda a "Série Camaquan". peferindo-me a uma empessa seqiencia clástica imatura, de carater predominantemente arcoseano, a preencher uma bacia sedimentar que de ixa cortar pelo rlo homónimo na altura de seu curso medio. Leinz et al. (1941) ampliaram e modificaram a estratigrafla descrita nos termos gerais de ent macosed Marica Camaquă.

Para Goñl (1962), az rochas do Premcambriano Inferior do Rlo Grande do sul eram estencialmente migmatiticas, homogeneas ou hem terogeneas, apresentando os mais diversificados tipos estruturais. Estas litologlas foram, na oportunidade, denominadas de Formacäo Cambai, cujos afloramentos-tipo podiam ser encontrados no arroio homôn imo.

Goñi et al. (1962) propuseran uma coluna stmatigráfica com- 
partimentada em trea unidades temporalmente distintas, a Formacáo Cambai, do Pré-Cambriano Inferlor, Mada como originalmente prom pogta, Formacáa Cerro Mantlaueiras, do Pré-Cambriano Médio, pertinente as asociacón de rochas maficas ultramafica metamorfizadas aflorantes na fracăo ocidental do Eacudo, o grupo Porongos, do pré-Cambriano Superior, cujo conceito, agora ampliado, Incluia a formacăo Vacacai, composta por todos of xistos exceto os da Formacăo Cerro Mantiquefras, os granitos da regito de EncrualThada do Sul e Formacto Cerro do Ouro.

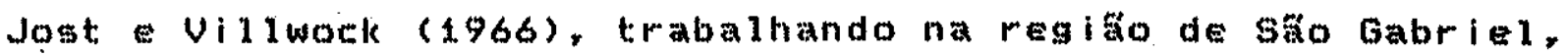
mencionaram una discordância angular entre a seqienciat de alto e balko graus metamórficos, redefinindo, en base as complexidades 1 itologica, estrutural metamorfica, o Orupo Cambai, mupostanente resultante de evento orogenito multo antigo. Neste mesno arti-9o, a formacose Corro Mantiquelras e Vacacai integraran o Grupo Porongos.

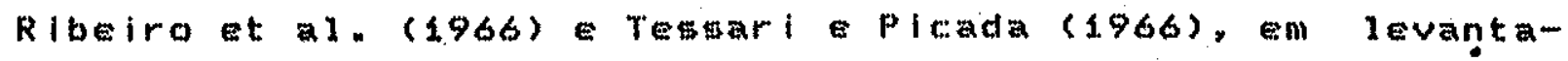
mentos geológicos detenvolvidos nas megiós de Cacapara do sul e Eneruzilhada do Sul, comentam nfo ter sido observada a inconformidade entre a Formaca Cambal e orupo porongon, incluindo a pri... meira no utimo. Nesse mesno trabalho, descreveram uma nova unlade basal, difcordante, denominada de Formacäo Encantadas.

Além dişo, identificaram rochat gedimentares valcânicag, englobadas sob a designacto de Grupo Bom Jardin, estratigraficamente colocada entre Formacáo Marica o orupo Camaquá, e deles Feparado por discordancias angulares, passivel de subdivisa dupa, de acordo com as caracterigticas estruturais e litológicas. 
Em Formaca Arroio dos Nobres (estenclalmente sedimentar) formam Gáo Crespos (vulcanitow ededimentitos associados). A primelra formacto foi ainda gubdividida em unidade hieráquicas menores: o membros Vargas Mangueirato (Tetarl Plcada, 1966). A subdivisáo da segunda, nos membros Hilário e Acampamento Veiho, fol dew vida Ribeiro ta $(1966)$.

O Grupo Camaquá, denominacto proposta em gubstitulẵo à série homônima de Carvalho (1932), foi redefinido subdividido por Ro-

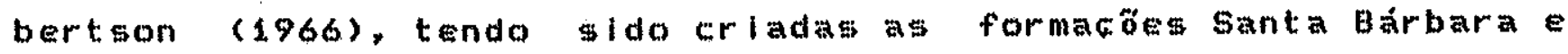
Guaritas, ambas repousando discordantemente sobre as unidades mais

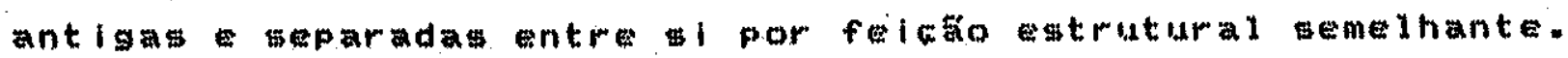

Williget a.$(1974)$ knijnik (1974) assumiram una coluna estratigrafica ligeiramente modificada, englobando no Grupo Porongos os sub-grupos Cambal, inferior, Vacacal, ste ultimo subdividido en uma unidade composta por sequênciag metassodimentares, na baste. Formacto cerro Mantiqueiras, no topo. A Formacäo Encantadas, como originalment proposta, continuou sendo a unidade mais antiga aflorante.

Ribeiroe Fantinel (1978) Ribeiro Lichtemberg(1978) demonstraram que o Escudo Sul-riomgrandense revela una regionalizacăo tectônica e. portanto, torna-se inviavel a utilizacto de uma coluna estratigrafica comun a toda reglay quando o criterio de correlacăo ara somente o da fimilaridade litologlcan Sugeriran, entäo, a redificacáto da estratigrafia do Escudo de forma particular para cada zona definfä, segundo critérios petrotectónicos. 
coluna estratigráfica dos depótios molassicos, que passou a cons-.. tituirmse de dois grupos: Bom Jardim Camaung, o primeiro composto pelat formacos Marlca, Hilarlo, Vargase Acampamento Velno, o litimo inalterado, permanecendo como originalmenta proposto por Robertson $(1966)$.

No mesmo ano de 1978 . Santos et a . propuseran para os mesmos depósito una subdivisâno etratigrafica similar a de Ribeiro Fantinel (1978), com um grupo basal (Marita), composto das FormaCós Pesteguelro ( Maricá de Ribeiro Fantined, op "eit.), Cerro do\$ Marting (subdividida nos menbros Hilario. Arrolo dos Nobres, repectivamente formactes Hilärio Vargas de Ribeiro e Fantine1. op. cit." Acamapamento Velho (ldêntica à de outros auto(r)

Nos dlas que corren, observamse uma tendencia de subdividir o Escudo do Rlo Grande do sul en fracö̌t que parecen revelar ambiencias geotectônicas distintas, cujas litologias componentes, por

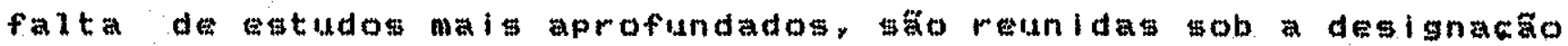
genérica ds complexos.

Na porcto legt do Escudo, mericionado o Compleso Granitico Dom Feliciano, originalmente definido por Tamar picada (1966), aflorante nos arredores dr eidade de igual nome. Egta mesma unidade foi referlda pelo projeto RADAMBRAsIl como Complexo toranitólde Arroio dos Ladröes (Telxeira, 1982) ou Suite Intrusiva Arroio dos Ladröes. (IsEler, 1984), denominacio original devida a picada (1965). O reatante da área orlental, inicialmente Incluida no Grim po Cambaí, após proposicáno de nơ ldentidade com as rochas aflo- 
rantes ao longo do aprolo homônimo, na porcano oeste, permanece im nominada, fazendo-se referencia a compos guaniticos especificos

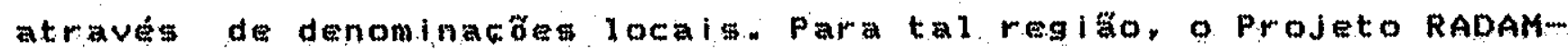
BRASIL tem at ilizado a designacto de Complowo Cangugu (Teixeira, 1982), mas anteriormente referido como Complexo Granitico de Leste por Ribelmo Fantinel (1978).

A unidade litoestratigrafica Grupo Porongom foi redefinida por Jost Bitencourt $(1980)$. Fragoso Cesar et al. (1982a) prom pöen que esta denominacto fique exclusiva das supracrustais dobradas e metanorfizadas aflorantes na fracto leste do Escudo gaúcho.

Ainda no leste, diferenciam-se granitóldes nas prokimldades de Eneruzithada do gul, definidos por Leinz (1945) como Grantto Encruallhada, citados como Complewo Granitico Encruzilhada (Tesmari e Picada, 1966), Complexo Granitólde Encruzilhada do Sul (Telkelra, 1982), sendo que os gnaisses asociados, orlginalmentes descritos como do crupo cambaí, sto referldos agora as sute Granitica Arroio Chantí (Jogt, 1984) ou ao Complexo Metamórfico Várzea do Capivarita (Frantz et 1.. 1984). A nomenclatura particular destas un ldades deve-ge a irdividuallacáco das mesmas através de limitem materializados: por extensas faixas miloniticas das zonas de transcorrênela denominadas de Passo do Marinheiro Vigia-Roque (Pleada, 1971).

A porcago oeste, por gua vez, admite uma dupla subdivisăor giona l atrues do Lineamento de Ibare (Hartmann Nardi, 1983). florando. ao sul de tal felcăo estrutural, rochas do complexo:Granulitico Santa Marla Chico. (Nardi Hartmann, 1979) granltódes reglonalmente associado a norte, rochas de balko a médio 
graug netamóricos componentes dos complexos Cambai (menses Fragoso Cesar Soliani Jr, 1984) ou Vila Nova (silva Filho, 1984), e aqueles conjunto litológicos que constituem o Cinturág de Rochas Verdes do Rio Vacacal (Fragoso Cegar e Soliani Jr, op.cit.), orim Ginalmente denominados de Formacto Vacacal, Formacáco Cerro Maritiquelras, como visto anteriormente, que agora pamsam ser mencionadom com romes locils, como Complexo Palma complexo Ibaré (Naumann et al, 1984), lgualmente anociados a mited graniticas divergas .

Os depódito gedimentares vulcanomsdimentarem, cujas gê-

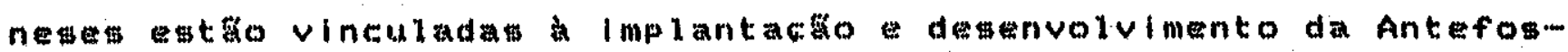
ma Moldubica do Sudegte (Fragowo Cesar et al, 1982a), emto sendo revisitados, medefinidos estratigraficamente reorganizados por Fragoso Cemar colaboradores (1984 1985) e feráo posteriormente discutidot.

\section{A Compartimentaço a Evoluço Geotectônicas}

Do ponto de vista geotectônico, registramos que diversos aum tores elaboraram eropuserami compartimentacós e modelos evolutivos distintom, ao longo do tempo, para o Escudo do Rio crande do Sul. Sinteticamente, destacamos Ims ler et al. (1965), que reconheceran duas grandeg unldadeg tectônicas, com histórlas geológicas distintas A primeira destä, na porca lesto do Escudo, foi capacterizada como un complexo gmaniticomigmatitico muito antigo, denominada "Craton Dom Feliciano". A segunda corresponderia à porca centro-ceste, onde afloram granitos, sequenclas metamófi-

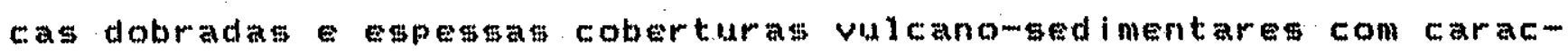
teristicas de depósitos molás icos, segundo a interpretacto daque 
I es pesquisadores.

picada (1971) admitiu que a regito centro-oeste do Escudo foi palco da "Orogenese Porongos", do Préctambriano superlor, e atri-.. buiu a "Craton Dom Foliciano" uma ldade préteambriana inferior a méd la.

Williget al. (1974) reuniman of dados geologlcos estrutu-

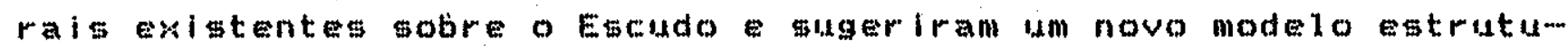
ral (estruturat de placas). na tentativa de explicar a evolucäo

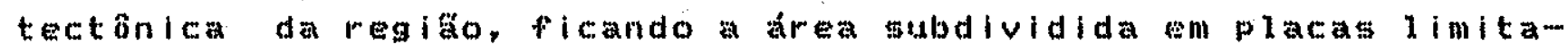
das por importantes zonas de falhamentos trangcorrentes, também portadoras de rejeitos verticais, responsávels pela formaço de fossas. altos struturals.

Neste mesmo trabalho, comentarios feitos em aneko, Cordani et. al. (1974) chamaram at:enca para o fato da que o padrángeocronológico encontrado no Uruguai. apregentado por ferrando fer-

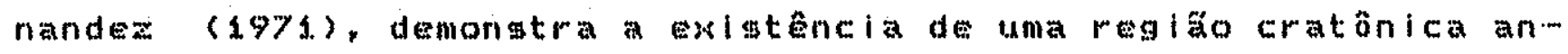
tiga na parte oestedaquele paíz, sendo que o limite entre esta área antiga a regico leste formada no premcambriano superior, parece entrar no Rio Grand do Sul. Da mema forma, continuaram, a provineia or lental do Escudo demonstra lima completa correlacäo com a regito congenere do Urugual. Etata diferenteg províneias ja .ham viam sido apontadas por Bossi at a1. (1967) e denominadab por Fer.... rando Fernandez (op.eit.) de "zocalo Predevoniano de La Cuenea del Rio de La Plata" "zocalo del Este y Sureste", sendo que, parm ra oprimeiro. Almeida et a1. (1973) propuseram a denominaca de "Craton de l.a Plata", cuja otorrancia no Rlo orande do sulera desconhes: idan 
Hasul et al. (197s) apresentaram uma subdivisa da frasa sul do enta denominado "Cinturăo Ribeira" en entldades geotectô nieas dos tipos "falkas de dobramentos" "macicos medianos", constituindo-\$e um trabalno de corralacto a abranger os estados meridionaig da Federacko o Uruguai. Nesta abordagen, a geologia do Préchambriano do Rio Grande do Sul compor-me-ia de fracós dos "Macico Mediano de Pelotas". "Faika de Dobramentos rijucas"e. possivelmente. "Macico Mediano de Joinvilie".

Ribeiro fantinel (1978), en bata a associacós petrotectôn nicas por eles descritas reconhecidas, dividiram o Egeudo Sulrio-grandense em zonas denominadas Madiana, Oeste Legte, que assinalarlam, retpectivamente, uma faika de subductán, uma regiáo de arco magmat lco implantado sobre um antigo escudo reativado e, por fim, un nivel relativamente mal profundo de um escudo também reativado. Segundo as palavia dos autorea, as zonas oeste leste ger lam" ". odua falka orogenicas de ldade bratiliana, correndo

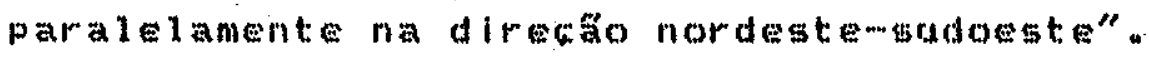

Face a novas determinacós radlometricas levadas a efeito sobre rochas granuliticas do sudoeste do Esudo do Rio brande do

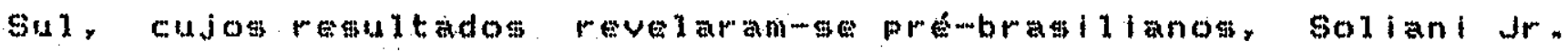
(1979) augeriu para a area tema uma dupla compartimentatato geotectônica, composta por uma "Faixa Móvel Bragiliana", correspondente

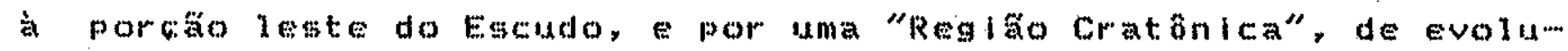

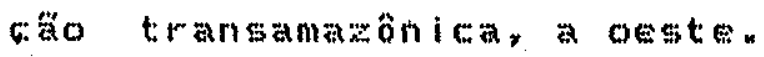

Jost a Btencourt: (1980) wost (1981), trabahando na porqäo petentrional da area do afloramento da "Faixa de Dobramentos Tijum sas". (sensu Hasui tet al. 1975) no Rio Grande do sul, concluiran 
pela exigtencia de dois conjuntos litológlcos distintos, denominados Orupo Cerro dos Madefras Complemo Cerro da Árvore, sendo o primeiro constituido de metassedimentos de balko grau smetarcóseos, quartaitom, xistom marmores), interpretado como tendo se depositado em ambiente de margam continental pasalva, do tipo Atlânticon o megundo compöe- de metandesitos, metadacitose tufos finos aos quala antercalan wistospeliticos, grafita wistos - raros auartzitom marmores. O compleso cerro da árvore foi interpretado como tendo gido formado en um arco de ilhas, potator mente transportado para oeste atraves de "nappes" inferiormente limitadas por oxtensas zonat de milonitom. Astim etarla demonstrada a vergoncia tectonica da unldade em directo a uma área cratônica colocada a ocidente. "

Un modelo alternativo de evolucto geodinamica foi proposto, e ven sendo defendido, por I

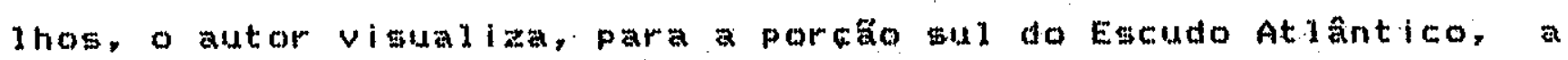
existencia de duas entidadetgeotectónicas os cratons do Rio de La Plata Dom Feliciano. colididos entre 1.000 e 680 in. a. passados. quando, am decorrencia do impacto, as rochas de bordo dos, me... gablocos foram significativamente remobilitadas. Corca de 100 m. após o choque, desenvolveram-3e. "rifts" intracontinentais que se deiwaram colmatar por "red beda", vulcanoghnese Intermediaria a ácida elutogance anorogânican

O Cration do Rio de La Platia, a oestex seria composto de terrenos "gresenstone" gnámicos, embora, como assinala o autor,

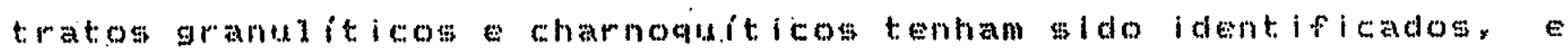

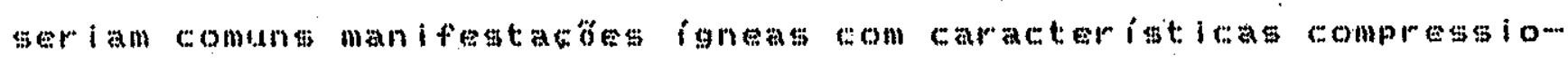
nais, de inicio. passando para uma geodinamica distensional com 
magmagente anorogsnica .

o Craton Don Feliciano, leste, estaria caracterizado por duas zonas petrotectônicas a Faixa Arcomfossa rijucas a Faixa Magmática Puda Grandegi A primeira representada pelos grupos Porongos (RS) e Brisque (SC) a asuinte pelo embasamento de leste, formado, segundo o altor, por gnaisses, diatexitos, metatexitos, "indiers de granulito", dioritos, anortositos, entre outros tipos litoldglcow ocorrentes como relictos.

\section{Enquadramento Geológico Reglonal do Escudo Sul-rio-grandense}

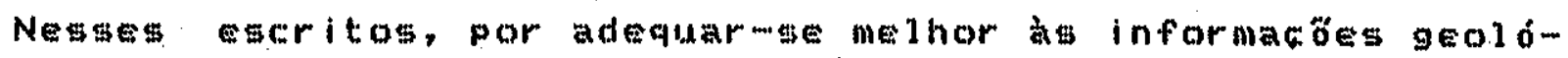
gicas aos dados geocronológlcowor nós colecionados, adotaremos, preliminarmente, o modelo geotectônico originalmente propogto por Fragoso Cegar (19g0) a seguir desenvolvido pelo mesmo autor - ses colaboradores. conforme passanos a discutir.

\subsection{O Cinturão Dom Feliciano o Cráton do Rio de La Plata}

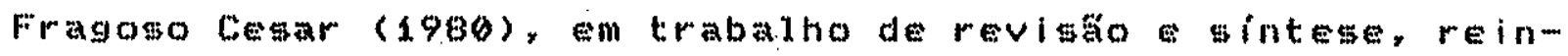
terpretou a acervo de dadom dibonivel para o sudeste da plata... forma sul-americana, ampliando significativamente a area de ocorrência do Cráton do Rio de Ima Plata, como passou a ser chamado, a te entäo reconhecido apenatiom algumas localidades do norte da Arm gentina e na portáto ocidental do fiscudo Urugualo. Gegundo este autor, ag ovidenciag geológicasugeriam fortemente a continuašo da unidade eratonica no oeste do Rio orande do Gul, gendo consti-. tuida dos conjuntos litológicos posicionados a ocidente da Bacia do Canaquä, e, levando en conta a extensäo setentrional das correw 
lacoses feltas por Hasul et al. (1975), o Macico Mediano de Joinvi... Ie representarla, face a algumag ldadeb radiometricas já reveladas, um acunhamento do Cráton do Rio de La Plata em direcáo ao norte (fign).

Considerando toda a área cratônica, propostacomofoi acima nistoriado, o autor mencionado reconheceu ainda que a mesna pode-..ria ser litológicamente subdividida em "terrenos gnássicomgranitcos", de ocorrencia dismeminada contre santa Catarina e o Uruguai, com evolugáo seológica altamente complewa, "cinturónes vulcano-sedimentaret", com caracterititio gerais de "greentone belts", do ocorrencias melativamente restritas mo sul e noroeste

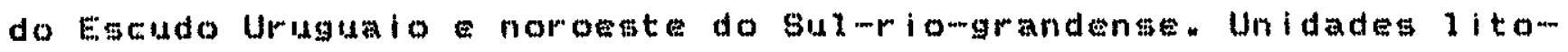
1óicas relacionadas ac Ciclo Brasiliano dempenhar iam o papel de depósitos de cobertura. astociados a manifestacous masmaticas con-m temporâneat, assentandow mobre a anteriores atraves de profunda discordânc la .

o apecto mai interemante desse trabalho talvez resida no fato de que, pela primeira ves, o Macico Mediano de pelotas a a falxas de dobramentos adjacentes, Tijucas do Leste uruguaio (Hasul et a 1., op.cit.), form apresentadat comoparcelas de una

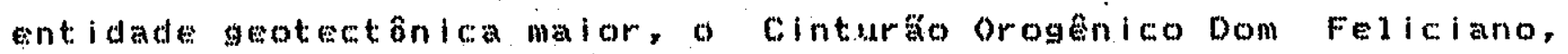
de lada brasiliana, marginal ao Craton do Rlo de La Plata ca ca racter lata por complexos metamórficompaniticomigmatiticos dism tribuidos em tras bandas paraledas, informalmente denominadas de zona Contral flancos ocidental oriental (fig. 2).

o. Fanco ocidental dessa faxa constituirla uma fracăo da crosta onde se associarian tectonicamente: (a) o embasamento pré- 
Brasiliano, composto de rochas gnatsoleas migmatiticas, ocorrendo ou de forma aparentenente concordante com o Craton do Rio de La Plata, onde a separacto só evidenciada, not tempos atuaj, cono auxilio da geocronologia (como no Urugual), ou na forma de nucleos de. Etruturat antiformala ou dônicas (Santa Catarina Rio Grande do 541 ); (b) sequências orogênicas brasilianas, representadas por parametamorfitos de balko grau interealados com metavulcanicas ácidas intermediarias (c) mequanciasepitalaticas imaturas com

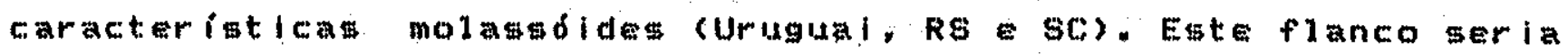
equivalente a Falxa de Dobramento rijucas. de Hasul et al. (op. (it. ), excetuandome om metamorfitos que ocorren, no Rio corande do sul, a oeste da Bacia do canaquá.

O Flanco orlental expôm- momente no extremo sudeste do Uru-

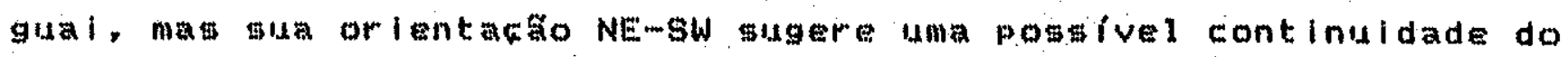
nesmo sob os depósitos cenozóicos da Província Costeira do Rio Grande do Sul. A semelhanga do Flanco ocidental, compöeme de rom chas parametamórficas de baixo grau. Esta unidade equivaler-se-ia a Faika de Dobramentos do Leste Uruguaio de Hassi et al. Cop. (ct.).

A Zona Central (Macloo Mediano de Pelotas de Hasui et al..op.

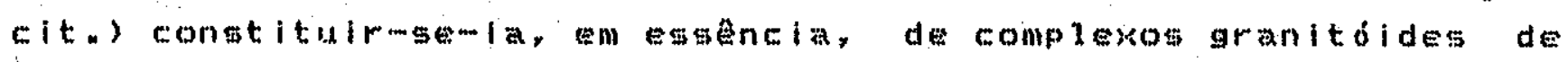
proporcốs batoliticas que \#e asocian a resíduos mignatiticos. Composicionalmente, estas litologiab variam de guartaomioritos a granitos, com termog monzoniticom, granodioriticos natureza calci-alcalina a sub-alcalina. Microgranitos pófiros e riolitos sa freqienteg neste dominio esta duma zona muito bem representada no Uruguai, Rio Grande do Sul Santa Catarina, conforme se ve na fig. 2. 


\subsection{As Associacöes Petrotectónicas do Cinturáo Dom Feliciano}

Com base na compartimentacoso geotectonica do gudegteda Plataforma Sul-amerlcana, proposta por Fragomo Cesar (1980), e rios trabalhos regionalg, de reconhecimento geológico os de gintem.

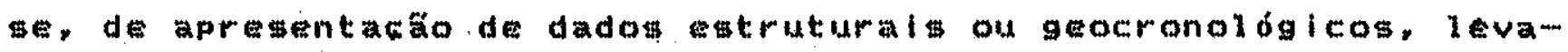
dog, a efeito Santa Cotarina, Rio Grande do Sul Uruguai, Fram

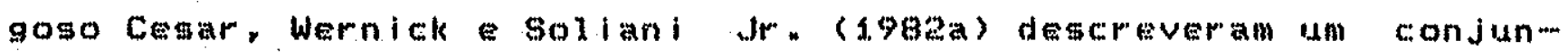

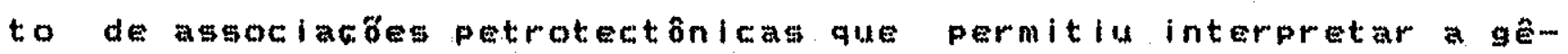
nese Evolug nigmos preconizados pela Tectónica de placas (fragoso Cosar,

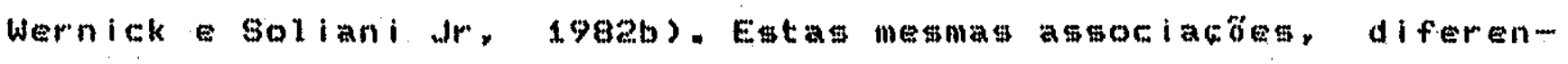
ciadas em conscilancin de suas distintas hlstorias paleogeográ

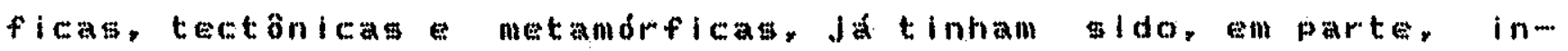
terpretadas por Ribeiro Fantinel. (1978), Ribeiro Lichtemberg

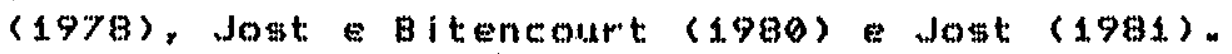

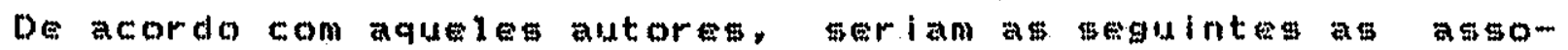

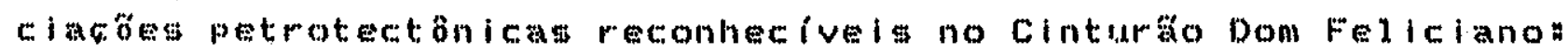

... Associaḉo do Embasamento No dominio da faixa de dobra-

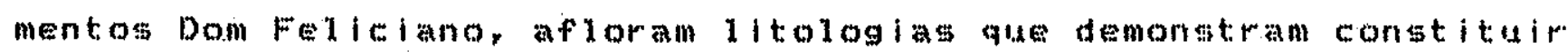

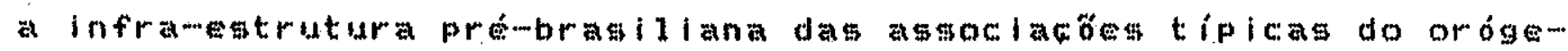
no enfocadon

De foto, en santa Catarina, a gul de Camborid, no trecho da

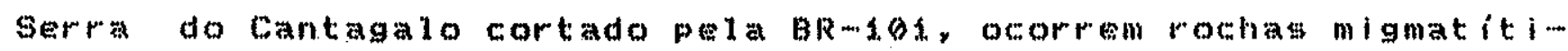

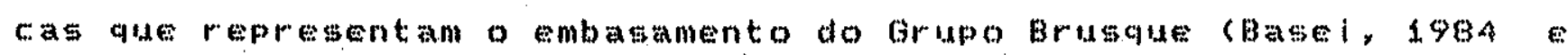

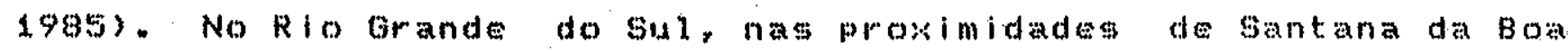

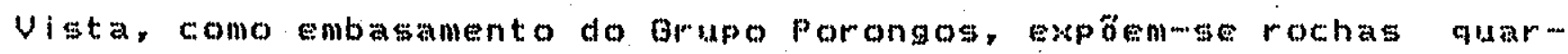

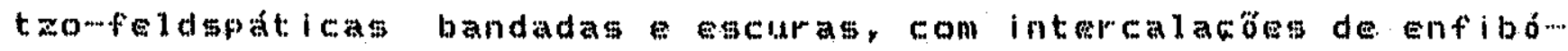


1io gnaigses muscovita witos, denominadas do Conaimges Encata clas. No Uruguai, o embamamento do cinturăo oroganico é representado por rochas gnáisaicas com aparente continuidade para a área cratônica. Emtas ocorrencias caracterlatarlan, assin, uma "associacáo Potrotectônica do embatamento" (fig. 5 ).

- Associaço de Margem Continental Passiva -.. No Flanco Ocidental do cinturgo Dom Feliciano, en digcordancia sobre o cmbasa-

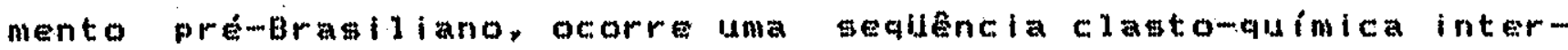
pretada por Jost (1989) como representativa de una deposicáno préorogenica acontecta em una margen continental paselva do tipo At lântico, como ja referido, dencominada por aguele autor de Grupo Cerro dos Madeiras redefinida por Fragomo Cesar, Wernick Soliani Jr. (1982a) como subgrupo e incluido no Grupo Porongos (fig. 3).

Estes ditimos perquimadores reconheceram que, cm Santa Catarina, no Grupo Brusque, correlato aos Grupos Porongog (RS) L La Valleja (Uruguai), a existâncla de metaréseos, filitos caleiferos, quartaitos, dolomitos metapelitos tamben sugere um amblente de margen continental passiva. As sequancias Arenoga (quartaitos e metarcósecos) e Argilomalcaria (filitos, filitos calciferos mámores do orupo livald ja foram Indicadas como, possivelmente, correlatas ao Subgrupo Cerro dos Made iras.

-.. Associacto de Bacia Marginal -wobre associacio anterior.

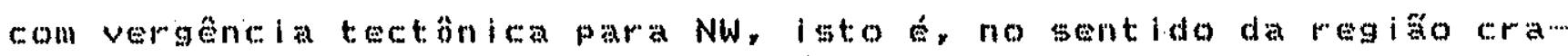
tônica, ocorre una sequancia vule anomedimentar, também integrante do Grupo porongos. denominada de Complewo Cerro da Ávore bJost Biteneourt, 1980; Jost, 1981). Fragoso Cesar, Wernick Soliani 
Jr. (1982a) Interpretaram-na como repreantante dog depósitos de 4ma bacia marglnal gituada entre uma margem continetal originalnente passlva, oeste, um arco magmático ativo, a leste (fig. 4). Evoluida durante a fase orogenica, teria gido carreada por sobre Associacto de Margem Continental Passiva ao longo da fase de encurtamento crustal congequente de uma colisto continental.

No Uruguai, pombivelmente correlata ao Complexo Cerro da Arvore. os autores sugeren a sequencia Ortometamófflca do Grupo Lam valleja, com clorita xistom, actinolititom prasinitos, além de Wigtos talcosos grafitosos intercalados metapelitos, conforme descricote de Ferrando F Frandez (1971).

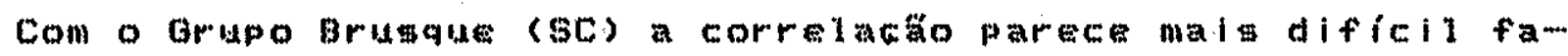
ce as descricốt ainda ger tanto. a ocorrancia do metagrauvaquge metariolitos xistificados. pode ser gugetiviva.

-.. Associacão de Arco Magmát ico -. Compresendendo a Zona Central do cinturato Don Feliciano. constitiense de complexos polifasicos representados por amplas áreas anatetica o migmáticas resulantes

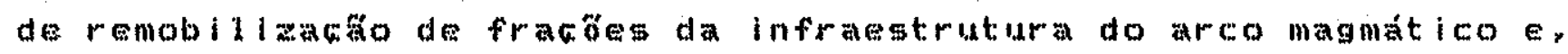
talvez, do embasamento, aseciados a conplexog graniticos polidia-

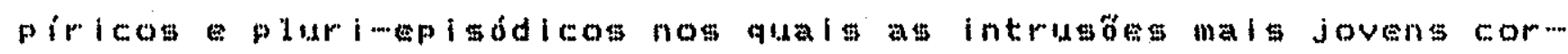

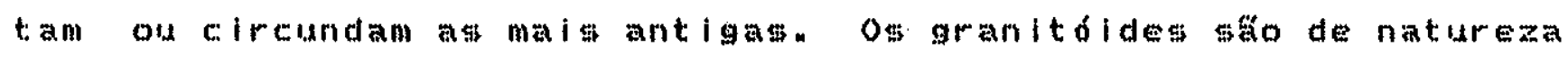
calcimalcalina a sub-alcalina, apenas localmente com carder al calino, equigranulares a porfirdides, leuco a mesocraticos apre-

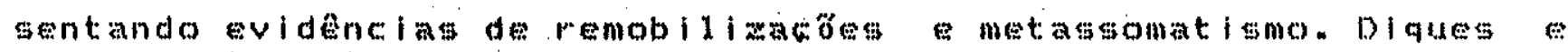
"plugs"de granitos póplirom, enxames de diques rloditicos, apliticos granofirlcos asocian-se fase final de evoluta do do cintu.... 
răo.

Conforme já sugerldo por Ribeiro Fantinel (1978) e endossado por Fragoso Cesar, Wernick Soliani Jr. (1982a), esta associam (a) de rochas parece repreantar um nivel crustal relativamente profundo de um arto magnático exumado (fig.4). As sequîncias su-.. pracrutais deste arco, da serie basaltomandesito-riolito, devem ter sido suprimldas por eromáo. Por outro lado, rochas vulcânicas potasicali provavelmente contínuas com a supramestutura do arco, foram preservadas na Associacto de Bacia Marginal.

Como reflexo da at Ividade do arco magmático, ocorren intru-

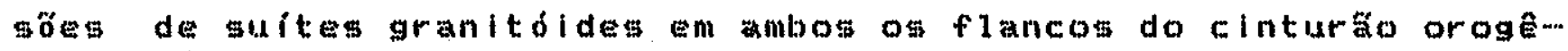
nico, afetando a litologiag geradas en guas bacias marginais, com as quals limitame atravé de complewos $\$$ lstemas de falhas respon-

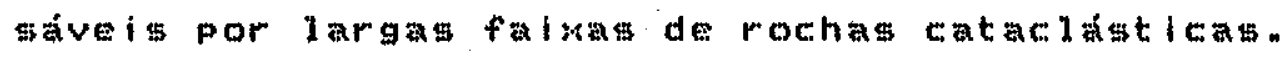

-.- Associacão de Bacia Frontal ... Equivalente a fanco Orien-

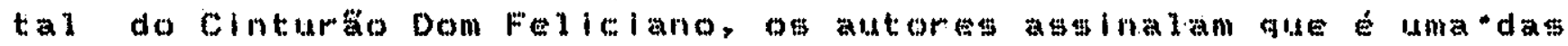

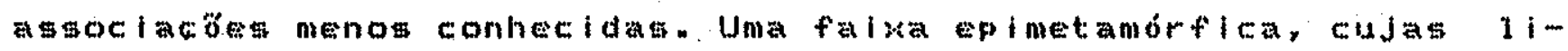

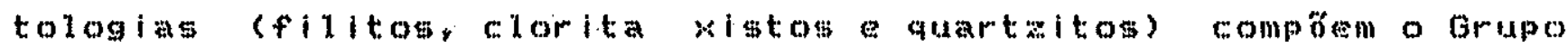
Rocha (Hasui et a " vilcanomsedimentar deponltada em uma bacia frontal a aroo magmán tico (fig. A).

-.- Associacónes Molássicas - Para Fragoso Cemar, Wernick es So-

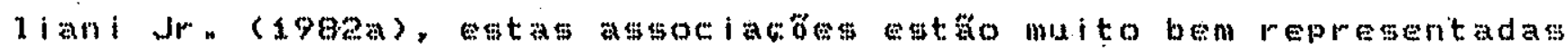
em Santa Catarina Rio Brande do Sul, podendo ser divididas, com

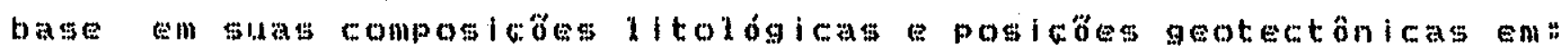

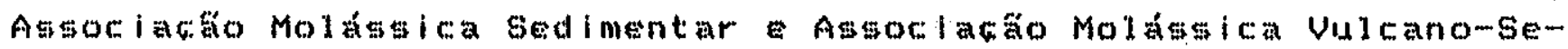


dimentar ( $f(g .5)$

A primeira, com ausente ou egporadica contribulcáo vulcânica, prenche uma calla tectônica qu serviria de linite entre o cintur rấo Dom Felicimo o Cratton do Rio de La Plata, denominada de An-

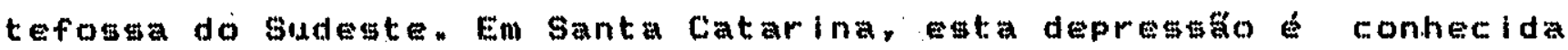
como Bacia do Itajai e, no Rio Grande do sul, como Bacia do Cama-

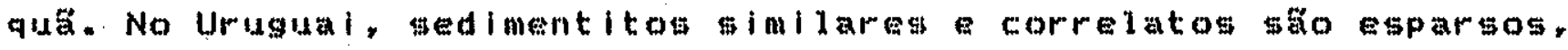
atestando una profunda erosäo desta asociacto.

No atado gadcho, os depósitos dessa antefossa recobririam Parclalment as rochas das asociacos de Margen continental pasgiva de Bacla Marginal, a leste, e etender-se-ian por sobre a

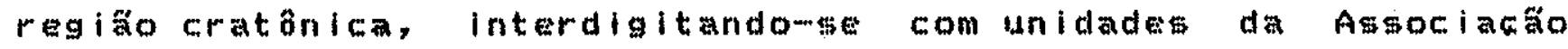
Mol ás

A Associaço Molassica Sedimentar fo compota, da base para o topo, de sequencias de leque thomarinos, sequênelas marinhas de aguas rasas, ambas podendo apresentar subordinadas intercalacós

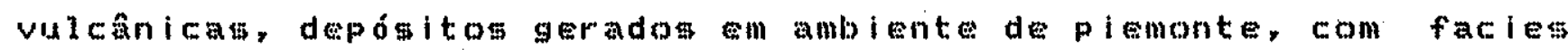

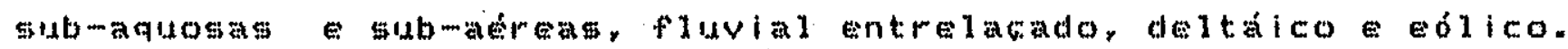

A Astoclactio Molatsica Vulcano-gedimentar resulta da at ividam de de centros magmáticos condicionados asos eruamentos de fraturas regionais, gerando rochas vile

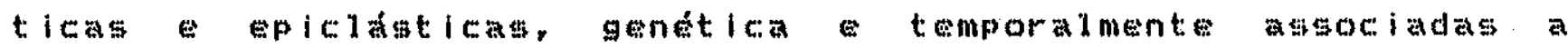
"gtocks" meso opiticetonicos.

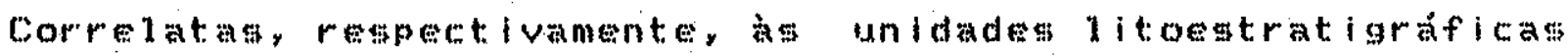

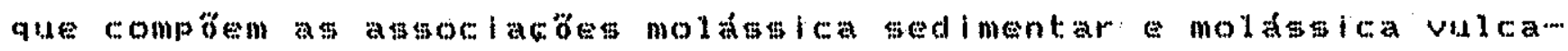


nomsedimentar, seriam os grupos Itajai, para a primeira, e Guaraw tubinha Campo Alegre, para a gegunda, em Santa Catarina cembora os autors lembrem que estes doil iltimos podem estar pracionados

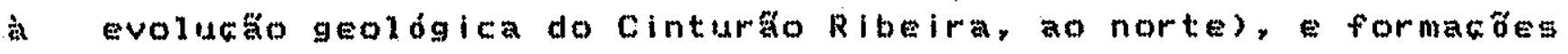
Pledras de Afilar Gierra de Animas, no Urugual.

\subsection{A Compartimentafs̃o Tectînica do Cráton do Rio de La Plata}

Para o Cráton do Rio de La Plata (sensu Fragoso Cesar,“1980), Fragoso Cesar Sollani Jr. (1984) Elaboraram uma compartimentacko tectônica prelininar em "clnturöes granuliticom" "terrenos gra

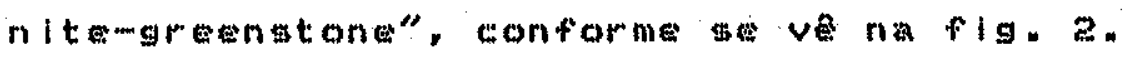

- Cintura Oronulitico de Ganta Catarina (Hartmann et al.. 1979) está representado no extremo getuntrional da regiâco cratônicar constituldo do gnalsses quartzomfeldapticos, gnalsses bas icos. kinzigitos, ultramafitos quartaitom metamorfizados nas faciess anfibolito grandito, sendo excasas as rochas graniticas. Do ponto de vinta estrutural, o cinturfo orientame preferencialment: segudo NE. .

o Cintura Gro Gulitico Valentines, proposto pelog primeiros

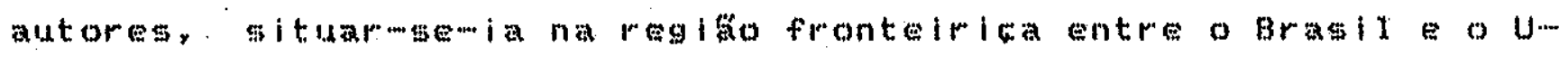
rugua i fordando, face as coberturas abdimentares paleozócas da

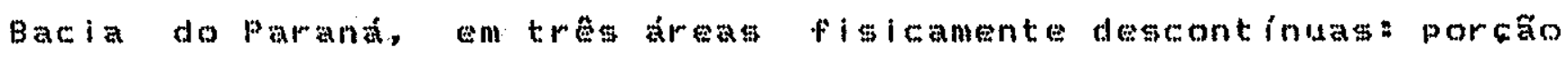
centromor- to do Escudo Urugualo (regiano de Valentines), "ilha cristalina" de Rivera cno norte do Uruguai, onde encontram-se as localidades de Vichadero Minas de Corrales e porcáo sudoeste do Egcudo do Rio Grande do Sul (fig. 2). Litologicamente, compöem

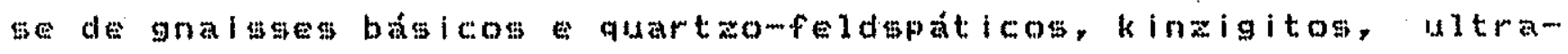


nafitos, anortositos, mámores, quartzitos ferriforos, entre outros, sendo frequentes intrusobes granit icas do cambriano. A or ien-tacto geral da unidade $\mathrm{NW}$

Tamban ser iam dola os "tarrenos granit ewgrenstone" do cráton do. Rio de la plata, Deparados pelo Cinturato Granditico Valentines: Terreno oranite-grenstone do Urugua e Terreno foranitegreenstone do Rio (irande do sul (fig. 2 )"

A Formactio Paso Beverino, que maig se assemedha a uma sequência tipo "greenstone" compöewe de metabasitos, anflbolitos, metarlolitos, Kistos magneslanos, clorita xistom, quartaltos wistos"grafitosos, com raros mármores dolomíticos. Alojame, ao que parece, entre batólitos ovaig de granitóde também intrudida

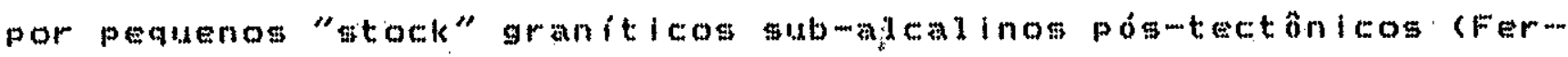
rando Fernandeat. 1971).

A. Formaço Arrolo brande caracterizame por metalavas básicas, anfibolitom, clorita xistos, rochas defiticas carenitos conglomerados) metamorfiandas "sto comumente intrudidas por corpos igneos de compos lo äo variavel cotre granodioritos leucogranitos (Ferrando Frnandez, opecit. ).

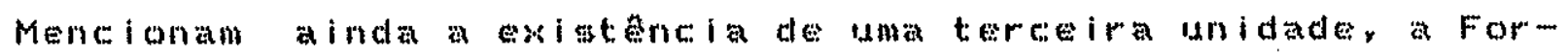
mata Montevideo, de grau metamófico medio, constituida por anfin bolitos, gnaibses wistos derlvados de rochas basteas, quartzo-

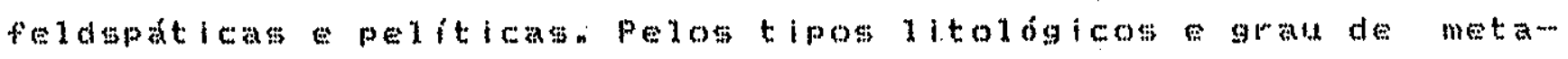
morfismo, os autors acham dificil caracterizanda como sectiencia do tipo "greenstone". 
Associado a ested cinturöes de rochas supracrustal ocorre l.m complexo graniticomgnáissico formado por granitóldes gnálssicos calci alcalinos, migmatios diversos, con regtos de anfibolitose ultramafitos, granitos de variog tipos, entre outros.

O Terreno Granite-greenstone do Rlo orande do Sul, delineado na porâno noroest do escudo homônimo, estarla composto de um esm pesso conjunto metamórfico de peridotitos, dunitos, basaltos, gabros cen parte transformatos om gerpentinitos, wistos magnesianos, anfibolitos, etc. , andateos, dacitos, traquitos (xistificados), acompanhados. de rochas pirociáticas químicas, caracterizando

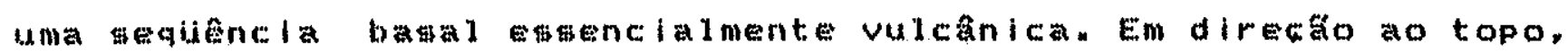

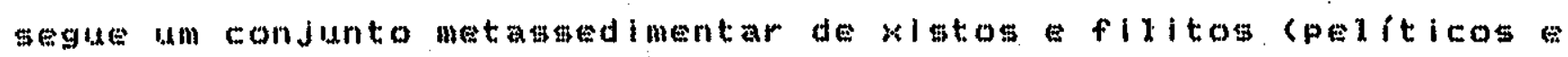
quartzomfeldspaticos), com carateristicas "flyshódeg", para ortoconglomeratos, graivaques, arcóseos, guartzitos sedimentitos quimicos. A hipótese de que estas sequencias de baixo grau constituam uma litoestrutura do tipo "grengtone belt" foi lancada por Nardi Hartmann (1979). Fragoso Cesar (1980) baseiame em l.tma dezena de motivos apresentados por Fragoso Cesar e Soliani Jr. (1984).

Concordantemente associado ao muposto "Greenstone Belt" do Rio Vacacai, ocorre o Compleso Cambai contituido de aranitódes

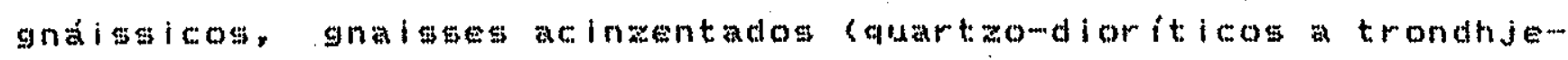
miticos, migmatitos, anfibolitos macicos gnaistes anfiboliti cos, ditramafitos, quartaitos, marmores, etcon, com varias fases de

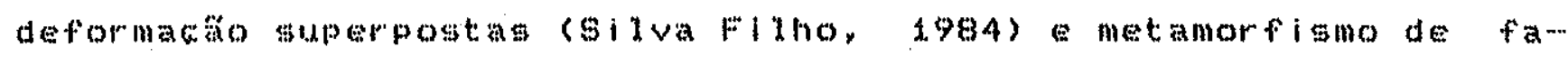
cies anfibolito. conforme já assinalado por Goñ Jost Q Viltwock $(1966)$, Ribeiro et al $(1966)$ e Ribeiro e Fantinel (1978). Nesta ára gro tamben comuns os aranitóldes isótropos. 


\section{Consideracỗes sobre a Gecronologia Reglonal}

O primeiro trabalho de integrata regional e sintese georonologica do Escudo Sulmiongrandense devido a Cordani at al. (1974). Neste comentário, os autores relacionam quaste uma centena de dados radiométricos relativos à rochas do Préclambriano Eo-

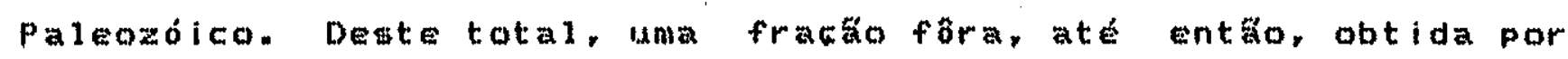
outros pesquisadores, no exterior ou junto a CPGeolusp, como os Minioli Kawaghita (1971), Imster al. (1973), Teixelra (1969), Ribeiro Teikeira $(1970)$, Formoso (1972) Robertson (1966).

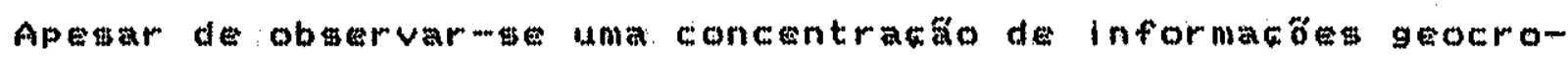
nológicas nas areas de Cacapava do Sul, Lavias do Sul Encruzi Ihada do Sul, vár los pontos dispergos en outras porcós do Escudo

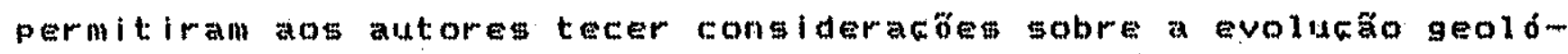
gica regional. A partir do padröo de laded encontrado no Uruguai e ralado por Ferrando fernandez (1971), la ama proposicto ini-

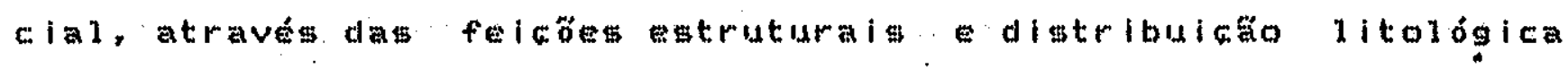
similares entre aquela Republica o Rio Grande do sul, de que o

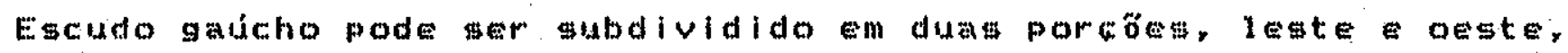
a primeira de evoluca orosiliana outra, face a ocorrencla de

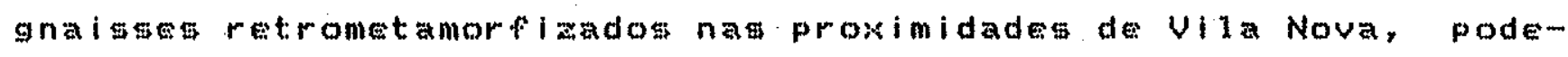

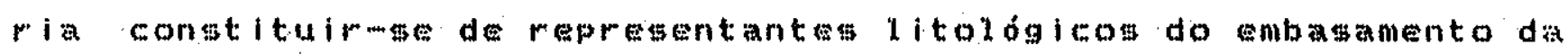
faika de dobramentos do Premcambriano superior.

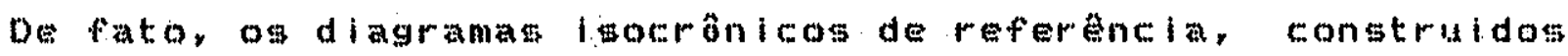
com dados Ro-Sr provententes de rochas do getor oriental con cam racteristicas sintectónicas coranitos com orlentaca pronunciada migmatitos) (a) pómtectônicas (granitos equigranulares finose grosseiros, isotropost, revelaram, respectivamente, valores de 650 
- $600 \mathrm{~m}$. das épocas evolutivas do cinturäo móvel parcialmente representado no leste do Rio orande do sul.

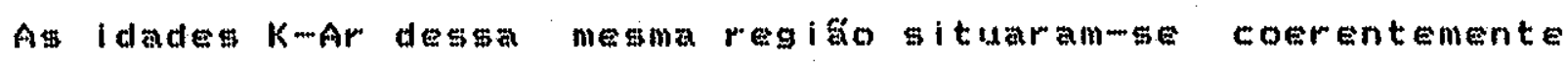
no intervalo caracteriatico do ciclo Brasiliano.

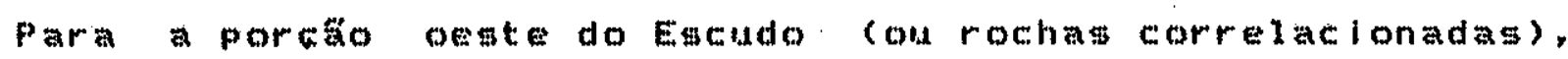

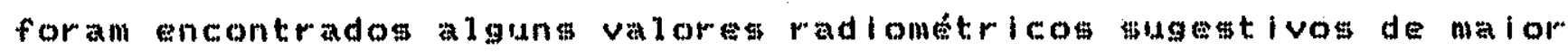
ant lguldade, \$Eja pelo metodo Kb-gr (Gnaimgas Encantadag), geja

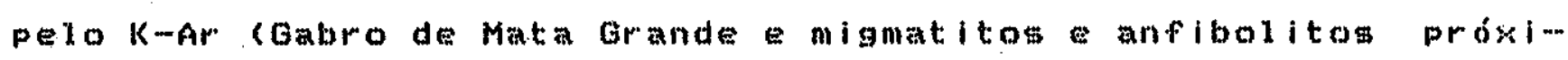

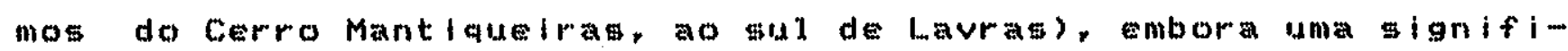
Eativa percentagem dos dados disfonivels revelassom idades brasim 1 ianag para lama grande vartedade de macicos graniticos, como os de

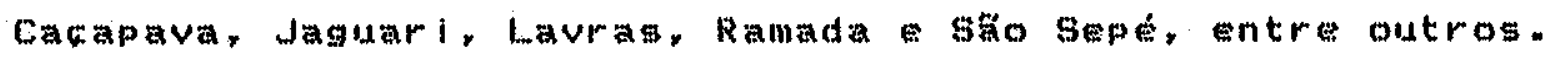

Da megma forma, og autores confirman qu a

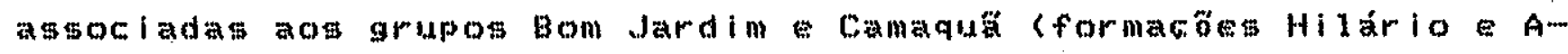
campamento Veltos, formaramma no final do Premambriano ou inicio do Fanteróico, tal como já havia gido revelado por Minioli e Kam wastita (1971.).

sartori (1978) laborou importante trabalho getoronológico no

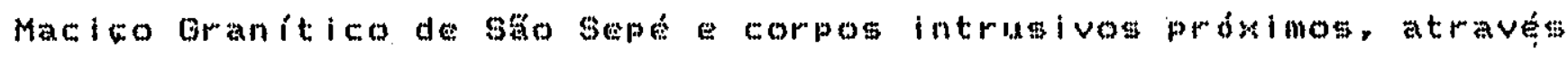
de diagramas isocrônicos Rb-sr, demonstrando uma evolucto polifá

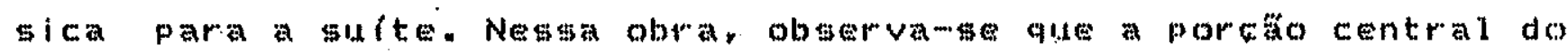
macico fornece a mas antiga ldade, cerca de 670 moneinterpretada como correstonde a fasto rochas purifericas, mais jovens, com tog mo a. tibilidade temporal com a fase posmtectonfen do menciondo evento 
orogenico. Em comentário adicional, o autor ressalva que, apesar. dos corpos graniticos sulmiompandenses terem gido classificados comogin, tardi póm-tectônicos (Wernick Penalva, 1978), no que se refere no complewo de sto sepe as duag fases fina rencaveis, seja por criterios petrograficos, seja por geocronológicos, mugere que og tarmos tardi fódutectónico mejam considerados equivalentes, ate que possam ser convincentemente caracteri$2 \operatorname{ados}$

toraça a un convênio firmado entre o Projeto RADAMBRASIL 0 Instituto de Geociencias da Universidade de sto Pador mais de meia centena de novos resultados radlometrlcos foi adicionada aos

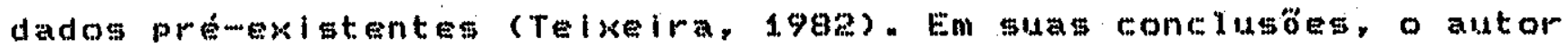
menciona o fato de que parece existir, na porcacocidental do Escudo, um fragmento erustal do proterozolico Infertor, semelhanca clo que pode ser claramente constatado no Uruguai, constituido por rochas do complewo canbai. As litologiag do chamado complexo Vacacal e Formaca Arroio das Ihas, tal como se propore no mencionado

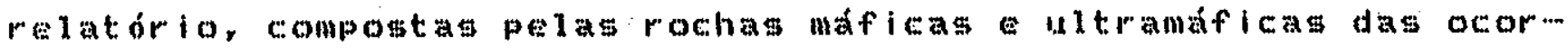
renci as de Mata Grande, Cerro Mantiqueiras, Palnas, etc., e xistos

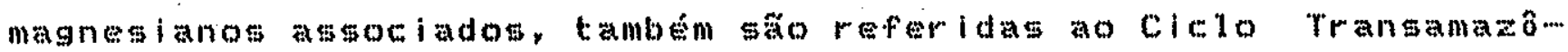
nico, portando evidancias de rejuvenescimentos brasidianos.

o Complexo Cangucu, unidade decorrente da ampliata da area amostrada, originalmente atribuida a Grupo Cambaí por similaridade litologica com partelas da fraco octo (Ribeiro et: al. $1966 \%$ Tessari picada, 1966, Carraro et a d y 1974) posteriormente arem ferida como cambal de towte por Ribeiro Fantined (1979), abrange quase toda a porcto oriental do Escudo, onde concentram-me rochas migmatiticas, gnábsicas graniticas, expostas a leste da dorsal. 
homônima. Este dominio. atraves de isóconas de referencia, foi considerado como essenclalmente brasiliano (Teixeira, 1982).

Igualmente brasilianos revelaranme outros doninios menores Individualizados na porga lesto do Egcudo, como os complexos gra-

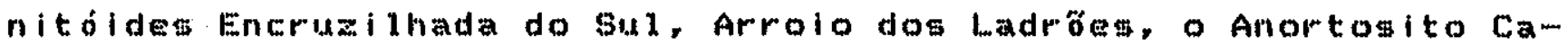
Plvaritar o Sienito Piquiri o Quartzomonzonito Campinas, com Eventualu problemas interpretativos.

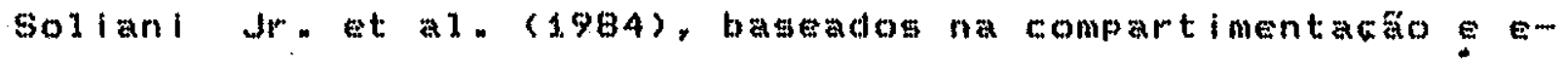
voluga to tectonlea sugeridas por Fragoso Cogar (1980). Fragoso Ce-

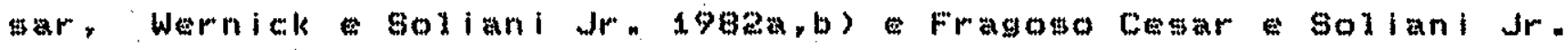
(1984), apresentaran uma sintege de todas as determinacónes radion... métricas obtidas em rochas eristalinasy crigtalofilianas sedimentares da porcto meridional do Escudo At lântico, abrangendo parte do Estado de Santa Catarina todo o Rio Grande do Sul Uruguat i. .

Sartori Kawamita $(1995)$, iniciando sm estudo gigtenático do Batolito Granitico de Cafapava do Sul, ralizaram analises pe-..

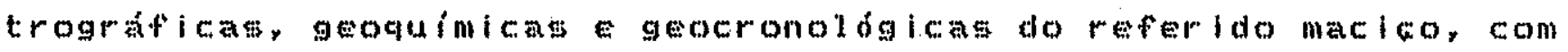
o objetivo de dirimir alguns aspectos controversos. Nosse artigo. os autores relacionam. 21 novag andises lsotipicas de idade, en rochamtotal, pelo metodo Rb-Sr, que somadas a 4 dados anteriormen-

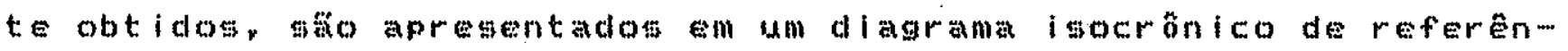
Ci: i a n

Por fim, cobe nencionar alguns resultados radtometricos Rb-gr

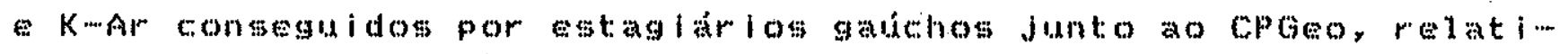
vos a corpos litologicos aflorantes on suas areas de estudos, cono 
e caso de Naumann ( 1984 ), que anal izou amostras de um granito intrusivo no Complexo Ibaré, Pinheiro Machado (em prep.), que descreveu os gnaisses associados aos ultramafitos da regiáo do cerro Mantiqueirag, sul de Lavrä, Remus (emprepn), que desenvolveu peqquisas nos gnaisses egranitóldes das proximidades do Arroio Cambaizinho,em săo Gabrie1, e Naime (em prep.), sobre os "stocks" graniticos da Ramada do Cerro da Cria. 
CAP ÍTULO, II I

\section{GEOCRONOLOGIA DA PORCXO LESTE DO ESCUDO SUL-RIO-GRANDENSE}

\section{Consideracôes Iniciais}

Com o intuito de apresentar ediscutir os dados geocronológicos, disponiveis para o Escudo do Rio trande do sul, de forma setor izada, adotaremos, neste trabalho, a compartimentacán tectônica proposta para area por Fragoso Cesar (1980), Fragoso Cesar et a1. (1982a, b) Fragoso Cesar e soliani Jr. (1984) conforme se visualiza na figura 2 . Sempre que necessário possived, utilizaremos subdivisöes a inda menores, tais como as propostas por Horbach et al. (no prelo, apud Issler, 1984), Frantzet al. (1984), Frantze Jost (1983), Jost e Hartmann (1984), entre outros.

\section{O Flanco Ocidental.}

\subsection{Ombasamento do Cinturão Dom Feliciano}

\section{Sintese Geológica}

No mapeamento geológico das quadriculas de Cacapava do Sule Encruzilhada do sul, Ribeiro et al. (1966) e ressari e picada (1966) definiram a Formagáo Encantadas, composta por gnaisses à biotita, hornblenda e granada e quartaitos à hornblenda. reconhecendo-m como unidade sotoposta ao Grupo porongos por discordância angular. Ocorrendo nas proximidades de Santana da Boa Vista e, mais a nordeste, a ocidente do Arroio dos Nobres, esta 
unidade foi sempre reconhecida como uma fracăo do embasamento aflorante como núleleos de estruturas dômicas ou antiforma is (fig. 6). De acordo com Jost (1981), a litologia mais representativa da unidade säo os snaisses bandados quartaofeldspaticos, de granulometria média a fina, coloracăo acinzentada escura. Associadamente, de forma menos comum, ocorrem gnaisses à anfibólio, quartaitos existosn

Os gnaisses quartzo-feldspatticos exibem bandeamento fino a grosseiro e, localmente, texturas lepidoblastica, porfiroblástica - poiquiloblastica, sendo mais comum a texura granoblástica fina orlentada. Fica, no entanto, a ressalva de que a maioria das amos... tras estudadas reveleram-ue cataclasadas.

Rochas com anfibólio, epidoto, quartzo feldspato também são frequentes. Corpos anfiboliticos sáo concordantes com o bandeamento tôm espesturas variando de um a algumas dezenas de metros * comprimento inferior a un quilómetro, com limite brusco ou transicional para os gnaisses vizinhos (Jost, 1981).

Quartzitos associados aos Gnaisses Encantadas forma reconhecidos apenas no Cerro dos Melos, cerca de a $\mathrm{km}$ a nordeste de Santana de Boa Vista $(f i g, 6)$. Ocorrendo como corpos de geometria complexa edimensöes variadas, esta litologia é granulometrica mente fina, com tons esbranquicados ou amaredados.

Os $x$ istos, concordantes com os gnaisses, ocorrem na forma de lentes menores do que $1 \mathrm{~km}$ năo săo muito freqientes. Seus componentes mineralógicos mais comuns săo o quartzo e a muscovita, com quantidades menores de K-feldspato eplagioclásio. Apatita, 


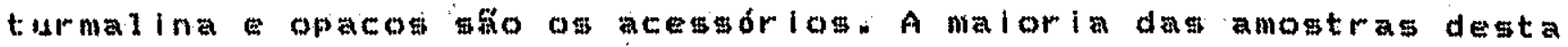
1itologia demonstra textura cataclastica pronunciada e pode ser considerada como nilonitos. Una genestexclusiva por deformacaso cataclástica, no entanto, n⿳⺈冂大 pôde ser confirmada (Jost:, 1981).

Do ponto de vista estrutural, esta unidade revela-se muito complewa, afetada por divermos eplsodlos deformacionais, falha-.

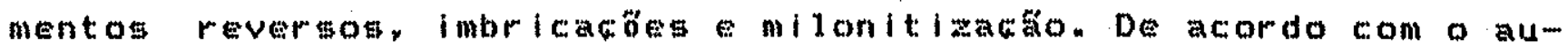
tor mencionado, ate mesmo a orlentacto reglonal das estruturas mesoscópicas dificil de ser determinadr, face às perturbacós acima comentadas aos afloramento pobremente preservados. Como agravante, at feicosed medidag parecem ter a cumportamento espacial modificado nos váriom mubdomíniog etruturals definldos por

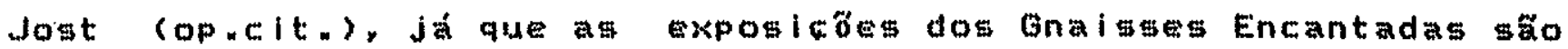
fisicamente degcontinuas. O autor assinala alnda que, embora năo se possa determinar com precisáo, as condicoss metamórficas, às qual foram submetidas estas rochas antes do intenso evento cataclástito revelado, atingiram facies anfibolito alto ou ate mesmo a facies granulito, conforme denonstram alguns relletos metanórficos preservados, como biotita vermelha, plagloclasio antipertitico, ortoclasto tolvez, andesina.

\section{Interpretaçึo Geocronológica}

Oprimeiro estudo georonológico desta unidade de rocha fol feito por Cordani et. al. (1.974)" Na oportunidade, os autores apresentaram uma itócrona do referencia, obtlda a partir de amosm tras coletadas dols afloramento distintos (fig. 6), cujo valor temporal indicado sugeria, par est litologia, uma idade transamazônica . A qualidade das informacosesontidas no referido diagram 
ma isocrônico, memontado de acordo com o modelo Williamson (Wil w lianson, 1968) (fig.7), Grecarla. A falta de linearidade contre os pontos analiticos fica demonetrada pelo resultado do MSWD. que supera o valor do nivel de corte, do elevado erro revelado pela ldade 0 ponto 258, provenlente de amostra recolnida nas proKimldades da ponte que cruza o Arroio olaria (fig. G) posicionamse acima da reta isocronica, aparentando uma nacogeneticidade. De qualquer forma, puderam os autores demonstrar que os Gnaisses Encantadas. alem de estrutural, tambén geocronologicamente se comportam como embatamento antigo da unidade bragli iana gobrejacente.

Telxeira (1982), en relatólo final enderecado ao Projeto RADAMBRASIL, relacionou trä novas análises realizadas en rocham das Proximidades de Santana de Boa Vistan A reuniäo de todos om pontos dimponiveigen un inlco diagrama lacmonico revelot que, ao contrairlo de obterme maior definlaž para a idade de taig rochas, os. gnaisas se comportam de forma marcantemente heterogenea, com dols dos treas novos pontos (LK-289C.1. C.2) posicionando-se fora do al Inhamento original (pig. $B$ ).

En sua interpretacko, Takeira (op. citin) relata que, se excluirmos os pontos $2 \$ 8$ eLK-289C.2, situados acima da isócrona, obtem-se um diagrma de referencia com a indicatán de um resultado anda trangamazónico, mas com um arro analitico comparativamente menor, o que Incrementa o mignificado do resultado fornecido. os pontos näo alinhados poderian pertencer a una lácrona mals antiga

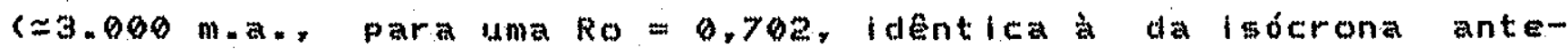
rior), sendo, entán, vestiglos ainda preservados de litologias arqueanats $(f i g .8)$. 
Soliani Jr. et al. (1984), retrabalhando os mesmos dados, sem descartaren a hipotege anterior, gugeren una interpretacáo adicional, qual seja os pontom questa definiriam uma nova isócrona, paralela anterior, mat com razto inicial malor, de aproximadamente $0,704(f i g .8)$, Eendo. portanto, também estas anostras tran gamazôn icas.

Para este trabalho, oito novas determinacoses foram aboradas. Antes de dimcutirnos o diagrama ifocrônico contequente, anaI I os mapas utilizados nas coletas, feitaspor cordani et al. (1974) epara reikeira (1982), tivemen, respectivamente, escalas

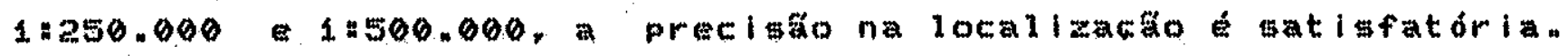
Como se observa na fig.G, os pontos $257 A$, D F, bem cono os ESJ-115B, C, F G orovani de un mesmo afloramento. Da mesma forma, os pontos 258, ESJ-117E e C LK-289C.1. C..2, Parecem derivar de uma igual ârear da qual está próximo o ponto RG-220. Constituen um afloramento distinto amostrat Es

Plotados os 15 pontos disponivels para os Gnalsses Encantadas

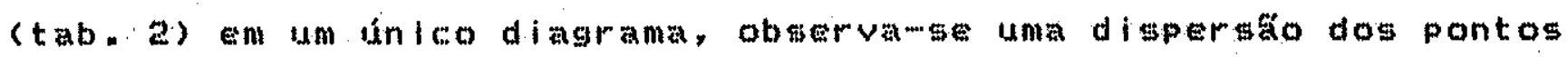
analiticos, comum en diagramas isocronicos regionala, mas confir. ma-se una tendancia para o a inhamento ao longo de un segmento de de reta definido. pelo menos, por nove amotras, cujo coeficiente angular sugere idade trangamazônlca (fig. 9). Se apenagegte conjunto for considerado (fig. 10), obtemme uma igónona com excen lentes indices estatisticos, a sugerir a lade do principal epigódio geológico a afetar estas rochas $(t=2.164+-91$ ma Rom0.7029). Razóes infelaig con valore degta ordem so fortemente sugestivas de derivacián mantelica da litologla analisada, atraves de acrecóes 
juvenís a crosta. No entanto. temme deterito a associacto de quartzitos aom Cnaigses Encantadas (Jost Bitencourt, 1986; Jost. 1981), demongtrando que om mesmos săo parametamórficoss para explicar tăo baixo valor para a referida razecto, estimamos, entáco, una importante contribulcto vuleanica advinda da crosta inferior ou do manto, na gênese do pacote rochoso or lginal.

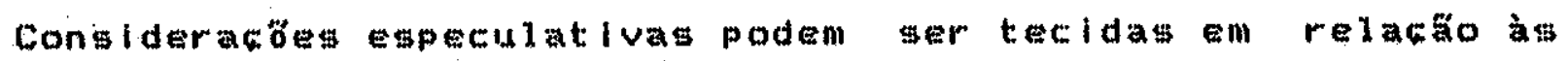
amostras discrepantes anterlormente excluidas (258, LK-289C.1 e C.2. ESJ-117日 C ESJ-11SF). O. conjunto formado por LK-289C.2, ESJ-117C, 25Q, ESJ-115F, ao qual se soma oponto $257 F(f i g .9)$,

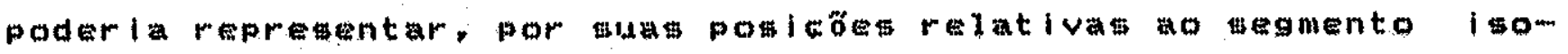
crônico I, fracớcsureliqula de crosta prétransamazônica. No entanto, esta alternativa aparenta ser batante improvavel, uma vez que a constructo de um diagrama isocrónicoparticular define uma razẫo inicial inverossimel de 0.6997.

Um dado digno de nota 4 qe as amostras 258, LK-289C.1 C.2

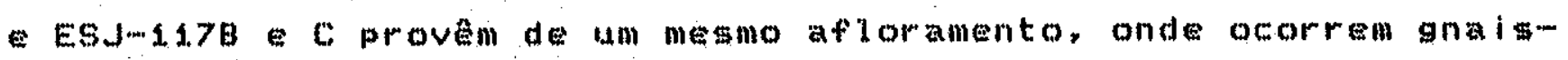
ses málicos intercalados con bandas feldspaticat claras bandas graniticas rosadas. O\$ pontos ESJ-117C \& LK-299C. E C.2 corresponden a gnalstes ocurom que definem uma lgócroma brasiliana, com elevado erro analitito (t = $590+-107 \mathrm{man}_{n}$ ), consequencia das inpreciabes no posicionameto dom pontos similaridade em termos da

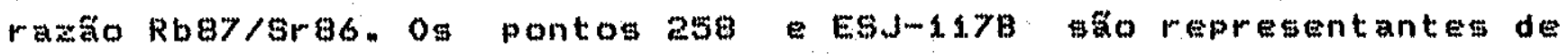

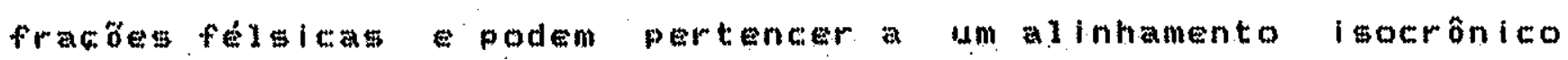
também brasiliano (fig. 9).

Como hipótege alternativa mais provável, partece que, neste afloranento, encontram-me rochas rejuvenescidas pelo evento geodi 
nâmico mencionado, revelando, as máficas as félateag, respecti vamente, razôs iniciai da ordem de 0,709 e. 0,710 . A manuteng ăo

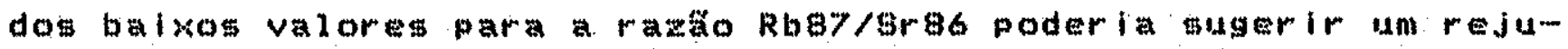
venescimento náo por adicto de material rocheso juvenil brasiliano as rochas transamazônica na simplemente que o ciclo superimm posto produziu condicôs tals que propiciaram a algumas rochas do embasamento uma homogenelzacăo isotópica interna, com elevacto da

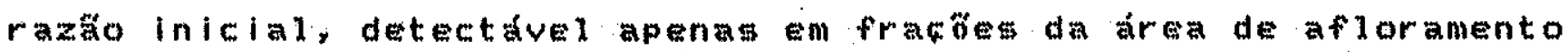
do mesmo.

A acto do ciclo orogenico mais Jovem sobre os onalsges

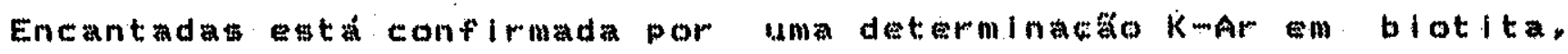
Extraida da amostra 2570, cujo rewultado de $553+$ to 10 ma. foi obtido por cordani ta $1 .(1974)$ eutra anfibolios provenientes de um compo antibolitico do "Dono de Santana", cuja ldade de

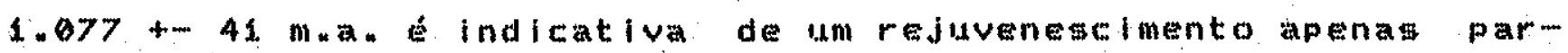
clal do matorial roctioso analisado (ESJ-H-5O, tab. 2).

Con estes dados, podeme imaginar aue as temperaturas, as quai esteve mujeito o embamenoto do cintura Dom Feliciano, durante o ciclo Brasiliano, nas proximidadeg de santana da Boa Vitta foram certamente superiorea a 250 - $3000 \mathrm{c}$ ctemperatura de bloquelo dablotital. mas no superaram significativamente valoreta da orden de 4 Hogc (temperatura de bloqueio do anfibolio). Sob es-

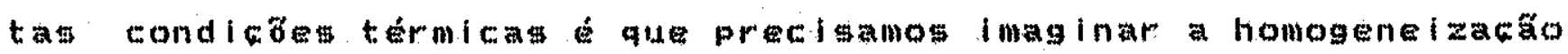
I wotóplea do SH. a nivel de rocha-total, pelo menos localmente. com o auxilio de uma intensa milonitizactio, o que efetivamente se verifican

De acordo com esta versáo, o ponto ESJu1isf (fig. 9) continua 
com sua posicto discordante no diagrama, por motivos ainda incertos. Ele pode pertencer a un megmento isocrônico bratiliano

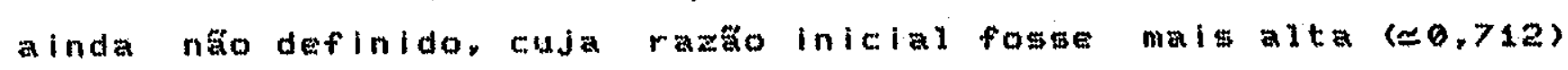
que as anteriores, o que reforcarla a hipotese de rejuvenescimento das rochas maig antigas. por pertencer un afloranento distinto do anteriormente considerado. Por outro lado, da observacáo da amogtra, conclui-ge que apesenca de 1 argasbandas $(3-4 \mathrm{~cm})$ quartzomfeldspaticas biotiticat podem ter determinado analise aobre uma fractao de rocha na homogenea representativa do todo. De qualquer modo, apenas a repeticá da analise poderá esclarecer tal degatinamento.

\subsection{As Supracrustais Dobradas e Metamorfizadas}

\section{Sintese Geológica}

O reconhecimento geologico detalhado do Grupo Porongog, componente da fracto getentrional da "Faixa de Dobramentog Tijucas" no Rio Grande do 541 , devldo a Jost Bitencourt (1980) Jost (1981) $(f i g(1)$.

Negte trabalhos, os autores propuseram duas unidades egtratigraficas malores, originalmente denominada de torupo cerro dos Madeiras Complexo Cerro da Árvore, posteriornente redefinidos como subgrupos pertencentes anidade Porongos (fragoso Cesar et

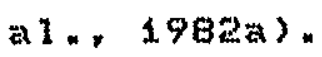

O primeiro, basal, essencialmente metassedimentar Iniciaw se con uma espegsa sequencla de metarcoseos (Formatio Arrolo dos Neves) Eobrepostos discordantemente ao embasamento (Gnaisses En- 
cantadas), seguido de quartaitos com intercalacós de xistos terminando com um conjunto peliticomearbonatico (Formacăo Arroio O1aria), perfazendo, no total, 2.500 a 3.000 metros da espessura.

A unidade superior, năo fornalmente mubdividida, constitui-se da base para o topo, de (I) uma sequencia de biotita xistos, gra-. nada kistos, estaurolita wistos andaluzita kistos, com quartzitos, muscovita xistose grafita kistos subordinados (Metapelitos Cerro do Facăos, con espessura ostimada de soo metros. Separados das outras litologias por uma zona de transcorrencia (sistema de Falhas Passo do Marinheiro-Picada, 1971), estäo estratigraficacamente motcopostos a (2) biotita kistos de granulacto muito fina, com eventuais lentes de quartzito e epesura suposta entre 500

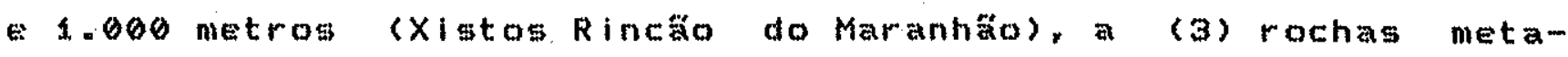
vulcânicas ácidas intemediarias. metatufog metacherto assom ciados metapelitos aluminosos, grafita xistos ocasionais lentes de muscovita xistos mamores (Metamorfitom Cerro Canbará), a (4) muscovita wstos, con lente de mármores quartatos, quartzommscovita xistom xistos. com cloritódas subordinados, e. finalmente, a (5) rochas metavulcânicas acidas interpretadas como quartaomórfiros quartaofeldspato-pórfiros (Metariolitos Cerro do Alenăoi.

\section{Interpretacăo Geocronológica}

As informacooses gocronológitas dimponivels para estas supracrustais sa incipientes. A norte da rodovia que liga pinhelro Ma chado a Seival (BR-293), o Projeto RADAMBRASIL coletol anostra (RB-.265; fig. 11) de um gnaisge milonitico (Teiweira, 1982; Hor... bach et a 1,1984 ) pertencente ao Grupo Porongos, cuja idade con- 
Vencional Rb-\$r, para Ro da 0,705 , indicou cerca de 915 m. 3).

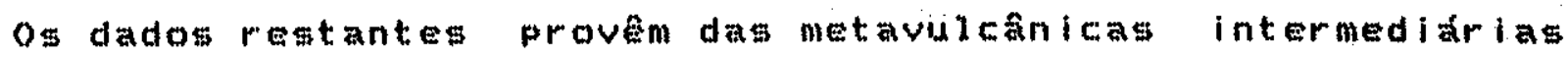
intercaladas 70 metamorfitos Cerro Cambará $(f i g n$ b), analisados tamben pelo metodo Rb-gr. As amostras, embora coletactagem um mesmo aflormento derlvan de dois derrames distintos ey portanto, náo săo cogenéticas A tertativa de congtructo de um diagrama igocrón nico de referencia demonetirou hue os pontos congiderados encontrammse digpersob definem un valor temporal con alto erro analitico. As idades convencionals resultanteg, apesar dos a 10 to valom

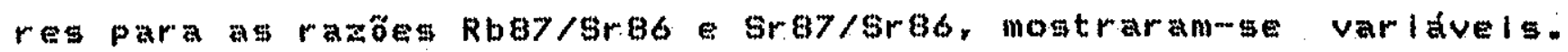

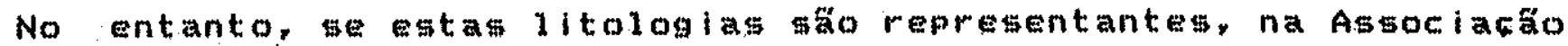
Petrotectônica de Bacia Marginal (Complexo Cerro da Arvore), da atividade vulesnica do arco magnatico contiguo, tagundo Fragoso Cesar te a 1. (1980a), o valor temporal de cerca de 800 m.a. (tab.

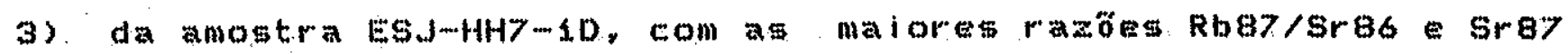
sr86, pode estar gugerindo a épota do evento extrugivom. As demals

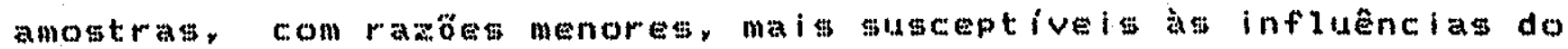
valor de Ro, apontaram idadto altas certamente parectompoguir

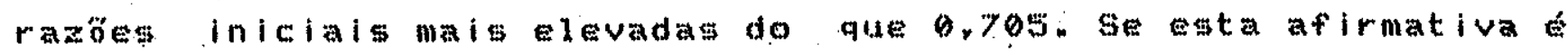
verdadeira também para a amogtira E $\$$ J

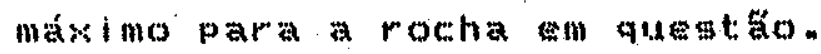

\section{A Zona Central}

\subsection{Sintese Geológica}

A zona Central do Cinturäo Dom Feliciano (Fragoto Cesar, 1980) corresponde, no Rio Grande do Sul, a uma falma constitulda funda-. 


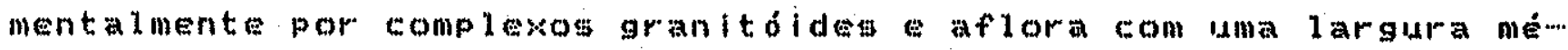
dia de $70 \mathrm{~km}$, com um comprimento de quas $400 \mathrm{kmy}$ desde os arredores de Porto Alegre, até Jaguaráco, no limite meridional do Estado $(f \mid g, 2)$

Os estudos ploneirom de granitóides desta área, por razöeseconomicas, face à mineralizacoses deso, so (1945), quando foram denominados os granitos Encruzllhada Campinas. Na decada de 60, varios outros trabalhos realizaram-se, em special nos arredores da cidade de Encruzlihada do Sul, entre os quals destacamos os de Formoso Carraro (1962), Sobre o Anor-tomito Capivarita, Picada $(1965,1966$ 1967), culminando com Picada (1971), sobre a ocorrencia de migmatios, granitos, gnaisses, pegmatitos glenitos no "Complexo Encruzilhada", alem de un "enmaio sobre a tectônlca de parte do Eucudo sul-riomrandense. Ribeiro et a1. (1966) e Tessari e Pitada (1966), respectivanente sobre geologia das quadriculas de Cacapava do sul Encruzilhada do Sul, com a denominacio de novos corpos graniticos.

Carraro et al. (1974), em geu mapa geolóico do Rio Grande do Sul. delimitaram apenas alguns corpos granitóldes na fracáo oriental do Escudo, preferindo inclulr no grupo cambai, indiatintanente, todas aquelag rochas a inda năo definidas ou mal avaliadas.

Importantes trabalhom provam de Ribeiro (1977), Ribeiroe Lichtemberg (1978) Ribeiro fontinel (1979), onde a regiáo agora enfocada foi, neste litimo, referlda como "Macico Granitico de Leste" composto por corpos graniticomgranodioriticos de dimensobs batoliticas, "stocks" sieniticos, diques apliticose roliticos, mortositos cataclasitos, alem de migmatitos. 
Nos ditimos anos, tonme observado uma crescente preocupacto dos estudiosos para com esta frea, tendo tornado de domínio públi-.. co vários escrito relativo ao reconhecimento caracterizacáo petrografica a litoquímica dos diversos corpos granitódes dominantes, além de abordagens gimliares realizadas sobre cutros tipos litológicos mubordinados. Ocorre mencionar os de Moreira Marimon (1982 1984), oprimeiro apresentando descricós petrograficas e

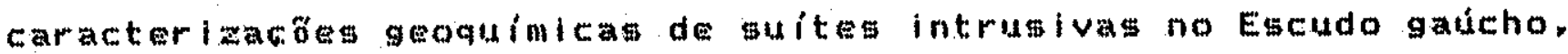
ordenada em faseg tectốnicas, o gegundo, relacionado a petrografia de rocha granuliticas ocorrentes no domínio da zona Central, conforme Horbach al. (1984). Frantze Jost (1983) apre-

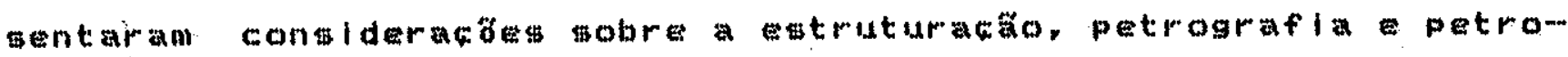
quimica dos divergos "gtock" do Granito Campinas, com vistas a un

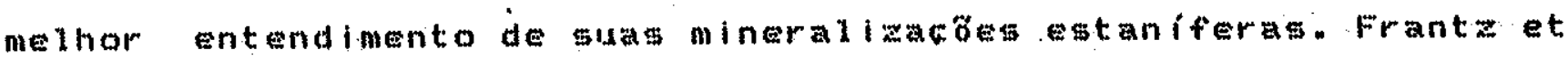
a. (1984) melataram novos dados petrograficos derlvados da regiáo de Encruzilhada do sul e Jome at al. (1984a), com base em informam

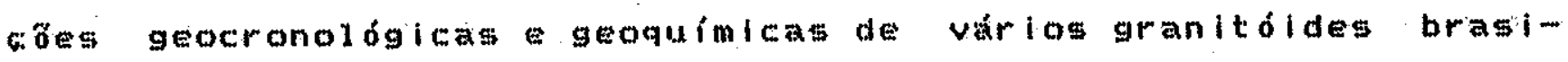
lianos do Rio Grande do sul, os interpretam a luz de alguns modem los de evoluc:a geotectônica apregentados para a área. Por fim, en trabalno mals abrangente, Its ler (1994) realizou igual tentativa com o intuito de oferecer subsídios ao \$eth modelo de evolucto geodinântca, apresentado com trabalhos anterloress (TEster, 1982 . 1983).

Vale inda mencionar que diversos mapeamentos têm sido desenvolvidos no leste do Etado, cono trabalhos de graduaca de a linos do Curso do Gologia da Univeraldade do Vale do Rio dos Sinos. Rem lacionamos os projetos Erval (1980), Cerro Chato (1980), Encrizi Ihada (1.982), Delfino (1983), Varzea do Capivarita (1983), Cangugu (1994a, b) Pimatini (1985). 
Nos dias qute correm, os conhecimentos gealógleos oriundos do. lest galcho cont inuam deficientes, mas se registram avancos significativos apos os levantamentos sistenatizatón realizados pelo Projeto RADAMBRASIL, nas folhag sH.22-Porto Alegre Sf.22Lagoa Mirim, conforme Horbach et al, (no prelo, apud Moreira e Mam rimon, 1982 apud $\mathrm{x}=1 \mathrm{Er}, 1984)$.

Há, entre os geólogos do Rio Grande do Sul, uma tendencia de dividirme informalmente os terrenos granitóldes de oriente en dua scubunidade estruturais, Individual landomse o "Bloco Encruzilhada". Iimitado a oete por um lineamento do tipo Acotela (FaIha Paso do Marinheiro, Heg. Picada, 1971), a sudeste pela Falha VigiamRoque, que empresta seu nome a outro sigtema de lineamentos, Q que, norte, He deixa cobrir pelos gedimentitos gonduânicos da Bacla do Parana $(f i g, 12)$, sendo considerado composto de litolom gias de idades prembramilianaze, portanto, diferencável dos restarites terrenos brasli ianos que compöen o "Bloco Dom Feliciano" (Jost Hartmann, 1984).

Podamos, entäo, a nivel das informacós atualmente disponiveis, organlzar a geologia da Zona central do Cinturato Don Feliciano(fig. 12, tab. 4) en:

- Complexo Granitóide de Leste, desfgnacón utilizada em substituiga a complexo Cangucu de Horbach et al. Sno prelo, apud Moreira Marimon, 1982 apud Ister, 1984), uma vez que a mesma denominaca ta da a corpos graniticos aflorantes nas proximidades da localidade homônima pertencentes a distinta unidade litológica. Engloba os granitóides ainda indivisos, os granitódes cata c. lasticos, os migmatitos gnaistes, as litologias mais raras 
como granulitos (?), lutranafitos, mármores pegmatitos, alem dos anortositos ocorrentes no "Bloco Encruailhada" (Anortosito Capivarita-Formoso e Carraro, 1962);

-.. Suite Intrusiva Dom Feliciano, composta pelo granito Arroio dos Ladröes os denominados de Cangucu, Capăo do Leăo, Pedras A1tas, Fortaleza Arroio do Bote, além dos corpos aflorantes nas provimidades de Porto. Alegre (Istier, 1984 e Schneider et al., 1974) o Sienito Piquiri (Picada, 1966 1971) aflorante nas proximidades de Encruzilhada do Sul. Associadas stariam as manifestacốc vulcânicas ácidas da Serra das Asperezas do Cerro Chato. Euta designacaro, por razós de precedencia priorldade cpicada, 1965) U usada em pernutacto con a Suite Intrusiva Arroio dos Ladröes de Horbach et al " (no preloy apud Ister, 1984);

". Suite Intrusiva Campinas, constituida pelos. "stocks" do Granito Campinas (cerro Branco. Campina, Taboleiro Pallista), nais o Grantto Figueiras (Imster, 1984).

As unldadeg litológicas acima mencionadas compöem o Bloco Dom Feliciano.

O Bloco Encruzilhada, por sua vez, constituimge de:

- Complexo Metamórfico Várzea do Capivarita, do qual fazem parte paragnals o, subordinadanente, ortognaibses de composicoôs Variadas. (Frantzet al., 1984). Esta mesma unidade referida como Sulte Gnaissica Arroio Chana em Jost (1984);

- Suite Intrusiva Encruzilhada, formada por granitóldes ori- 
ginalmente referidos como de Encruzithada.

A este bloco estrutural associam-se, como já referido, o Anortosito Capivarita o sienito piquirl, além de pegmatitos lentes de nármore

\subsection{Interpretaç̃o Geocronolófica}

Cordani et al. (1974) compuseram, para o leste do Eacudo do Rio Grande do Sul, a primeira Eintese interpretativa dos resultados geocronológicos obtidos pelos metodos Rb-Sr K-Ar, gracas a um programa de cooperacåo cientifica entre o cpgeo/usp o Io/univerisity of Texas, en Dallas. Na aportunidade, coleta de amostram concentrou-ge nass proximidades de Encruzilhada do Sul, mas tambén foram realizadas amostragens nat regiôn de Don Feliciano. Pelotas, Cangucu Pinheiro Machado, durante o levantamento de Perfís ao longo das rodovias que Interligam as referidas localidandes.

Por ter um carater preliminar, de reconhecimento, o trabalho

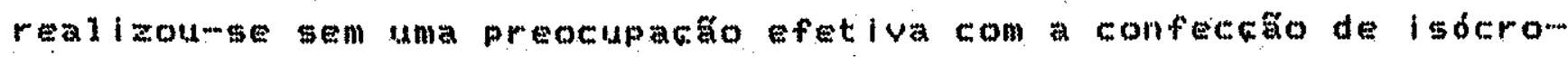
nas a partir de amostras provententes de um mesmo afloramento ou de compos circunseritos. Os autores construiram dois diagramas isocrônicos de referencla onde o criterio de participacăo de uma amostra com ou en outro diagrama fol petrografico. Astim. granitódes com orlentacto textura pronunciada mineralogl dimilar. incluindo migmatitom, constituiram um conjunto mepresentativo da fase sintectônica do cintura mo mól (flg. 13), enquanto ó termos

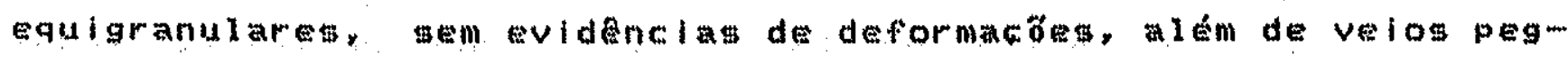

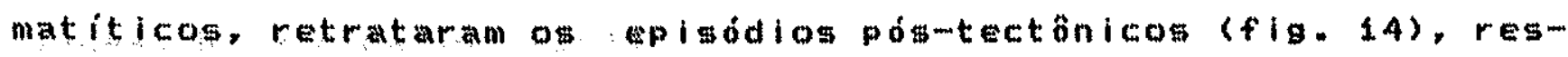


pectivamente acontecidos por volta de 650 : $590 \mathrm{m.}$. . . conforme concluiram.

As idades K-Ar em mineral separados situaram-we no intervalo típlco do ciclo Brasiliano, refletindo diferentes eatáglos do resfriamento regional.

O Projeto RADAMBRASTL, no inicio da atual década, adiclonou 19 determinaco radiometricas as da porctio oriental do Escudo. gendo 14 pelo método Rb-Sr g pelo método K-Ar, interpretadas em conjunto con premexistentes por Telkelra (1982).

Para o Complexo Granitólde de Leste (Complexo Cangucu. segundo o projeto RADAMBRASIL) há a proposica de dola alinhamentos lsocrônicosprincipais, decorrentes de epocas importantes de homogenelzaço isotópica $(f \mid g, 14)$ o mais joven, con cerca de $650 \mathrm{~m}$. a., definido esmencialmente por granitóldes dos arredoreg de. Encruzilhada do sul, o mais antigo, com valores da ordem de $750 \mathrm{~m}$. a.. Caracterizada por un conjunto maior de amostras provenientes de diversos locais do "Domínio Cangucu" "Para Teikeira (op.cit.), esta idade mais elevada sugere a existencia de fracöes crustais prebrasilianats, parcialmente rejuvenescidas. no interior do comm plexo Granitolde de Leste, o que, de acordo con o mesmo autor, fica maig claramente evidenciado atraves da amostra GF-334, um gnaisse coletado a NE de Pinheiro Machado (figs. 1. 19 ).

As determinacoses K-Ar, por seu tiuno, continuam conferindo um padráa gecomonológico tipicamente brasiliano para o lester com idades concentradas no intervalo $620-530$ ma las litologias supostamente mai antigas, como os granulitos (?), 
tal como friman Teixeira (op.cit.) Horbach at. (1984).

O Anortogito Capivarita, somente estudado por este metodo. a imilarmente forneceu resultados do Préchabriano superior.

Para o "Complexo Tranitoide Entruxilhada do Sul" "Teixeira (op. Eit.) definiu un periodo de atividade ignea entre 670 e 500 m. *. 1.6), o que tambem me constata pelas jades convoncionais calculam

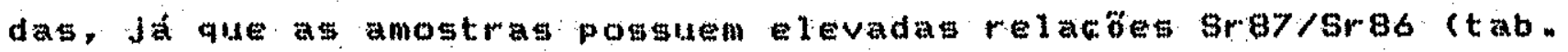
$7)$

De acordo com o mesmo autor, o "Compleko Granitóde Arroio dos Ladröes" tevelou um bom al inhamento de pontos ao longo de um

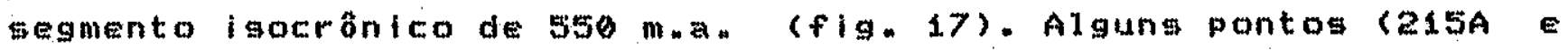
219c), no ntanto, posletonarammg, no diagrama originat, abaixo

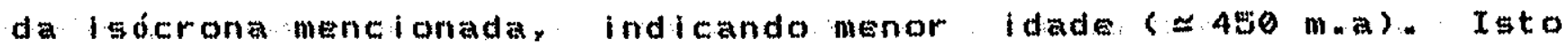

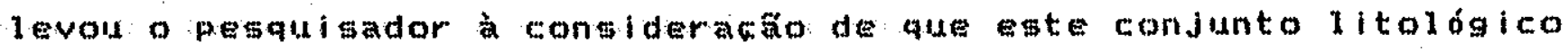
meria composto de rochas originadas no intervalo de 550 a 450 2., estandoy ent tectônita regional.

E:m a

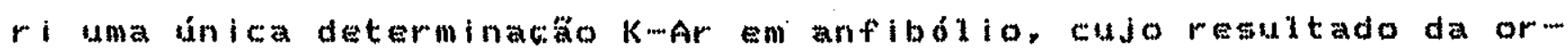

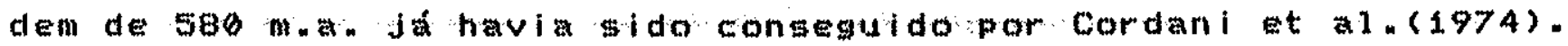

O Granito Campinas, com quatro momtras analisadas pelo metom do Rb-Sr, revelod problemas interpretativos face a falta de controle da racto inicial no diagrama lsocronico, al ado a dispersäo dos pontos. A reta de melhor ajuste mente tait pontos mostra una 
inclinacto referente a ua lade aparente da ordem de $790+-100$

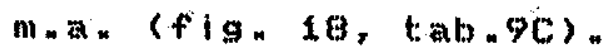

Para est trabalho. mais 37 analiseg radiometricas foram incorporadas a acervo anterior, sendo 22 pelo metodo Rb-Sr (17 das quais obtidas por Halpern et al, 1974), 10 pelo metodo K-Ar e 5 pelo. método dos tracos de fissäo em apatitas Este incremento de dados, apesar de pouco numeroso, proplctou a constatacio de interessantes fenômeno geológlcos atraves de um melhor entendimento da histórla térmlea da area, gracas à associacăo de metodologias distintas, cujos valores temporai fornecidos tem diferentes sigm nificados figicos.

De modo alstematizar as interpretacóg que ge seguirăo, discutiremos a Zona Central do cintura bon Feliciano de forma setoricada.

\section{Bloco Dom Feliciano}

\section{Complexo Granitólide de Leste}

Esta unidade (denominada de Complewo Cangucu pelo Projeto RADAMBRASIL, de acordo com Horbach a ", no prelo, apud Telixelra, 1982 apud Ister, 1984) engloba uma grande diversidade de litologlas que năo puderam ainda, face ao graudos contecimentos a-. tuais, ser individualizadas mapeadas como corpos distintos.

Indiferentemente, gáo aqui incluidos gnaisses, migmatitos, tonalitos, granodioritos granulitos (?), entro outros, cuda cam racteristica comum é uma forte marcante foliacio. Associadanen- 
te, ocorrem aranitódes diversos, acinzentados ou rosados, porfiriticos ou cuigranulares. grosseiros ou finos, com foliaca aldsente ou apenas Inciplente.

Embora existam algumas dezenas de amostras. provententes deste complexo, analisadas pelo metodo Rb-Sr, hma interpretacão geocronológica só possivel em carater regional (fig.19), com

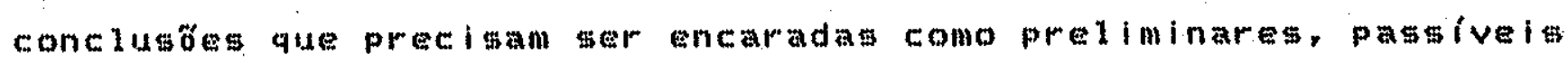
de significativas alteracoses com o advento de novos estudos geocronológlcos orientados pela proses aco dos levantamentos conhecimentos geológlcos.

o critér to textura há pouco comentado, asuociado a observaCôte de ordem petrografica, como a existancia ou nä́ de minerais neoformados suas quantidadeg relativas, tal como ja havia felto Cordani et al. (1974), foi utilizado na subdivisto das anostras analisadas em dof conjuntos de referencia, com carater regional. que sergo abordados separadamenten

As rochas com textura orientada autancla ou incipiente neoformacta mineral constituiram o primeiro grupo de amostras cujos resultados analiticos encontramme plotados na fig. 20. A despeito de una relativa dispersa de pontos, imposta pela diversidade dos tipos litologicos, eossivel vislunbrar tendencias a alinhamentos de onde săo feitas algumas. I1 acós.

Inicialmente, os pontos 4, $5,33,16$ 16 assinalados com circulos cheios, correspondem a um mesmo tipo litológico (migmatito) aflorante na porcto centrowal do Complexo comitólde, entre as cidades de Pelotas e Pinciro Machado (Pigniq). Tres amostras prom 
vêm de um me\$mo afloramento (ES J-29D, F B ) as restantes deri... vam de outra exposiço distante cerca de $40 \mathrm{~km}$ (ESJ-36A B). AO tentarmos a constructo de un diagrama lacronico con as primeiras, obtivemos uma ldade de $861+-38 \mathrm{~m} . \mathrm{a}$. $\mathrm{Ro}$ at 0,7062 , com excelentes indices gtatisticos $(f i g .21\rangle$. A inclusa dos pontos 36A $B$, para o tracado de una isócrona de referencia, praticamente mantêm inalterados os remultados (845+-28m-a., Ro $=0,7068$ (fig. 22).

Ao adicionarmos ao diagrama isocrônico mo questa ấo outros pontos analiticos derivados de litologias similares (migmatitos, gnaisses tonaltos que ten en comum uma forte follactos

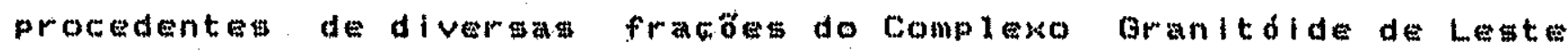
(fig.19), o resultado temporal conseguido é concorante com o anterior (827 +- $25 m_{n}$.

Dos nove pontos que compón o diagrama da flgura 23, dois (2178 223B) ja tinham sldo utilizados por cordani et al. (1974) (fig. 13) interpretados como representantes da fase sintectónica

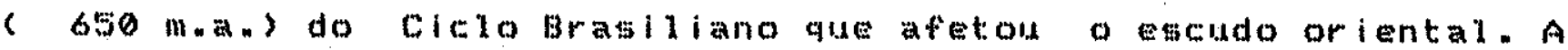
observaço da figura em questáo revela que os pontos considerados posicionanme acima do segmento itocrônico, sendo tugestivos de valores temporal matorea.

Dols outros pontos (LK-169 LK-135) ga devidos a Projeto RADAMBRASIL (TEixeira, 1982) sendo que ste autor asociou-os aos de Cordani et a. (op cit.) (fig. j.5), definindo uma reta de referencia cujo coefletente angular apontou una ldade da orden de 750 m. . . .

Os cinco pontos restantes, com preflxo ESJ (29B, D E F, E $36 A$ 
- B), retultam do presente trabalno e esta mendo considerados pe1 a vez primeira. Idade lsocrónica, mesmo que de referencia, com tal magnitude. Para o leste do Escudo sul-rlomgrandense, inaudita.

Vajores temporais malores do que 650 man ja havian sido interpretados por relkeira (op. eit. ) como sugestivos da ocorrenncia de fracón cruata das, preservadas entre os granitóldes mals jovens da zona central do Cintura Dom Feliciano. No entanto, pelas caracteristicas litogeoquímicas fatólcas dos granitódes enfocados. ben como pela Ha asociacta com outros termog petrograficos, como me discutirá nos capitulos finals deste relatório, idades desta orden poden rem presentar un epládio gerador de rochas em uma fase precoce do cic10. Bragiliano na porsáco meridional do Escudo At ântico. En complementacto, vale a pena lembrar que, para o Cinturäo Damara, Kröner (1982) relata a existência de evento magmático prét-tectônico há 840 m. a. Pagmados.

Exeluidos os pontos anteriormente discutidos, uma outra reta isocrônica de referenciar também regional, pode ser visualizada (fig. 20, II fig. 24). Montada com nove mostras de litologias descritas como granodiorito, grantos acinzentados ou simplesmente granitos (Teixeira, 1982 cordani, anot. campo), com orientafáo local de biotitas imbricacto de $k$-feldsatos (tab. 5 ), indicou $4 \mathrm{~m}$ Valor temporal de $77 \mathrm{~s}+-36 \mathrm{~m} . \mathrm{a}$. Rom Ro,7060 parecte regigtrar outro importante evento de homogenelazato isotólfa acontecido na porcto orlental do Escudo do Rio Grande do Sul. Esta possibilidade, aliás. já havia sido levantada por Teineira (1982). 
Os pontos componentes deste diagrama sân, em grande parte, os mesmos utilizados por Cordani et al (1974) na caracterizacăo da fase sintectônica do ciclo Bragiliano no sul do Brasil. As dife-.. rencas residem no fato de que, para a atual isocrona, foran considerados apenas os pontos ocorrentes no Bloco Dom Faliciano, ex-.. cluldat as amostras do Complexo Matamófico Várzea do Capivarita (antiga formactio Cambaí, como se ve en Cordani et al " op.cit), do Bloco Ercruzilhada, que pode, Eventualmente, apresentar distintos aspectos evolutivom geocronológicos, tal como creen alguns

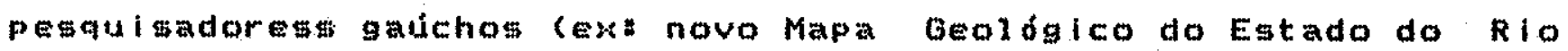
Grande do Sul, om elaboractio pelo DNPM, 19 Distrito, Porto Alegre e. apresentado no IIO Simpóato sul-brasileiro de Goologia em outubro de 1985, em Florlanópolig). Além dismo, acregcentanos ao dia... grama os pontos analíticos conseguidos pelo projeto RADAMBRAsIL (Teikeira, opncit., Halpern et al.(1974)"

Podemse entho aventar a hlpotese de que valores temporals médios da ordem de $750 \mathrm{~m}$ a. relacionamme tambem a uma fase iniclal de desenvolvimento do orógano em foco. a semelnanca do que se dá com o Cintura Damara, conforme Kroner (1982),

O a Inhanento das amostras deseritas como granulito e charnoenderbito (LK-169 L.K-25BB) BElo Projeto RADAMBRAsIL (Teixeira, op. (it.), como verifica nos diagramas isocrónicos comentados, e bastante curloso pelo fato das razós inicials obtidas serem elevadas $(0,706$ e.707) para tals tipos de rocha. Ao contrário de corresponderem a exposicotes do embasamento, como preconiza Horbach et al. (1984), tratarme-iam, ao que parece, de litologias precocemente geradas no ciclo Brasiliano. 
Algus pontom posiciorados abalwo das laberonas apresentadas $(f i g .20)$ como os 19, 20 21 (respectivamente, 216, 215A 211A, \$Eg n Cordani et a 1., 1974), poden ralacionarme a rochas que, enbora revelem caracteriaticas mineralólcaselou texturais dominantes gugestivas de fase sintectônica, apresentan idades ou razôn Inicials menores que as anteriores.

Associndamente à rochas já diacutidas, ocorren, no complexo litológco oriental, granitóldes nafo foliados costinuan incluidos nesta unidade somente por nâo terem sido ate agora individualizados, apesar de sels diferentes significados geotectônicos - ldade.

Estes tipos litológicom (granitóldes acinaentadom ou róseos, homogêneos, porfiriticos ou equigranulares) definem um evento mag mático ma i joven, congldarado como póstuctốnlco por cordani et a1. (1974). De um total de 15 amostras disponivels, 12 alinharamge ac longo de uma isórmon de referencia regional, cuja idade,

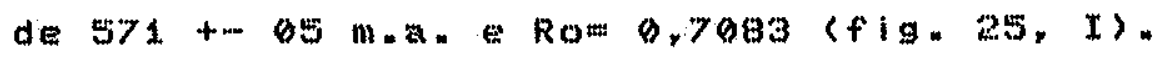

Entre os 12 pontos considerados, três proven de un mesmo a-

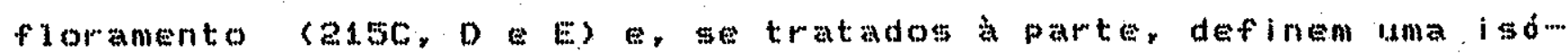
crona de $547+\ldots .7 \mathrm{man}$. com ko 0.709 (fig. 25, cícculos cheios, efig. 26$\rangle$.

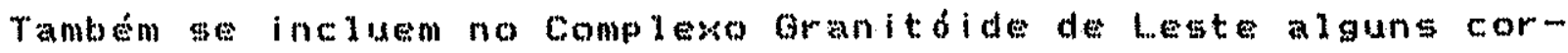
pos representantes dos entos magnaticos mais tardios da cuolucăo geotectônica. E o caso dos pontos 220D, Ee G, oriundos de uma intrusa granitica em rocha carbonatica aflorante ao sul de pedro Osorio (fig.19), na pedreira conde Matarazond que definem uma isó- 


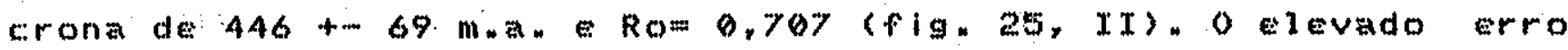

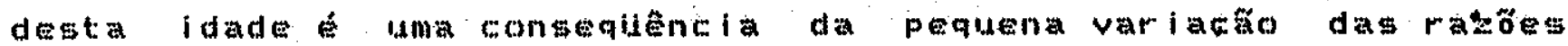
RbB7/Sr86 que definem os pontos analitico de um controle ná⿴囗十 fetivo da razáo inicial por indisponibllidade de un mator número de amogtras nas proximidadeg do eiko sma7/sr86.

De todas as unldade que constituem a portaco oriental do Esw cudo Sul-rio-grandense, o complexo Granitód de laste é que a cumula o mator numero de determinacobes rolometrleas pelo método

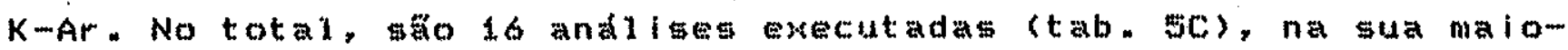
ria en minerais oparados, sendo que 10 das amostrats for an sistematicamente coletadas de granitóldeg postados ao longo de un perfil WNW-ESE, trangversalmente disposto a estrutura reglonal, entre as. Cidadea de Pelotas Pinheiro Machado (fig. 19), das qua estudaran as biotitam con o intulto de ampliaremm os conhecimen-m tos relativos história termica da regiag a lo longo do segmento conslderado. Os resultados, produzidos para este trabalho, já foum

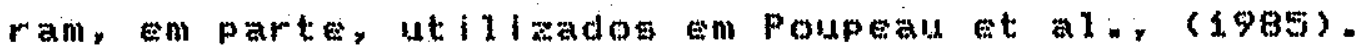

Outras 2 andi ises foram obtidas num coppo máfico cuja borda seccionada pela rodovia BR-293, que liga as cidades acima mencionadas. As anailises restantes provêm de amostras recolhidas de corpos litológicos due depertaram intereste cientifico, como granulitos (?), esparmos nos domínios do complexo de lesten

A primeira ldade K-Ar obtlda biotita de rochas graniticas do oriente gaucho se deveu aresch at a 1.973$)$, cuja amostra foi coletada na pedreira do IPA (Instituto porto Alegre), na cidade homônima, com resultado de $635+\ldots 27$ man, posteriormente divilgam do por Cordan 1 te $1 .(1.974)$. Estes autores, na mesma oportunida- 


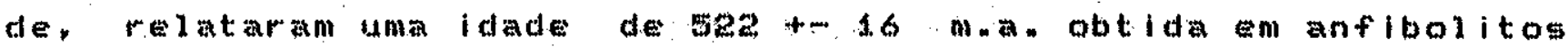
(amostra 220B〉 separados d nucleos anfiboliticos boudinados encontráveig en mármore da Pedreira Matarazo, a SW d Pedro Osório.

- Projeto RADAMERASIL VElo a seguir, com quatro novas determinacöes concentradas an rochas relativament raras no contexto geoloóglco do leste impróprias datacöed pelo mátodo Rb-Sr. Săo anostra de gabro, norlto, anfibolito egranulito (?) (LK-112, GF371A, GF-371E LK-1.69) que forneceram, respectivamente 4m9 + 14 ,

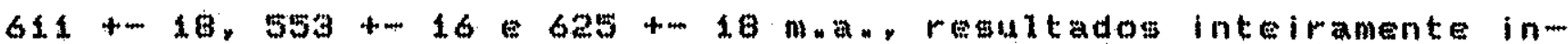
Eluidos no Ciclo Brasiliano.

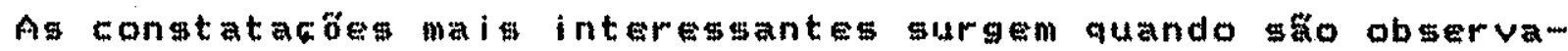
dos os valomes temporaig a ditribulato das amostras ao longo do perfil Pinheiro Machadomelotag. Como primeiro fato, verifica-ge que as idades sáo sistemat lcamente menores no sentido leste, ini

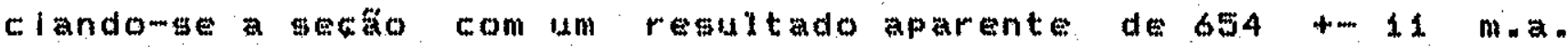
(ES, J-27), a ocidente, terminando com un valor de 528 tw 6 ma. (ES.l-39) na extrenidade oposta (fig. 27, gegnento A-A"). Egte conportamento reflete ou uma taxa de resfriamento menor nas prowimi dadeg da costa atual do Estado, sendo que temperaturas da orden de 250-3000C (temperatura de bloqueio da biotita), em un episodio de variacaro tomica descendente, foram atingldo primeiramente no oeste, ou a exposicto, na superficie topografica atual, de niveis crustais cada vez mais profundoge, por isso, sujeitos a resfriam mento tardio em relacăo aos anteriores.

Uma analise global dos dados permite que me agrupe os resultados cam dois conjuntos que revelam tendencias gimilares de. dem 
crescimo de idade de W para E, sendo, no entanto, menor na lit ima fraca (fio (fig. 27 , segmentos $B-B^{2}$ e C-C C ). A descontinuidade que se materializa entre os pontos ESJ-34 E ESJ-35 cconvém notar que as biotitas desta amostra săo portadoras de alteracón quimicas impostas pelo fenômeno cataclástico evidenciados pelo baixo teor de $K=3,9 \%$ coincide com a importante Faixa Cataclástica de Cangucu (Poupeau et al" op " eit."), aflorante desde as prowimidades de Porto Alegre e prolongandowse ate o Urugua (fign 19) . Como os deslocamentos de fracöes crustais sâo anteriores às idades aparen-tes K-ar, ao longo da faixa cataclástica mencionada, os mesmos fizeram permanecer por mais tempo acima de 30000 as biotitas da amostra ESJ-34, relativamente a ESJ-35, sugerindo que o bloco ocidental desceu em comparacta com o or iental,podendo ser conseqiante de empurrấo de leste.

De acordo com Silva Fitho (inf, verbal), a faika cataclastica aludida registra deslocamentos crustais transcorrentes, conforme atestam as lineacócs estruturais presentes no plano da falha. Neste caso, a componente vertical deve ser anterior à transcorrencia que aproveitou linhas de fraqueza estabelecidas há mais tempo. De qualquer forma, a referida feicato estoutural responsabiliza-se pela justaposicäo de fracóes da crosta com historias termicas apenas similaresn

Os pontos analiticos cujas posicots sto excepcionais (ESJ-32 e ESJ-38, fig. 27) derivam tambem de amostras portadoras de impor... tantes feicoós cataclasticas que propiciaram, como se vê na tabela 5C, alem da alteracto quimica das biotitas, revelada pelos batwos teores de potássio, uma perda considerável de argónio radiogênico. 
Como trabalho complementar, amostras dos mesmos afloramentos foram estudadas através do método dos tracos de fissăo. Apenass quatro, no leste do Escudo, revelaram-we adequadas ass análises, em termos de homogeneidade na distribuicano do urânio nas apatitas os resultados, conseguidos por dois diferentes observadores (A $E$ B), foram bastante coerentes e, ao longo de todo o perfil, mantiveram-

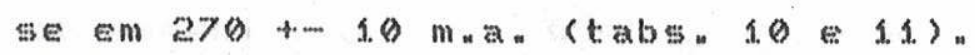

Valores desta ordem eram inéditos no Préchambriano do Rio Corande do Sul, já que os minerais usados nas determinacóses K-Ar ou Rb-- Sr possuem temperaturas de bloqueio superiores a das apatitas para tracos de fissáo.

Conforme assinalam poupeas et: al. (op. (tit. "), o resfriamento, abaiko de $300-2500 C$, se deu, ao longo do perfil amostrado, há cer... ca de 650-530 m. passadose temperaturas inferiores a $1100 \mathrm{c}$ (temperatura de bloqueio da apatita para os tracos de fissăo) só foram at ingidas há $270 m$ na " nom estes dados é possivel calcular uma tawa media aparente de resfriamento, no intervalo de tempo mencionado, da ordem de $0,50 c / m_{n}$ a. , como seguen

$$
\begin{aligned}
& 2500 \quad-11000 \\
& 550-270 \mathrm{man}
\end{aligned}
$$

A similaridade entre as idades obtidas em amostras à "temperatura ambiente", isto é, amostras que näo sofreram qualquer tratamento termico, aquelas conseguidas posteriormente a aquecimentos da ordem de 300,310 e $3200 \mathrm{c}(\mathrm{tab}, 10)$, indica que os tracos de fissăo näo for am afetados por apagamentos parciais, o que é compativel com taxas de resfriamento superiores a $40 \mathrm{cosm}$ a no in -.. tervalo de 150 a bogc, quando, respectivamente, comecam a ficar 
parcialmente regigtrados e completamente preservadow os tracos de

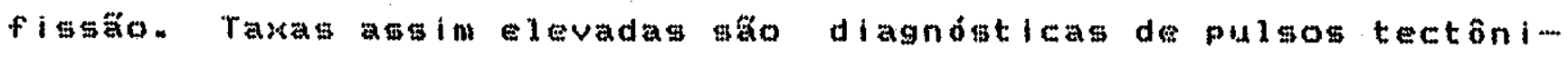
cos, no tempo indicado.

Esta impressato fica reforcada quando se observan avaliacos dos movimentos oscilatóriog da Plataforma sulamericana, cono as. de soares te al. (1974), que ja haviam, en base a estudos estratigráficos na Bacia do Parana detectado uma fase de rectruturacáo tectônica da sinécliat, nog tempos do permiano. com o desenvolvimento de arqueamentos Interiores. Ao que parece. o Escudo Sul-riom grandense, do ponto de vigta estrutural, pelo menosem sua poráa centro-legte, definiuge como un arco (Arco de Rio brande) trans... vergalmente à Ba do Parana, no pariodo mencionado. A homogenea distribulatio de resultados temporate por tracos de fissa ao longo de todo operfil (fig. 27 ) demonstra que os movimentos verticals relativos de blocos, constatados pelas descontinuldades K-Ar, foram anterlores a $270 \mathrm{~m}: \mathrm{ann}_{\text {. }}$

\section{Suite Intrusiva Dom Feliciano}

A designacto original do Complexo tranitico Dom Feliciano foi proposta por Tessari Picada (1.963 apud Tessari Picada, 1966) com o intuito de denominar uma expressiva massa de rochas graniticas continuas con grande variaco textural modal, ocorrente a $\mathrm{SE}$ da Folha de Encruzilhada do sul, predominando granitos avermelhados de granulacta métia aromeira, com poucos máficos a quatzo arredondado.

Para oprojeto. RADAMBRASTh, a Suite Intmisivariolo dos Ladroes, como passou a aer referida (Horbach et al, no prelop apud 
Moreira Marimon, 1982, apud Issler, 1984), compöem-ge de grani... tos normats de alcali-feldspato granltos aflorante como um grande corpo nos arredores da localidade de Dom feliciano menclonado como a ocorrencia Arroio dos Ladróten Além desta, fazem parte da mesma thite corpos menores como os aranitos arroio do Bote, Pedras Altas, Fortaleza, Cangugu e Capáo do Leăo, entre ou$\operatorname{tros}(\operatorname{tg}, 12)$.

Genericamente, Moreira Marimon (op. Eit. descrevem esta litologia como equigranular, varlando de media grossa e, as vezes porfirolde, com predonínio das coloracón marron avermelhada clara, róma ou cinza clara. Microscoplcamente, a textura comum a hipidiomórfica a composicăo mineralógica principal a de K-feldspato, quartzo elagioclásioe, subordinadamente, anfibólio e biotita. Os acessórios maim comung sto o zircáo, a fluorita, a apatita e opacos. Segundo os mesmos autores, a Suite Dom Feliciano revela quimismo alcalino, com alguns termos calci-alcalinos, mostramme diferenciados, com evidencias de terem sido submetidos a processos metassomáticos durante ou após o seu a lojanento.

A ocorrencla Arroio dos Ladröes, na porcto norte, heterogêm nea pode resultar de intrusöeg multiplas. As occirrencias menores

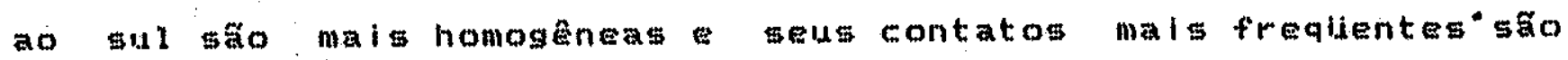
tectônicom, jă que astociam-\$ aos grandes falhamentos regionais. Também eximten contatos nitidos gradacionais, permanecendo as caracteriaticas de plutonitos pós-tectốricos.

A interpretaço geocronológica que fazemos para a Suite Dom Feliciano nato em essencia, distinta da apresentada por Teixeira (1982) e comentada anteriormente. As diferencas que the observam 
sto apenas estrategicas baseiam-ge nos fatos a seguir apresentados.

Primeiramente, uma discrepancla relaclonawe ao numero de pontos lut I lizados na confecco dos respectivos diagramas isocronicos. Enquanto aquele autor enumera dez pontos analiticos, neste trabaino listamos apenas tinco amostrat como pertencentes a suje. Este fato we deveu a impossibilidade de consulta ao mapa geológico das folhas Porto Alegre Lagoa Mirim, do Projeto RADAMBRAsIL, que durante a elaboraço desto texto encontravame no prelo, o que impediu o conhecimento das dimensöes e limites precisos dos corpos graniticos que constituen a unidade. Desta forma, apenas aqueles indiscut ivelment pertencentes a la que foram levados en conta.

Assin pertencem aos diagramas lsocrônicos daquele autor e deste trabalho ot seguintes pontos comins:LK-1798, 212, 213 e. 219 C. (tab. 6). Og pontos a10A B, uados por Teikeira (op. cit.) foram descritos como portadores de caracteristicas sintectônicas por Cordani (anotacónes pessoals), o mesmo ocorrendo com o 215A, que, somado aos pontos 215C, D E. pelo menos ao nivel das informacoses disponivels, estar iam nos dominiog do Complexo Granitóide de Leste (fig. i2). Por fin, o ponto 24t, ainda Inedito, E devido a Halpern et a. (1.974).

O tracado do segmento isocrônico para os cinco pontos provenientes da Sufte Intrusiva Dom Feliciano (fig. 2B) permite que se atribua a mesma uma idade de $544+\cdots \mathrm{m}$. excecaro do ponto 219c. que pertence ao corpo granitico capa do Leão, os outros provem do próprio Granito Arrolo dos Ladröet. 
aos granitódes noto follados do Complexo de tegte ou na figlura 26 en particular, os pontos 215C, D E Já haviam fornecido um resultado isocrônico concordante com este aqui relatado. Isto sugere que nos domínion do complexo mencionado deven existir granitóides da Suite Dom Feliciano no ino ividualizados ou denominados ate o presente.

Tres determinacoses radionetricas Rb-Sr en rocha efusivas ácidas, pertencentes a Zona central do Cintura Dom Feliciano, es... ta disponiveis até o presente (GF-453.1, GF-453.3 GF-330). Teixeira (1982), en sua interpretacto, relacionou esta ditima amostra aे V. VIcânicas Acampamento Veiho, plotando os doig primeiros pontos em un diagrama onde foram tratadas as igocronas por ele conseguidas no embasamento gaucho conclulu pela possibilidade desta atividade magmática egtar relacionada ao evento mais antigo 6750 m.an) que, portanto, distinguir-se-ia da ocorrencias efusivas ma is Jovens, denominadas Asampamento Velho, com ldades varlaveis de 570 a $540 \mathrm{~m}$. nals levadas dos pontos GF-453.1. GF-453.3 relacto do do.GF 330, para $R O=0,705(t a b .5 B)$. Porm, o autor chama a atencta para, se forem adotadas razós Inleiais maiores, da ordem de 0,710

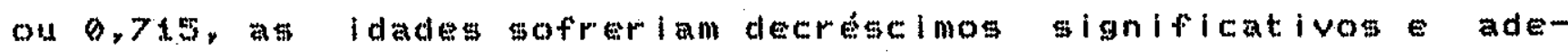
quar-se-iam ao tipo de manifestacko magmatia que, normalmente, é tradia na evolucto geológica de uma átrea.

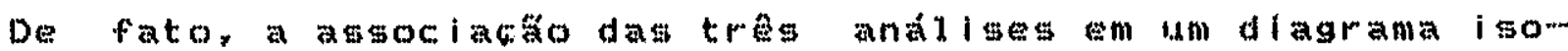
(crônico (fig. 29), já que derivam de ocorrenciag prómimas (fig. 19), permitiu que se obtivestem coerentes resultados como uma ida de de $560+\ldots$ 1. ma any para $R O=0,714$. 
A idade convencional de $571+\cdots 12 m_{n}$. Para o ponto GF-330 conflavel en funcáo dos alto valores revelados por guag razóses i … motópicas (tab. $5 B$ ) posicionam, ambos os resulados, o evento vuleanico como temporalmente comelato acos granitóldes năo foli a dos do Compleso de Leste da Suite Don Feliciano.

\section{Bloco Encruzilhada}

A massa granitica aflorante nas proximidades de Encruzilhada do Sul, na frata noroeste da zona Central do cinturáno Dom Feli-.. c. iano, foi originalmente definida como Granito Eneruzilha (Leinz, 1945) poot (ar lomente redenominada de Complexo Granit leo EncruziThada por Tessarl ploada (1966).

Otrabalho geológico mais recente relativo a regiáo é devido a Frantze a 1. (1984) nel os autores reconhecem duas unidades ou sequêncian litológicas distintag, compostas, a primeiraprincipalmente, de gnaisses policiclicos, a megunda, de corpos graniticos de fácies petrograficas diversas indeformados e intrusivos na seqiênela anterior, definindo batólitos polifástoso.

De acordo com om mesmos autores, a seqiêncla gnálsgica de Encruzi hada do Sul formada por paranaisses aluminosos, calci-si... I l catados a quartzomfeldspaticos, Intimamente associados, seguidos de metamortositos a subordinadamente, de ortognalsses de compom S6 Go granodioritica a tonditica, sando denominados de complexo

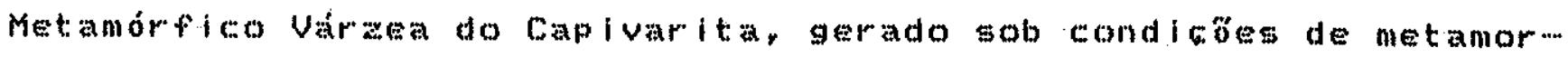
fimo de facie anfibolito superior.

Cumpre assinalar que tete mesmo conjunto rochoso foi referido 


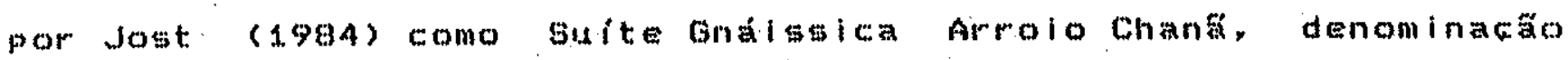
atribuida a Frantem artigo ind endio.

A "Gequencia Granitólde" (Frantzet al, op. cit.., aqui refe... rida tomo Suite Intrusiva Encruallhada, se faz representar por corpos de dimensôn batoliticasy com texturas variácis mas predow minantemente grosseira, de porfiritica a equigranuar, composi-

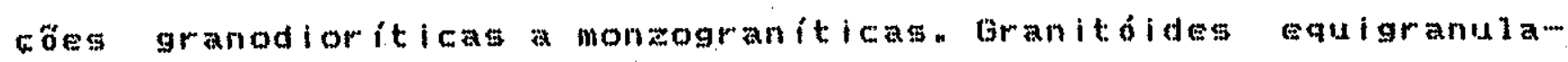
res medios finos, de composicho principal sienogranitica subordinadamente, de granodioritos K-feldspato granitos, recortam os termos mais grosseirow condicionados por zonas de falhas.

Geocronologicanente, os eritérios utilizados no agrupanento de amostras do Complexo Granitóide de Legte, para a construcáo de igócronas, foram os mesmos observados na subdivisăo das rochas do B loco Encruzilhada. Assim, os pontos arialisados (tab. 7A) puderam ser subdivididos em doib conjuntos, um portador de caracteristicas

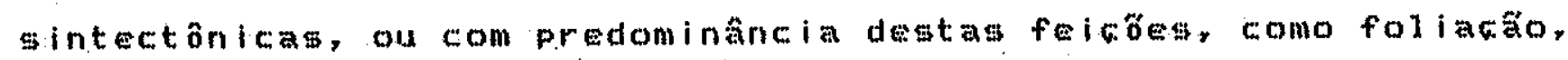
e ausencia ou pequena quantidade de minerais neoformados, outro constituido por granitóides isótropos ou compredominancia de materiais neoformados ot segmentos definidos por estes conjuntos (fig. 30), en congeqiênela do tipo de amostragem realizado (fig. 31.), gấo de referencia e regionais; mas contêm pontos analiticos cosenet icos capazes de fomecer valores temporali verdadeiros, como se verá adiante.

A Isócrona $I$, montada a partir de granitóddes fortemente foliados ou petrograficamente classificados como do tipo sintectoni-.. co (amostras 286, 283, 285, 287 288, representadas por pontos cheios na fig. 30), corresponde a mais antigo evento geológico 
detectado no Bloco Encruzilhada, definindo uma idade de $619+\ldots$ i. m.a.. com Ro caracter isticas petrográficas da amostra LK-161B, ela parece per... tencer a este primeiro segmento sua inclusco no cálculo da idade năo altera

Og granitoides tardios, por sua vez, representados por termos de granulata grosseira fina, equigranulares no geral camostras a78A, B C, $281,286, L K-194$ \&K-199), rapresentam un evento magnático mais jovem, temporalmente posicionado através do segmen-

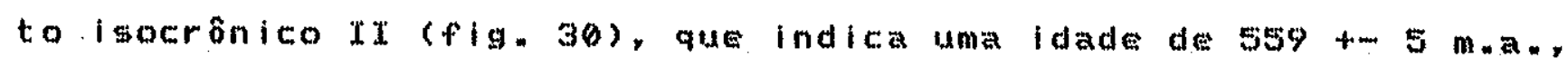
Com Ro $=0.716$.

Embitidos neste segmento encontramme os pontos $278 A, B$.

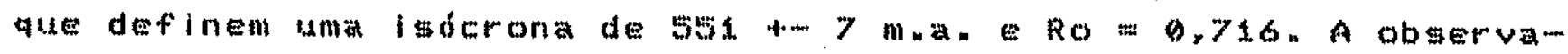
cấo dos mapas onde se astinalaram os locais amogtrados permite supor que os pontos 278 (A, $B$ C) 281 coincidem, respectivamentie, com os L.K-199 LK-194, isto , form coletados nos mesmos a-

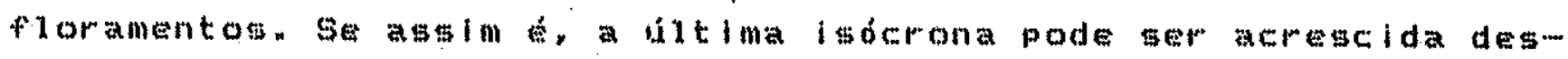
te ponto adiclonal (LK-199) negte caso, define-ge uma ldate de

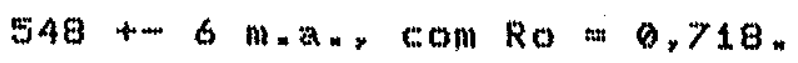

a preciso ressalvar que na figura 31 os locals de amostram gew 280 e 186 encontram-3e, respetivamente. assinalados en áreas mapeados como pertencentes a suite Intrutiva Eneruzilhada complexo Metamórico Várate do Capivarita, sendo os pontos analiticos resultantes inversamente utilizados na figura 30. As caracteristicas petrograficas geocronolólcas indicam como correto o segendo procedimento. devendo a localizacta das amostras em unidades erroneas. ao fato de ter sido deilizato. como baste para a figura 31 . 
carta geológica de pequena escala (1.aso.000) de Tegsari picada (1966). Se itilizado o esboco geológico da regino de Encruzilhada do Sul apregentado por Franto at. (4984) e compilado de mapea-

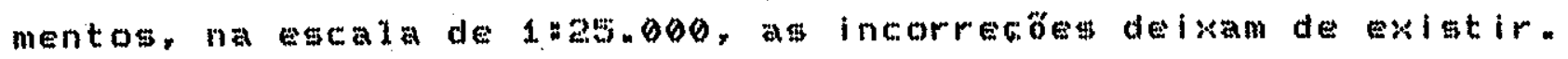

O5 pontos 282 e 289, provententes de amostras com caracteris

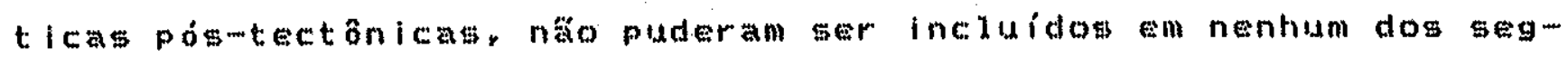
mentos isocrónicos. Aquele, provavelmente, pertence a corpo granitico tardio com raza inicial distinta. Tal como o granito 286 , a amostira 282 deriva de intrusa que produziu, no contato con suas encalwantes, feicós de alteracto térmica coordani, anotacós de (ampo). Ofitimo motera minaldevidented de cataclase, que pode ter sido o fenómeno responsável pelo seu comportamento nfóco colinear.

Em sintese, apesar do tratamento geocronológico genérico para o Bloco Encruzilhada, partir da figlura 30 deduzwas que a idade de referencia (I) do Complexo Metamórfico Várza do Capivarita bratiliana $(\simeq 620 \mathrm{~m}$. a. $)$, nẩo havendo motivo aparente para conside-ra-1o como unidade mals antiga (Proterozico Inferiom os Arqueano, segundo proposta de alguns autorst. O gegmento isocrónico II poaciona as manifestacoote graniticas intrusivas no intervalo $560-$ 550 m. qijencia litológica do Bloco Encruzilhada parecen contemporâneos à Suite Intrusiva Dom Feliciano do bloco homôn imo.

Apenas duas idades K-Ar täo referidas aos granitód co Encruatihada provem de biotitase de anfibolios separados de uma mesma amostra (Form-i). As biotital forneceram um valor tempo-

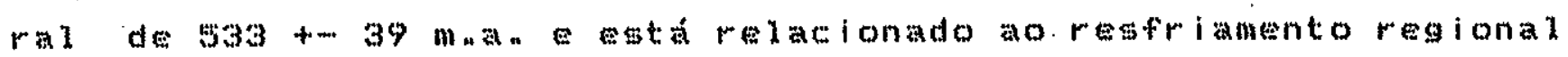


da área. O resultado de cerca de 1.000 m.a. conseguido na fracáo dos anfibolios (tab. 78) questionável por fugir ao padräo brasiliano encontrado em toda a porca oriental do fiscudo. sendo este ponto a única exceto. Este parece ser um dado inconsistente. fruto de problenas analiticos, uma vezo a amostra deriva de granitóide de fáclesequigranular (Formogo, 1972): A repeticăo da analise possibilitaria constataca de possivel acidente dupante a realianco da mesma.

Também ocorrentes no Bloco Encruzilhada, em sua porcăo setentrional, os Anortosito Capivarita Sienito Piquiri receberam al-

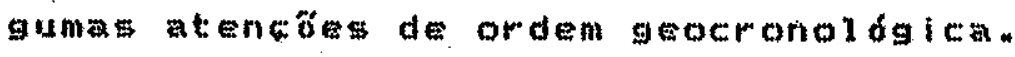

A primeira unidade foi denominada originalmente estudada por Formoso carparo (1962), sendo as investigacos increnentadas por Formoso (1972). Segundo Frantz et al. (1984), sâa conuns cor-. pos de metanortositos associados ao Complexo Metamórfico Várzea do Capivarita. Estes, com granulometria média a grosselra concordantement orientados com o bandeamento principal dos gnaisses, tên como constituinte mineral principal plagioclasio do tipo betownita -anortita e, Ecundar lamente, máficos como cilnopirowênio, anfibolio biotitan

Mais apropriadas a este tipo litoldgico sáo a determinactos radiometricas pelo método k-Ar. existindo 4 resultados em minerais separados (tah. $8 B)$.

A primeira tentativa de obtenciáo da idade do Anortosito Capivarlta se develu a Formoso $(1972)$, atse analisouplagioclásios do

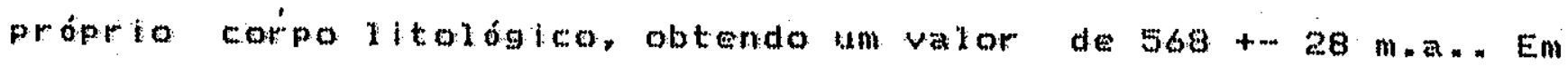


seguida, cordani et ad. (1974) apresentaram dois novos resulados, emplagioclásio em anfibólio, de anfibolitos que recortam a unidade maior. As idades conseguidas foram, nos dois casos, superiores a 650 man, mas os altos teores de Ar atmosferico revelado pelas anal ises obrigam que estes dados sejam tomados com cautela. Teixeira (1982), ut i lizando biotita separada dos mesmos corpos an fiboliticos, consegue uma nova informakáo temporal de $610+\ldots 18 \mathrm{~m}$. a." Se esta unidade esteve sujeita a metamorfismo de facies anfi-.. bolito (Frantzet aln, 1984), as idades, obviamente, referen-se à época do resfriamento deste episódio geológico, sendo, portanto, minimas.

Apesar da inadequacto, face às desfavoráceis relacóces de Rb e Sr, das rochas anortositicas ass andises radiometricas por este método, encontram-se dois resultados isotópicos camostras $276 A$ e c. tab. 8A) sobre os quais se podem fazer algumas consideracoses. En consequancia dos teores extremamente baixos de Rb nas amostras, os valores da razán Rb87/Sr86 foram sempre inferiores a 0.01 . Em um diagrama isocronico, estas baikas razós definem pontos muto próximos do eixo Sr87/8r86, isto é, as quantidades Sr87/Sr86 destes mesmos pontos săo, praticamente, equivalentes à razáo inicial da rochan Assim, os valores conseguidos de 0,7027 a 0,7033 (tab. 8A), correspondentes a Ro, sto coerentes com os de rochas derivadas por diferenciacäo a partir do manto. Uma terceira ana 1 i-. se provinda de banda anfibolitica contida no anortosito (ponto 279, tab. BA), também revela razăo similar, confirmando uma or igem mantélican

ral como ocorre com os gna isses co Complexo Metamórfico Várzea do Capivarita, com os quats se astociam, os corpos anortositi... 
cos se deixam intrudir pelos granitos tardios da suite Encruzidha cian.

o sienito piquiri foi denominado sinteticamente estudado por pieada (1966), tendo permanecido isento de estudos complemen... tares ate recentemente, quando Jost et: ad " (1985) descreveram um importante conjunto de dados relativos as feicobes estruturais, texturais, mineralógicas, petrológicas, de diferenciacáo de magmas alcalinos e de meconismos e profundidade de intrusáo da unidade em foco.

Dotada de estrutura planar, cores pardacentas escuras e granulometria variád de fina a grosseirar esta rocha apresenta uma mineralogia Himples assencialmente o ortoclásio eanfibódio e/ou pirowenio, podendo ou náo associar-wse o quartan como minerais a cessórios podem ocorrer microclínio. plagioclásioy biotita, entre outros, de forma permitir a caracteriacaco de tress tipos litologicosprincipais, ou seja, alcali-wienitos, alcali-cuartzo sienitos e alcali-granitos, com variedades que dependem da participacáa de anfibólio, piroxênio e biotita en diferentes proporcóses modais

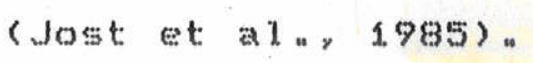

o Lnico dado geocronológico disponivel na literatura para o sienito piauiri foi obtido por cordani ettal. (1974), atraves do método K-nr em anfibólio, cujo resultado é de $580+\cdots$ as ma. tab.9B).

Netse trabatho, apresentamos quatro analises Rb-Sr (tab. 9A), devidas a Halpern et al. (1974), que, por näo terem propiciado a c.:onstrugáo de um diagrama isocononico de boa qualidade, permanecen. 
ram ineditas ates at data. A tentativa de confeccionar una isócrona de referencia revelou que o alinhamento dos pontos é precario (fig. 32), pedundando en un erro analitico elevado (t =61s+$99 \mathrm{~mm}$. E Ro $=0,7063)$.

A incertexa neste resultado gecoronoldgico, functio da sofrivel colinearidade das amogtrasto pode ger consequencia da prover niencia multipla das mesmat, de afloramentos diferenteg, com ra-

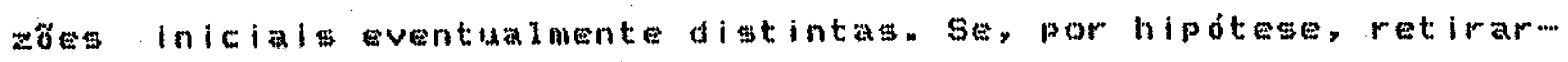
mos o ponto 291 dos calculos da idade, por mostrar-se, entre todos, o mals discrepante, o diagrama isocrônico resultante passa a fornecer um valor temporal de $606+\cdots 98 \mathrm{~mm}$. RO $=0,706$ MSWD $=$ $0,33$.

Quanto ao Granito Campinag, nenhuma analise adicional foi desenvolvida desde Teixeira (1982) nada possivel acrescentar interpretacáo gecconologica desta unidade feita por aquele autor - Já comentada (tab. $9 c)$. De qualquer modo, o valor temporal disponivel, através de diagrama isocrônico Rb-Sr de referencia ta de $785+103$ m.

Para concluir, cabe mencionar uma ldade $K$ mar de 606 tw $18 \mathrm{~m}$. a. obtida em flogotipas extraidas de una ocorrencia carbonatica (mármore) a nordegte do Bloco Encruzilhada (fign 3i, tab.7C; Cordani et al, 1974), outra ldade K-Ar de 541 +- 277 ma a partir de biotitas separadas de um granodiorito que ocorre como embasanento da Bacia do Parana na regiag de Torres, amostrado atravé de sondagen realizada pela PETROBRÁs, tendo, a megma amostra, fornecido também uma ldade Rb-Sr. convencional, Bara Ro $=0,705$, de 640 m. (tab. $5 A$ SC), segundo cordani a 
mo, encontram-ge dimponiveis para o leste do Escudo do Rio Grande do Sul tras analise\$ Rb wsom anfibolitos provenientes de aflora nentos gituados nos arredores de Cangueu pelotas (fig. 19), que, embora nấo definam um segmento lacrônico de boa qualidade (fig.

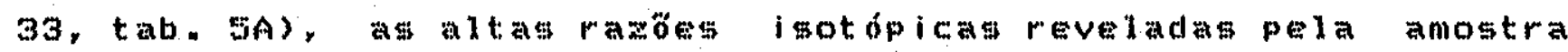
22bc permite que te atribua a la ua idade convencional de cerca de 850 ma.. Para Ro $=0,705,0$ que reforca possibilidade de termos tido, como já meneionado, um evento de homogeneizacão iso tópica precoce no quadro evolutivo da area, ao redor do tempo conEiderado.

\section{Consideracões Finais}

Com base no que se acaba de expor, éposivel sugerir ou chem

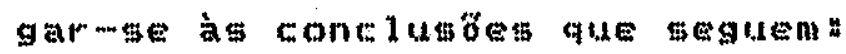

- a porctio loste do Emeuto do Rio Grand do sul representa rema parcela do cinturato Dom faliciano, conforme compartimentacáo tectônica adotada neste trabadho, litologicamente subdivisivel em um Flanco Ocidental a uma Zona central;

- no fanco ocitental afloram esporadicamente graisses quartao-feldspat icos que constituem o mbasamento do einturta conaisgest Encantadas), cuja ldade Rb-gre trangamazônica ( Neste domínio predominam metassedimentitos metavulcanitos que caracterizam litologias supracrustais dobradas metamorfizadas (orupo porongos), pouco conhecidas do ponto de vista geocronológi... co, estando disponiveis algumas idades Rb-sr convencionais, cujo valor mais confiavel de cerca de 800 ma. para hm dos episódios vulcânicos gerador de ardesitos que se intercalam nos Metamorfitos 
Ciero Cambará, detatigraficamante situados no quarto guperior do Orapo

$\because$ Z Zona Central de Cinturónom Feliciano corresponde a fai-

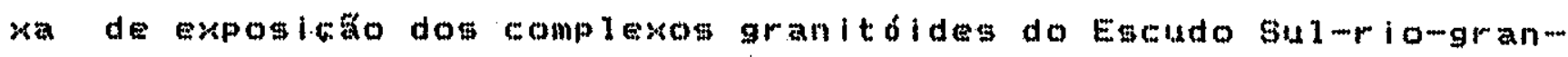
denst Oriental (mubdividida em dus contidadeg dwrominadas BIoco Dom Feliciano Bloco Encruallata) chjag litologiag constitidin t: em (1) rochas com toktura orientada e ausente ou incipiente neom formacăo minaral (2) rochag imotropas con caracteristicas póstectôn ictas

- no Bloco Dom Feliciano predominam termos magmaticos atribuidos is rates de areo magmatico exumado, cujo desenvolvimento

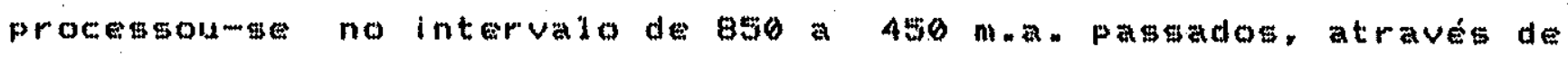

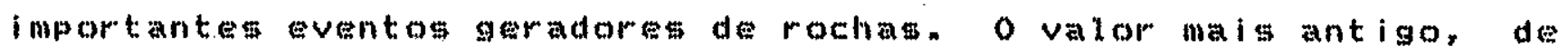
850 - 830 m.

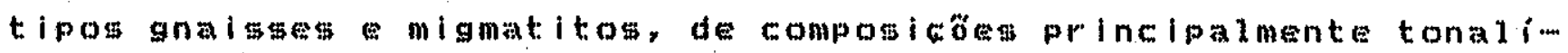
tica, quatzomdioritica trondhjemitica. Og termog granodioriti-

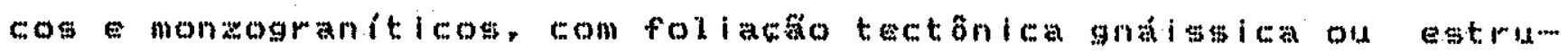
turas primarias devida

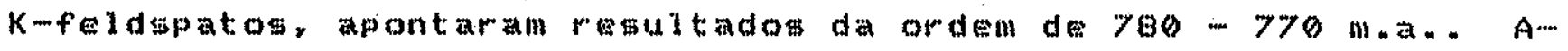

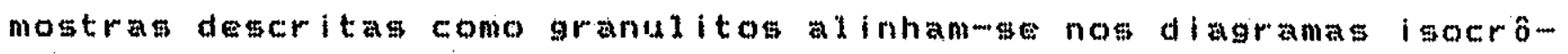
nicos há potaco comentados, cojas ra

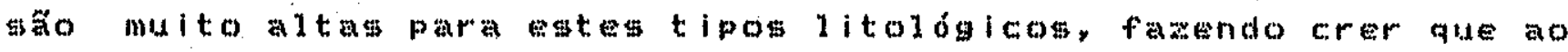

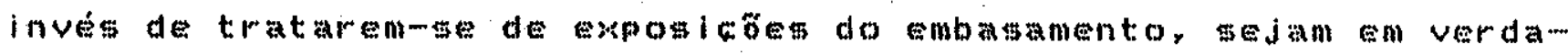
de rochas precotemente geradas no Giclo Bragiliano. Valorestempon rait d

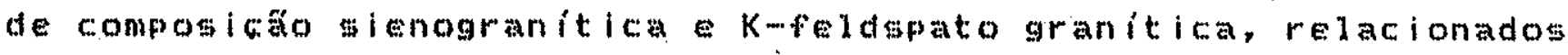

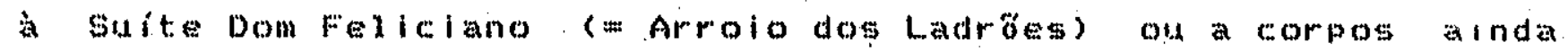




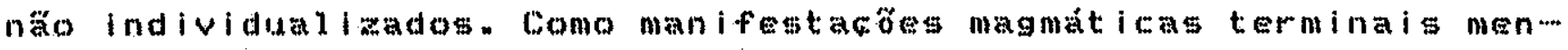
cionamos. Iocalmente, veios filös graniticos, cujo diagram isocrónico fornece valor de cerca de 450 m. a. Em base à razóng iniciais, varláveis de 0,706 a 0,709 , atribuime à diversas suítes uma derivactóngenerica a partir de materials sialicos infram crustais, com contribuicón mantelicas gupracrustais diversas. Os resultados K-Ar en RT, plagioclásio. amfibólio e sobretudo, blotita (Tb asooc), cobrem um espectro temporal que oseila de 650 a 450 man. com valores menoreto ocorendo predominantemente no setor oriental. Este comportamento é sugegtivo de ascengáo de blocos a leste, postivelmente conseqiante de fallamentos inversos

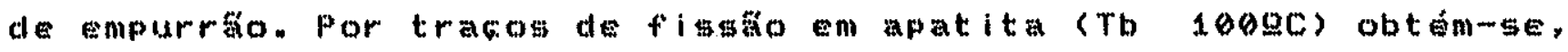
deforma generalizada, uma idade da ordem de 270 m.a. ao longo de: um perfil legte-oeste trangveral hentidade, Verificame, assim, que os deslocamentos mativos de blocos erustas säo anterlores ao valor temporal ha pouco mencionado este parece relacionar-se com a estruturacato do Arco de Rio Grande, quando da evolugáo tec.... tônica da Bacia do Paranáy

-.. O Bloco Encruaithada compöemse de duas sequencias litológicass. a primeira formada por para ortometamorfitos (complexo Me-

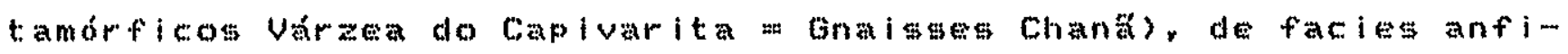
bolito. a segunda de granitódes diversos temporalmente dis tintos; que recortam a seajencia anterior. Os termos gnáissicos,

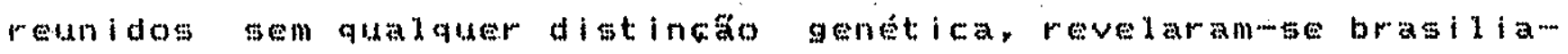

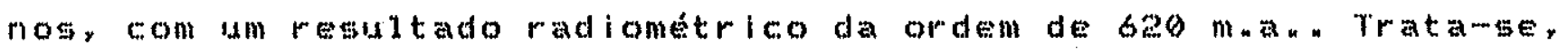
evidentemente, de um valor temporal médio e ponderado ja que deri-.. va de diagrama iscorónico definido por anostras geradas en tempos distintos, mas aparentemente prómos. A unidade granitica posi... ci ionoume no intervalo $560-550$ man, parecendo que os termos pe- 
trografico mai finos tardios sato cronocorrelatos suite dom Feliciano do bloco homónimo. O Anortosito Capivarita o sienito piquiri, ainda incipientemente estudados, revelall idades preliminares K-Ar Rb-Sr Incluidas entre 650 \& 570 ma a.

- observa-me, agsim, que o Ciclo Brasiliano, no Rio Grande do Sul, ampliamse consideravelmente do ponto de vitta temporal, sendo reconhecidos importante episódios de gerafón de rochas no intervalo de 850 a $550 \mathrm{~m}$ a... De maneira esparsa e local, atividades magmaticas na forma de veios fióses graniticosterminais revela ram idades de ate $450 \cdot \mathrm{m}$. a... 


\section{GEOCRONOLOGIA DO EMBASAMENTO DA PORCAO OESTE DO ESCUDO SUL-RIO-GRANDENSE}

\section{Considerafbes Iniciais}

o reconhecimento primeiro de rochag antigas naporcäo meridional do Estudo At lantico deu-se no mbasamento do Uruguai. quando Bossi at al. (1967) mencionaram acomencia, a ocidente, de rochas estruturamente separaveis das sequencias gupracrustais

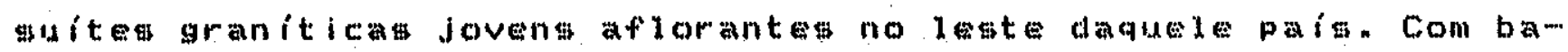
se en dados geocronológicos obtidos. por Hart (1966) Umpierre Halpern (1971), Ferrando Fernandez (1971) denominaram esta anti-ga entidade, atribuída a proterozóico Inferior, de "zocalo predevoniano de la Cugnca del Rio de La plata", contraposto ao "zocalo del Este y Sumeste", do Proterozóleo Superlor a Eomaleozóico. aflorante ra margen at lântica.

posteriormente, Almeida te ad. (1973), em um trabatho de sintese sobre opremambriano da plataforma Sul mamericana, definiram a entidade mais antiga cono Craton do Rio de la Platar cuja extensăo para sul se darla, por sob os depómitos de cobertura, ate a Argentina (Sierras de Tandil, Aaud Bayas).

A possibilidade de prolongamento do Craton do Rio de la plata para o Rio brande do sud surgiu com o desenvolvimento de varias

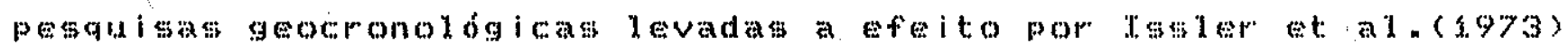
e cordani et al. (1974), que revelaram indicios de fratós crustais pre-brasilianas notse listadon 
A descoberta de rochas granulitieng na regino sudoeste do Es cudo do Rio Grande do sul (Nardi Hartmann, 1979), datadas como do Proterozóico Inferior (\$oliani Jr., 1979 soliani Jr. et al., 1983), tamberm favorecen tal hipotsen

Da nema forma, os trabalhow de Minioli (1972) e Cordani

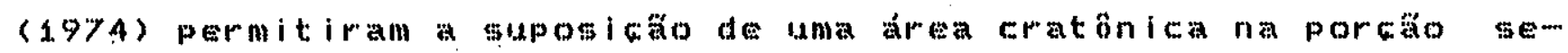
tentrional de Santa catarina, depole denominada de Craton de Luís Alves por Kail (1979 1980).

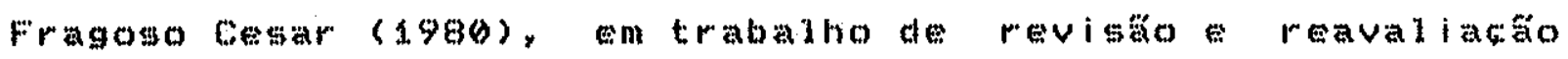
dos dados geodolcos, complacionou o ceraton do Rio de ta Plata, conforme definldo por Almeida to al. (1973), com as rochas antigas da porcáa ocidental do Escudo gabcho, incluindo ai, alén dos gram nilitos do Complexo Santa Maria Chico (Nardi e Hartmann, op.cit..),

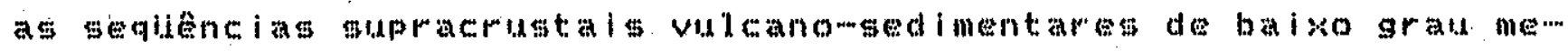
tanórfico, associadas a graritóldes diversos, concentradas, emespecial, na porcä́n noroeste do Escudo. Ëa ad cáno,postulou que estes

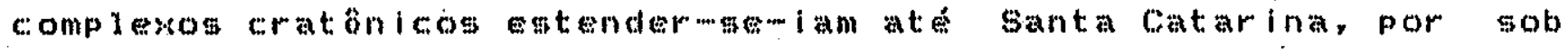
os sedimentos da Bacia do Parana, Mecorrendo como oraton de Luis Alves. Tal correlacto já havia sido, em parte, proposta por Hasui et al. (1.975), na definicäo do Macico Mediano de Joinville.

Hartmann Nardi (1983), en estudo que ablanged todo o oeste do Escudo sul-mio-grandense, reconheceram cue as rochas de alto grau metamóplico do compleno Granulitico Santa Maria chico ficam

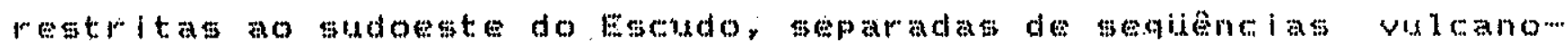
sedimentareg e de rochas gmanticas folladas, de baiso a medio graus, caracteristicas da fracko noroeste, pelo lineamento de

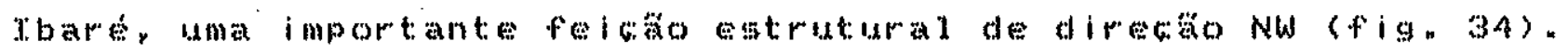


Apesar das diferengasionstatadas, Jost Hartann (1984), en sua descrica ganor ica da Provineia Mantiqueira (Almeida et aln, 1.977), tratam o oeste do Escudo gaucho como entidade úntca, referido como "Bloco Săo Gabriel", correlactonádel ao "Bloco Joinvil -... le" reconhecido na regifo da cidade homônima, em santa catarina.

Namann et al. (1984), em base à diferencas ja apresentadas.

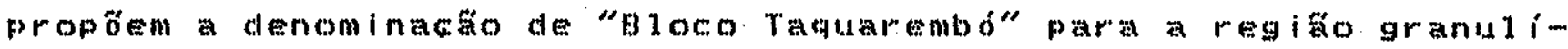
tica granitica a sudoeste do l. ineamento de lobré, ficando a de signacăo " Săo babriel" exclusiva dos terrenos de menor grau metamórfico, a noroesten

Fragoso Cesar e Soliani Jr. $(1984\rangle$, em um ensaio tentativo de compartimentaga to tectônica do craton do Rio de La Plata, lembram que o conjunto de rochas estruturas que compöem esta entidade pode ser sibdividido om daas grandes unidades" um embasamento do Proterozóico Inferior argueano e dma cobertura de idade brasiliana, Essencialmente do tipo vulcanomsedimentar molassóde, con\$eqiânte de at:iviades diastróficas contemporaness. O embasamento,

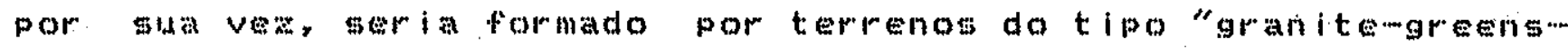

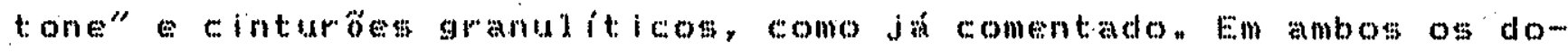

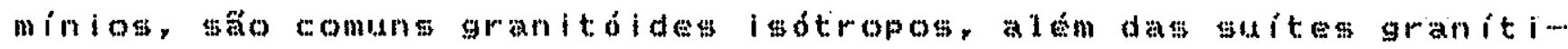

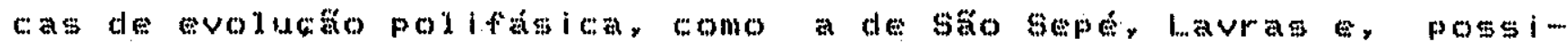

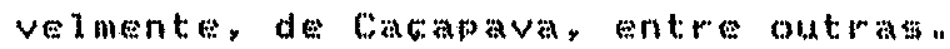

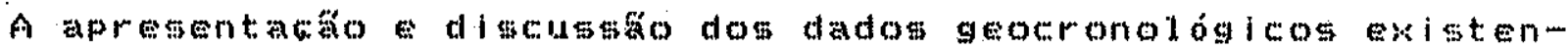
tespara a porcano ocidental do Escudo do Rio orande do Sul, tal como foi felto no capitulo anterior, seraco calcadas na compartimentacio tectonica geral vista acima (Naumann et al. y 1984; Fragom so Cesar e Soliani dr., 1984). Para consideragónde carter re- 
gional mais restrito, sempre que possivel necessario, serág utilizados trabalhos desenvolvidos por varios atores, en maior grate de detalhe, como os de Nardi Hartmann (1979), Hartmann e Nardi (1983), Bitencourt (1983), Bitencourt: Hartmann (1984), Naunann et al. (1984), Silva Fitho (1984) Koppet al. (4985), entre os que abordaram apectos diversos dos terrenos granditicos "gra nite-greenstone" do oeste do Escudo, e, entre os que enfocam as suites graniticas Intrusivan, destatames os de Sartori (1978), Nardi (1984) Sartori Kawathita (1985).

\section{Bloco São Gabriel: terrenos do tipo "granite-greenstone" do Rio Grande do Sul}

\subsection{Sintese Geológica}

Desce os trabalnos pioneiros de Goñi et al. (1962), Joste Villwock (1966), Jost (1966, 1979a, b), Ribeiro et al, (1966), Ri..

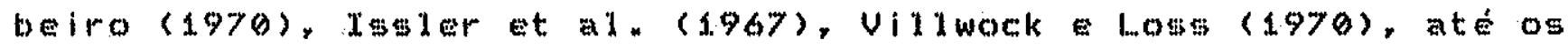
mais recentes de Sabert (1978), Garcia Hartann (1981), Rego (1981), Oliveira (1982), Natumann at al. (1984), Koppe et al. $(1985)$, Naime Veigel (3985), Neconhecente que a geologia da

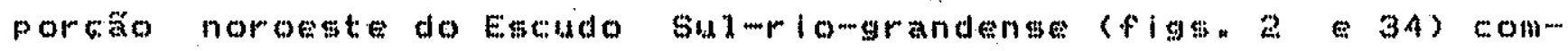

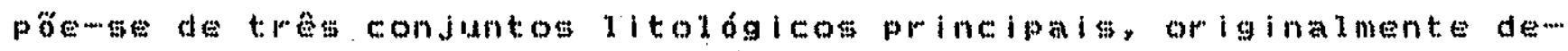
nominados de Cambaí, Cerro Mantiaueiras Vacacá, com variacóca

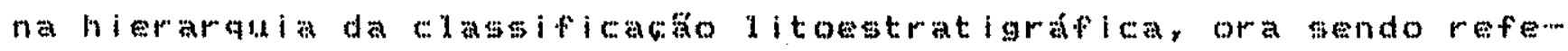
ridos como grupo ou subomgrupo, ora como formacto.

Para Ribeiro fantined (1978), as litolosias que ocorrem na zirea considerada sato passiveis de agrupamento em duas associafós, uma formada por espesas sequencias de filitos, xistos, mew. 
tabasitos, quartzitome marmores, equivalentes ao que se denomina no leste de Grupo porongos, um conjunto de gnatgses, migmatitos, xistos oflolitom parcials, referidos como pertencentes ao Grupo Cambi, que engloba, portanto, grande parte dag rochas anteriormente descritas como formacoses Como Mantiqueiras e Vacacai no oeste.

A primeira associagäo tem, para estes astorea, como área de ocorrancia típica, o alto estrutural que conten o oranito de Cacapava a feicazo diagnóstica principal seriam as cristas de orientacäo NE- SW, como carater reglonal, de mamore dolomiticomaturaito, tal como ae apresenta na localidade-tipo do cerro dos porongos - Torpinhas . Há, porén, como mencionam os mesmos pesquisadores, a louma diferencas marcantes ontre at exposicón de leste de oeste do Grupo Porongos. Na porcago ocidental, eata unidade carac...

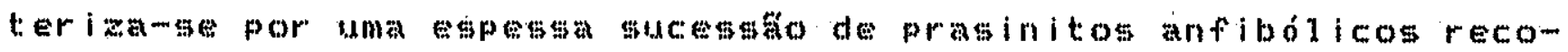
bertos por uma medimentacto pelitica ou arenosa do tipo "flysch", sendo que os mámorese quartatos associactos intertalamme ora ros prasinitos, ora nos filtos wistos derivados daglela sedi... mentac: הă

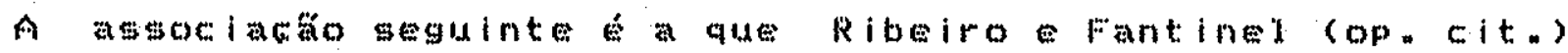

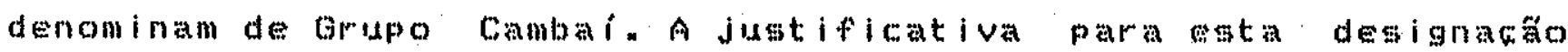
litoestratigrafica baseiasu no fato de que os autores consideram - Grupo Cambai como uma associacáco petrotectonica onde se encon... tram conjugados termos litológlcos diferentes, possivelmente con grats metamóricos ou evoluca petrogenetica diversos, mas que se repetem sistemationente en diversos dominios do Eseudo ocidental,

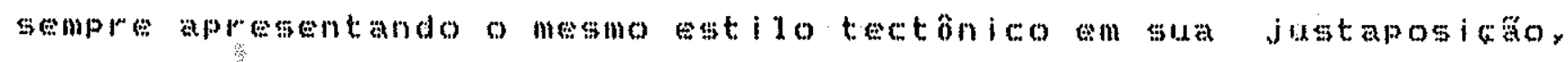

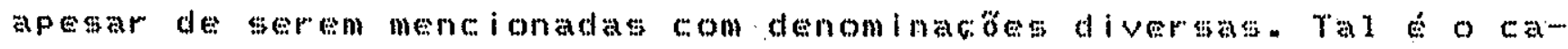


\$O, por exemplo, das rochas que foram nomeadas de formaga córo Mant i clue iras a

Na área. de Vila Nova -... Arroio Cambai, localidadertipo da associacăo, esta éformada por migmatitos derivados de anfibolitos, por peridotitos merpentiniardos e lentes de mámore näo megnesia no, alem de granito gna

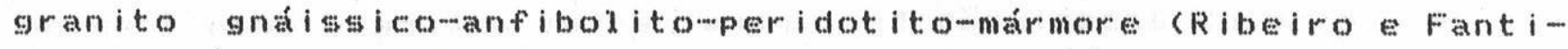
$n \in 1$, op $n$ (it: n)

A partir de Nardi e Hartmann (1.979) Fragoso Cesar (1980),

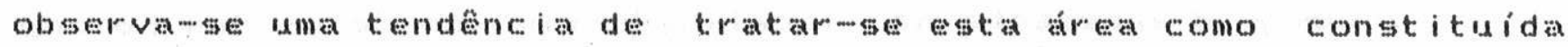
de associacóses de rocha caracteristicas de terrenos do tipo"

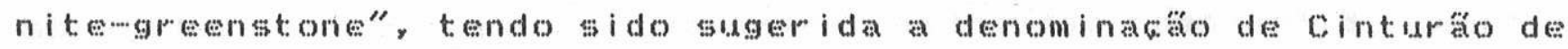
Rochas Verdes do Rio Vacacai (Fragoso Cesar soliani dray 1984),

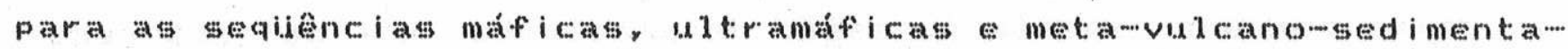
res, concordantemente astociadas a gna

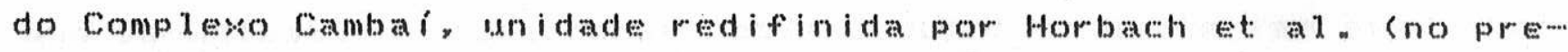

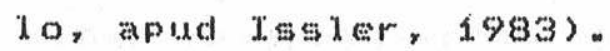

A primeira unidade, entäo, estaria composta do um expressivo pacote metamófico formado de peridotitos, dunitos, basaltos gabros, normalments transformaclos em serpentinitos, wistos mage a ianos e anfibolitosy entre obtros coriginalmente referidos a For

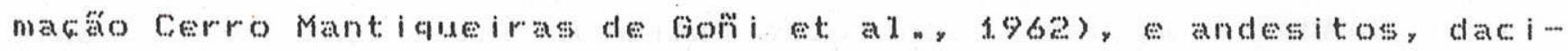

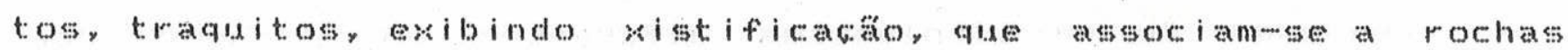

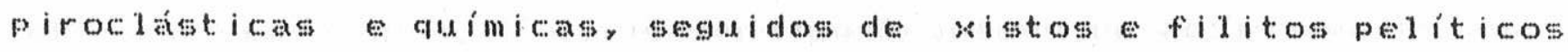

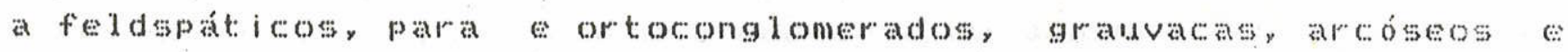
quartactom (geralmente relacionados pelos diversos astores a

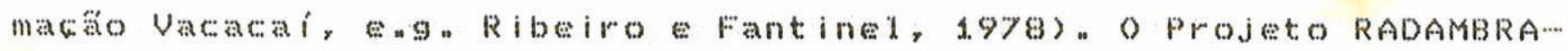




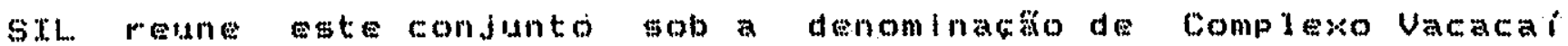
(Issier, 1983 ).

O Complexo Cambat foi definido como formata por toñ $i$ et al. (1962), Estim referida por outros autores (e w 1.966), ou redefinida como sub-grupo (WIIIig al " 1974) ou grupo (wost viliwock, 1966 Carraro et al ", 1974).

Fragoso Cesar e soliand Jr. (1984) consideraram o complexo Cambai como unidade constituía por granitóldes gnás sicos diver..sos, ultramafitos, quartatos, marmores e rochas calci-silicatadas, entre os principals, variag vezes deformados portadores dis metamorfismo de facis anfiboliton

Gilva Filho $(9984)$, por gua ves, propos que as rochas consideradas por Goñi (196а) como migmatitos homogeneos heterogeneos, que afloram ao longo do Arroio Cambai, equ sto na verdade, orto

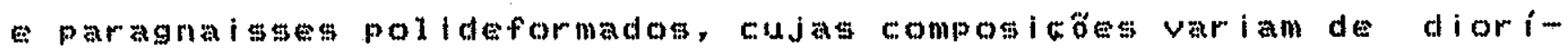
tica, passando por tonalitiantrondhjemitica, at é granodioritica,

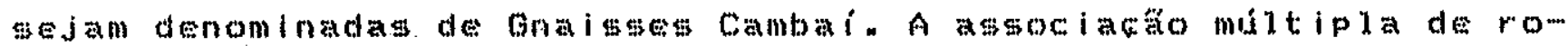
chas constituida por tats gnaissesy corpos básicos ulerabaicos, diques rioliticos polideformados, quartzitos mámores, que rew

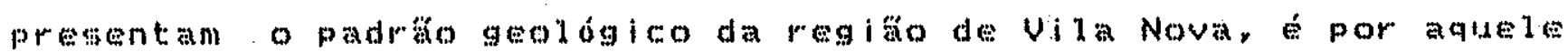
autor designada de Complexo Vila Nova.

Nos tempos que correm, face aos conhecimentos ainda prelimi nares, tom se proposto denominacoses estratigraficas particulares

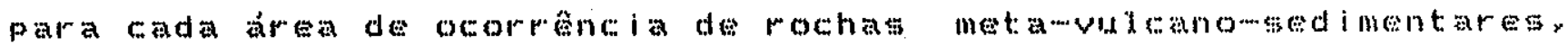
referidas, genericamente, por complewot e \$ub-divididas em seqien-

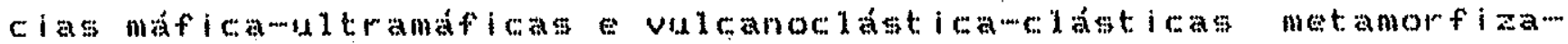


das na facies ximtos verdes. Assim de que ja foran denominados o Complexo Palma (Garcia Hartmann, 1981), formado pelas sequencias Cerro de Ouro cna qual Nauman et al, 1994 , ineluem o Macico Má-. fico-ultramáfico Passo do Tvo, estudado por oliveira, 1982) e Pontas do Sal 50 , cujas composicoss säo, respectivamente, apontadas a cima; o Complexo Ibaré, dividido nas sequencias Corticeira e Bela Vista (Naumann et a $I_{n}$ op. (it. ) o Complexo Bomboroca, igualmente

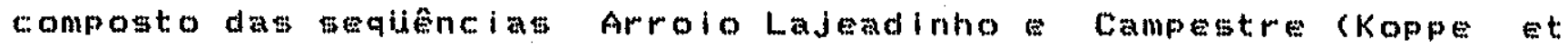
a., 1.9853). Embora sen designacăo formal. Naime Veigel (1985) também reconheceni, na area do Arroiodas Capivaras, norte da Vila

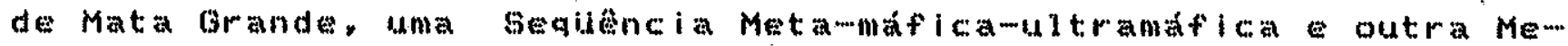
ta - vid canomedimentar.

Bitencourt (1983) referme aos metamorfitos que circundam o Batólito de Cagapava do sul como Complewo Metamórfico passo feio ( = Formacio Arroio das Ithas, do Complexo Vacacaí, seg. Teikeira, 1.982). S落o metapelitos, anfibolitos, meta-veleanoclásticas metaw vulcanicas, mármores e rochas calei-silicáticag, quartzitom, wistos magnesianos. rochas quartaxomeldspaticas que est iveram sujei tas a dois eventos metamóricos regionaisy o primeiro de facies anfibolito o segundo de carater retrogressivo facies xistos verdes. Na borda norte da suite Granitica Cacapavay os metamorfi-

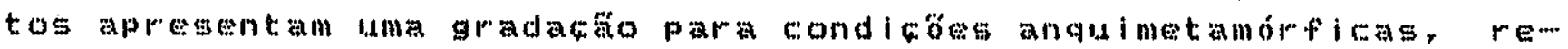
sultantes de cxposicoses de nivele crustais superiores ainda preservados (Bitoncourt, op " cit: ")

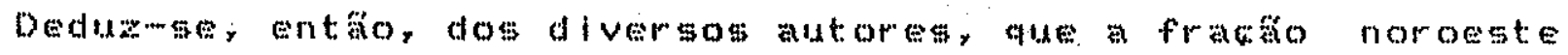
do Escudo do Rlo Grande do Sul se faz representar por rochas gna... issicas diversag (Bna is máficas e metavideanowedimentares, regionalmente concordantes 
conforme atestam Naumann ot al. (1984), Koppe et al. (1985), entre outros, definindo-se o que Silva Filho (1984), denominou de Complexo Vila Nova, seguidas por suites graniticas intrusivas, po... lifáticas na sua maioria, e sedimentitose vilcanitos de carater mol ás sicon

Com bate nos aspectos estruturaig, silva filho (inf. verb.) ordena temporalmente os conjuntos litológicos componentes do complexo vila Nova, na reglág homónima, en (19) Gnaisses Cambaí, mais antigos por apresentarem o maior numero de fases deformacionais, seguidos pelas sequâncias (20) metamaficamitramaficas (39)

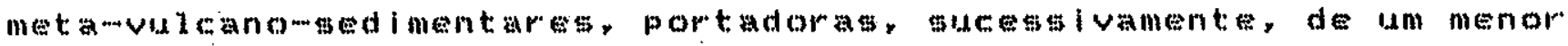
numero de feicón tectónicas, que coincidem, desce as primeiras, com as deformatoos tardias registradas nos gnaisstas mencionatos n

Em todas as ámg detalhadament etudadas, as rochas gnássicas sâa atribuidas, sem questionamento, a unidade Cambain As sew

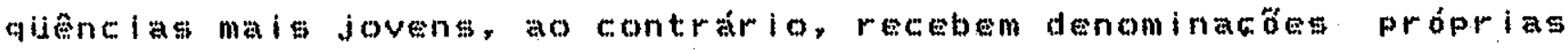
E docais. Sea, en un futuro proximo, for possivel constatar uma

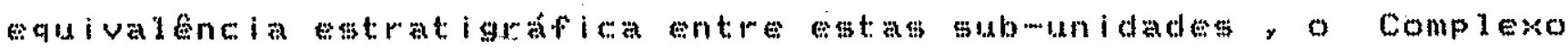
Vila Nova ficaria, entäo, composto dos conatsose cambai, de uma sew qijência do tipo "Curro Mantiqueiras" outra do tipo "Vackaci". o que, na pratica, näo altera de forma significativa o quadro estraw t: igrafico definido ha mats de duas déadas.

\subsection{Interpretacâo Geocronológica das Sequências Máficamultra- máficas e Vulcano-sedimentares}

msprimeiras determinacöes geocronológicas conseguidas em litologias do embasamento da porcáno noroeste do Escudo do Rio 
Grande do sul, exeluidos os complexos granititos, sato devidas a Issler et al. 〈1973), trabalhando sobre plagioclásios derivadou do Gabro de Mata Grande (flg. 35), atraves do método K-Ar.

Esta como bato tom sido complacionado ou incluido now conjuntos maficowatiramáficos do Bloco săo Gabriel por vários es-

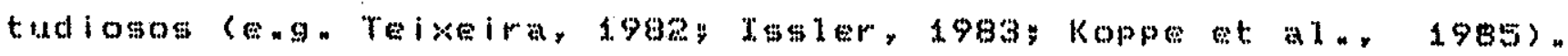

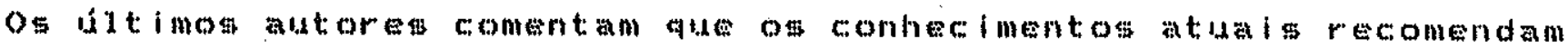
a inclusto deste corpo intrusivo na sequencia Arroio Lajeadinho. do Complowo Bossoroca, uma asociacta de rochas málicas, ultramá ficas e vicanomsedimentares, metamorfica deformacionalmente concordant com o Complexo Cambai comalsses Cambá de Silva filho, $1984)$

Foram determinados valores temporats minimos de $2.182+\cdots 16$ 1.826 tw 55 ma. para a litologia enfocada, tendo sldo, adicionada outra análige, utilizandome os mesmos metodo material, executa-

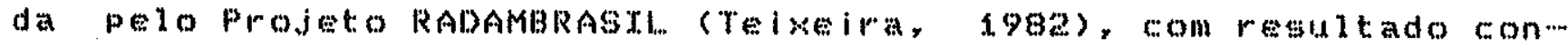

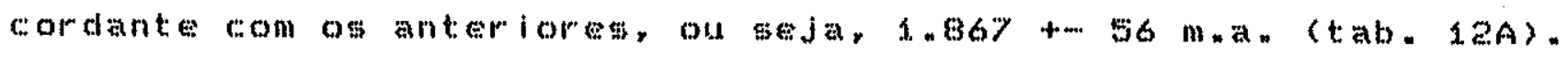

Tratamento simidar fol dispensado ao Complexo bas ico-ultraba mico de Pedrag Pretas (Marini Della Fávera, 1963; Muratorie

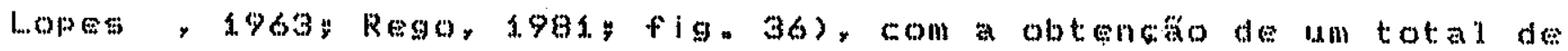
cinco valores Kar em materiais diversos (tab. 12B) "Os estudos radiometricos pioneiros neste complexo sâ oreditados a sartori (1.978), com a determinacto de duas idades en plasioclásios de an-

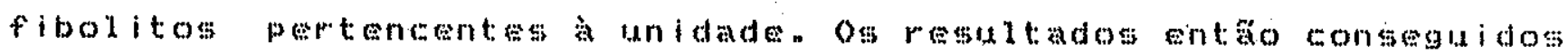

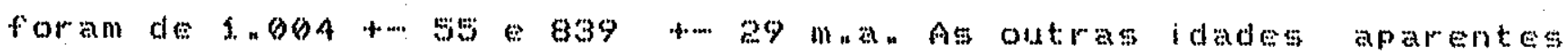

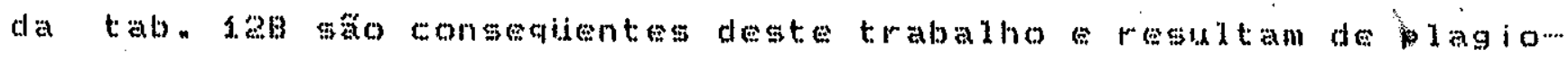

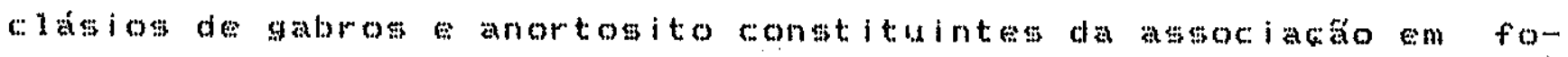




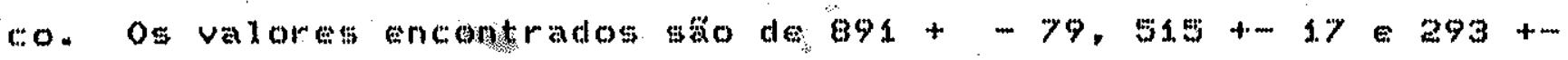

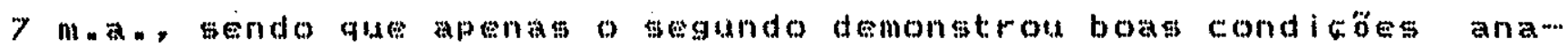
liticas. o resultado primeiro a duvidoso em vista do alto teor de Ar atmosterico presente na amostra, aliado baima quantidace de K. Por outro lado, as idadeg indicadas por sartori (op. Eit. p) permiten considerar anidade cono prewragiliana, parcialmente rejuvenescida nestecicio. O valor aparente mail jovem revela que os

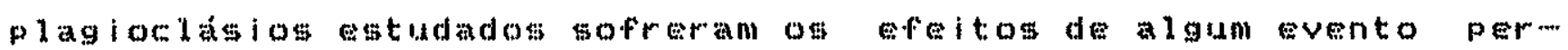
turbador, o que alterou a sua capacidade de retencáo do Ar. A idam de de 515 mnan pode significar orejuvenescimento completo da aw mostra. impogto pela suite Granitica de Săo sepen.

Ma is tras rochas de composicoses similares foram analisadas por reikeir (1982), da área de falm (SE de si. Gabriel), do Arro-

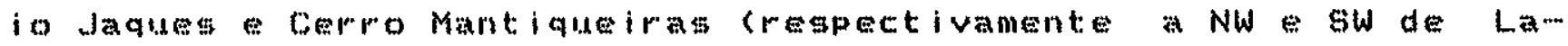
vras do sul; fig. 37). Para a metabasica de pama, reveladora de

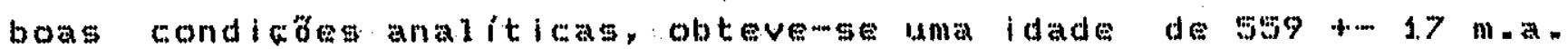
(tab. 12c), valor tipico de reafrimento braslitano. o metagabro do Arroio dactess, associado a wistos mapados como do tipo Vacacai, mag atribuido ao "Complexo cambal" pelo projeto RADAMBRAstL. indicon um resultado de sia t... 19 m. Cerro Mantiqueiras, por sua vez, com levada quantidade de Ar at-mosferico e balko teor de $K$ (tab. feE), fornecer um valor temporal

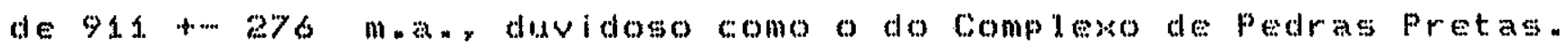

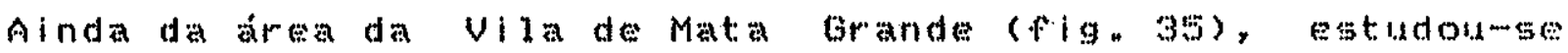

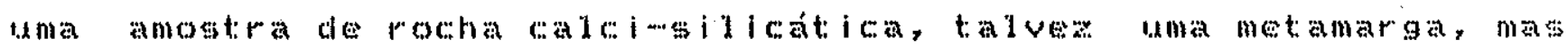

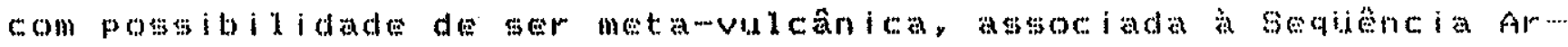

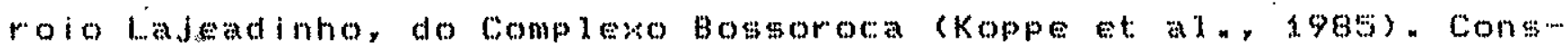
tituida, em essancia, de homblendas, acompanhadas da quartzo, 
plagioclásio, clorita e actinolita, revelou, pelo mesmo metodo ra... diométrico, em anfibólio, uma idade de 681. + 44 ma a (tab. 12F). Outra amostra também referida como calci-milicatica da seciuencia Pontas do Salso (Complexo Palma), composta de actinolita c quartzo, ma is epidoto epacos, supostamente de or igem sedimentar, mass cuja filiagăo ignea náo é descartaday, apresentou uma idade de 805 +.- $38 \mathrm{mn}$ an, tendo sido analisada através de seus anfibólios (tab. 1. 2 F ).

A sul da regiăo de cowitha do rabuleiro, a cerca de $1 \mathrm{~km}$ ao norte do Lineamento de loaré, no limite meridional do Bloco säo

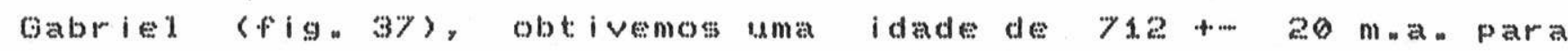
muscovitas retiradas de um muscovita wisto mapeado como do tipo Vacacai (tab. 12a).

No contexto das análises comentadass poder-me-iat incluir um resultado K - Ar em feldspatos or iundos de um gabro que aparece como embasamento dos sedimentitos da ginectise do paraná, nas prowimidades de Esmeralda, NE do Rio Grande do Sul, cujo valor geocronow

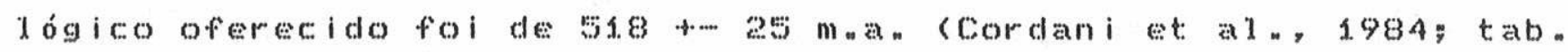

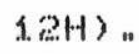

Estes dados Konr sugerem as seguntes hipotesesobre a genese

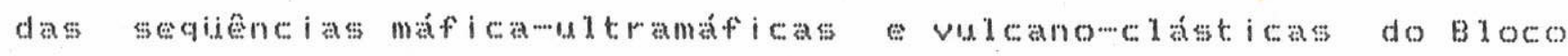
Gáo Gabriela ou (a) estes conjuntos ditológicos originaram-se no Proterozó ico Thferior (Arqueano?), revelando idades de resfriamen... to transamazonicas (Gabro de Mata brandes), rejuvenescimentos parciais (complewo de pedraspretas) ou rejuveneseimentos completos c Complexo de Pedras Pretas, metabásica de Palma, calcionilicatica de Mata orande) durante o Brasiliano, ou (2) ocorreram dois ou 
mals eventos geradores destes tipos rochosos, o primeiro no prote... rozóico Inferior, com rejuvenemeimentos parciais ou totais de fra6otes da crosta no proteroadico superior, outro(s) negte interm valo de tempo com a formagáo. de novos termos litológicos de composicós a

Apesar dos teores defavoraveis que as rochas máficas eultramáficas apresentam para análises pelo metodo Rb-Sr, setedeterminacós das razótes sr87/5r86, para uma estimativa de seus valores iniclais, form realizadas em amostras do Gabro de Mata Grande, do Cerro Mantiqueira ede Sequidencia Arrorlo Lajeadinho (tab.13).

É preciao mencionar ainda, para concluir a aprementacáo dos clados geocronolóicos daw sequictas meta-vulcanomedimentares do

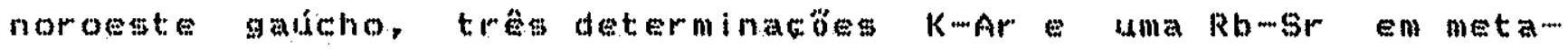

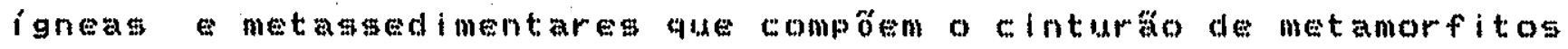
que envolve a Suite toranitica Cacapava do sul (compleko Metamóri t:o Passo $F(0)$.

A primeira determinaca radiometrica para esta unidade foi real izada através de convânio entre a DOCEBEO e o CPGeO-IG/USP permanece Inedita. Aqui, Para um mierodiortto em RT, obteve-ge uma

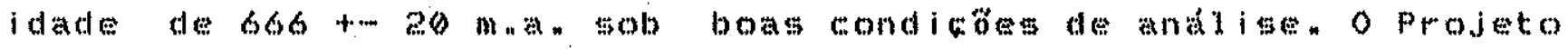

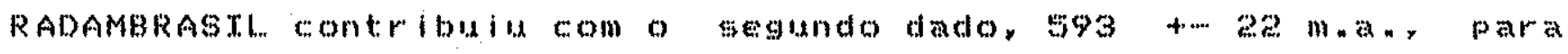
um metambatalto tambon extudado em RT. Este trabalho oferece o terceiro resultado de $5 \$ 6+\infty 9$ mon para muscovitas retiradas de um muscovita quartatio ocoprente a sul do batólito granitico de Cacapava (fig. $37 ; t a b$. $14 A$ ).

A Linica analise Rongr desta associacesolitologica desenvol- 


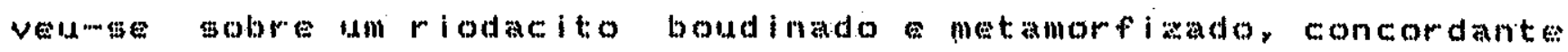
com a foliacto reglonal e aflorante a NW da cidade de Cacapava do Sul (fig. ay). A idade convencional, para Ro:n 0,705 , de $618+\cdots$ 1. 67 m. a. (tab, 14B).

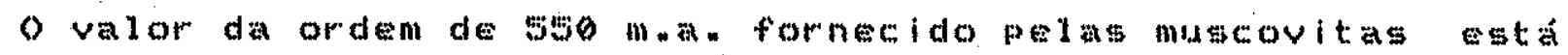
indicando a epoca do restriamento regional para temperaturas infew.

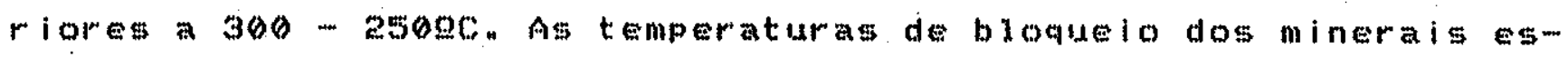

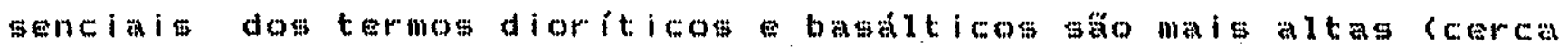
de 4509C) as idades des 590 o 660 man, tamben mínimas, já que se relacionam a respramentos litolósicos, demonstram que a época do Evento magnatico e certamente anterior ao valor mal a levado.

\subsection{Interpretacão Geocronológicas dos orto e paragnaisses e suites intrusivas associadas à unidade Cambaí}

A primeira invest is aço gecocronológica de certo vulto, levada a Efeito na rogino ocidental do Escudo Sulmiomgrandense, fédevida a Cordani et a . (5974). Na oportunlade, diversas unidades litow lógicas conhecidas foram amostradas, especialmente aquelat afiorantes na regiande Cacapava do sul t...avrag do sul, seologicanente medhor conhecida na epoca mencionada. A maioria das analises,no entanto, concentroum nas suites graniticas intrusivas, cono a de

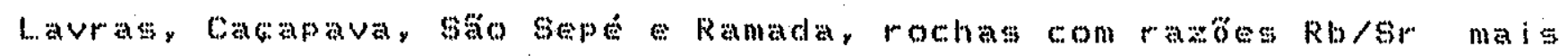
apropriadas e interpretaca mai

De um total de 18 determinacoses apresentadasy apenas 6 rela

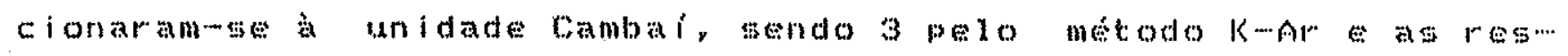
tantes pelo RB- 
O primeiro grupo compôsme da migmatito de anfibolitos dos terrenos Cambat aftorantes a sw de Lavras do Sul $\{f i g .37\rangle$, dos quais se separaram os anfibolios que forneceram valores temporais de $700+21,755+23=736+\cdots 22$ m. al. (opn (itn) comentam que estes valores sáp pouco mais antigos que os normals para a fase sintectónica do Ciclo Brasiliano e explicam que podem significar perdas pareiais do argonio de rochas do embagamento aquecialas durante este ditimo evento.

As demai detorminactos (Rb-Gr) derivam de um corpo granitico róseo, levemente orientado näo individualizado entre as rochas

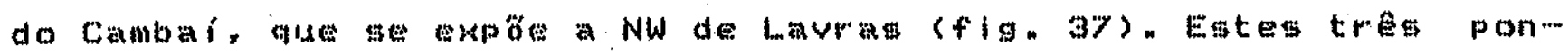
tos anditicos (244, 24 w 246$)$ foram apresentados como parte de uma isocrona de referencia paras rochas graniticas da regito. de Cacapava - Lavrate coja idade encontrada foi de $610 \mathrm{mon}$, para Rom $0,705$. Tratadom separadamente, estes pontos indicam para a litolow

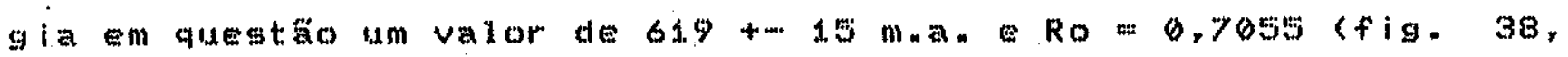
tab. (16A).

Os graisese anfibolitos que circundam os metabasitos Cerro Mantiqueiram voltaram a ser estudados por Pinhelro Machado (em. prep.) e cinco novas determinactós. K-Ar em anfibolios, provindos de gnaisses e metahornblendito, ratificaram os mimeros obtidos por

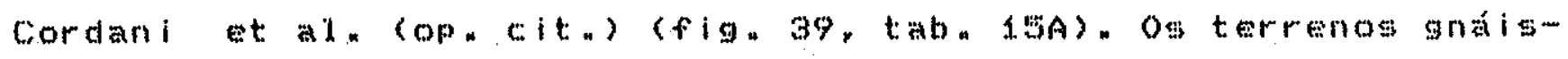
sicos ocorrentes a sw de Lavras partem revelar, de forma sistenám. tica, um padräo radiometrico K-Ar com valores de idade aparente levemente superiores ano parato brasiliano tipico, da orden de 685 $+-12,734+\cdots 0,757+-12,767+-23,6816+28$ m. 
tentrionais do Bloco săo Gabriel, como $682+\cdots$ ag ma. em um meta-.. tonalito aflorante entre Vila Nova e Vila Rutino, analisado pelo Projeto RADAMBRASRL em biotita (Teikeira, 1982, fig a 37, tab. 15B),

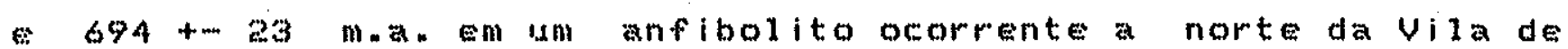
Mata Grande, proximidades do Arroio das Capivaras, já no limite do embasanento com os sediment: itos gonduänicos ( $f$ is " 37 , tab. 15B).

Além desses, alguns outros molutados radionetricos K-Ar fow ram procurados, destacando-se dolade cordani et: a1. (1984) para rochas do embasamento atingido por sondagens nos domínios da Bacia

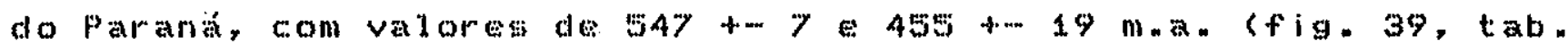

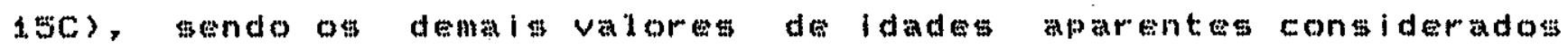
gem significasấ geológica face a problemas analiticos decorrentes de alteracoses intempericas, ou incapacidade de retencäo do Ar pelo

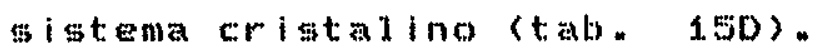

Os resultados tipicos do ciclo Brasiliano acima mencionados, en conjunto com outras determinacöes no Parana santa catarina, permitiram aqueles autores vislumbrar uma continuidade para sw do Cinturgo orogsnico Ribeira, por sob os depósitos sedimentares pa leo-mesozóteos do sul do Brasil.

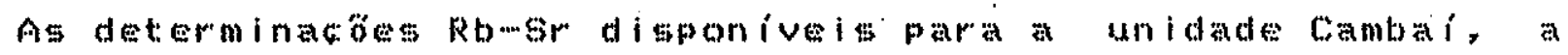

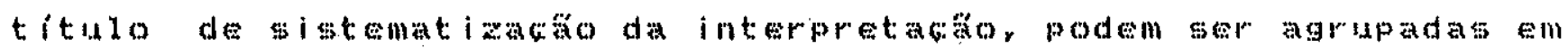
conjuntos relativos dos tuas areas de proveniancia. Assim, discuti-

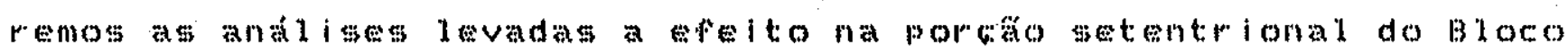
Sâno Gabrel, subdivisivel em zona do Arroio Cambaizinho, zona de Vila Nova, anona danga do Velocindo - Mata Grands (figa, $4 \Delta\rangle$, na

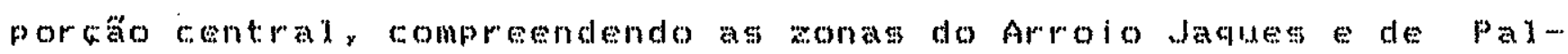

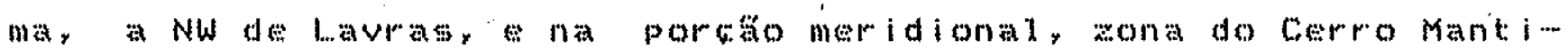




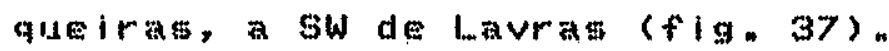

Região - Setentrional … A regiăo stentirional do Bloco São Gabriel e, entre todas, a melhor confecida do ponto de vista geow lóico geoconolótco e pots servir de área de referencia para estudos similares nas outras regiós.

As investigacós mais completas relativas aos "Gnaisses Cambal". apesar de ter sido estudada uma pequena fraca do todo que 5e apresenta no oeste do Escudo Sul-mplomgrandense, gấo devidas a silva Fitho (1984), que eleger a area de vila Novay face ass signi... ficativat exposicosed de rochas ai ocorrentes, como a mats mepresentativa destes tipos litológicos. Embora as dimensobs dos torrew nos analizados mejan redusidas, o nivel de detalhe a que desceu este autor, seja no campo petroduimico. seja no campo estirutural, o. Sen procedentes.

De acordo com aquele autor, as rochag que constituem os aflo-

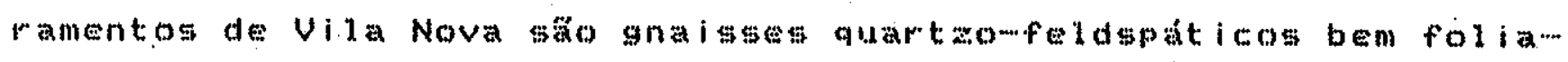
dos, com bandal ou lentes de anfibolito, aos quais me aspocia uma suite intrusiva coja composicaso varla de gabro, passando por diom rito, tonalito trondhjemito, ate uma asociaco do granitódes que inclui granodioritos, adameditos, riolitos e pegmatitos. Raras a delgadas camadas de quartzito podem ocorper nos gnaisses graniticosm rodo oconjunto litolósico fol submetido a deformacós pow I ifasicas e metamorfismo de fatien anfibolito, seguido de processos metamórficos retrogmenivos defacies wistos verdesn

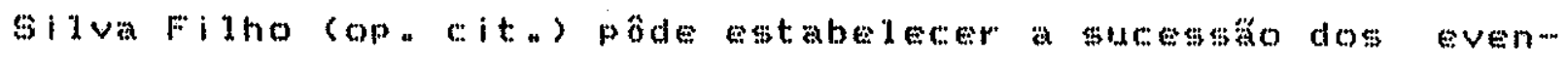
tos geradores de rochas baseando-se nas relacón entre unidades 


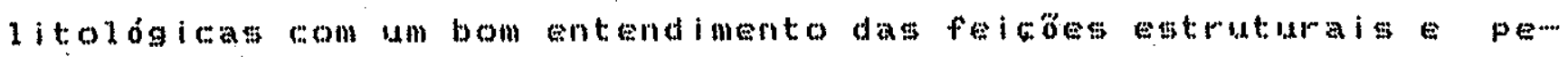
troquimicas. Das quatro sub- áreasestudadas (fign A1), a IV destaca-me por ter permitido o estabelecimento da sequencia estrum tural face as bem expostas feicôs deformacionais, ordenadas por

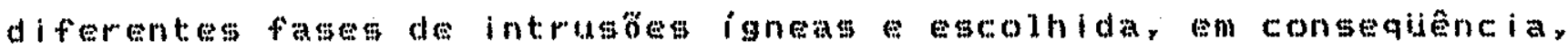
como a ma is favorál à interpretacöes petrogeneticas. Nesta sub-

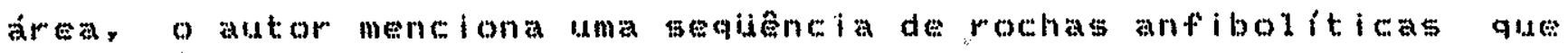
gradam para gnatses quartaofeldspaticos, leucocraticos e bandados, atraves de termos trangitón los representados por hornblenda.. biotita blotita gnaissesponericamente referidos como gnaisses dioriticos. Estes for am intrudidos por fracosestonaltica-tronanjemiticas. sum corpo dioritico menor veios granodioriticos concordantes discordantes. Emtes Lltimos, que em alguns pontos säo pegmat itos, parecem corresponder ao material intrusivo mais joven.

Como se verifica, a complexidade estrutural e a diversidade litológica do Cambai gấo matores do que menclonam os trabalos descritivos anteriores a falta dastes conbecimentos induziu a interpretacöes geoconológicas genericas, resultado de coleta de

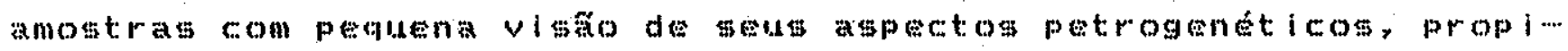
c. iando, apenas, a construgăo de diagrama isocrônicos de referen cia onde misturaram rochas de tipo de posicotes cronolosicas diferentes.

Um exemplo do que actaba de ser dito é o que pode ser feito com as amostras ronidas na figura 42. todas provenientes das prow. Wimidades de Vila Nova $(f i g n A \theta)$, mas descritas simplisticamente como gnaissess migmatitose metatonalito (tab. 16B) wEvidentemente. reunem-ge aqui termos litologicos de carater e idades distintos e o reflewo desta atitude traduzwe en uma isócrona cujos pontos 
ana 1 iticos encontramms bastante dispersos . Os resultados obtidos

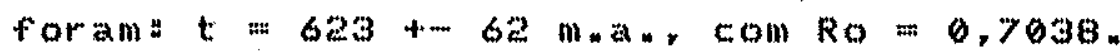

Cago cindo - Mata Grande (fig. AQ) referidas. genericamente como gnaig-

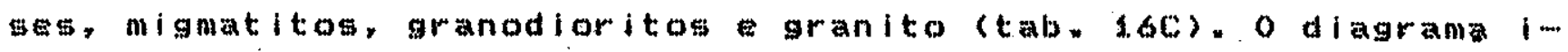
5ocrōnico regultante (fignA3) de melhor qualidade etatistica pontos ben digtribuidos ao longo da isócrona continuob indicando loma idade brasil lana náo multo diferenta da anterior, mesmo com a

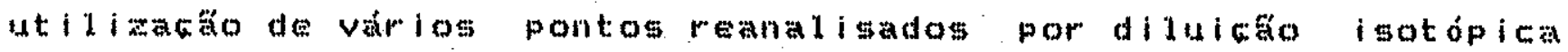

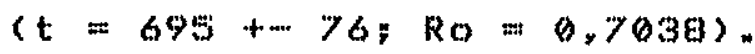

Caso a amostras relacionadas na tabela 16 (a) tomadas submetidas a estudos potroquimicos petrograficos de

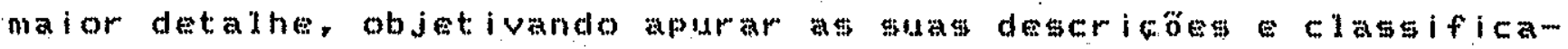

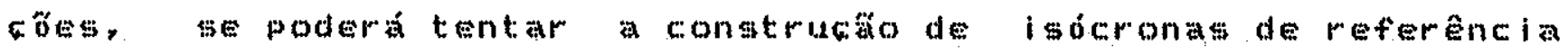
compostas dos mesmos tipog litológ icos.

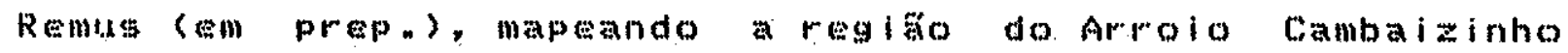

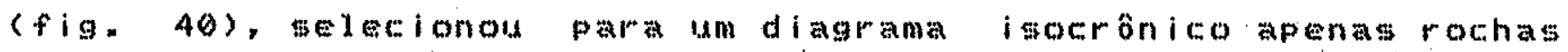
Petrográficamente descritas como granodioritos com variacóng para

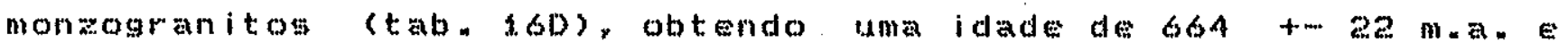

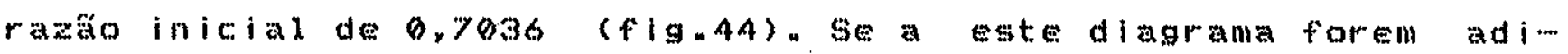

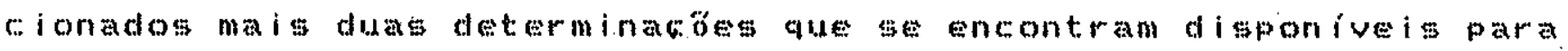

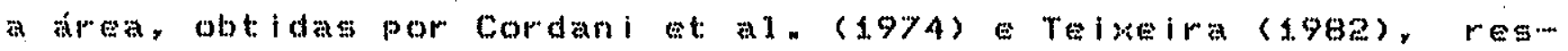
pectivamente a fracua aplitica de um migmatito a um granodiorito

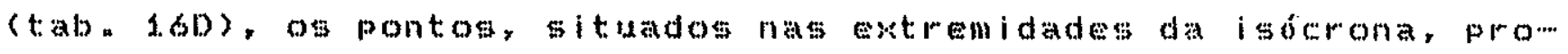
duzem uma leve motacico da mesma recluzem o valor temporal para

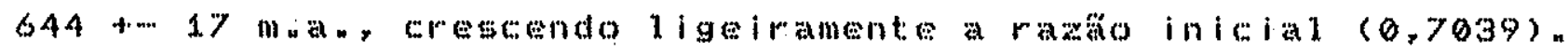


En vista das conclusös de Silva Fitho (1984), optamos por investigar geocronológicamente os diversos tipos litológicos assom ciados caracteristicos da dnidade Cambai na area de Vila Nova, atentos a cronologia estrutural enta definida sempre que pos-

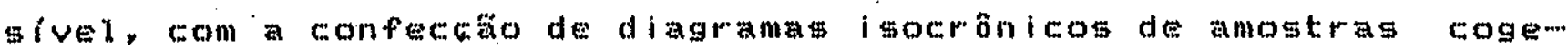
néticas. En assim procedendo, foram constiruidas as isocrónicas representadas nas figuras 45, 46, 47?48, montadas, respectivamente, com amostras de gnaisseg dioriticos, tonaltos trondhjemitos, granodioritos e adamelitose, por fim, pegmatitos, litologias estas consequentes de fenômenos petrogenót icos sucessivamente mais jovens.

A mistura de tipos petrograficos, como nos diagramas 46 e 47 , deveume a impossibilidade de obtenco de resultados significati vos face a escastes de pontos analiticos de uma ínica variedade de pocha. Este intento foi atingido apenas com os gnaisses dioriti cos, dos quais a ancotras revelaramme adequadas aos estudos ram

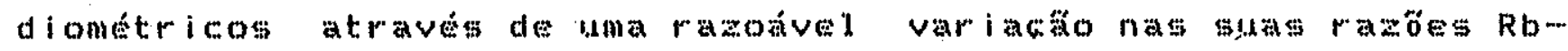
Sr. Provenienteg de um mesmo afloramento sab-o area IV Silva Fi-

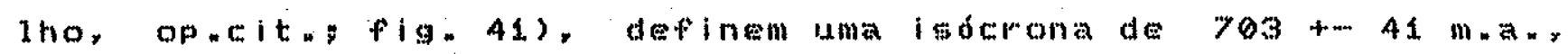
com Ro $=0,7038$ (fig. 45; tab. 16E).

Os tonalitos trondhjemitos, tratados em conjunto deriva dos todos da sub-area $\operatorname{TV}(f i g n$ 4h), determinam uma isócrona de 673 ta. $65 \mathrm{~m}$, 3.6F).

Os granodioritose adameditos, por sua vez, permitem delinear

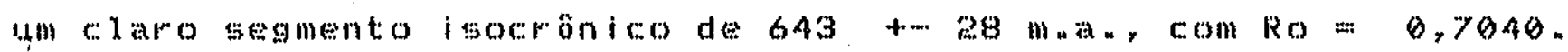
(fig. 49 . tab 16C) apesar das amostrats procederem de diversas sub- 
artes (I, IT, ITIA C. IV: fig. 41).

Finalmente, treg amostras de pognatitom da sub-area II. (fig.

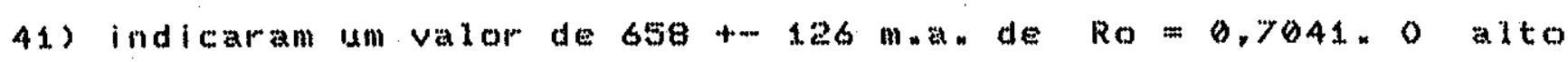
erro observado no remitado radiometrico devewg a promimidade dos

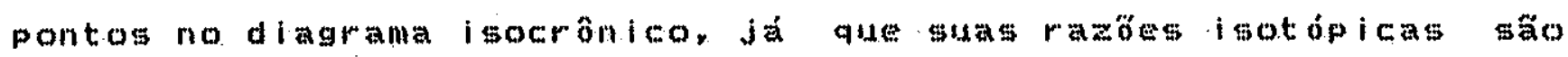
bastante gimilares (fig. 48, tab. 16H).

Percebe-se, entán, quev apesar de todos os valores há pouco mencionados situarem-ne dentro de seus mutuos eros analiticos, sendo, portanto, concordantes, dáme um decrételmo genérico de i w daded conforme a cronologia relativa indicada por silva filho rop. [it.>. com luma duracäo virtial dos eventos petrogensticos da ordem de 60 milhöes de anos (de 700 a $640 \mathrm{man}$. . como ge vê na figura

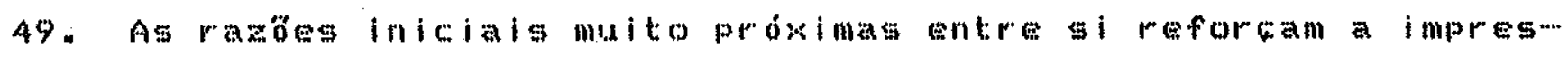
sấo de cogenticidade das rochas, sendo os valores sugestivos de derivacto mantelica. A tendencia aparente de crescimento en funcăo

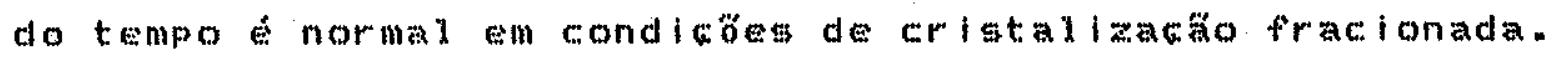

A peunla d uma reta de melhor ajuste com inclinacto corresponctente a uma idade aparente da ordem de $665 \mathrm{~mm}$ a. Notame uma tondência das amos... tras mals joveng (numeros mais altos na figura, conforme cronolom gia relativa eradiometrical posicionaremmeg suckssivamente, mais distantes en rolacäo a origem, o que parece indicar una diferenciaca progressiva na ganese destag litologias, correspondendo a um increncoto na razong Ro total/sr total.

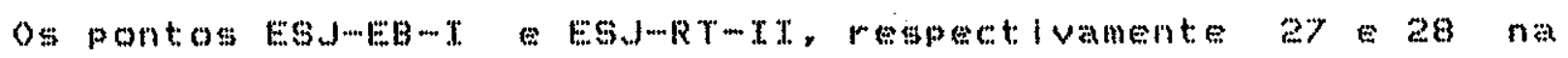
figuraso, colocados abaiko da isocrona, correspondem a um anfibo- 
lito a dum riolito. Hendo and lates linicas destestipos de rocha. o afastamento das mesmas em pelacio a lsocrona de referencia pode

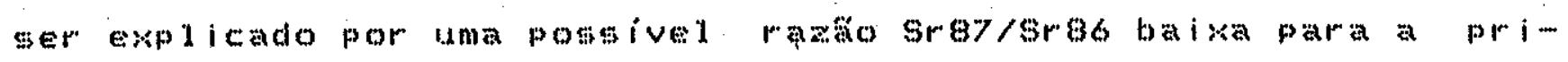
melra exara o riolito, que revela uma idade convencional da or dem de $500 \mathrm{mna}$ (para $R O$ igdal a 0,705 ), apenas novas investigacö poder po indicar su significado dentro do contexto geológico da arean. Apesar deste dique acido encontrarme estruturalmente deformado (silva Filho. inf. verb., a semelhanca dos outros corpos intrusivos, o resulado conseguido indica, preliminarmente, tratarmse de uma das ma $i$ sovens manifestacöes magmaticas ocorrentes"

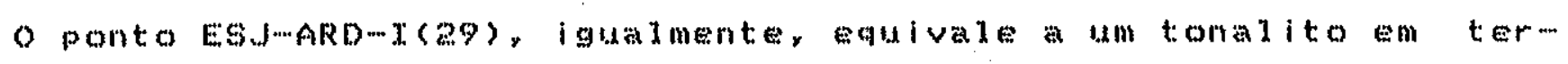

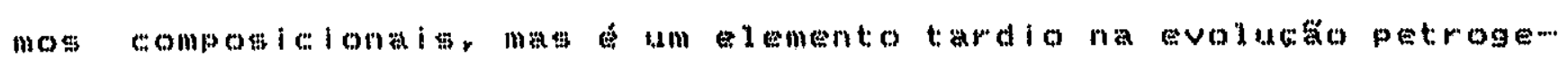

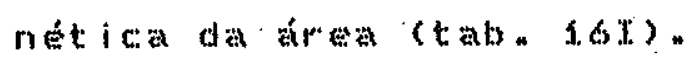

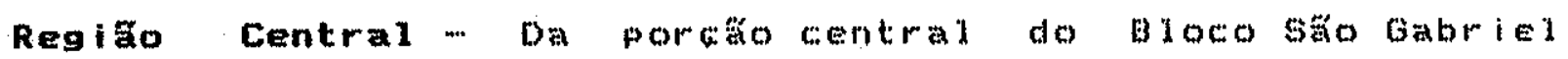
(fig. 37) foram estudadas apenas a amostras provenientes da uni... dade Cambai, sendo b"da zona de Palma s da zona do Arroio Ja-

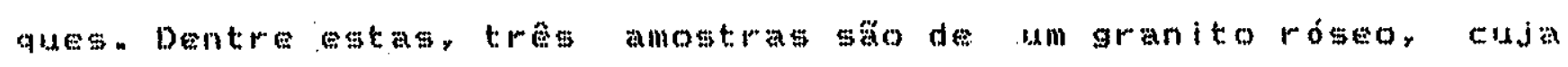

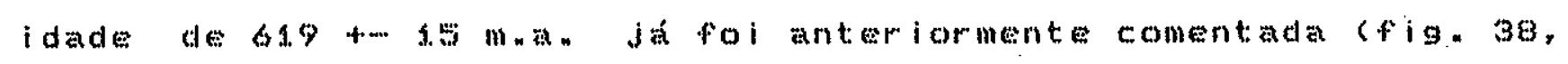
tab. 1 $6 A$ ). As amostras restantes da zona do Arroio. Jaques foram descritas como gnaisse e metadiorito (tab. Sy), enquanto na zona de Palma as rochass sa roferidas como monzodioritose dioritos

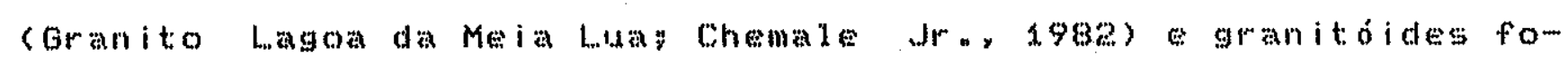

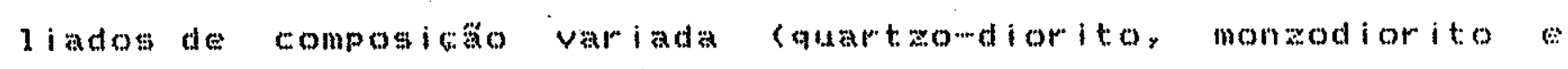
granodiorito) a gnaisse (Metagranito Lageadoy Chemale Jr. "op. (it. $)(t a b .17)$, todos indistintamente incluidos no "complexo cam bai" por Namann et: al. "(1984).

O peaueno numero de amostras radiometricamente analisadas, o-

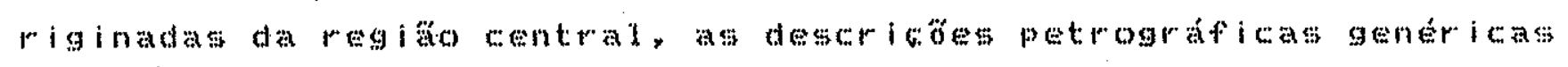


e a asencia de controle estrutural conhecimentom petroquimicos para o estabelecimento de uma cronologia relativa, tal como readizado na area de vila Nova, permitem, apenas, a contruca do un diagrama isocrônico comm para todos os pontos e interpretacö́s geocronologicas tentativasu

A linha de melhor ajuste resultante dos cáloulos que levam em consideractio todas as amostras disponivels para a regla co central

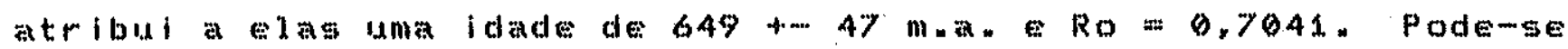
vislumbrar, no entanto, que o d agrama revela a associacaro de, pelo menos, dois conjuntos litolólcos distintosa um congtituido das

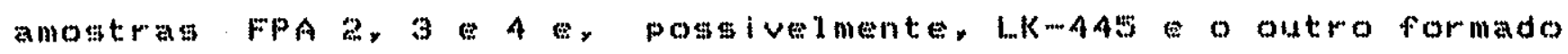
de $243, E 5 J-1,-3,5, F P A-1$.

Contiderandowsestes subconjuntos individualmente (fignsi),

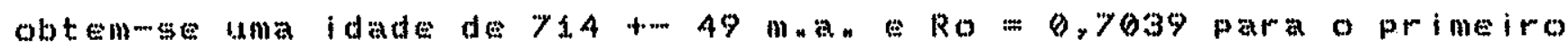

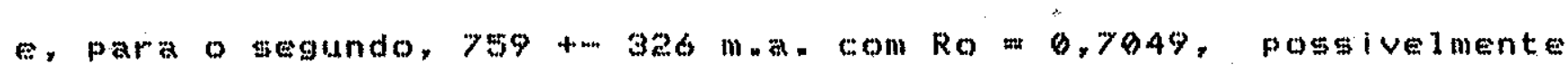
correlacionáveis aos anaisses dioriticos de Vila Nova.

Se, por outro lado, imaginarmos que o ponto LK-445, um metadiorito. pertensa ao subconjunto dois (monzodiorito, diorito gnaisseas), entäo definems um segmento isocronico de idacte igual a

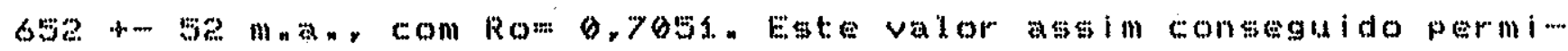
te que o subconjunto em foco seja agora correlacionado as suites intrusivas da área de Vida Nova, granodioritos do Arroio Cambaizi nho litologias diversas da Ganga do Velocindo mata Grande.

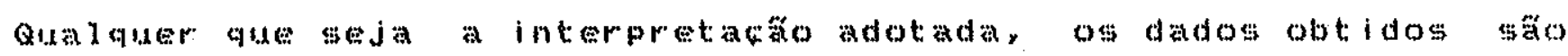

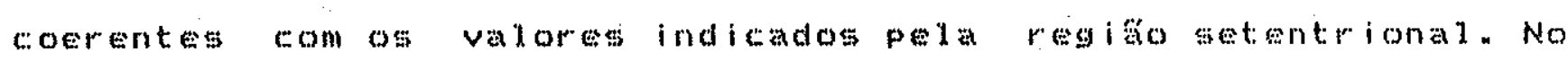
entanto, sota littima abordagem parece melnor por produsir resulta dos com erros analiticos razorveis o condizentes a 
Região Meridional ... Do ponto de vista geoconologico\% a

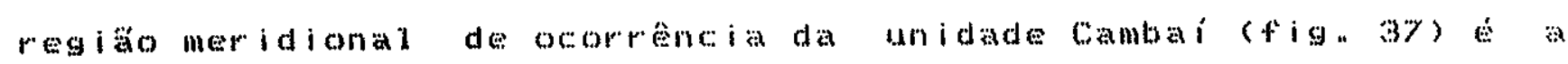
mals complexa, denotando uma mistura de litologias cristalinas com

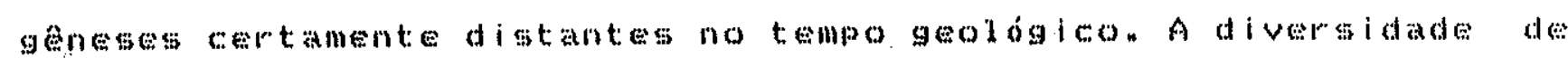

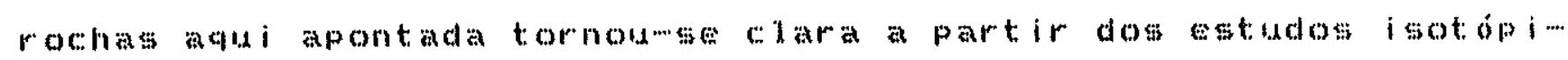

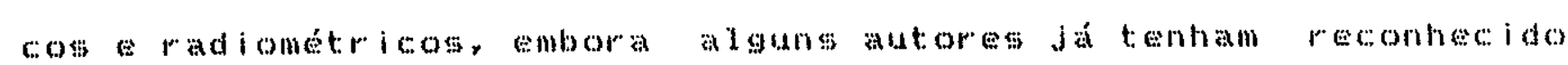

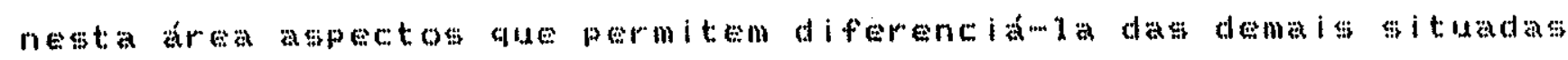

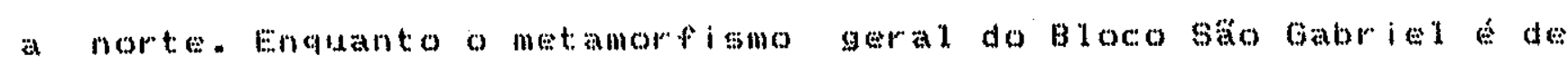
facios

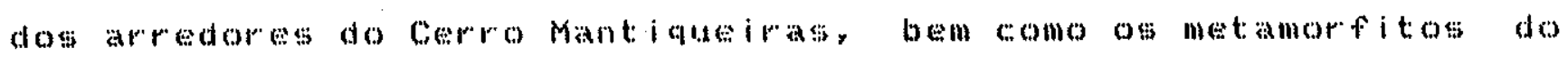

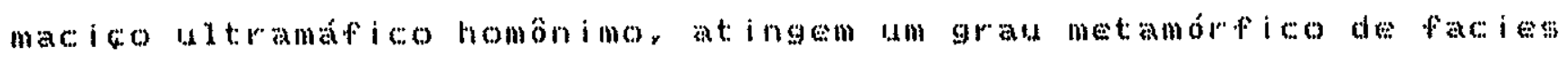

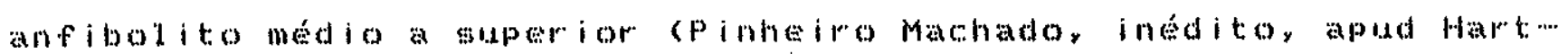

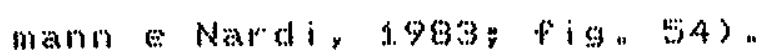

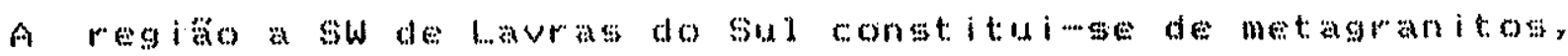
gna is

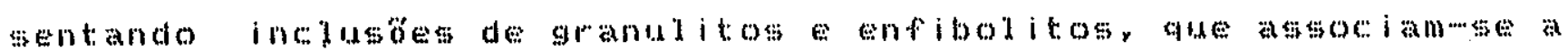

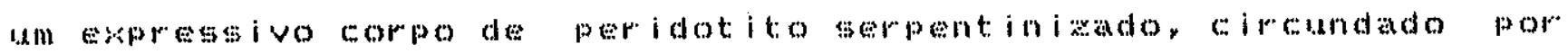

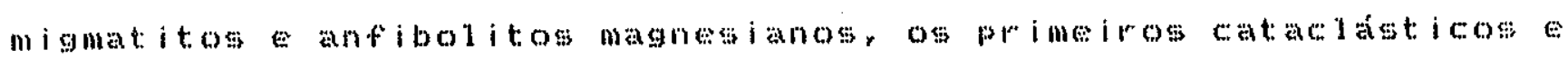
os alt imos revelandowe como metabasitos blastomiloniticos

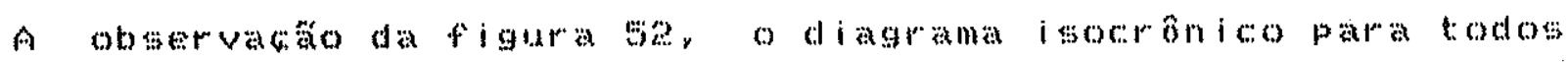

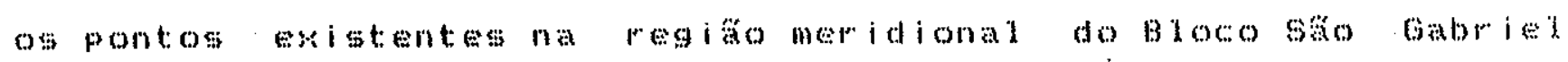
( área, provem de amostrag coldetadas a

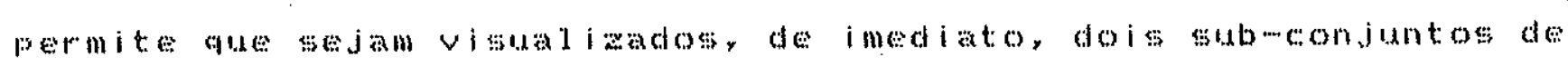

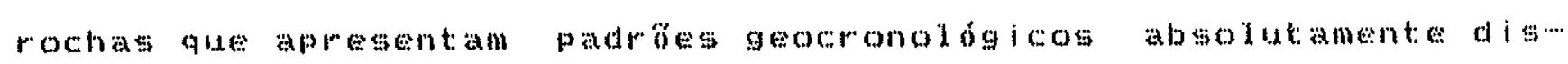

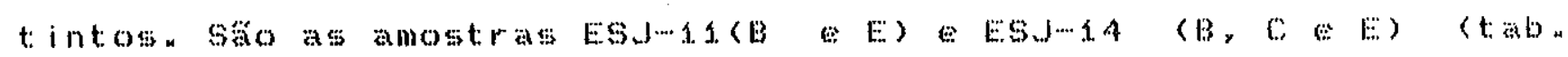

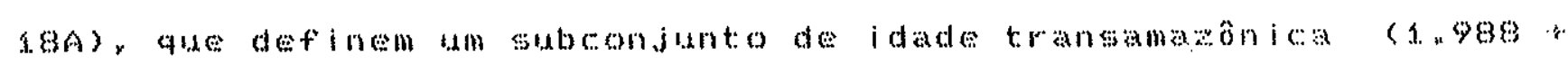
.... 133 m. 
brasilianas, mas de interpretaca merecedora de alguns comentarios adicionaita face a dispersäo dos pontos analiticos as ldades K-Ar comparat ivamente ma iores n

Oprimeiro subconjunto é constituido de rochas gnaissicas (ESd-11) com bandas maficat (anfiboliticas) felsicas (quartzom feldspaticas) e gnal

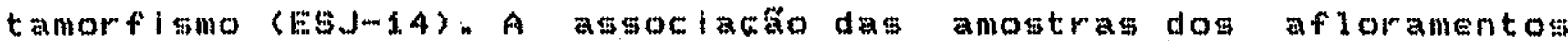

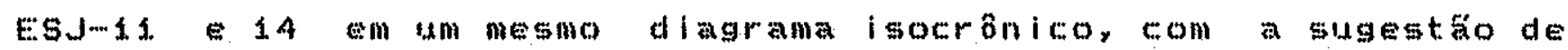
pertencerem a mesma unidade tectónica, indicaria que o lineamento

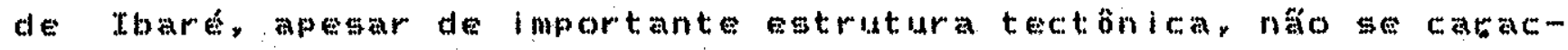

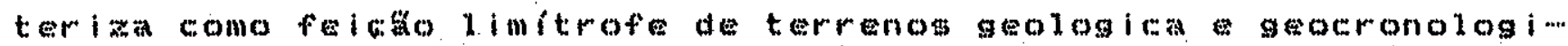
camente distintos. Alias, o metamorfismo de grau módio que predomina na fracto sul do Bloco säo Gabriel pode ser indicativo de terrenos com coracteristicas transitorlas entre os de mais alto

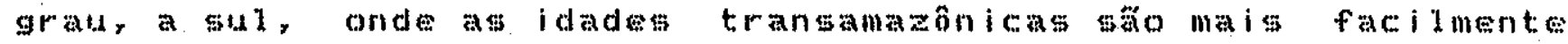
obtidas, os de baixo grad, a norte, onde os valores brasilianos såo ma is comsns

O segundo subconjunto compöense de tres amostras anfiboliticas cbandas migmatiticas com hornblenda anfibolito, amostras a 378,0 e 239 ) duas quartanfeldspáticas (bandas graniticas, amostras 2370 E E) Atraves da reuni

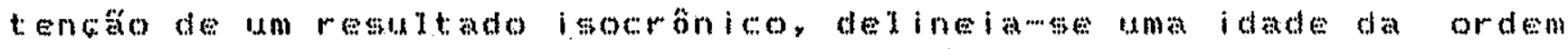

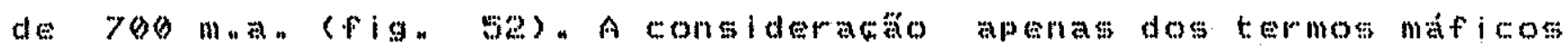

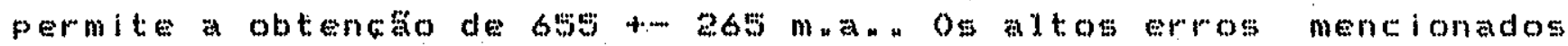

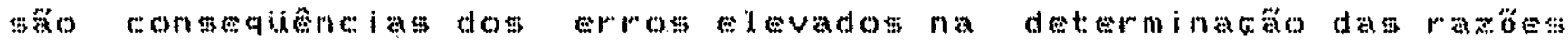
isotópicas dos pontos individuais da pequena distribuigádo dos mesmos em relaca a 


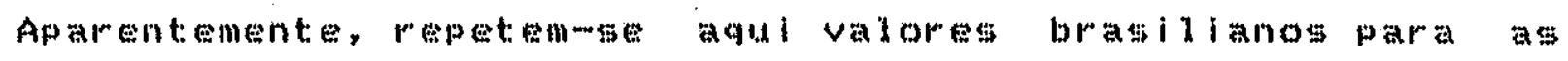
rochas cofocadas, confirmados pelas anal ises K-Ar tem anfibólios extraidos das mesmas litologian, com idndes mínimas levemente su

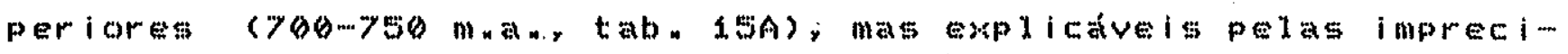

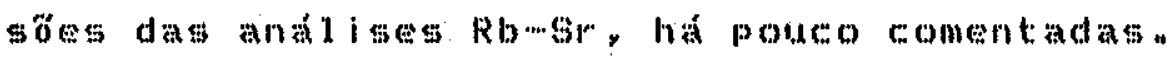

Igual raciocínio pode ser extendido aos outrog pontos que

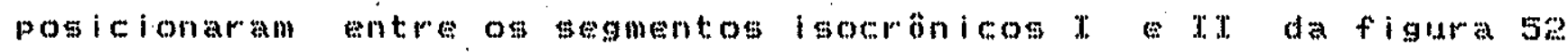
(tab. 28C). As amostras de preflxo PM, tratadag em conjunto com os pontos LK

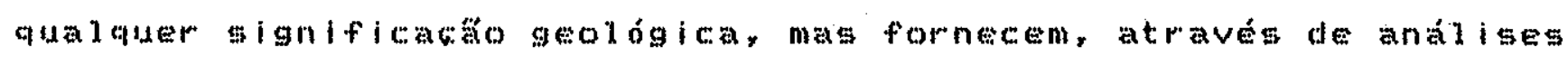

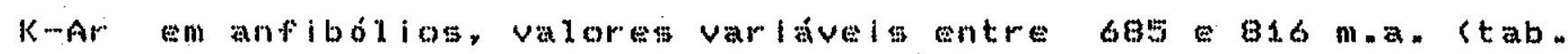
(1. 5 A ) .

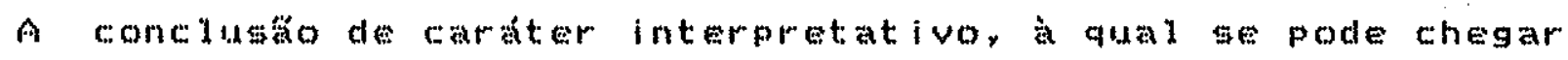
para a unidade Cambai, aflorante ta todo o bloco säo Gabriel,

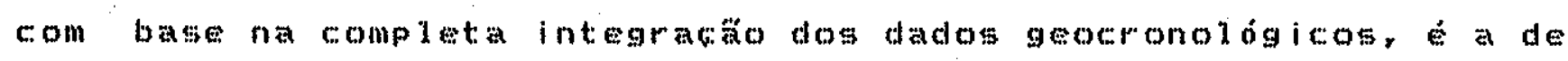

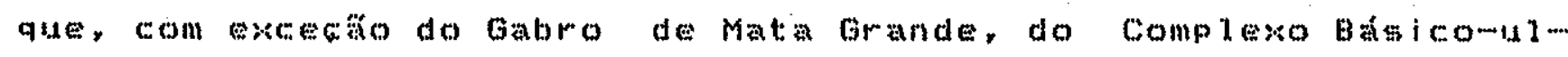

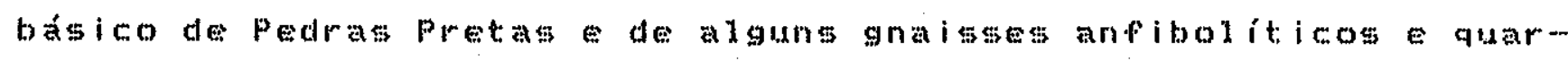

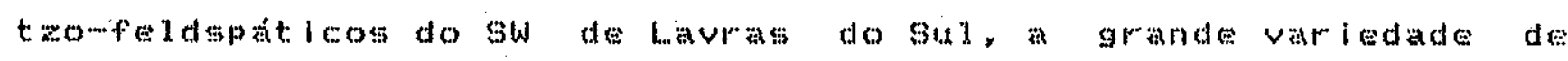

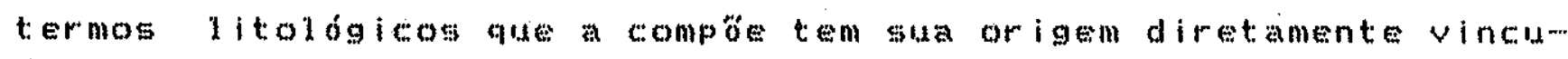

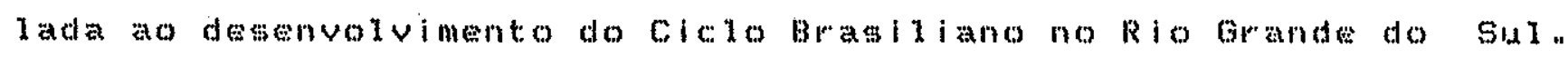

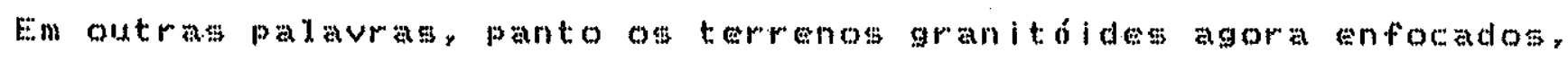

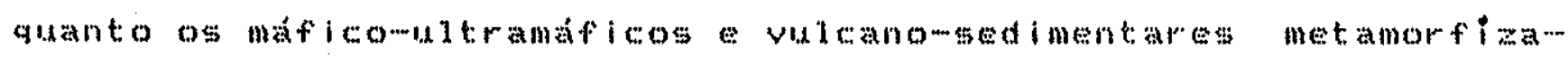

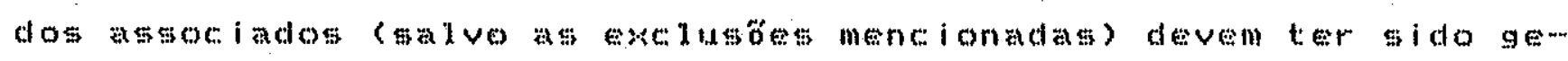
rados no intervalo de 390 mna a 6 a ses precoce Intermexi

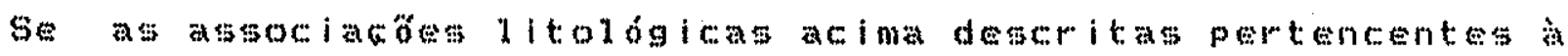
unidade Cambá, forem supractusta 
(E.g. Silva Filho, 1984), o Gabro de Mata lorande o Complexo de Pedras Pretas podem representar, respetivamente, o nicleo de uma estrutur dômica un megamenclave engolfado pelo episódio magmático sán Gepe. Assim, com adicto de algung gna vras, estas litologias corresponderiam ás dicas atuanente conhecidas exposicöes do embasamento da orogenesterasiliana, noss

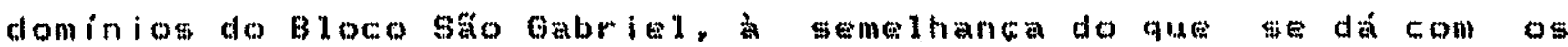
Gna isses Encantadas. Como estes, suas ldades poder iam também estar relacionadas a cielo rransamazonico. A razato inicial de 0,704 , a pontada pelo segmento isocronito I da figura say pequeno retralhamento crustal reglstrado pelos gnatsog anfiloliticos equartzonfeldupaticos dag proximidades do bineamento de I... baré, dos qual provem amostras, not tempos do ficlo Transama-

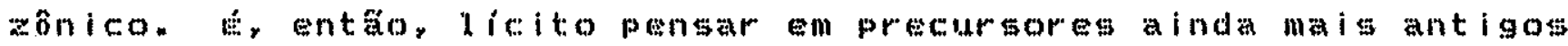
para tais tipos rochosos.

\section{Bloco Taquarembós terrenos granuliticos do Rio Grande do Sul.}

\subsection{Sintese Geológica}

As primeiras ocorrancias de rochas granditicas em áreas rem lat ivament amplas do ooste do embatamento sulmiomsandente for am destritatapós mapemento geológito efetivacto por formandos do Curso de Geologia da Universidade do Vale do Rio dos sinos (Unisi... nos, 1979). Os resultados desta atividade levaram Nardi e Hartmann a propor a dosisnacia formal de complaxo Granulitico santa Maria Chico par os terrenos de a to grau que tem como local-tipo as cabeceiras do Arroio Banta Maria Chico, nas prowimidades de Dom pew drito. O complewo compón nulitos), gnaisses batsicos, anortositos, ultramafitos, metapelitos 
(gnaisses à sildimanita) marnores.

O grat maximo de metamorfismo, como mencionam, ed de facies gramitito, de pressaco media alta, mas a presenca de hornblenda circundando pirowenio aponta para outra fase metamórfica de facies

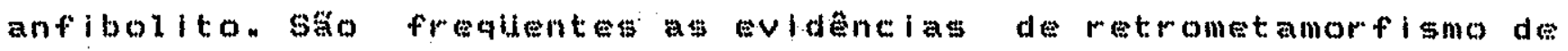
facies wistos Verdeg representado por recristalizacto presente en

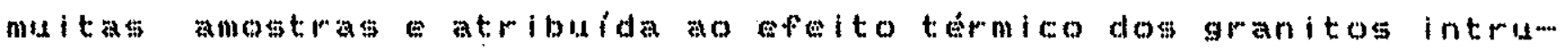
\&ivos.

A área de afloramento dos termenom grand it: icos pode ser visualizada na figura 58 , conforme lavatamentos realizados por Hartmann e Nardi (1983), restringindome a fracano noroeste do B10co Taquarembó, mas ocorrendo de forma quase continua.

No complexo aparecem algumas pequenas intrusöes de granitó-

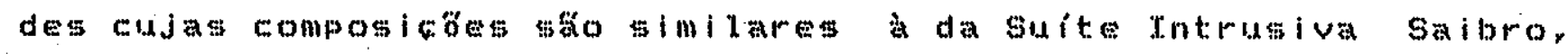
definida por Hartmann e Nardi (1982). Efeltos de intensa cataclam

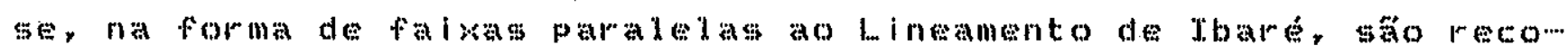

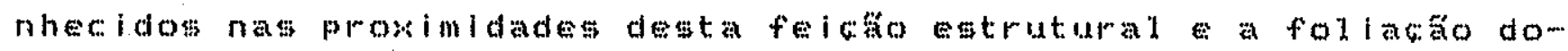
minante tom dimecaro $N W$.

Para leste, conforme mapeamentos real iondos pelos graduandos da Universidade Federal do Rio Grande do sul (UFROS, foge), apare... cem rochas graniticas ( $f i g .54$ ) do tipo hornblanda-niot ita ponzow granitos, com raras variacóses para senogranito, isótropos a levew. mente bandados, cortados exporadicamente por diaus de diorito, andesito a pesmatitios, anglobados sob a designacto de complexo Granitico santo ffonso (Hartmann Nardi, L983). No interior desta

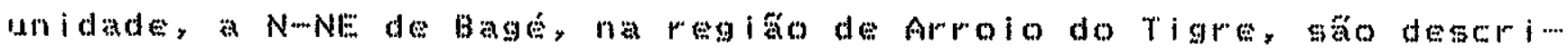




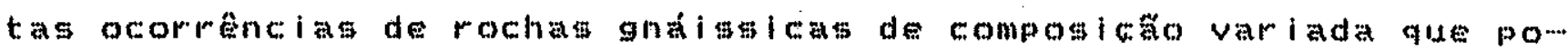
clem, eventualmente, \$er correlacionadas aog metamorfitos do Complewo Santa Marla Chico (Hartmann Nardi, s983). Tratawe de biow. t: ita gnaisses, gnaismes trondhjemiticos. gnalsses granodioriticos a tonaliticos. sendo frequentes as evidenciande importante cata c: 1 a $m$.

\subsection{InterpretaGăo Geocronológica}

Assprimeiras tentativas de determinacäo da idade do complexo Santa Maria Chico form feitas por sollani Jr. (1979), através dos

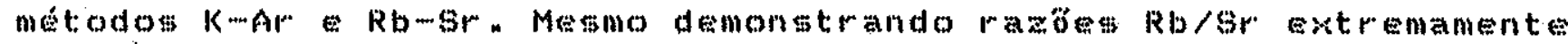
ba ixas r uma coleta numerosa de amostras permitiu que fosse seleCionado um af loramento de gna is nas prowimidades do Arroio raquaremboxinho, com razós isotón icas

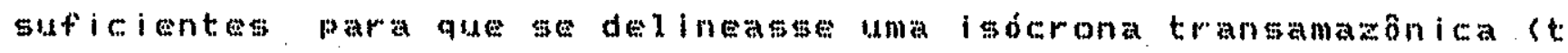
$=2.030+73 \mathrm{mn}$. blicada por soliand Jr. "at a

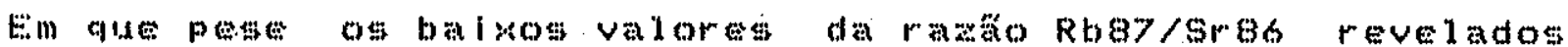
pelos pontos quo compöen tal isócona, a idade transamazonica foi confirmada atravos de reandiso das amostras junto a lo laboratorio

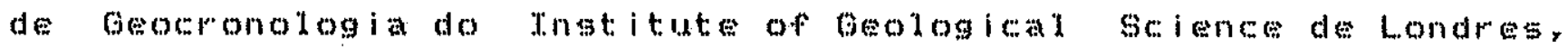

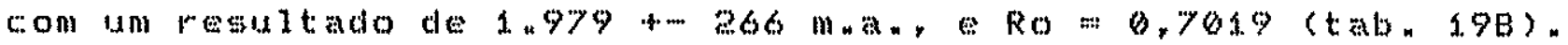

com o intulto de precisar melnor este dado geocronológico. novas ana 1 gess foram tentadas incluindomse o uso da ténica da di-

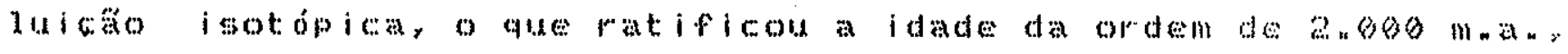

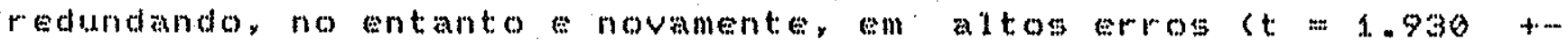
$434 \mathrm{~m}, \mathrm{H}, \mathrm{Ro}:=0,702 \mathrm{~A})$. 
A figura big corresponde a un diagrama locoronicosom que foram

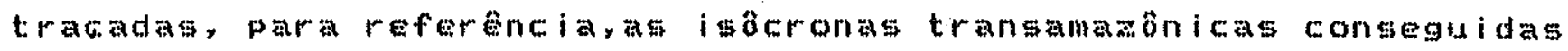
a partir de grantéoides Cambar da regiäo meridional do bloco găo Gabrlel (fig. ges) do Complexo Granulitico Santa Maria Chico. A inclusäo de o pontos analiticos derivados de rochas gnásisicas e migmatiticas de provenianciag diversas do Bloco raquarembó (fig. 54), obtidas pelo Projeto RadAMBRASTl ou por esta trabalno, reve... low que tres aledes parecen pertencer aos conjuntos litologicos prembrasilianos, sendo os restantes ma is novosi que o rransamazôni... co, consequentes da moblidade tectonica do final do préchambriano. provavelmente relacionados ao Compl wo Granitico Santo Afonto.

Os segmentom laseronicos há pouco comentados possuem razós inicials da orden de O.702 Q.704. Como ja mencionado por Soliani Jr. et a1. (1.984), de acomdo com Moorbath (1975), baixas razöes iniciais, do tipo manto superior, de muitos gnaisses antigos indi-

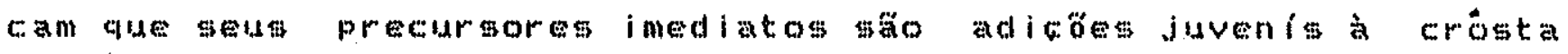
continental realizadas na, ou proximo a, época da idade obtida. intervalo entre o momento da cextracto de material igneo juvenil a

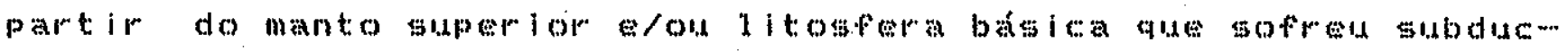

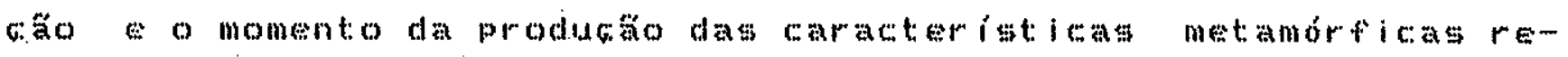
gionais dos complexos gnalssicos derivados pode ser menor do que 50 ou 300 mithose de anos, estando dentro da incerteza analitica

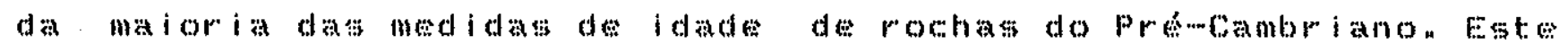

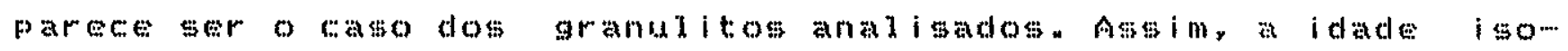
cronica obtida pode indicar a cooca do evento coprespondente a a

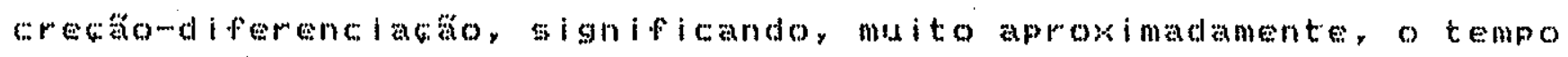
de formaco da unidade rochosa em questäo. Uma senese a partir de retrabalhamentos crustais pote ser sugerida para os termos ditolón

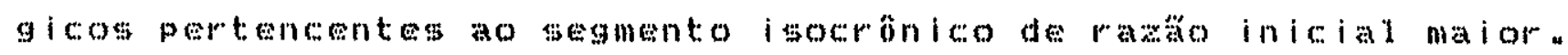




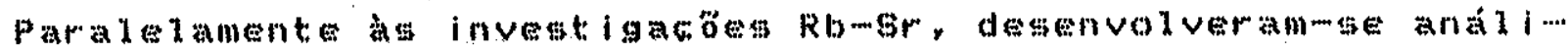
ses Konr em diversog tipos litologicos da entidade tectônica, (tab. 20 ) sendo detectados valores coerented com o restriamento

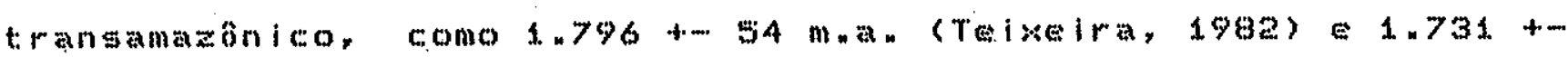
4h. Mn. (cordani et a, 1984 ), resultados que denotam rochas an antigas, mata parcialmente rejuvenescidas por etempe de Ar, como aqueles incluidos no intervalo $1.600-1.000 \mathrm{~m}$. orlundog de granitádes brasil lanos ou de litologlas que poden ter tido una origem precoce no quadro evolutivo, mas que foram isotow picamente rejuvenescidas. pois suas idades concentram-we entre 730 e $530 \mathrm{mn}$ a...

Os valores temporats prómpatianos obtidos em anfibódios e plagioclasios, minerais que apresentam forte retentividade para 0 Ar, demonstiram que o evento tectónico do premcambriano superior näo produziu nas rochas analidadas temperaturas gionificantemente maiores do que 40000 .

o Complexo Santa Marla Chico tambem merecen estudos pelo mé todo Pb-pb, desenvolvidos junto ao Laboratorio de Geoconologia do Departamento de Beologia Mineralogia da Universidade de oxford, Inglaterra. Ao todo foram zo análises (tab. 2a) sobre rochas der i... vadas de quatro afloramentos distintos, interpretados atomes de tras d c agramas isot do i coss.

A a

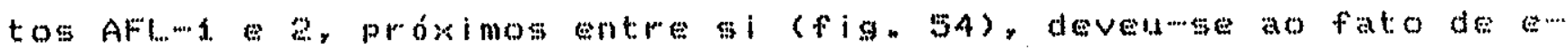
videnciarem, basicamente, o mesmo padro radiometricon Das 8 amos-

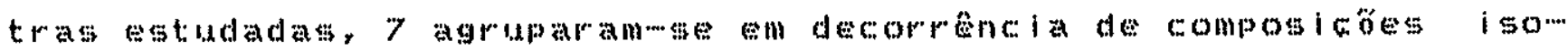

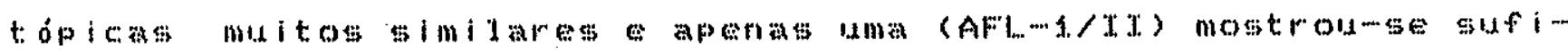


c: ientemente diferenciada para permitir o tracado de uma reta pasm sante por ela pelo ponto medio do conjunto das damais amostrast $(f i g .97)$. A idade aparente conseguidafoi de $2.367+121-132 \mathrm{~m}$

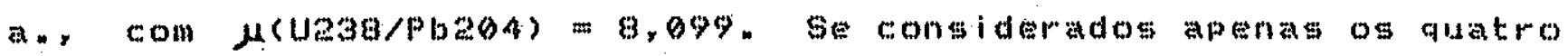

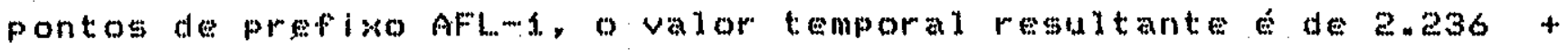

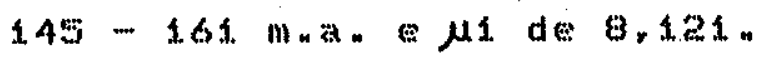

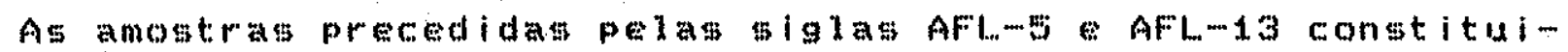

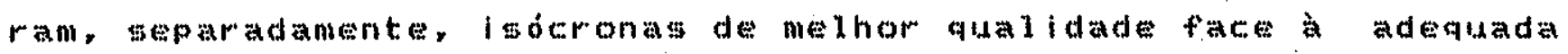
distribuicio do seus pontos nos respectivos diagramas isotópicos

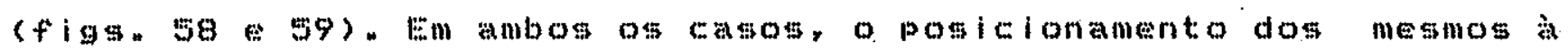

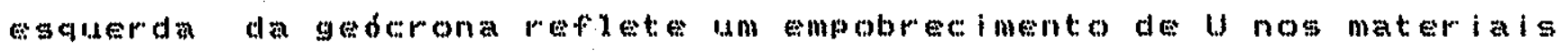

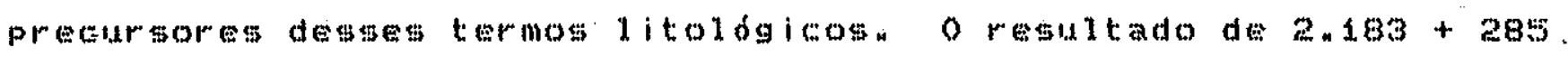

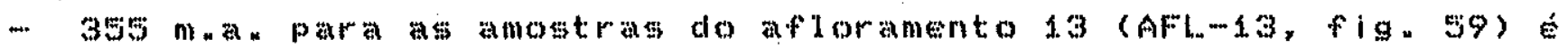
comente com a lande ja apontada palo metodo Rbugr.

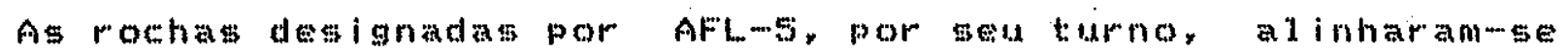

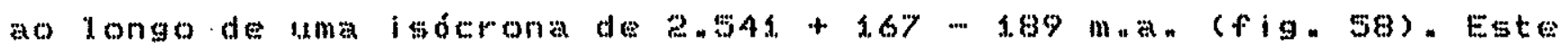
resultado to evidentemente, distinto dos demais, posicionandoms

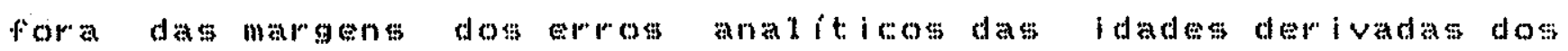

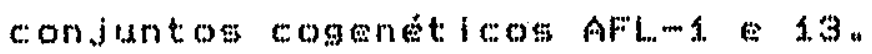

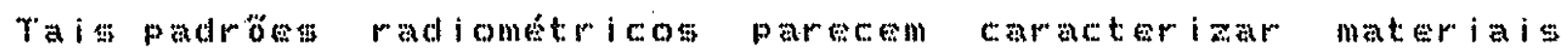

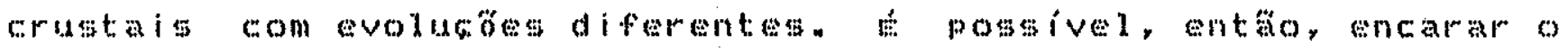
Complexo Granul itico santa Maria chico como tondo sido gerado no

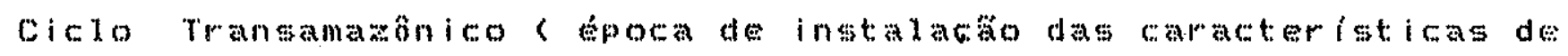

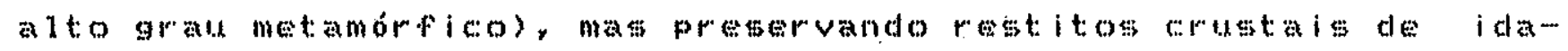
des mis ant is a t: es 


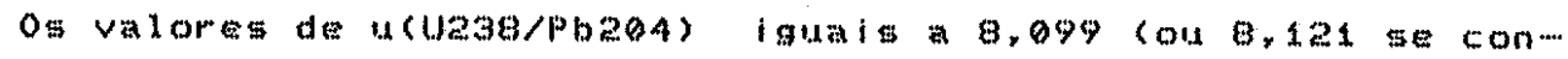

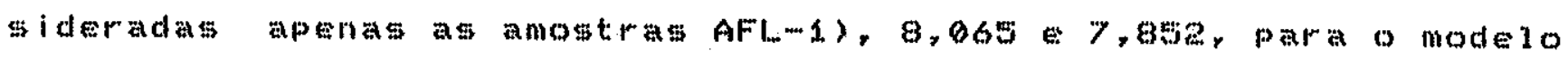
de evolucăo simples, gäo indletivos de uma derivacta direta do marito na epoca apontacta.

A efetivaciác do ciclo Bratiliano pode ter promovido, em parte. tha mobilidade quimica de U e/ou Pb. Rb, Sr, K e Ar nestas litologias revelada pela dispersa de alguns pontos nos diagramas Rb-Sr e Pbopber sobretudo, Pelas idades K-Ar distribuidas entre o

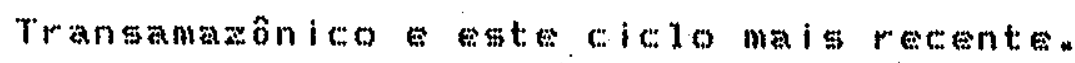

Por tiltimo, como parte das invegtigacoses gecronologicas por

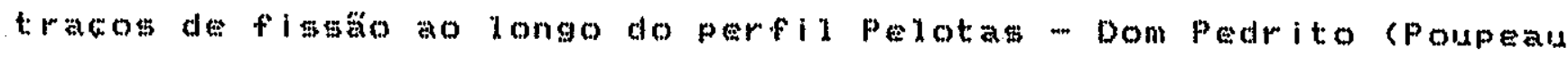
et a1., 1985), apatitas extratdas de amostras do afloramento AFL-2 to Complexo Granul tico Santa Maria Chico (fig. SyA) indicaram uma ldade de $216+$ lo man (tab. 2aA) revelando que o resfriamento destas rochas, para valores inferiores a 12000 , aconteceu om um tempo relativamente racente, fruto de um isoerguimento de carater epirogenético, do inicio do Mesozóico.

\section{Consideracőes Finais}

Em face ao que actaba de ser visto, épreciso enfatizar alguns aspectos de ordem conclusiva em relata a porazo oesto do Escudo sul-riongrandense, como seguem:

-.. a porcano ocidental do Escudo do Rio orande do sul admite uma subdivisäo om duas unidades gototonicamente distintas, Bloco sto Gabried o B 1000 Taquarembo, respetivamente constitui-

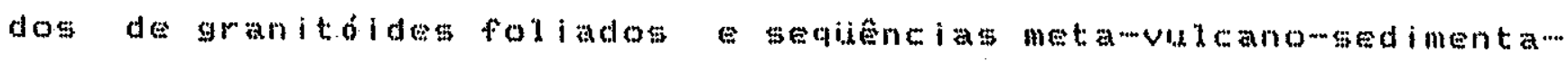


res, de baiko a médio graus de metamorfismo, terrenos granditi cos, ambos intrudfos por granltóides pouco foliados ou isótropos matis jovens:

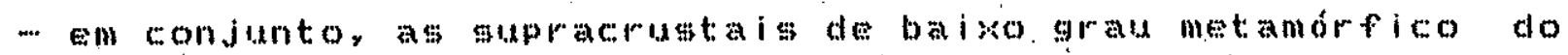

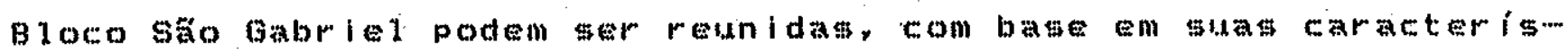
t: icat geocronologicas, en doiagrupos: oprimeiro composto do Gabro de Mata lirande e, posslvelmente, do complexo pedras pretas, com ldaded da ordem de 2,000 ma e de outro formado pelos demat tomplexog, cujas idadeg varian de

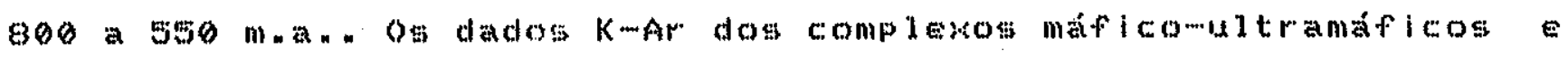
vuleanomedimentareg do NW gadoho possibilitam doas hipoteses sobre a gêneme dos metmos "ou (1) estos conjuntos litologicos ori-

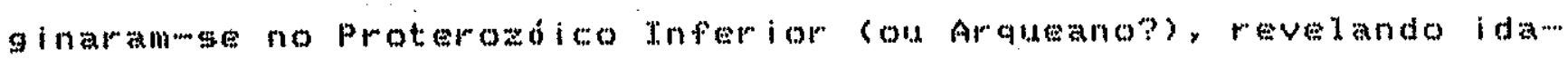
des de resfriamento tranatazonicas, rejuvenescimentos parciais e completos durante o ciclo Brasiliano. ou (a) ocorreram dois ou mais eventos geradores desteg tipos rochoscs, oprimeiro no proterozóco Infurior, com possiveis rejuvenemeimentos de algumas de suas fracoses (complewo Pedrats Pretas?) no proterozico Superior, e outro neste intervalo da tempoy com a formaciono do novos termos $1 \mathrm{i}$...

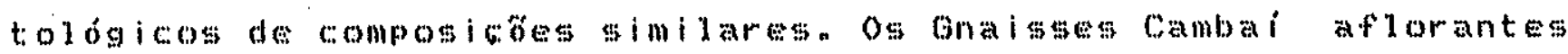
nas regios do Cerro Mantlquelras, Vila Nova Mata Orande, atra-

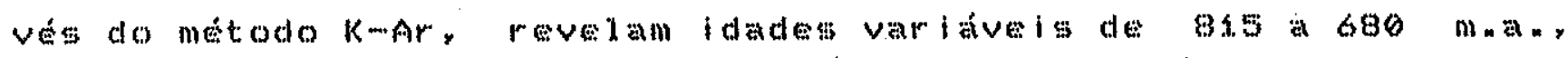
com diversos valores concencrados ao redor de gso ma a " De igual

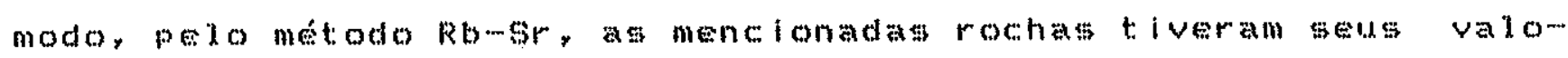

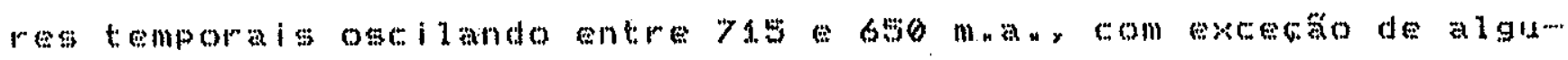

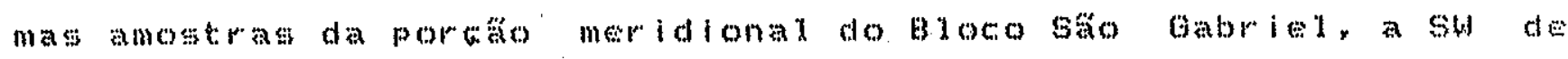
1... avras do sut, onde fragmentos crustats de idade transamanonica puderam ser identificadosin A conclusaro que advám da interpretacăo

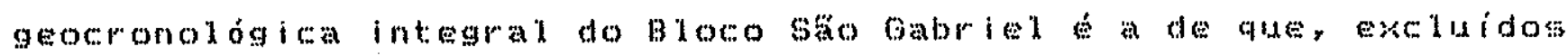


o Gabro de Mata Grande, possivelmente o complexo Pedraspretas algung gnalss

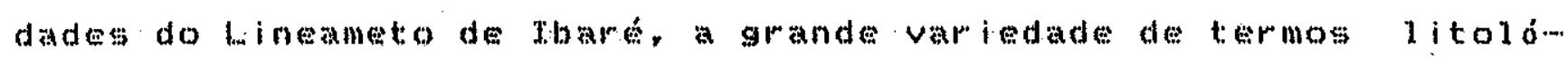

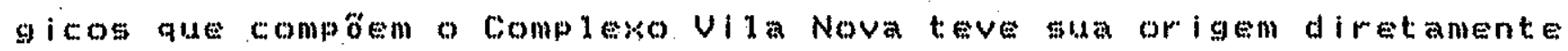

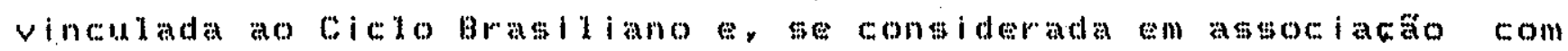

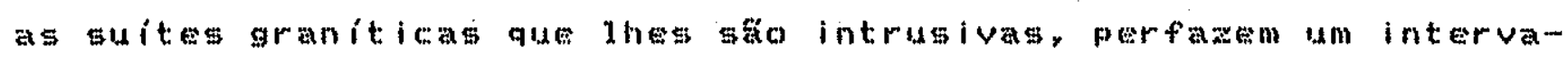

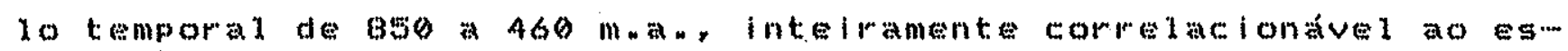
timado periodo de desenvolvimento tectionico da porcáto leste. As

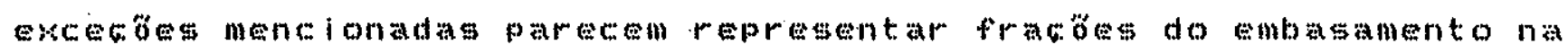
forma de expogicón

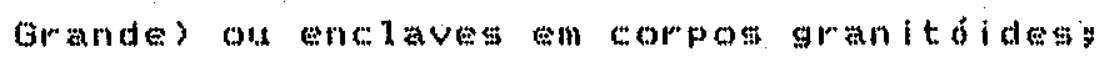

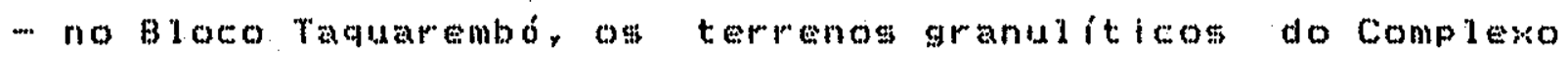

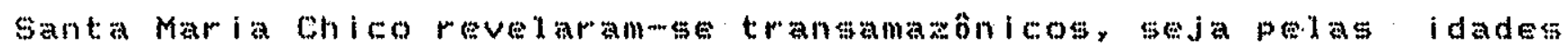

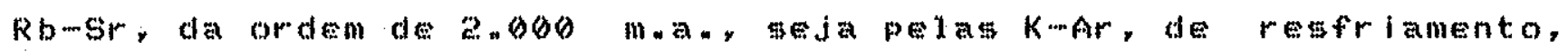
com valores máximos da ordem de 1.800 mn

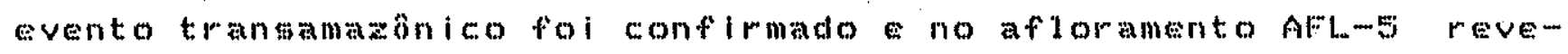

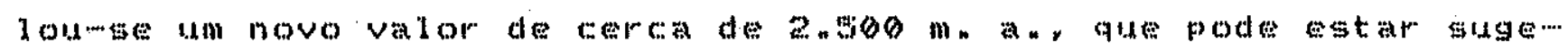

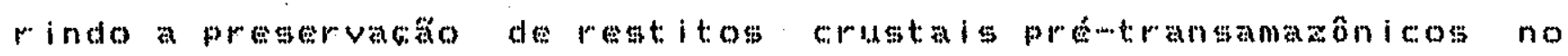

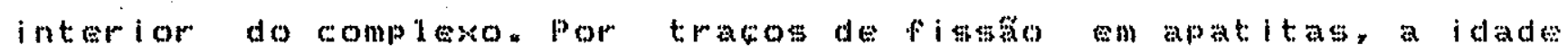

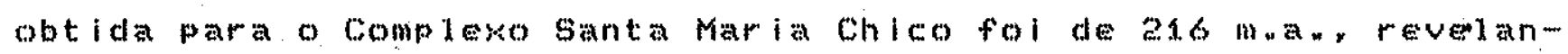

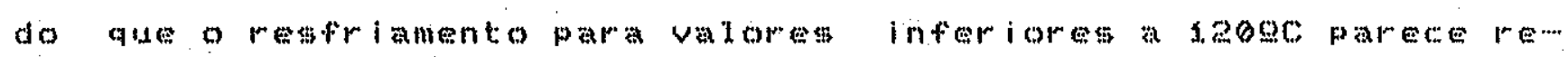

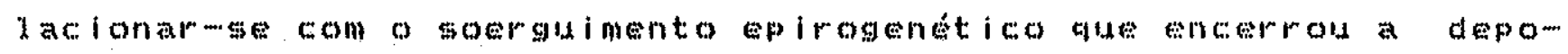

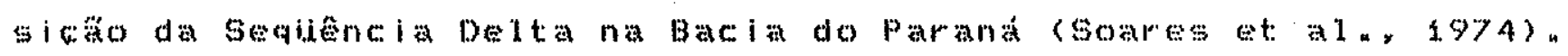




\section{AS SUITES GRANITICAS INTRUSIUAS NA PORGAO OESTE DO ESCUDO SUL-R IO-GRANDENSE}

\section{Consideraçôes Iniciais}

Numeromos corpos grariticos intrusivos atestam a frequencia

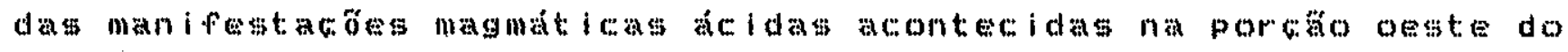
Estudo do Rio orande do sul. Fistas mostramse como "stocks", bató-

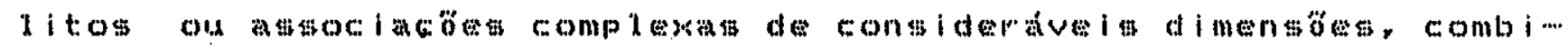

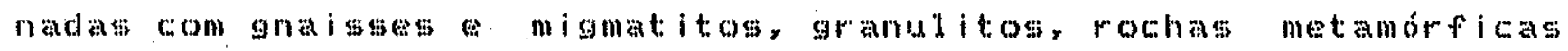

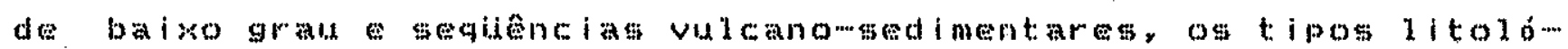
glcosprincipais que compon os terrenos ceristalinos ocidentais.

At ingindo om area pma percentagem estimada de 40 a $50 \%$ das

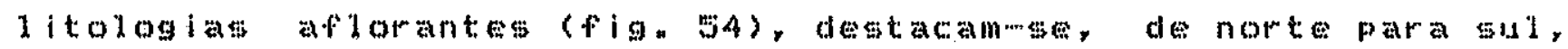

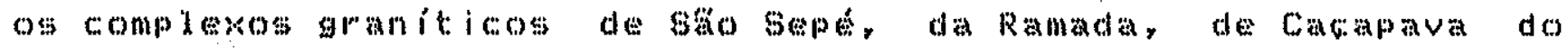
Sul, de Lavras do sud santo fions, alem dos batolitose

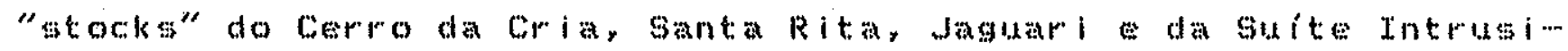

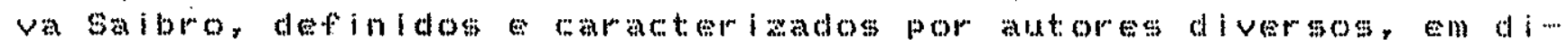

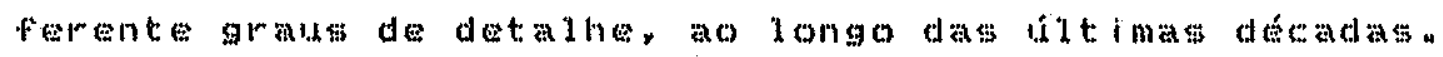

Hartmann Nardi (1983) Nardi (1984) retonheceram freg gra

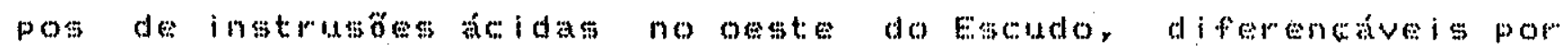

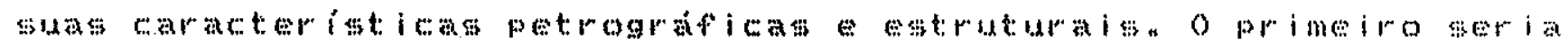

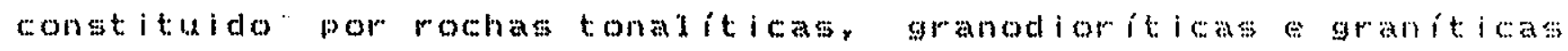

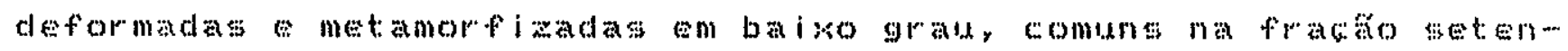
trional (e ja discutido no capitulo anterior como onaisses Cambaí, 
geg. Silva fitho, x984), o segundo por termos granodioriticos monzograniticos sem evidericias de metamorflismo ou deformata, representado, por exemplo, pelas portös centrais dos complexos de

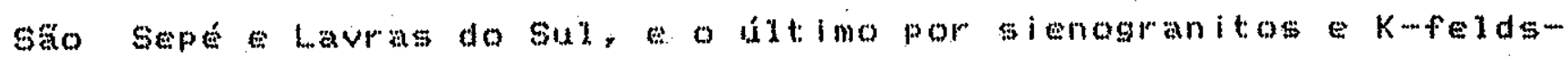
pato granitos chtre os quais se incluem a sulte Intrusiva Saibro. o Granito jaguart os pertitargranitos dos complexos de säo Sepe e. Lavras do sul, entre outrosis

De acordo com os mesmos autores, as rochas do grupo z parecem. ger calcimalealinas, ombor a a gumas amostras partencam ao campo

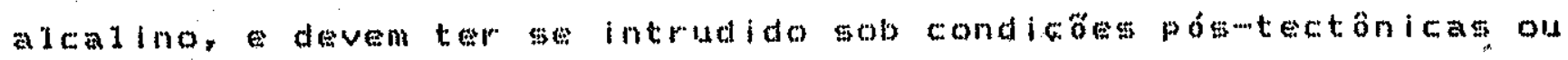

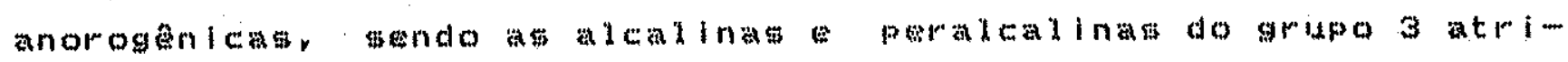
buidas a d t ima fase.

O\$ primeiros levantamentos geocronológicos levados a tefeito

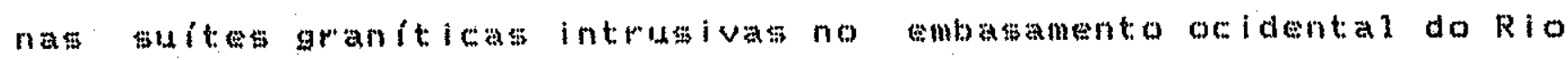
Grande do sul sto devidos a Robertuon (1966), Minioli kawahita (1971) e Dresch et al. (1973), que concentraram seuts toforcos not

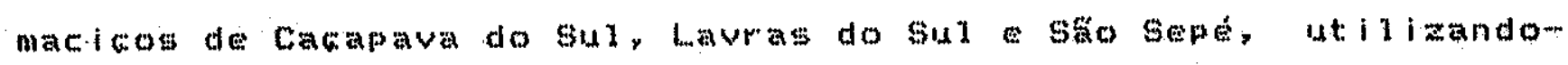

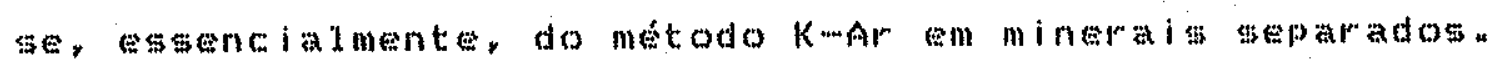

Cordani et al. (1974) incrementaram os conhesimentos radiomer tricos relativos a estas unidades com a aquisicáde cerca de wat dezena de novas anditises, agora pelo metodo Rb-Gr. sendo incluido nat investigacoses o Granito da Ramada. Na oportunidade, atraves de

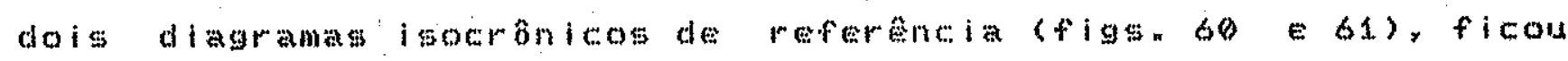
claro que on batolitos de Lavras do sul comapa do sul cemparm te, já que dois pontos analiticosposicionaram se abaixo da isocrona), astociados a outros granitódes indiferenciados do Cambat. compunham um evento magmátio prococe correlacionável à fase 
antectonica do ciclo Brasiliano, enguanto os macicos do sá sepé - da Ramada, com raxos pb/sm atamente favoriveisg definiam um valor temporal compativel com a fase póstoctônica a o qual se inclairam algums pontos derivados dos riolitos Acampamento Velho,

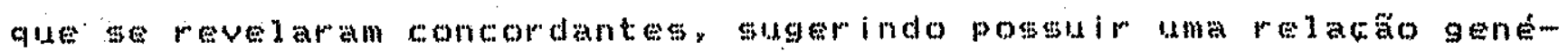
tica com os granitos mencionados. A ste litimo evento os autores atribuiram os pontos näo alinhados do Granito de cacapava do sul.

A partir de 1978, com as pesals isa de sartori no Complexo de Sac sepe, at

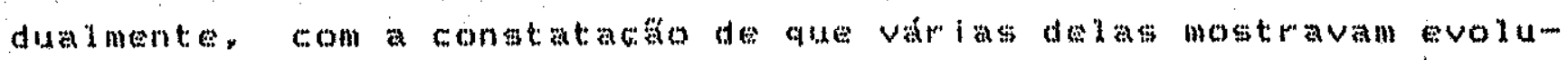
落o polif

\section{O Complexo Granitico de São Sepé}

De acordo com Sartori (1978), o Complewo branitico de săo Sen po. Como foi por ele denominado, congrega tipos litolódeos dism tintose maperveis (Nig. 36). Na parte centrowst do macico ocorre um microgranito monaconitico a na centromorte, um granito monzom

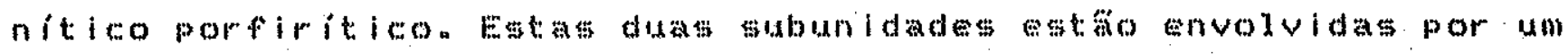

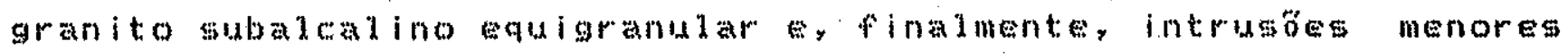

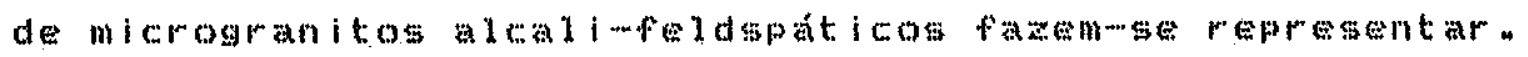

O batidito granitico de sato sep gerou uma faima de hornfelses. con largura da ordem de uma centena de metrosig tanto nos me tamorfitos vulcanomedimentares da sequansia Campestre quanto nos

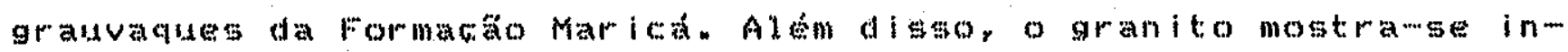
trusivo en um derrame de lavas basalticas atribuido ao Menbro Hilário (gartori, op " (cit..)" 


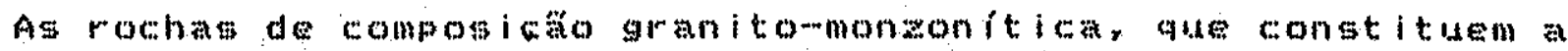

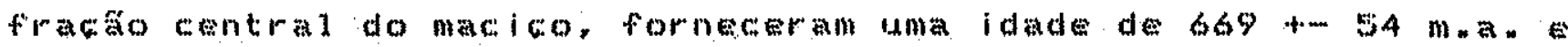

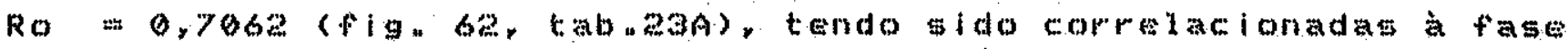
sintectonlea do cicto brasiliano. Os granitos subalealinosperifericos, por seu tumn, definiram uma isónona de referancia de sey 4-- 7 man, com Ro 0,7067 (fig. G3, tab. 23B), compativel con a denominada fase pós-mectônica do referido evento diastofófico.

Os microgranitos intrusivos, associados a amostras de riol $\mathbf{i m}$ tos do Cerro rupanci, al inharam-

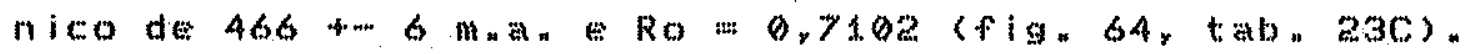

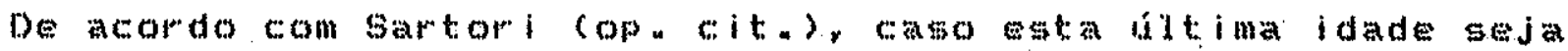

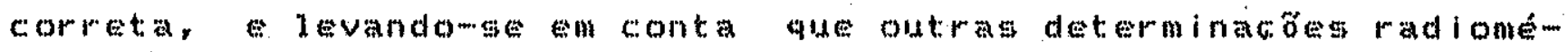
tricas sobre riolitos de areas distintas, aborada por Minioli - Kawashita (1971) Cordani et al. (1974), apontaran um evento efusivo por volta de 500 mon retaria, entag, configurada una

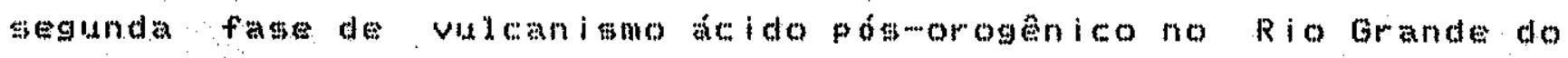
Sul a primeira contemporanea zépoca do intrusa dos granitos pós-tectónicos a outray, de carater alcalino, associada a intrusöes de microgranitos, cormsponderia ao encerramento das ativida... des igneas do ciclo Brasiliano.

Ainda, segundo o mesmo autor,pelas razón iniciais fornecidas

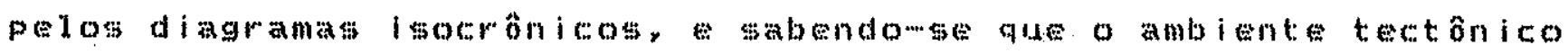
estabelectdo durante o prembambriano superior teve como substrato uma crosta de natureza continental conaluses Encantadas e suas ca-

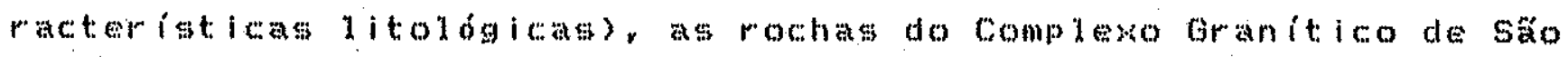
Sepe poder ian sor uma consequencia de fenomonos anatecticos atuantes no substrato ensialico, no material do próprlo cintura orogem 
nico (Faika Dobrada R Iteira Regia orogen icado Sudestes conforme

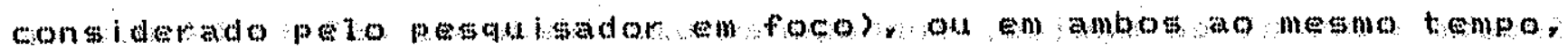

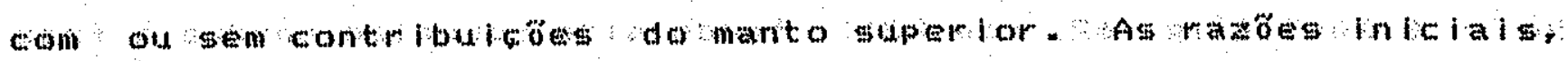

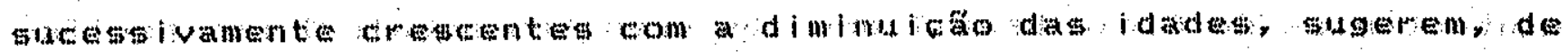

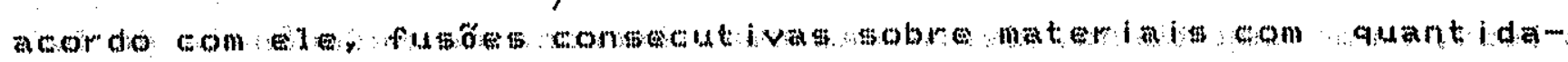

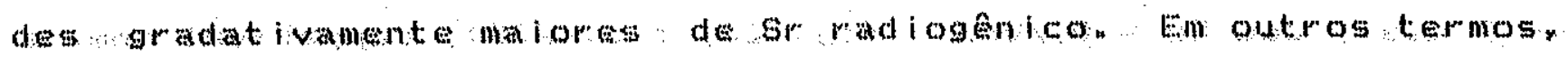

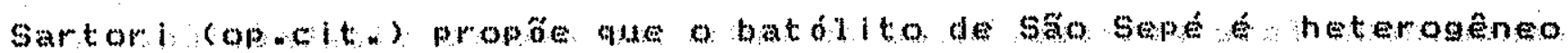
e. polifásico. originado de processos anatecticos de rochas crusw

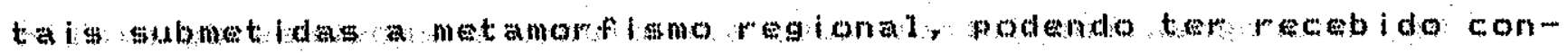

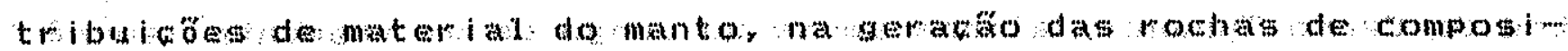

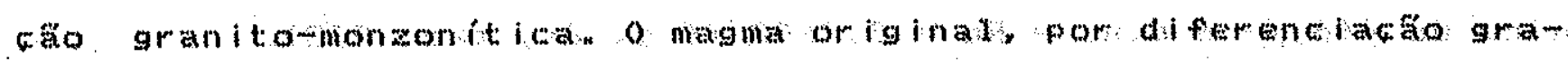
vitativa, há cerca de 670 man teria se dividido em duas fracós distintas, uma no fundo do reservatorlo, compostapelos aninerais

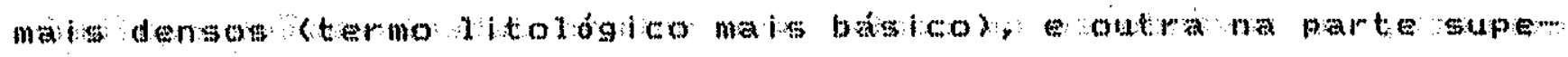

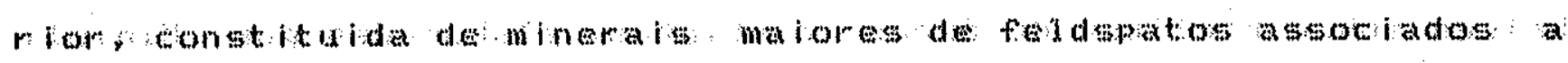

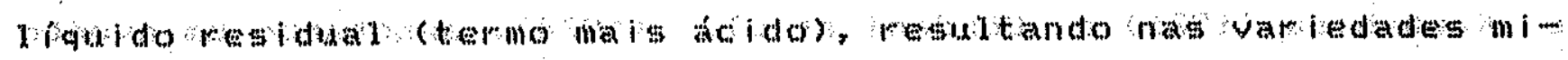

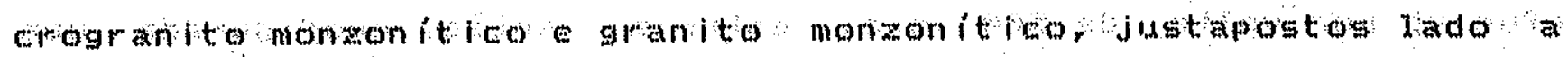

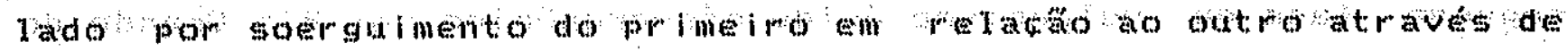

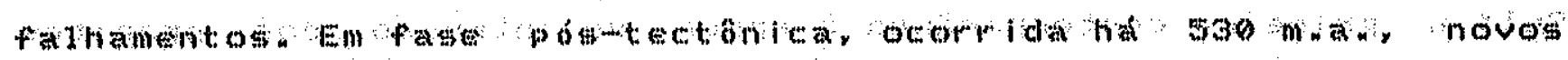

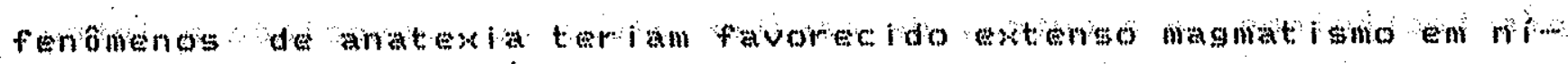

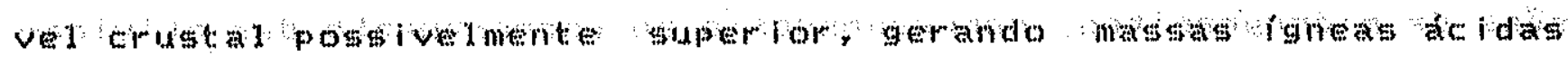

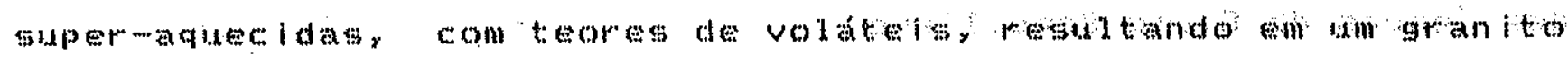
sub-alcalino de epizona, com enclaves de mierogranito monzonitico

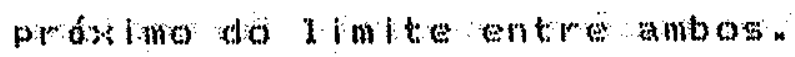

Por fim, o temino do ticlo orogento aconteced apos novala

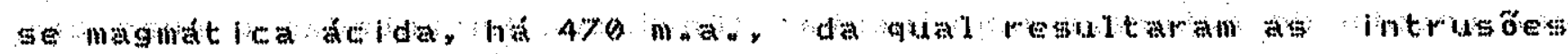

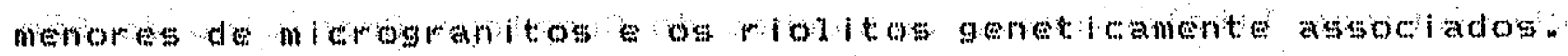

Apenas duas aralises K-Ar sta relaclonada a macloo de Sáno 


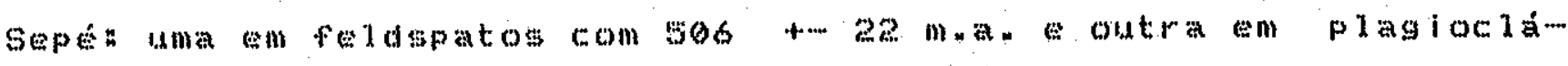
sos concontrados da cornubianito desenvolvido sobre as videano-

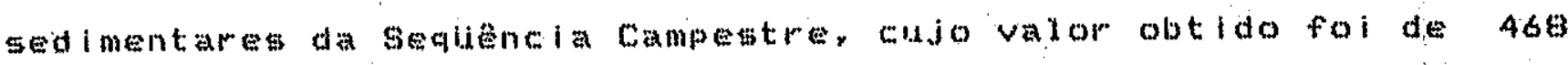

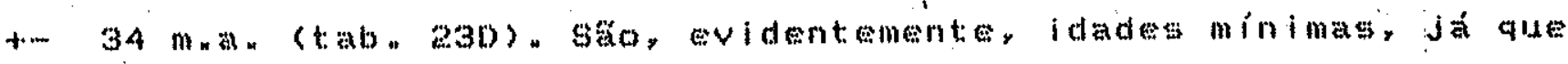

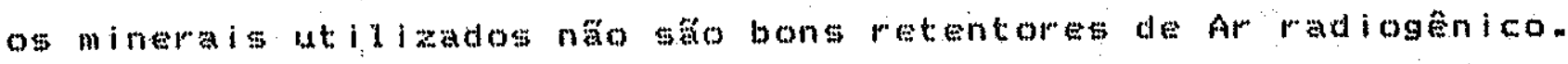

\section{Os Granitos Ramada e Cerro da Cria}

On compos graniticos da Ramada do Cerro da cirla (fig. 65 ) foram denominados ofoneiramente estudados por teina et al.

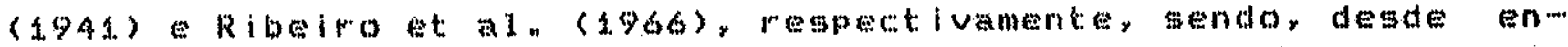

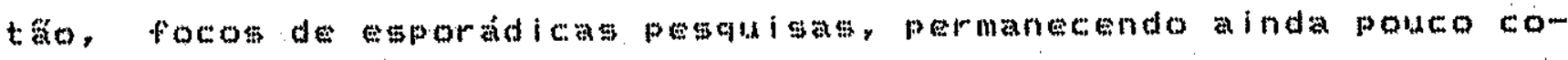
nhecidom do ponto de vista geológleo geocronolósicon

As primeiras and 1 ises radiometritas em amostras do "stock" da

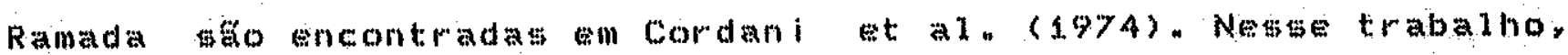
os tres pontos consegudos foram incluidos em un diagrama imoró-

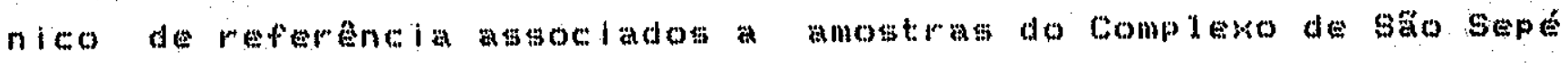
(bordo) dos rolitos Amampamento Velho, fornecondo un valor tem-

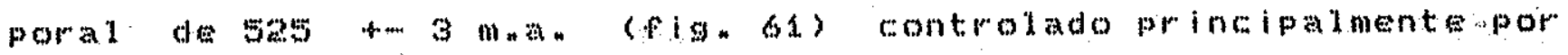
estasitologian

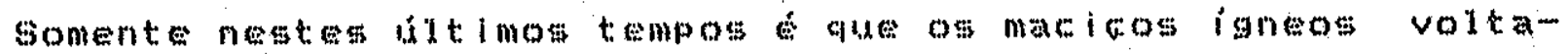
ram a ser visitados de forma sistematica coriteriosay passando a

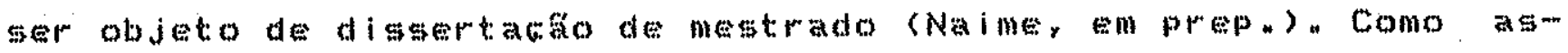
sinala opesquisador, no "wtok" da Ramada. podem ser definidos

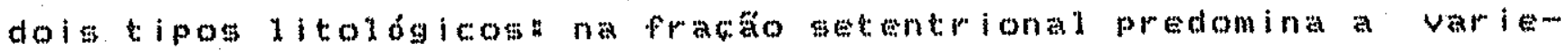

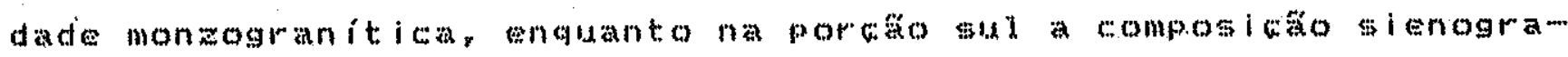
nitica e mais importante onde tambémse nota que em direcăo

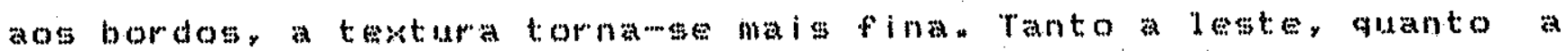




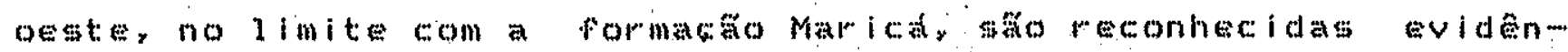
ciat de metamorfismo de contato.

De igual modo, o oranito Corro da cria revela variacós petrogrificas entre as frato encontram os levantamentom nato permite, ainda, o adiantamento. de

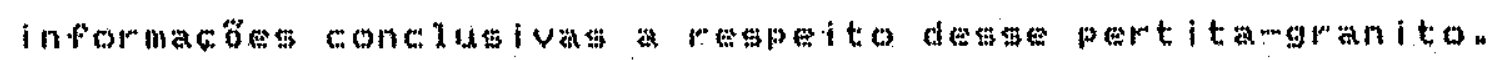

O. Etudo geocronológito dratas unidades vem sendo feito por

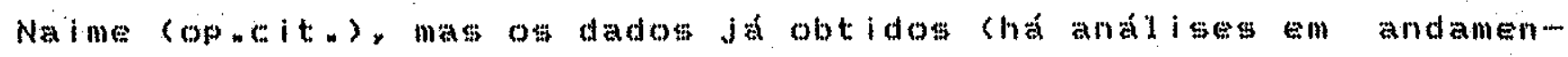

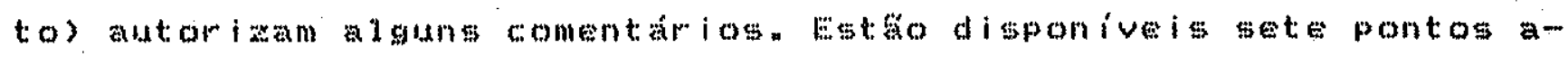

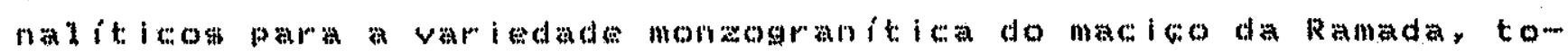
dos derivados de rochas coletadas numa area de cerca de 1,5 kne e com caracteristicas petrograficas batstantw mimidares plotados em um. diagrama isocrönico, alinham-we a longo de luma reta de $466+\cdots$

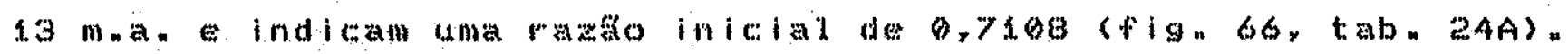

A julgar por esses resultados, os monoogranitos da Ramada sato

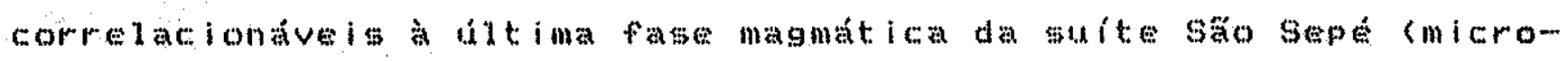
granttos intrustuos), identicos na ldade na maso inicial. Se a

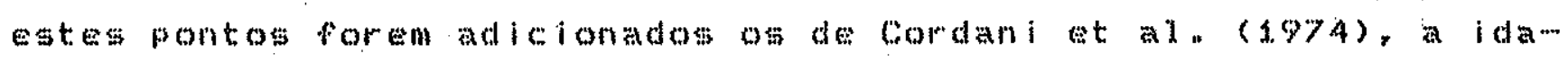
de indicada sobe para $48 \%$ +. 1. ma a y continuardo cronocorrelata

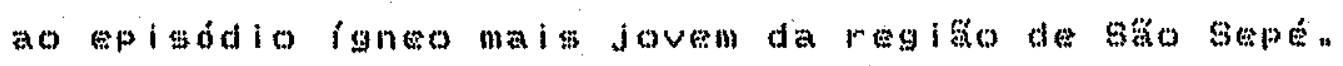

mmostras pertencentes à variedade sionogranitica estä́o en fage de andise, nato havendo dados som disponibididade.

O pertitargranito Cerro da Criag por sua veay to portador de ba ixos teores de Sr. Face a raxa Rb/Gr altamente favoravel, it i

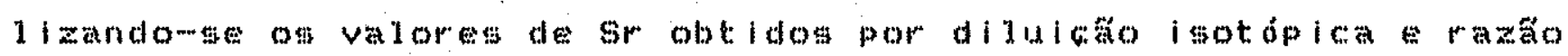




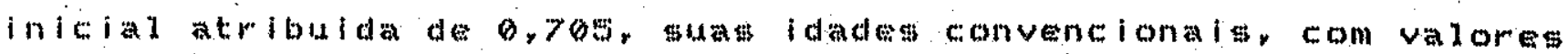
da ordem de $590-560$ m. c:

Estes resultados preliminares apontan no sentido de conferir

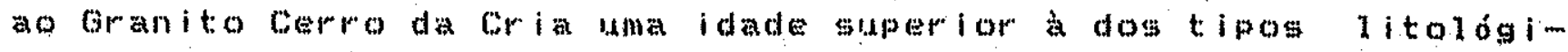

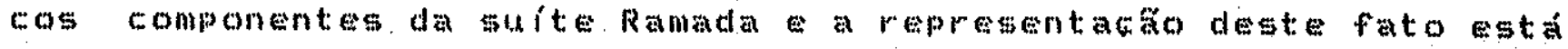

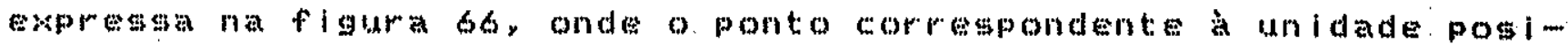
c. I ona com a facies de bordo do lomplexo de suo sepen

\section{O Batólito Eranitico de Cacapava do Sul}

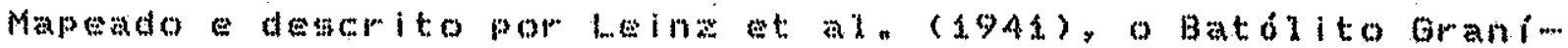

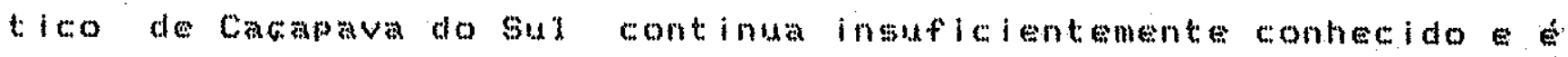

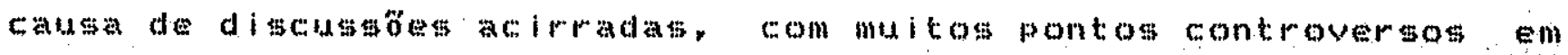

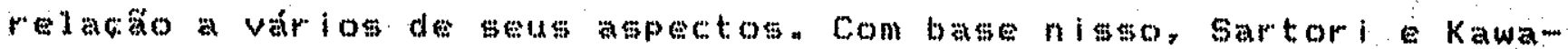

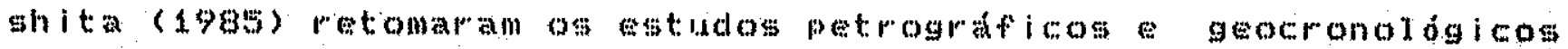
do macico com o objetivo de contribuir com novas informacose de ordan composicional tovolutivan

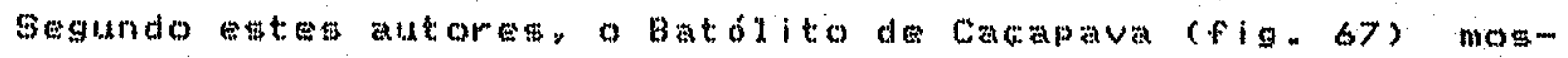

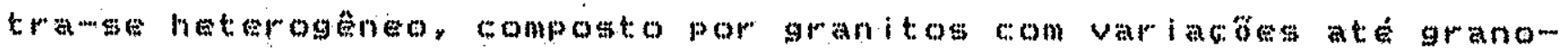

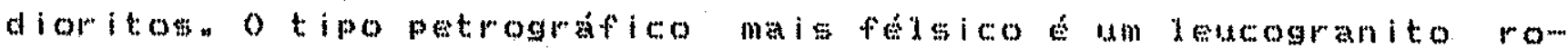

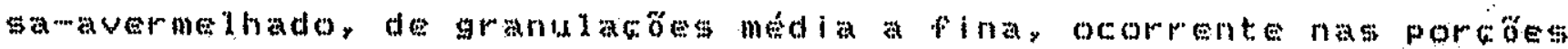

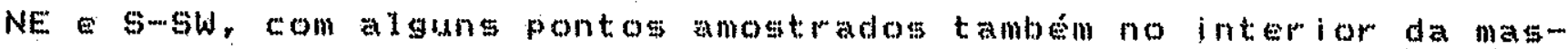
saranitica $(f i g i \theta) .7$

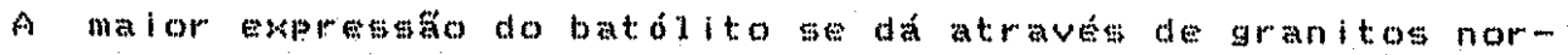

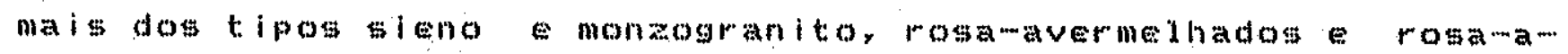




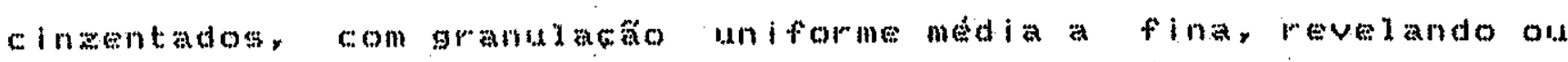

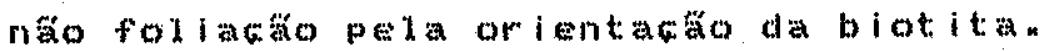

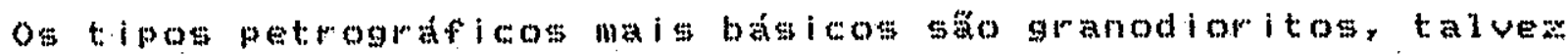

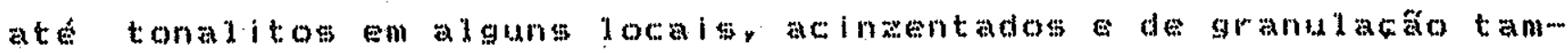
bem uniforme, media a fina, compondo, principalmente, as partes

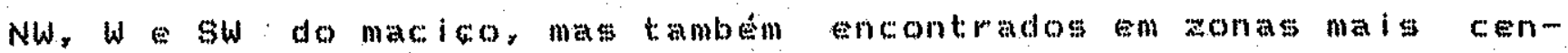
tr r a is.

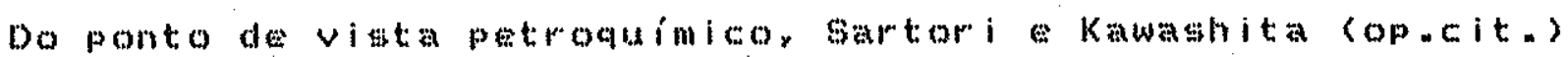
mencionam que estas rochas revelam um "trend" catcionlealino, par

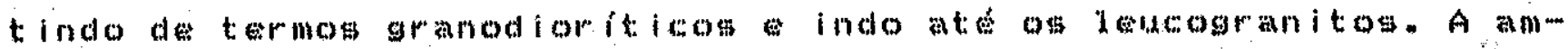

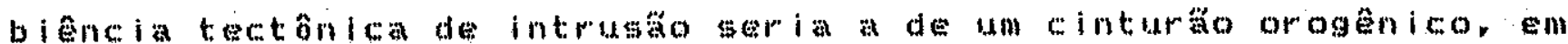

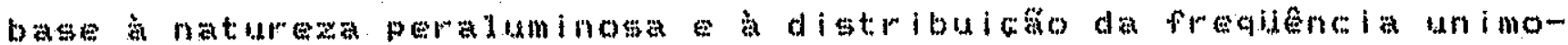
dal do indice de difarenciato

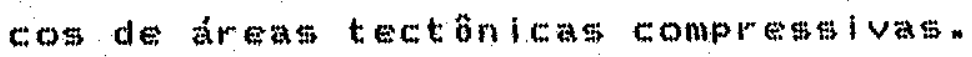

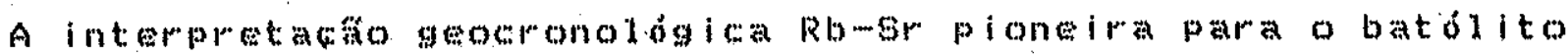

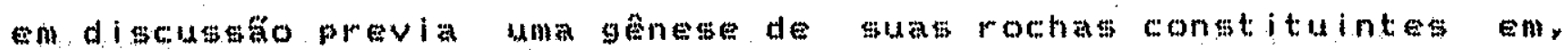

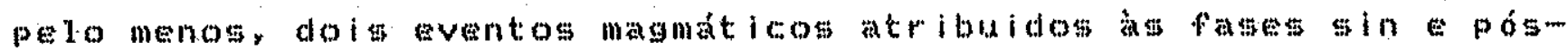

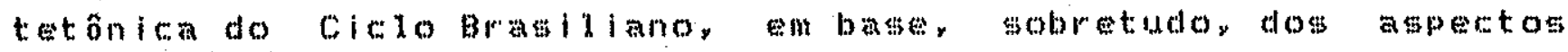
theturis da

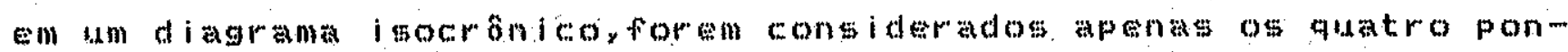

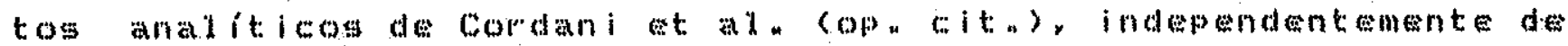

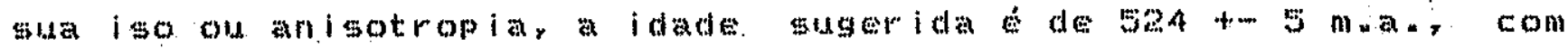

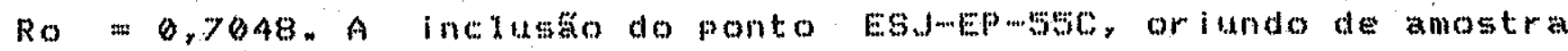
fort emente foliadis coletada proximo ao fontato ge com a encaim

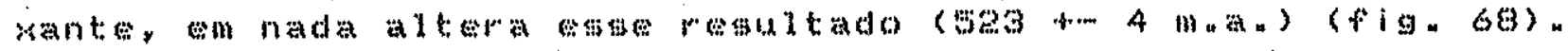

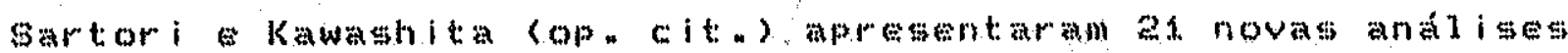




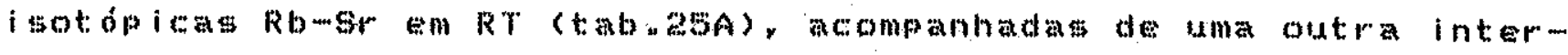

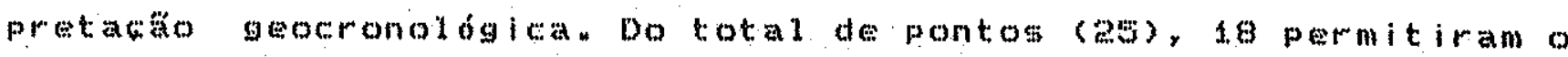
tracado de uma Isocrona com $552+4$ man $20=0,705(f i g .6 \%)$. que também reflete media das idades conveneionais das anostras

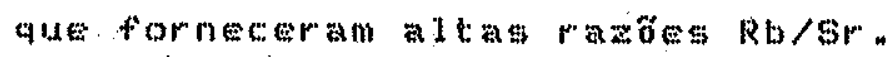

Da observacto da figura mencionada, percebewse ser grande a dispersato dos pontos and ittcos, sobretudo naspronimidades da ow rigem do diagrama. Este dado foi interpretado como indicativo de Hima homogeneizaca isotón ica incompleta entre os materiais do manto superfor da crosta que originaram obatólito. Assim, as variedade bat

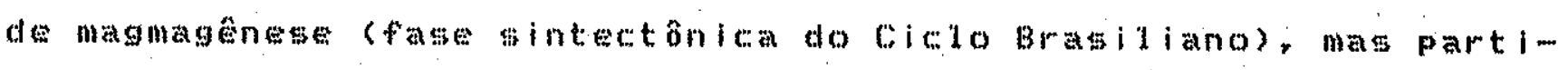

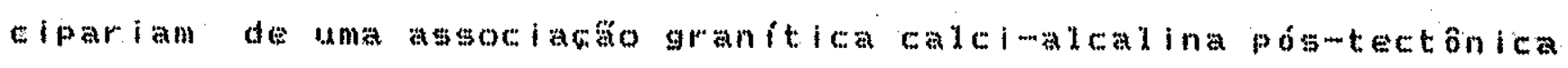

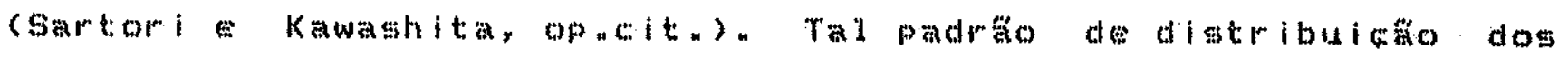
pontos analibicos poderia, no entanto, estar refletindo a incon-.. temporareidad de pulsos magnaticos geradores do batólto, atraves de segmentos tsoeronicos distintos and ná dofinidos, que

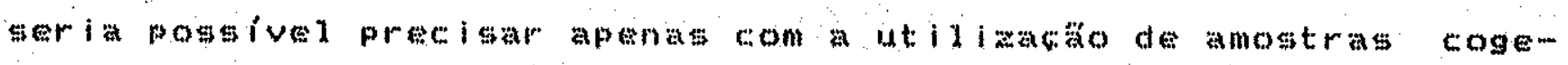

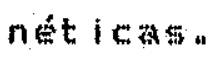

A suspeita acima enunciada encontra suporte também nas idades aparentes K-Ar disponiveis para os granitoldes de Cacapava do sul. Valendome dos dados originata de Minioli e Kawahita (197a), 1igo iramente menores do que os recaledados segundo as novas constantes propostas por steiger dager (19y7), exom erros de 2 .

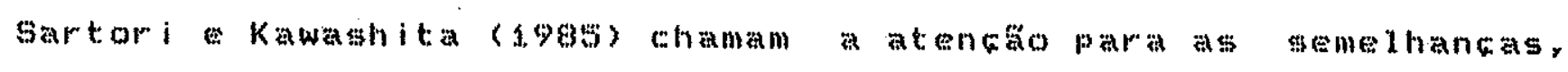

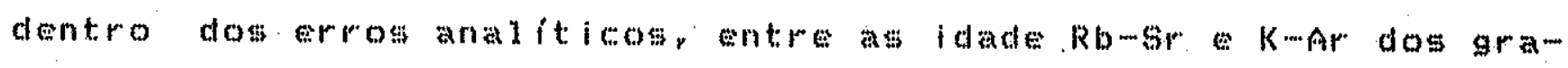
nitoides de Cacapava do sul. Tal padra geoconológito. comentam,

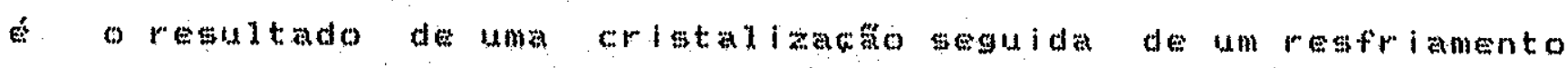


muto rapido, tiplico de final de ciclo oroganico. mem eventos tec-

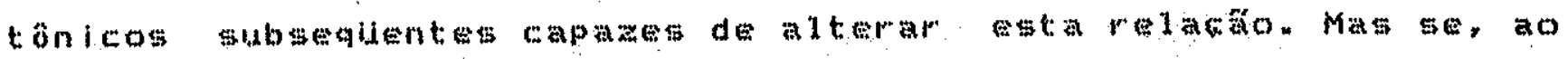
contrario, atilizarmos os valores padiometricos recalculados, a concordancia entre as idades fornecldas pelos dois diferentes mé

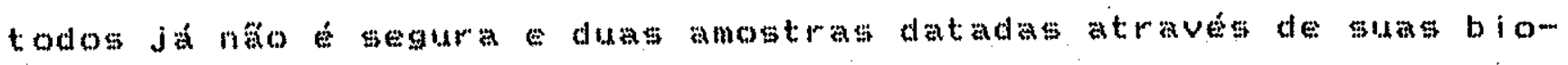
titas (tab asis) revelaram valorest temporai

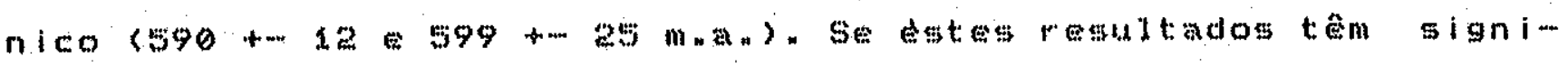
ficado geolófoo, possivel que o pluta granitito de Cacapava

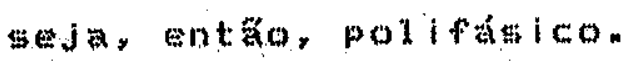

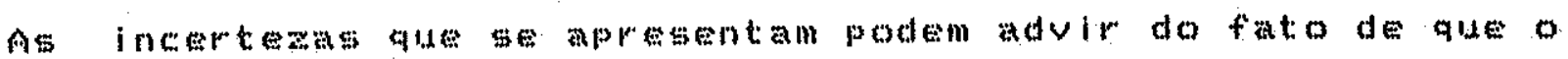

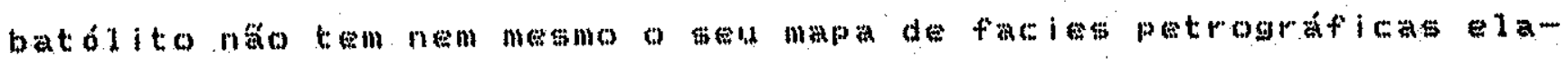

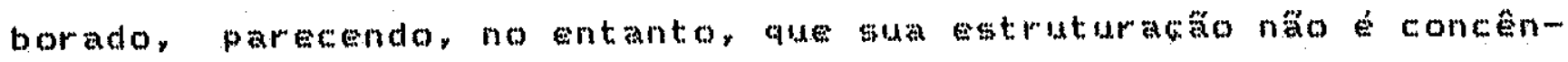
trica, somelhanca de outros macicos gatichos com o intuito de contribuir com a continuldade dos satudos relativos ao complexo. executamos mapas de tendencia superficial (49grau) a partir dos

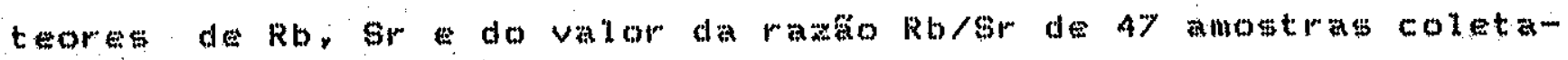
daspor sartori, a procura de Indicios mbetivos de variacós fam ciologicas (figa 71, 72 73). Dos frats o que melhor corresponde

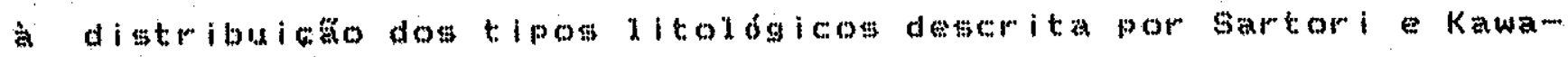

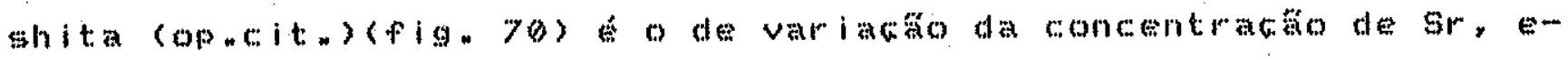
lemento que oscila amplamente de acordo com a facies petrografica, ao contrílo do Rb que apegenta um intervalo de flutuata muito

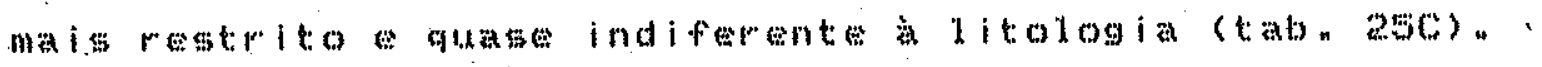

Ee a i 6 crona da fig. 69 tem a sua idade altamente influen-

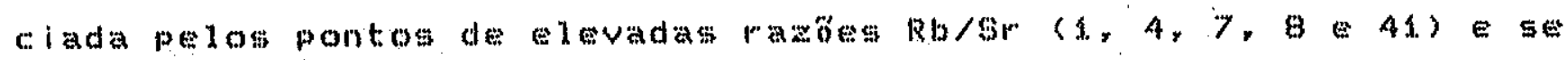
Esses leucogranito asta concentrados bobretudo na fracáo $N E$ do macico, a procura de facies litologicas diferentes com teores de Rb E de sr particularso e idades possivelmente distintas) para a 
coleta de amostras cogeneticas deve ser feita, por exemplo, nos monzogranitos ou granodioritos da portáno centromoste do batólito. nos sienogranitos de E S-SE, ou nos mieno monagoranitos das fracose centroms e SE. De igual modo. os granodioritos-tonalitos

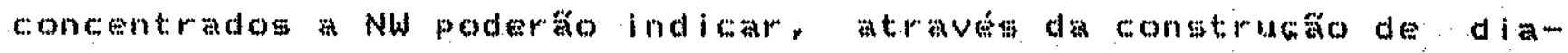
gramas isocronicas sub-regionais, desde que exista, o carter plurimepi sódico do complakon

O\$ valorem de $600-590 \mathrm{~m}$. relacionados a um evento petrogenetico pouco mai antigo, de 600 -.

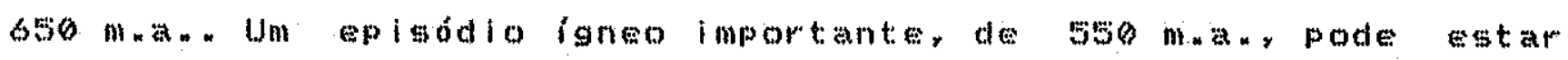
rafletido no segmento isocponico geral para obatólto, época em que formaram as rochas de maior rasto Ro/sr, ex ro encerramento da atividade mamatica, granitos rósos podem ter sido produzidos ha $525 \mathrm{~mm}$ m, contemporaneamente aos granit 6 ides sub-alcalinos do

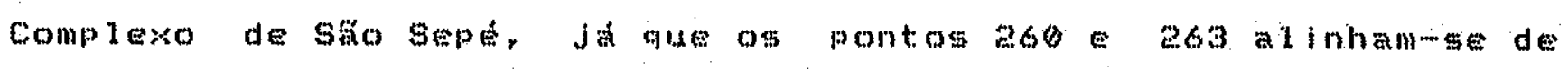
forma apropriada no diagrama da referencia apresentado por cordani et. al. $(1974)(f i g .61)$.

\section{O Complexo Granftica de Lavras do Sul}

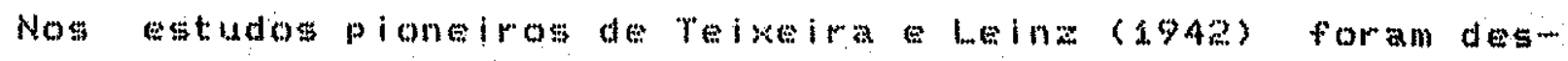
critos dol tipos litológicos astociados componentes do complexo Granitico de tavras do sul " um granodioritico com textara porfiri-

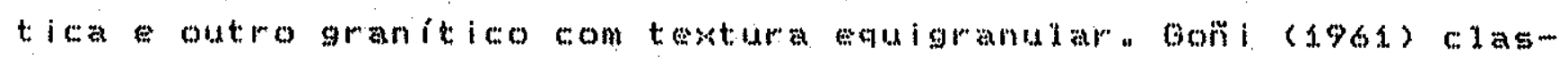

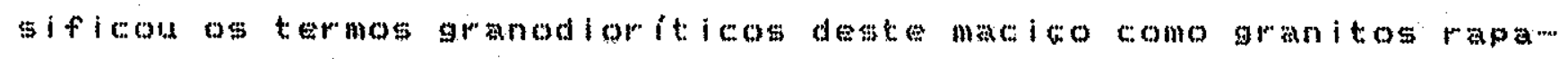

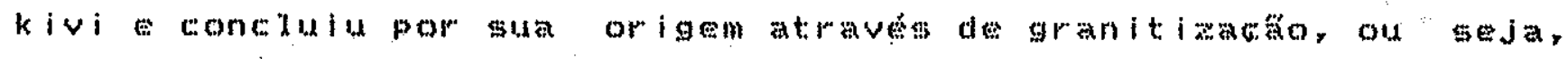
por metasematismo potás que . 
Para Ribelro et al, $(1966)$, o complexo possul gênese magnati-ca e revela evidencias de ser posterior a vulcanitos de unidades molassóddes do Rio Grande do Sul. Sartori (1979), Reisthel (1980) E LFRGS (1980) reconheceram que o complexo em foco constitui-se de granodioritos monzogranitos, am sua porso central, ede sienogranitos pertitamranitos que circundam an udade anterior, sendo correlacionáveis, respectivamente, por suag caracteristicas petrograficas, ta semelnanca do que se da com outros complexos, as faseg sin e póstectônica do ciclo Brasti iano.

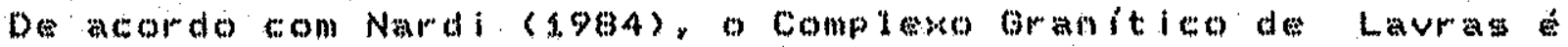

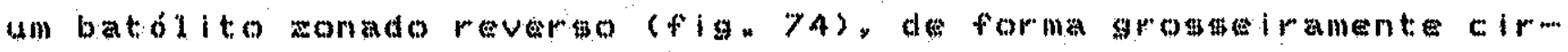
cular, no centro do qual afloram granodoritos monzogranitos que gradam Bara aienogranitos pertiticos com towtura rapakivi cada voz mais abundante, enquanto gue no bordo do macico passam a predominar os pertitamranitos.

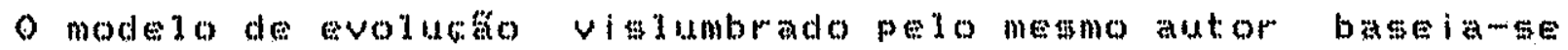
en mecanismos aimilares a subs idencia de caldeiras, segundo Chapman $(1976)$, propose um bloco granftico calci-alcalino (shoshoniticos engolfado por magmas alcal inos ascondentes que também geraram as suites intomivas daguari ga soro (comentadas adiante). Da mistura de ambos formarammes as rochas da faika de transigán.

Atraves da leftura de trabalhos diverson deprenderse que a

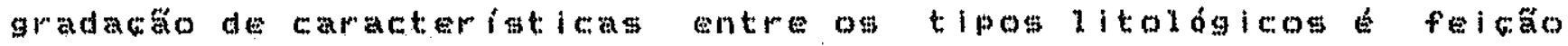
marcante osta enfaticamente evidenciada em Nardi (op. cit.) por

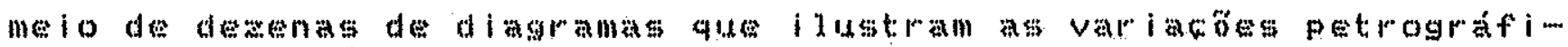

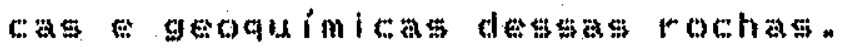




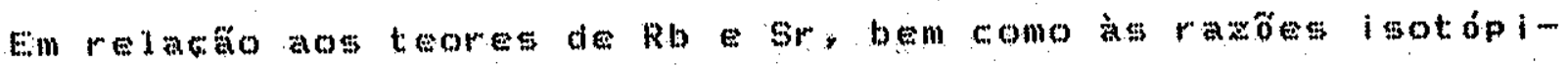
cas desses lementos, o fenômeno gradacional persiste e possivel sobocar para o maciso sma gubdivisto interna malo completa, como

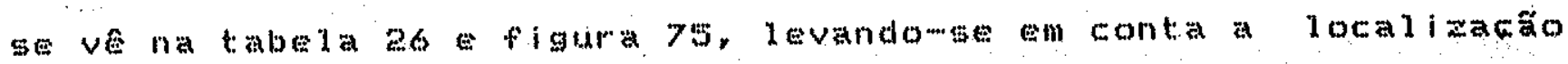
dos pontos amostradom anal isados.

A portacontrol do complexo granitico admite ser dividida

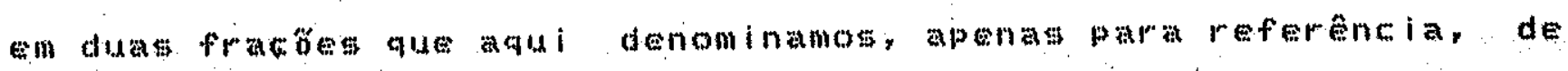
"nícleo interno" "núdeo externo" do maciso. o primeiro possul

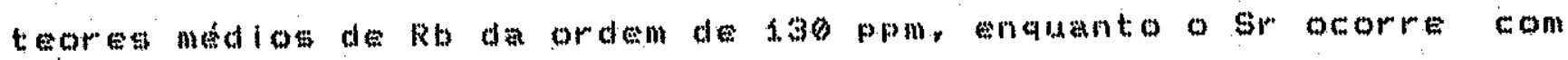

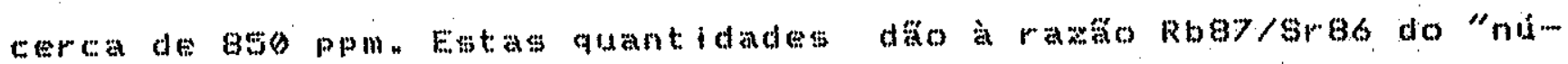
cleo interno" valores varlaveis entre 0,38 o, 03 . No diagrama da

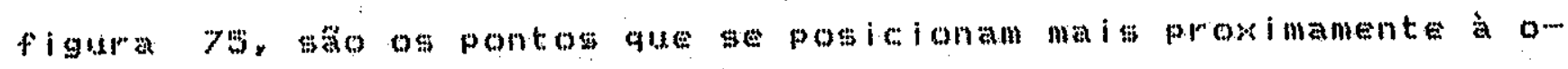
rigem.

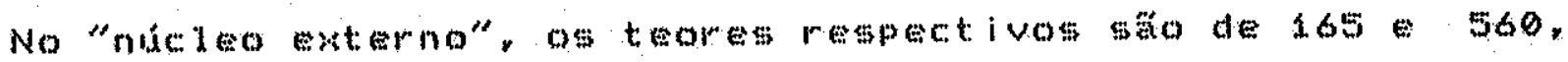

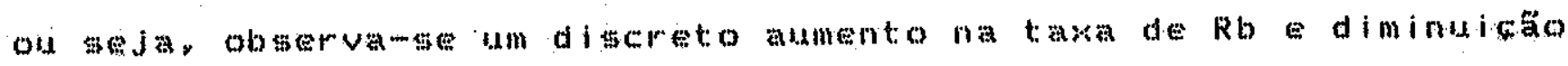

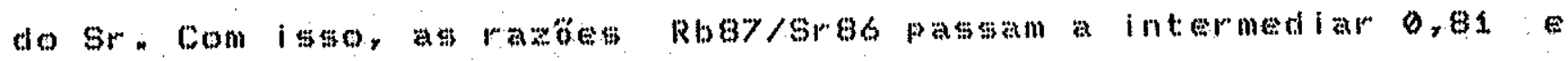
9.91.

Nos termos litológlcos de transicano o fenómeno repete-me En-

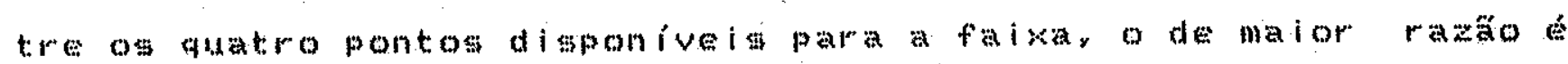

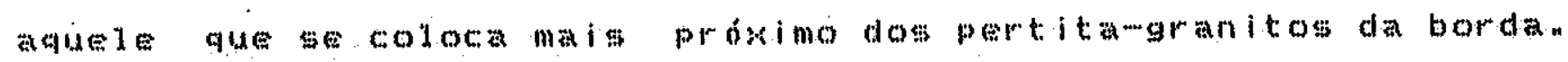
Negse ancl intermediario, o Rb ascende para teorem medios de 220

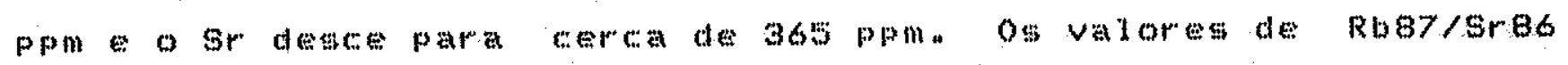
pastam a variar de 1,20 a 2,34 (tab. $26 A)$.

Finalmenter na sona perifurica o que se constata que ob

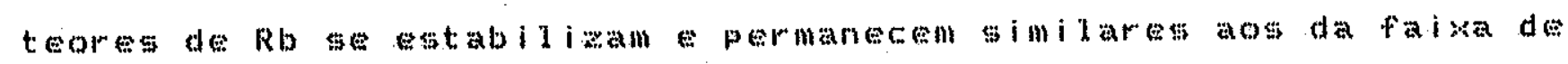
transicáno. o gr, no entanto, continua decrescendo, com teores de 


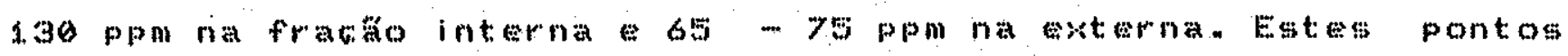

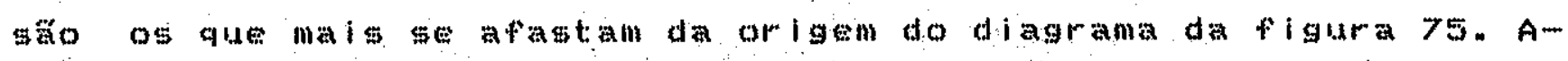
penas un caso aparentemente discrepante fol constatado entre os 21 pontos analiticos disponivels parato mactoon o ponto Ls-3 (figs. 74 - 78, apesar de tor sto coletado na falma mapada como transicional, apresenta carater isticas isotopicas de litologia peri ferican. Fubora o domínio na area de coleta seja de termos ditolóm gicostranicionat, a presenca de rochas com facies petrograficas

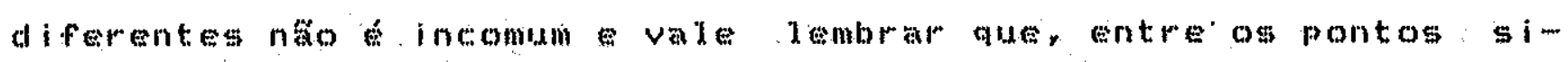
tuados a NE do complexo, a amostra em foco a a due se posiciona mat longe da zona central.

A congtrug a de segmentos isocrônicos de referencia, para ca-

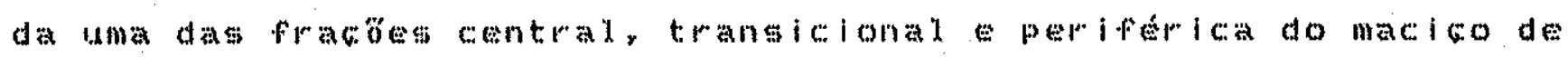
Lavras, aponta no sentido da atribuiga de lades distintas para

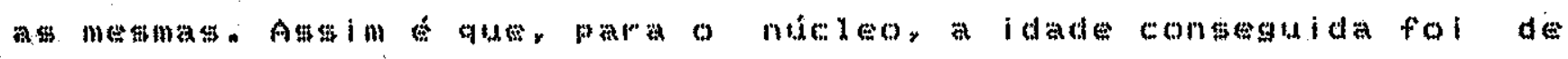
$653+\cdots 34$ man (pign 76). A na linearidade dos pontos analiticos sugare a inclusaro, no mesmo diagrama de termos litológicos com

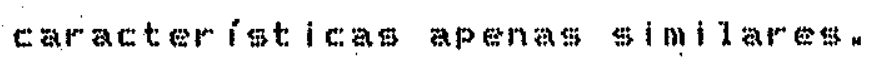

Para as rochas transicionalat a ldade sugerida de $592+-46$

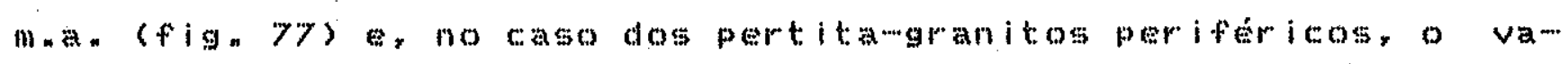

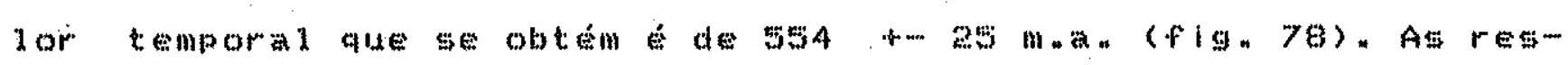

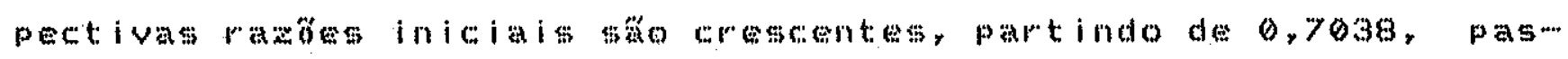
sindo por 0,7042 enegando a 0,7050 no cinturato externo.

O comportamento isotópico do macico de l...avmas com guas ida

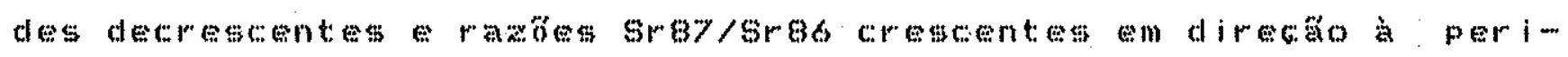
feriar a definita de uma linha convexa em diasrama isocronico (fig. 7s), as variacós contimus nos teores de Rb e Sr, alem dos 
aspectos petrograficos petroquínicos gradactonai apontados por Nardi (1984) induzem a imaginar para o memo uma gênese calcada

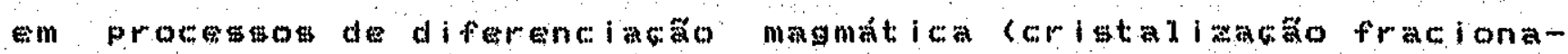
da) . Se assim tivease acontecido, a garaco da unidade teria se i...

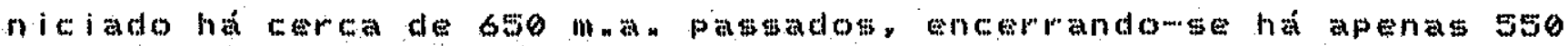
m. a . sendo possivel encontrarem-se idades intermediarias a estas duas extremas, como a indicada pelo valor de $590 \mathrm{~m}$ an y nos termos litologicos de transicanon

A formacta dos granito ides de Lavras no irreal decurso de 100 ma. implicaria com restriamento extremamente lentor o que ge fon-

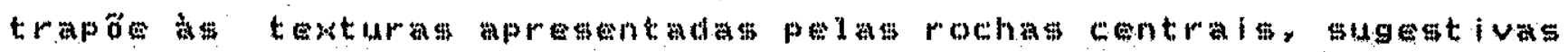
de consolidata am niveis cordsta is pouco profundos a

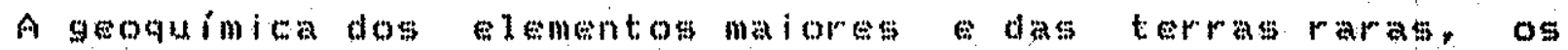
calculos baseados nos coeficiontes de partiga de alguns elementos mtraco, atilizacto de razón lementares, indican que os tres tipos litológleos principais comonents do batólito näo ge melacionam por diforenciacaro magat:ica porque nato apresentam "trends" tipicos de rochas comagnateas (Nardi, op. Eit).

Os termos extremos (de midede de bordo) parefen ter, respectivamente, afinidade calcimalcalina adcalina. o primeiroy uma suite de ambiente compressivo, formado por sranito do Tipo I

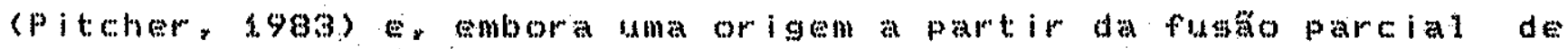
rochas dominantemente íneas possa ser aventada, as evidencias geoquimicas sto mals consigtentes com uma derivacto mantelica. Litimo, uma suite mamatica de ambiente distensivo, caracterian Se por granitos do tipo A (pitioher, op. Citn), originados ou por ceistalizacto fracionada de aleal i molivina basaltos derivados do 
manto, conforme pensamento de vários petrólogos, ou por fissóno parcial de rochat granuliticas, prosentes nas proximldades, como lenDra Nardi (op. eit..).

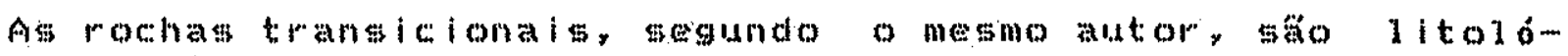
gias hibridas que resultam da assimilate de rochas da zona cen tral pelos granitos pertiticos mais jovens, redundando em diagram mas petrograficos gequimicos nos quatsos tipos litológicos rew velam variagöes contínua de mus caracteristicas. A towtura rapa-

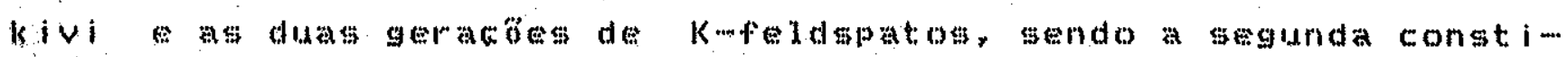
thida de mesopertitas, sago, de acomdo com o pesquisador, feicoses diagnósticas de rochas transicionara trefletem o processode as \$imilacta

Um aspecto, no entanto, permanece obscuro no quadro evolutivo do macico de Lavras se as rochas transicionais eperifericas dew rlvam de um nesmo magma parcialmente diferenciado pela incorpora-

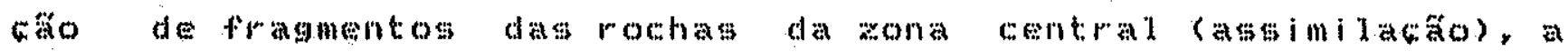
cristalizaco de ambas an parclas deve ter se dado concomitantemente er nestace coso, as ldades padiométricasy relativas a fechan mento dos sistemas, deveriam ser similares, diferindo apenas nos

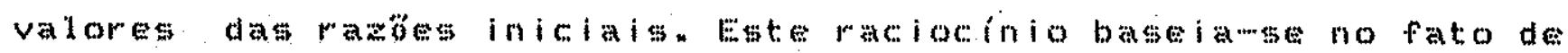

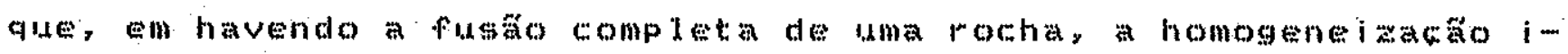
sotopica do sr seprocessa en em taso de novo resfriamento, a idade a ser registrada referewe a butimo evento petrogenetico.

Se aceitamos os valores de 650 e $550 \mathrm{~mm}$ an, darivados de diagramas de reforenciar como significativos das lades dos eventos responsaveis pelas geractos dos granodioritos e monzogranitos cen

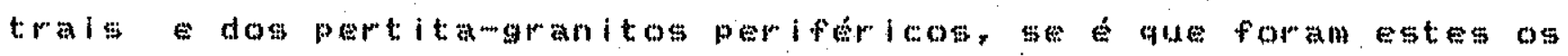


únicos pulsos magmáticos ocorridos na formagto do complexo, idades intermediariag de 590 mon, tambem de referancia nos levarlam amaginar.que, no tempo de encake do magma mai jovem, se prom cessou um rejuvenescimento apenas parcial das litologias ma is antigas este fenómeno aconteceria somente no caso da rocha afetada ter permanecido no etado sólido. Assim, sem a abertura do sistema rochoso precedente, haveria a aperposica de um novo wistema, proventente do magma jovem, por exosolută mineral atraves dos $1 j-$ nites cristalinos da rocha precedente. O grad de rejuvenescimento.

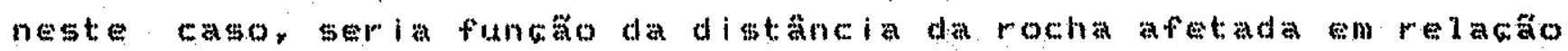

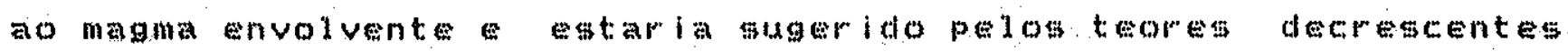

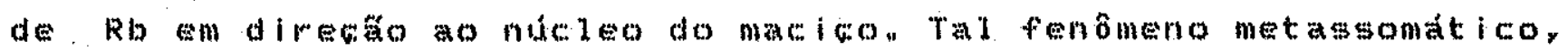

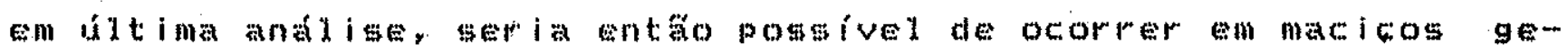

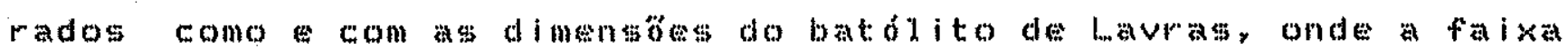

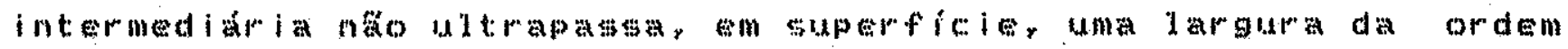

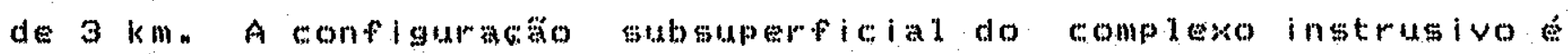
desconheciday mas ter ímos. que mupor un volume magnát ico envolven-

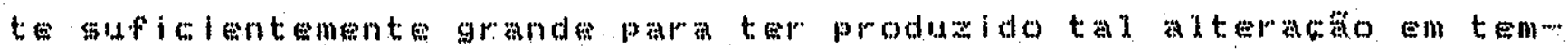
po condizente.

Vala ressaltar, no entanto, que valoreg temporais de 580 a 600 mon. \$obretudo pelo metodo K-Ar om biotitas, sáo comuns no "stock" batólitos da porta oeste do Escudo do Rio Grande do

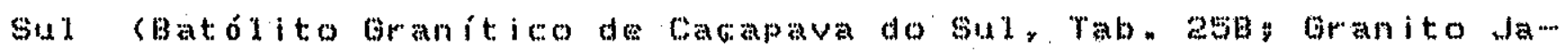
guari, tab e7s; Branito rimbava, tab. $28 B$ y ganitoldes do Bloco racluarembó, tab. 20 tambom no complexo de Lavras do Sul, tab. 26B) e devem estar relacionados a um importante evento de soergimento erustal, ao qual podem ter sa associado epiádios de magman gentse, dando significado geologico ao Valor obtido a NE do bató-

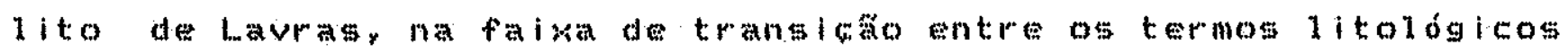




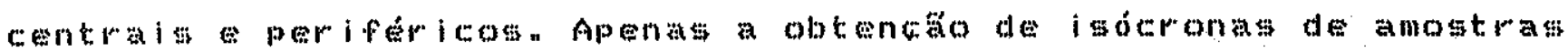
cogeneticas ou a utilizacto de ontros metodos radiometricos poderão solucionar sates aspectos alnda controvertidos"

Entre as sels idades K-m en minerais separados existentes para o complexo de l...avras, pode-me destacar doisgrupos distintos. O primefro composto de analits maliadas sobre biotitas fe feldspatos extraidos dos granitos centraisetrangicionaise o segundo sobresericitas obtidas de rochas hidrotermatmente alteradase mineralizadas a ouro sulfotom diversos

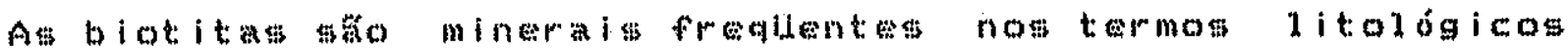
internos do batodito, sendo raras nos pertikamaratos periféri-

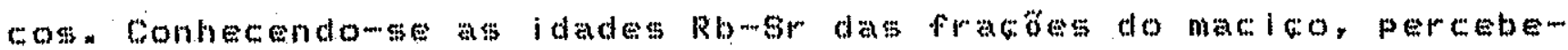

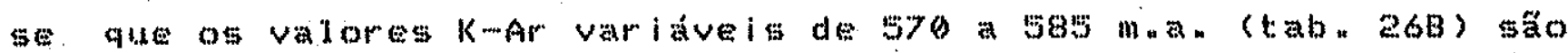
relat lvos às rochas ma is antisas estas no foran totalmente rejuvenescidas por anderimento quando da colocaco dos granitos de: borto. Uma única análise, com cerca de 530 ma. y pode ser incluida nestas consideracoson

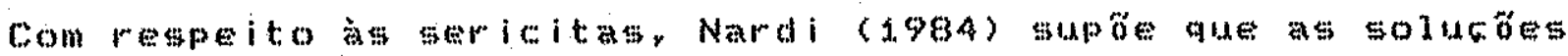
hidroterma is tenhan sido geradas didant o "emplacement" doe per-

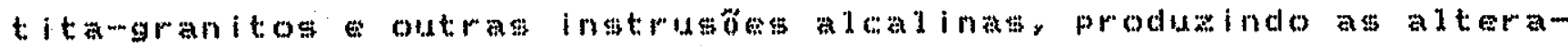

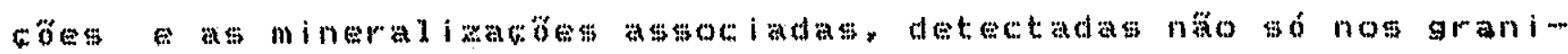

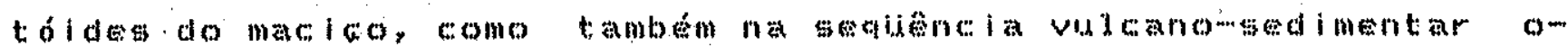
corpente nas vizinlangas (fig. 74), seriamy portanto, mineraig tardiamente gerados no quadro evoluti ivo da árean

Os valore temporais formecidos pelats sericteas radiometricamente ostudadas, no entanto, näo chdossam esta hipótess. Com ida- 
des minimas da ordem de 600 ma. (tab 26B), partecem resultar de

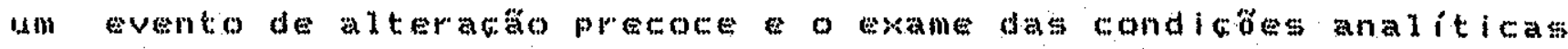
das amostras nô detectou qual auer problema que pudesse colocar tais resultados sob suspeitan

Em suas conclusốs, Nardi (op. cit. , menciona que se as nineral izatobs de ouromsulfetos do Complexo oranitico de Lavras forem consideradas em conjunto com as existentes na sequencia vulcanosedinentar circundante, uma zonalidade gerat pode ser sugerida"

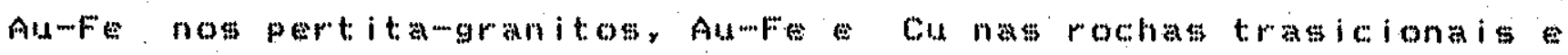

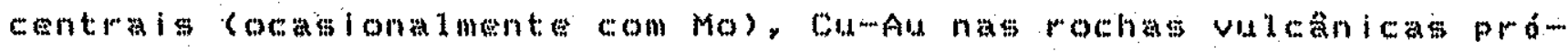
Mimas a romplexo ph Ag (Au?) na sequarela vulcanowedimentar.

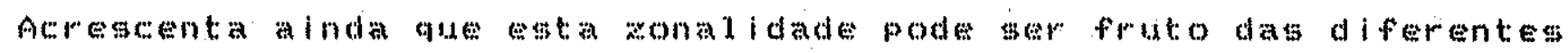
aflnidades dos sulfetos desses elementos, mas nofo fictafatada a possibilidade de que estas diferentes ocorrencias possam represen

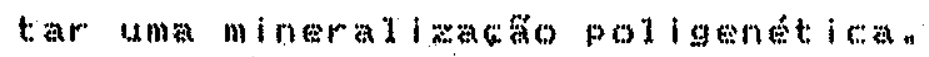

Estudos adicionais, com o objetivo precipuo de elucidar o can rater mono ou polifasico das alteractes hidrotermals, precisam ser realizados. Apesar das serteitas da amostra ESJWN

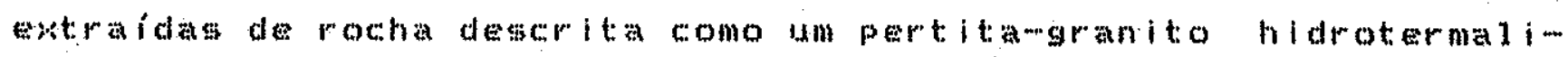
zado, o que tornaria o valor de 602 m. a " inadequato. a presenca de

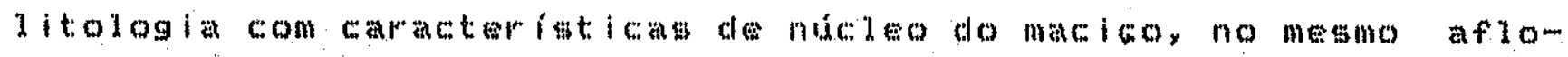

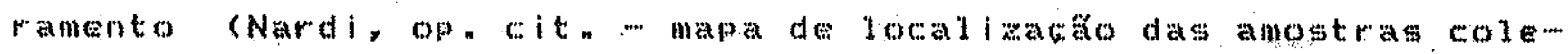
tadas): ná⿴囗十 afasta a possibilidade dos minerals analobados terem ido gerados em episádio precedente ao desenvolvimento completo do bat ól ito.

DeRos Fernandes (198A) descreveram, a NE do macico, rochas charnoquiticas. contato com a pochas graniticas do complexo 


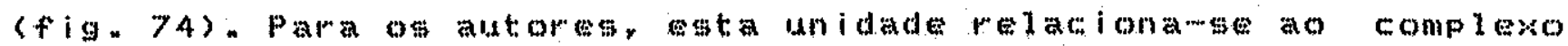
granulitico ocorrente na regito de Bage - Dom Pedrito e corresponderia a luma fracto de crosta mais antiga engolfada pelo magmatismo Lavras . Duas amotiras de charnoquitos foram analisadas pelo método Rb-Gr (tab. 2oC) revelaram-se concordantes com o segmento isom. crônico de referencia do batodito (fig. 75). Se incluidos no diagrama para as rochas do nucleo do macico de Lavras, com quem aprew

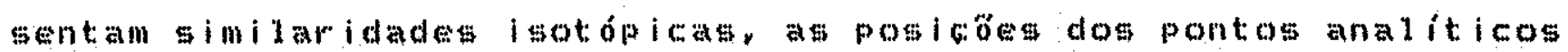
sugerem caracteristicas particulares pars as as rochas conferindomines uma certa individualidade (fign 76). Se, por outro lado. os charnoquitos forem associados aos termos porifericos do batóli-

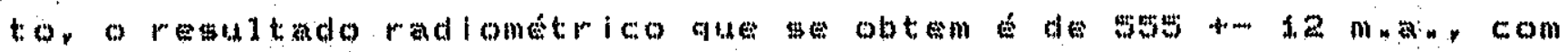
a mesma rasta inicial, e muito bom ajute dos pontos a sagmento isocronico (tig "79).

Astim, com bats nesses dados prediminares, sugerense uma hipoteme aternativa para a genese de ta ser comprovada ou afastada por satudos posteriores.

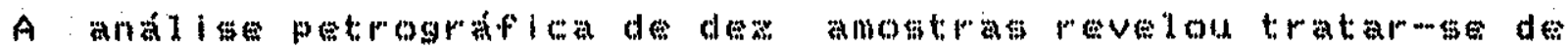

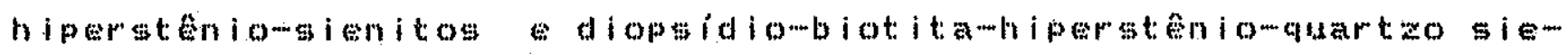
nitos, Estruturalmente macious, de fábrica homófona e, texturalmentey com caracteristicas nitidas de igneas plutonicas carranjo hipidiomorfico etuigranular fino a medios, conforme Defos Fer..

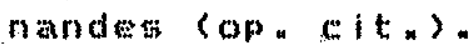

A assembleia mineralogita prococe, continuam os autorest constitui wase de ortopiroxenio com cristais prismaticos curtos estreitamente associados a clinopirokenio. Os plagiociasios (An $25-$

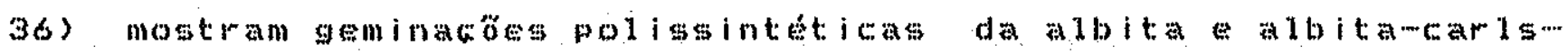


bad, aparentumente originados na faste inicial.

Secundartamente. aparecem lamelas de biotita marrom-avermeInadas, de incenso plectroismo, envolvendo os piroxentos, eviden ciando uma or igem, pelo menos em parter posterior. o k-feldspato - o quarta săo componentestardios o primeiro dabundante e mosm tra reacöes com plagioclatsio através de contatos corroidos. sutam rados, alem de mimequitos. o quartzo, em pequena proporgámo, arédrico de extincta normal pode indisar condicoses amenas na cris-

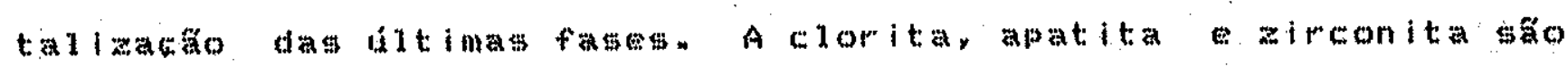
minerais menow alududant

As\$in, wemelhanca do gue oeorre com outros complewos graniticos charnoquitos astociados, (wa nomplexo Granitico Socorror SP), no macico de Lavrats tais granitóde a hiperstênio poden representar uma facios marginal dos granito idesperifericos que se

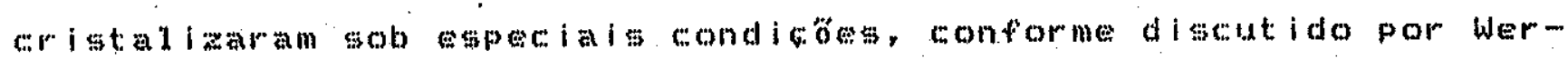
nick at. (1984),

\section{O Granito Jaguari}

Denominado descrito por Joste Villwock (1966), o macico Jaguar i um sienogranito a biotita, sendo este o lnico mineral máfico presente na rocha ocorre a oeste do complexo foranitico de Lavras (fig. 80 ), com auem faz I imite atraves de falhamento, a presenta composica alcalina onde sag frequentes os feldspatos pert: it icos a

A somiarlade desse granito com os granitos leucocrátcosequigranulares do batólito de laveas faz com que seja dificil esta 
belecer as relatöes entre les. (Nardi, 1984). Como comenta este autor, há avidenclas que sugerem una idade malor para odaguar $i$, como xenólitos daglela litologia incluidos nester mas a provenionci i destes fragmentom na os granitom perifericos do Complewo de l.avrats o oranito daguar $j$ asco a mesma unidade referida como complexo branitico Jaguari-Lam Vras do Sul (williget al, , 3974).

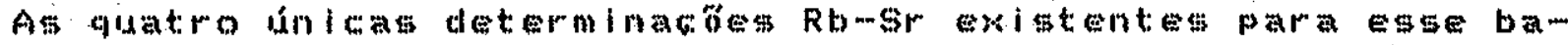
tolito sa devidas a sartori (3978), que ineluidos referidos pon tos analiticos em un diagrama isocrônico de granitód des sub-alcalinos equigmulares da regiag ocidental do Escudor onde aparecem amostrag das unidades găo Seber Lavras do Sud, Cacapava do Sul e Ramada, com corca de s30 ma a o Segundo o peferido autor, a amostra

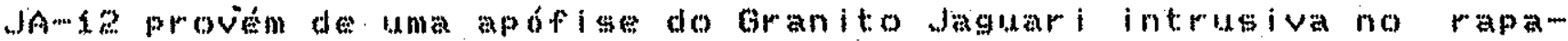
kivi Lavras, enquanto as demais pertenem ao domínio Jaguari.

Se osas amostras forem tratadas isoladamente, definem um

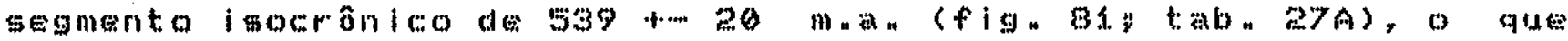
at coloca com concordancia tomporal com os portita glanitos da pew riferia do complese de l...avratson

A a

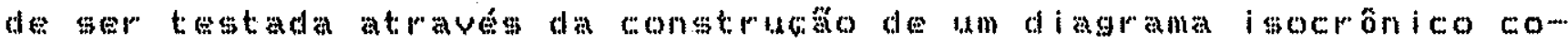
mum ( nece o mesmo, mas ha, no entanto, uma tendeneta de pontos analiti cos do Granito daghar i posistonaremse inferiormente ao segmento

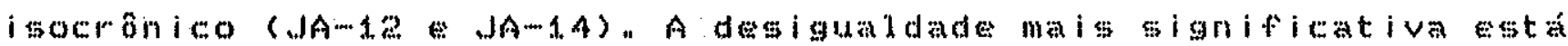
entäo, nats razoses iniciais anquanto os granitoides de bordo do Lavras apontam valor de 0,7050, o Granito dagiar i fornecte 0,7029, 
denunciando, uento um material-fonte distinto, pelo menos menor contribuica infractusta l na gene do magma original, sendo praticamente mantélicon

Ha apenas tres tentativas de dataka Konr em biotitas do batólito Jaguari, feitaspor Minioli e Kawashita (1971). Ag idades obtidas sto coerentio com os dados Rb-sr, exteto o valor de 620 man que os próprios autores atribuem a problemas analiticom năo

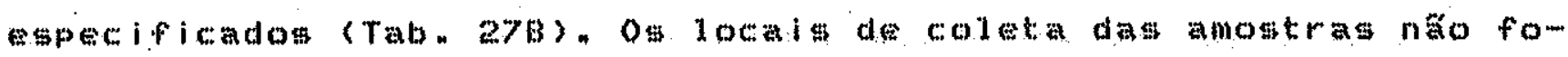

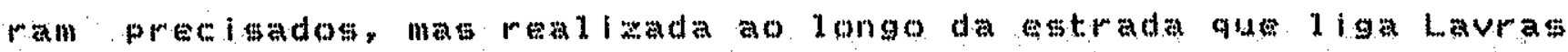
do Sul a Ibar.

\section{O Branito Timbaúva}

Denominado por Naumann (1984), o Granito Timbaúa é um "gtock"

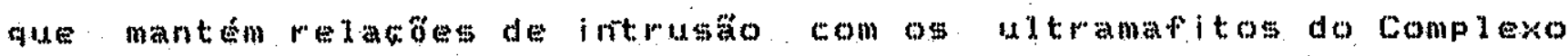
Ibare (fig. 80), Petrograficamente, Varla de tonalitos a granodio-

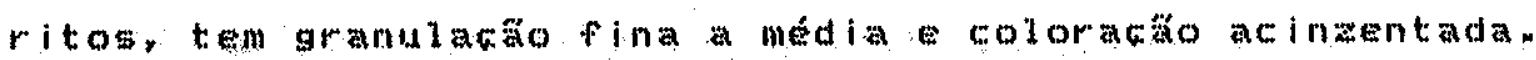

Por tratar-se de unidade inclusa nos estudos para laboracáa de dissertacato de mestrado tema de estagio no cpoeo-Io/USP, a-

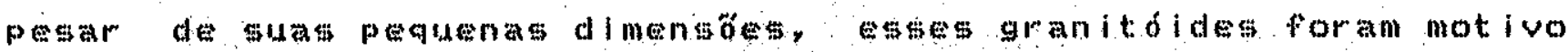
de seis analises Rb-mr to tras K-Ar tem diferentes minerais ctabs $28 A(B)$

A construcaro de um diagrama isocronico de referansia (fig. sugere uma idade de $647+-34 \mathrm{~m}$. assim, que o memo unidade cronocorrelata a sutes intrusivas assoriadas aos onaisses Cambal, ben como aos termos centrals dos

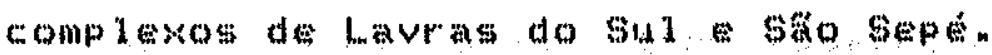




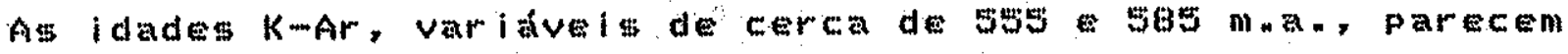
corresponder a valomes resultantes de amostras parcial ou total mente rejuvenescidas pela "fase mamática póstemtonlca" dos complexos graniticos do oeste, nato refletindo o resfriamento da fase gintect 6 ica apontada pela idade Rbusr.

\section{B. O Complexo Granitico Santo Afonso}

O Bloco raquarembd dominado por um complexo granitóide, com variacöes composiclonatis de granodioritos, monzogmantos sienogranjtom con teuturat porfiriticas, que se estende por uma grande area ao sul do luneamento de Ibare (flo. sa). Ainda pouto conhe... cido, foi denominado, por Hartimano e Nardi (1982), de Complexo Eranit ico Sant: Afonson

Para esta unlatade confecelorou-se un diagrama lsocrônico de referencia (fig. 84) com nove amostras provenientes de tres aflom ramentos distintos, dois nas margens da rodovia que liga Bagé a

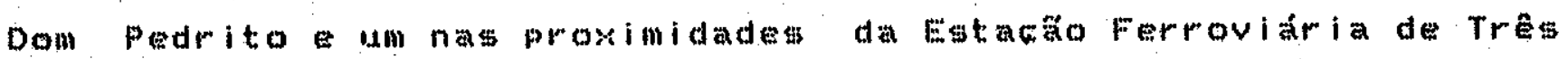
Estradas $(f \mid g, 5 A)$, todos de monzograntios

Os calculos realizados produzimam um resultado temporal de $568+\ldots 8 \mathrm{ma}, \mathrm{com} R \mathrm{a}=0,708$, para o Complexo Santo Aforso, o que o posiciona no tontexto masmático "pós-itectónico" do oeste do Escudo do Rio Grande do $3 u$.

\section{A Suite Intrusiva Saibro}

Intrudidos na unldade anterlomente comentada, foran individualizados vários corpos, aproximadamente circulares e de pequenas 
dimensôs (diametros de alguns quilometros), compostospor perti ta-spanitos, wentualmente portadores de riebecklta, englobados sob a designacko de Sulte Intruglva Gaboro CHartmann Nardi, op. (cit: ), de carticer. alcalino a peralcalinon

Existe para a mesma apenas uma determinacáno radiométrica RbBr. obtida pelo Projeto RADAMBRASTl. no Riebeckitamgranito Santa Juliana, ocorrente nas prowimidade de Dom Pedrito (fig. 54 ). A

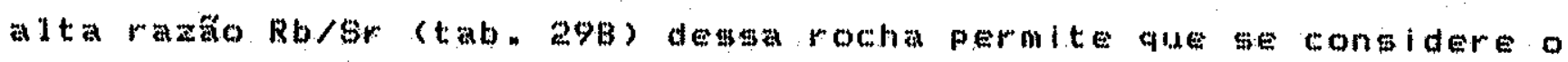
valor de $587+\cdots 9$ ma como de boa qualidade interpretativay sig... nificando a época em que ested granitoide alcalinos encaikaran-se nos complexos santo Afonso santa Maria chico.

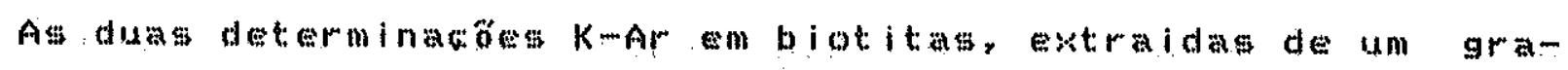
nodiorito de un oranitóde porfiritico coletados nos domínios do Bloco Taquarembó (amostras EsJ-48 49, tab 20, fig. 54), ofereceran, respectivamente, os valores de $528+\ldots 8$ e $581+\cdots 26$ m.

\section{Consideracóes Finais}

Os dados geocronológlcos disponiveispar os macicos graniticos da porcano ocidental do Escudo do Rio Gerande do sul permitem a

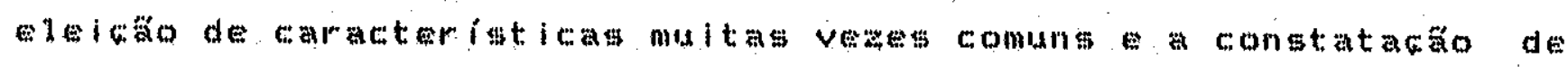
aspectos mercedores de destaque como os que sato listados a se guir:

-.. as sutes intrusivas do oeste gadcho correspondem a mani-

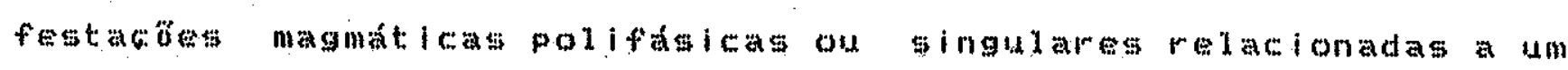

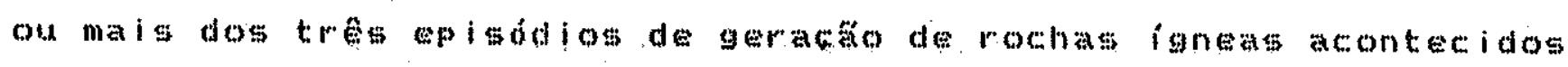

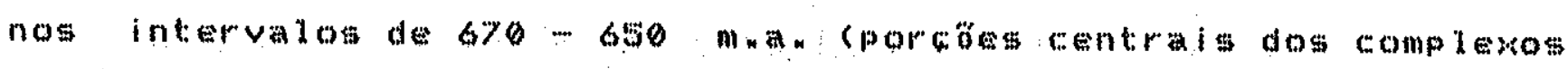




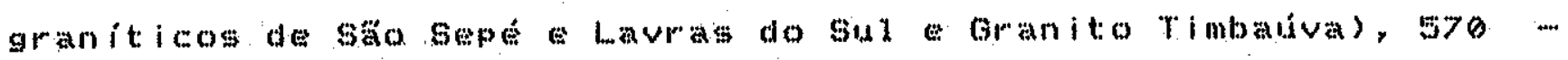

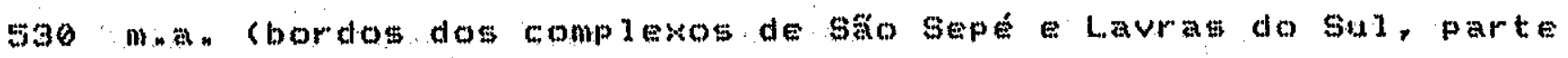
do Complewo Granit teo Santo Afonso. granltos Cerro da Cria, Jagua

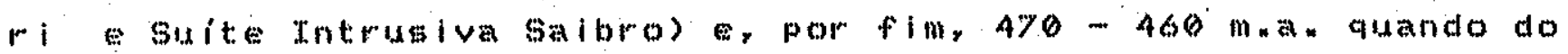
"emplacement" do Granito da Ramada dos microgranitos intrusivos no complexo de säo sepe (fig. 90). As raxóte iniciais Sr87/Sr86 apontadas pelos. respectivos diagramas isocmonicos, variaveis de

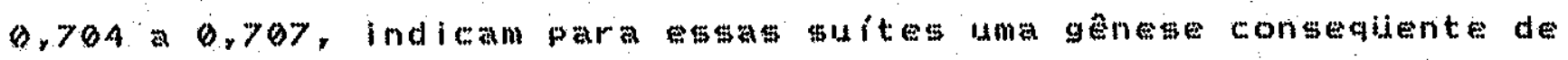

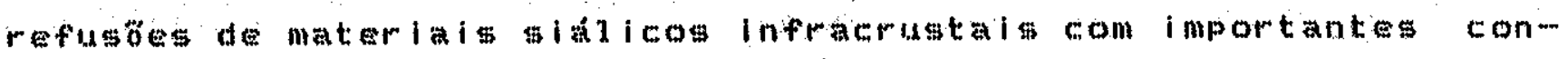
tribuicóne mant

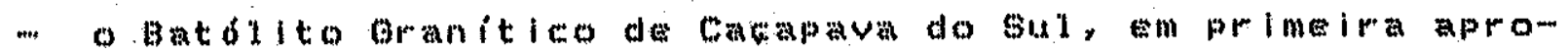

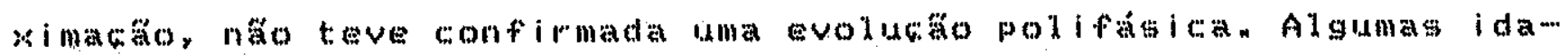
des K-Ar de maior valor alguns pontos analiticos que se posiciom

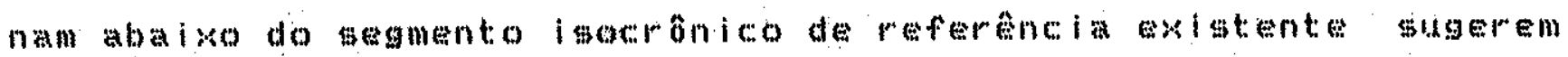
a postibilidade de evolucto multipla do batolito

o Complexo oranitico de l.avras do Sul, um batólito zonado rew Verso aproximadamente circular, tem os granodioritome mongogranitos (shoshoniticos) do centro os pertitamanitos periféricos

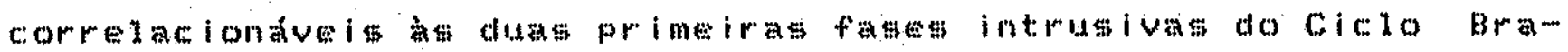
siliano. A fax de transicaro, de simogranitompertiticos, com

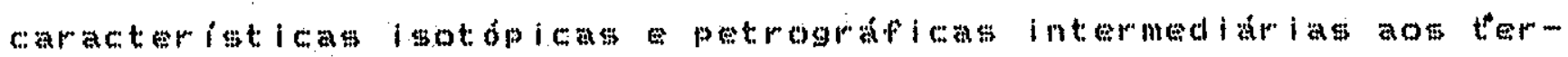
mos wextemos fornece uma "i dade" isocronica da ordem de 590 mna." A geocuimica dos elementos maiores e terras raras, o coeficiente

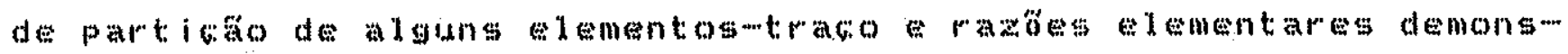

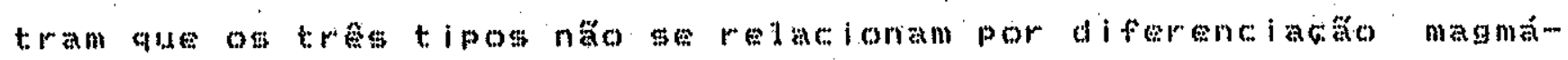

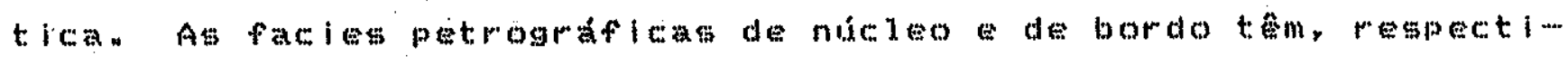

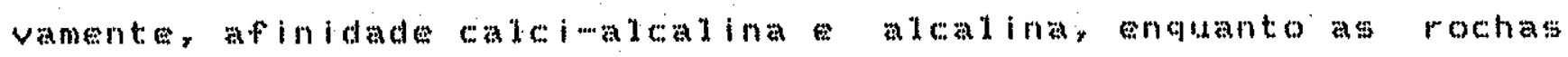
transicionai sa 
similaca parcial da primeira pelo maga jovem. o valor de 590 m. a.. ac nivel dos conhecimentos atuats. näo tem seu gignificado perfeitament compreendido, podendo pepresentar un valor anómalo resultante de diagrama isocrôntco no qual incluiram-ge amostras de proveniencias diversas, uma "idade" consequente de rejuvenescimen... to isotopico parcial ou, ate mesmo, a epoca de um pulso magnático

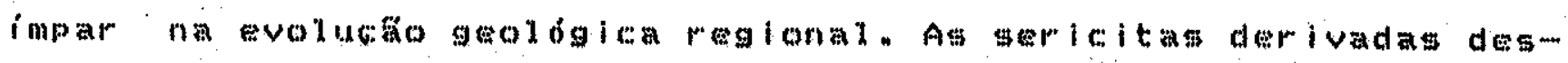

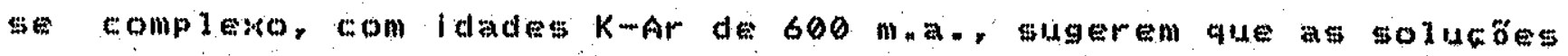

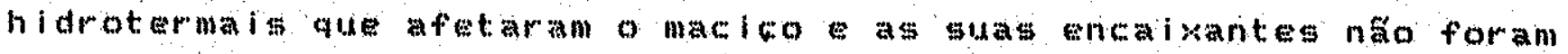

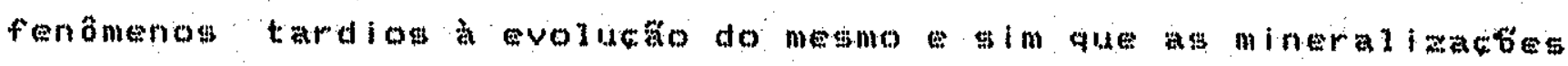

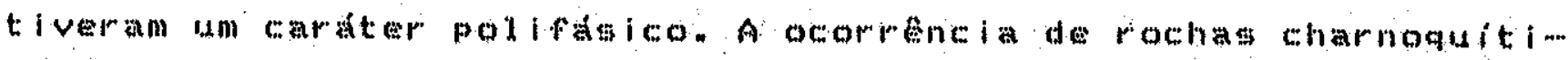

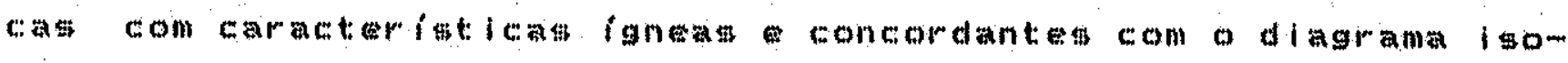
crônico das rochas perifer lcas do macico de Lavras permiten supor que as mesmas correspondem a diferenciados de bordo do batólito em questor

- Granito Jaguar i tem idade isocrônica de s40 m.an. concordante com facles perifericas do Complewo de Lavrasp porem com razác inicial menor, mantelica, de 0,7029 , o que o diferencia da unidade anter ior. 


\section{OS DEPÓSITOS MOLASSICOS E VULCANITOS ASSOCIADOS \\ DO ESCUDO SUL-RIO-GRANDENSE}

\section{Considerafóses Iniciais e Sintese Geológica}

Como resulado da instabilidade gatectonica que afetou o Escudo do Rio Orande do sul now tempos finais do Bramiliano, instalou-shy na strutura denominada de Anteromsa do Budeste CFragoso Cesar et a y 1982a), um espeso pacote rochoso representado por

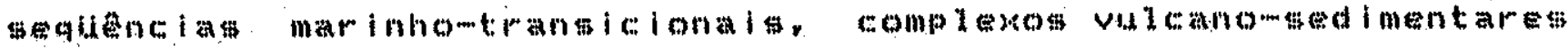

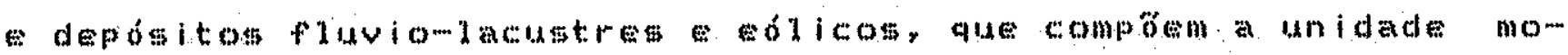

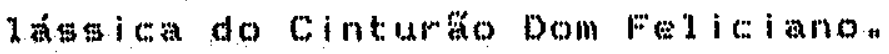

Após o recontecimento pioneiro de Carvalho (1933), o conjunto 1itologico foi repetidamente estudaco por varios pesquisadores e

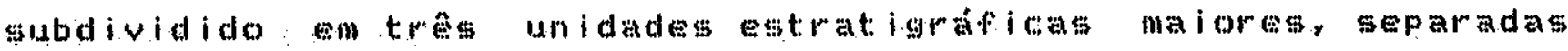
por discordancias. Fomaga Maricá, Gropo Bom Jardim ge Grupo Cama-

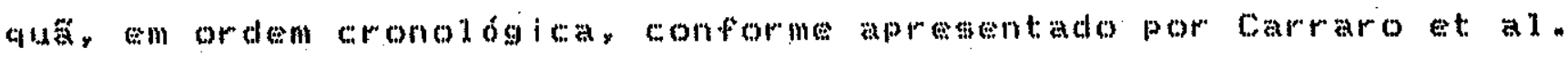
$(1974) e$ Williget: 4 . (1974),

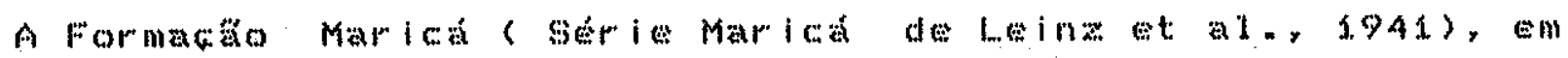
parte tambem denominada de Formacto pessegueiro contos et al., 1.978), representa a unidade basal dos depositos molássicos, repousando sobre litologias igneas metamorticas ma is antigas atraves de profunda superficie te discordancian Revelando indicios locais de metamorfismo de soterramento old de contato junto aos granitos

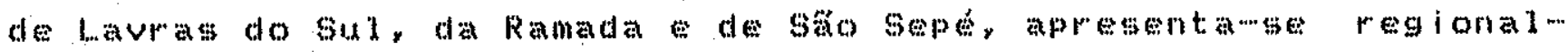

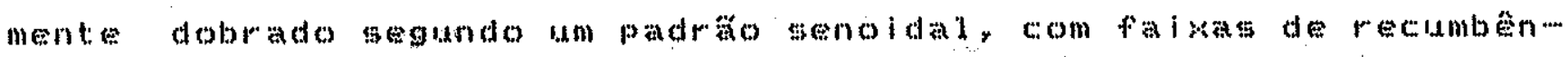


cia cavalgamento, maptura cataclase (RIb fro fantine1,1978).

O (Grupo Bom Jardim (RIbeiro eta , 3966) fol definido como

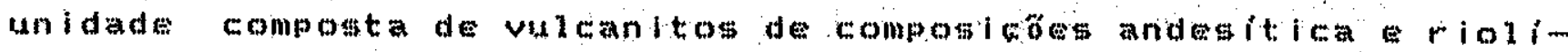
tica intercalatos com litologlas pirociasticas epiclasticas. Essencialmente sedimentar na porcato basal vulcanico no topoy como originalmentedeserito. Ribeiroet al "(op. cit n) propuseram, resm pectivamentse, as formacoses Arrolo dow Nobres leom os membros Mangutira Vargas) Cretpos. (membros Hilario Acampanento Velho), separadas por discordancia angular. Este conjunto foi posterform mente redefinido, patando a colbir uma unidade superior reciassificada como Formaço Acmpamento Valho (cordani ot al, 1974)

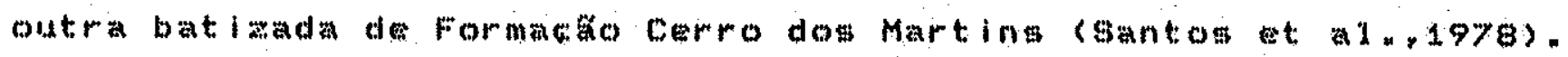
Esta, por sua vesu, admitiu uma litofacies vuldanoghnica (Andesito Hilariol outra sedimentosantea, que tem recebido diversas denominacoses. (Arroio dos Nobres ou Vargas) com diferentes classifica-. coos na hierarquia etratigratica.

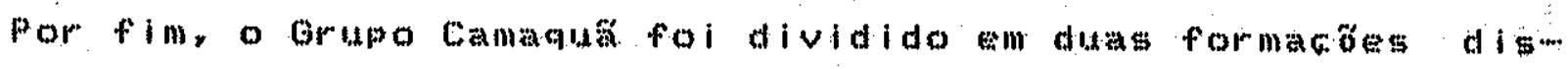
cordantemente sobrepostas, Santa Bárbar a Guaritas, de acordo com Robertson $(1966)$,

Na decada de 80 , o que ete tem observado săo tentativas de analise entendimento da evolucto global dos depósitom molásicos E simplificata do quadro atrat lanfico calcado no reconhecimento de que unfodedoutrora distintamente denominatas nada ma is săo que Var iacoses faciológlcas de uma entidade litológica maior.

Com ste espirito, destacam-se os trabalhos de Jost (1984) Fragoso cesar et a. (1984), nos quals os referidos autores recomendam, com base no decrescimo do metamorfimo deformacoses na 


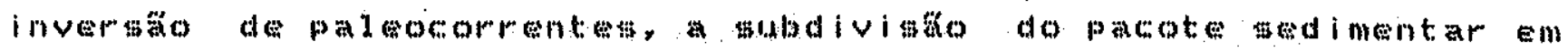
dols subconjuntos refer los como molassas precoces tardias dentro das quais puderam ser. identifleadas diversas bejencias e facies medimentares.

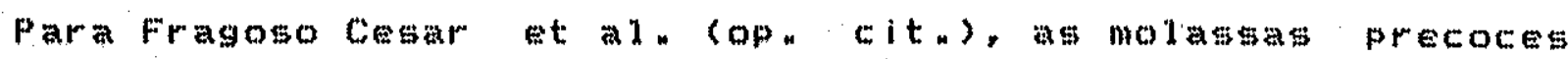

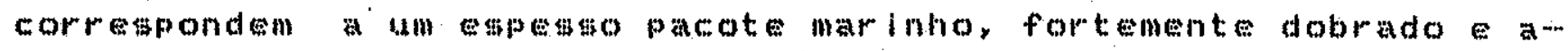
fetado por falhamentos de empurráa vergentes para NW, onde se reconhecem. \$equencias de leques marinhos mepresentados por turbidi tos de aguas profundas. intercalados com moltos, sedianeias marinhas de águas rasas geradas por acto de ondas, com eventuais ex-m

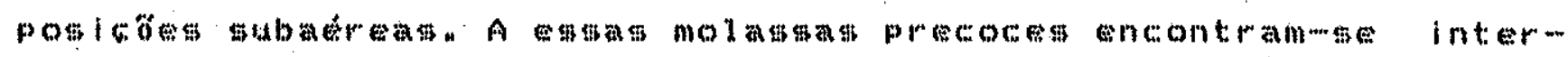
calados derrames básicos a intermediarios (Hilario) de afinidade alcalina (Roisemberg at a . . 1983).

As molassas tamdias solo predominantemente continentais, com possiveig sedimentos marinhos rasog na porforo basal. Os ambientes deposicionais reconhecidom foram o marinho raso (ou lacustre?), o piemontico, ofluvial entrelatado, o deltáco o dólico, com esm cassos elocaliandos derpames basicos a intermediarios intercalam

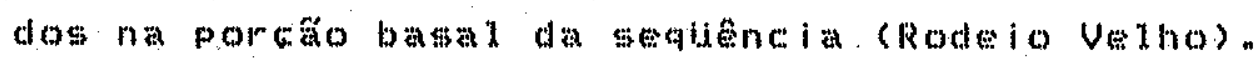

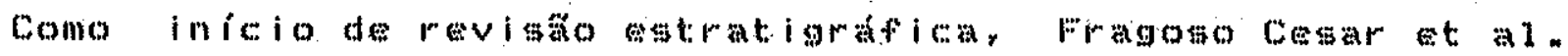
(1984) propuseram que todo o conjunto molastico fosse englobado en

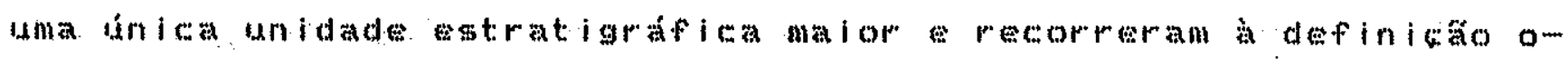
riginal de Carvalho (1932 -.. Germe de Camaduan), feunindomo no Grum po Camaqua

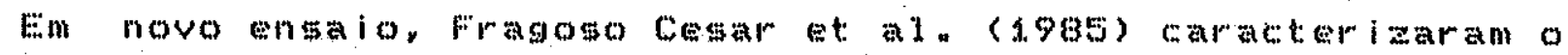
Grupo Camaqua como composto pelas unidad 


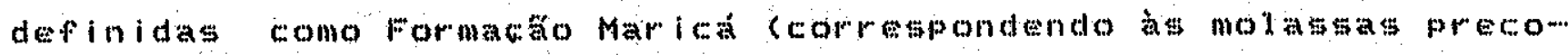

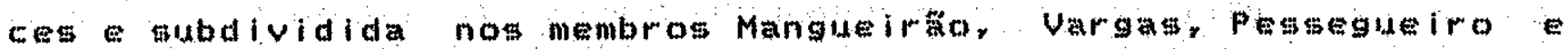
Hilario), Formacto Acampamento Velho (vuleanitos rioliticos daciticos con vilcanoclaticas opiclasticas muborinadas) forma-

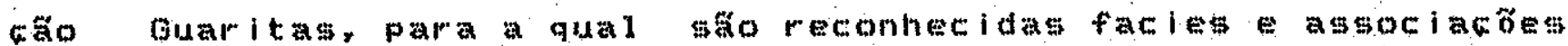
de facies (associacádo de arenitose multos, arenitos com estrati-

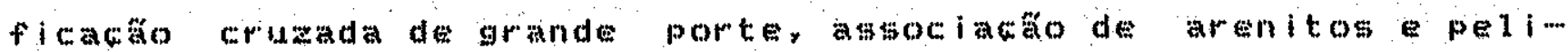
tos), patsivels de mapeamento, mas ainda năo caracterleadas como membros. Nesta categoria, apenas os vilcanitos Rodeio Velho.

\section{Interpretacão Geocronológica}

Os primeiros dados geocronológicos obtidos de forma sistemática nos vild anitos associados aos depósitos molassicos do crupo Camaqua sto creditados Minioli e Kawashita (1970), havendo ape-

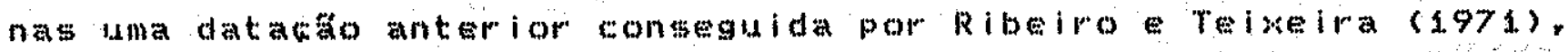
todas pelo metodo K-Ar"

cordanj at a (1974) inerementaram os conhecimentos geocrom

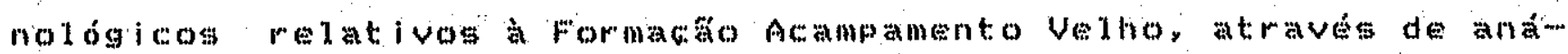
lises Rb-sr en RT. Na oportundade, interpretaram as idades variarveis de sio a s35 man "dos "andesitom" Hilario, como minimas, fato imposto pela orectria retentividade do Ar por parta dos feldspatos ou rochas feldapóticas utilizadas nas analises no dado interessante aquele fornecido por um hornfels consediente da intrusăo do Macico de Lavrasy cujo valor similar ao do granito cau sador do metamorfimo do contato corresponde a lade mínima da enCa ixante. As litologlas cujog resultados foram inferiores parecem ser portadoras de fenomenos nidrotermais posteriores sua formaFáo (tab. 30). 


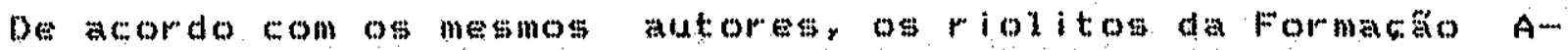
campranto Velho apresentam concordancia entre as idades obtidas

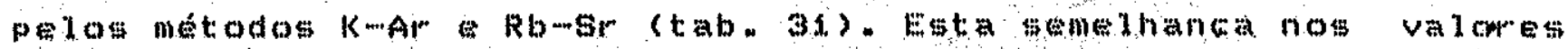

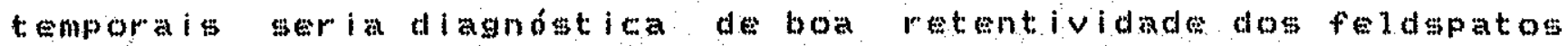
componente da pocha, ná⿴囗十 mals coming nos vulcanltos Hilario. lrog pontos analiticos foram

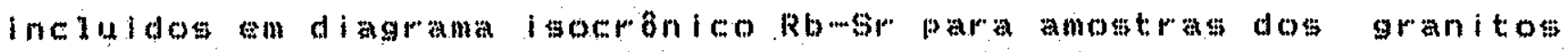
Ramada a sa stope (fign 61$)$ e revelaram bon alinhamento com o gegmento de ges man (cordani et al. 1974)"

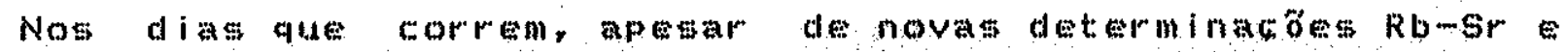

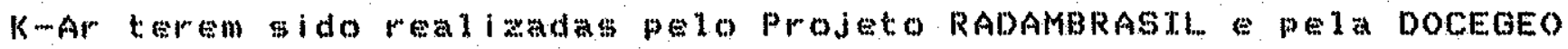

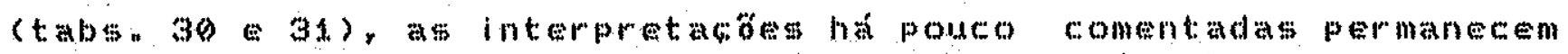

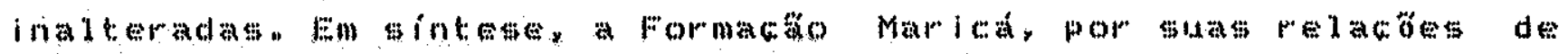
contato. G mais antiga qus os granitiódes poriféricos dos complem

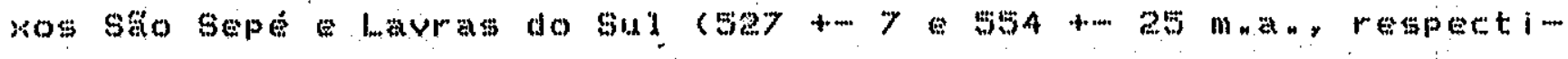
Vamentes. As idades KuAr disponiveis para os valeanltos associados

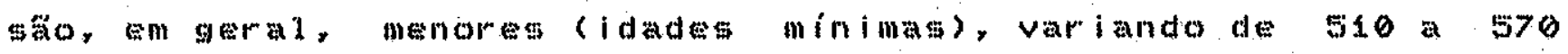

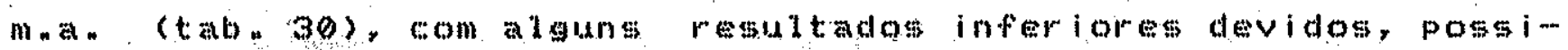

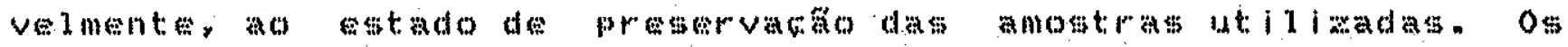

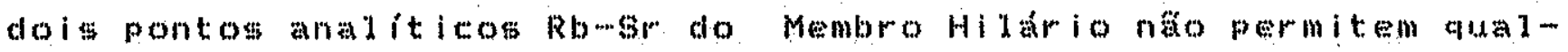
quer comentario adicional, ja que apresentam baikos valores para a

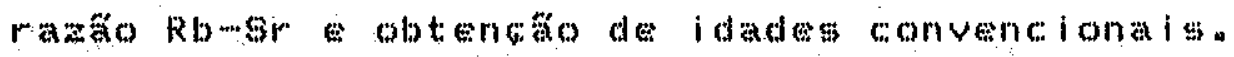

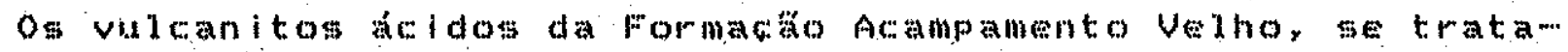

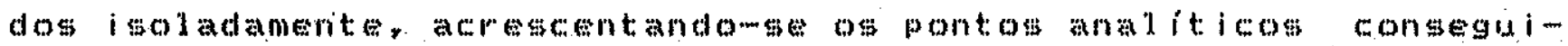

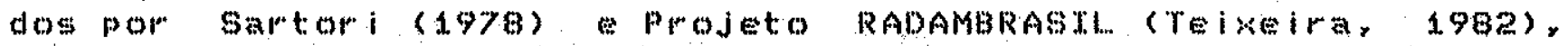

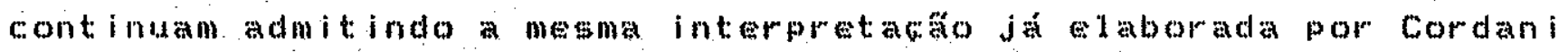

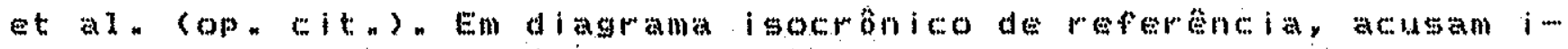

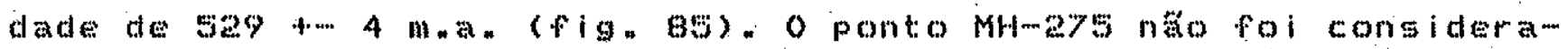


do no cáculo da idade há pouco mencionada, pois a amostma coletada exibs lmportante diaclasmento que pode ter permitido a atuaca de processos intempericose abertura parcial do sistema químico com o consequidente desvio de sua posicato verdadelran os pontos cr-6 er-38, ja abordados por Gartori (1978), pareem pertencer a um segmento isocrôico pouco mals jovem, confirmando a hipotese do autor de clois pulsos vuleânicos ácidos pós-otectonitos na volucáo geodogita do liscudo gaticho (fign 85). Se for metirados, a ldade aparente tamberm a razo inleial so mantem.

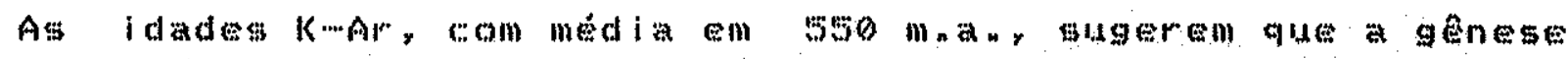

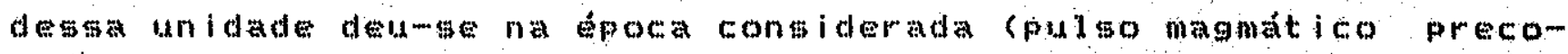

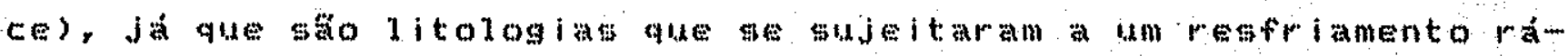
pido.

Uma importart contribuita à cronologia dos depóstos sedimentares da Bacia do Camaqua da mineralizacoses cupriferas associadas fol dada por Bonhomme Ribeiro (1983), atraves da dataca de fracose argilos be lo método KmAm. A tentativa de datar a épo-

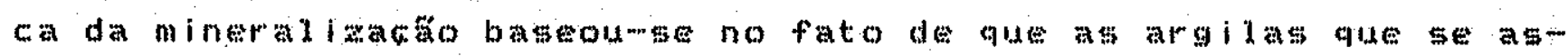
socian aos minerios sato, no geral, neoformata ou whito transformadas pelo evento mineralizador, podendo ser a valor obtido considerado como próximo da idade de "mi ta en place"

Paralelamente, amostrats de argilas do Membro Mangueiráa e da Formata Guarta for fom tomada nasproximidades da Mina camaqua com a finalidade de comparam-som os resulados relativos a deposic a date unidades encaikanteg dos veios minaraliandos.

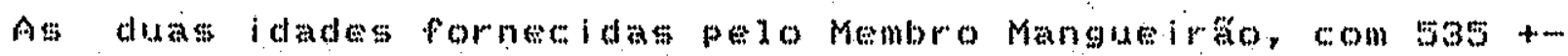




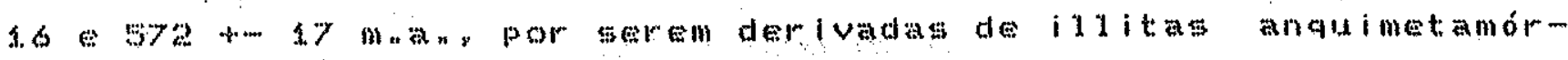

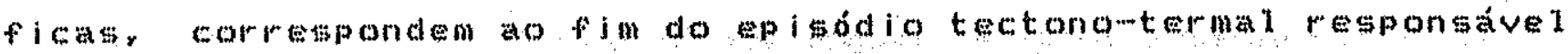
por to is alteracöos sendo o everio deposicional certamente mais

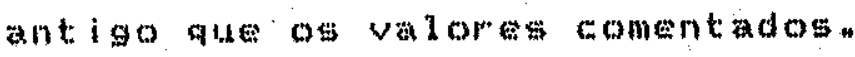

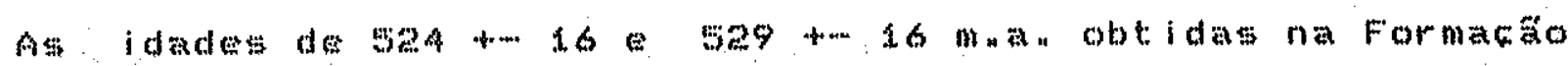

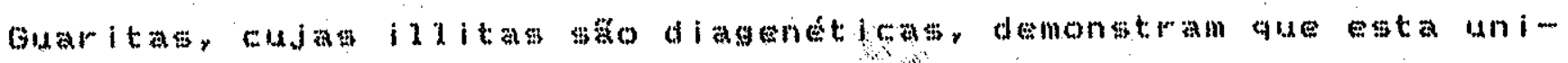

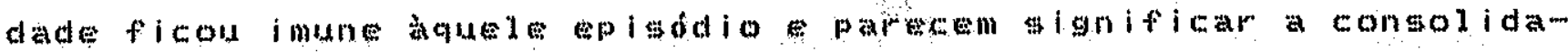

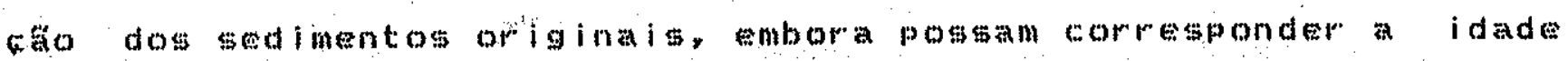

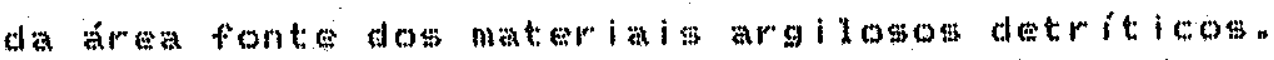

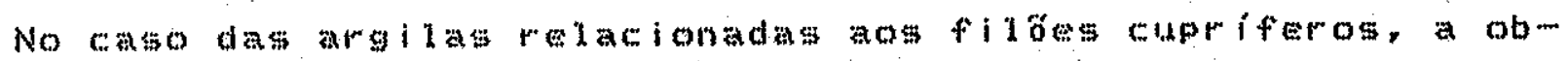

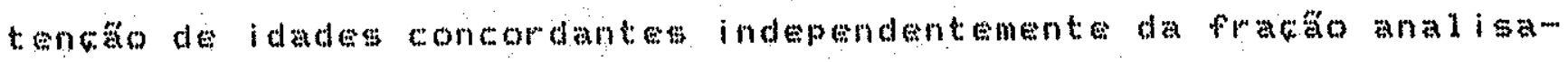

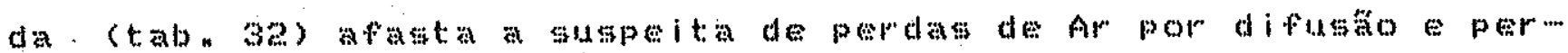

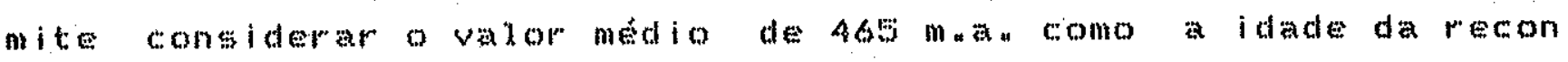

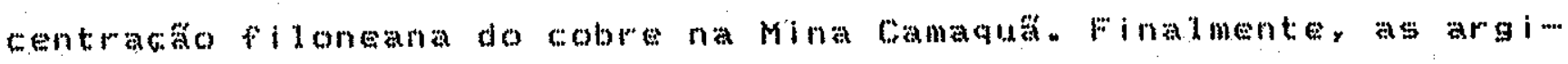

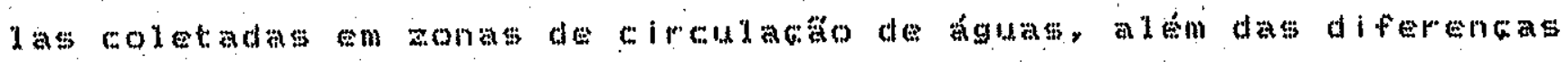

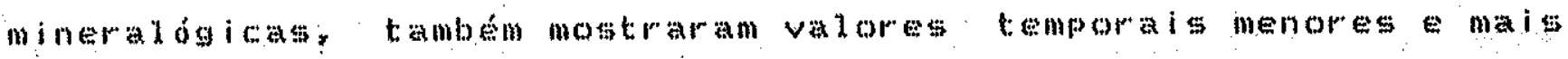

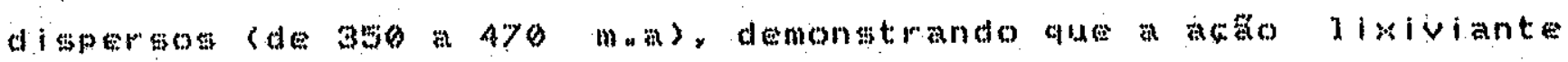
da obtidas

\section{Correlaçăo com os Eventos Plutônicos}

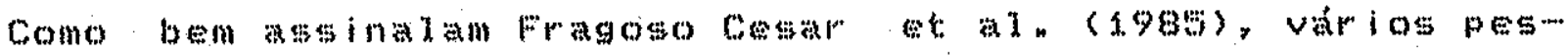

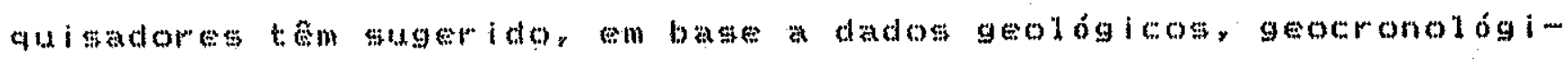
cot gooquimitom, uma contemporaneidadte e ate commomaticidade,

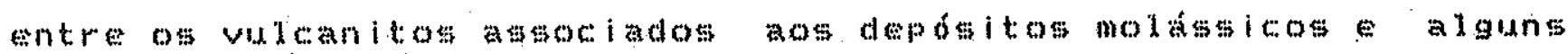
termos litologicos pertencentes a complexos ou suites graniticas intrusivas na porta ofsta do Escudo do Rio Grande do Sul. 
Gegumda Nardi (1984) Nardi l. ima (1985), os granodioritos - monzogranito do nuteleo do Complexo Granitico de Lavras do Sul podem ser correlatclonados, de acordo tom analiseg geoquínicas, aosi vulcanitos do Membro Hilario, ambos com camater shoshonítico.

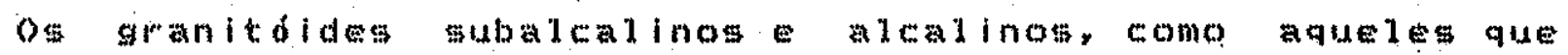

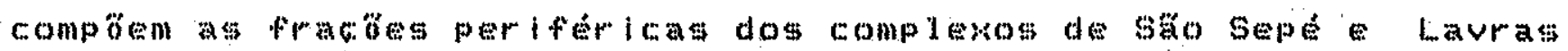
do Sul, produzem efoitos metanóficos de contato na unidade Maricá, săo imaginados commagmaticos dos valcanitos da formata A campamento Veiho (cortani te al "1974" Sartori, 1978),

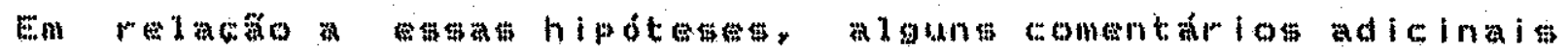
podem ser feitos, levandome em conta a totalidade das informacós radiométricas hoje disponivel.

Para o Membro Hilário, apenas duas analises Rb-Gr for am rea-

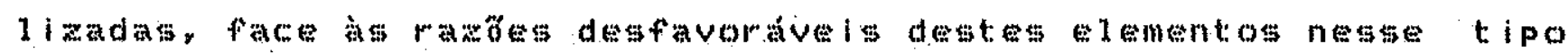

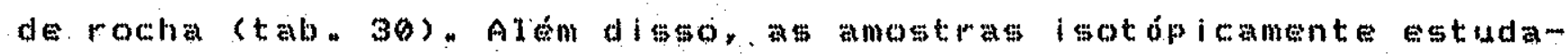
das proven de ocorrencias diferentes (F de Lavras do Sul E E de Dom Pedritop fig. 86), o que torna insegura qualduer tentativa de interaretagañon

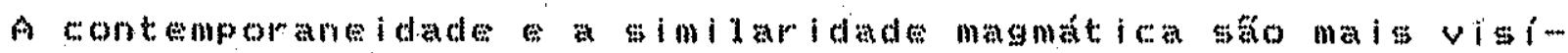
Veis entre os miolitos da Formacto Acampamento Velno cepisodio ew

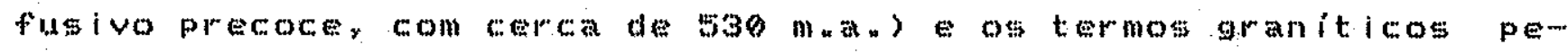

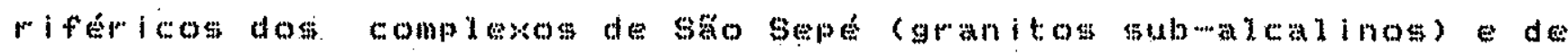

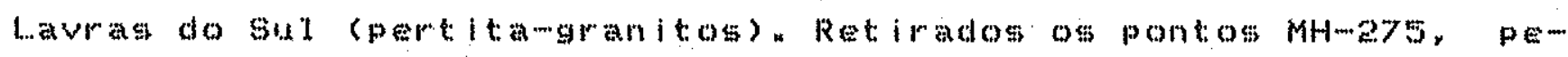

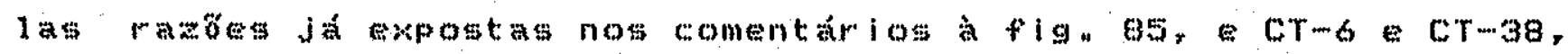
pertencentes a um possivel episodio efusivo tardio, o ajuste das suites igneas a um semento isocronico comm e bastante bom (figs. 


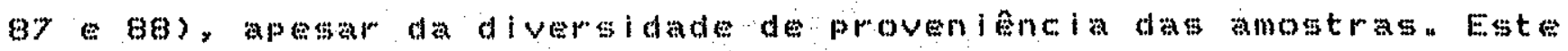

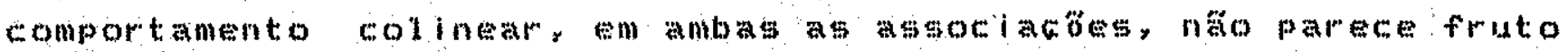
do acosin

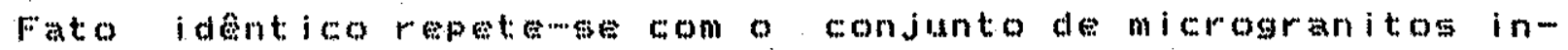

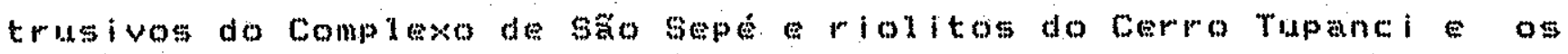
monzogranitosi do" wokk" da Ramada (fign g9), que acham, indivi-

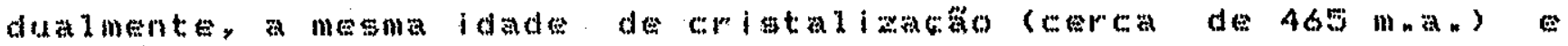

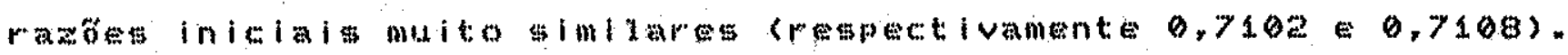

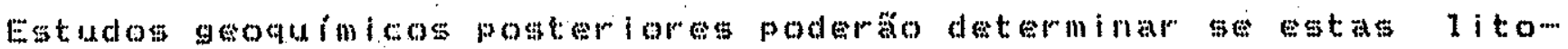

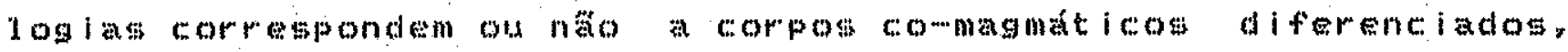

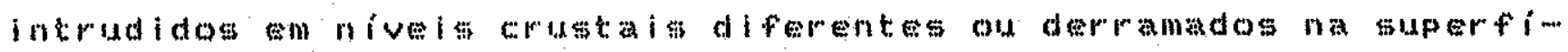
is is

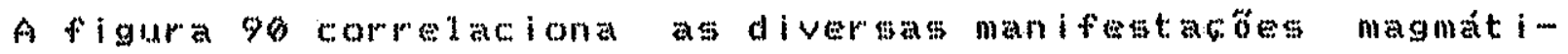
Gas acontecidas no dominio da porkzo ocidental do Escudo do Rio

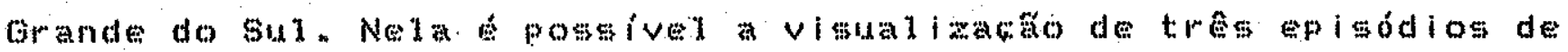

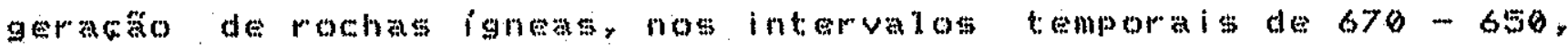

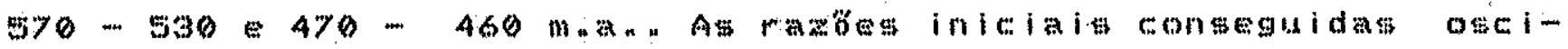
I

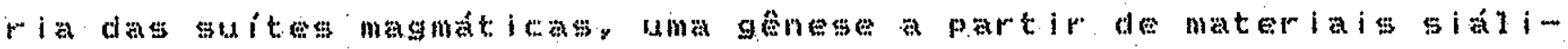

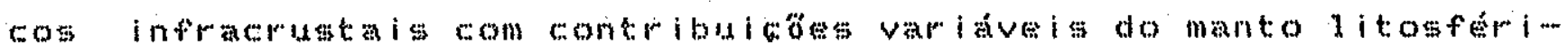

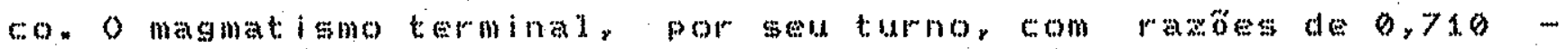

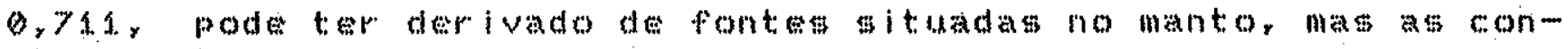

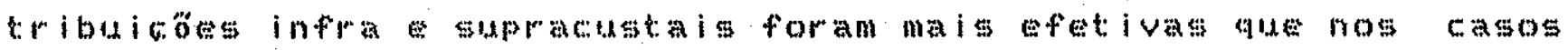
precedentsens

\section{Consideracóes Finais}

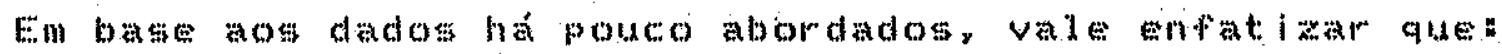




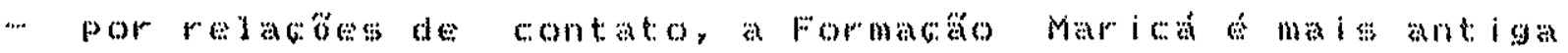

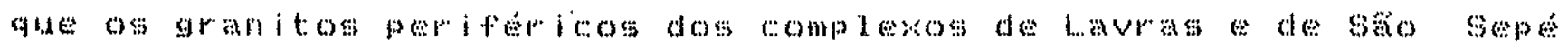

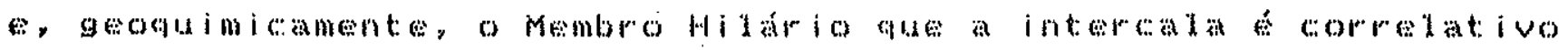
da fracta

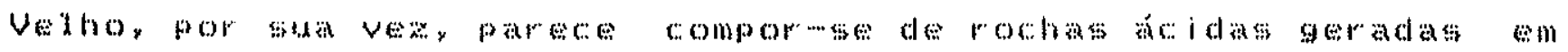

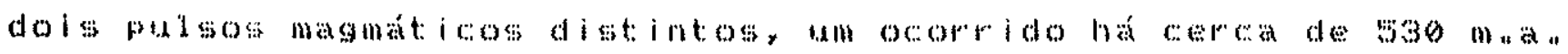

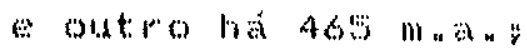

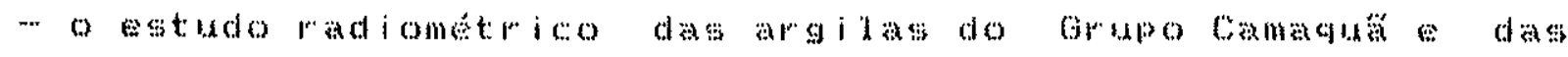

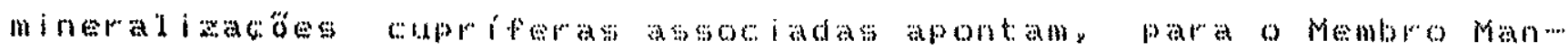

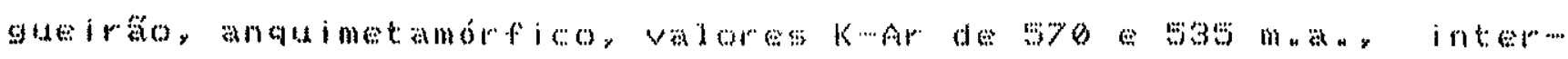

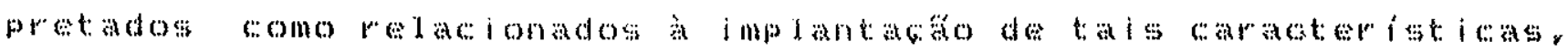

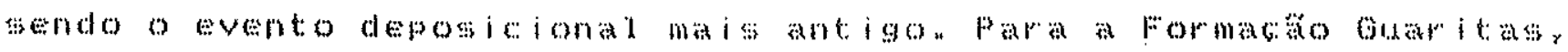

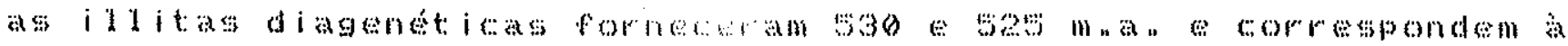

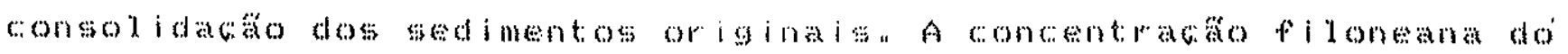

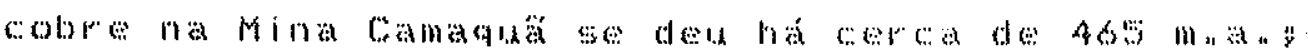

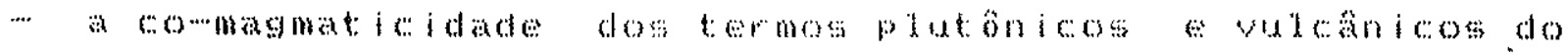

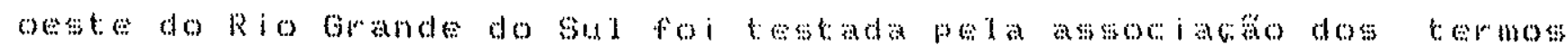
relacion

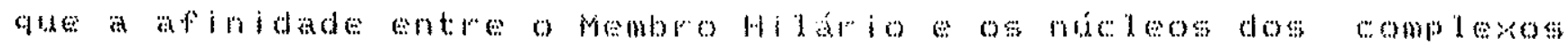

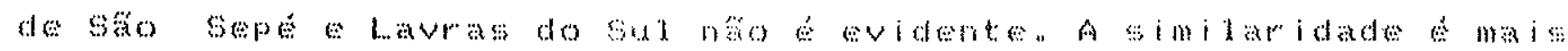

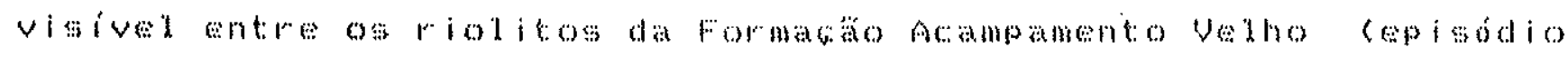

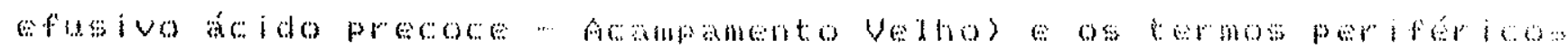

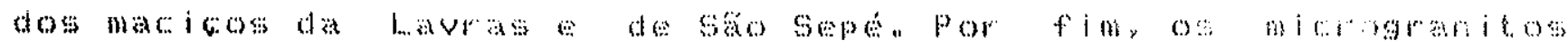

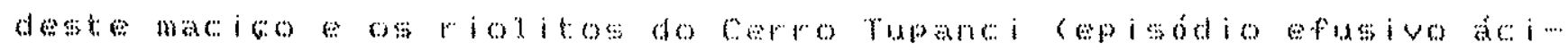

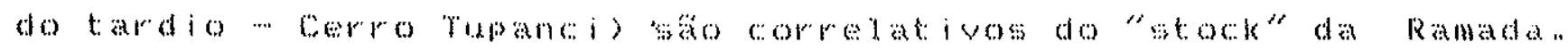
Tempora Imang equ

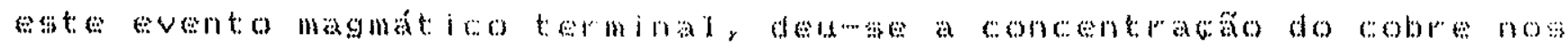

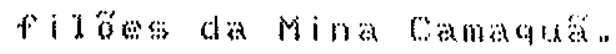


CAP X́TULO UII

\section{COMPARTIMENTACAO E MODELO DE EVOLUCAOO GEOTECTÓNICA}

\section{PARA O ESCUDO SUL-RIO-GRANDENSE NO CONTEXTO GEOLógICO REgIONAL}

\section{Consideracōes Iniciais}

o) exame de artigos cientificos concernentes a possiveis subdivisóes geotectónicas a propogicto de modelos evolucioriáriom para O Egcudo do Rio Grande do Sul, publicados por Vários autores ao longe da iltima década, demonstra que as hipótese elaboradas

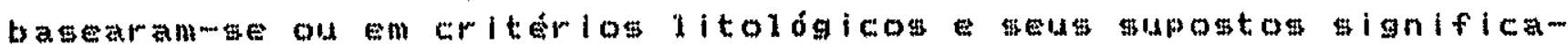
dos petrotectonicos, ou em eriterios extruturals e geoguimicos, nem mempre levando em conta of dados de cunho geocronológico. parte de um acervo, at entro, fragmentarlo e carente de interpreta

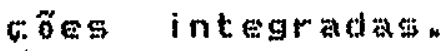

Reconhecendo a importância das metodologias de levantamento geológlco empregadas acima mencionadas, é preciso, contudo, lem

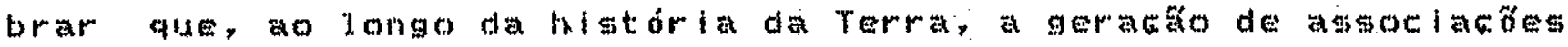
de rochas, com caracteristicas geoquimicas o estruturate simila res, tem ocorrido nos mait diferentes intervalos de tempo. en am bienteg geotectónicos as vezes distintos. A recorrancia de condi...

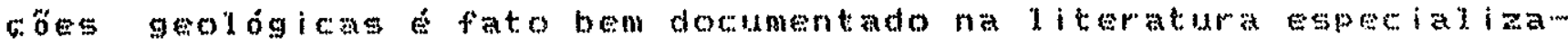
da os oxemplos numerosos nordani e Brito Neved (1982), nos cow mentários relativos ao craton do gäo francisco, chamam atencáo para o fato de que diversos complewos rochosos interpretados comes

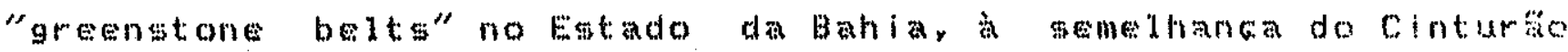

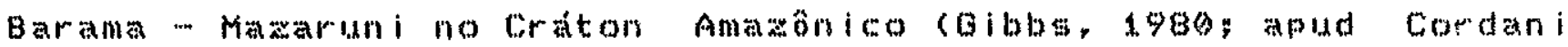
e Brito Neves, opneit., , tam idade proterozóla inferior, o que 


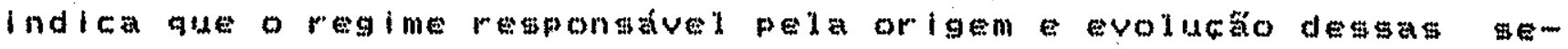
quenclas permanecelu at lvo até, pelo menos, z. 000 ma a passados.

Tarney at a $1.97(6)$, face à analogias litológicas, metamórficas estruturals identificadas. Hsando exemplos modernos do Pacifico ocidental, bem cono baseados nos mecanismos supostos pe105 quals a bacias marginals parecen ter geradas, propuseram que - ambiente getotetônico dewas entidade fo correspondente atual

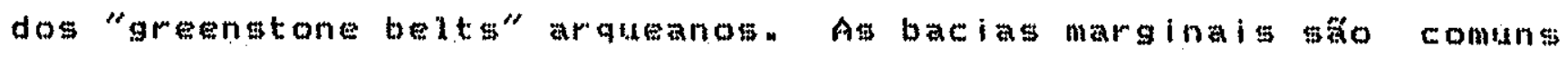
nos tempos fanerozólcos talve maj significativa equivalencla geoldglca aos antigos cinturoses vulcanowsedimentares corresponda o Complewo "Rocall Verded" do Chile Merldional, cuja ganese iniciouse no Coretácon

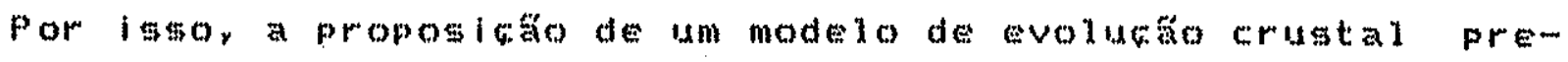
cisa reunir a maior quantidade de informacose advinda dos mais diferentes getores das geoclencias. Entre testes, o que posiciona no tempo os eventos geologicos deve ser merecedor de atencaro e crédi... to. sempre que executado de forma judiciosay gob pona de atribuirmos todo un auadro de acontecimentos regionatio mecanismos e prow cespos particulare de um dado intervalo de tempor quando, ra verdade, poder iam ser decorrentes de procedimentos outros temporal -.. mente diferenciadosn

\section{A Compartimentakåo do Escudo do Rio Grande do Sul}

A cbtencia de cerca de 230 novos dados geocronolónicosy como parte deste trabalho, a reinterpretacta integrada de todas as a-

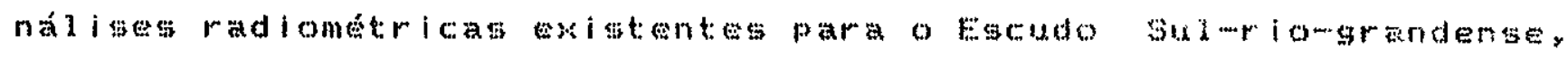
perfazendo um total de mais de cinco centenas, tal como apresenta- 
da nos capitulos anterioresy permitiram a congtatacto de que as

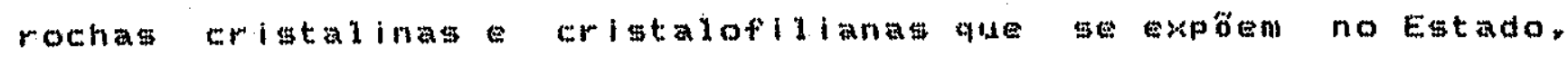

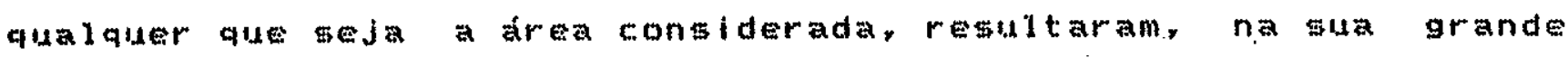
matorlay da lmplantacto do desenvolvimonto do Cicio Brasiliano na regía. En cutraspalavras, pelo menos con base nos metodos ra-

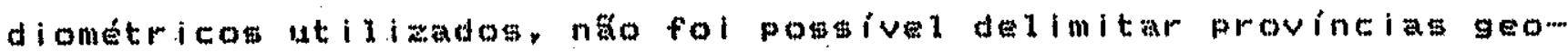
lóglcas evoluldas en ciclog orogenicos distintos, como sto observa

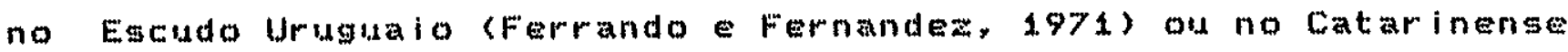
(Kaul Teixeira, 1982$).$

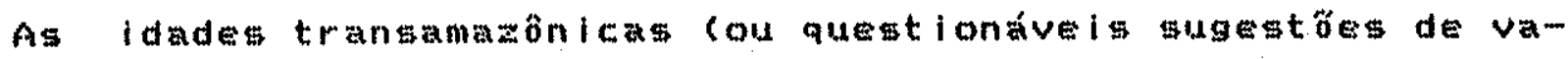

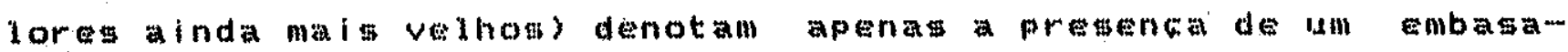
mento antigo a aflorar de forma esoradica conalsges Encantadas, Gabro de Mata Grande e, postivelmente, Complawo de Pedrab Pretas ou restrita (complexo Granulitico santa Maria Chico).

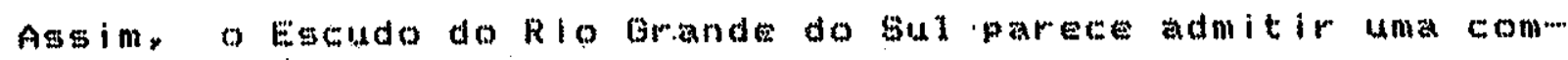

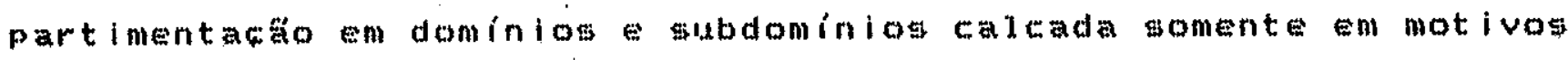

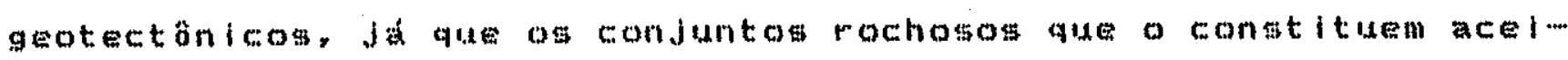

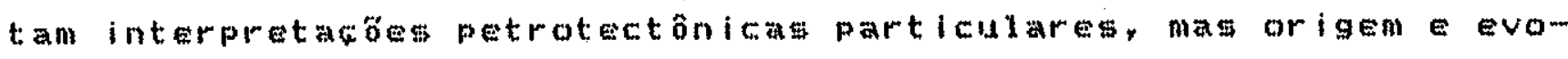
lucko

Os comentarios foitos nos paragrafos antariores revelan que

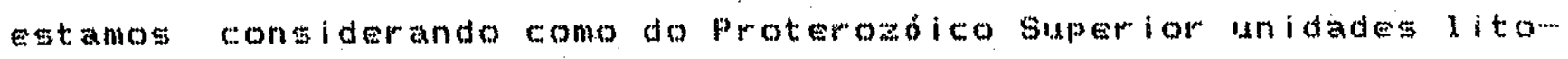

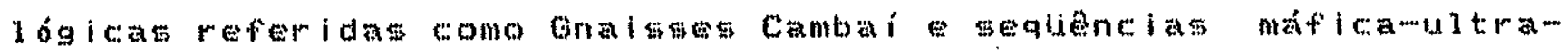

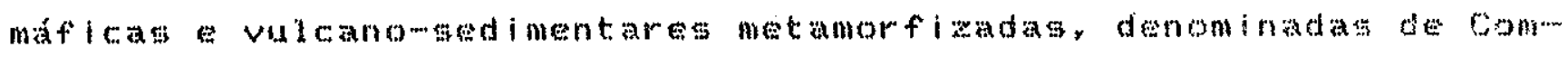
plexo Ibare, Complaxo palma complaxo Bosmorocar ontre outrom.

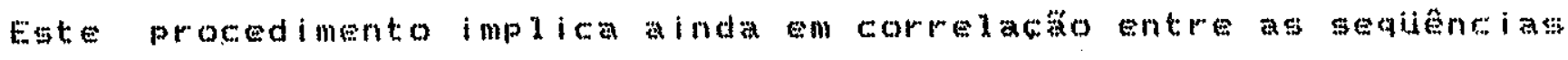

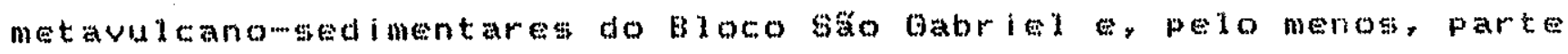

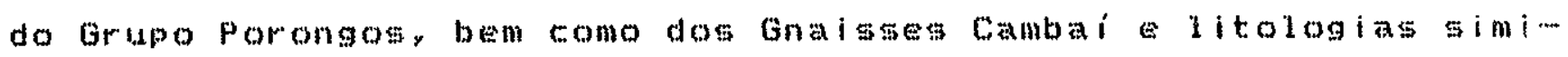


Iares do Complewo Metamófico Varata do Capivarita, no Bloco En-.. cruzilhada. Todo o conjunto comporia, entáno domínio ocidental.

Aparentement contemporâneos à supracrustais ha pouto men cionadas. constituindo o dominio oriental, săo, na maior parte, os granitóldes de varladam facleg petrografica pertencentes ao que at agora denominamos de Complexo Granitólde de Leate ifig. 91).

\subsection{O Bloco Dom Feliciano: exposigáp principal de batólito granitólde de evolucão brasil iana}

o complewo tiranitólde de Lete, aflorante na porta oro oriental do Etucudo do Rio Grande do Sul e correspondente a Bloco Dom Feli-. ciano, está mendo encarado por Fragoso Cesar, Figueiredo, Soliani Jr. Faceinl (em prepn) ciomo um bat óllto componto, multi-intrugi-m vo polifádico(Batólito Pelotas), a conter diversas sultes (no sentido de Henderson et al ". 1980) ou supermidades (no sentido de Pitcher, 1979) de granitódes plitong gerados por sucessivos episodios magáticos relacionados as fases tectionleas da faixa món vel que sencontra.

Como lembram os atores, o termo "batólito" empregado para descrever uma área contínua de exposica de granitóldes de compon... Si gáo varlada, formada por corpos plutónicos de configuracäo múltipla, a qual se assoclam septos mppa infractutats, en tudo similares aos clássicos batólitos fanerozólcos de alguas regiós orogênicas, conforme discutidos, por exemploy por pitcher (1983).

Uma possivel continuidade desta massa granitica para o uru- 
guai mul de sarta Catarina permite que a contidere de dimen-

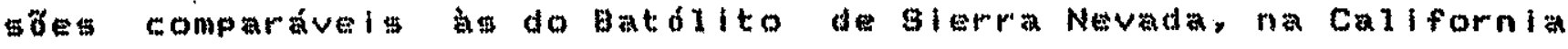

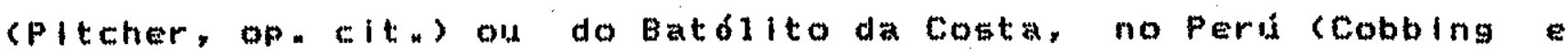
Pitcher, 1972).

No Rio orande do Sul, o Batólito Pelotas tem sua área de ex-

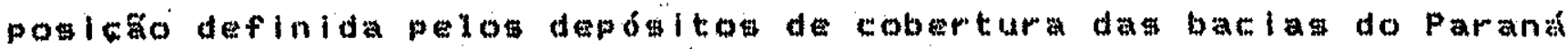
- de,pelotas, a norte 1 ste, respectivamente, por uma conspi-

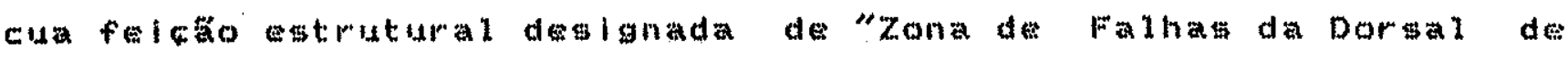

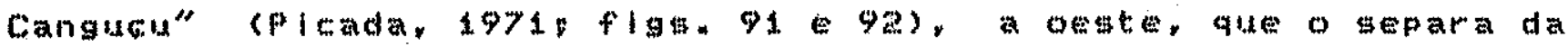

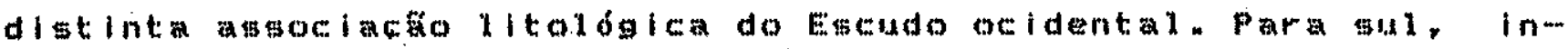
gressa da forma fisleamente contínsa no Urugual.

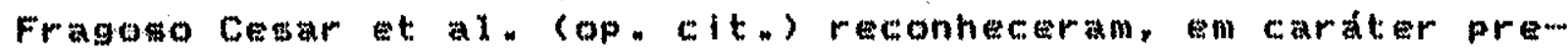
limlnar em base a criterlog petrograficos, gaquimicos geocro-

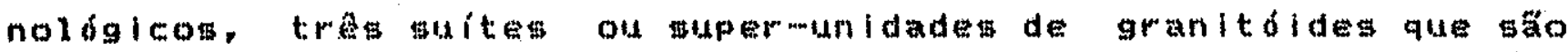

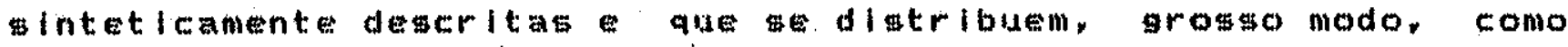
esquematizado na figura 73. Os conjuntos litológlcos recontecidots

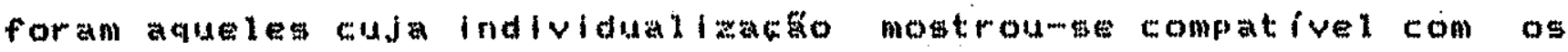
levantamentos realizados eam escera reglonal, compespondendo a uma primeira aprowimato mob ats novo enfoque. A semelhanca dos batólitos de sierpa Nevada de costa do Perd rBateman Dodge 1970 Pitcher, 1974, apud Pitcher, 1978), no Batolito Pelotas o elemento alicio torname mats importante com o tempo, ldentificandow

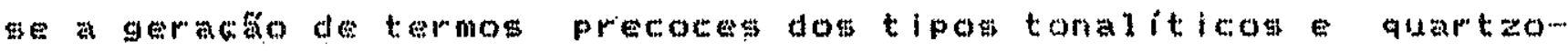

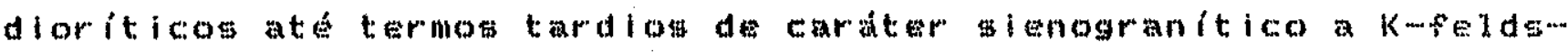
pato granitico. No entanto, cono asinala o mesmo autor, cada su-

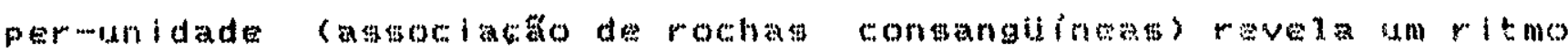
proprio no sentido batico- acido. de tal forma que facieg petrow

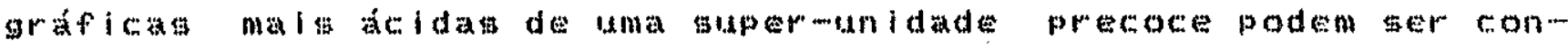


fundidas com an facies mats batcas da sufte seguinte, equivalendo a claros epládilos de recorrencia petrogenética ao longo do tempo.

As caracteristicas a seguir apmesentadas permiten atribuir a

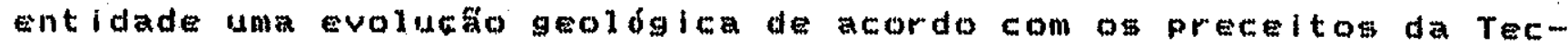
tônica de Placas. Hendo constituida de litologlas repregentativas de niveis crustals profundos, Interpretadas como correspondentes a exposicato das ralzes de um arco magnático polifálico, conforme mupeitado por Ribeimo Fantinel (1979) endostado for Fragoso Cesar et al. (1982a, b), Imster (1982) e Jost at. (1984), entre

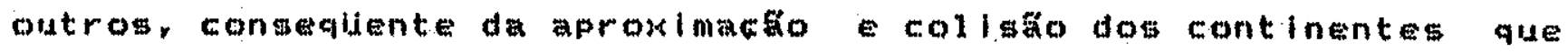
inclulam og cratone do Rio de La Plata do Kalahari.

Granitóides deformados da fase precoce -... Alnda em astagio de mapeamento, portanto nấo ropresentada na figura 93 , est suite ten as mas melhomes expolcónes na área de piratini embora possa ser encontrada ao longo de toda a estrutara batolitica. Mostram we conc enclaves de conflguracốt diversag, de dimengós de alguns centimetros a varios quilometros, com dlatintomgraus de digestäo - aspecto petrografleo do gnalases migmatíficos com es-trutura predominante estromatitica composta por bandas de espessuras centimétrica a decimetrica.

Tratame de tonalitos (tamben trondhjemitos) equatzomdiorin tos malano letecoraticos, com ocorrencia gubordinada de termots dioritlcos e granodioriticos, metamorficados na facies anfibolito.

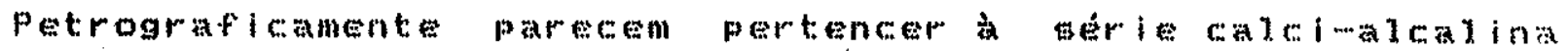
tonalitica (baixo-k) poderiam ser clastificados comogranitódes do tipo I (Cordlihatrano), representando o resultado de subductáno 
de tipo (Benloff) com eonsuma de placa oceanlca gob margem continental ativa (Andina) degenvolvida no bordo oriental do cráton do Rio de La Plata.

Diagramas isocrónicos Rb-Sr de referencia forneceram para egtas litologias, cono ja visto, valores temporais entre 660 eges

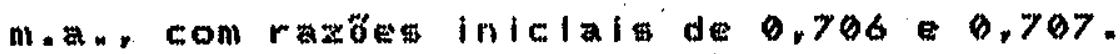

\section{Granodioritos monzogranitos da fase principal .. Os grani-} tólde que compöen esta suite constituen mals d $50 \%$ da área ex-... powta do batólto apresentam várlat facles petrograficas, com

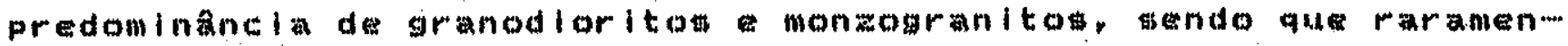
te aparecen tonalitos gienogranltom, com textura comum porfiritica e, subordinadamente, equigranudar a inequlgranular fina gromeirat.

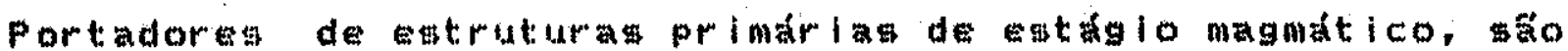
reconhecidos bandeamentos igneos com intercalason decimetricas de duas ou mal facles, lineacobs de megacrlatais de Kufeldspato frem quentement imbricados, orientacto thenclaves da suite gnatsoica precoce em diferentes grata de digetatar entre outros. Como estruturas tectonicas, pouco importantes, mencionamos a presenca de faixas de protomilonitos, mitonitos blatomilonitos demartando

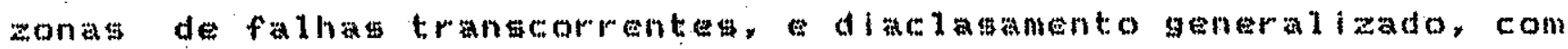
prenchimento de velos flö por termos quartzomfeldspáticos como pegmatitos, aplitos, rolitos micrograntos, além de apofin

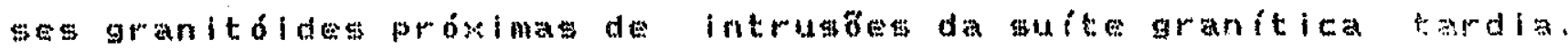

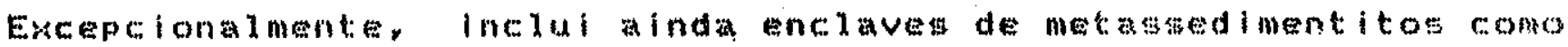
mármores, wittog quartzitom. Enclaves granuliticos (?) tom sido

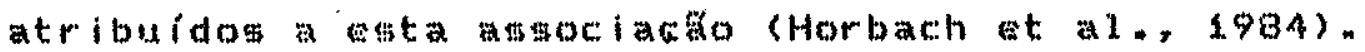


Os dados petrografleos \$ugerem una corregpondencia dos mesmos - sérlecalci-alcalina gromodioritica (medlo-k) tratando-se, prom vavelmente, de gianitoldes do tipo I. (Caledoniano), consequentes

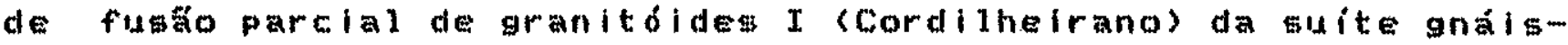

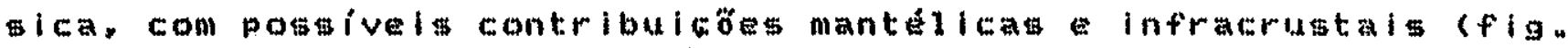
94), por encurtanento e pomamento da crosta em periodo sin a

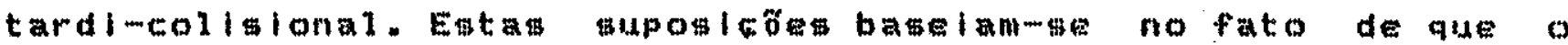

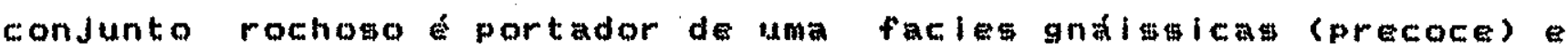
conten enclave da mite anter lor ou comporta termog mlgmat fticos, o gute insinua uma or lgem cristal.

A idade de referencla da white foco ede $775+-36 \mathrm{~mm}$. a razåo inicial de 0,706 , coerente com o intervalo próprio da "asyociaço tipo", é aderuada para um material-fonte crutal há pouco acreacido por diferenciaca do manto.

Conven observar que esta muper-unldade compreande um complexo polldiapírico que on resultados acima reveladog devem represen-

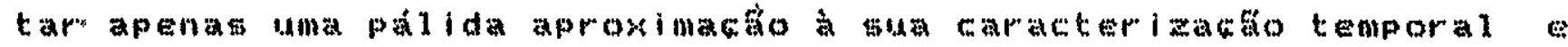
genética. Levantamentos geodolcos de detalhe, que possibilitem una coleta aproprlada de amostoras para a geocronologia petroguimica podarbo Indicar no futuro a duracto o tipo do evento gerador da mema, ben como postivei pulsos de mamaganese.

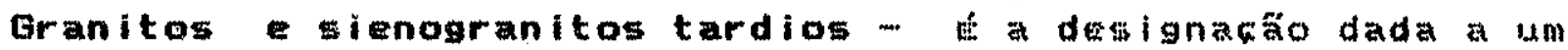
conjunto mutimintruativo de corpos graniticos dispostos ao longo dom grandes falhanentos regionatg de directo $N E$ (fig. 93 ) que recebem denominacöes local proprias como mostrado na figura 22. 
lares porfiriticos, con granulometria media grosteira. Petrom

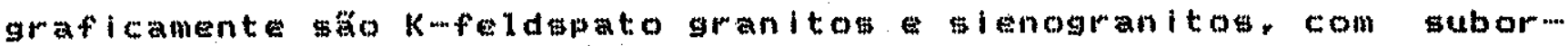
dinadas ocorrancias de monzogranito rara de quartzomienitos.

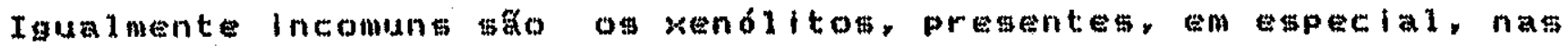
proximidade do contato com suite da fate principal, sendo os

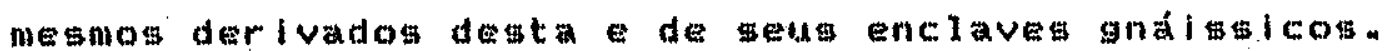

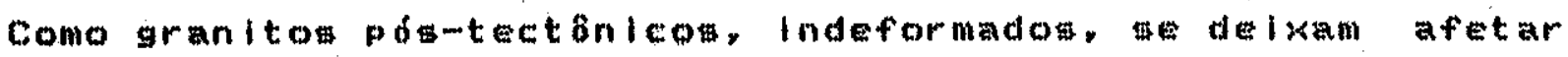

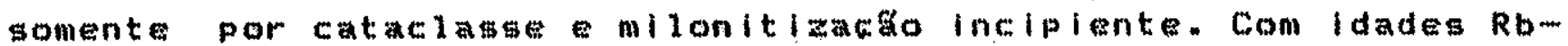
Sr de referencla da ordem de sso m. a. Ro to 0,709 , geoduimicamente tendenteg a intervalo translelonal calcinatalino a alcalino. correspondem a granitoldesi do tipo I (Caledoniano) resultantes de refutós crustais com pequena ou ausente contributago mantelica (fig. 94). Temporanente correlatos a etta sidte serian, en grande parte, os derramen rioliticos da Serra das Aaperezann

Representantes hipabissal de un magmatimo tardio, do tipo

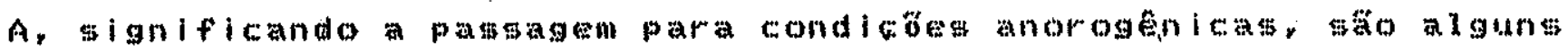
pequenos corpos graniticos velos quartaoneldapaticosy cuja lda-

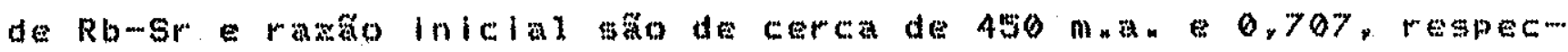
t Ivamente.

Da observacto da figura 93 constatawe que as suites mais antigas ocupam mator área de afloramento na parcela mertolonal do batólito exposto no Rio Grande do Gul. Oa granitód des da fase tar...

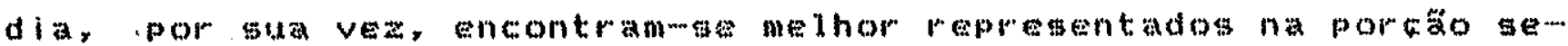
tentriona1. Ente fato pode estar Indicando um adsrnamento da entidade para NE, permitindo que se tenha, em guperficles uma visăo da

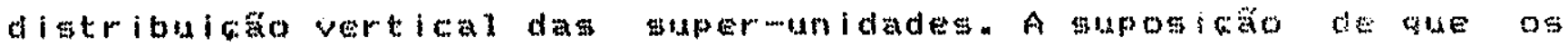
gnaissem da fase precoce de evolucto do Batditopelotas resulta 


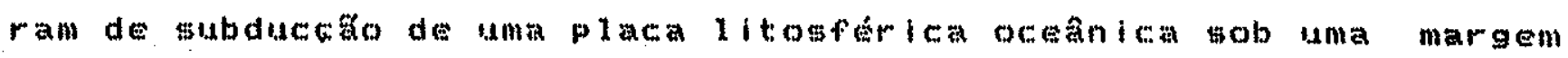
continental ativa Implica na existencia de uma crosta sialica. Em-

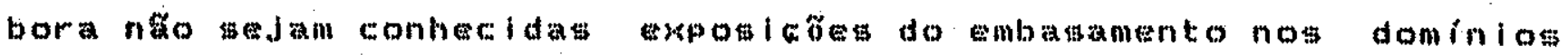

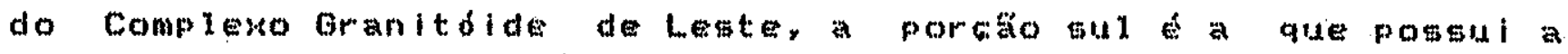
mator probablidade de deinar emergir rochas tipleas dessa asoo

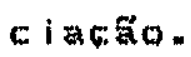

\subsection{Os Blocos Encruzlihada Sấ Gabriel: uma fracão de bacia marginal de evolucấo bras il l iana}

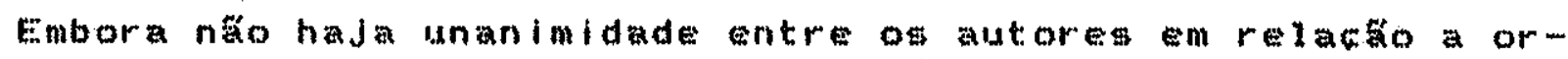

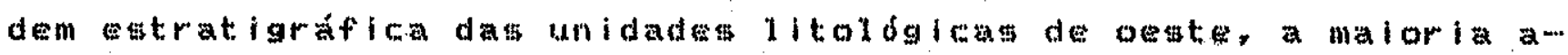

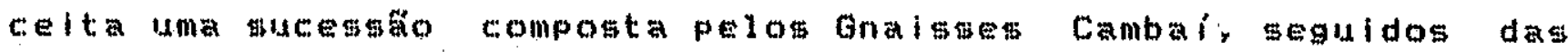

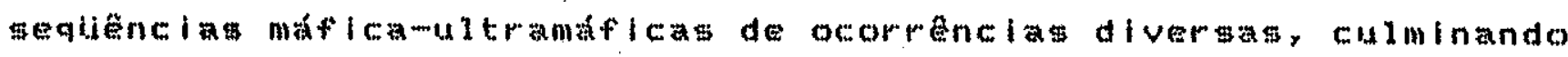
com as sequencias metavulcanomgedimentares, que revelam, em. conjunto, uma lmportante concordância estrutural, scodo que, entre as

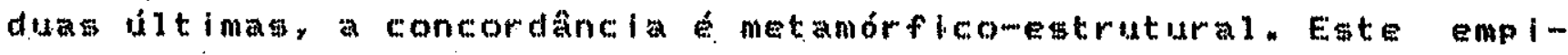
Thamento estratigrafleo reprementa, we verdade, a seriacto já prom

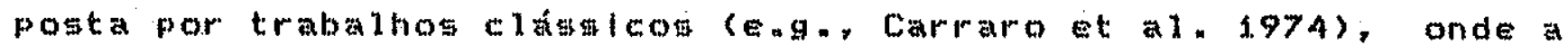
unidade basal ara orupo Cambai, seguido do Grapo porongos gubdi-

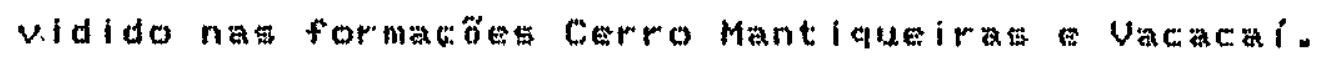

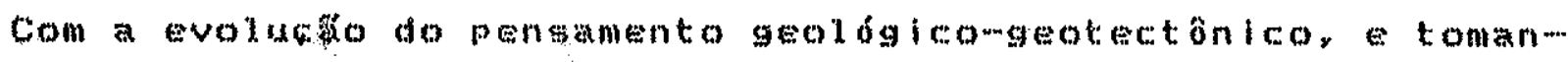

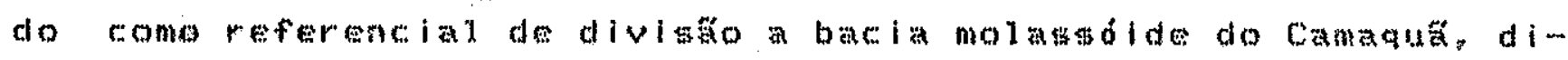
versos astores (eng. Ribeiro Fantinel, 1979 , wost Bitencourt,

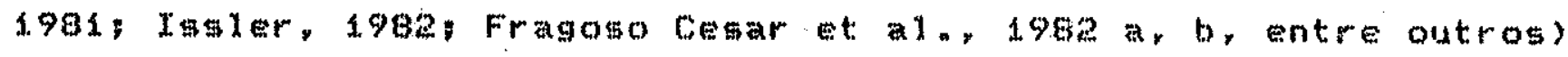

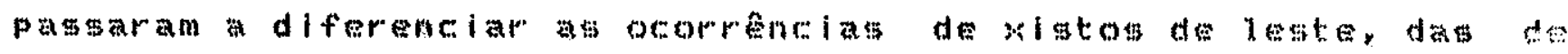

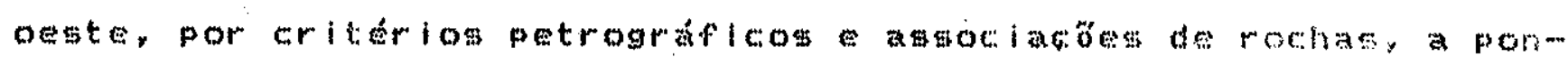
to do termo porongog ficar restrito a sequancia clastomímica vulcano-sedimentar metamorflada de leste supostamente gerada no 
Ciclo Braglitano, enquanto o termo Vacacai passou a espeificar uma asoclacáo. Elmilar ocorrente no osste, concordante com os gnaisges, migmatitom granitóldes diverson, descritos como cinturä́ de Rochas Verdeg do Rlo Vacacal " Considerado em conjunto con o Complewo Cambai, constituiria uma litoegtrutura do tipo "granite-greentone" atribuld a Arqueano ou Proterozóteo Inferior CNardi Hartann, 1979. Fragomo Cesar, 1980; Fragoso Legar e 5ollani Jr, 1984, entre outrow autores..

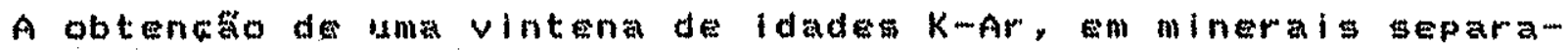
dos en rocha-total, e confecáco de uma dezena de diagramas Rb-. Sr, com isócronas reta de referencia, reunindo ma tos analiticom. Interpretados em conjunto com todos os dados pré... existentes relativos aos granitod des da unidade cambai e metamorfitos de baixo gran qua a sucedem, revelarain que, com excecto do Gabro de Mata Grande, pomeivelmente do Complexo pedras Pretas

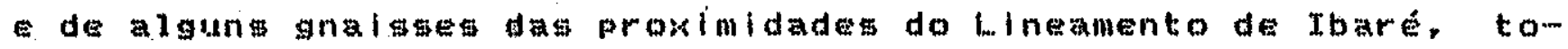
dos os valored diftributramm no intervato de cerca de 815 a 520 m.an com ignificativa concentracta 95). A imprestato de rochas jovens tambén fornecida pelas radoes

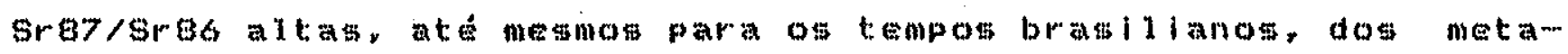
4) Itranafitos do Cerro Mantiqueirate do Complewo Bossoroca stabs.

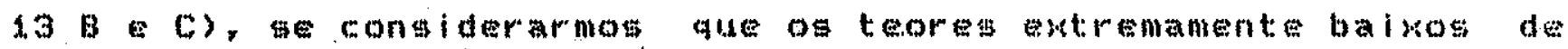
Rb fazen com que. as razón de Br obtidat valor inicial"

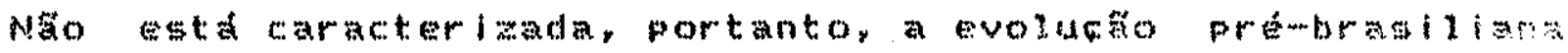
do framento NW do Egcudo do Rio orande do sul. ho contrarto, ob-.. gervamse uma similaridade temporal con ag rochas que compón os blowos Dom Feliclano Eneruzilhada, confirmando, como lá, que os 
limites do Ciclo Brasiliano superam o intervalo ate enta imaginado.

Correlacóe geocronológlcas podem ser feitas entre os gnaisges da regiáco de Vila Nova, no oestey e da regico de Encruzilhada do Gul, a legte. Os primeiros, atraves de isocronasede retas de

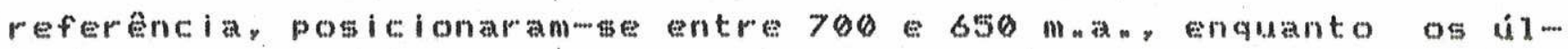
timos, por diagrama isocrónico regional, com possibilidades de in-

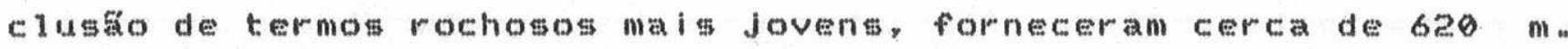
a. Algumas idades convencionais, no entanto, de rochas com altas

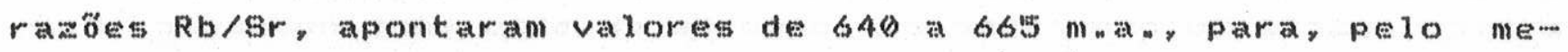
nos, parte dest: conjunto (tab. $7 A)_{\text {. }}$

Contemporâneas parecem ser também as seqiâncias de baixo grau, já que idades Rb-Sr convencionais conseguidas em metavulcanitos do Grupo Porongos, aflorante a leste da bacia molassód de do

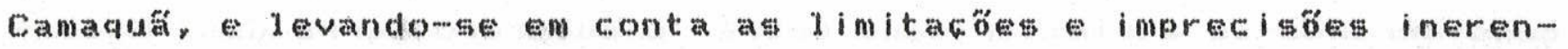
tes a metodologia, parecem concordar com os realtados do ocidente (cerca de $790 \mathrm{~m}$.

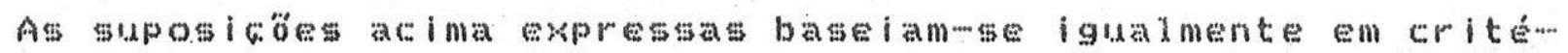
rios de ordem petrogrática de associacoses de rochas.

Silva Fitho (1984) comenta que, na regian de vila Nova, ou Gna isses Cambai constituem uma unidade supraciutal composta por rochas metassedimentares intrudidas por magmas de composicases va--

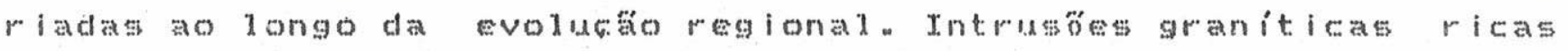
em K relacionar.we-nam aos estágios finais como decorrancia de fu... söes por espessamento crustad conseqidente das deformatón impostas à ärean. 


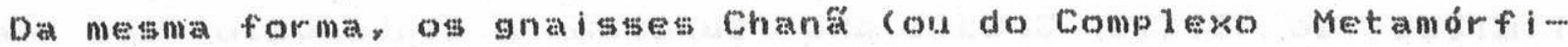
co Váraca do Capivarita) aflorantes no Bloco Encruailhada, outrora

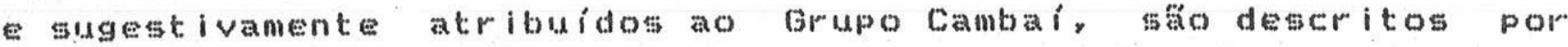
Frantzet al. (1.984) como compostos por paragnaisges seguidos por metanortositos ortogna ritica, tardiamente intrudidog por massas graniticas isótropas.

Em continuacaro, Ribeiroe Fantinel (1978), quando degerevem as rochas metamórficas aflorantes no alto estrutural que encerra o

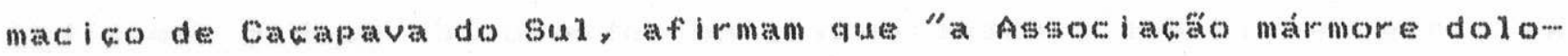
mitico-quartaito ocorrendo ac longo de cristas contineamente alinhadas na directo NE-SW, de extens Porongos, conforme o mesmo se apresenta na localidade tipo, isto

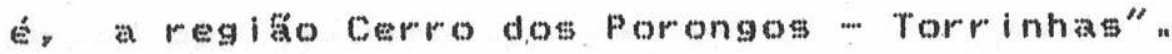

A mesma correlacăo fol sugerida por Jost Bitencourt (1980) considerando-me a similaridade entre o subgrupo Cerro dos Madei ras, nas prowimidades de santana da boa Vistay es os metamorfitos de Cás; lentes de mármore intercaladas em rochas calcimsilicaticas.

Os referidos astores, em as

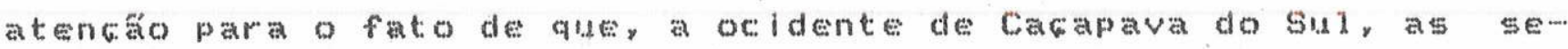
qidencias xistoms a metavulcânicas bósicas, serpentinitos, peridotitos e piroxentios

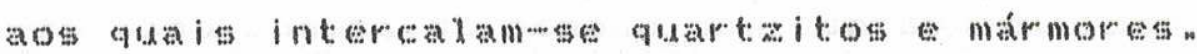

A ocorpêneia destes tipos litológicos máficos e ultramáficos

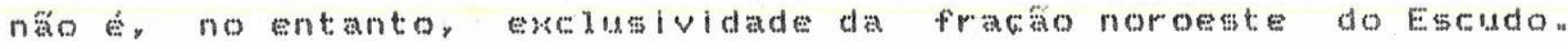
dost e Hartmann $(1979\rangle$, por exemplo, descrevem rodingitos associa- 
dos a compog ultramaficos a leste oets da bacia molagsolde, respectivamente. ao tul do Munlciplo do Cachoeira do sul na regia do Cerro da Cirla, Municiplo de gto sepé. Ribeiro (1981) relata, noroeste de Pinheiro Machado, a existencla de un corpo de perldotito serpentinizado, concordante com as atruturag primárias do Grupo Porongos, no qual o autor reconhece textura "spinifex" congagra as rochas como komatitom, procedimento tanbsm observado em Fragoso Cesar e soliani Jr. (1.984) para rochas da fracäo ocidental.

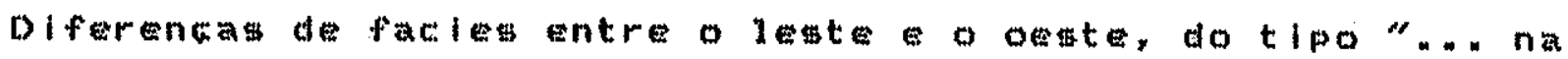
Zona Oest os marmores ma ma

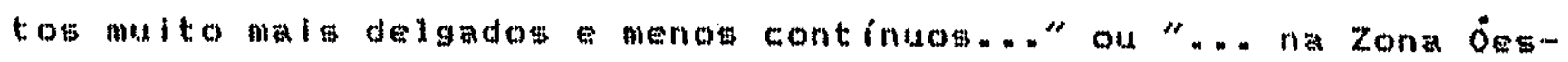
to os componentess do plusch" sto predominantemente arollosos, en quanto na Zona Lesto prodominam na aliencia componentes arenosos

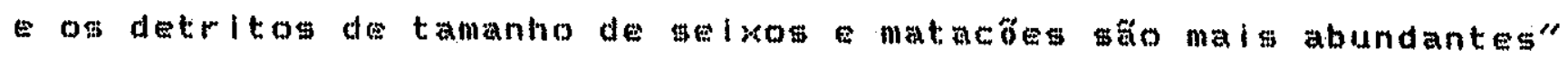
(RIbefro Fantinel, 1978), poden, evidentemente, ser explicadat por diferencas paleogeograficas observadas na bacia deposicional.

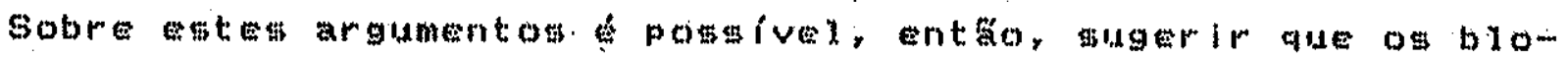

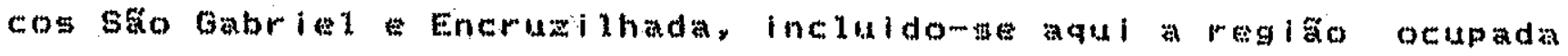
pelos metamorfitos porongos, constituem a de sequenclas supracrustais Intrudida por e Interealadas com metaigneas de composi...

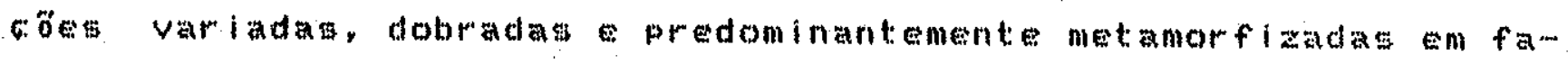
cies anfibolito de ldade bratilana, aue permitem raratio exposi... 6. öes do embanamento trangamazonico, como no Cerro das Encantadas ou na rato de Mata Granden

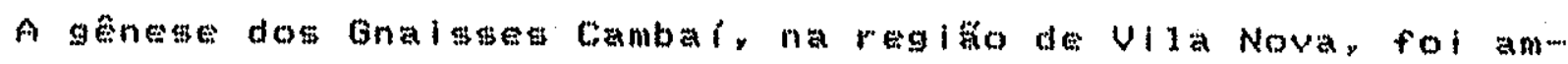

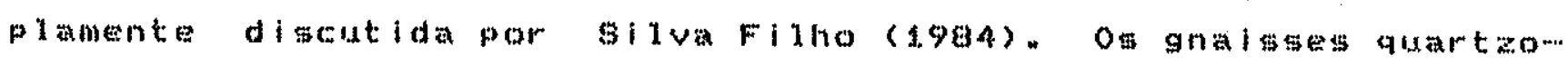


feldspáticos (dioriticos, tonaliticom granodioriticos), quando plotados no diagram $c$ ang de Niggi $(f i g, 96)$, demongtraran derivar, en grande parte, de misturas pelito-dolomito, consistente com abservactó de ocorrencia de lentes de mámores na área ou con a associacho a camadas de quartzitos com os quais poden estar Inter ac amadadown

A suite intrusiva gabromdioritomtonalitomtrondhjemito de vila

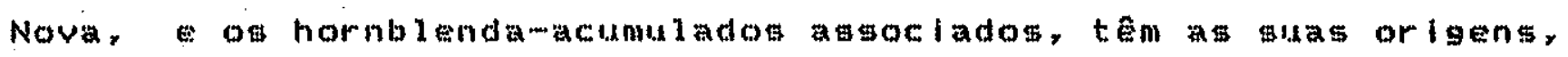
ew bage evidericlag geoquimicat diversage as relacós de campo.

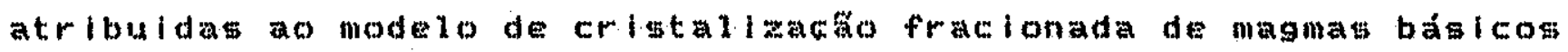
(silva Filho, op. (Et n).

A guite granitolde, composta por intrustos tabulares de espessuras varladas e deformada por dobramentos, parece corresponder a magmatigmo alnda sintectónico g geoquimicamente, representa uma

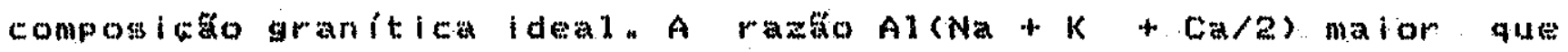
1.1. demonetra que esta associacto litologica peraluminosa. que, en conjunto com of fato de que apresenta em alguns lugarest fragmentosureliqula de blotita gnaisses engolfados pelos granodiom

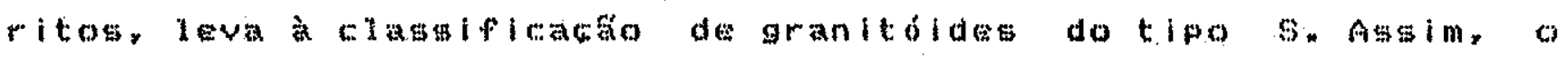
conjunto parece resultar de fusápo parcial dom gnalgses dioriticos

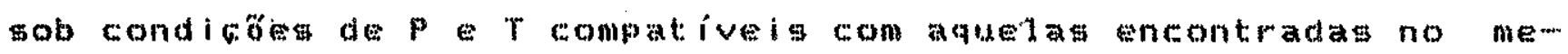
tamorfismo de facies anfibolito, mas a contributeoses mantelicas

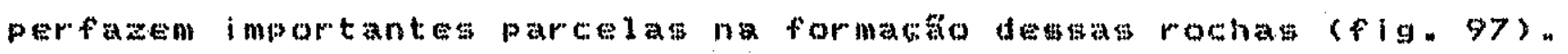

Os termos finals da sequencia sáto lam dique riolitico pegmatitos. Oprimeiro sugere ter sido produzido de masma profundamente situado na crosta (fig. 98$)$, enquanto os litimos derivaram de magmas com elevado conteudo de água. 
Para a Interpretacto da evolucto tectónlca da arear Silva Fitho (op. cit.. menciona a prence da suite tonalito-trondhjemito como felcho lmportante. Segundo larker (1979), Iembra o autor, tais suites podem ser encontradas quatro gituacóng geodolcag principals, qualwsejam: (1) terrenos de gnalswes cinzentose de idade. arqueana: (2) nas periferias de "greenstonemblta" arqueanos: 〈3〉 na borda de margeng contlmentala do proterozólco ou paleozdico (4) a longo de bordag de nargeng continental do Mesozólco ou Conozíñ

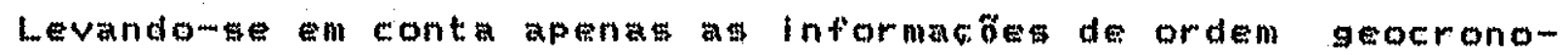

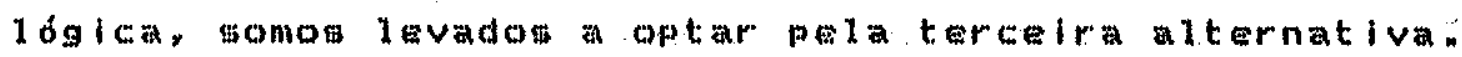

A flguras 98 e 99 (Silva Filho, op. elt.), diagramas Rb

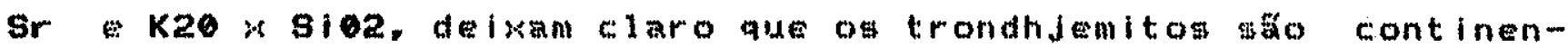
tais, o que também confirmado pelos estudos dass terragmaras que revelan padrö altamente fracionadom, coon valores para ag terras-

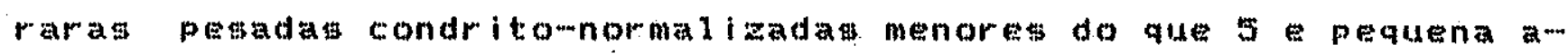
nomalla positiva de Eu (fig. 1.06).

Ainda da figura 98 deduzome que ot trondhjemitos podem ter

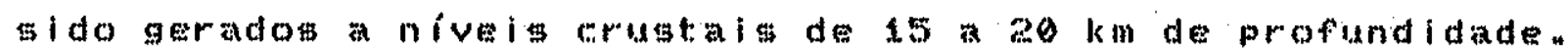

Com bast nag evidencias em parte sintetiadas nag linhas anm terlores, Silva Filho (op. cits) conclul que o Compleso Vila Nova

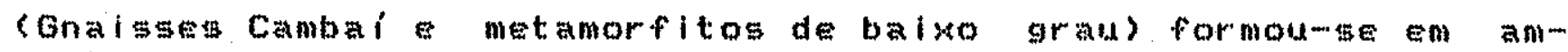
biente tectönico do tipo margem continental, corropondente tegoria 3 da claseificata de Barker (1979), onde as suites tonalitomtrondhjemitos podem associarme a zonas de subducto ou a a bertura de bacia marginal Hubatalaria, sendo tipicanente acompa 
nhada de suite quartzomdiorltomonalitomganodioritomgranito.

o autor citado visualiza a inda que o movimento horlacontal ti... po-nappe fol o mais importante lemento na evolug de Vila Nova, nos quais uma gufte gabro-tonalitomtrondhjemito intrudiu rochas supracrustais durante intenga fase de "thrusting", \$eguida pelo encalke sintectónico de magmas graniticos alto-k consequentes de spesamento crustal.

As condicon tectoonicas sob as quais egteg tipos litológicos

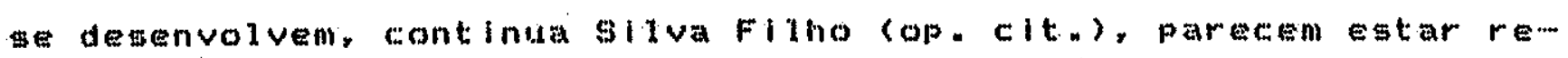
lacionadas ou a colisto de blocos litomfericos envolvendo una margein continental passiva, ou ao fechamento de uma bacla de "backarci" na qual a a gem cratônica.

A primeira hipóteste carece de evianclatgeotectônicas conclusivas, Ja que exige a presenca de congpicua linha de sutura en-.. tre os blocom colididos asmociacto litologica adequada. No Escudo do Rlo brande do sul, a bacia molastólde do Camaqua poderia, eventualmente; ter se demenvolvido sobre estar mascarando una felcaso etruturn 1 dessa ordem, o mesmo acontecendo para a $B$ acia do

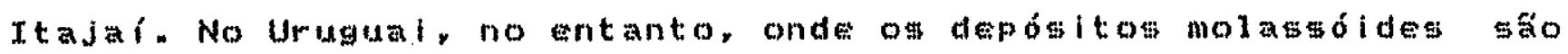

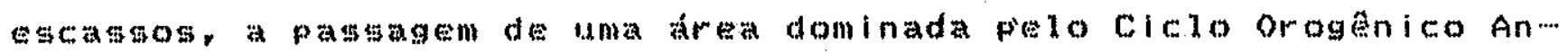
tigo (W), para a degenvolvida durante o cicilo orosentico Jovem (E), respectivamente comedaclonados aos diastroflumou Transamazonico

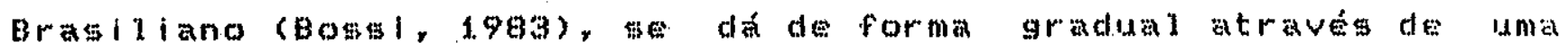
falka onde as idades revelam rejuveneselmentos parciais sob in-.. fluencla da orogenese nova (Ferrando ef Fernandez. 197a). 
Silva Fitho $(1994)$, en complementacto, alertat para o fato de

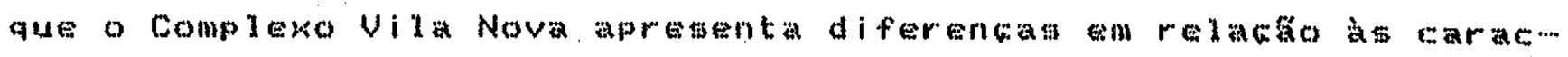
teristicas maiores dos complekos gerados nationgens destrutivas de placas litosferlos, como: (1) o seu "trond" calci-alcalino cligtinto do "trend normal" de Nockolda Allan (1954) pelo me-

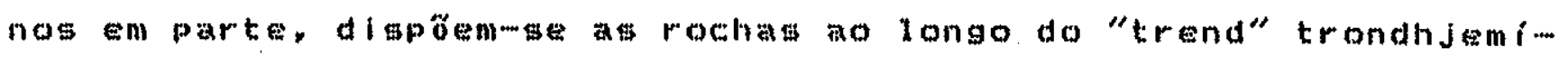

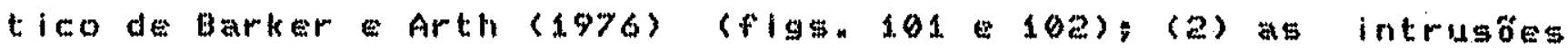
foran controlada por movimentod planares e na ocorom massas diapiricas; (3) as rochas tonaliticas granodioriticas săo vários pontos perentuals mis ricas en sion quando comparadas com litow

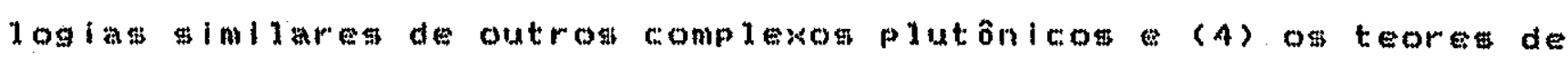

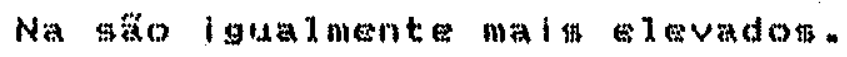

Silva Filho (op. tit., afirma anda que as lontes de acumula-

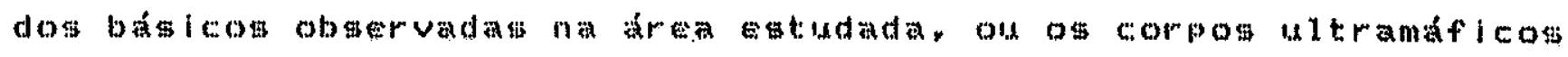
aerpentinizados ocorrentes a oeste de Vila Novar năo precisan ser.

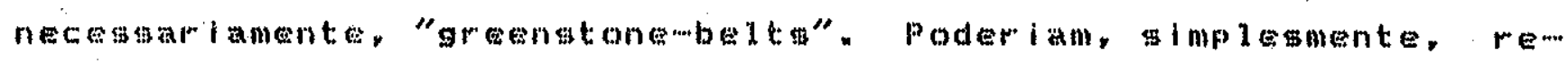
presentar produtos de diferenclaco prococe por cristalizacto fra-

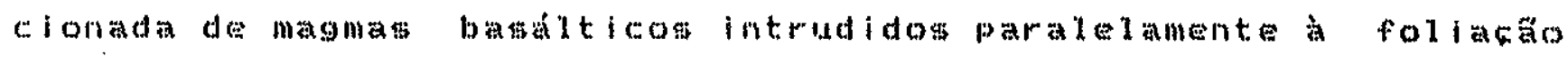
dominante dos gnalsasen.

En se tratando de bacia marginal vale lembrar que sua origen

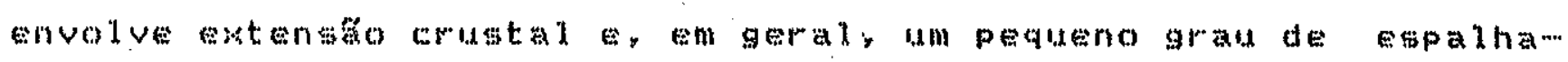
mento de fundo oceânico com o consequente "tamplacement" de dípi-

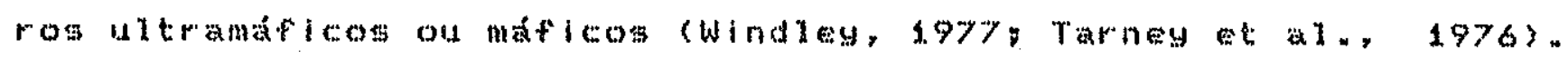

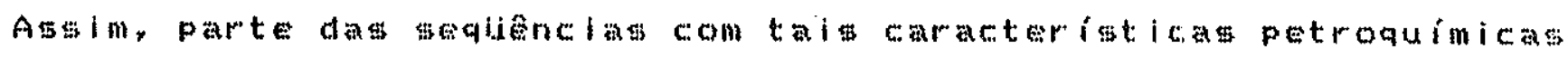
poder la ser encarada, do forma atemativar como representantes de associaco ôs ofioliticas Os mafitos ultramafitos encontrados nas

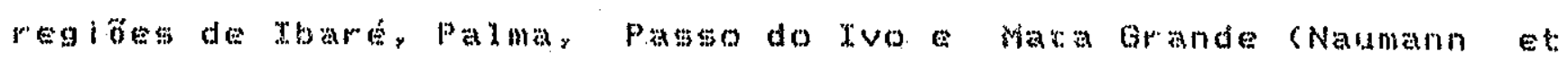

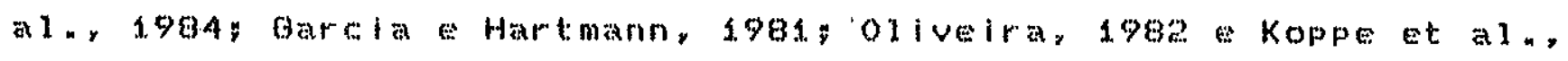


1985) mubdividen-me em thos petrograficos coerenter com esta pos-

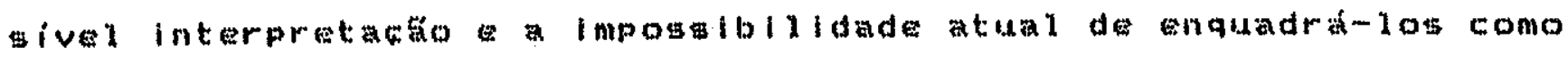
restitos de crosta oceânica pode mer devida a studos incompletos ou a caracterioticam particularea que eventualmente apresentem. Tratamse apenas de um reavivamento de hipotese de trabalho uma vez que outrom atores ja

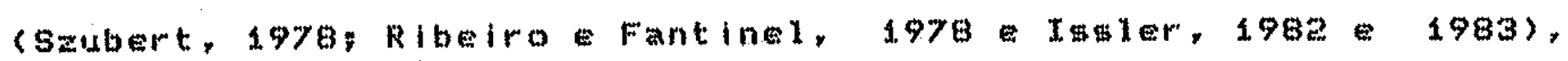
porén em outros contexto geotectônicos.

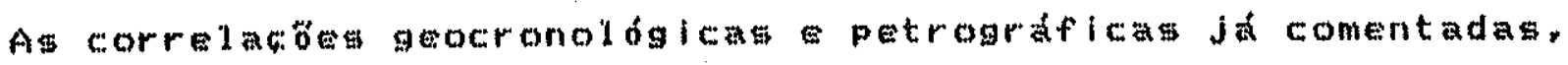

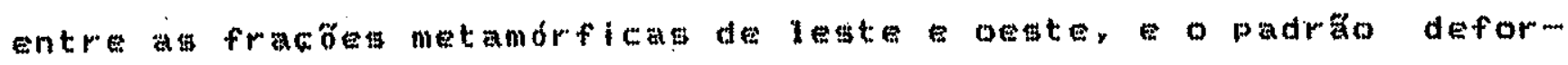

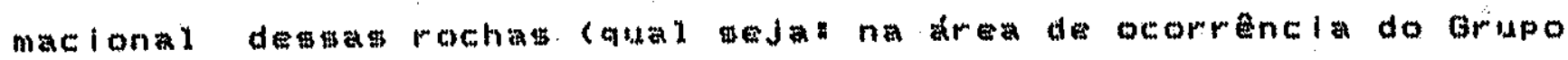

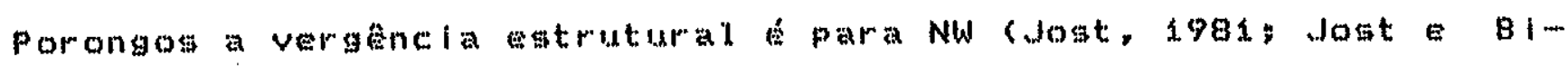
tencourt, 1980), na regito devila Nova, silua Fitho (inf. verb.)

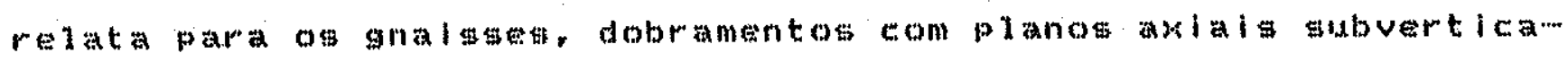
1 lazadot, mergulhando ora para NW, ora para SE Naumann et a 1 . (1984) Koppet al. (1985) afirman que a follacto metamórfica NE doa complemos Palma Bossoroca mergulha proferencialmente para

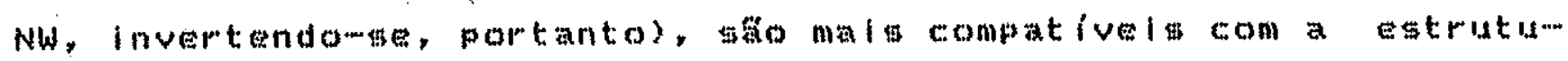
racto anforme de uma bacia marglnal cujos metamorfitos de bordo

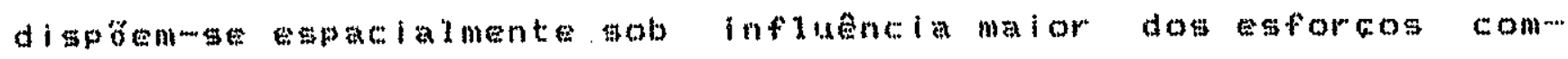

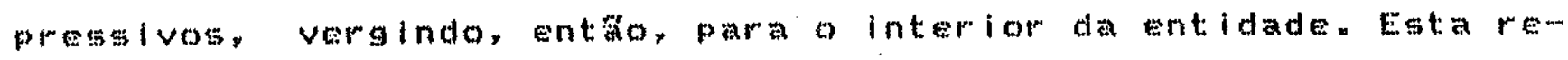

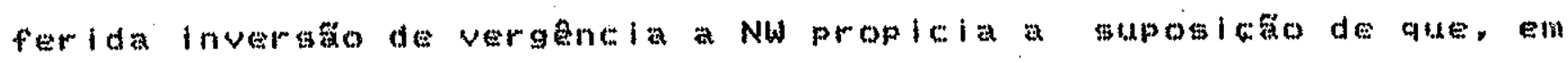
ge tratando de borda, o combatiamento pode star exposto a oester ou

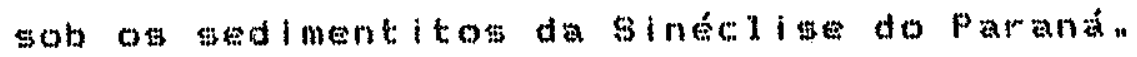

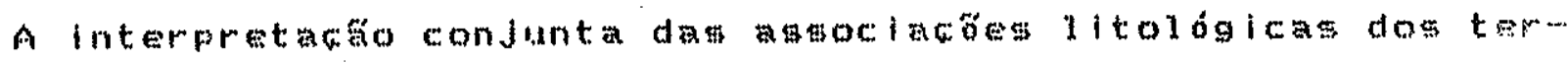

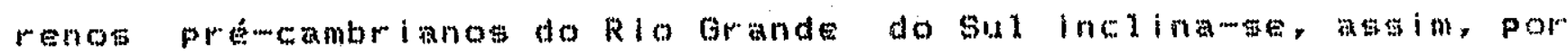
uma origen consegitente de fechamento de bata marginal para as rochas que compon a supratstrutura dos blocos Encruailhada e sab 
Gateriel.

\subsection{O Bloco Taquarembó uma fracto de Macico Marginal no Escudo Sul-rlo-grandense.}

O termo macico (Macico Central de toolás, Cordanl e Brito Neves, 1982; Mactco Mediano Pernambuco - Alagoas, Brito Neves et al., 1982b ou Maclco Marginal de Curltiba, Campog Neto, 1985) ten sido usado de forma parcimonioga na literatura geologica bratiolira, significando, do ponto de vista geotectônico, domínios individua-

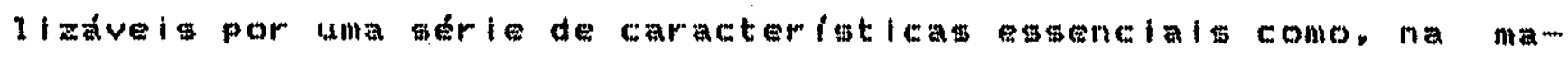
forla das veres, intercalarem-me a cinturoteldobrados, con os quais nomalmente relacionam-se atravé de profundas aconas de faIhas, revelar un padra estrutural mesto conplewo (denotando uma nittoria deformarional policiclical, apresentar dado geocrono-.. lólcos sigestivos de una or lgen evolucko arqueara ou proterom

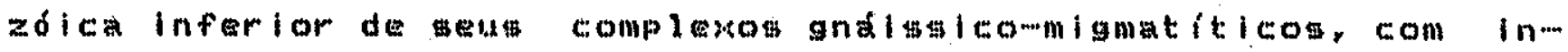

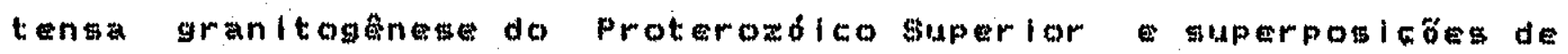

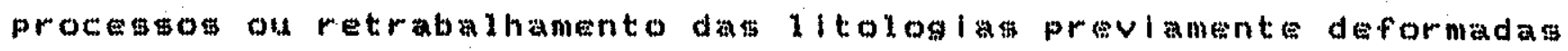

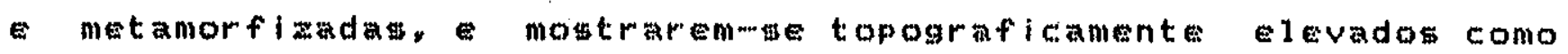
consendencia de seus tipos litoldgicos constituintes conaisses. migmatitos granitos, os primeiros resultant de metanorfismo de

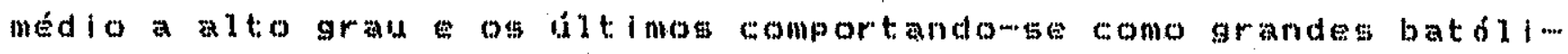

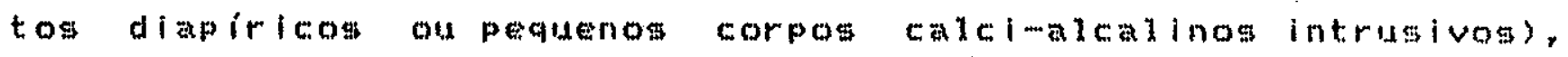
$(B+1$ to Neves et al, 1982 , b).

Os qualificativos central, mediano ou maginal procuran posicionar os macleos no contexto gotectonico regional a a cassifin cacaso tentativa do Bloco Taquarembo como uma parcela de mactco marginal se deve a fato do mesmo parecer corresponder, junto com 
os terrenos aflorantes nas "ilhas crigtalinas" de Rivera e Aceguá, e regiöes de Valentines e Nico Peréz, como será vimto adiante, a

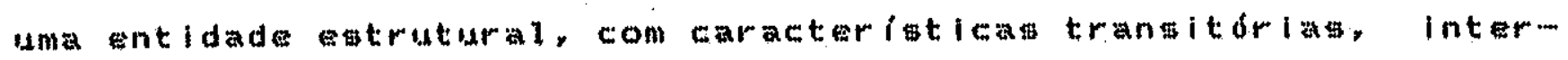
posta aos Cinturkio Don Faliciano Craton do Rlo de la plata

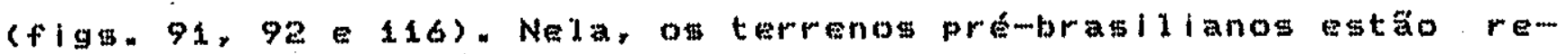
presentados por rochas granulit leas do Complewo Santa Maria Chico que se dimtribum de forma quase continua a norooste oeste do

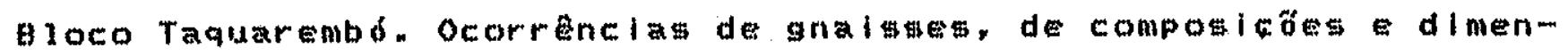

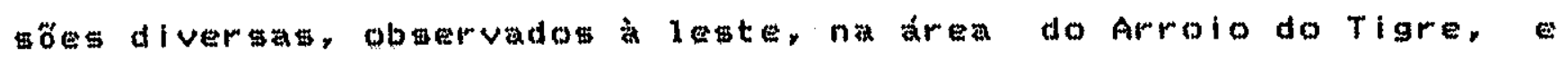
geocronologicamente correlatos aos aranulitom, parecen representar

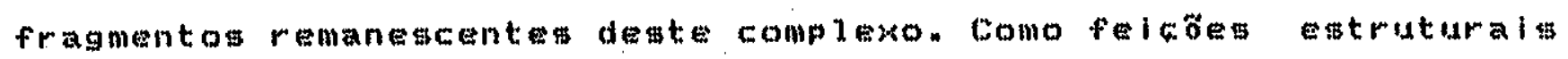
destacanme uma interna catacläe paralela an Lineamento de Ibaré e follaca âo dominante de direcano NW.

OE granitoldes ma jovens corresponden a trestaos litolo-

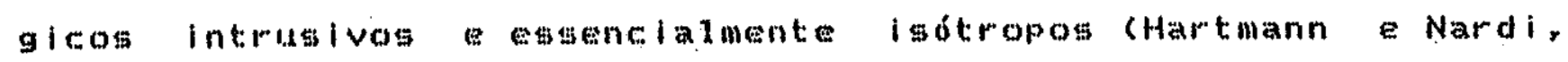
1982): O Complexo Ormitico \$anto Afonso com dimensós batoliticas

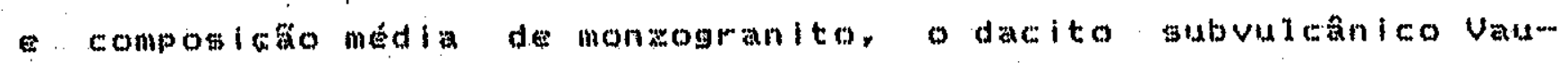
thler, porfiritico, com matrizfina, que me mostra semelhante ao primeiro do ponto de vista minemaloleo auimico. a suite Intrum

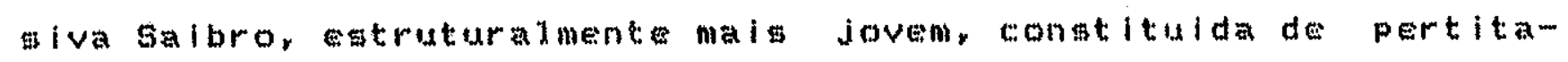
granitos com ocorpanciat locals de rlobecklta a a a irina.

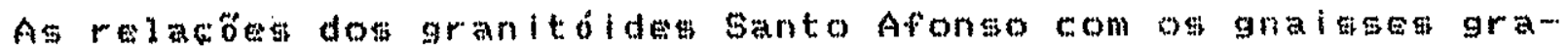
nuliticos apontan para a intrusgo dos primeiros ra parte alta de uma crosta rigida sialica.

A neoformatäo mineral decorrente de metamorfismo de contato.

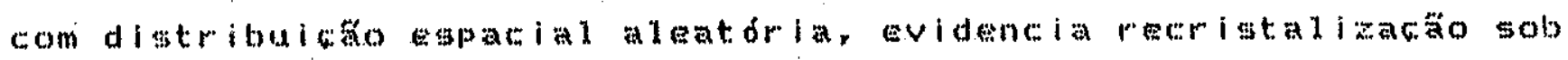

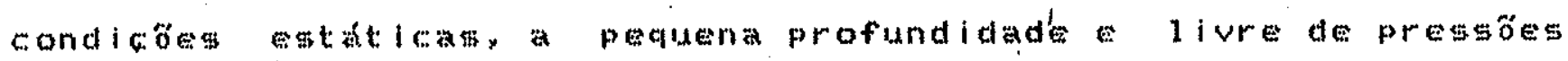


dirigidas (Hartmann Nardl, op. cit.). A relatáo geológica fundamental a de lum fragmento eratónico granitoides intrusivos. gugestiva de Zona Marginal.

os autorea mencionados apresentam temtes de alguns indices geoquimicos Para a suites Santo Afonso Saibro. A primeira, a qual adicionaran-se as subvileanleas Vauthler, nostra elevadas ra-

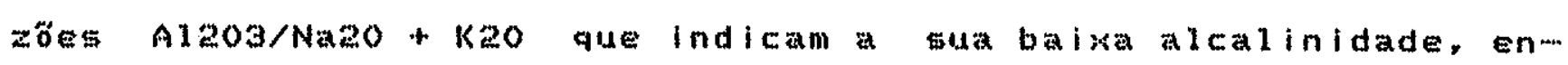
quanto para a Suite Salbro as razónes conseguldas sto da orden de 1. ou pouco mais, revelando rochas se nato peralcalinas, pelo menos de alcalinidade levada.

A uti 1 izagăo do diagrama de Wright (1969; apud Hartmann Nardi, 1982) revelou que as amotrat do Complexo santo Afonso po... Gicionamowe natprokimidades da linha limitrofe entre os campos

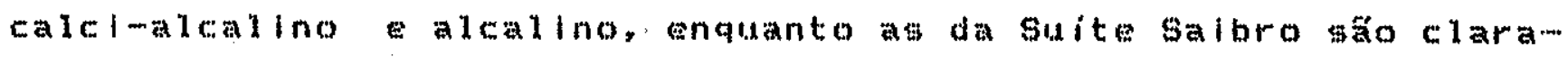
mente alcalinas $(f i g, 163)$.

Con relacto a gaturacio em alumina, as rochas revelaran-se predominantemente peraluminosas, o que aponta ambiente comprestivo de geractio.

De acordo com os indles do Petro at a . (1979y apud Hartmann e Nardi, 1992) para granitas com teoret de 8102 entre $70075 \%$ a

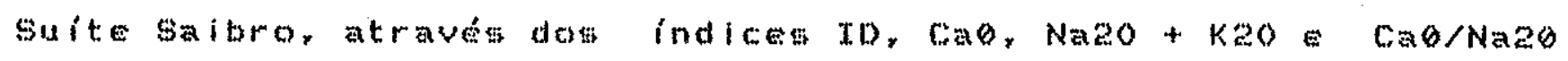
+ K2O, situoumb cam ambiente distensivo, gendo que apenas a razăo $F \in O F E$ + MgO posicionoume prowimamente a valor medio para granitos de ambientes compresulvosn

A a 
Taquarentó parece representar um magmat imo desenvolvido sob condicós de paraplataforma. Os grantos santo Afonso podem ser classificados como do tipo $I$ (Caledonlano). megndo Pitcher (1983), demeritos como rochas rleasem quartao (at lngem ate $45 \%$ de volume de rochas, portadorat de frequentes xendlitos de dimensós

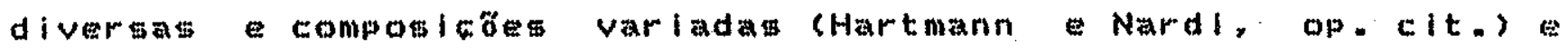

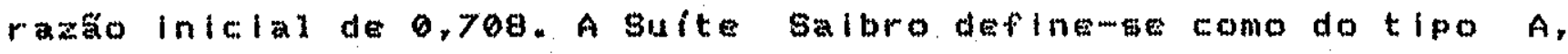

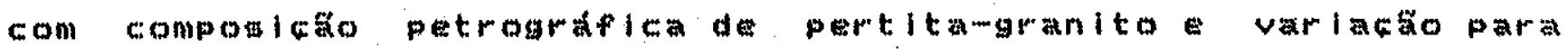
Henogranitos, pertitiomienito sionitos (Hartiann E Nard, op. cit.), alcalina, ocorrendo de forma miltíla como Intrusố peque

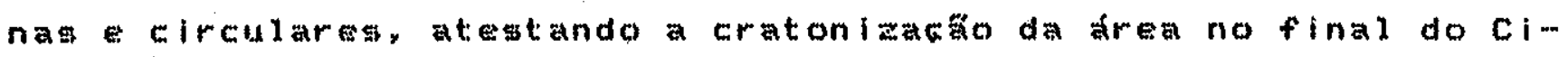
clo Bratiliano.

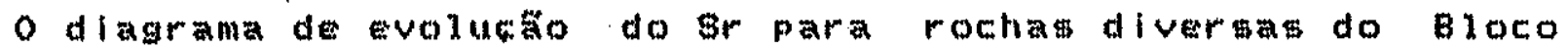
Taquarembo (fig. 104) revela uma diversidade de materlal-fonte para os protolitos prembrabilianos la ocorrentes. O Complexo Santa Marla chlco, apesar de associado a marmores formacónes ferrifer. ras, teve uma ganeme a partir de importantog contribuicós do nanto, agsemelhandomse termos litoldglcos derivadose acreseldos a crosta durante ou pouto antes do evento metanórfico que os afetou.

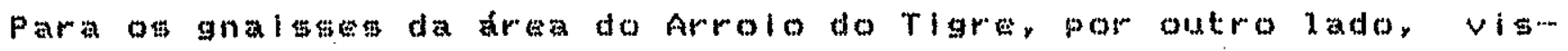

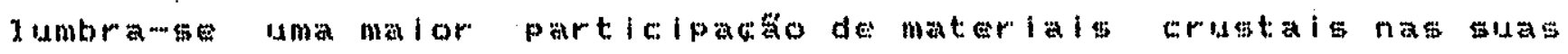
geracöed. O Complexo toranitioo Santo Afonso apresenta indubitavel origem partir de refusón da crostan

\subsection{Ilhas Cristalinas de Rivera e Aceguá: o prolangamento me- ridional do Macifo Marginal}

Circundadas por gedimentitos gonduanicos da Bacia do Paraná. Expöenm no norte do Urugual, ro Departamento de Rivera nas 
proximidades da localidade de Aceguá, parcelato do enbasamento précambriano. mendo referidas pelos pasdigadores daquele país como "ilhas crimtalinas" de Rivera e de Aceguá.

Precionzl et a ( $\quad$ ) descrevem para a primeira (fig. 105), gnals\$Es mugcovititos lou biotiticos, anfiboliticos anfiboli-

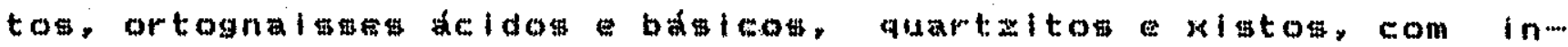
tercalacós frequented de rochas granitleas, incluldos indistintamente no que denominam de Complexo Basal. Entre talj rochas têm Eido reconhecidos metamorfitos de facleg granulito.

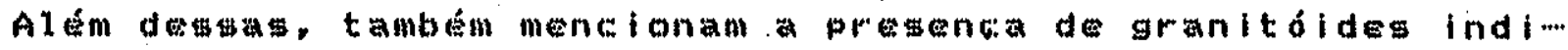
ferenciados genericamente descritos cono calci-alcalinos, de granulometria media porfiritica, em geral hornblendombiotiticos, lescogranitos, granodioritos granitos orientados.

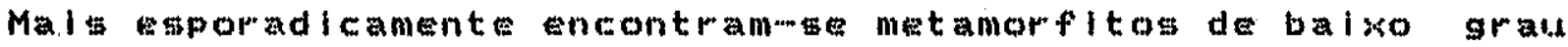
- ectinitos diversog. Granitódies de earater tardi a póp-tectónico, de facies dioritica a granodioritica, constituem os maclcos do Arrolo Carpinterla, na regiaco centromul da "ilha", Amarillo, na porca contromorte, e Vichadero, no extremo oriental (fig. 105 ).

Dez de doze amostrato coletadas de metagranitioldes quartzofeldopaticos fortemente follados, aflorantes ao longo da Rota 28 , partindo da localidade de MInas de Corraleg em diregäo SE (fig. 105, tab. 330), permitiram a constructo de dm a Rb-Sr de referancia con a indicato de um Yalor temporal de 2.272 $+33 \mathrm{~m}$. res (ES, 99 ESJ-1000) revelaram fortes indicion de alteracto in-

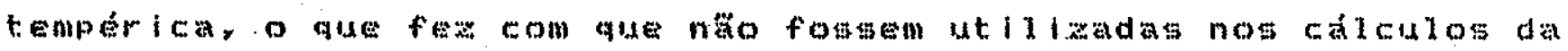


idade explica os posicionamentos de meus pontos analiticos de formag discrepantes. Ag idadew convencionala para anbas, uma va que possuem altas razöes Rb/Sr, găo, regpectivamente, 1.763+- 57 e 1.982 +. $71 \mathrm{mn}$. Indiscutivelmente prébrasilianas. Deste mesmo conjunto, plagloclásios analisados pelo método $K-A r$ (tab. 33C) forneceram resultados da ordem de $950-970$ man. refletindo a influencia parcial de um clelo orogenico mais jovem ous actape de argônto por imperfeló̃es no reticulo erletalino dos minerais.

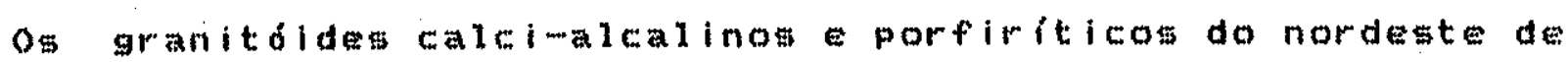
Vichadero cabecelran do Arrolo Amaril lo definiram outro segnento

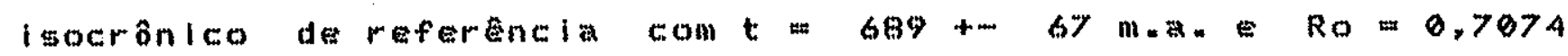
(fig. 107, tab. 33D). Pelat ldade caracteriatica quimica, estas

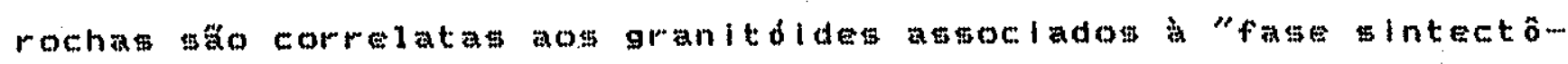
nica" do ciclo Brasiliano no oeste gácho, assemelhandome a uma associactio do tipo I (caledoniano).

Com o intulto de verificar me os pópfiros de K-feldspatos presentes nas amotorateram ou na roulantes de blastese brasiliana sobre rochas mais antigas, o que poderia propleiar uma incorrecto na atribulato da idade destas litologias, andisamos em paralelo porcöes detes minerals separados das matrizes desus rochas orlginais. A collnearldade observada entre estes materiais (fig. 107) permite assegurar ac valor temoral conmegido o significado de spoca de erlstaliacaro da rocha na qual tamben os $k-$ feldspatos pe formaram.

Provavelmente contemporaneas aos granitód des porfiriticos sejam asochas descritas como dioritos granodioritos, cujas ida... des K-Ar en biotitia plagloclásio fornblenda posicionaram-se no 


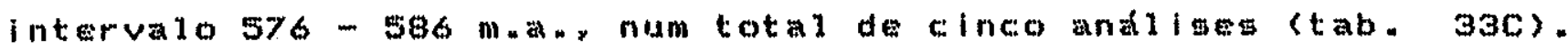

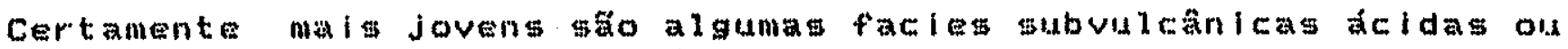
diqued báficom, preliminar petrograflcamente descrito cono de carater alcalino, sugestivos de una asociaga do tipo A, cujos valored K-Ar em rocha-total. Interpretados como próximos da geraC: $(\mathrm{tab} .3 \mathrm{sc})$.

A I Iha Corigtalina de Acegua (fig. 105) tamben teve algumas de guas litologlas estudadas pelos métodos Rb-gr e K-Ar. Mal conhecida do ponto de vista geógico, a la ta atribulas termos petro-

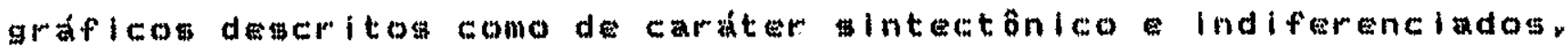
dos tipos graniticos heterogranularea, grosgeiros, porfiroblasti-

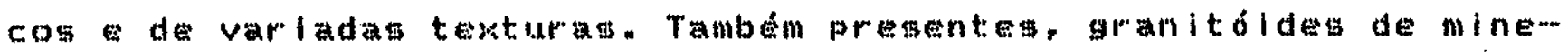

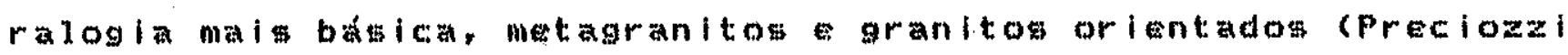
et $1 \ldots ?)_{\text {. }}$

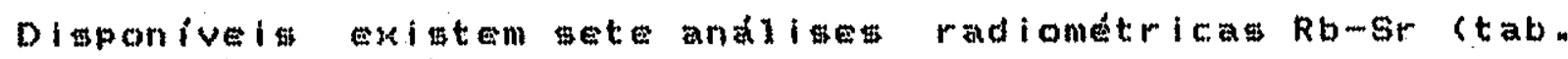

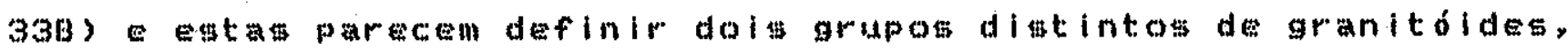
un de facies granodioritica e monagranitica (tipo x - Caledoniano) outro con alenogranltos Kufeldgpato granitos (tipo A), es...

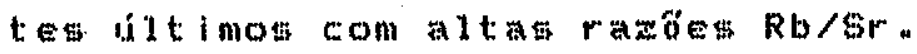

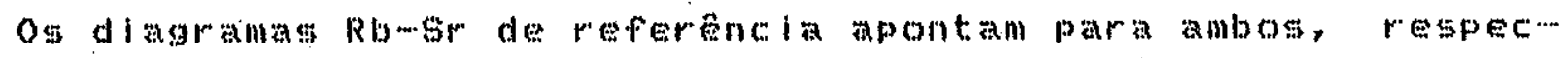

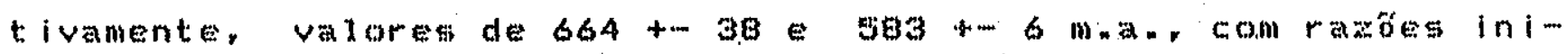

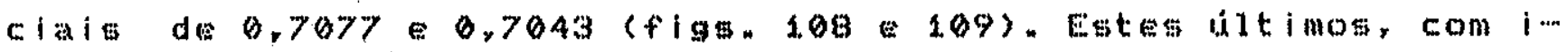

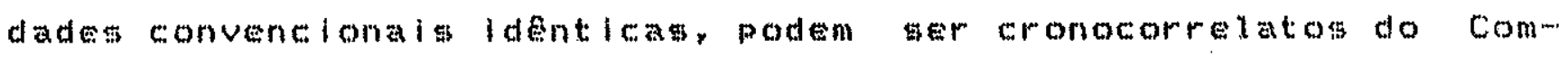
plexo Oranitico Santo Afonso, enquanto os prineiros, ainda näo ldentificados no Bloco raquarenbó, tem gua presenca sugerlda por uma idade KaAr suberlor a $580 \mathrm{~m}$. 


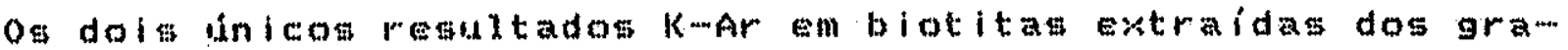
nitódel malgantigos foram da ordem de 575 a $600 \mathrm{~mm}$ a (tab. $33 A$ ).

A correlagăo das litologias desta "Ilha cristalina" de Aceguá com a de Rlvera o Bloco raquarembi pode ser sugerlda en base à presenca, ma primeira, de metagranitos granitos orlentados (näo datados) pela idade de cerca de 665 mon. conseguida, comparável

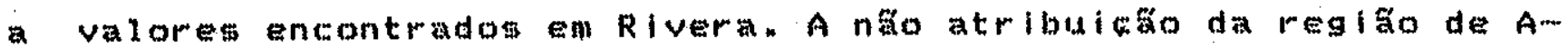
ceguá ao Bloto Dom Feliciano se deveu ao fato de terem desconhecidas. ate o momento. neste dominio, cifras temporale similares. Uma hipótese aternativa seria lmaginar que entag rochas relacionam-se a bacia marglnal do Cinturcho Dom Feliciano, ser comentada se-.. gluir.

No diagrama de cuolucato do gir para as rochas das áreas en foco (fig. ifo) flea patente uma importante contribulazo do nanto na geracto dos metagranitóldes transamazônicos e K-feldspato gratnitos anorogenleos, encuanto as demals litologlas analisadas derivan de fundidon da cromtan

2.5. Sistema de Falhas Dorsal de Cangucua estrutura litite entre as entidades batólito bacia marginal do cinturâo Dom Feliciano

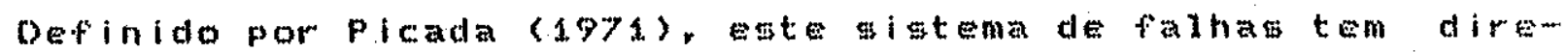

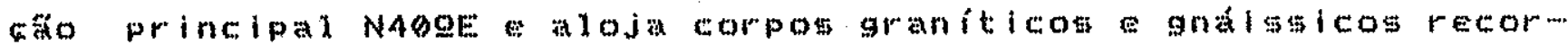
tados por brechas, milonitose cataclastos de grandas dimensónes.

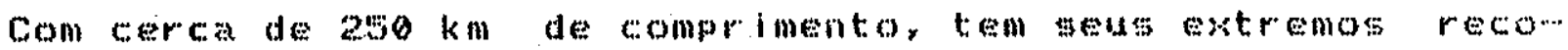
bertos por sedimentitos da Bacia do Parana e se deisa gectionar em 
duag metade pelas falhat trangerrenteg $N-S$ do sigtema Passo do Marinheiro (plcada, op. cit. , (fig., 91).

Nos \$eus 5 a 10 qullometrot de largura, a 1 inham-se concordantes com o ectinitom Porongom, divermom corpos dos denominados granitom Comdilhelra Augen Onal\$ses Vigia, com dispersas ocorrências de graigent (fig. gas). En perfil trangvaral, pode-se en contrar ate uma dezena de falhats asociadas, clujos planos subver.. t

De acordo com Fragoso Cesar et ad. (en prep. ), a Suite cordi

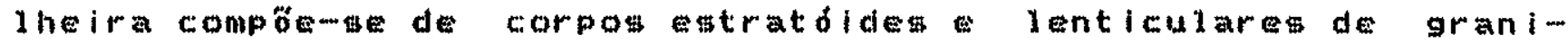
tóldes claros a muscovita ou a dias micas compontuacón de tur... malina elou biotita. Petrograficamante, gáo granodiorltos monzogranltog, raramente gienogranitom, de granulacta media a grosgelra, predominaritemente equlgranular.

Os Augen Gnal Ihelra pospuen compostato forna do jazimento minllares. Tratase de gnalsses. oftalmiticos claros comporfiroblatos de K-feldsw pato plagloclato io at irados.

Ocontato entre estag unidades, con og metasedimentos in-

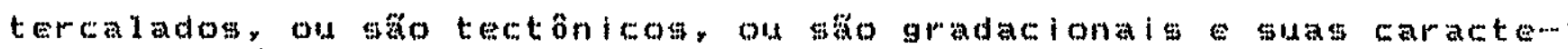
risticas claramente sinorogenicas. Leucogranitos macicos, contendo xenólitos de metastimeditos dobrados, sugerem que pelo menos

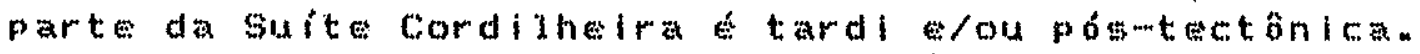

Em suma, a folga pode sor encarada como uma faixa sincine... mática de granitoides do tipos encaikados en una linha de sutura 
intraplacag (mubduceto tipo A de Ampferer), entre o arco magmát ico tipo Andino a bacia marginal do ocidente (figt. 91,92093$)^{.}$

\subsection{O Lineamento de Ibaré estrutura limite entre as entida- des Bacia Marginal do Cinturão Dom Feliciano e Macico Margi- na 1}

Originalmente referida como fossa do waguarl, orlginada por un olstema de falham tenslonals, de tracado irregular, com deslow camento verticala de blocom de até contenas de metros (Williget al, 1974), esta feica passota a ser deriominada l. ineamento de Ibaré (fIg\$. 91 92) apó a publicaço de Hartimann Nardi (1983), embora rấo tenha tolo, ats o presente, merecedora de costudos mais detalhados.

A Importância geclóglca desta estrutura reside no fato de que a mesma é a entidade divinora de terrenos com caracteristicas metamórfleas tectônicas distintas. Ao ful, ficam os terrenos de facios granulitica follace regional NW, enquanto ao norte as rochag gato de fation xigtos verdeta anfibolito, orientadas segundo NE. .

Naumann et al. (1984) consideraram o compleko granulitico com

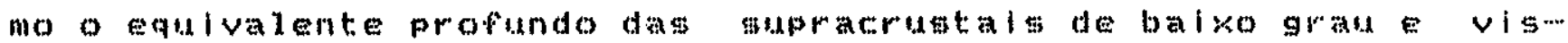
lumbrarm, para a justaposicăo de ambos, a ascencăo do bloco meri-. dional, através do linemento em patat com seu consequente des.gasterosivo ate expolato dos nivei bagala da crostan

Os resultados geocronolosicos comentados neste trabalho de monstram, no entanto. que nấo há identidade temporal entre as fram 
6:ố: en discussăo. fato que ja era sugerido pelos "trends" estruturais regionalmente discordantes. Oparalelismo da foliaca observado nos dols blocos nas proklmidades de Ibaré (Naumann et al., op.cit.) parece relacionarme ao comportamento rígido do mais antigo durant o degenvolvimento estruturacáa do mais novo.

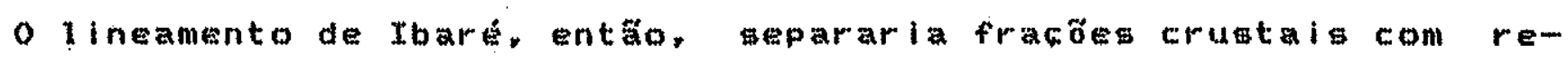
sistente enbasamento, na fracko meridional. esubestrutura deformável ao norte.

Apesar dog granitóldes intrumlvos corresponderen a uma alta percentagem no volume de rocha aflorante ao bul do sibtema de faInas, a frequencia de rochas malsentigag que o brasiliano, a diminuicaro dos termos gnálsmicome a disposicto das lineacoses de forna predominantemente ortogonal ao "trend" nordegte do cinturăo Dom Feliciano, fato obviamente constatado na "ilha cristalina" de Rivera (fige 105), foram os critérlos determinantes para propo-

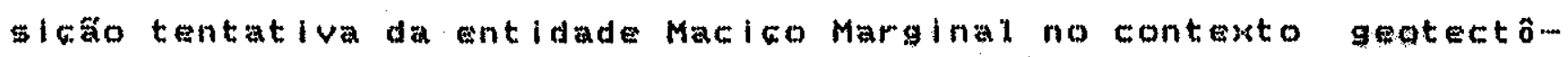
nico da área $(f \mid g .116)$.

Näo se pode, contudo, tomar tal felcamomimite de forma absoluta, ja que sto conhecidos alguns afloramentos de graisses anfi-..

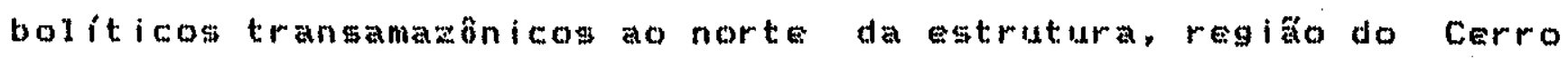
Mant laueiras, beil como gna imses quartzomfeldspatteos brasllianos a sid1, nas proximldadeg do Arrolo do rigre.

As reativacós tardias a que esteve sujeito o sistema de fraturas ficam evldenciadas no interior da zona falhada onde os sedimentitos gonduanitos da Bacia do Parana (subgrupo Itararé Forma 6. Rio Bonito) apresentan mergulfos de alto angulo. 
Para norcegte, o Linemento de Ibare tem sua continuidade interrompida pelos depóatos de cobertiura do Fanerozicos enquanto que na direcáco studeste parece Infietir no sentido antimorario. As regióes de afloramento de granitóldes cortadas pelos arroios das Palmase Velhaco. posicionadag SE de Lavras sul da área das

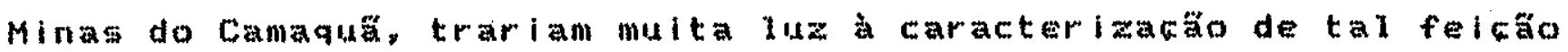
$\langle f \lg .91\rangle$.

\section{Modelo de Evolucão Geotectônica para o Escudo Sul-rio-granden- se}

\subsection{Aspectos Gerals}

No initio do prefente relatório procuramos apresentar de forma intetica a evoluço dos conhecimentos sobre a geotectônica das rochas premcambrianas do Rio Grande do Sul, em particular, e do Brasil Meridional Uruguai, no geral, contatando sarem varios os astores que sugeriram modelos de desenvolvimento. na grande maiom ria.calcadog na teoria da rectônlca de Placas (Ribeiro e Fantinel, 1979; Jost Bitencourt, 1980; Jost, 1981; Fragoso Cesar, 1980;

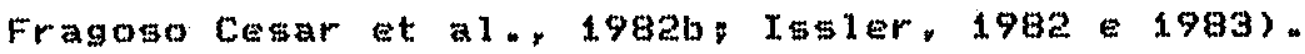

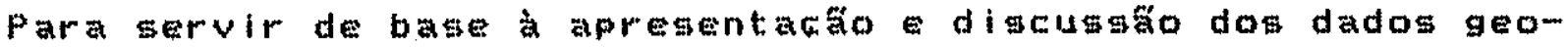
cromológicos obtidos intersegtados de forma integrada com os

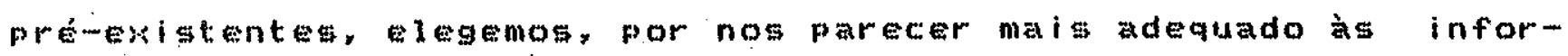

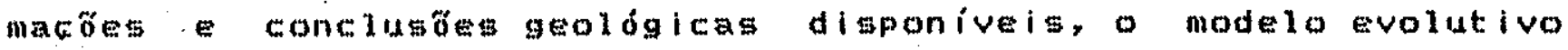
propogto por Fragoso Cegar at al. (198еb), obedectomo, no garal, a

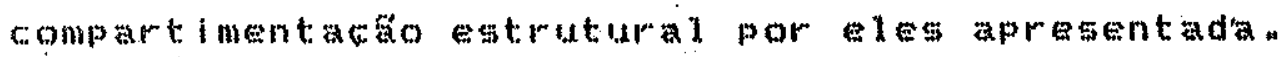

Após os levantamentog e studos aqui abordados, deduzme que 
tal modelo resiste ao, agora maior, acervo de dados radiométricos e estes permitiran un melhor ajuste dos mecanismos de geracăo dass rochas envolvidas, proplelou a correcto elou o entendimento de alguns aspectos controversos e o detalhamento de fenômenos anterior -. mente vagos, indefinidos ou apenas delineados.

A diferenc maior constatada reside na necessidade de recompartimentar-me o Escudo gaucho, do ponto de vista geotectônico. Euprimindome área de exposicáo do Cráton do Rlo de La Plata, atribuindo ao Bloco raquarembo a conotacto do macico marginale ampliando-me, en consequencia, os domínion do cinturáno Dom Feliclano, com o bloco sáo Gabriel pasando fazer parte de mia bacia marginal.

Alterame também o intervalo de tempo dentro do qual a falka

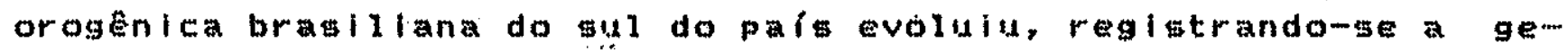

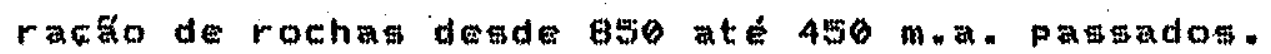

\subsection{Estabelecimento do Quadro Cronoestrat igrafico}

AE litologlas transamazonlca afloranteg no Escudo do Rio Grande do.sul, associada a unidades cronocorrelatas de Santa Catarina e Uruguai, permitem que se Imagine para o Brabil Meridiom nal. uma ampla area crustal desenvolvida no tempo menclonado, em cuja borda oriental superpuseran-mo fenômenos geológicos do ciclo Brasiliano.

Acompanhandoms o quadro cronoestratigrafico estabelecido por Batei (1985) para o Cintura Dom Feliciano em Santa Catarina, per cebe-se que o mesmo pode ger aplicado para o prolongamento da en- 
tidade no Rlo Grande do sul, nog dols terqog finals de sua história evolutiva, ja que os eventos inicials nág foram la reconhecim dos. Denominaremos, de maneira informal e apenas para referencia,

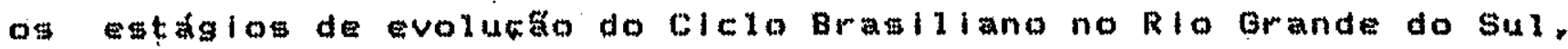
usando, para tanto, designatos geograficas onde este episódios, pelo menos ao nivel dos contecimentos atuals, encontram-se melhor repremtados.

O fenbmeno orogenico sul-riomgrandense, do proterozóico superior. como vislunbrado por aste trabalho, erenedido por una deposicáo plataformal, en margen continontal passiva, identificada pelo Subgrupo Cerro do Madeiras, basal no torupo Porongos, há mais de 850 ma. (fig. 114). Por volta desses tempon comeda o fechamento de um oceano proto-At lântico, com subduçăo de crosta oceânica para gob a paca litomerica continental \$ulmamerlcana, caracterizando uma subduck talam ma borda continental cavalgante, um arco magmático do tipo Andino cujas rochas resultanteg se deixan repreantar pelos granitódes deformados da fase precoce calci-alcalinos do tipo I Corditheiranos, Peprepentantes do Evento Piratini. Como feic a as-

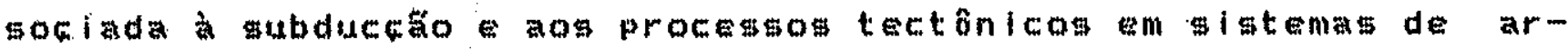
co, implantange, a oent, uma ampla bacia marginal que passou a receber gedimentos clasticose químicos, aos quals asociaram-se manifestacoses magmaticas basicas, em epecial a ocidentev e intermediarlas ácida a oriente, nas prokimidadet do arco vulcânico.

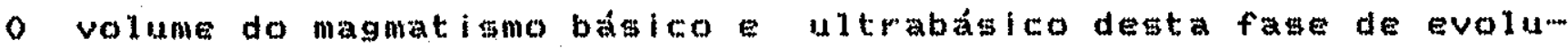
6. Ko. normalmente abundante, parece ter gido pequeno, ou pelas condicose ducteit da crosta, ou por sua empentura elevada que náo pernitiu un fraturamento intenso da mesmay gracas a ajustes internosin 


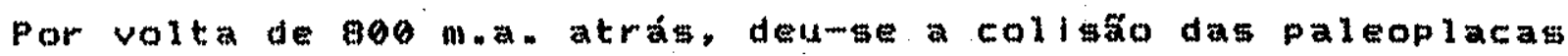
que Inclulan os critons do Rlo de La Plata do Kalahari, consistindo na primeira fase de deformacto, quando fol gerada a Zona. de Fratura da Dorgal de Cangucu, sma sutura de colisáo intraplaca (subduccáco do tipo A de Ampferer) entre o arco magmático a bacia marginal, em cujo interior potclonou-se a sute Corditheira, do

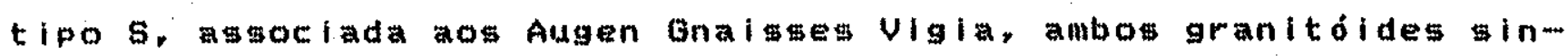
colisionals (Fragomo Cemar et al. y emprep.). Om metamorfitos consequentes deven ter desenvolvido sua primeira foliacko, enquan-..

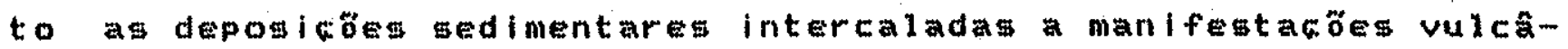
nicas prosgegulam no âmbito da bacia.

Com o encurtamento e espesgamento crustal, o arco magmático evolulu para o tipo Caledoniano e proporcionou a formacắn dos gram nitódes da fame principal (tipo I - Caledoniano) in a póscolislonal, rewiltante da füfo parcial da suite precoce de possiVeis rochas do embatamento (Evento Pinheiro Machado). Os efeitos deste fenômeno de colisăo năo sâno claros no domínio da bacia mar ginal, mas registram-se en seus metamorfitos idades desta orden (fig. 95).

o. incremento de rigidez náa do arco magmático e prosseguimento do esforcos confinantes produziram o fechamento da baCla marginal, com a implantacto da follacto NE en todo o cinturóno - o estabelecimento da predoninante vergoncia NW. Emte parece ter sido oprincipal evento tectono-termal acontecido (Evento Vila Nova), produzindo o pleo metamórfico nas gequeneias supracrustais está videntio na figura 95, confirmando a importancia do periodo temporal compreandido entre 750 e $650 \mathrm{~m}$. 
A esta epoca pertence o magmatismo sintectónico de tendência trondhJemitica calcimalcalina do Complewo vila Nova e, possivelmente, o vulcanlsmo de difermelados maficos ultramáficos. En estagio tardi-tectônico, intercalado às sequências clásticas quimicas em processo deposiclonal, ssociaram-se epiodios igneos de caráter intermediálo ácido. Pode pertencer a esta etapa o Anortosito Caplvaritan

o soerguimento regional que me sulis propiciou a colocacăo de diapiros granitoides ainda sob regime compressivo (nicleos dos complekos Săo Sepé, Lavras, etc.), derivados do processo de gubduc-

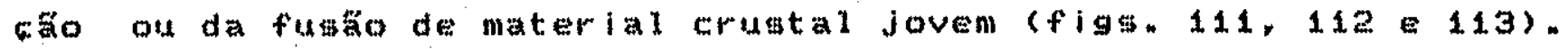
Contemporaneo ou ligeiramente gubsequente foi o inicio da deposi6. So dos sedimentos molassóides, aos quais intercalamme vulcani-

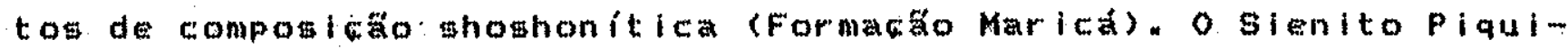
ri pode representar uma das últimas manifestacoes masmáticas desta fase.

Ao redor dos $550 \mathrm{man}$. observawe um novo pulso tectốnico que resultou em dobramentos de eixos de direcaro NE Planos axiais mergulhantes para sudeste, corrempondendo as primeirag deformacótes

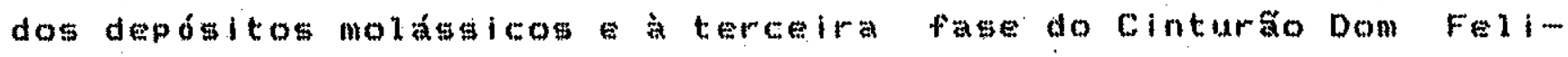
ciano. Reativatoes Inversas dos principais lineanentos, gugeridas pelo padra de decrésclmo das idade K - Ar, no sentido leste, transversalmente ao arco magmático, a colocacáo final de granitóldes, agora rem regme distensivo (Sulte Dom feliciano, no lado leste; fracós de bordo do complexos de Săo Sepe Lavras do Sul, granitos. Cacapava Jaguari, nabacia marginal, e Santo Afonso Saibro, na borda do macico marginal hoje gupostos constituiram os principais episodios desta fase (Evento Dom Feliciano). As gêneses 
destes corpos granitóldes dos tipos I e/ou A pode ter se dado a partir de refusoos crustats, de materiaig mantélicos ou de materiais hibrldos (figs. 111.112 e 1.13). O encerramento do pulso aconteceu con as manifestacobes vulcanicas ácidas da formacáo

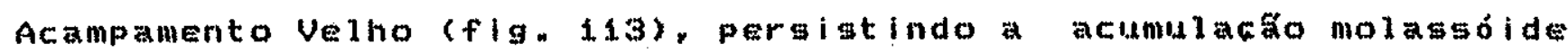
(Fornac ăo Guaritag).

como atividade final regigtraram-se amplas inflexố descontinuas, observada con facilidade na gequencia molassóde tardia (segunda fase deformacional nat molassas quarta fase no cinturăos, acompanhadas de reativacós trangcormentes nos principaig lineamentos. Magmatismo básico ácido do tipo A, esparsos nos dominios da bacla marginal (Granlto da Ramada, vulcanitos do Cerro Tupanci mierogranito intrusivos do complexo de são sepé, figs.

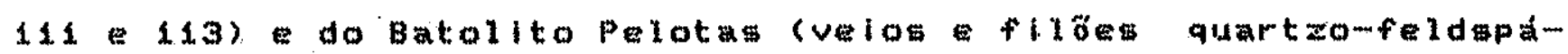
ticos) representan ms litimas manifestacón igneas registradas, há 460 m.a. (Evento Tupanci/Ramada).

Seguiumst, entăo, o resfriamento reglonal a etabilizacăo tectônica da área (Quadro cronoestratigrafico-tabela 36)"

\section{Possiveis correlacôes de entidades geotectônicas na porcão me- ridional do Escudo At lântico e ajustes com a Província Damara.}

As entidades geotectônicat que compóen o quadro geológlco do Précambriano na porcho merldional do Escudo At lantico afloram de maneira desmontinua, em, parte recobertas por sedimentitos da bacia do Parana, em parte por sedimentos inconsolidados da planície costeira do Rio Grande do Sul o Uruguai, fleando dificil, às vezes, a Identificacto correlacta de suas parcelas, sobretudo em se 
tratando dos terrenoss ocidentais (fig. if 6 ).

Entre o Rlo Grande do Sul o Urugual cilar a correspondênEia dos granltóides do Batólito Pelotas das supracrustais da bacla marginal (grupos Porongo e Lavalleja), uma vez que mua exposicöes revelam uma continuidade fílica quase completa.

Os metanorfto da Bacia Frontal (Fragoso cesar et al.. 1.982a) ocorrem somente no Uragual, noto sendo conheclda qualquer outra area ectinitica posicato geogafica mimilar, ou sejar a leste do Batólito Pelotas (fig. 1.5."

Para norte, a partir de Porto Alegre, o que se observa é uma

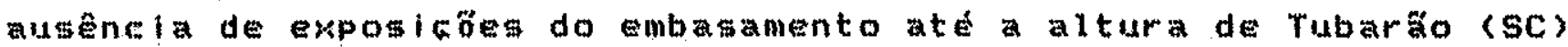
(fig. 116), agravada pelos parcos conhecimentos geológicos em disponibilidade para a fraço merldional do Escudo Catarinense. A porcto setentrional desta unidade é melhor conhecida, superpondowe divergos trabalhos, entre os quais destaca-me o de basei (1985). Este autor $r$ lata que, no âmbito do Grupo Brusque, o magmat ismo do tipos ś o dominant:e, enquanto que internamente ao cinturso Dom Fellelano paggam a prevalecer co granitódide do tipo. I. embora

Em ordem cronolófica, Batsel (op. Cit., relaciona, para a regiäo, of granitóldes follados indiferenciados aflorantes a oeste

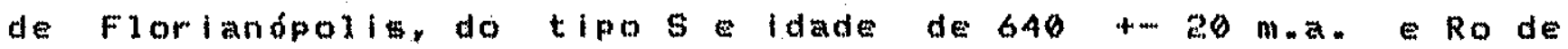
0,708 a $0,74.1$. Temporalmente Hilar a suite Valsungana (640+-

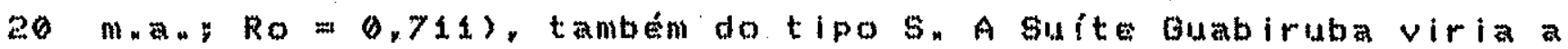

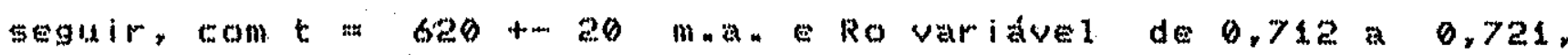
sendo também do tipo s. Para encerrar o estaglo sin a tardi-tectô- 
nico, o autor menciona suite Sắo Pedro die Aleântara, do tipo I ldade da orden de $600+-20 \mathrm{~m} . \mathrm{a}$. . com Ro $=0,708$. Relacionadas ao

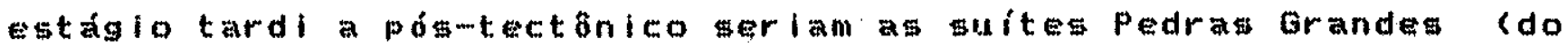
tipo I. com Ro de 0,710 a,728) Subida (tipo A, com Ro de 0,700 a 0,705$)$, ambas com cerca de $540+\ldots 20 \mathrm{~m} \mathrm{a}_{\ldots}$.

Em outro trecho, o autor mencionado relata no ter obtido, na área trabalhada, indicacóses da presenca de materiais rochosos derivados do conmumo de placa oceânica, questionando a correlacăo entre os terrenow crlatalinos catarinenses a porcto oriental do Rio Grande do Sul, alegando diferencas radiometricas superiores a 200 ma. Elferencas geolódcas, en tre tratando dos tipos petrograficom tonaliticos quartaomioriticos nä́o ocorrentes naquele Estado.

Com base na associacto litolóica atribuida ao bloco EncruziIhada cpara ertognaisses intrudidos por, pelo menos, duas gera-m Göes de granitóldes isótropos - Frantzet a . 1984) nas idades radiometricas discutidas nette trabalho $620+\cdots 10 \mathrm{~mm}$. E Ro = 0,708 para os primeirose $560-550 \mathrm{ma}$. Ro $=0,716-0,718 \mathrm{pa}$ ra os littimom, gendo o mals jovem correlacionád a Sufte Dom Feliciano) postivel sugerir que no Estado de Santa Catarina aflora un conjunto rochoso similar ao do Bloco Encruzilhada, ou geja, uma associacaro de bacia marginal, onde os granitóldes do tipo I re.g. Suite Pedras Grandes) representarlam apoflses do magmatismo desen-m volvido no vizinho batólito, a memelhanca do que se dá com a suite Dom Feliciano que intrude os metamorfitos da bacia marginal, no Bloco Encruzilhada. Se é isto o que ocorre, o limite entre as entidades geotectônlcas brasilianas (batolito - bacia marginal) poderia cormegonder, na fracto getentrional, a aternativa da figu- 
ra 116. Un dado. que corrobora esta hipotese ven a ger as lades da ordem de $700 \mathrm{~m}$. a. conseguidas nos biotita gnaisses da catinga na Faixa Ribeiráo da Prata, a noroeste do cinturato, similares aquelag encontradas nas prowimidades de Vila Nova, no Rio Grande do sul.

E preciso manter en mente a possibilidade de termos afiorandor no sul do Escudo Catarinense, uma fracto do batolito Pelow tas representada pelos granitódes da fase tardia csulte pedras Grandes - SC $\approx$ Suite Dom Feliciano-RS).

Ferrando Fernandez (1971), baseadom ent Hart (1966) Um- U pierre E Halpern (1979), asteguram que na metade ocidental do Escudo Urugualo os granitóideg gintectônicos tên ladas compreendi-

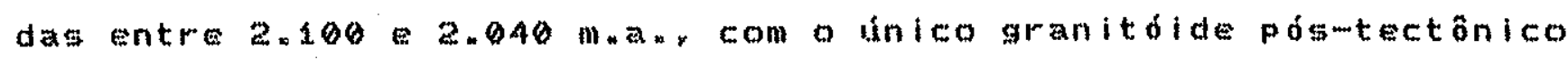

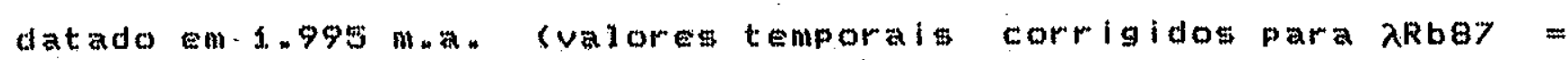
$1,42 \times 10^{-11} a_{0}^{-1}$, seg. Steiger Jäger, s.977). Nas proximidades da faika brasiliana, a leste, a obtención de idades se torna dificil, com tendencias a valores menores a gnificativa indetermina Eăo por dispersazo dos pontos analiticos. Como exemplos, mencionam os granitódé de Nico Peréze Cerro Colorado, cujas andises po-

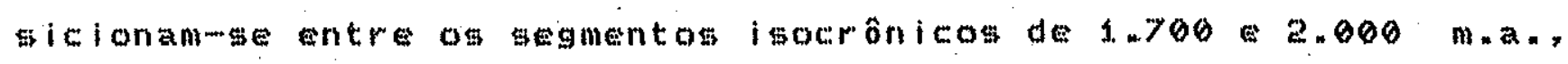
e os granodioritos de soca, com valores de $1.600 \mathrm{~mm}$ a y alén das idades bratilianas de cerca de 580 ma. an migmatios granitos intrudiaos. A conclusăo dos autorese a de que a regiäo de Nico Perez (fig. 1SS) deve ter sido afetada on distintom graus pela orogênew brasiliana contigua. mas o carater cratônico continua preservado. Esta zona de influência do ciclo mais jovem parece estar inclusa no triangulo delimitado pelas falhas que ligam piriám polis a Sarandi dei $Y_{i}\left(S_{*} Y_{n}\right)$ e Fray Bentos a Valentines (UN) 
$\langle f i g=115 \div 116\rangle$

Ao norte do falnameto Fray Bentog- Valentines, Bossi. (1983) descreve, tentativamente, um nucleo primitlvo, do qual também fam ria parte a "liha crigtalina" de Rivera (fig. 115). Segundo o cientigta, a falba de direcáa leste-oeste represtonta bordo nerim dional de ocorrencia de piroxenitos quarteitos augiticos, alem de sparar fragmentos crustais estruturalmente distintos cN7OQE para as rochas garadas no ciclo Orogenico Ant go N7ogw para as demals bltuadas ao nortel. En adifo, menciona que hádiferencas do ponto de vista econômico, encerrando o "Nícla primitivo" possiveis jaximentog de ouro, ferro mámores intensamente recrista1 ixados.

Como vimos nos itens 2.1. 2.2. degte capitulo, a "ilha cristalina" de Rivera o Bloco Taquarembó representan fracổ crugtal onde afloram metagranitódidestrangamazónicos, com forlaEto NW, Intimamente astociados a granitódes bratilianos, geralmente isdtropos, com ldades variavels entre 650 esso m. a., sendo que estes littimos podem superar em area om primeiros. Por similarldade geologica, Bogsi (op, cit.) correlaciona os metamorfitos e granitóldes da "Iha" de Rlvera aos da regi äo de Valentines. Embo-.. ra nó haja dados quantitativos relativos a egta littima regiäo, as mesmas foram, neste trabalho, resnidas, pelos motivos já expostos nos itens mencionados en carter tentativo, na entidade Macleo Marginal.

Os dopósltos molassóides gedinentares vulcano-sedimentares dos grupos Itajai (SC), CanaquS (RS) formafóng Piedras de Afilar - Sierra de Ánimas (Uriguai) parecen ser temporalmente correla- 
tos. Mas conotacto de Antefossa Molássica mó pode ser apllcada Para as acimulacöes das extrentdades norte e sul do cintura Dom Feliciano. No Estado do Rio Orande do Sul, a dispomicáto da molassa no contexto geotectónico caracteriza, diferentemente, uma Intrafogsin.

Por outro lado, a compartimentata geotectônica e os estágios

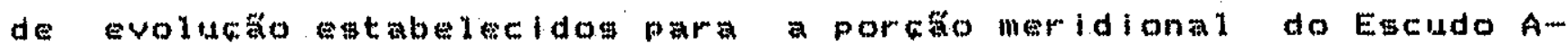
tlântico revelam um notável ofignificativo ajuste geológico geocronológico com os termenos do sudoeste da África.

Kröner $\{1982\}$, em base a dadom $\mathrm{Rb} / \mathrm{gr}$, demongtrou que a histom. ria evolutiva do cintura oamara (tab. 37 ) fol consideravelmente mals longa do que a da maioria dow cinturóes fanerozólcos contecidos, tal como ja enfatizado para o Cintura Dom Feliciano. A simi-.. larldade temporal entre os doig orógenog năo se restringe a duracăo total do epgódio diastrótico, mas também evidente a equivalencia dos pul tos de magnagenese co de deformatio registradom nos donínios de ambas as areas. Asmim. wer lam correspondentes, respec-.. tivamente, os eventog Palmental - Pinheiro Machado, Lsakos-Vila Nova, Salem - Dom Feliciano e, por fim, Alaskito - rupanci/Ramada, como ge deduz da objervaga comparada das tabelas 36 a 37 . Corre-

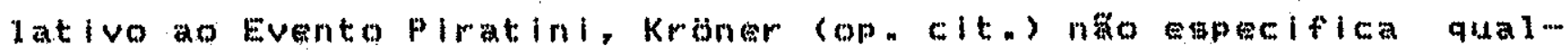
quer episódio termal, mas menciona a Intruago de sienito viscanimmo ácido como manlfetacto magnat icas premoroganicas.

Oconjunto de entidades geotectônicas fica completo con a justaposica dos continentes sul-merlcano africano, após o tram balho de Harthads et al. (1985), que, ao sumarlatem a evolucáto crustal do sw da Africa nos tempos do proterozótco, afirman qut 
recongtrucosed paleomaneticas para os exatons do kalaharle do Congo săo sugestivas da exlatencia, no préciambriano superior, de un oceano (denominado Adamator) a separar talifragmentos crus-. tais, prologando-ge ampliandomse para gul até a Provincia TranSantártica $(f i g, 147)$.

A origeme o posterlor fechamento desse oceano, ao longo da sutura oflolitica mepementada, de forma quame contínua, pelas falkas de corpos anfiboliticos metabasalticos do entorno ocidental do Craton do Kalaharl (flg. 119), säo fenomenos aog quals recorren os mencionados autores para explicar uma sérle de aspectos até enta controvertidos na evolug go geotectốnica dos cinturôs Damara, Garlep Saldania. A subducfóo da litosfera oceânica Para sob o. Craton do Rio de La plata, no processo de fechamento do mar Adamastor, que motiva lmplantacáa do arco magmático hoje representado pela exomicöes profundas do Batolito pelotas

\section{Recomendacóes Finais}

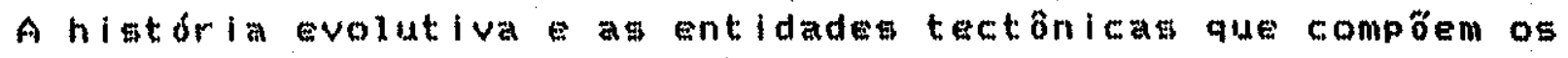
terrenos oremcambrianos do Escudo Sul-riomgrandense, tal como divisadas neste relatório, basearam-se, esgenclalmente, como visto nos capitulos anteriores, em dados radometricos obtidos atraves dos métodos K-Ar Rb-\$r, gendo quantitat fvamente pouco expressivos os resultados advindos de outros istemas latópicos o acervo geocronoldgico hoje disponivel para a area mencionada soma cerca de cinco centenas de análised Uma parcela importante deste total tem que ger entendida como idades minimas (K-Ar) dos materiais rom chosos investigados, Gignificando époeas de resfriamento, fenómeno geológlco atsociado aos levantamento epirogenéticos regionais, 
cuja posicion no tempo precisa ser também determinada.

A fraço mafor e de idades Rb-Sr, convencionals ou isocrônicas, mas os resultados foram, en grande parte, conseguidos de conjuntos de rochas nem sempre cogeneticas, conslderados, portanto, como valores de referencia. Apesar disso, a obtencä́o de idades similares, pela construg aco de numerosos diagramat isocrônicos. derivados de grupos de amostra provenientes de areas distintas de una mesma unidade litodemicar nos leva a crer que tals cifrag temporals são merecedoras de credito têm o bignificado genético a las atribuido quando das interpretacöes correspondentes.

Estamos convencidos de que o quadro temporal ora apresentadz encontra-me estatelecido nos geus termos mais gerais e náo deverá sofrer no futuro alteracoses ignificativas. Há, no entanto, muito por fazer no gentido de aprimorar ou refutar os modelos de evolum Găo. geotectionica propostos para a regiăo por vairlos autores definir como verdadeiras ou falsas hipoteses ate agora apenas delineadas

Prosmeguir nal aplicacto dos métodos K-Ar ou Rb-Sr passa a ter sentido somente no waso de levantamentog sistemáticos para o en tendimento da historia termica de areas definidas ou na obtencato de valorez isocranicos de amostrag consangilineag associados a um perfeito controle das relactos estruturaia das litologias estudaa Nova Este deve ser o procedimento nog estudos a seren realizados nos domínios do Batolito Pelotan, onde, en um mesmo afloramento. sắo observados váriog pulsog magmáticos que podem estar temporalmente separados por dezenas ou centenas de milhöes de anos. Como 
agravante, em taimentidade geotectónicar poesivel recorrencia de tioos petrograficos torna inviavel a asmociasa dos mesmos em um um único diagrama latotopico.

Fenônenos geológlcoscomo época da diferenciacáo a partir do manto acrescäo a crosta, o tempo de residencia na litosfera, os graus etipos de contaminacád a passagen dos magmas precursores por ciclo sedimentar anterior ou retrabathamentos por superpo-.

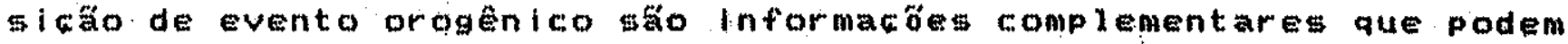
ser consegulda pela combinacă de duas ou mais metodologias geocronológicagi. Em congequência, recomendamó a obtencto de um número maior de dados Pb-Pb, U-Pb em zircóes Sm-Nd, este sobretudo para o estabelecimento das idades dos conjuntos maficos altramá-

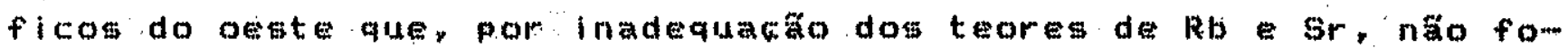
ram ainda conhecidas odem estar relacionadas a mais de um epiSódio magnático.

Gostariamos que os pensamentom aqui expresos fossem tomados apenas como alternativag possivei e que ficasem sujeitos a in-

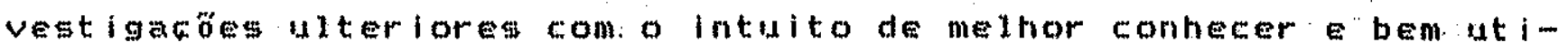
lizar os parametros o potencial geológicos do Eseddo sulmiom grandense. Assumir algumas. das ldeias discutidas neste tmatalho implica en alteracta de conceltos vigentes, en reformalacosed de cunho estratigrafico. em mudancas nas orientacöes de futuros tra-m balnos geológicos e na modiflcaço da testrategla de prospectád de recursos economicosn 


\section{AGRADECIMENTOB}

A realizacto do prebente trabalho of fol pomsivel gragas ao apoio advindo de pessoas de instituicoseds quals o autor gostaria de externar seu profundo reconhecimento.

Ao Prof. Dr. Umberto 0. Cordani, orlentador, meu prelto de

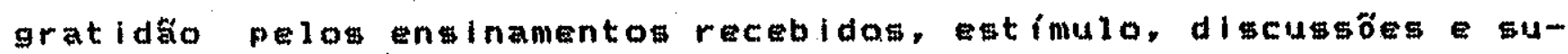

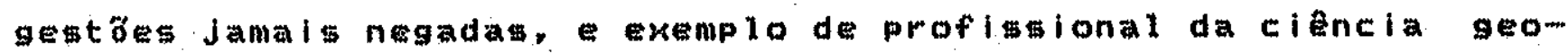
cronológica, incanarvel dedicado as mas atividades docentese de pesquisa.

o mesmo sentimento extengivel ao Prof. Dr. Koji Kawashita que, além de ter estado senpre à dispogláa para enoinar e discutir. fol o responsavel malor pelas andlises espectrómetricas aqui apregentadam, atraves de un trabalho revelador de abnegaco impar.

Agradecemos tambén aos colegas professores geocronólogos Antonio Romalino s. Fragoso Cesar, Colombo Celso Gaeta Tasminari. Wiluon reikeira Miguel Angelo 5. Bamel, do Ingtituto de Geociências da USP, Oswaldo Siga dr., Ralmundo Montenegro G. de Mon-... talvăo Roberto da SIlva I\$\$ler, do Projeto RADAMBRAsIL, pelo auwilio emprestado nos diferentes monentos do andamento desta pesquisa pelos exclarecedores, debates que, en mito, influenciaram nas interpretacöes conelusós aqui assumidas

Com ot profemores Breno Corrêa da Sllva Filiho, Hardy Jost, L.auro U. Stol Nardi, Léo Afrâneo Hartmann. Marla de Fátima Bitencourt e José Carlos Frantz, do Instituto de Gecionclas da Universidade Federal do Rio Brande do Sul. Pedro Lulz Partorl O Olavo 


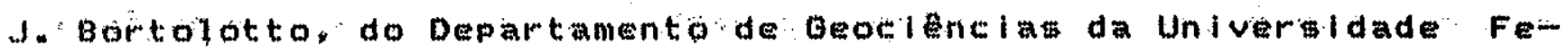
deral de Santa Maria, Lidiz Alberto $D^{\circ}$ Ávila Fernandes, Farid Çhemal Ju. . Carlos Henrique Nowatzkl Milton Antonlo A. dos Santos, da Universidade do Vale do Rlo dos sinotipela colaboraca e in-

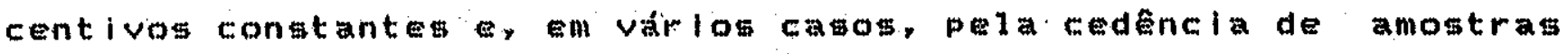

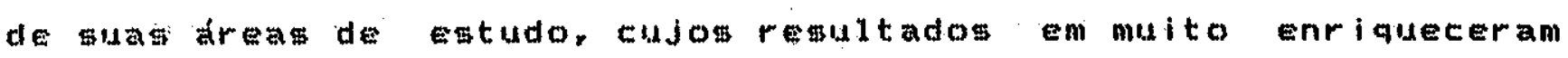
este trabaliro, o autor considerame en débito.

Aow doutore Gerard Poupeal, Stephen Moorbath e Paul N. Tay-

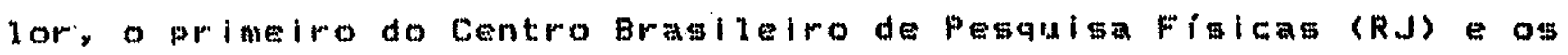
seguintes da Universidade de Oxford (Inglaterra), por teren prom porcionado aportunidade de realizarem-medeterminacós geocronom lógicas por Tracos de Figağo pelo método Pb-Pb, bem como, ao Dr. Martin Halpern, da Univeraldade do Texam, por ter permitido a ut llizaço de dezenas de análises Rb-Sr alnda inéditas, que multo contribuiram para o entendimento de alguns dos aspectos pesquisadose, algumas vezes, foram decialvas no equacionamento resoluGลัง de problemas levantados, comsignamos os melhorę agradecimentos.

roda a gratid知o igualmente conderocada aos tecnlcos e funcionárlos do CPGo, Ivone Sonok $i$ Helen Sonoki, Clátadio comerlatti. José Elmano de A. Gouvela, Jorge Gouvei de Almeida, Margarida Martins, Cladio dos santos, Joss Roberto Medeiros, Décio Duarte Rosas claudete Salinas, ao fisicokel Sato, pela mals variada colaboracáno emprestada no longo do estudo representado por estes escritos.

Externamog todo o notso agrado aos primos Joaquim floriano de Toledo Netto L Loi Hastog Aguiar de Toledo que, atraves de 
sets carinho e tenctoo. sempre tornaram amena nossa permanência Em Sto Paulo.

Finalmente, agradecemos bolsa de pós-graduacko oferecida pela CAPES, através do Convênlo PICD/UFRos, com qual fomos contenplados durante parte do tempo dedicado a presente levantamento, a todas aquelas pessoas que das mal diferentes maneiras contribuiram par a efet ivacto do trabalho ora apresentado. 


\section{REFERÊNCIAS BIBLIOGRAFICAS}

ALMETDA, F.F.M. AMARAL, G.; CORDANI, W. "O. KAWAGHITA, K. (1973) The Precambrian evolution of the south american cratonic margin south of the Amazon river. In: The Ocean Basin and Margins, (Nairn Stehli, Eds.), Plenum, P. 1411-1446, New York.

ALMEIDA, F.F.M.; HASUI, Y.: BRITO NEUES, B.B. EUCK, R.A. (1977) Provincias estruturais brasileiras. Atas do VIII Simpósio de Geologia do Nordeste, p. $363+391$, Campina Grande.

AMARAL. , G.; CORDANT, U.G.; KAWASHITA, K, REYNOLDS, J.H. (1966) Potasslum-argon dates of basaltic rock from southern Brazli. Geoch. et Cosmoch. Acta, 30 $=159-18 \%$.

ARDEN, J. GALE, N.H. (1974) Separation of trace amounts of uranium and thorium and their determination by mass espectrometrie igotope dilution. Anal. Chem., 46: 2:-9.

ARMSTRONG, R.L." (1966) K-mAr dating of plutonic and volcanic rocks in orogenic belts. In: Potasslum-Argon Dating, (0.A. Schaeffer \& J. Zähringer, Edg.), p. 117-131, Springer - Verlag. Held lbersw

BARKER, F. (1979) Trondh, Jemite definition, environment and hypothe is of origin. Inn Trondhjemites, dacites and related

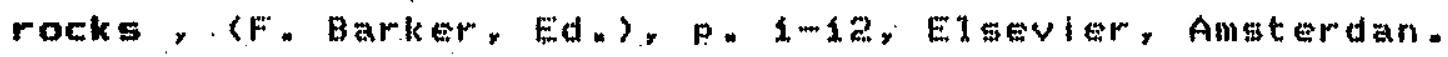

BARKER, F, ERTH, JW. (1976) Beneration of rrondhjemitic-tona 
It ic liquids and Archaean bimodal trondhjemite-basalt suites..

Geology, $4=596-600$.

BASEI, M.A.S. (1984) O cinturäo Dom Feliciano em Santa Catarina. Relatório de Atividades, Fapesp. Gäo.paulo (inedito).

BASEI, M.AnS. ( 1985$)$ Cinturäo Dom Feliciano em Santa catarina. Tese de Doutoramento, Curso de Pósmoradua do TG/USP; Sto Paslo (Inédito).

BITENCOURT, M.F.(1983) Metamorfitos da regiäo de Cacapava do Sul, RS. Geologia e relacón com o corpogranitico. Atas do Io Simp. Sul-bras. Geol., . 37-48, Porto Alegre.

BITENCOURT, M.F. HARTMANN, L. A. (1984) REconhecimento geOquimi co dog xistos magnetinos da regia do Pasó Feio. Cacapava do Sul, RS. An. XXXIII Congr. Bras. Geol., 6: 2607-2,614, Rio de Janeiro.

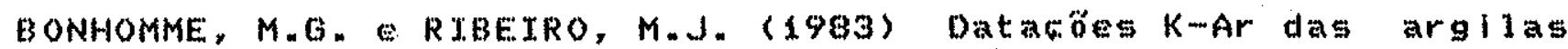
associadas a mineralizacöes de cobre da Mina Camaqua de suas Encaixantes, Atas do Io Simp. Sul-bras. Geol., P. 82-B8, Porto Alegre.

BOS5I, J.: FERKANDO, L. ALBANELL, H. (1967) Basamento cristalino del sureste de Uruguay. UNESCO (inédito).

Bossx, J. (1983) Breve reseña sobre conocimiento geológico del Estudo Predevontano en Uruguay (Sud Americia). Zbl. Geol. Palaont. Teil I $(3 / 4): 417-429$, Stuttgart. 
BRTTO NEUES, B.B.; BEURLEN, H. E SANTOS, E.J. (1982) Characteristics and mineralizations of the Archaean and Early Protero rozoic of the Borborema Province, Brazil. Rev. Bras. Geoc.. $12(1-3): 234-239$. (Anais do TSAP), Sáo Paulo.

BRTTO NEUES, B.B.; SIAL, A.N.; RAND, H.M. E MANSO, U.V. (1982) The Pernambuco - Alagoas Massif, Northeast Brazil. Rev- Bras. Geoc-, $12(1-3): 240-250$ (Anaim do ISAP), Săo Paulo.

BROOKS, C. HART, W. WENDT, J. (1972) REalistic use of two-error regression treatments as applied to Rubidium-Strontium data Rev. Geophysics and Space Physics, 10 (2) : $551-577$.

CAMPOS NETO, M.C. (1.985) Evolucăo do Pré-Canbriano paulista e re-... giöes adjacentes. Atas do so simp. Reg. Geol., (Mesas Redon-das), SB(G/SP, vol. 2, P, 561-585, Sáo Palon

CARRARO, C. C. " GAMERMANN, $N_{n}$; EICK, $N_{n} C_{n}$ " BORTOLUCCI, C... H. ETNTO, J.F. (1974) Mapa Geológico do Estado do Rio Grande do Su1. TG/UFRGS, Porto Alegre.

CARVALHO, P.F. (1932) Reconhecimento geológico no Estado do Rio Grande do sul. Bol. Inst. Geol. Mim. do Brasil, 66: 1.-7e, Rio de Janeiro.

CHAPMAN, C.A. (1976) Structural Evolution of the White Mountain Series. Geol. Soc. Am., Mem. 146, p, 281,-300.

CHEMALE JR., F. (1982) Geologia da região de Palma, São Gabriel, Rio Grande do Sul. Dissertacáo de Mestrado, Curso de Pós- 
Graduacán em Geociencias da UFRos, Porto Alegre (inedito).

COBBING, E.J. PITCHER, W.S. (1972) The coastal batholith of central Peru. Jour. Geol. Soc. Lond., 128= 421-460.

COLEMAN, R.G. EETERMAN, Z.E. (1975) OeEanic plagiogranite. Jour. Geophys. Res =, 80: 1.099-1.108.

CONDTE, K.C. (1973) Archaan magmatism and erustal thickening. Geol. Soc. Am. Bu11., $84=2.981-2.992$.

CORDANI, U.G. (1974) comentärio sobre as determinacós geocronológicas disponiveis nas folhas Assunción e Curltiban In: Carta Geológica do Brasil ao Milionésimo. texto explicativo das foThas Assuncion Curitiba, DNPM, P. 58-72, Brasilia.

CORDANT, U.G. (1980) Fundamentos de Interpretacáto geocronológica. Bol. nQ 6 do XXXI Congr. Bras. Geol.. Cambor í.

CORDANT, H.G." HALPERN, M. BERENHOLC, M. (1974) ComentäIOS sobre as determinacós geocionológican na Folha porto Alegre. In * Carta Geológica do Brasil ao Milionésimo, texto explicativo das folhas Porto Alegre Lagoa Mirim, DNPM, P. 70-84. Brotatia.

COROANT, U.G. BRTYO NEVES, B.B. (1982) The geologic evolution of South Amerlea during the Archatean and Early Proterozoic. Rev. Bras. Geoc., $12(1-3)=78-88$ (Anais do TSAP), Săo Patdo. 
CUNHA, F.M.B. (1964). Ëtudo pretiminar de integracáo do prémambriano con ou eventos tectônicos das baciat bedimentarestorasileirat Ciencia-Técnica - Petróleo, 15: 1-70, Petrobras , (CENPE $(3-D T U E X)$, Rio de Janeiro.

CORDANI, U.G.; SATO, K. MARINHO, M.M. (1985) ThE geologic eVolution of the ancient granlte-greatone termane of centralsouthern Bahia, Brazid. Precambr. Res., $27(1-3): 187-213$, Ans$t \in d d a m$.

DEROS, L.F. FERNANDES, L.A.D. (1981) ROChaB charnockiticas no Escudo sulmiomgrandensen. Acta Geol. Leop.. 13 (9):25-44, s. Leopoldo.

DRESCH, R.A.C.F FIGUETREDO FE, P.M.; FORMOSO, M.L.L. (1973) CO-

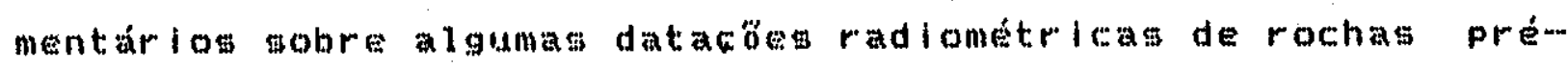
cimbrianas do Rio Grande do Sul. Ir Congr. Latino-amer. de Beol. P. 1617-1623, Caracas.

FAURE, G, (197\%) Principles of Isotope Geology. John Wiley \& Sons, 46A P.. New York.

FAURE, G. POWELL, J.l. (1972) strontium Isotope Geology. Springer-Verdag, 488 .. New York.

FERRANDO, L“A " FERNANOEZ, R.N. (1974) EEquema Tectônico Cronoesteratigrafico del Predevoniano en Uruguay. An. XXX Congr.

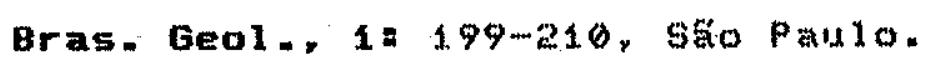

FORMOSO, Mul..tn (1.972) Geologia da Folha de Capivarita, RS. Tese 


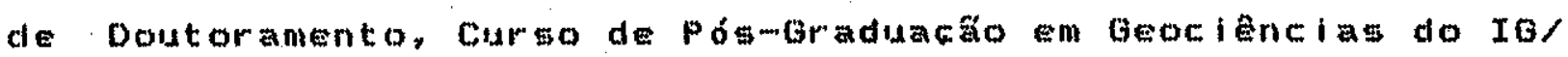
USP, Sa Pauto (inédito).

FORMOSO, M.L.L. CARRARO, C.C. (1968) Anortosito de Capivarita, Rio Pardo, R.S. An. Acad. Bras. Cienc., 40 (3):361-372, Rio de Janeiro.

FRAGOSO CESAR, A.R.S. (1980) O Craton do Rio de La Plata o Cinturão Dom Feliciano no Escudo Uruguaiombut-riograndenge. An. XXXI Congr - Bras. Geal .. $5=2879-2892$, Canbor id́.

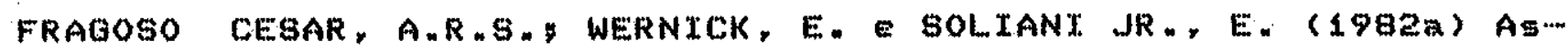
sociacổes petrotectônicas do cinturăgo Dom Feliciano (SE de Plataforma Sul-americana). An. XXXII Congr. Bras. Geol.. 1 : 112. Salvador.

FRAGOSO CESAR, A.R.S.; WERNICK, E. E SOLIANI JR., E. (1982b) EVOLuca Go Gotectônica do cintura Don Feliciano - Uma contribui m cáo atravéda aplicacto do modelo de tectónica de placas. An. XXXII Congr. Bras. Geol., 1: 13-23, Salvador.

FRAGOSO CESAR, A.R.G. GOLIANI JR * E. (1984) Compartimentagáo tectônica do Cráton do Rio de La Plata. An. XXXIII Congr. Bras. Geol., 5a 2426-2434, Rio de Janeiro.

FRAGOSO CESAR, A.R.S.; LAUINA, E.L. "PAIM, P.S.G. FACCINI, U.F. (1984) A Antefossa Molásica do Cintura Dom Feliciano no Escudo do Rio Grande do Sul. An. XXXIII Congr. Bras. Geol.. 7 . $3272-3283$, Rio de Janeiron 
FRAGOSO CESAR, A.R.S. FACCINT, W.B.; PATM, P.S.G.; LAUINA, E.L. 6 ALTAMIRANO, J.R.F. (19g5) Revistöo da Estratigrafia das Molassas do ciclo Brasiliano no Rio. Grande do Sul. Atas Iro Simp. Sul-bras. Geol ., P. 477-49, Florlandpolis.

FRAGOSO CESAR, A.R.S. FTGUETREDO, M.C.H. SOLTANT JR., E. E FAC CINI, U.F. (cm prep.) O Batólito Pelotas (Proterozóico Superior/Eo-paleozóico) no Escudo do Rio Grande do Sul.

FRANTZ, J.C. JOsT, H. (1983) Petrologia dos granitos estanifem ros do Rio Grande do Sul. Atas Io simp. Su1-bras. Geol.p. 4967. Porto Alegren

FRANTZ, J.C.; LIMA, E.F." MACHADO, R.P. NAUMANN, M.P. (1984)

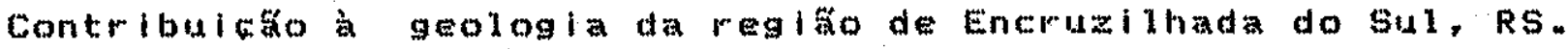
An. XXXIII Congr. Bras. Geol.. 5: 2407ma16, Rio de Jareiro.

GaRCIA, M.A.M. HARTMANN, L." A. (19ai) Petrologia do Complexo PaIma, RS. Acta Geol- Leop. $13(9)$ 51 …12a, S. LeOpoldo.

GIRARDI, U.A.U. (1973) Descricấo petrográfica das rochas do Embasamento do Rio Grande do Sul. CPGEo -. IG/USP. S. Paslo (rel. intin , inedito).

GoNI, J.C. (1961) O rapakivi Lavras, jazidas metaliferas as\$ociadas, Rio Grande do sul, Bramil. Bol. Esc. Geol., UFRgs, 7: 191. Porto Alegre.

GONT, J.C. (1962) origine dog roches ultrabaiques et serpentineuses du Prembambrien du Rio torande do Sul (Bresil). Moded de 
gisenent et mineratigation. Bol. Esc. Geol., UFRGS, 12: 1,-89, Porto Alegre.

GONI, J.C.F Goso, H* ISSLER, R. S. (1962) Egtratigrafia e Geologia Económica do Premanbriano Eo-faleozólco Urugualo e Sulriomgrandense. Avulso da Esc. Beol., UFRGS, 3: 1-105. Porto A$1 \in g r e$.

HALPERN, M.; CORDANI, U.Q, BERENHOLC, $M_{n}$ (1974) Geochronology of Rio Grande do Sul State, Southeastern Brazil. CPGeo - IG/ USP, Sago Palo (rel. int., inedito).

HART, $S$. (1966) Radiometric ages in Uruguay and Argentina and their implications concerning Continental Drift. Geol" Soc. An.. Annual Meeting, San Francisco.

HARTMANN, L. A. (1982) Textura metamórfica de olivina en taleoserpentinitos da regi $16(12): 179-188$. Sắ Leopoldo.

HARTMANN, L. "A." SILVA, L.C. ORLANDI FO, $V_{*}$ (1979) "COMPIEXO granulitioo de Santa Catarina - Defcricäo Implicacöes genéticas. Acta Geol. Leop:, 10 (B):45m75, Săo Leopoldo.

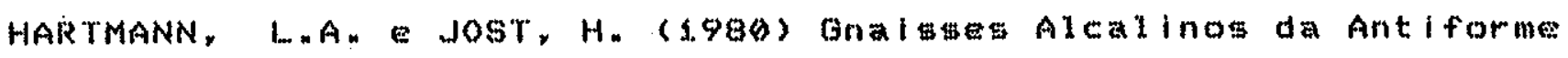
Capané (RS). Acta Geol. Leop.. 11(7):13mas, São Leopoldo.

HARTMANN, L.A. NARDI, L.U.S. (1982) OA Granitos Santo AFonso, Saibro Vauthier da megia do Arroio Santa Maria Chico, Dom Pedrito. RS. - Geologia, petrografia quimica dos elementos 
maiores. com interpretactio gectectônica. Acta Geol. Leop.. 16 (1.2):153-178, sato teopoldo.

HARTMANN, L."A. E NARDI, L. V.S. (1983) Contribulcäo a Geologia da

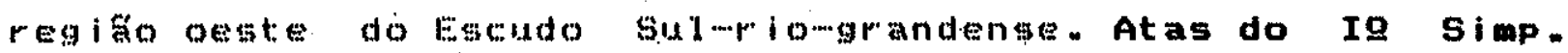
Sul-bras. Geol.., P. 9-18, Porto Alegr..

HARTNADY, C. JOUBERT, P STOWE, C. (1985) Proterozoit erdstad Evolution in Soldthwestern Africa. Episodes, B (A):236-244, Ontárion

HASUI, Y.F CARNEIRO, C.D.R, EOIMERA, AnM, (1975) ThE RIbEira

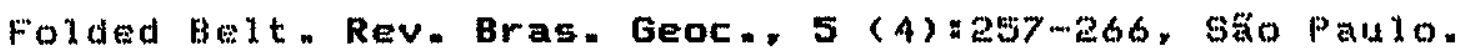

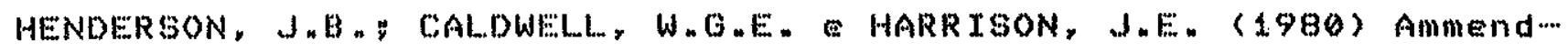
ment of code concerning terminologe for igous and high-grade metamorfic rocks. Geol. Soc. Am., Bull., 91 (6):374-376.

(1) 1986

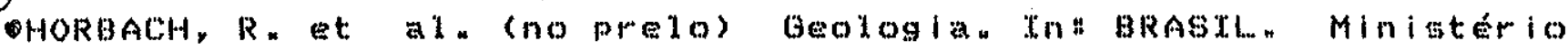
das Minas Energia. Secretaria Beral "Projeto Radambrasil. Folhas SH.22/21 e SI.22. Porto Alegre - Uruguaiana e Lagoa Mirim. Rio de Janeiro (Levantamento de Recursos Naturats, 33 )*

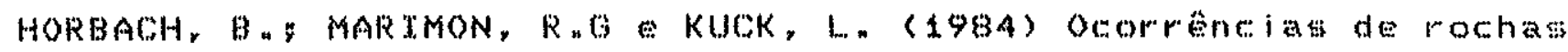
granditicas no Macico Pelotas, Escudo Sul-rlomgrandense. An. XXXIII Congr. Bras. Geol ., 7: 3143-3150, Rio de Janeiro.

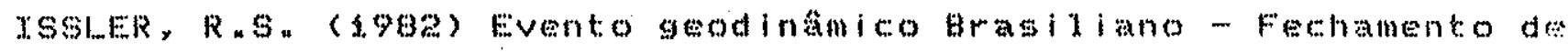
ocenno colisto continental dos cratong Rlo de la plata Dom Fediciano: granitos duas misas ofiolitos. An. XXXII Congr. 
Bras. Geo1, 1:24m3E, Salvador.

ISSLER, R.S. (1983) Evolusfo crustal da faika arcowfossa rijucas - faica magmatica Pedras Grandesa Cráton Dom Feliciano. Atas do Io simp. Sul-bras. Geol.. P. 19-36. Porto Alegre..

ISSLER, R.S. (1984) Granitos e granitóides da Região Sul. Projeto RADAMBRASIL. 54 . . Florianópolis (rel . int. , inédito).

ISSLER, R.SH JOST,H. UTLLWOCK, J.A. (1965) Esbofo pre1iminar da geotectốnica no Escudo Rio-grandense - Conferencin ia proferida no nutiteo riomgrandens da SBo, Porto Alegre.

ISSLER, R.S.; BURGUER JR., C. ROISEMEERG, A* (196\%) Corontto da área de Mata Grande. Munitipio de Săo sepé, Estado do Rio Grande do sul. An. XXI Congr. Bras. Geol.., . 182.197, curitiba.

JSSLER, R.S. D DRESCH, A.C. E ROISEMBERS, A. (1973) GEOCronologia do Gabro de Mata Grande. Municílo de Säo Sepe. Estado do Rio

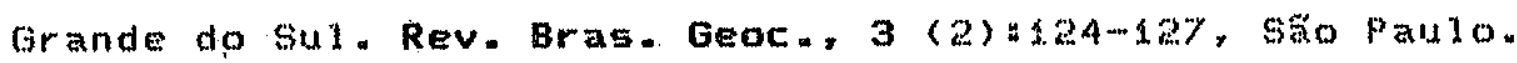

Jost, H. (1966) Complexom basicos ultrabasicos do Alto Rio Va cacaí, Gáo Gabricl, Rio Grande do Sul, Brasil. Notas e Estudos da Esc. Geol.. UFRGS, 1 (2): $59-61$, Porto Altare.

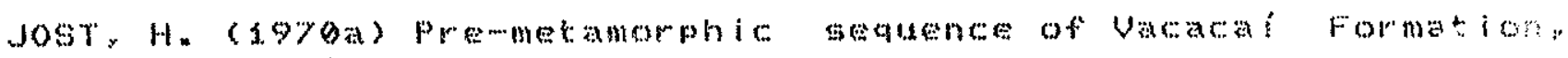
Porongos Group, Rio Grande do Sul; Brazil. Notas Estudo de Ese. Ged . "UFRGS, $2(1): 5-14$, Porto Alegre. 
Jost, H. (1970b) Esboco geológico da Folha "Cabeceiras do Rio Vacacai" Să Gabriel, Rio Grande do Sul, Brasil. Bol. Esc. Geo1.. UFRGS, $16=1-47$, Forto Alegre.

Jost, H. (1981) Geology and metallogeny of the Santana da Boa Vista Region, South Brasil. The University of Georgla (Ph.D. Thesis), Athens.

JosT, H. (1984) Sedimentagato vileanismo durante o ciclo Brasiliano no Rlo. Grands do sul: una revlsăo. An. XXIII Congr. Bras. Geol., 7= 324t-3esty, Rio de Janeiro.

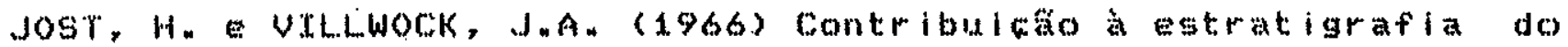
Promembrimo no Rio torande do Sul "Notase Estudos da Esc. Geo1.. UFRGS, 1 (1) $1,3+26$, Porto Alegr

JosT, H* BTHENCOURT, M.F. (1980) Estratigrafia tectonica de uma fractio da falwa de dobmamento rijucas no Rio torande do Sul "Acta Geol. Leop., 11 (7):ay-5y, sago Lepoldo.

Jost, H. HARTMANN, I... A. (1.979) Rodingitos do Rio Gonde do Sul,

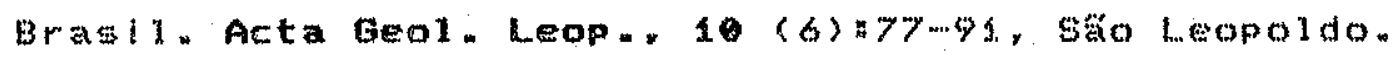

Jost, H. MARTMANN, L. "An (3984) A Províneia Mantiqueira: Setor Meridional. Ina Pré-Cambriano do Brasil (Almeiday FF.M. Hä-

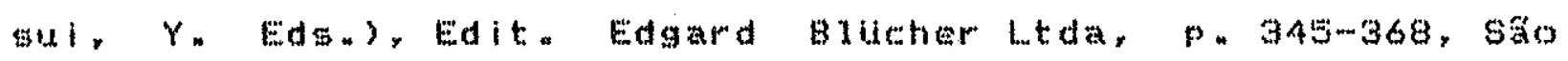
Piatio.

JOST, H. FRANTZ, J.C WERNICK, E. (3984) Implicacóng geotectonlcas da varlacáco composicional tempora a regional dos gra 
nitódes do diclo Brasiliano no Eseddo Sul-riomgrandense. An. XXXIII Congr. Bras. Geol., $6: 2978$ 3000, Rio de Janeiro.

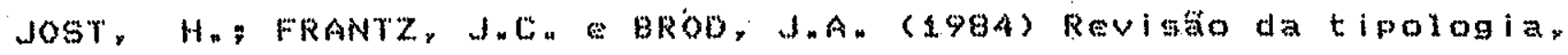
cronologia sionificado geotectonico dog fallamentos do Escudo Sul-riomgrandense. An. XXXIIX Congr. Bras. Geol.. 4: $1707-$ 1720 , Rio de Janeiron

JOST, H. BROD, J.A. HOLZ, M.; KUHN, A. FLOR, M.A.D. FKRONBAUER, A. DrLLEMBURg, S. (1984) Geologia strutural, petrografia petrologia do sienito Pianiri (Proterozdico Superior), Rio Grande do sul. An. IXg simp. Sul-bras. Geol." H. 63-81, Flom rianópolis

KAUL. P.F.T (1979) Pre-Cambriano Eopaleosóico do Nordeste de

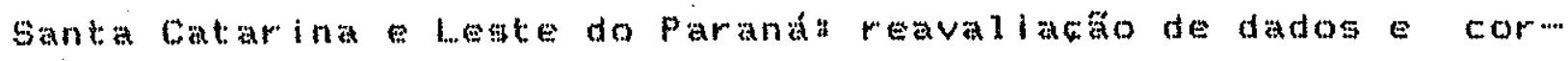
relacta com a Africa. Atas Iro simp. Reg-Geol., 1 : $1-15$, Rio ciaro.

KAUL., PF.T. (1980) O Craton de Luigi Alves. An. XXXI Congr. Bras. Geol . . 5* 2677-2683, Canbor $i \dot{\alpha}$

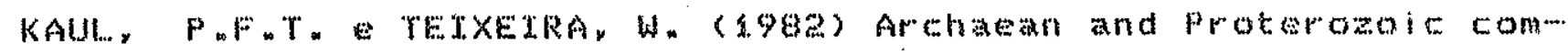

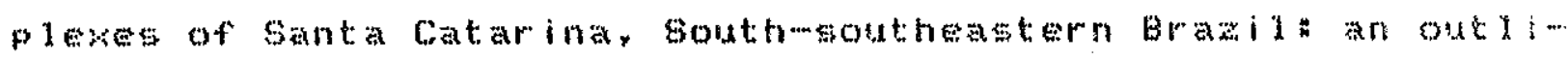
ne of their geological evolution. Rev. Brasa Geac=v $12(1-3)$ : 472-182 (Anais do ISAP), Sấo Pallon

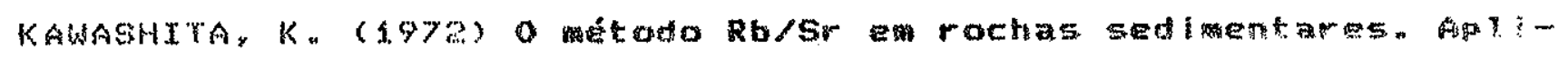
cacáo para as bacias do Parana e Amazonas. Tese de Doutoramen

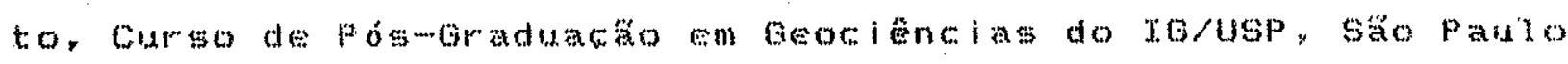


(inedito).

KNIJNIK, P.R. ( 1974 ) Carta geológica do Brasil ao Milionésimo. rexto Explicativo da folha Uruguaiana, DNPM, 34 P., Brasilia.

KOPPE, J.C.; HARTMANN, L."A.; LISBOA, PFF, E MONTETRO, R.N. (1985) Aspetos geolópicos betratigráticos do complexo Bossoroca, Săo Sepe, RG. An. Iro Simp. Sul-bras. Geol. . P. 32-36, Flortanópolis.

KOPPEL, V. GRLNENFELDER, M* (2979) lsotop GeOChEmistry of lead. In: Lectures in Isotope Geochewistry (E. Jither o J.C.

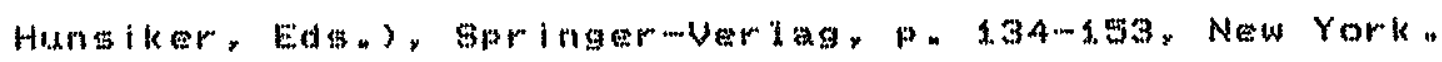

KRONER, A. (A9ge) Rb-.Gr geochronologg and tactonic evolution of the Pan-African Damara Belt of Namibia, Southwestern Africa. Am. Jour. Sci., 282: 1.47\%,-1507.

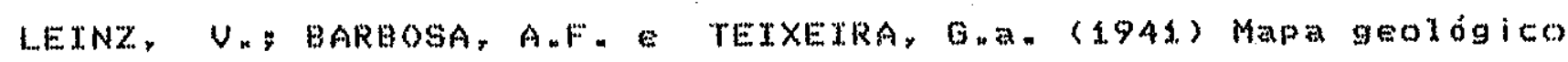
Cacapava - Lavrats. Bol. Div. Prod. Min., Secr. Agric. Ind. e Con $, 90: 1,-39$, Porto Alsgre.

LEINZ, V. PINAGEL. H. (3945) Estanho Tungstenio no Rio forande do sul. Parte I meologia da area mineralizada. Bol- Div. Fom. Prod. Min. DNPM, 70 s. 190, Rio de daneiro.

MACEDO, M.H.F" (1982) Les systemes isotopiques rubidium-stronciuph et potassium-argan dans les squiments carbonatso Application a la datation du Protérozoique sedimentaire dil Brésil dans les Etats de Bahia sant Catarina. Tet de Doutoramento. Univ. Lauis pasteur, strasbourg, Franca (inédito). 
MACEDO, M.A.F.; BASET, M.A. ${ }_{n} ;$ BONHOMME, M. B. E KAWASHTTA, K. (198a) Dados geocronológicos referentes as rochas metassedi-

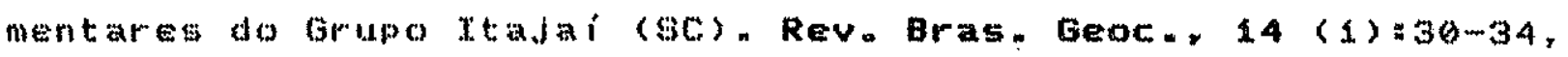
Săo Palo.

MARINI, O. DELLA FÁVERA, J. (1963) GeOlogia da Guadricula Arroio

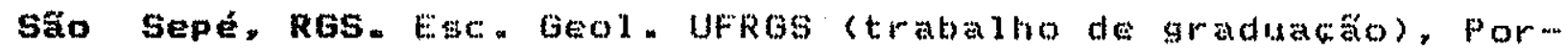
to Alegre (inedito).

ME INTYRE, G.A. B BROOKS, C. COMPGYON, W. E TUREK, A. (19GG) ThE

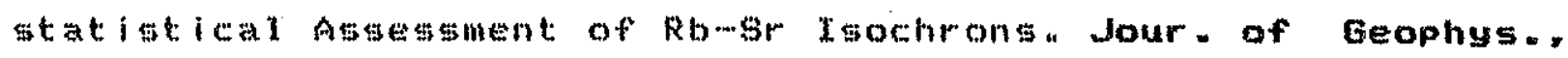
Res., 71 (22) a 5459.5468 , kichmond.

MURATORI, A. LOPES, JA $(1963)$ BeOlogia da Quadricula Arroí

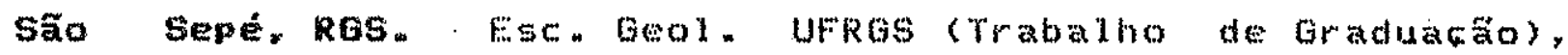
Porto Alegre (insito).

MINIOL.. B. (1972) Aspectos geológicos da regiảo litorânea Picarras - Barra Velha (sc). Teste de Doutoramento, Curso de Pós-

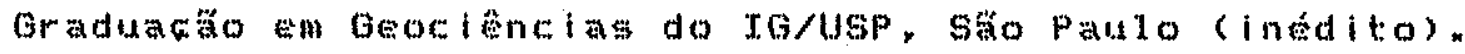

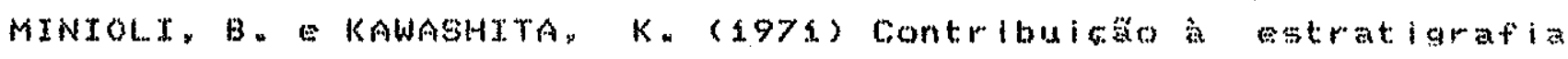
do Eompaleozíco do "Escido kiomgrandense" "An. do XXV Congr. Bras. Geoling $1=5.93-199$, sto Patro.

MOORBATH, S. (1975) Geological interpretation of whol mow isom chron from highmpade sneiss terraing Nature, 255 (5.507): 391. Londets.

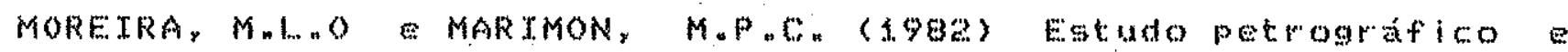


litoquimico da rochas graniticas do Escudo sul-riomigandense. An. XXXII Congr. Bras. Geol., 2:566-376. Salvador.

MORETRA, MnLOO. Z MARTMON, M.P.C. (198A) Putrogmafia dos granuli... tos do leste do Escudo sulmriomgrandense. An. XXXIII Congr. Bras. Geol. 9 - 4463-3474, Rio de Janeiro.

NAESER, C.W. (1.96\%) The use of apatite and sphene for fission... track age determinations. Bull. Geol. Soc. Amer.. 78 is $153-$ 1520.

NAIME, R. (Em PrEp.) Geologia do Complexo Granitico Ramada e do Granito Cerro da Cria. Dissertacádo de Mestrado. Curso de Póm

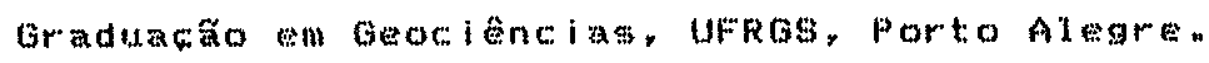

NAIME, R, UETGEL, R. (1985) FEicote geológicas da zona do Arro10 dag Capivaras, Mata Grande, Sho Sepe. RS. Atas. Iro Simp. Sul-bras. Geol., P. 37-45. Florlanópolis.

NARDI, L.U.S. (1984) Geochemistry and Petroloy of the Lavras Granite Complex, RS, Brazil. Uriv"de Londres, 268\%", Tese de Doutoramento (indedto)"

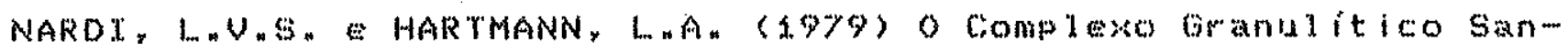

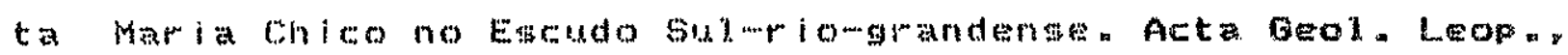
$10(6): 45-7 \%$, sán Leteopoldo.

NARDT, LUVG G HARTMANN, L. "A. (A980) Estido geoquínico de rochas

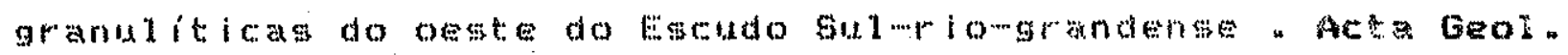

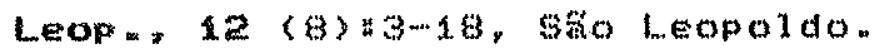


NARDI, L.U.S. LIMA, E.F. (1985) A associagto shoshoritica de Lavras do Sul, RS. Rev. Bras. Geoc., 15 (2):139-146, Săo Pawlo.

NAUMANN, M.P. (1984) O Complexo vulcano-sedimentar ultramáfico e granitóides da região de Ibaré, RS. Dissertacto de Mestrado,

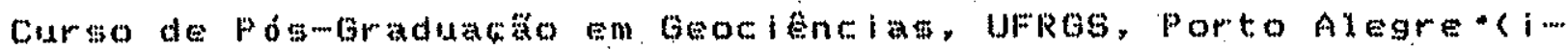
néditor.

NALMANN, M.P. HARTMANN, L. "A. (1984) Cornubianitos ultramáticos e metassomatitos associados da regläo do Arroio Corticeira, Ibaré, RS. An. XXXII Congr. Bras. Geol., 9:4279-4290, Rio de Jangeron

NAUMANN, M"P. "HARTMANN, L., A.; KOPPE, J.C. CHEMALE JR "F. (19BA) Sequencias supracrusta granitos intrusivos da regia de Ibaré - Palma. RS.- Geologia, aspectos equatigraficos e consideracos geotectónicas. An. XXXIII Congr. Bras. Geol , 5: 2417-2425, Rio de Janeiro.

NOCKOLDS, S.R. ALLEN, R. (1953) The geochemistry of some ig.. neous rocks seriesi "Geoch. Cosmoch. Acta, 4: $242-65$.

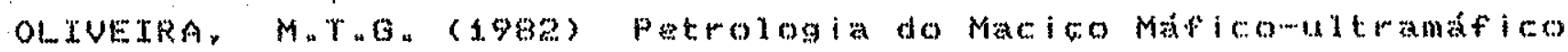
Passo do Ivo, Sáno Gabriel. Rlo Grande do Sul. Acta Geol.

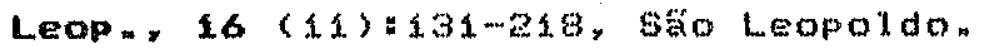

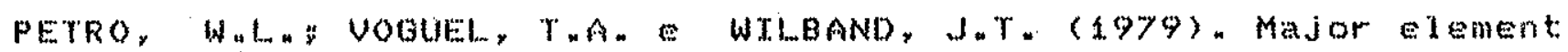
chemigtry of plutonic roek suites from compressionat and estensional plate boundaries. Chem. Geol., 26: 217-235. 
PICADA, R.S. (1965) Ocorrancia de migmatitog, granitos e graisens controlados por fraturas regionais, Encruationa do Sul, RS. Bo1. Esc. Geol., Ufrgs, 14:7-59, Portio Alegre.

PICADA, R.S. (1966) Sobme acorrencia de rochas lamboaniticas no Complewo Encruailhada, RS. Notas e Estudos da Esc. Geol.. UFRGS, 1 (2):9-13, Porto Alogra.

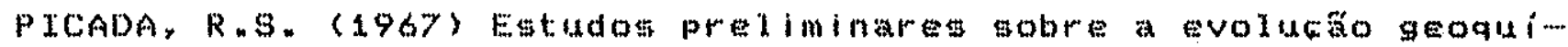
mica mineralóglea do Macico Oranitico Encruzilhada Publ. Esp. Esc. Geol.. UfRGs, 14: 1-87, Porto Al tore.

PRCADA, R.S. (197.) Ensaio sobre a tectonica do Escudo sul-riow

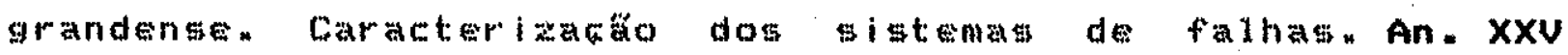

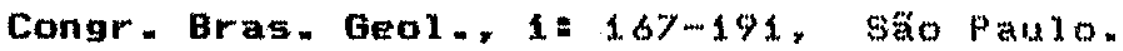

PINHETRO MACHADO, R. (EM PrEP.) UItramafitos Enaisses do Cerro Mant iqueiras, RS. Dissertacto de Megtrado, Curso de Pósmora-

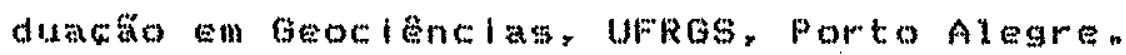

PITCHER, W.S. (197g) The anatomy of a batholit. Jour. Geol. Soc. Lond $=135=15 y+182$, London.

PITCHER, W.s. (agge) Granite tope and tectonic environment. In: Mountain Eutiding Processes, (K.J. Hsid, Ed, ), Fcademic Press. P. 18-40, Now York.

PICHER, W. N (9983) Granites typology geological environment: and melting relat lonships. Ina Migmatites, melting and meta-

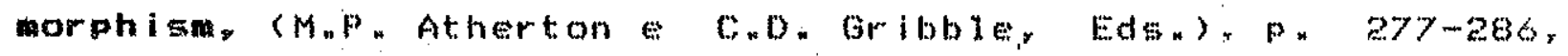


London.

PORADA. H. (1979) The Danara-kibeira orogen of the Pan-african, Brasiliano Cycle in Namibia (Southwest Africa) and Brasil as interpreted in terma of continental coll ision. Tectonophysics. $57: 237-265$, Amsterdam.

POUPEAL, (3. (1981) Fission-track dating. Ciencia e Cultura, 33 (3):325-352. Rlo de Janeiro.

POUPEAU, 6.; BOLIANT JR., E.; KAWASHITA, K.;BATTELLT, R.; BERBERT, Mn CESAR, M.F" (1985) Um perfil geocronológlco (K-Ar/Tracos de Flgắo) leste oeste no Escudo Sul-rio-grandense. Atas ixo simp. Sux-bras. Geol.. "308-321. Florianópolisin.

PRECTOZZI, F, SPOTURNO, S. HEINZEN, W. ROSEI, P. (?) REPUbIica Oriental del Uruguay - Carta Geológica. Min. Ind. En.. Dir. Nac. Min. Geol. Esc. 1.

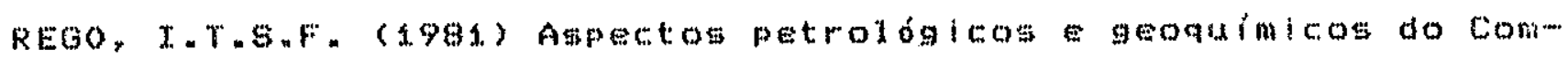
plexo Básleomitrabation de Pedras Pretas, Rio Grande do Sul.

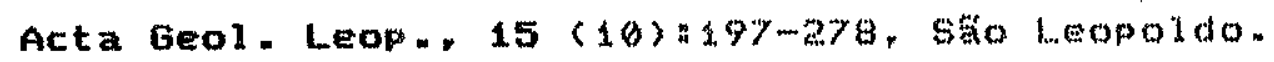

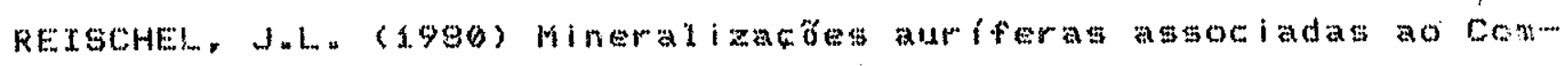
plexo Granitico de Lavrati do Sul, RS. An - XXXII Congr. Brasa

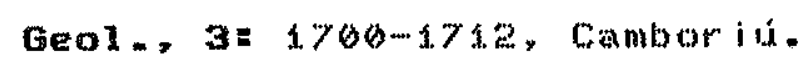

REMUS, Mu.R. (emprep.) O Complexo Vulcano-sedinentar do Arroio Cambazinho, RS. Digmertacko de Mastrado, Curso de Pós-oradua 
C:

RIBETRO, Mnd. (1979) Mapa previsional do Cobre no Escudo Sul-riograndense. Nota Explifativa "DNPM (Serie. Geol., 3; Secăo Geol. Exon, 1.), 104 p.y Brasilia.

RIBETRO, M. (1970) Beologia da Folha de Bom wardim. Rio brande do Gul, Bramil. Bol. Div. Geol. Min. Bras., 247: 1.m142, DNPM, Rio de vaneiron

RIBEIRO, M" (197y) Mapa Geológico da Quadricula de Piratini,

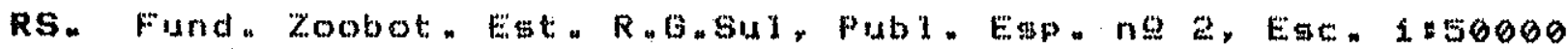
Porto Alegre *

RIBEIRO, Ma (198j) Ocorrancia de komatitos no Escudo do Rio Grande do sul. Theringia, Ser. Geol, 6 : 79 -nge, Porto Alegre.

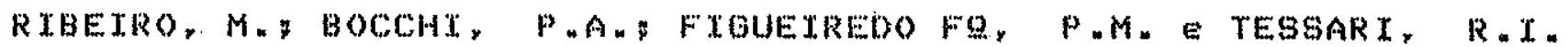
(1966) Beologia da Quadricula de Cafapava do sul, RS. Bol. Div. Fom, Prod. Min., DAPH, 127: 1,-33z, Rio de Janeiro.

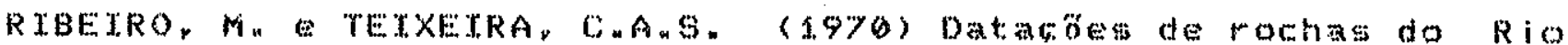
Grande do sul sua influencia nos conceitom estratigraficos e

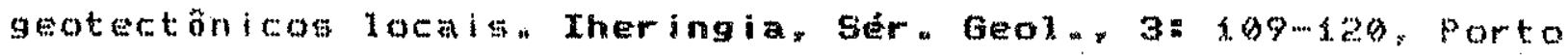
Alegra.

RIEETRO, M. FANTINEL, L.M. (1978) Associacöes petrotoctonicas

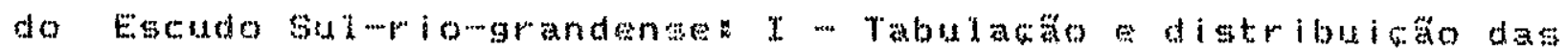
As Theringia, Sér. Geol , 5: 19-54, Porto Alegre. 
RIBETRO, M. LICHTEMBERO, E. (197G) Sintese da geOLOG a do Escudo do Rio Grande do sul. An. XXX Congr. Bras. Geol.. 6: 2451 2463, Rerife.

ROBERTSON, J.F. (1966) REVImion of the stratigraphy and nomenclature of rock units in the cacapara lavas region, state of Rio Grande do Sul, Brazil. Notase Estudos da Esc. Geol.,

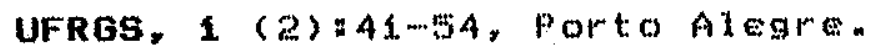

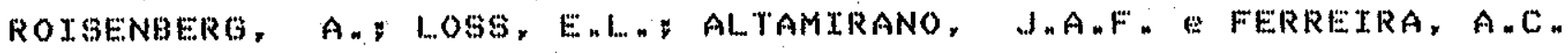
(1983) Aspetom petrológitos ge gauimicos do vulcanismo pré-

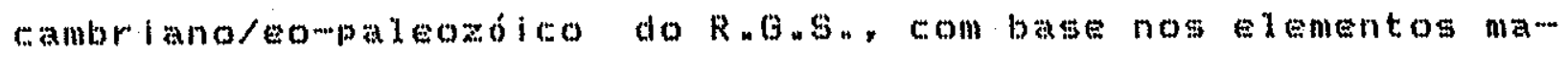
ioreg. Atas ro simp. Sul-bras. Geol., P. 273-285, Porto Ale$g r+$

SANTOS, E.L.; BECKEL, J.; MACEDO, „M. GONZALES FO, F. CHABAN, M. (1978). Divisáo litowetratigrafica do Eowambriano - Pré... Cambriano Superior do Escudo Sul-riomgrandense. An. XXX Congr. Bras. Geol.. 2=676-684, Recife.

SARTORE, P.L.". "Petrologla do Complexo Granitico de Säo Sepe. RS. Modelo Evolucional de Granitos do Sul do Brasil. Tsse de Dou-

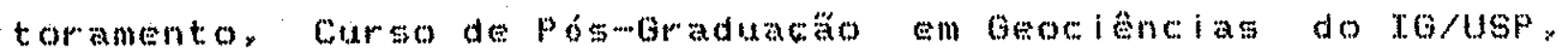
Săo Paulo (inetito).

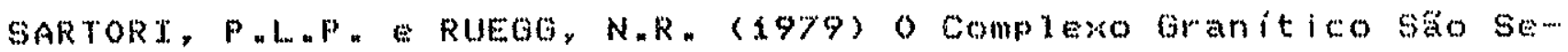
pé, Rio orande do Sul, a evolugäo das rochas graniticas da regiăo orogenica do sudeste. Bol. Inst. Geac. USP, 10:69-78. Sสัo Pan 
SARTORT, P.LAP. KAWASHTYA, K. (1985) PEtrologia e geocronolo... gia do batólito Granitito de Cacapara do sul, ks. Atas rro Simp. Sul-bras. Geol.. . 162-11: Florianópolis."

SCHNEIDER, A.W. LOSS, E.L. E PINTO, J.F." (1974) Mapa Geológico da Folha de Porto Alegre, RS. JG/UFRGS, Mapa no 7 , Porto AI gre.

SILVA Fo, B.C. (19ga) Geologg of the polyphase deformed precanDrian terrane of the Vila Nova region, State of Rio Grande do sul, Southern Brazil. Part Ia Petrogeresia Acta Geol- Leop..

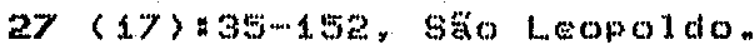

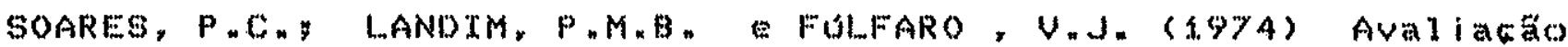
preliminar da evolugăo geotectônica das bacias intracratônicas brasileiras. An. XXXIII Congr. Bras. Geol.. 4: 61-84, Porto Alegre.

SOL. IANI JR., E. (1979) Tópicos Especials em Geocronologia - Relatório Final. Cur

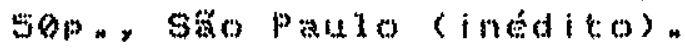

SOLIANI JR, , E " FRAGOSO CESAR, A.R. K. (1984) Panorama georonológico da portano meridional do Esw cudo At lântion. An. XXXIII Congr. Bras. Geol.. 5: 2435-2449, Rio de Janteiron

GTETGER, R.H. JAGE, E. (1977) Gubromisaion on Geochronology: convention on the use of defay constants in beow and cosmow chronology. Earth Planet. Sci. Lett. . $36.359 \ldots 362$, Amsterdam. 
SZUBERT, EN $C_{n}(1978)$ Uma astociacto ofiolitica completa, Palma,

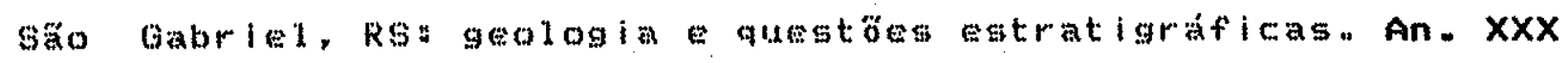
Congr. Aras . Geol , $1=467-476$, Recife.

TARNEY, J.F DALZTEL, I.W. WTT, M.J. (1976) Marginal Basin "Rocas Verdes" Complax from s. Chile: a model for Archaean Greastone Belt formation. In: The Early History of the Earth, (windley, B.F., Ed.), John Wiley \& Sons, P. 131-146, London.

TATSUMOTO, M. KNIGHT, R... AL ALEERE, C.ul. (1973) TIME difference in the formation of meteorites as determined from the ratio of lead-20y to lend-206. Science, $180=1279-1283$.

TEIXENLA, C.A.S (1969) Relatório de estágio no Centro de Pesquisas Geocronológicas da USP. CPGeo-IG/USP, Sfo Pallo (inedit:o).

TETXETRA, E.A. LEINZ, V, $(1942)$ OMHO nO Bloco Butiá. Bol. Div. Fom. Prod. Min., DNPM, 50: 1-31, Rio de Janeiro.

TEIXETRA, W. (1982a) Folhas SH.22 - Porto Alegre, SI.22. Lagoa Mirim EH.21 - Uruguaiana . Interpretacão dos dados radiométricos evolucấo geocronológica. Projeto RADAMBRASTL. Florianópolis (rel. int. "inédito).

TEIXETRA, W. (1982D) Folhas SG.21 - Assunción, SG.22 - Curitiba e SG.23 - Iguape Consideracôes sobre os dados radiométricos $e$ Evolucão geocronológica. Projeto RADAMBRASIl. Flomianópolis (rel. int., inedito). 
TESSARI, R.I. PICADA, R.S. (1966) Geologia da Quadrienla de En crinilhada do sul, Rs. Bol. Div. Fom. Prod. Min. DNPM, 124: 1147 , Rio de Janeiro.

TILTON, G.R. (1973) Imotopic lead ages of chordritic meteoritesn Earth Planet. Sci. Lett., 19: 321-329, Amsterdam.

UFRGS (1980) Mapeamento Geológlco da Folha de Lavmas do Sul. RS.

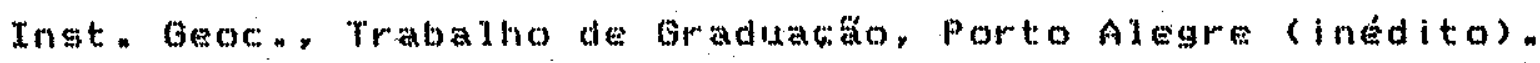

UFRGS (1961) Projeto Torquato Severo - Passo do Tigre. Ingt.

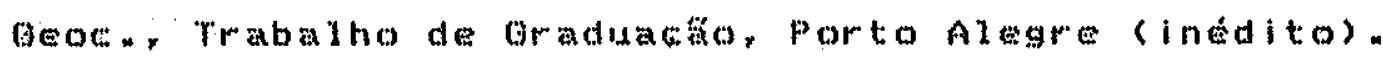

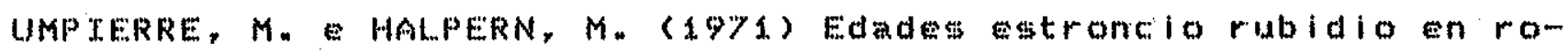

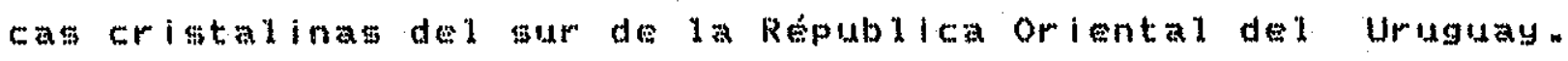
Rev. Asmoc. Geol. Argentina, 26 (2) $133-151$, BuEnos Aires.

UNTSINOS (1979) Geologia de parte das Folhas de Ibare e Tres Cerros. RS. Depton Geok, tentro Tecnologico, Trabalho de Gradia-

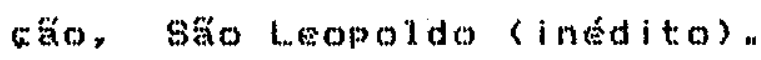

UNIGINOS (1996a) Projeto Erval. Depto. Geor., Centro recnologico,

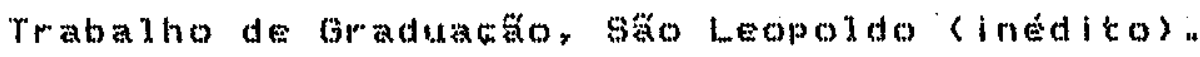

UNISINOS (1980b) Projeto Cerro Chato. Depto beot, centro retonom

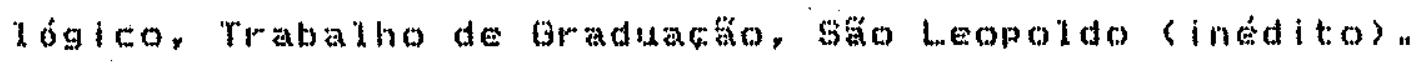

UNISINOS (1982) Projeto Encruzilhada do Sul- Depton OAOC, CEntro

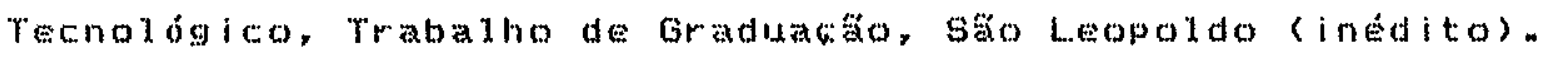


UNISINOS (1993a) Projeto Delfino. Depto. Geoc, Centro Tecnológico, Trabatho de Oraduacto, sa to Lopoldo (inedito).

UNISINOS (1993b) Projeto Várzea do Capivarita. Depto. Geoc., Centro Tecrológico. Trabalho de Graduacăo, săo Lepoldo (inéditoln.

UNIsINos (1984a) Projeto Cangucu (Is Parte). Depton Gedoc. Centro Tecrológlco. Trabalho de Graduacto. Säo Leopoldo (inédito).

UNISINOS (19846) Projeto Cangucu (IIa Parte), Depto "Geoc.. Cen-

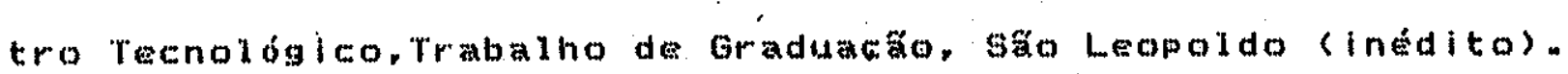

UNISINOS (1985) Projeto Piratini. Depto. Geoc. , Centro Tecnológico, Trabalho de Graduacto. Sáco Leopoldo (inédito).

VILLWOCK, J.A. L LOSS, E.L." (1970) Um novo tipo de complexo basicomitrabático na faixa serpentinitica do Pré-Cambrlano do Rio Grande do sul. Notas e Estudos da Esc. Geol., UFRGS, 2 (1):1522, Porto Alegre.

VLACH, S.R.F. CORDANI, U.G. (1985) A sistemática Rb/Sr em rachas granitoides: consideracöes interpretativas, limitacões exemplos brasileiros. Workshop sobre granitogenese mineralizacós associadas, Caruaru, PE (inedito).

YORK, D. (1966) Leat-mathares giting of a straight line. Can. Jour. Phys., 44: 1079-1086.

YORK, D. E FARQUHAR, R.M. (1.972) The Earth's age and geochronolo- 
9y- Pergamon Presis, 178p, Oxford.

WERNICK, E. E PEALVA, F. (\$978) Contribularo ao contiecimento das rochas granitóides do sul do Brasil. Rev. Brasm Geoc.. Q (2):

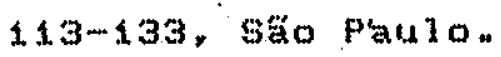

WERNICK, E. DIDIER, J. A ARTUR, A.C, E HORMANN, P. (1.984) CaraCterizacăo da zona marginal. charnockítlca do Compleso socorro nos arredores da cidade homônima, SP/MG. An. XXXIII Cóngr. Bras. Geol., 6= 291.9-2934, Rio de Janeiro.

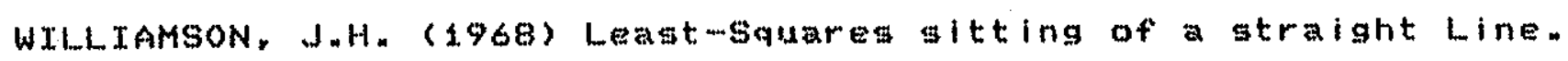
Can. Jour. Phys., 46: $1.845-1.847$.

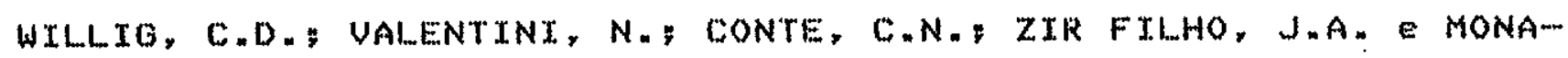
fO, O.A. (1974) Carta geológica do Brasil ao Milionesimo. Texto Explisativo dag folhas Porto Alegre Lago Mirim, DNPM, 99 P.. Brasilian

WINDLEY, B.F. (197\%) The Evolving Continents. John Wi1Ey $\$$ Sons, 385 p., Now York 


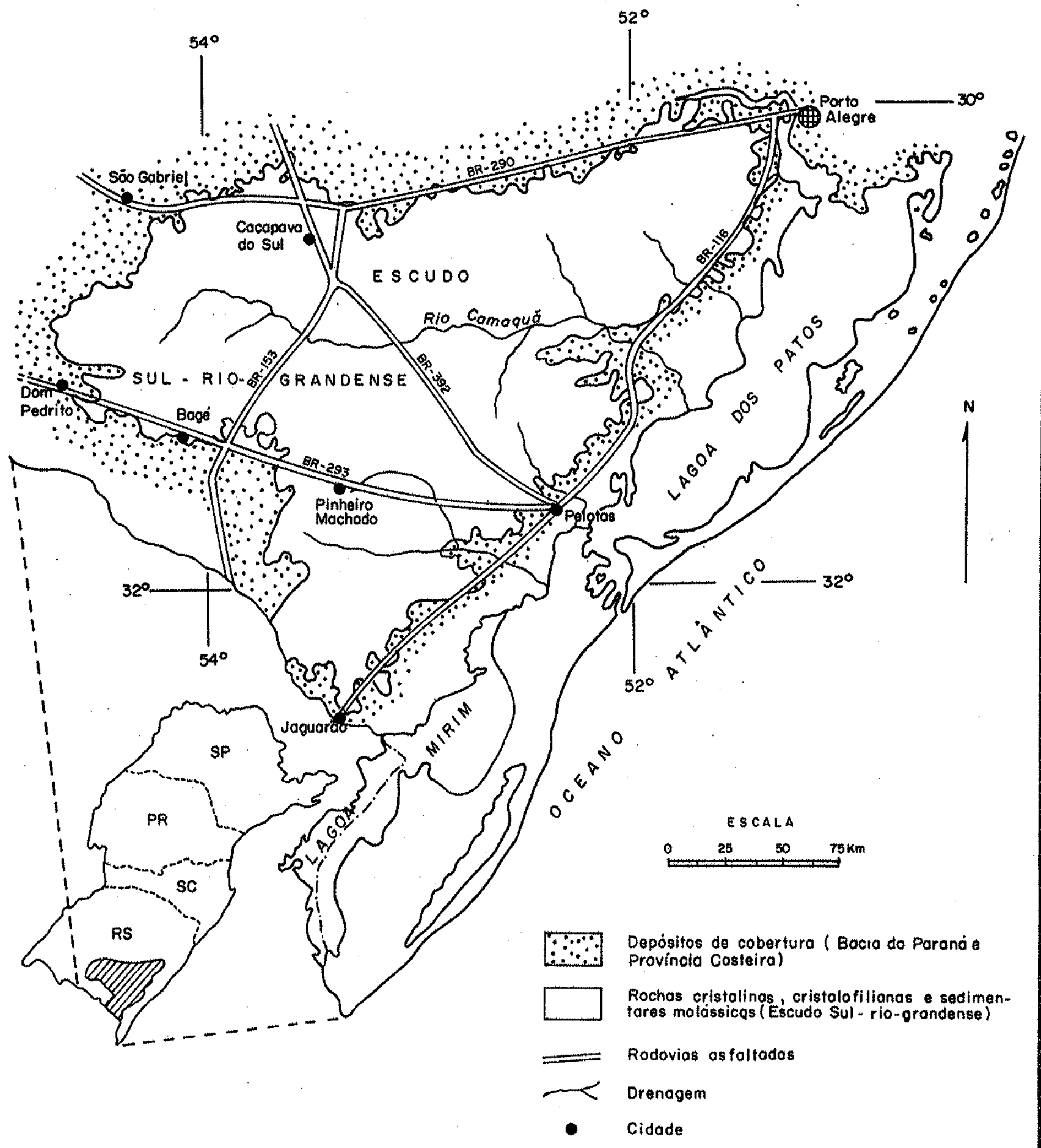

FIG. 1 - LOCALIZAGÄO DO ESCUDO SUL-RIO-GRANDENSE NO ESTADO DO RIO GRANDE DO SUL E PRINCIPAIS VIAS DE ACESSO. 


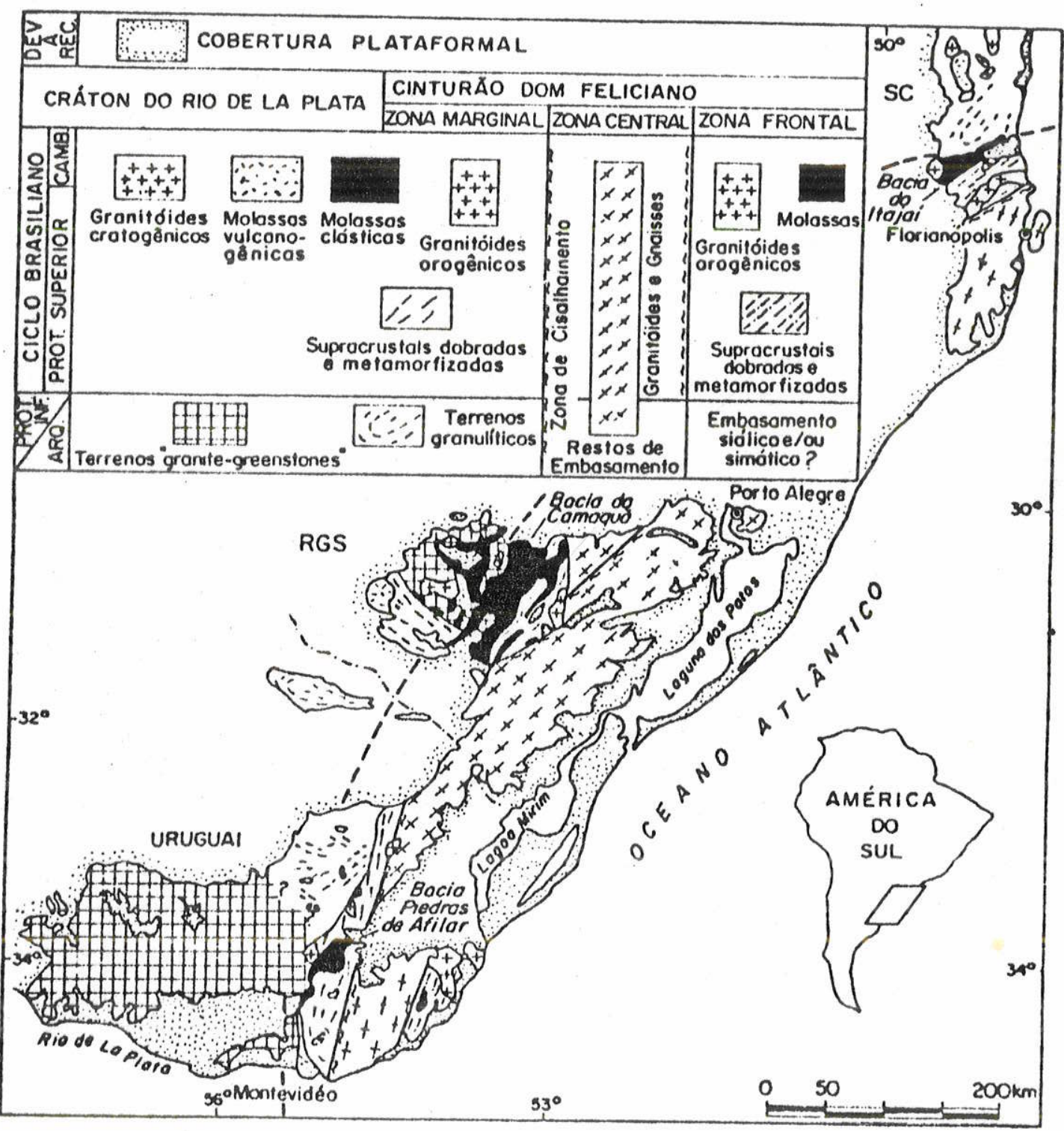

Fig. 2: Esboço geológico e geotectônico do extremo meridional do Escudo Atlântico (modificado de Fragoso Cesar e Soliani Jr.,1984). 


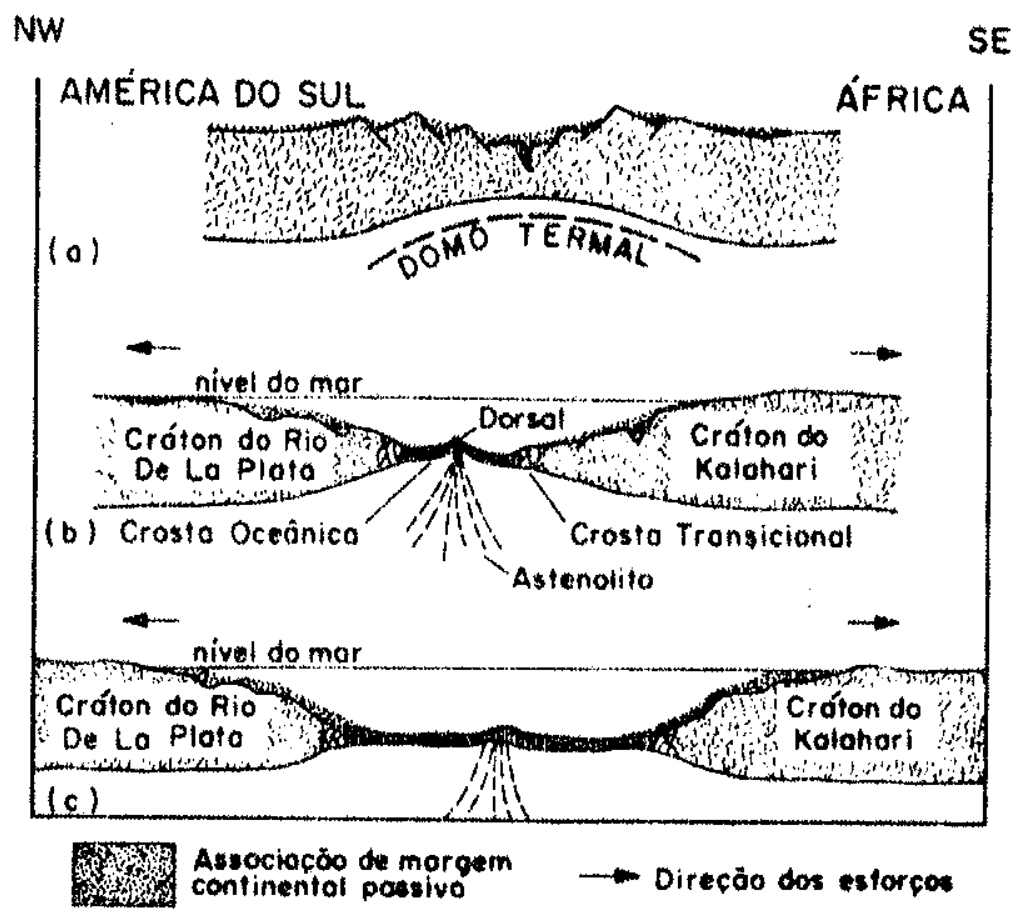

Fig. 3: Estägios evolutivos na formação do proto-Oceano Atläntico Sul, no Prë-Cambriano Superior: (a) estägio "rift"; (b) estägio "Mar Vermelho" e estägio "Atläntico", com indicaçäo dos depósitos da Assoclação de Margem Continental Passiva, seg. Frago so Cesar et al. (1982a). 


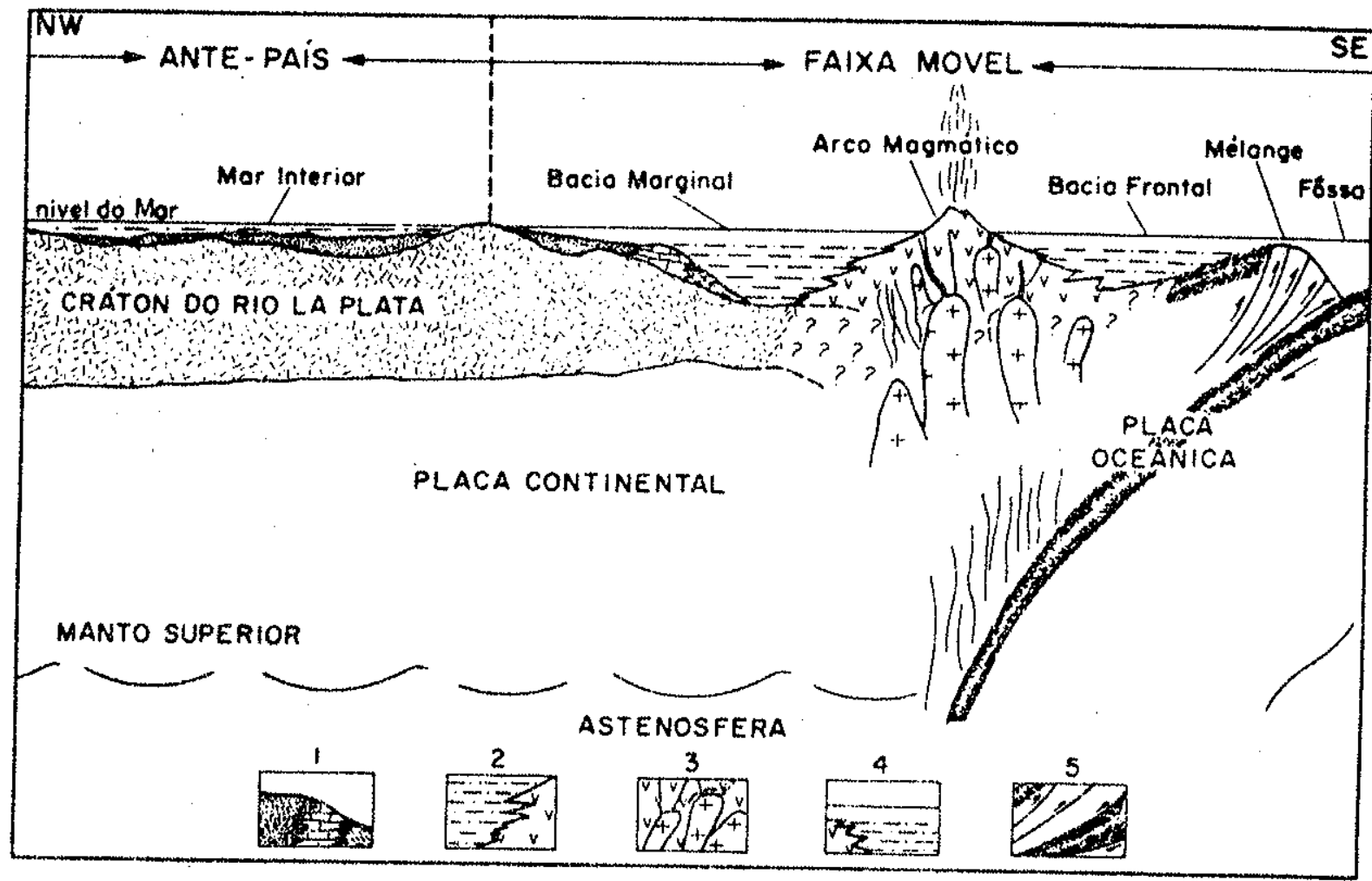

Legenda: 1 - Associação de Margem Continental Passiva (e cobertura cra tônica correlata);

2 - Associação de Bacia Marginal (e cobertura cratônica corre

3 - Assocíação de Arco Magmãtico;

4 - Associação de Bacia Frontal;

5 - Associação ofiolito-Mélange.

Fig. 4: Seção hipotëtica do Cinturão Dom Feliciano e borda oeste do Cinturão Gariep no Proterozóico Superior: compartimentação pa leogeogräfica e associações petrotectônicas, seg. Fragoso ce sar et al. (1982a). 


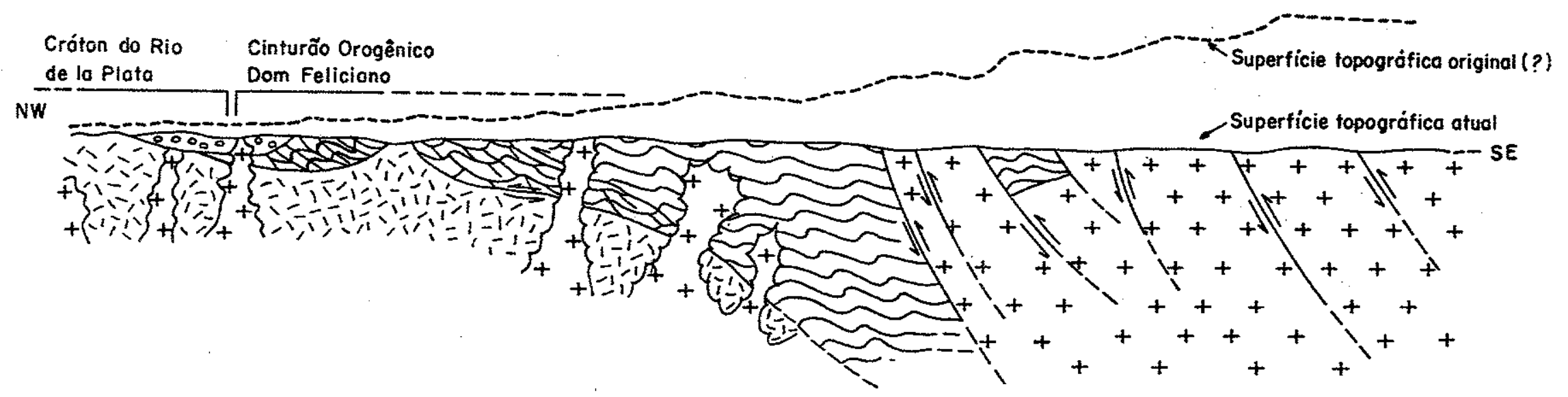

$\because \because 0$ Associação molássica

++ Associação de arco mogmático

Associação de bacia marginal

Associação de margem continental passivo

Associoção do embasamento

FIG. 5 - ASSOCIAÇÕES PETROTECTÔNICAS dO CINTURÃo dOM FELICIANO ATRAVÉS dE UMA SEÇÃo geOLÓgICA hIPOTÉTICA E TRANSVERSAL Ȧ UNIDADE GEOTECTÔNICA. 
epósitos de cobertura

[t+ Granitoides

[-7 Grupo Porongos (Metomorfitos Cerro Cambará)

[2,?] Gnaisses Encantados

II cidade

$=:=$ Rodovio principol

$=z$ Rodovia secundorio

Drenagem

258 Ponto de coleto
de amostras

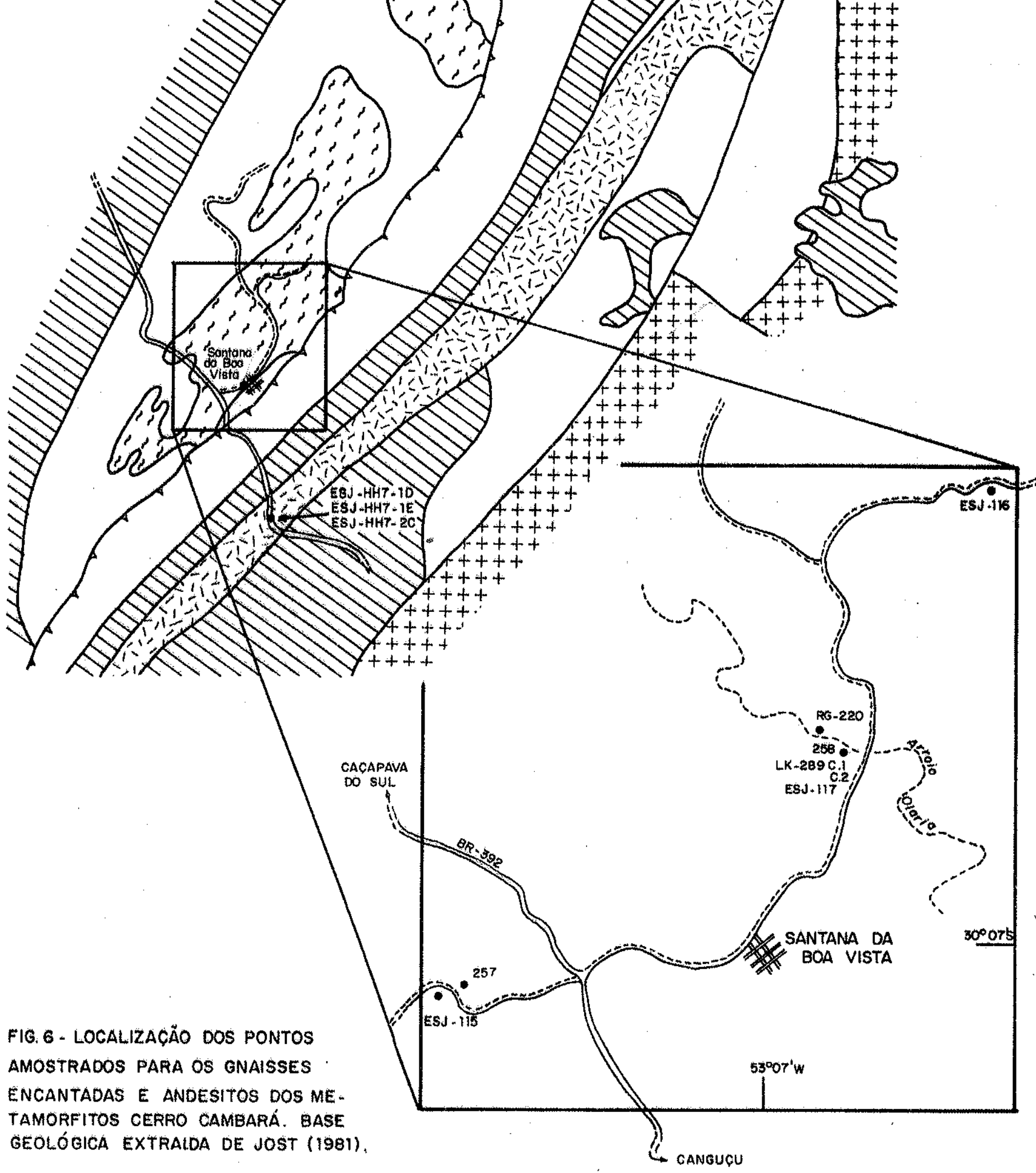




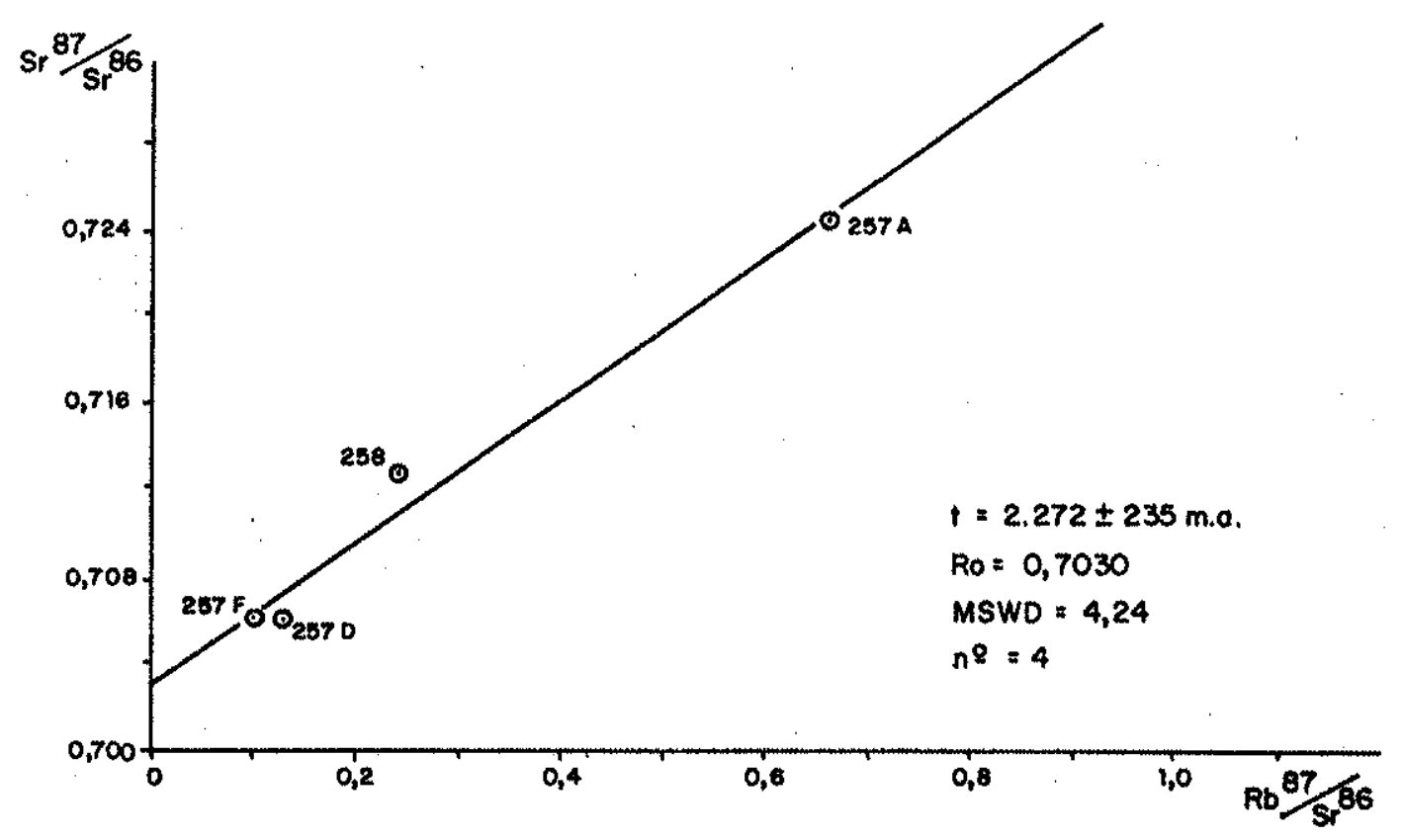

Fig. 7: Diagrama isocrônico Rb-Sr de referência dos Gnalsses Encantadas, seg. Cordani et al. (1974).

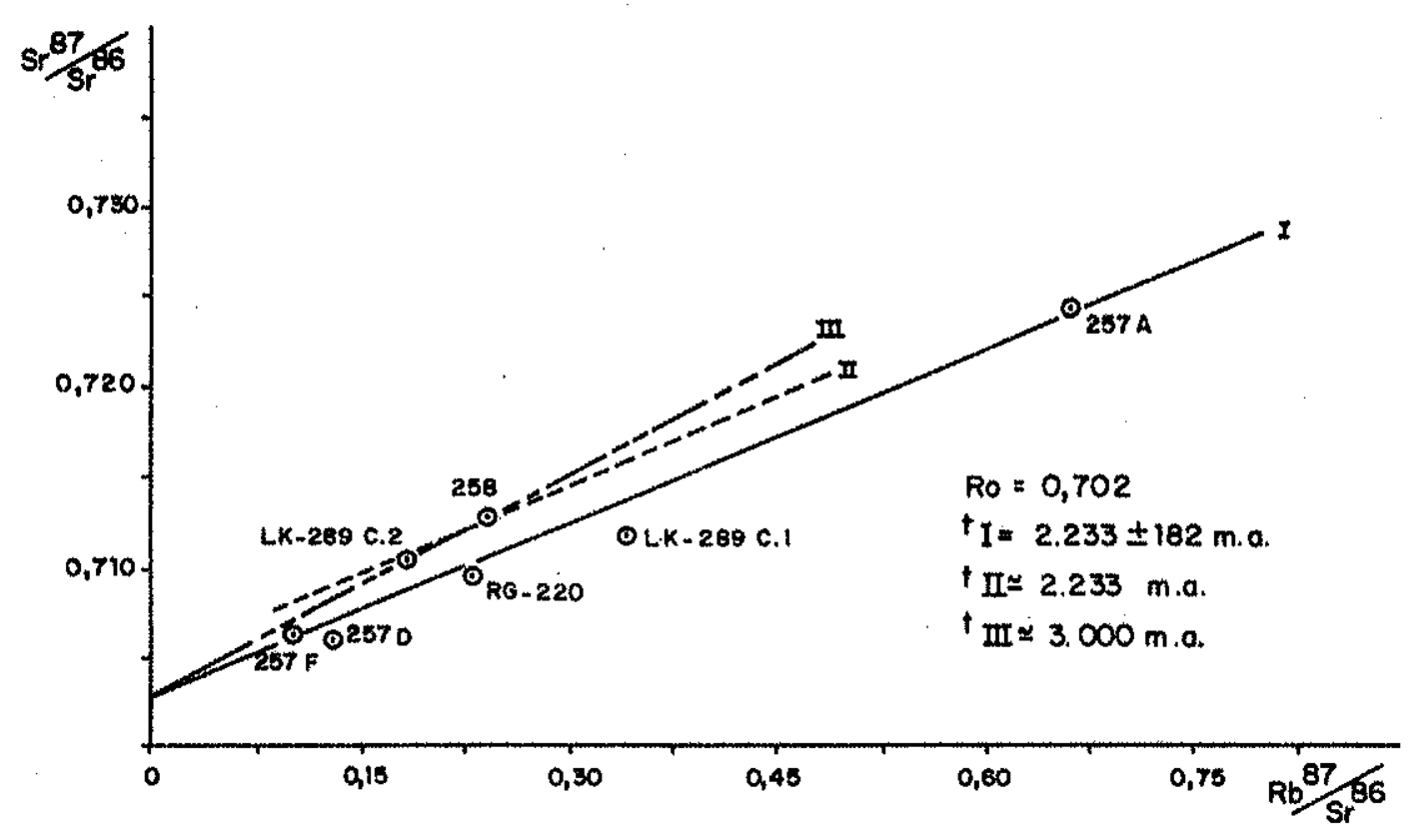

Fig. 8: Diagrama isocrônico Rb-Sr de referêncla dos Gnaisses Encantadas e possibilidades de interpretação, seg. Solliani Jr. et al. (1984). 


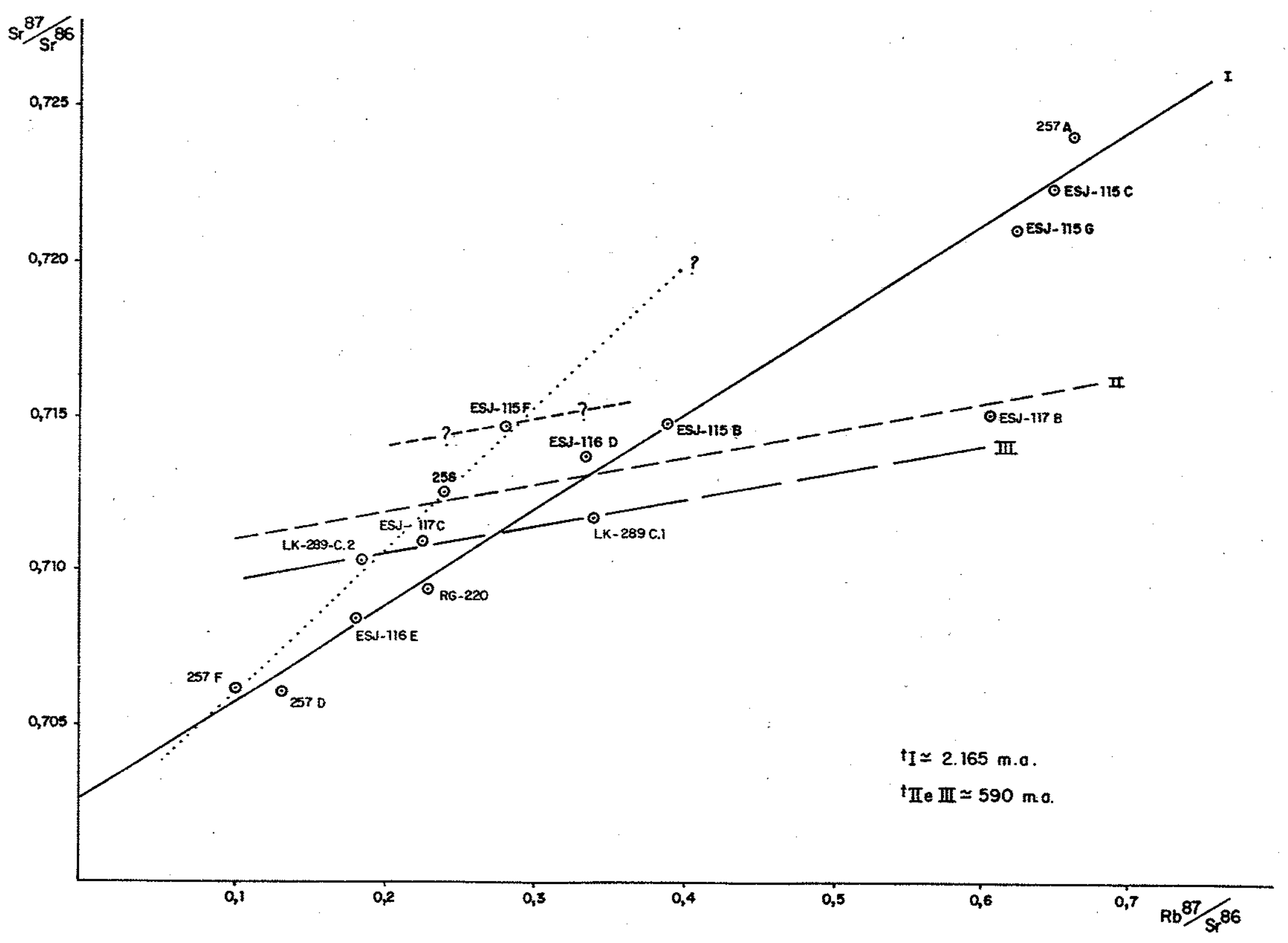

Fig. 9: Diagrama isocrônico Rb-Sr de referência dos Gnaisses Encantadas com os novos pontos analíticos e possibilidades de interpretaçäo. 


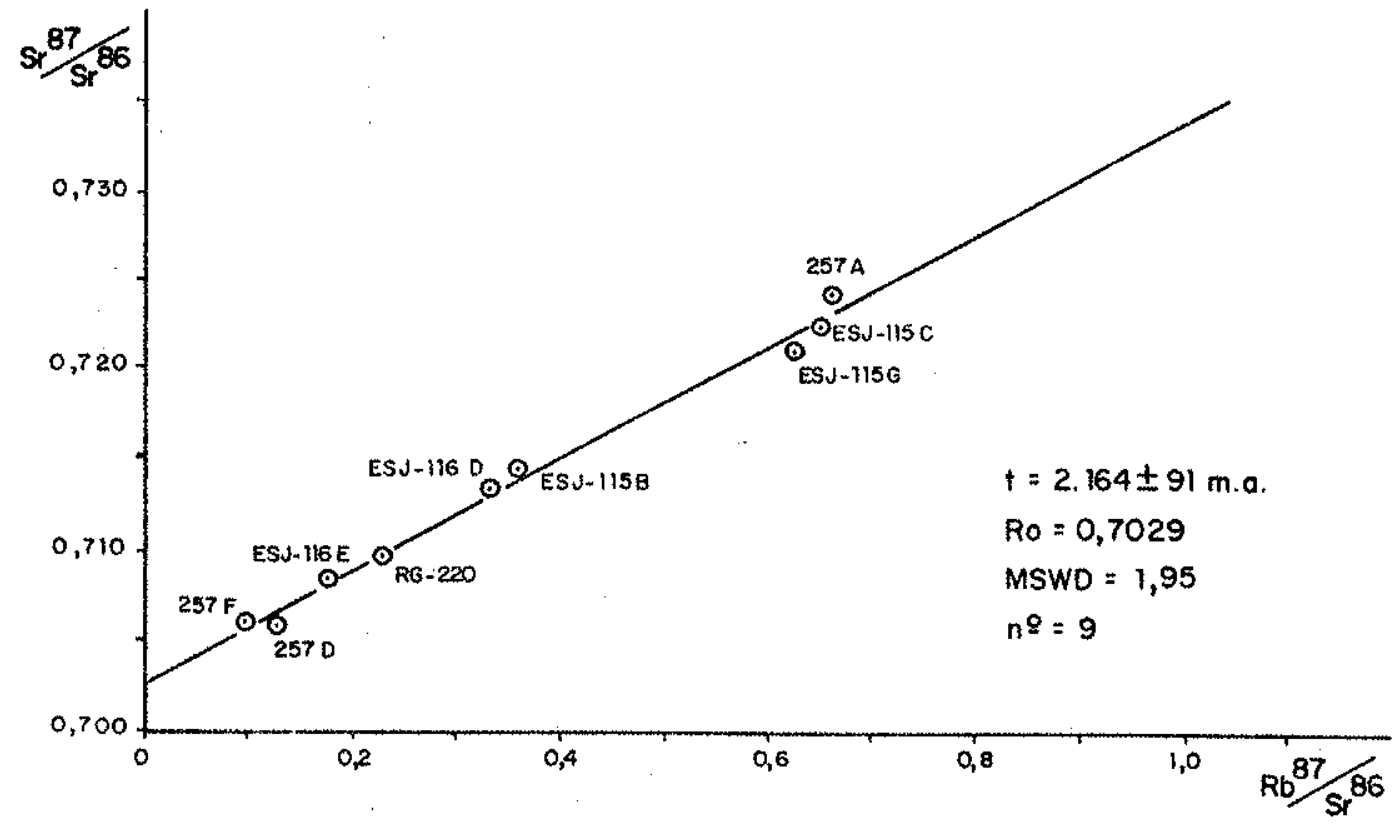

Fig. 10: Diagrama isocrônico Rb-Sr de referëncia dos Gnaisses Encanta das com exclusão dos pontos discrepantes. 


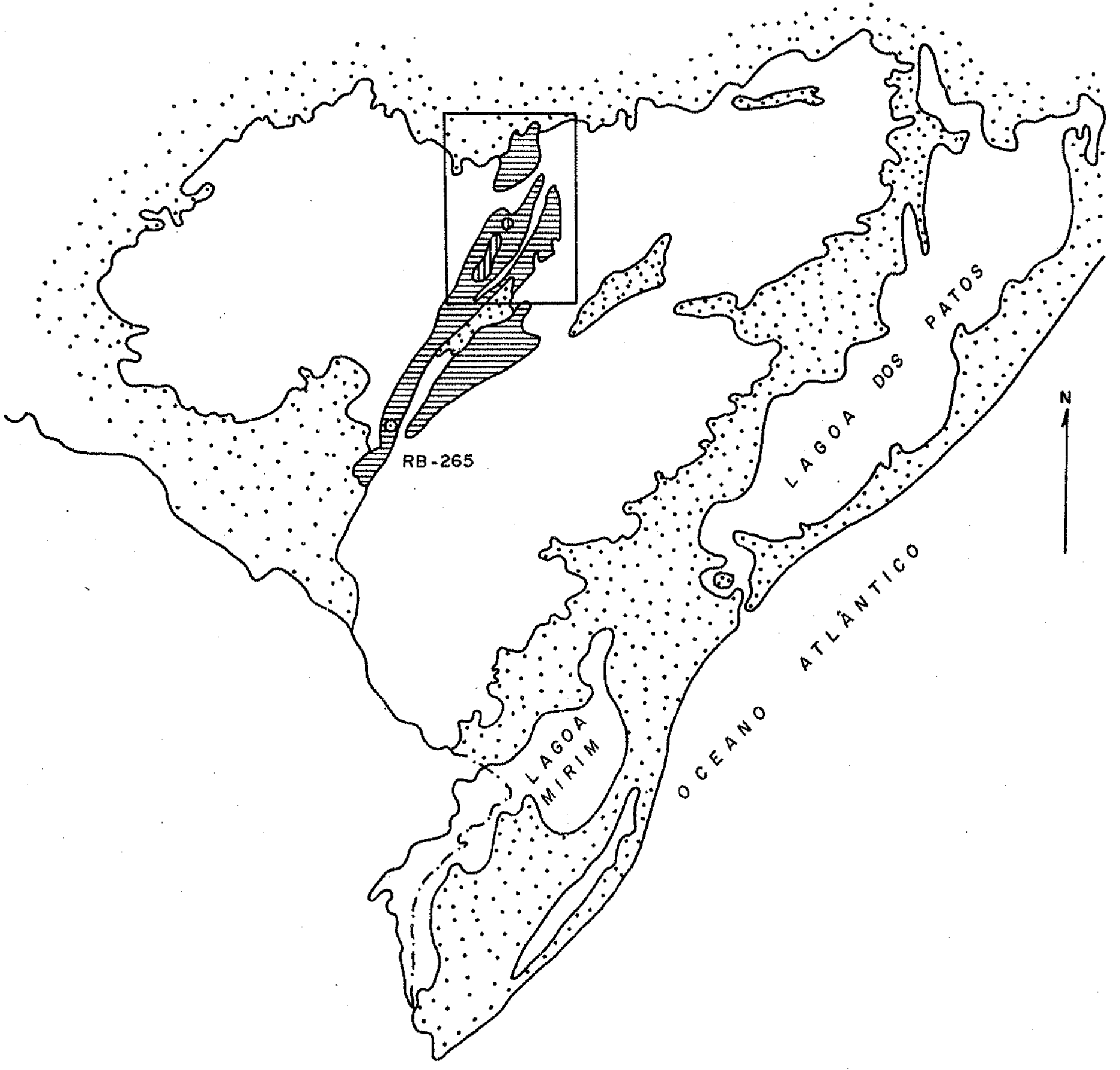

$\therefore \because$ Depósitos de Coberturo

Grupo Porongos

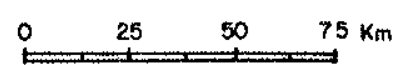

\section{[IIIIII] Gnaisses Encontadas}

Outros unidades litológicas do ESCUDO SUL-RIO-GRANDENSE

- Ponto de coleta de amostra

FIG. 11 - ÁREA DE OCORRÊNCIA DOS GNAISSES ENCANTADAS E GRUPO PORONGOS, NO RIO GRANDE DO SUL, E LOCALIZAÇÄO DO PONTO DE COLETA DA AMOSTRA RB-265 (TEIXEIRA, 1982). A REgIÃO dELIMITADA NO MAPA CORRESPONDE À ÁREA dA "FAIXA dE dobRAMENTOS TIJUCAS" ESTUDADA POR JOST E BITENCOURT (1980) E JOST (1981). 


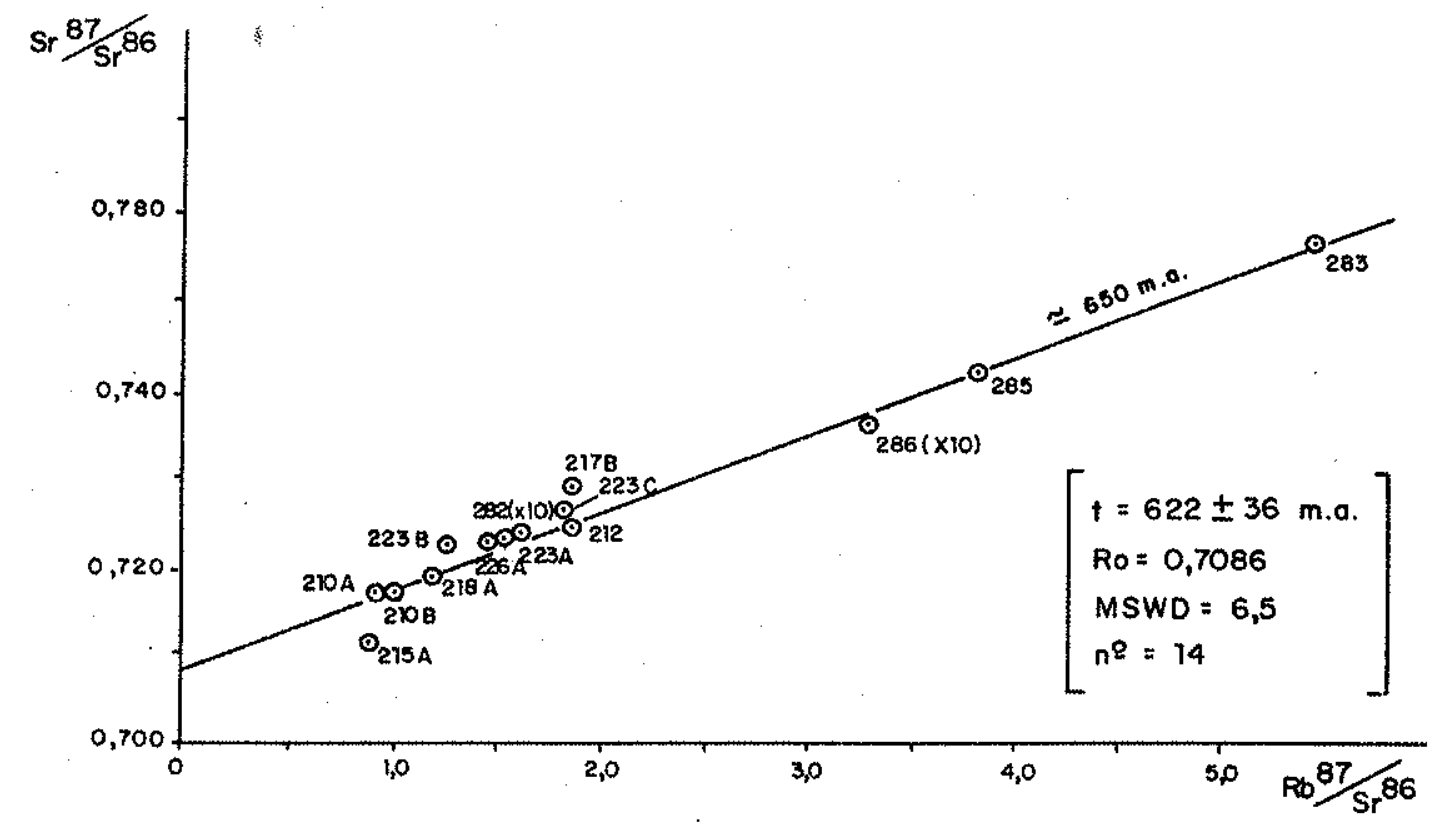

Fig. 13: Diagrama isocrônico Rb-Sr de referencia de rochas graníticas com características sintectōnicas da porção orlental do Escu do Sul-rio-grandense, seg. Cordani et al. (1974).

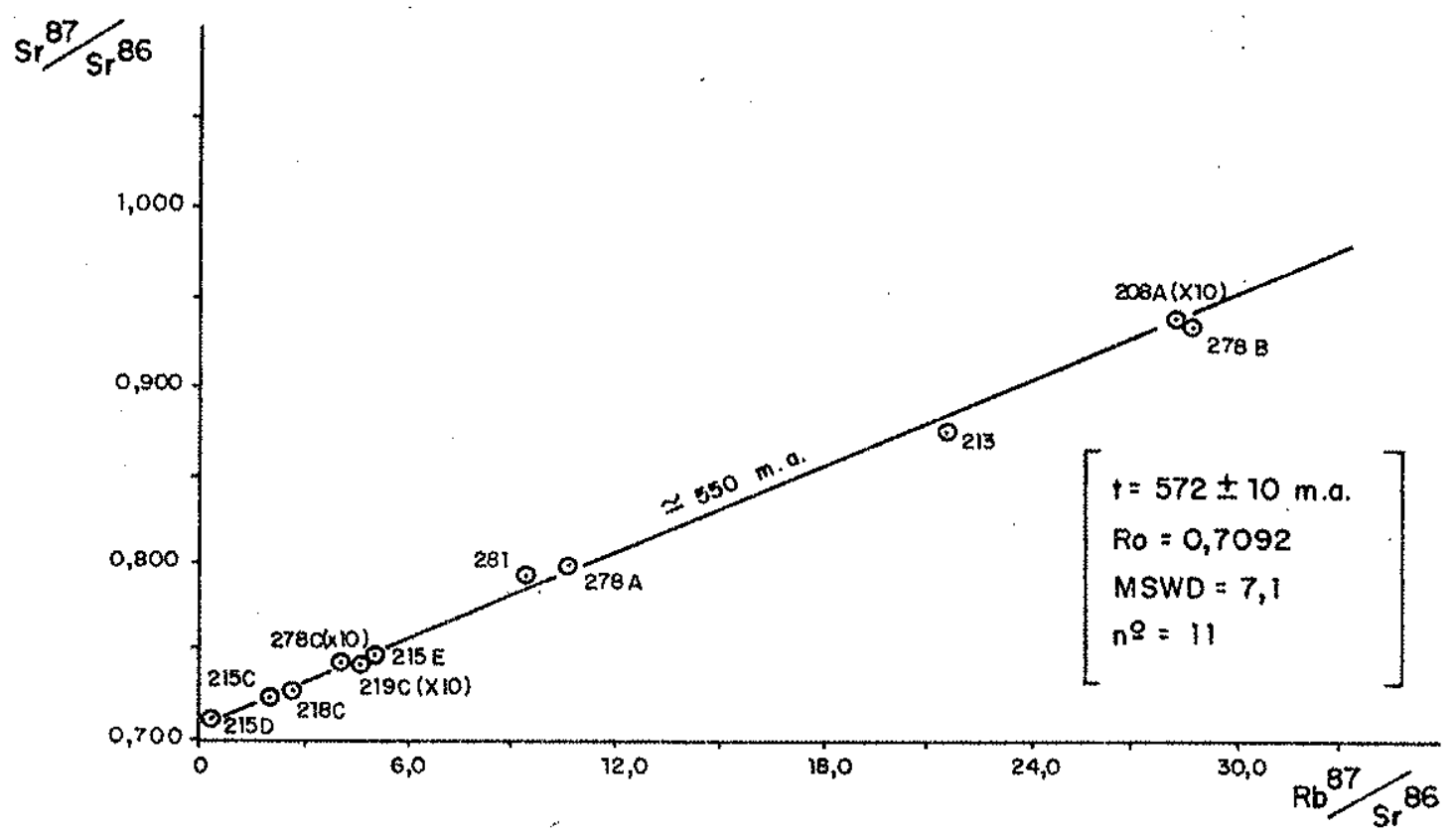

$\mathrm{Fig}$. 14: Diagrama isocrônico $\mathrm{Rb}-\mathrm{Sr}$ de referência de rochas graníticas com características pös-tectönicas da porçäo oriental do Es. cudo Sul-rio-grandense, seg. Cordani et al. (1974). 


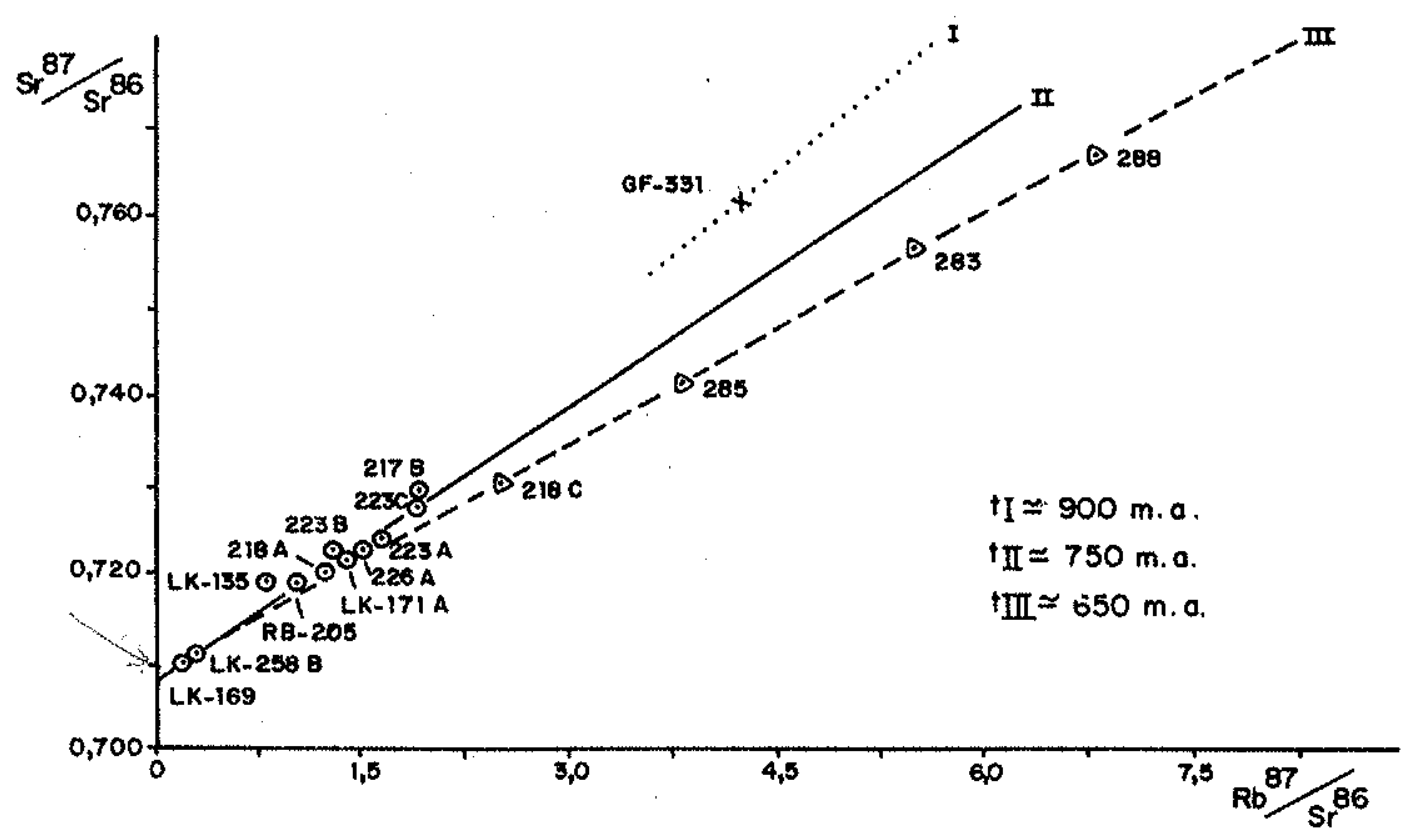

Fig. 15: Diagrama isocrônico Rb-Sr de referência de granitöides diver sos do Complexo Canguçu (Complexo Granitöide de Leste), segTeixeira (1982).

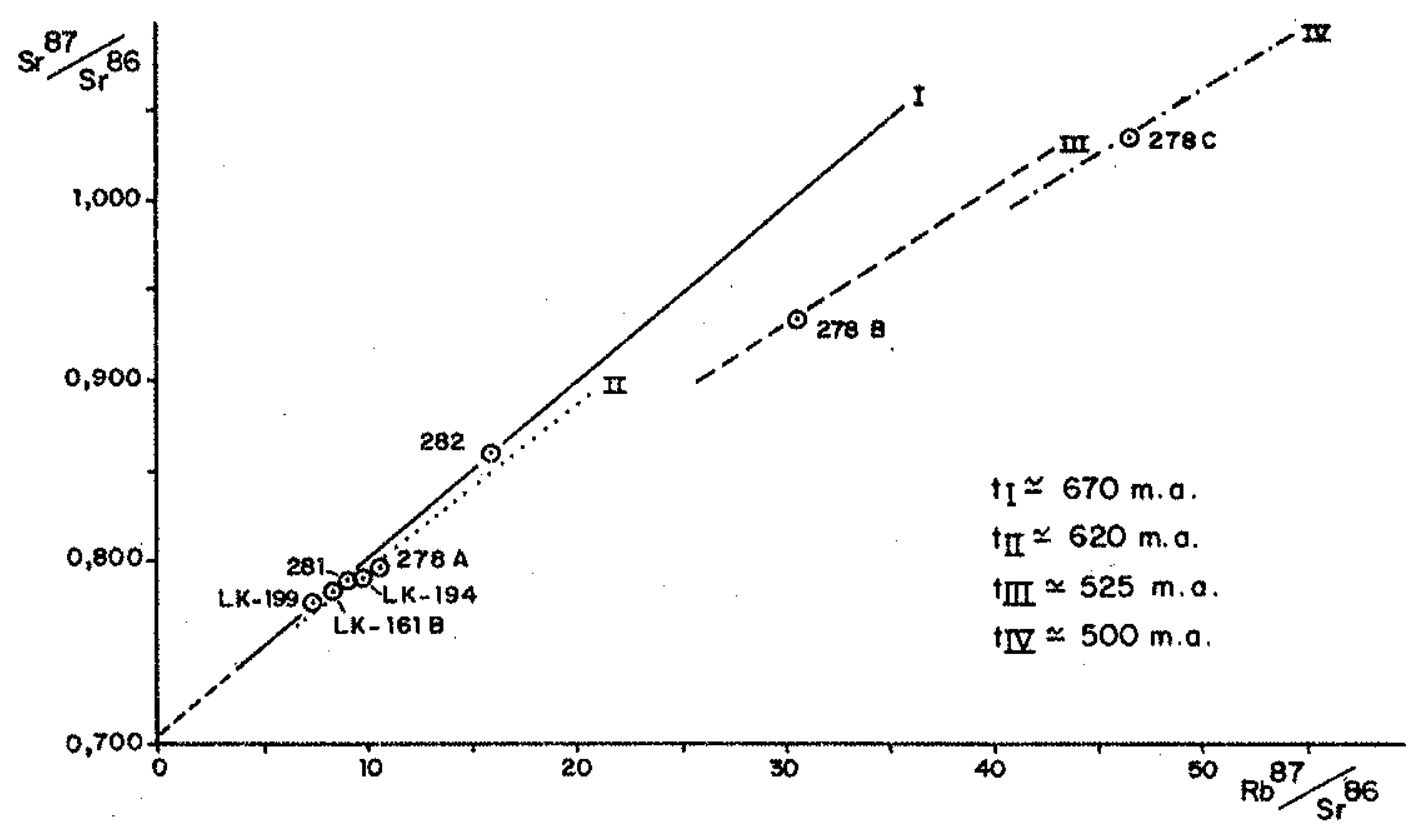

Fig. 16: Diagrama isocrônico Rb-Sr de referencia de rochas do Complexo Granitöide Encruzilhada do Sul, seg. Teixeira (1982). 


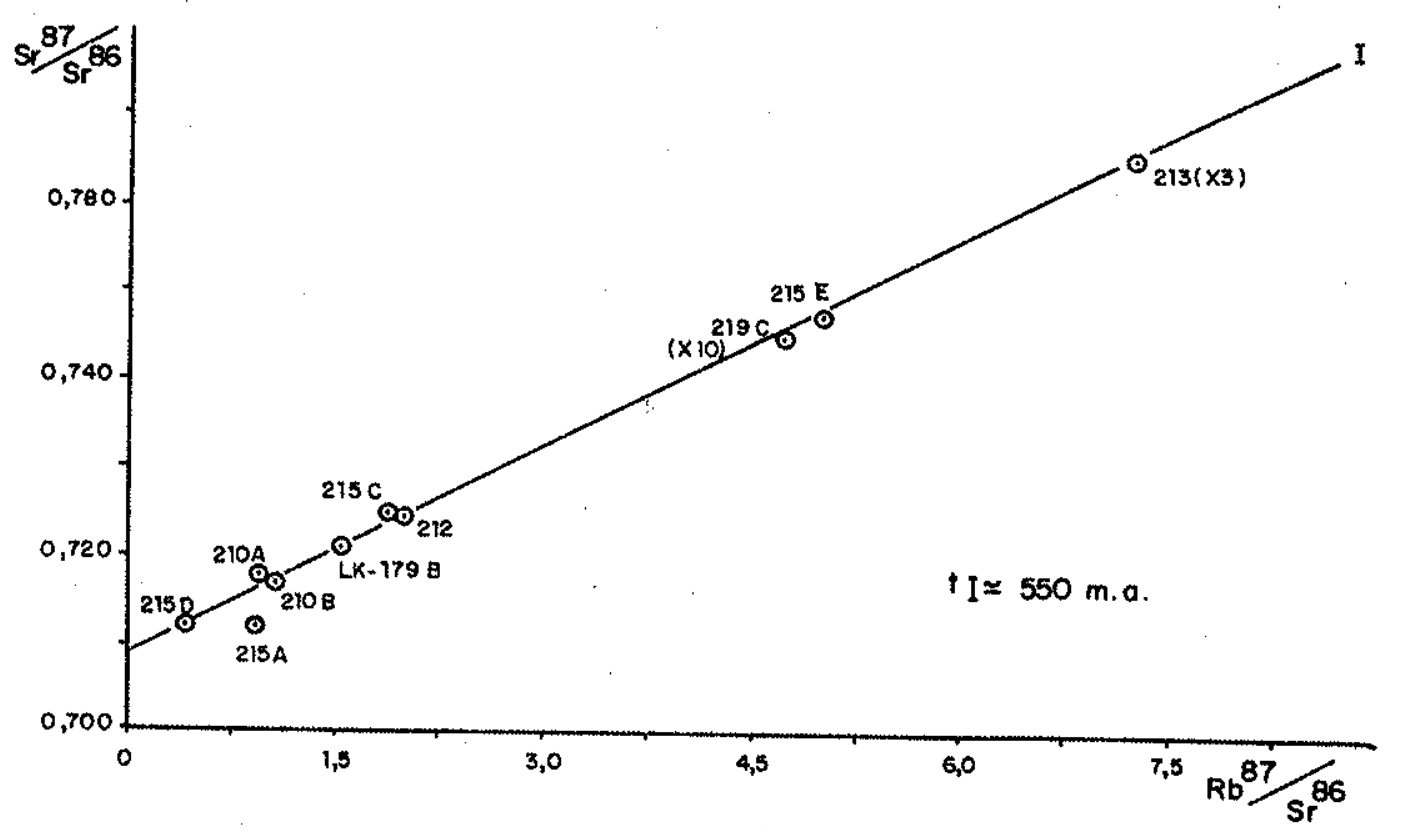

Fig. 17: Diagrama isocrônico Rb-Si de referência de rochas da Suíte Intrusiva Arroio dos Ladrões (Suíte Dom Feliciano), seg. Tei xeira (1982).

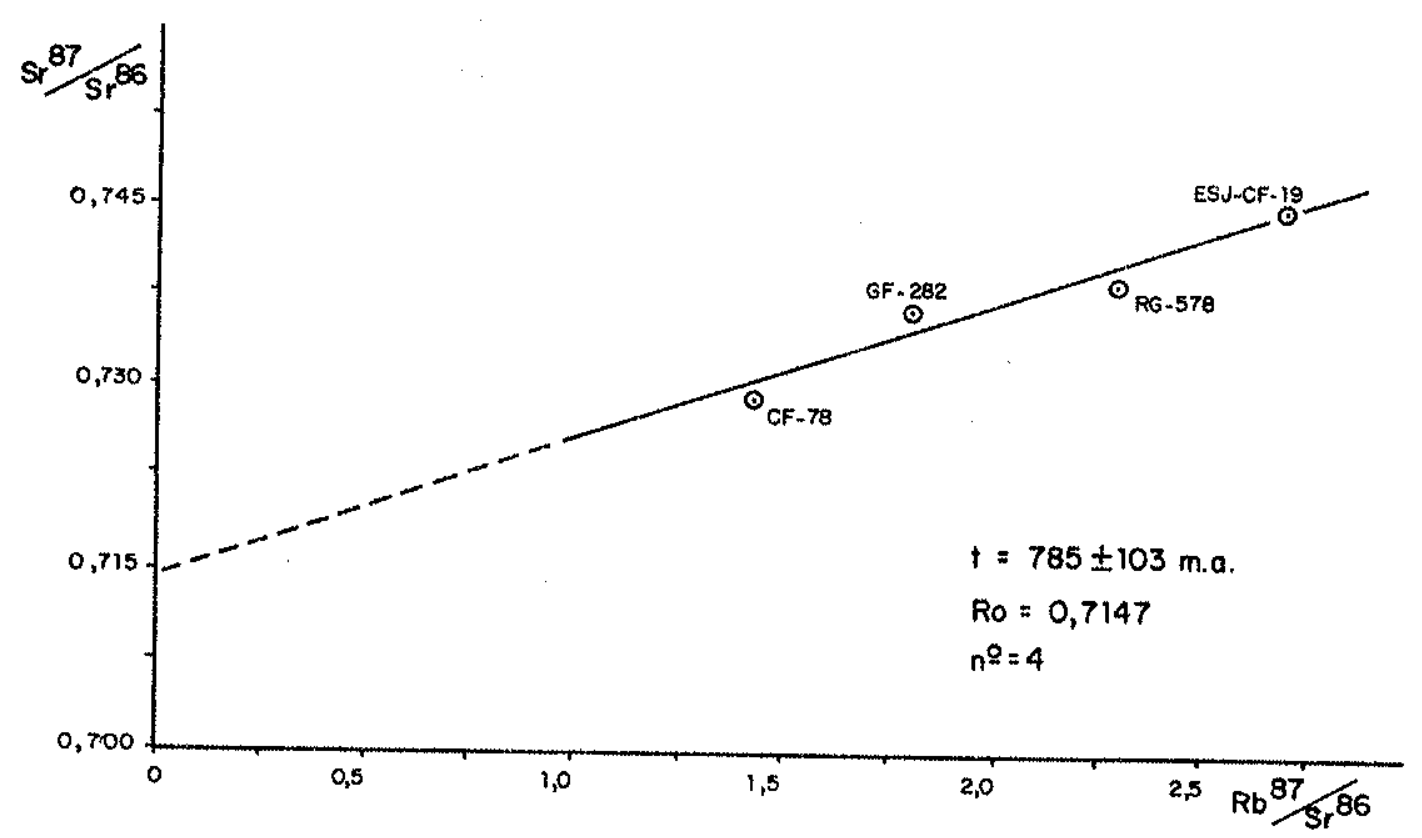

Fig. 18: Reta de melhor ajuste (Rb-Sr em RT) de amostras da suite Intrusiva Campinas, seg. Teixeira (1982). 


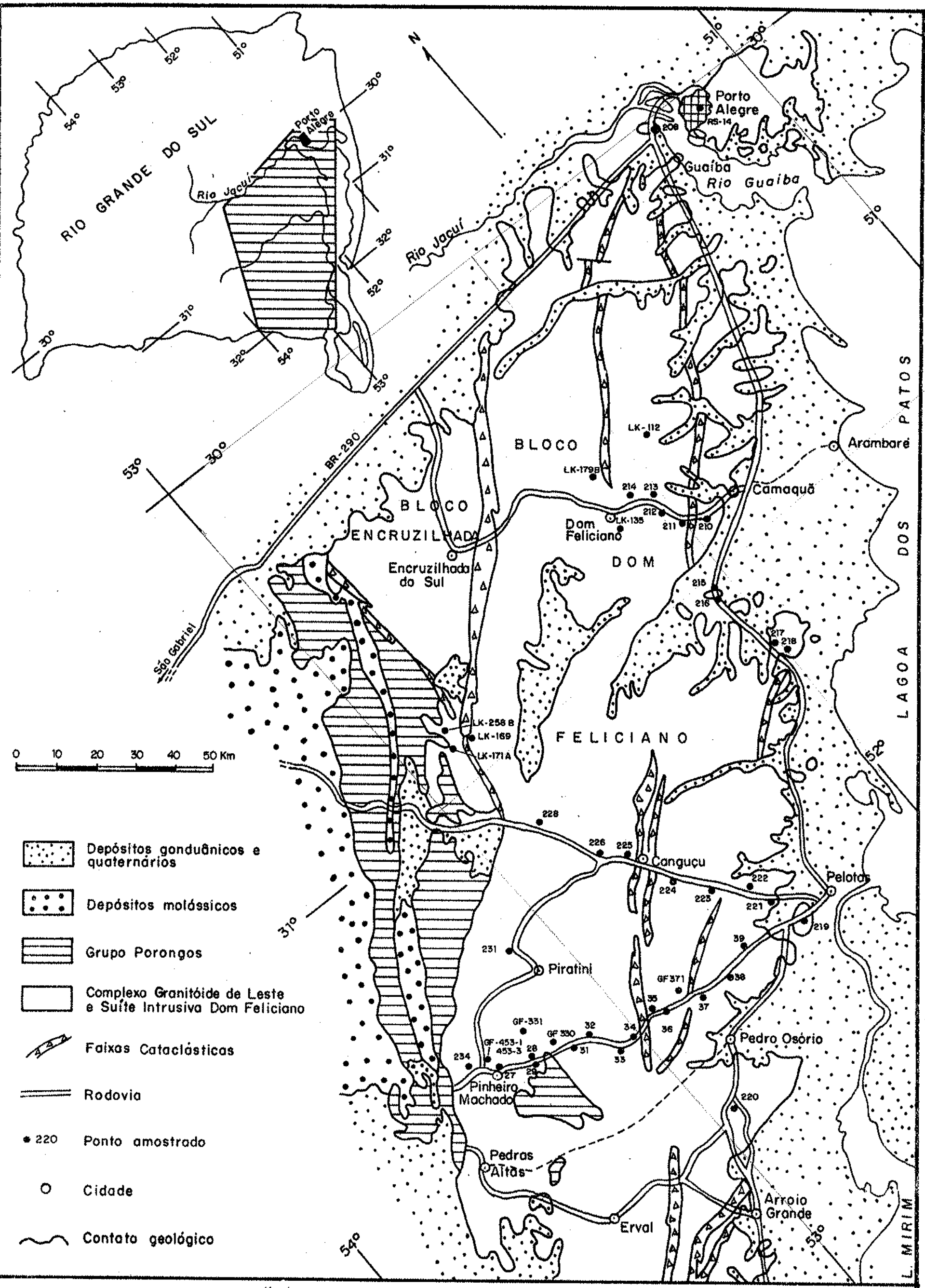

FIG 19 - MAPA dE LOCALIZAÇĂO dOS PONTOS AMOSTRADOS, COM DATACÁO RADIOMÉTRICA, NOS DOMINIOS DO COMPLEXO GRANITÓIDE DE LESTE E SUITE INTRUSIVA D. FELICIANO (BLOCO DOM FELICIANO). BASE GEOLÓGICA SEGUNDO WILLIG ET AL. (1974), CARTA GEOLÓGICA DO BRASIL AO MILIONÉSIMO, FOLHAS PORTO ALEGRE E LAGOA MIRIM, COM MODIFICAÇÓES OS PONTOS 27 a 39 SAO PRECEDIDOS PELA SIGLA ESJ. 


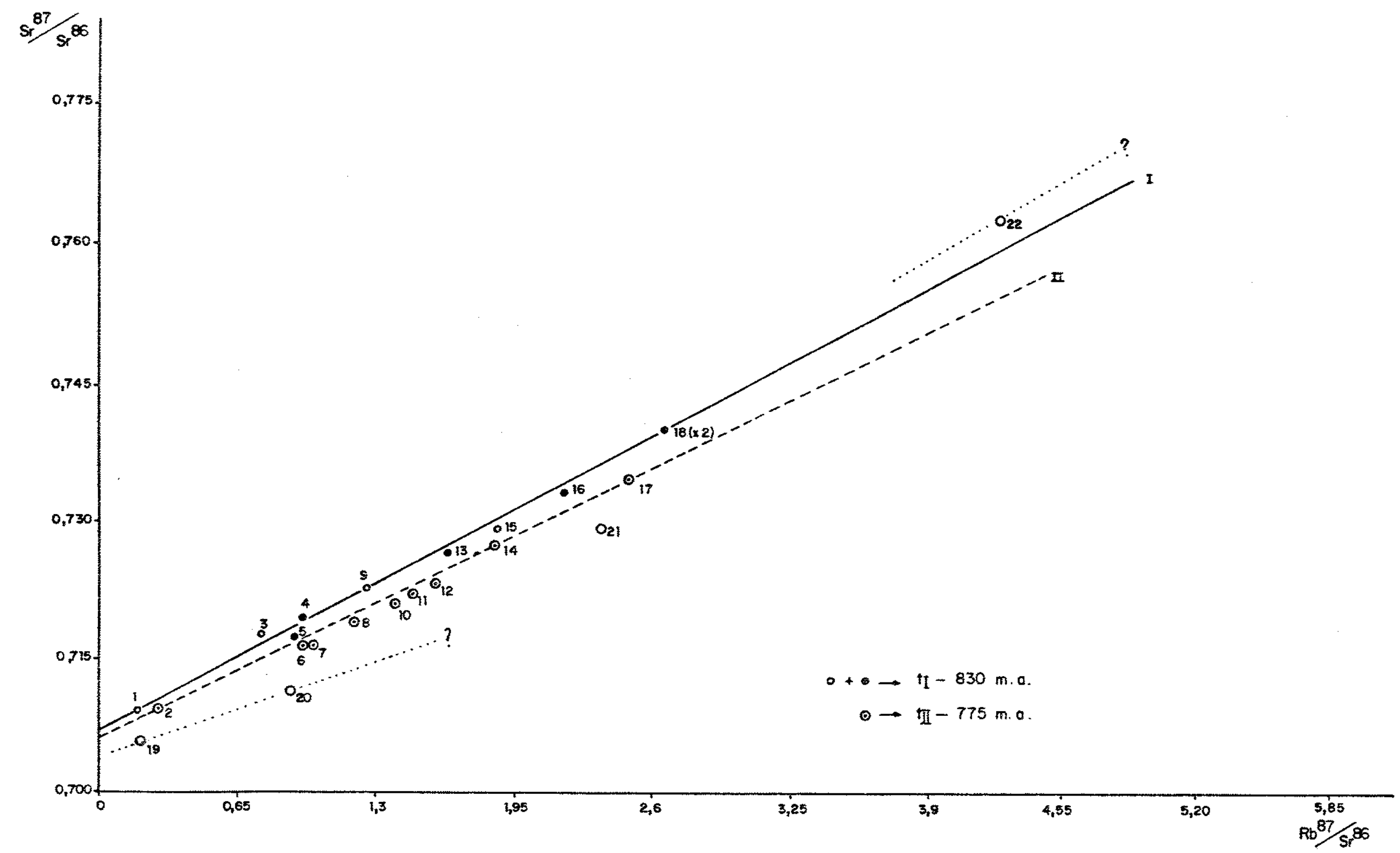

Fig. 20: Diagrama isocrônico Rb-Sr de referência dos granitöides folliados do Complexo Granitöide de Leste. Pontos com simbologias diferentes párticipam de segmentos isocrônicos diferentes. A identificação dos mesmos po de ser feita na tabela 5 ou nas figuràs 23 e 24 . 


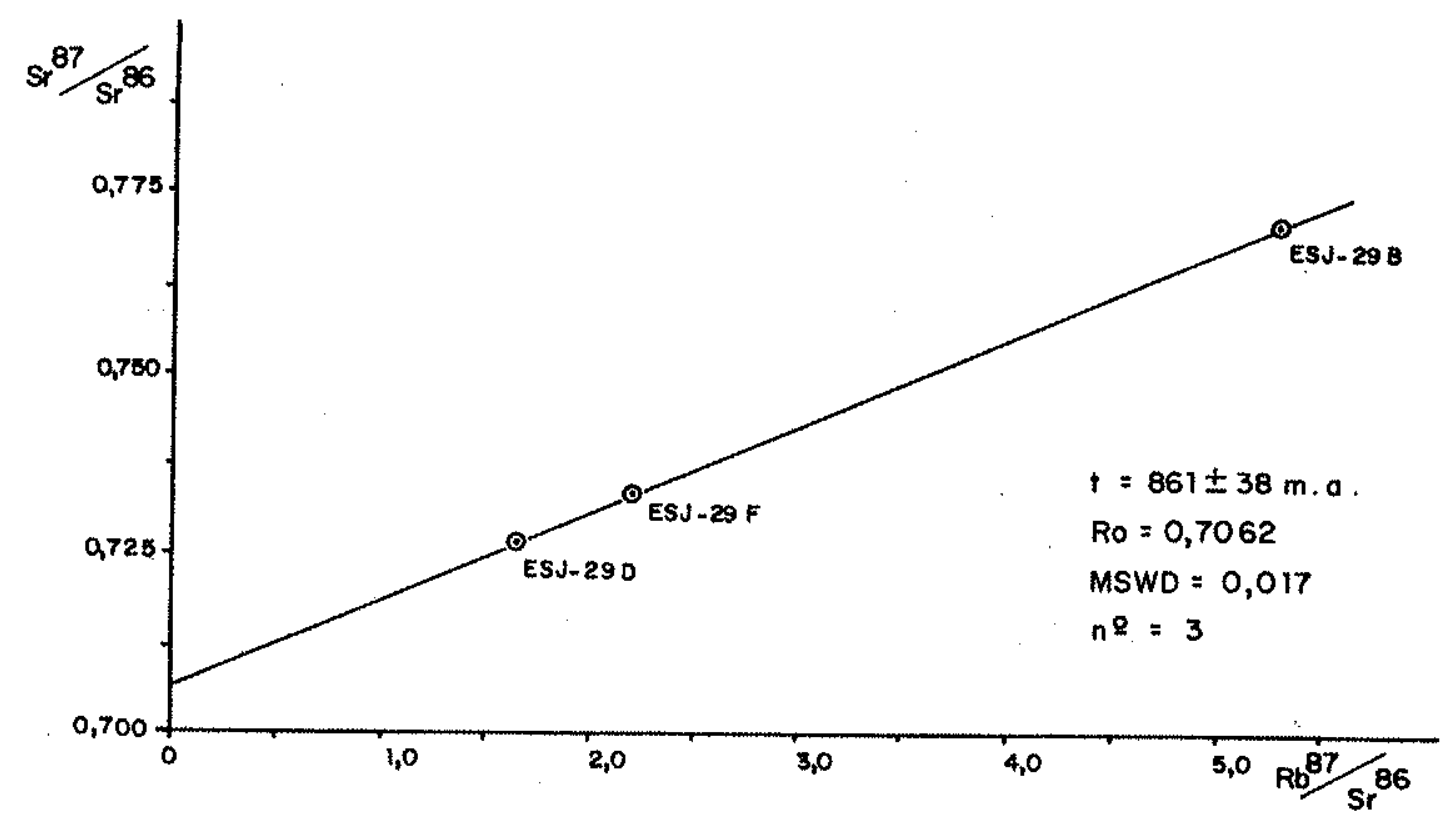

Fig. 2l: Isöcrona Rb-Sr de migmatitos da porção sul do Complexo Granitöide de Leste.

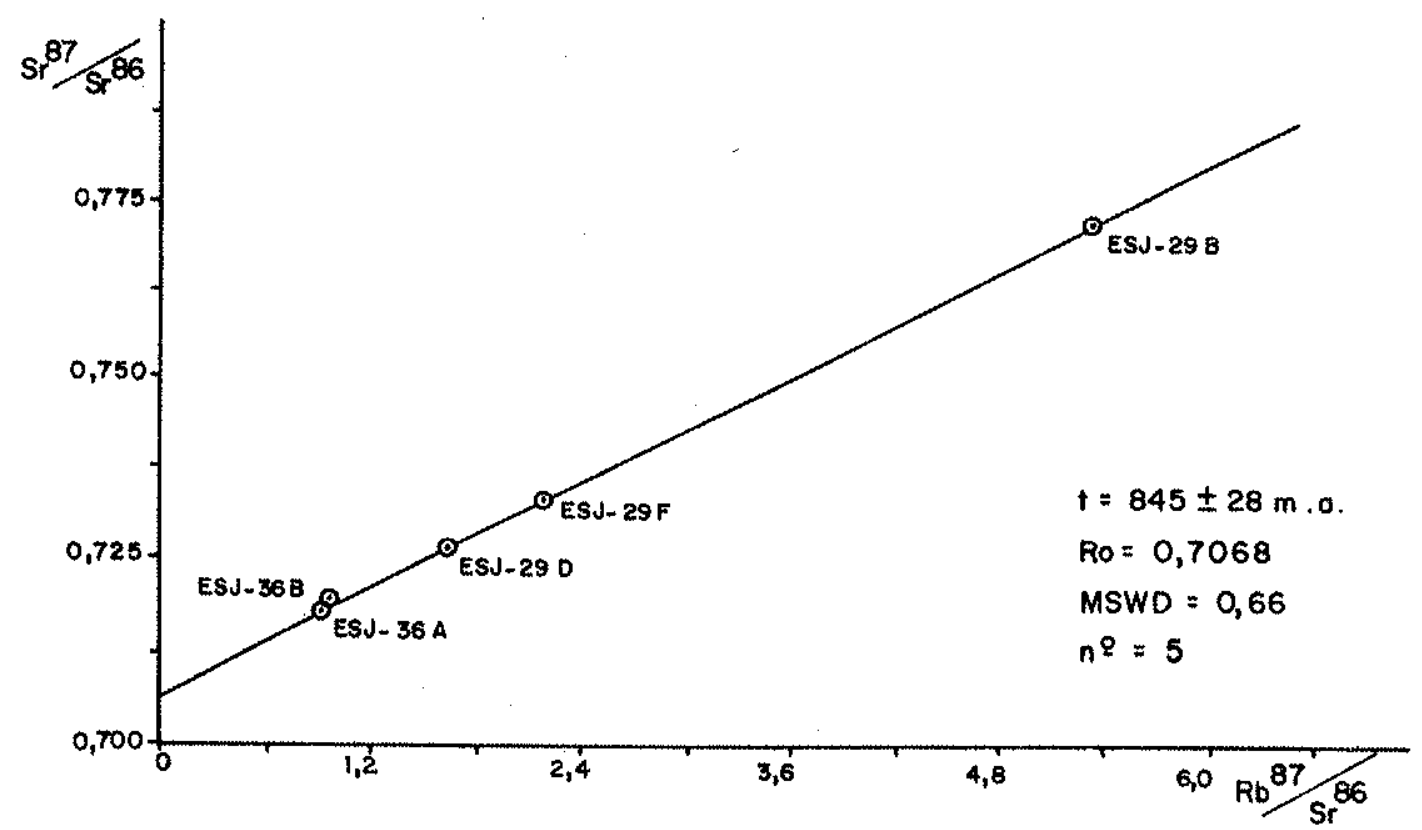

Fig. 22: Diagrama isocrônico Rb-Sr de referência de migmatitos da por ção sul do Complexo Granitóide de Leste. 


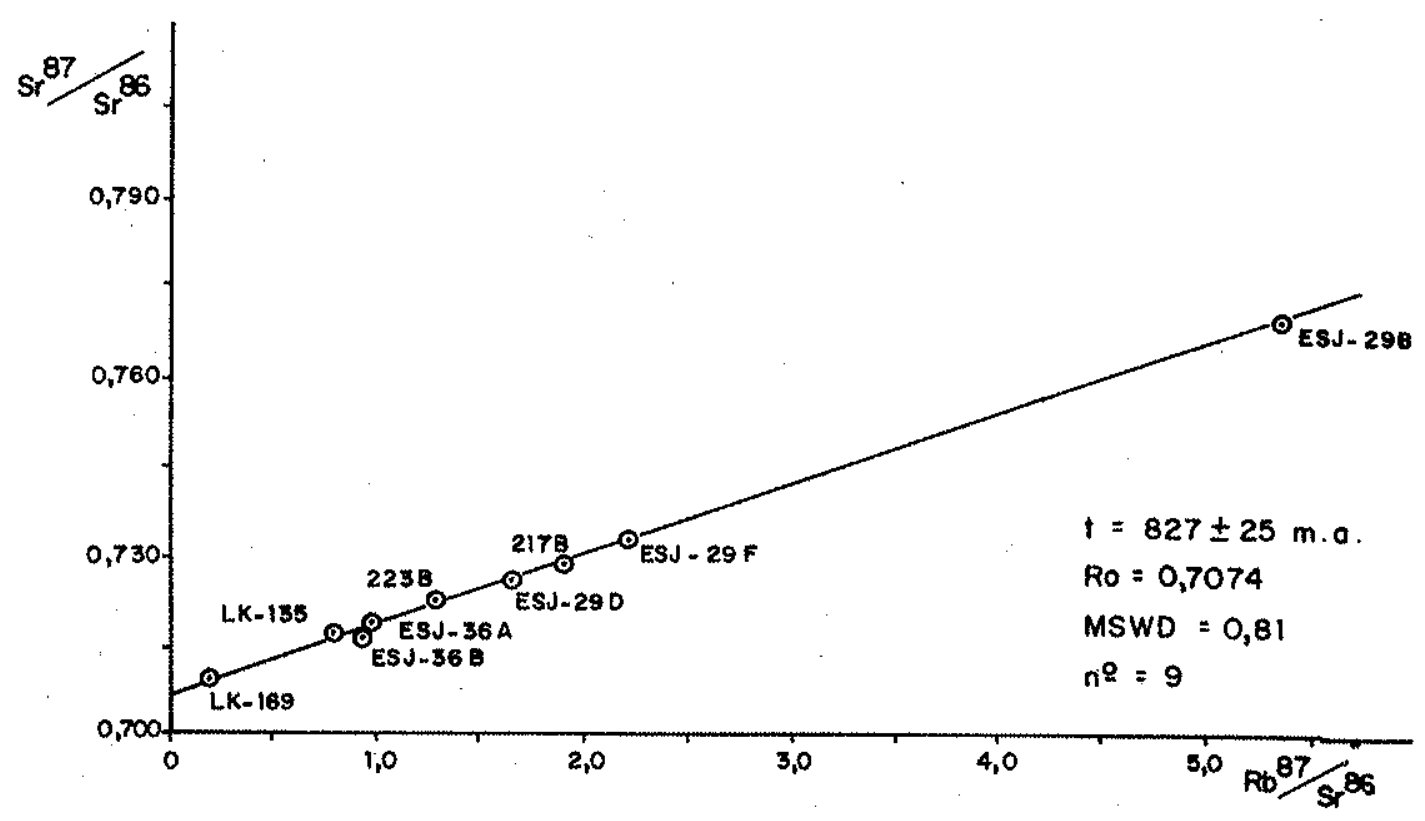

Fig. 23: Diagrama isocrônico Rb-Sr de referência de granitöides folla dos (migmatitos, gnaisses e tonalito) do Complexo Granitöide de Leste. Corresponde ao segmento isocrônico I da figura 20 .

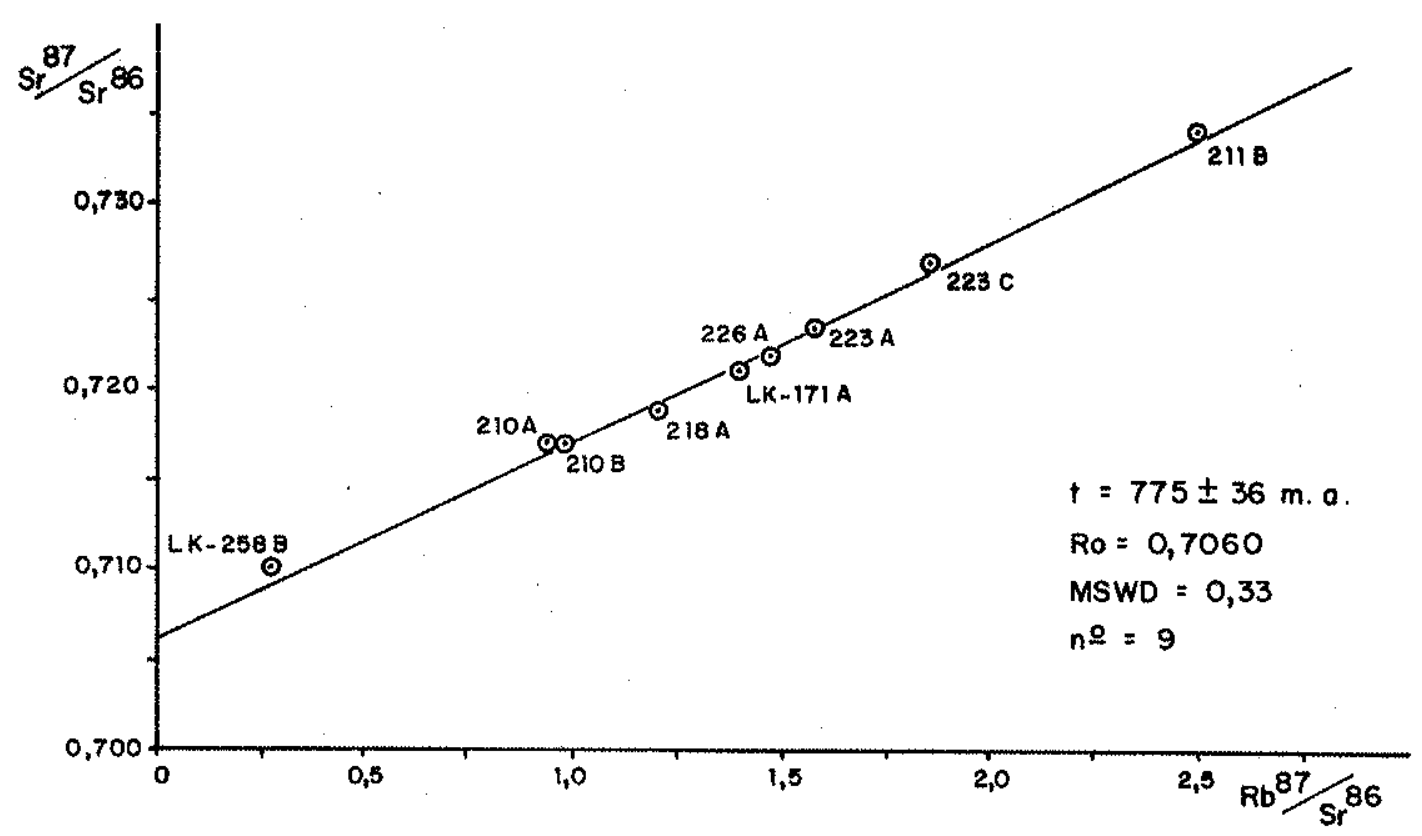

Fig. 24: Diagrama isocrônico Rb-Sr de referência de granitōides folia dos (granodioritos, granitos acinzentados e, em menor nümero, gnaisses e migmatitos) do Complexo Granitöide de Leste. Corresponde ao segmento isocrônico 11 da figura 20. 


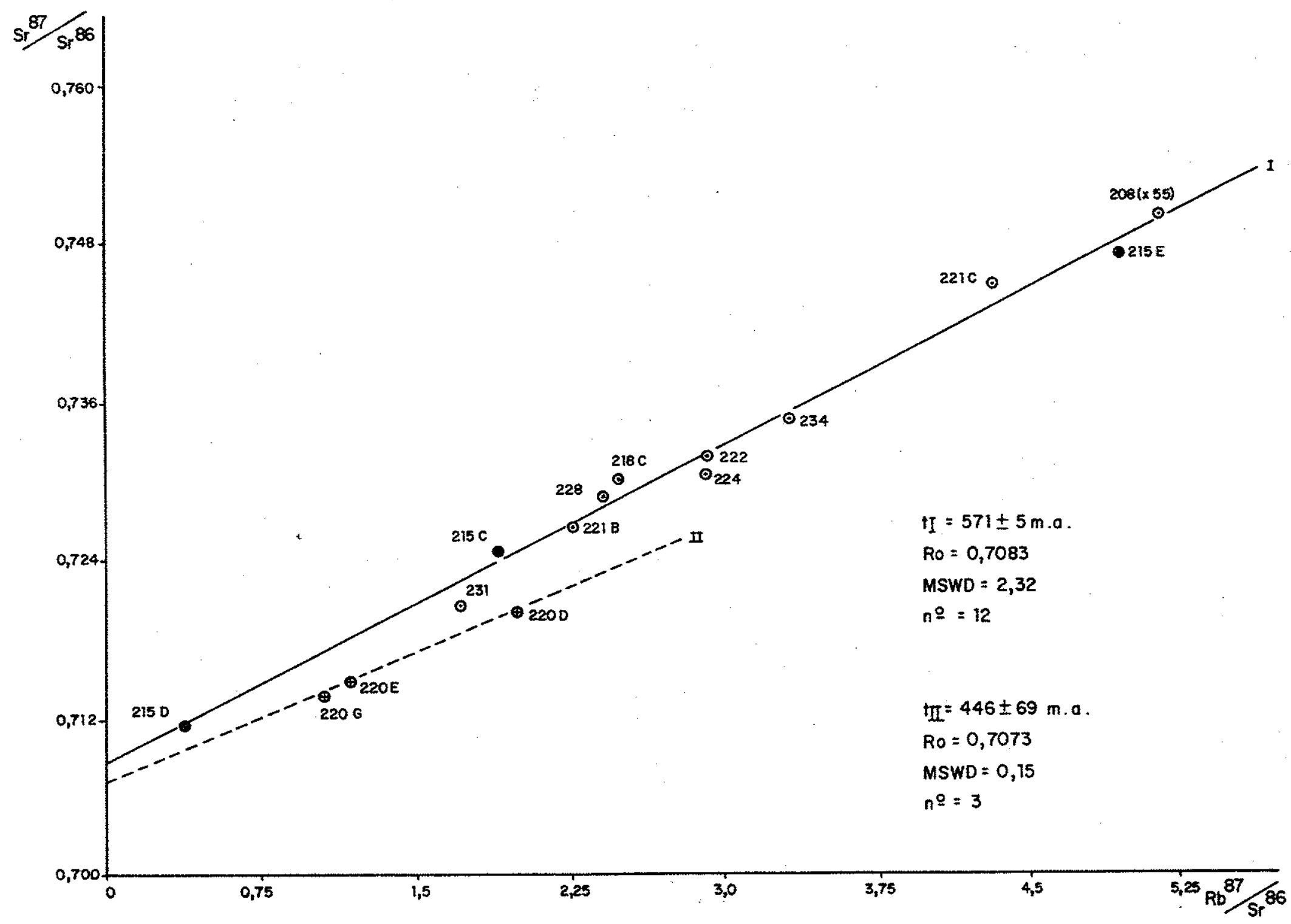

Fig. 25: Diagrama isocrônico Rb-Sr de referência de granitōides não folliados do Complexo Granitōide de Leste. 0 segmento isocrônico $\|$ deriva de amostras cogenéticas. 


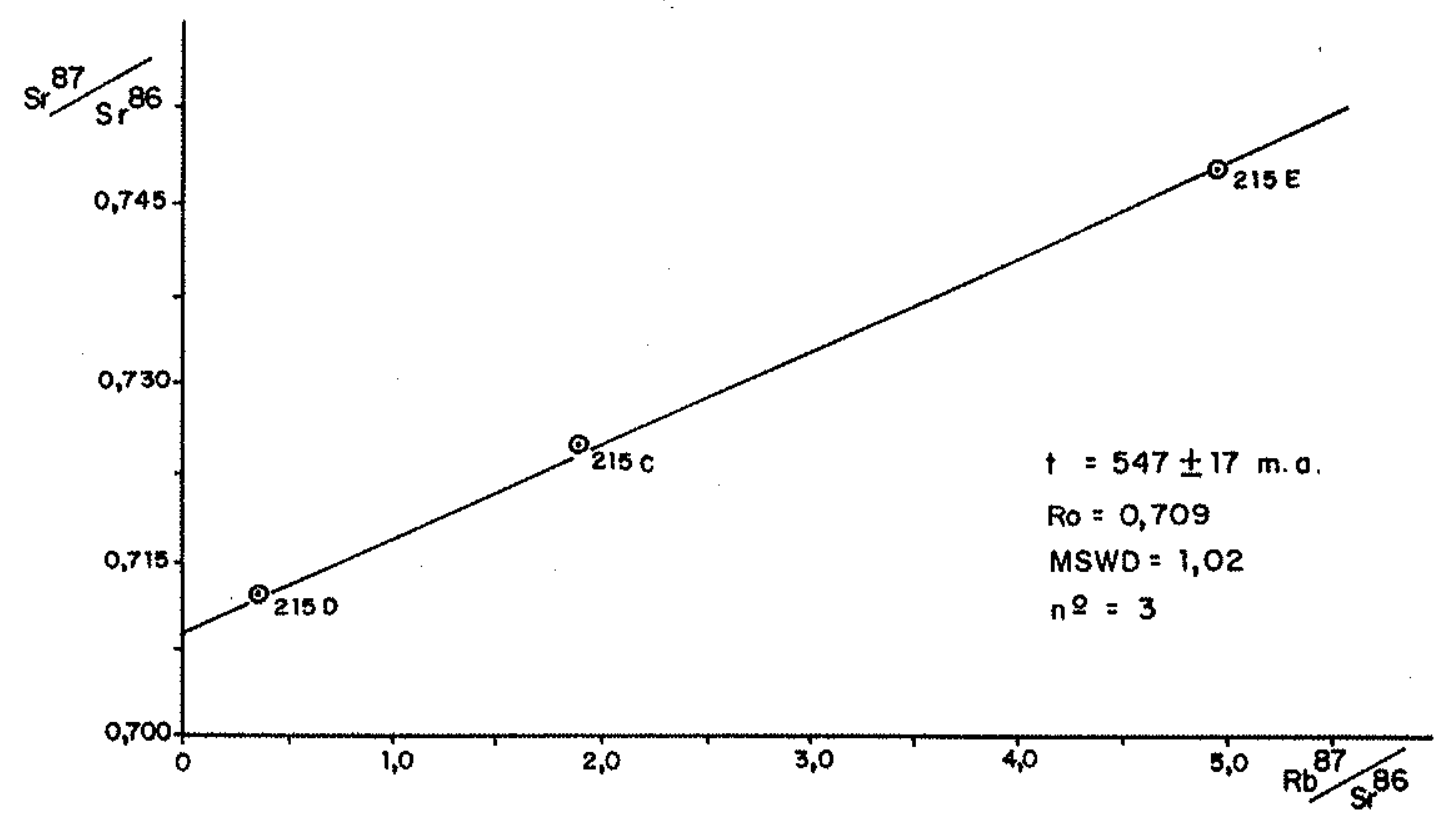

Fig. 26: Isōcrona Rb-Sr de granitōides cogenēticos, não foliados, do Complexo Granitóide de Leste. 


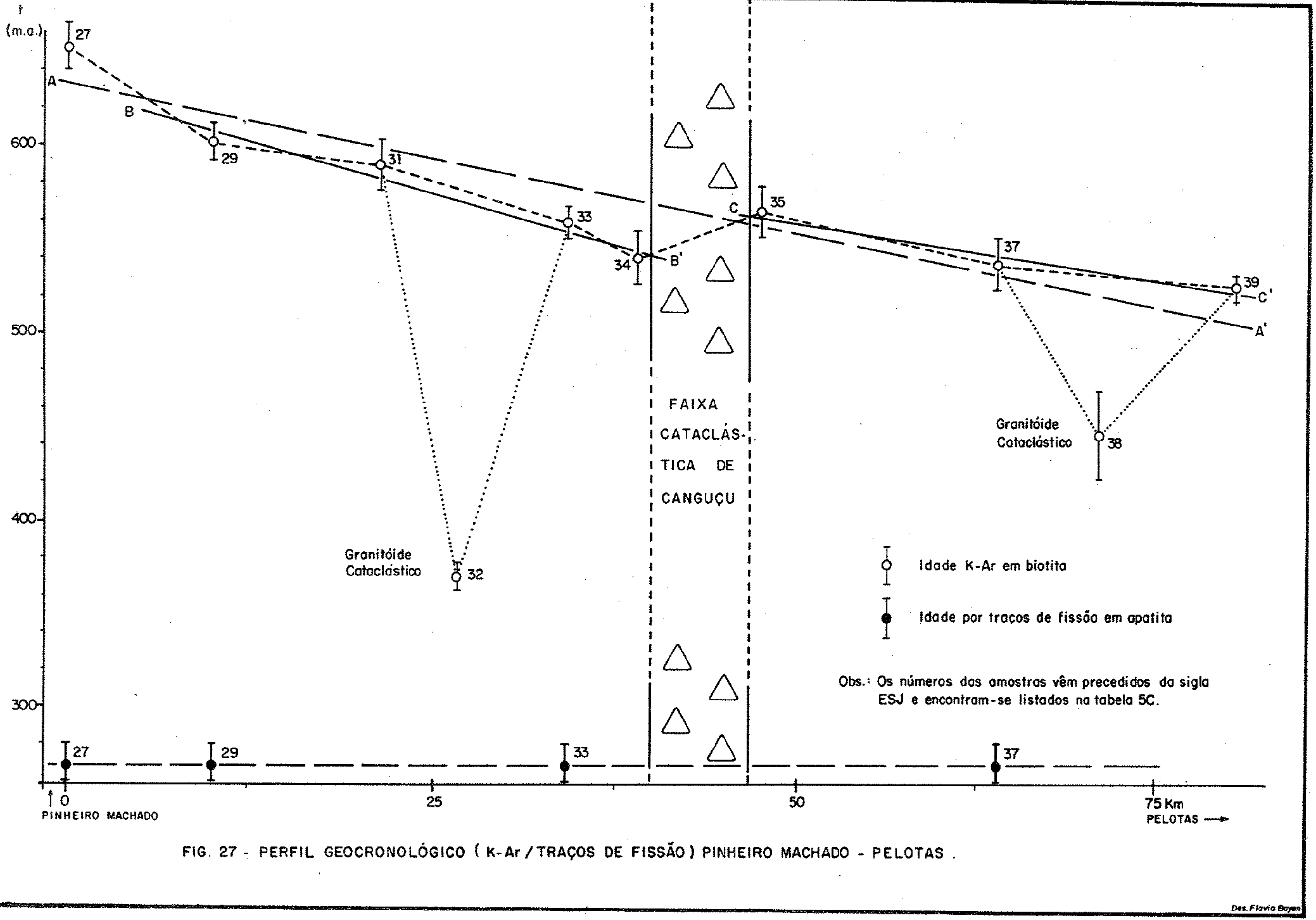




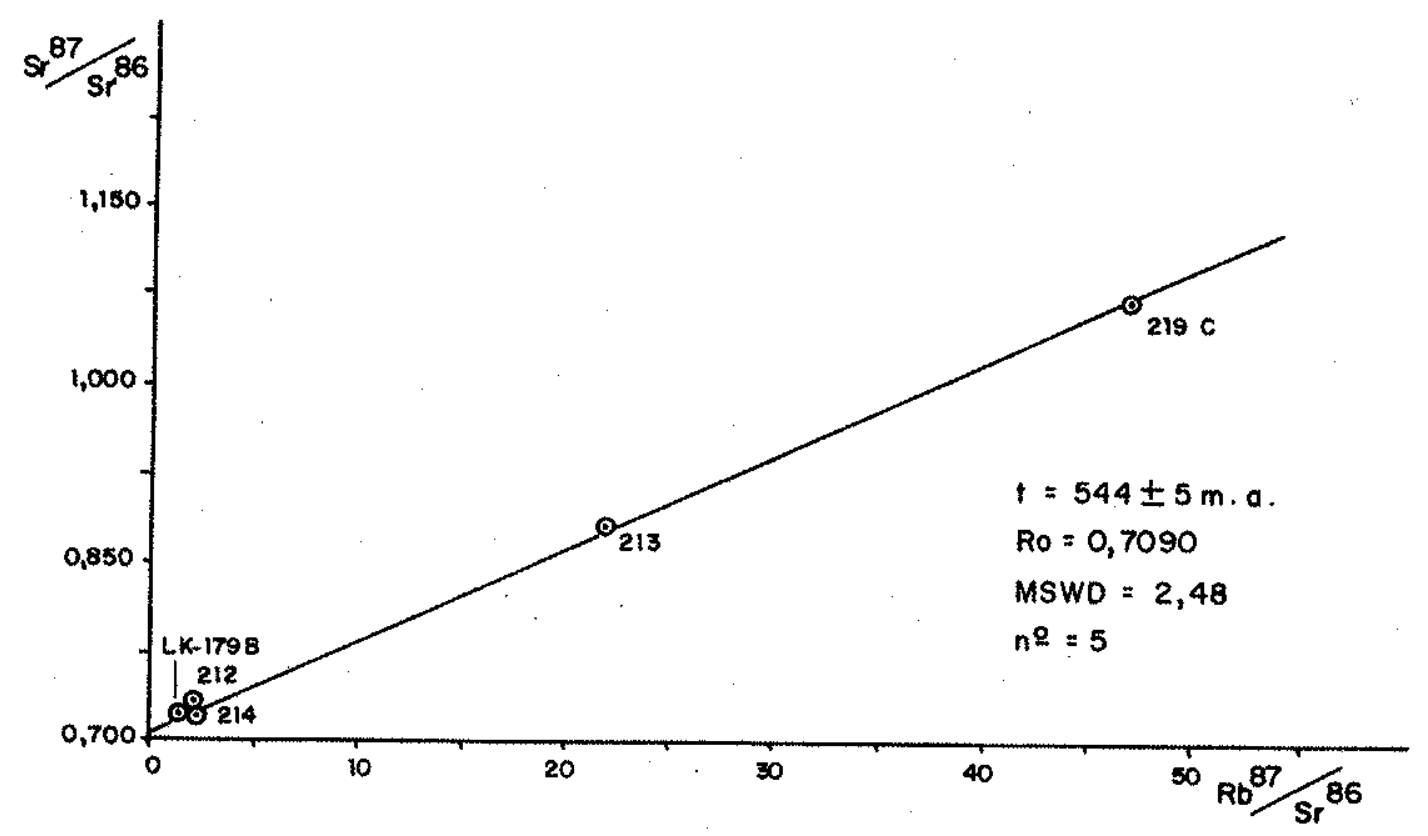

Fig. 28: Diagrama isocrōnico $\mathrm{Rb}-\mathrm{Sr}$ de referência de rochas graníticas da Suíte Dom Feliciano.

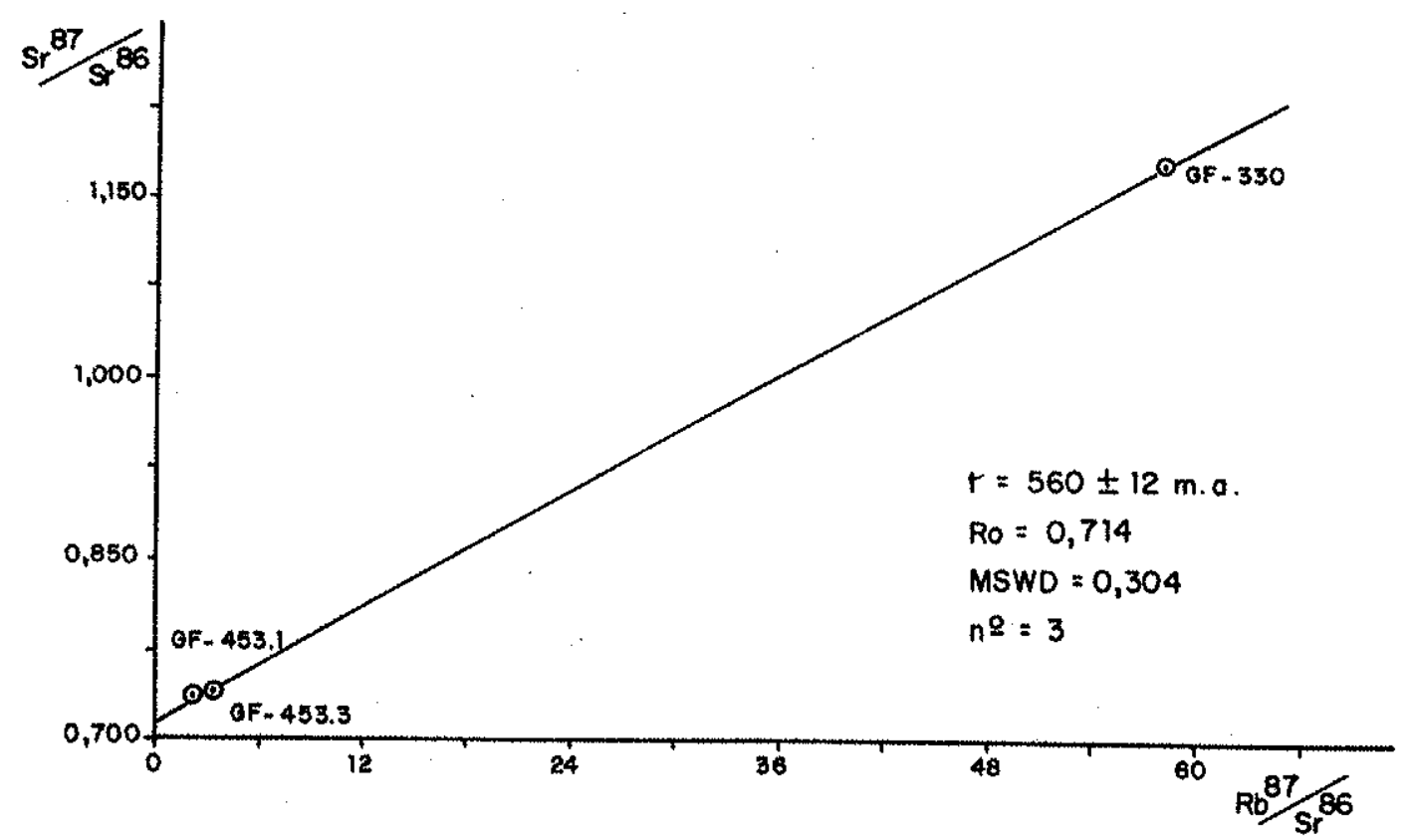

Fig. 29: Diagrama isocrônico Rb-Sr de referência dos vulcanitos äcidos da região de Pinhei ro Machado. 


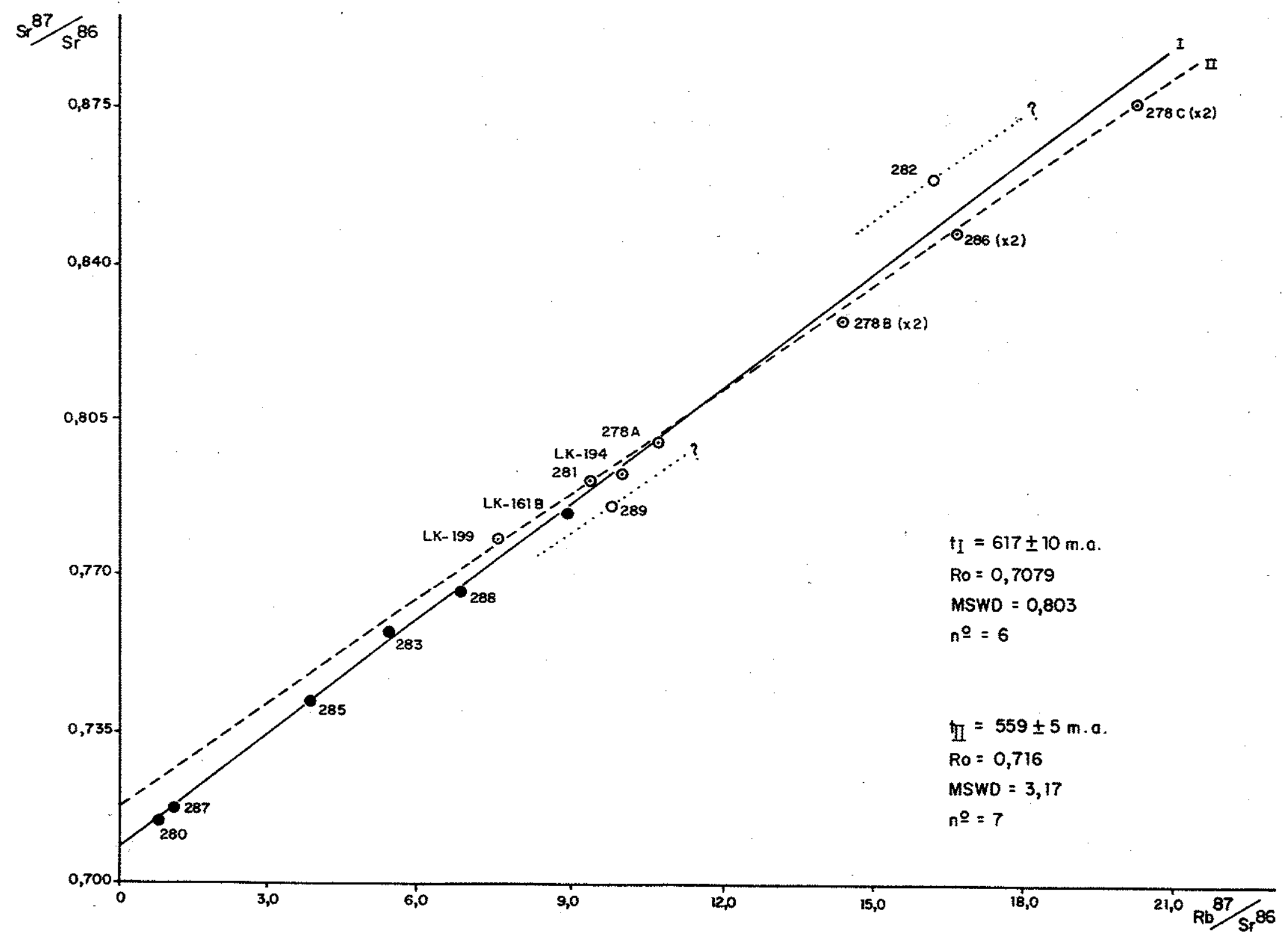

Fig. 30: Diagrama isocrônico Rb-Sr de referência de grani töides do Bloco Encruzillhada. 0 segmento isocrônico foi definido por amostras foliadas e o segmento 11 por amostras isótropas. Os pontos $278 \mathrm{~A}, \mathrm{~B}$ e $\mathrm{C}$ são cogenéticos e definem uma isócrona de $551+-7 \mathrm{~m} . \mathrm{a}$.. 


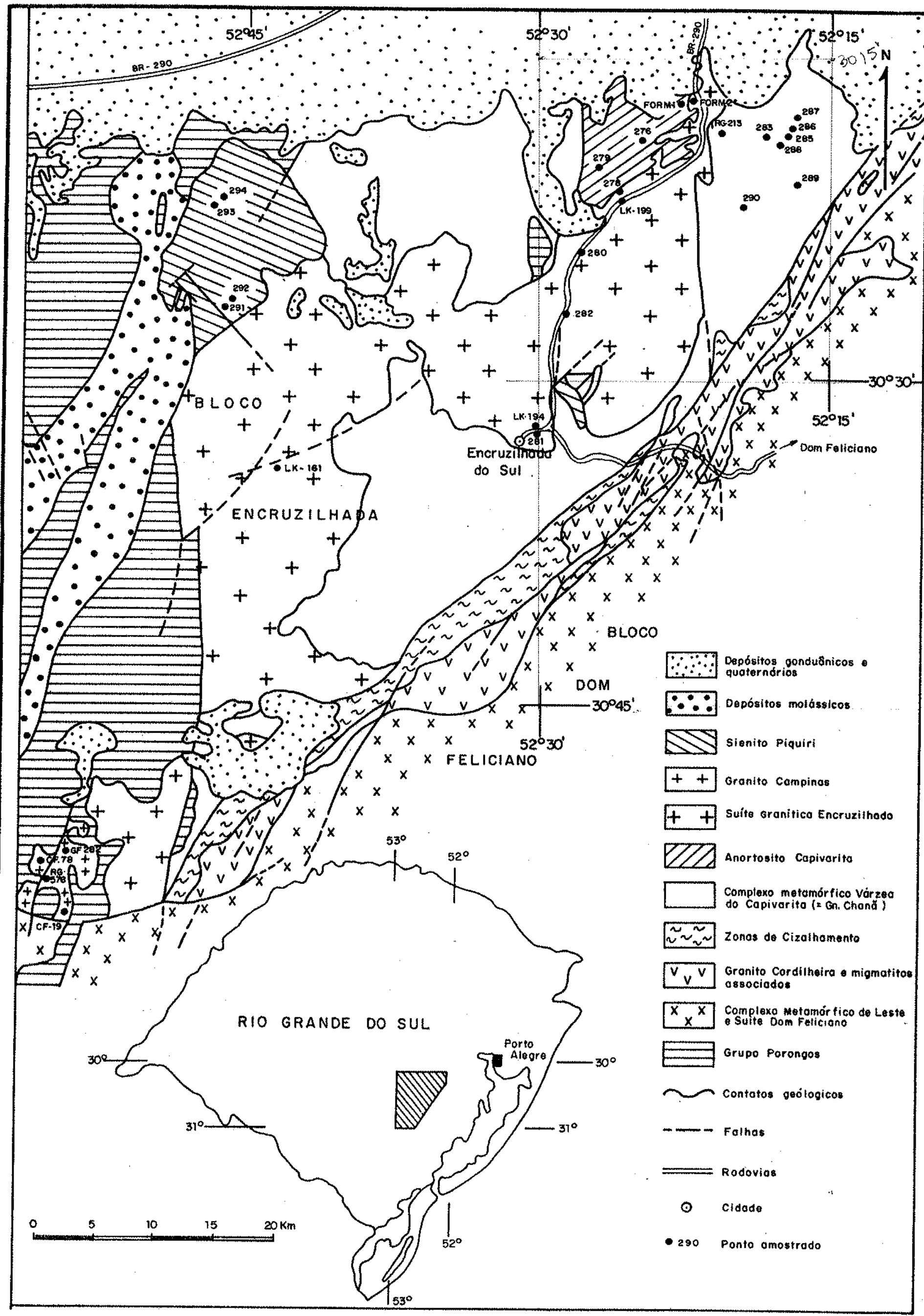

FIG. 31 - MAPA DE LOCALIZAÇÃO DOS PONTOS AMOSTRADOS, COM DATAÇ̃̃O RADIOMÉTRICA, NOS DOMINIOS DO BLOOCO ENCRUZILHADA. BASE GEOLÓGICA SEGUNDO TESSARI E PICADA (1966), COM MOdIFICAÇŏ́S 


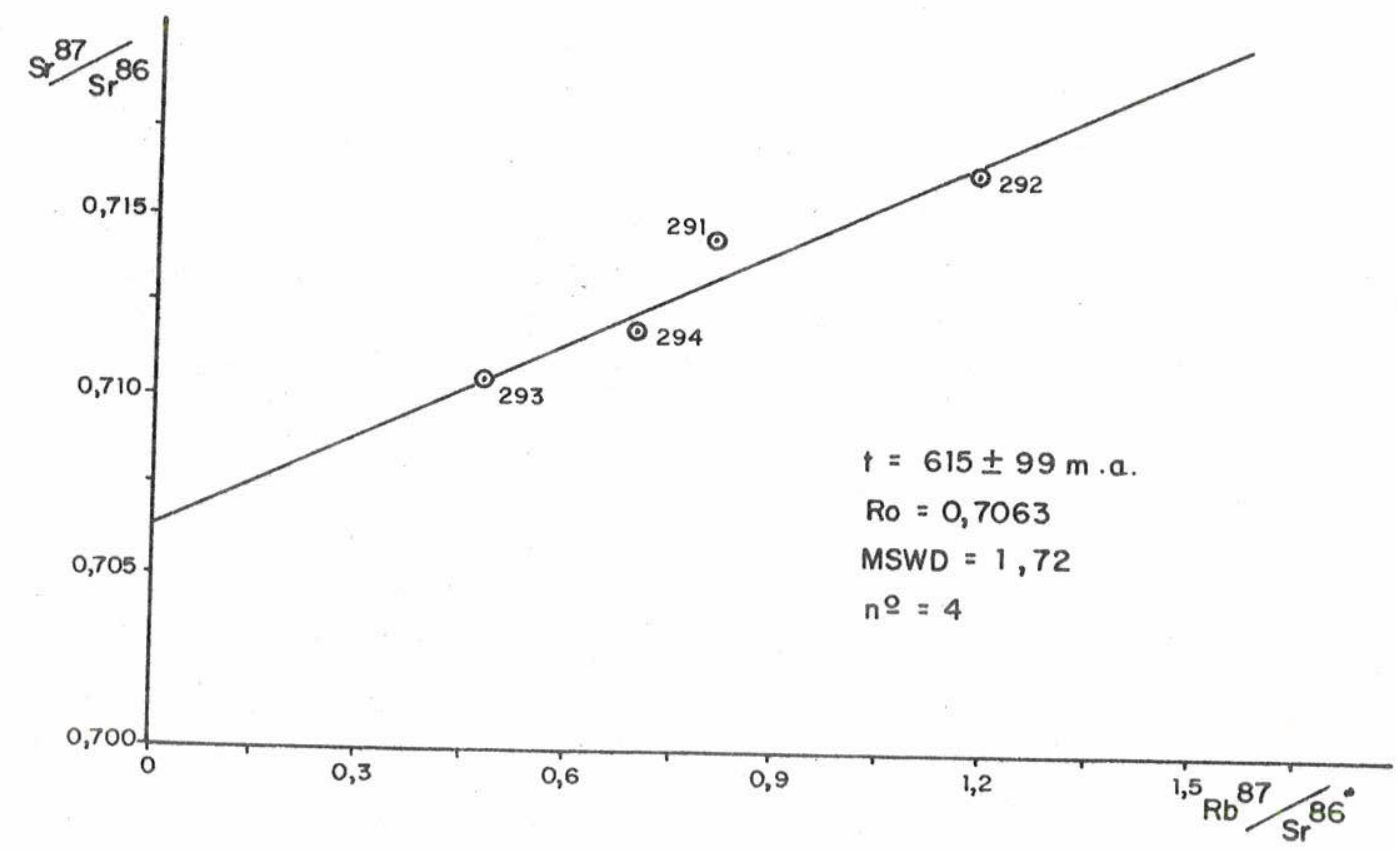

Fig. 32: Reta de melhor ajuste (Rb-Sr em RT) de amostras do Sienito Piquiri. Excluindo-se o ponto 291 , os resultados do diagrama isocrônico passam a ser: $t=606+-98 \mathrm{~m} \cdot \mathrm{a}$.; Ro $=0,7060$ e $M S W D=0,33$.

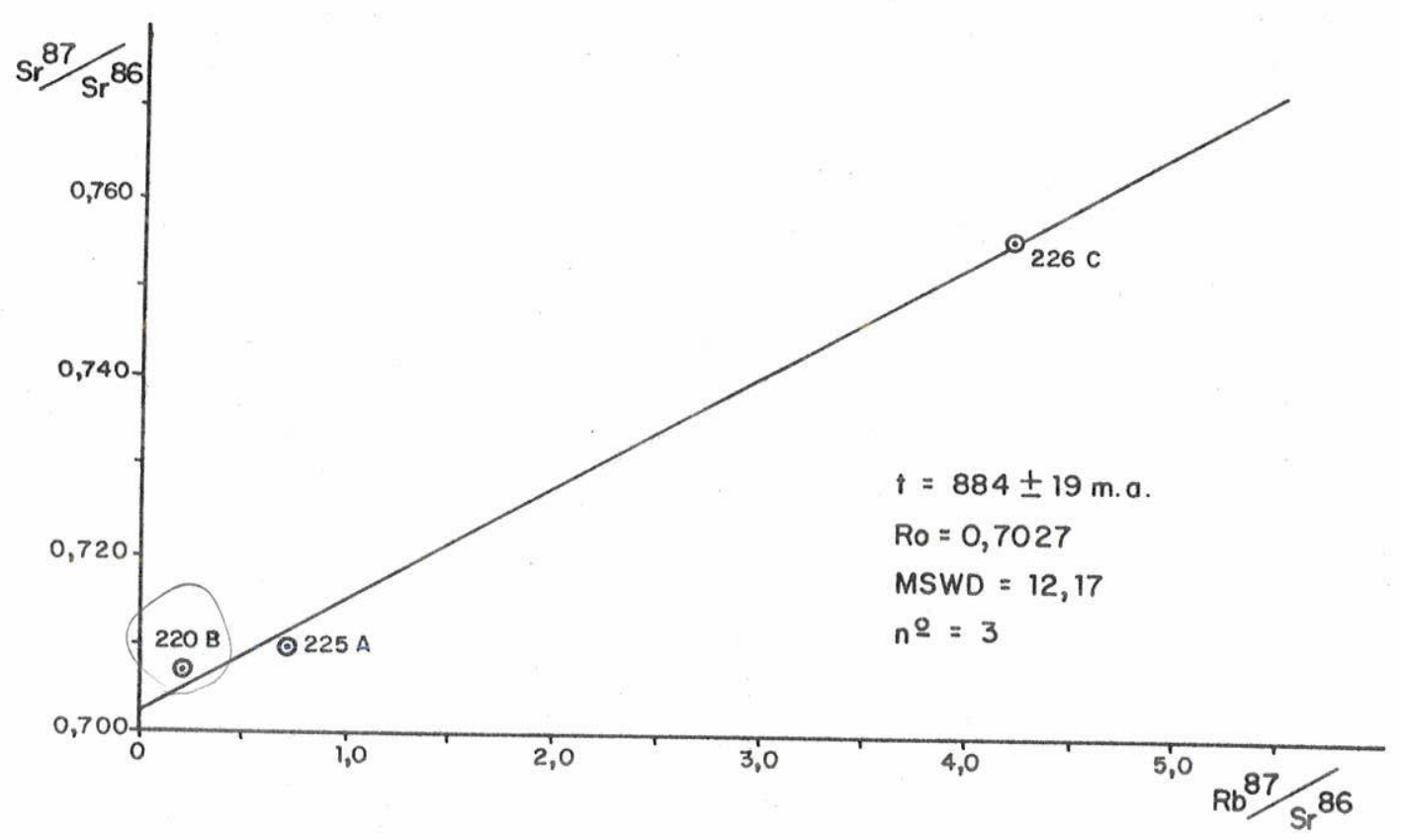

Fig. 33: Diagrama isocrônico Rb-Sr de referência de anfibolitos do Complexo Granitöide de Leste. 


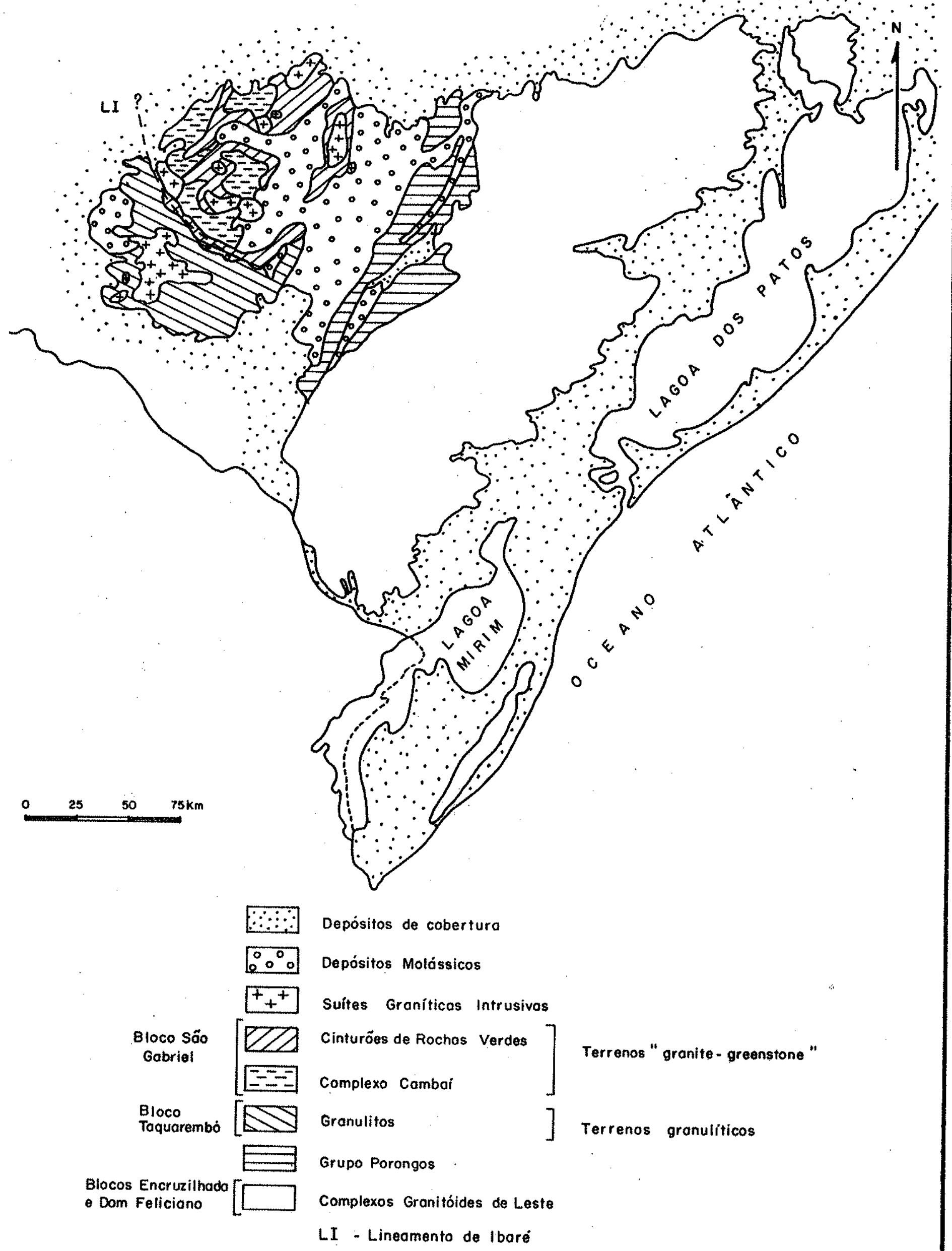

FIG. 34 - ÁREAS DE OCORRÊNCIA dOS TERRENOS" GRANITE-GREENSTONE" E GRANULiticos NA PORÇÃO OESTE DO ESCUDO SUL-RIO-GRANDENSE, SEGUNDO ISSLER (1984)(MODIFICADO). 




Fig. 35: Mapa geológico da ärea de Mata Grande (seg. Issler et al., 1973) e a localização dos pontos amostrados. 
- MAPA geológICo da aEgIäo de são sepé, Rs -

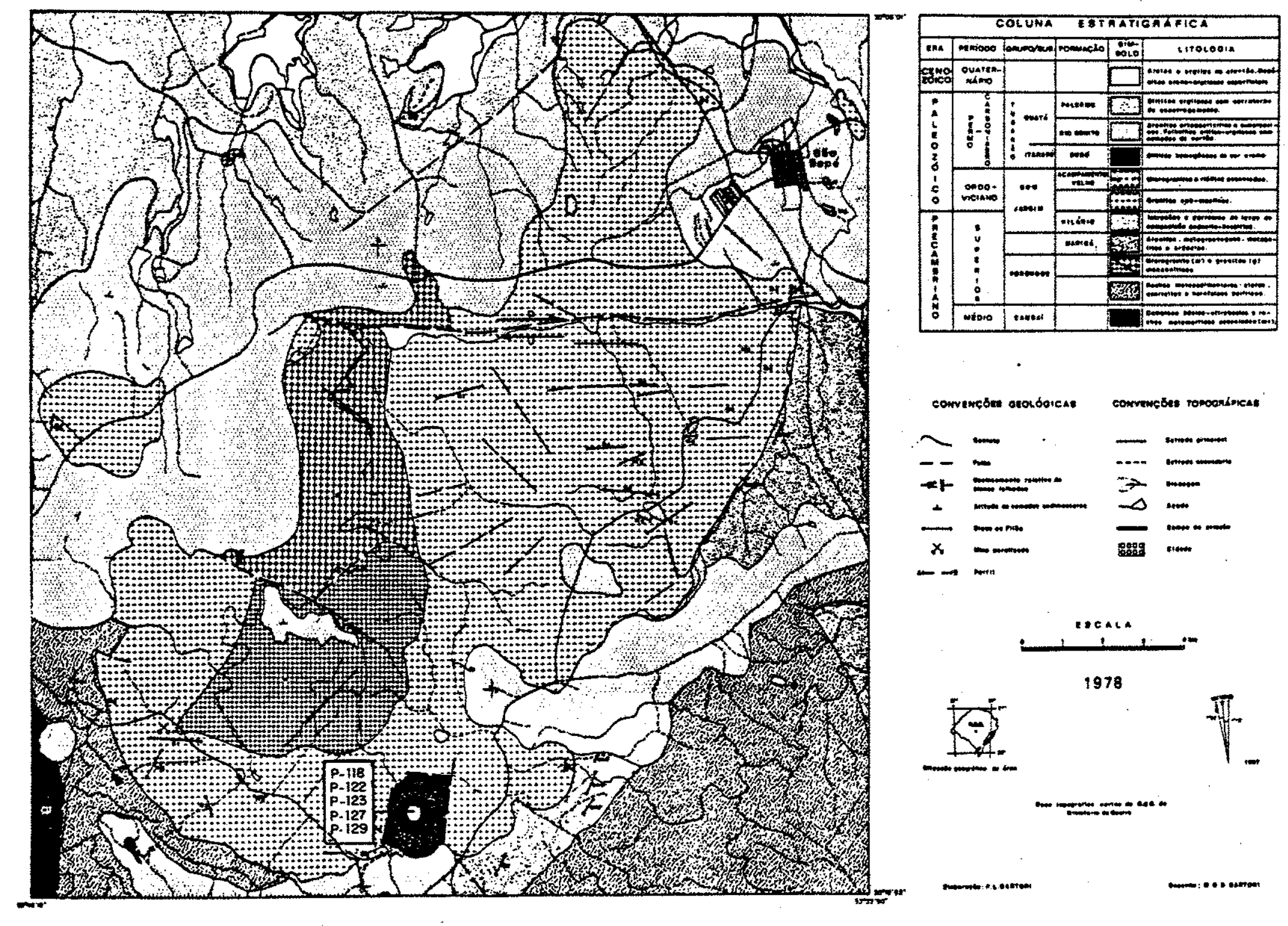
Fig. 36: Mapa geolögico da região de São Sepé (seg. Sartori, 1978) e as
local izaçós do Complexo Básico-ultrabäsico de Pedras Pretas e dos pontos amostrados. 


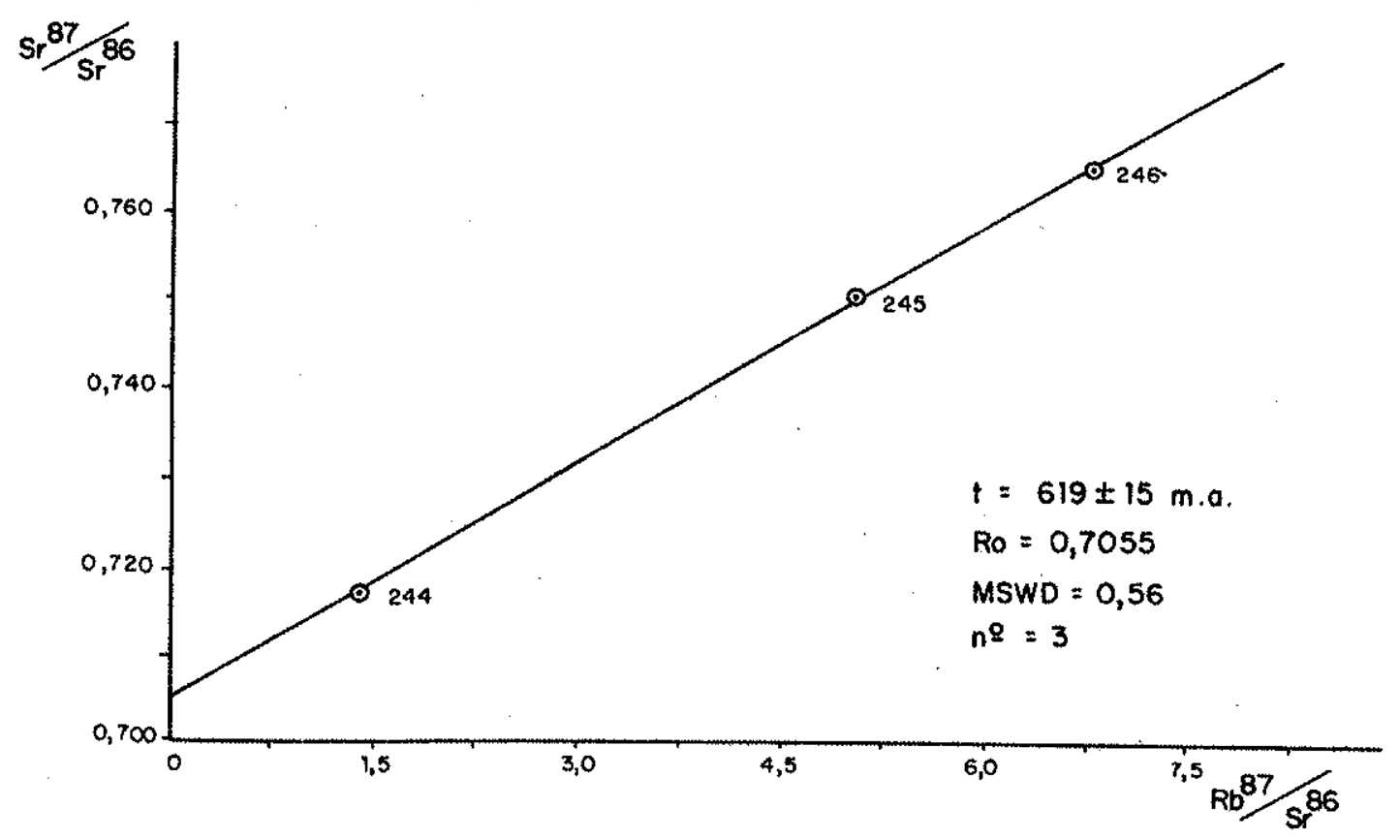

Fig. 38: Diagrama isocrônico Rb-Sr de referência de granitöide indiferenciado associado à unidade Cambaí na região central do Bloco São Gabriel. 


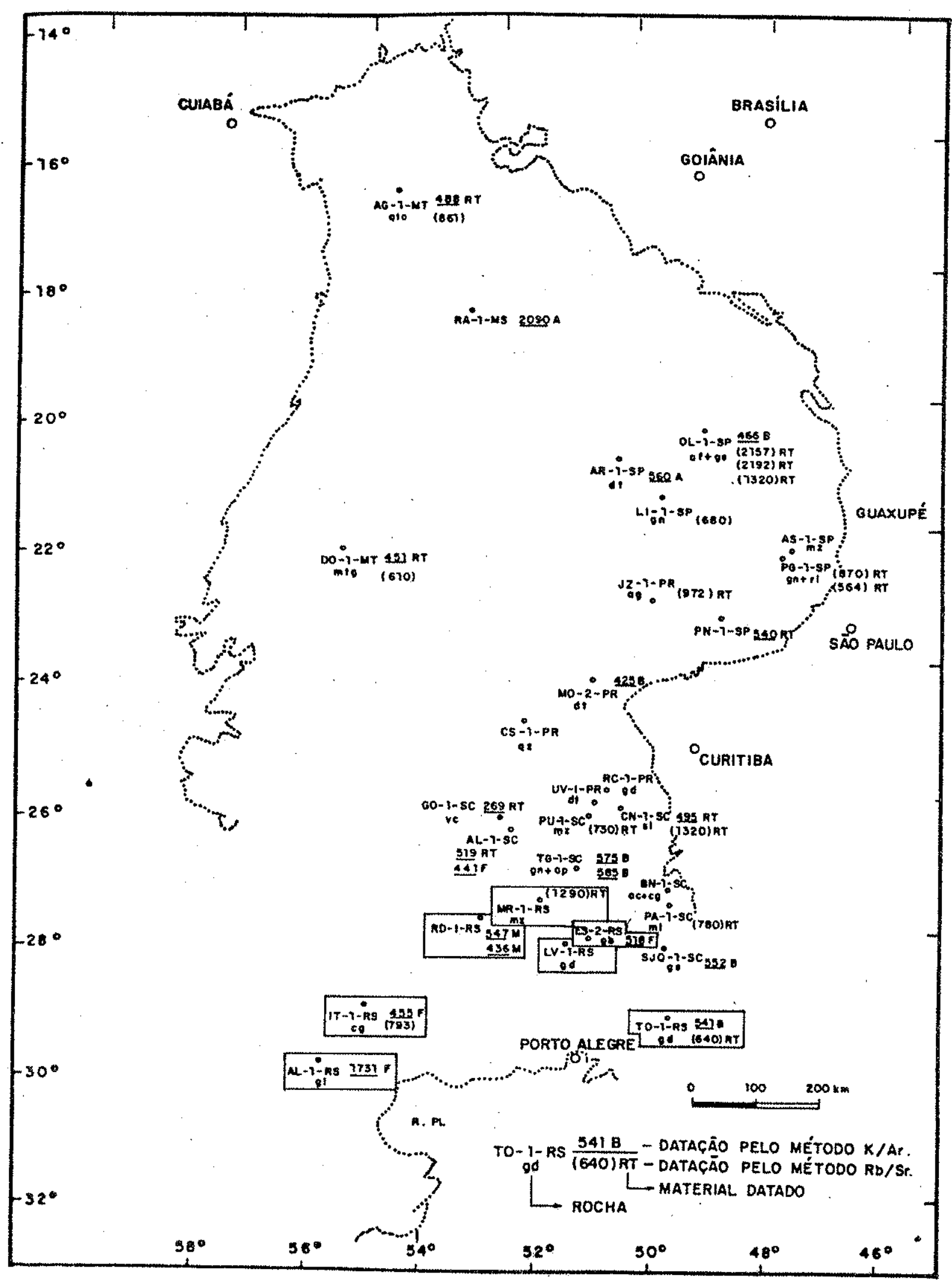

Fig. 39: Localização das sondagens que atingiram o embasamento da Bacia do Paraná, com informações petrogrä́ficas e/ou geocronolögicas, seg. Cordani et al., 1984. A ênfase é dada aos poços perfurados no Rio Grande do Sul. 
FIG. 40 - LOCALIZAÇÃO DAS ÁREAS DO ARROIO CAMBAIZINHO (1), VILA NOVA (2)

Rodovia

$\because \because:$ Sedimentitos fonerozóicos

$\because \because$ Depósitos molássicos

$+千+$
$+t+$ Suites groniticos intrusivas

Dequiêncios

D vulcano-sedimentores

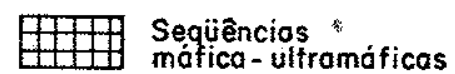

$\square$ Gnoisses Comboi

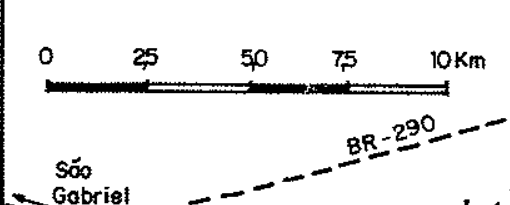

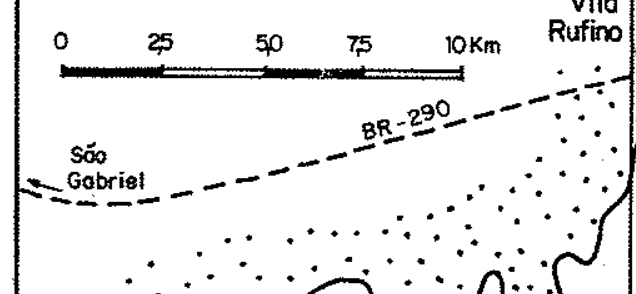

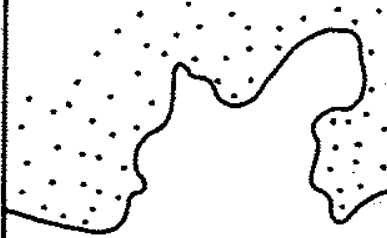

$\therefore \therefore\}$

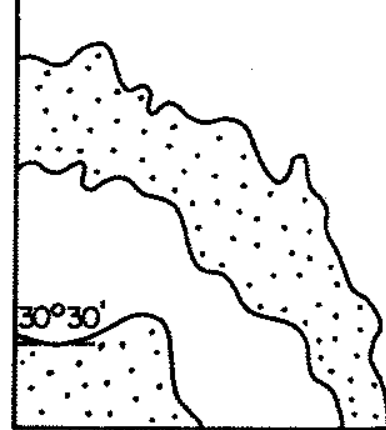

DO BLOCO SÄO GABRIEL 


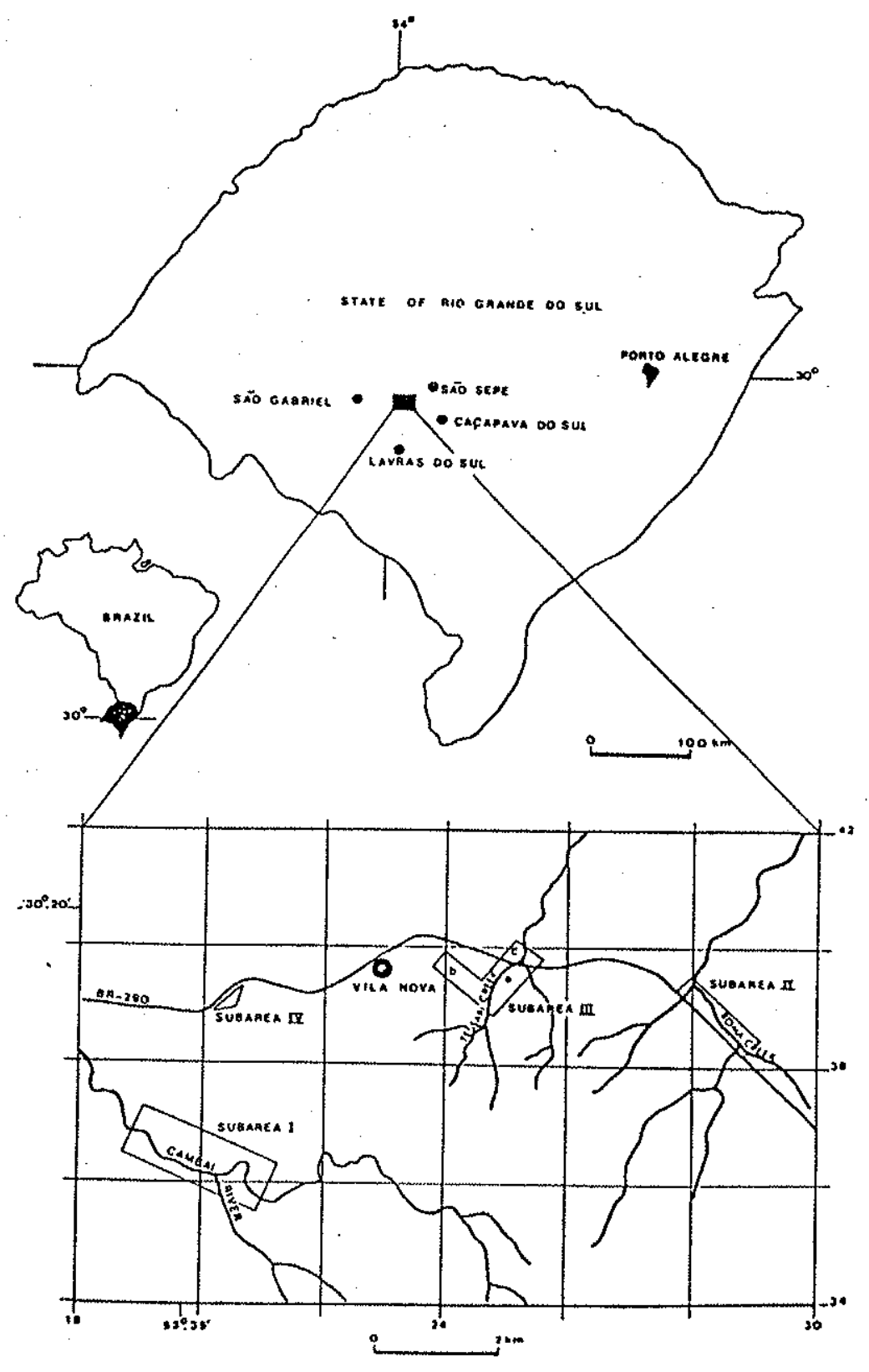

Fig. 41: Localização das subäreas estudadas por Silva Filho (1984), na região de Vila Nova, de onde provêm as amostras que compõem os diagramas isocrônicos apresentados nas figuras 45, 46, 47 , 48 e 50 . 


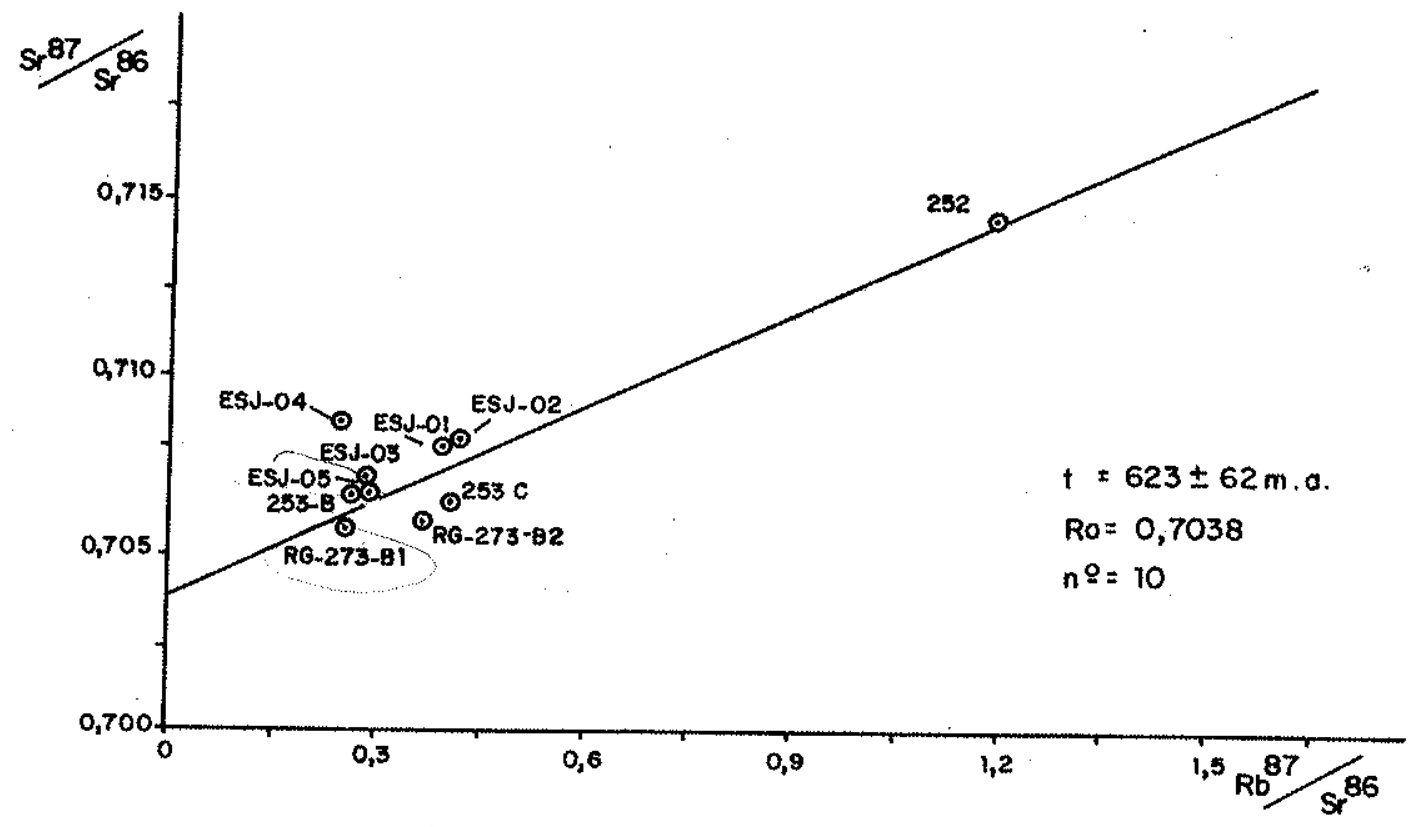

Fig. 42: Diagrama isocrônico Rb-Sr de referência de granitōides diversos da ärea de Vila Nova.

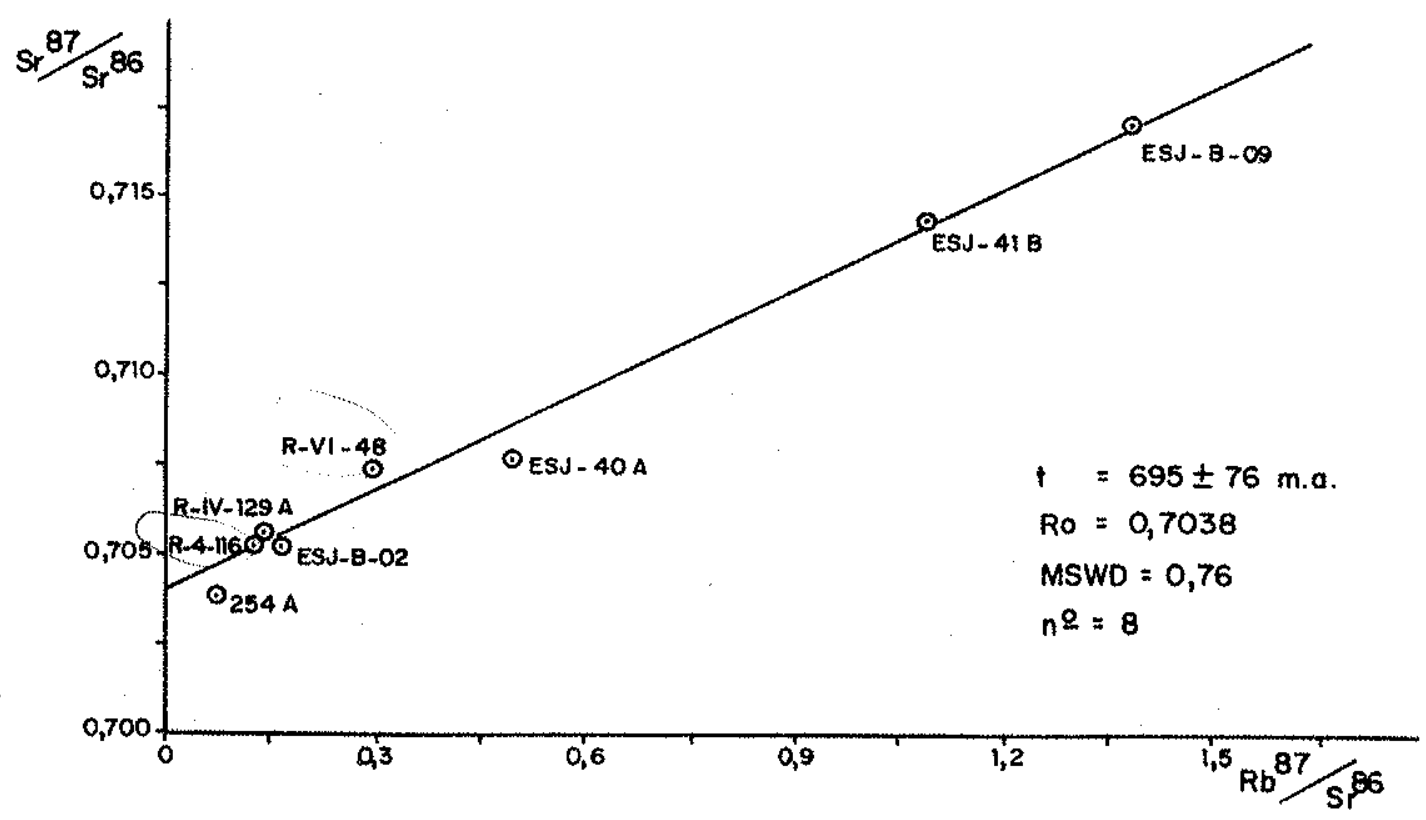

Fig. 43: Diagrama isocrônico Rb-Sr de referência de granitöides da ärea da Sanga do Velocindo - Mata Grande. 


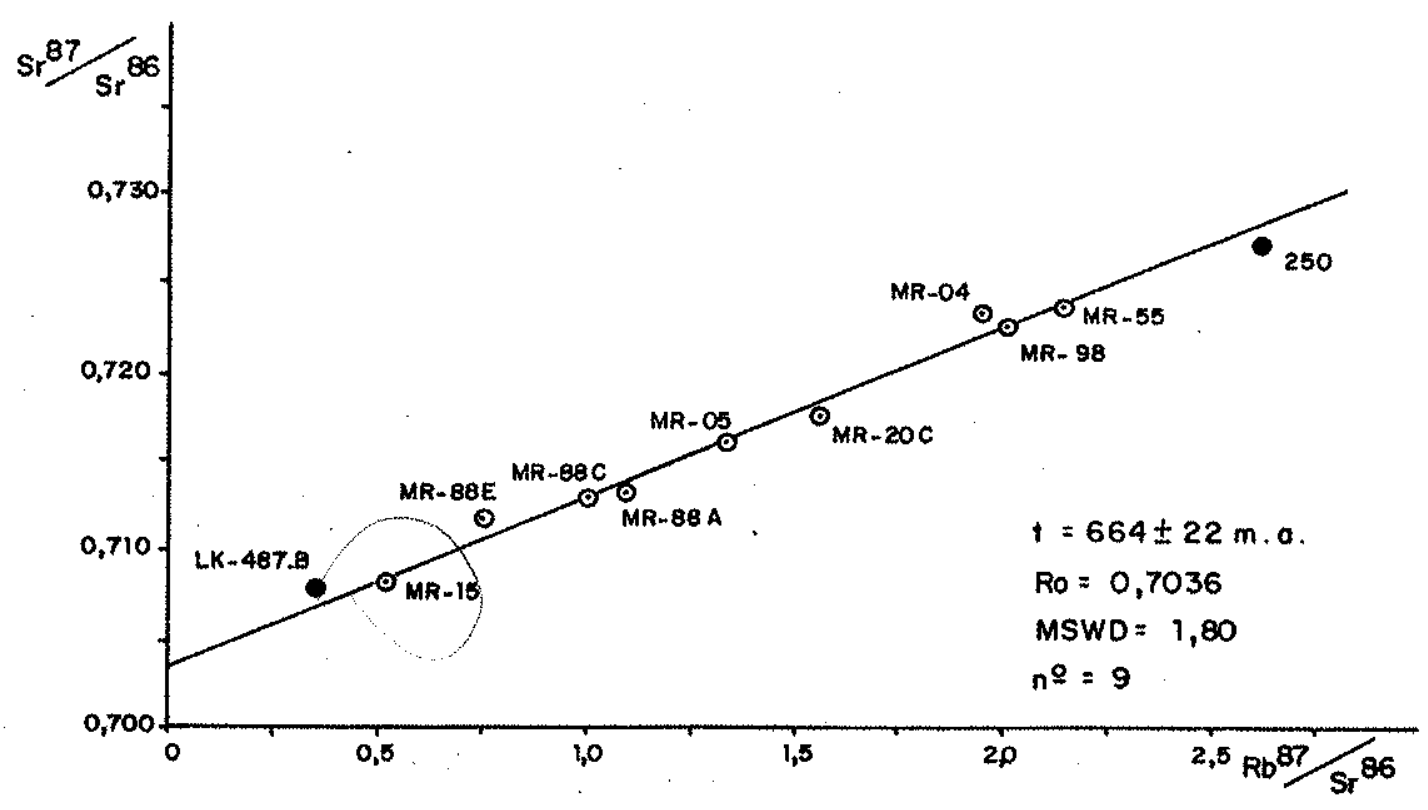

Fig. 44: Diagrama isocrônico Rb-Srr de referência de granitöides da ärea do Arroio Cambaizinho, seg. Remus (em prep.). Os pontos assinalados com círculos cheios são devidos a Cordani et al. (1974) e Teixeira (1982) e se incluidos nos cälculos da idade esta passa a ser de $644+-17$ m.a..

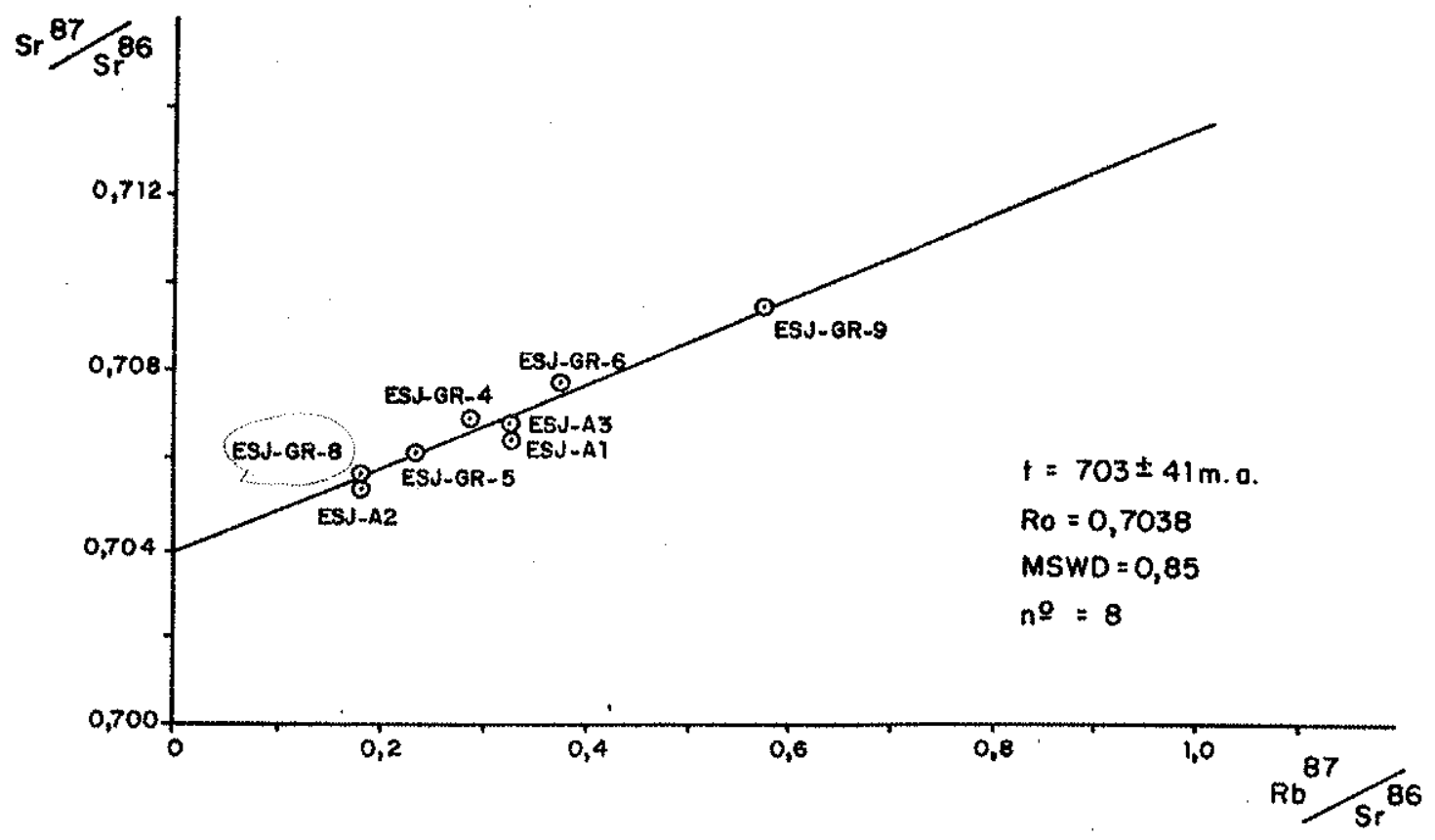

Fig. 45: Isöcrona Rb-Sr dos gnaisses dioríticos da subärea IV da região de Vila Nova. 


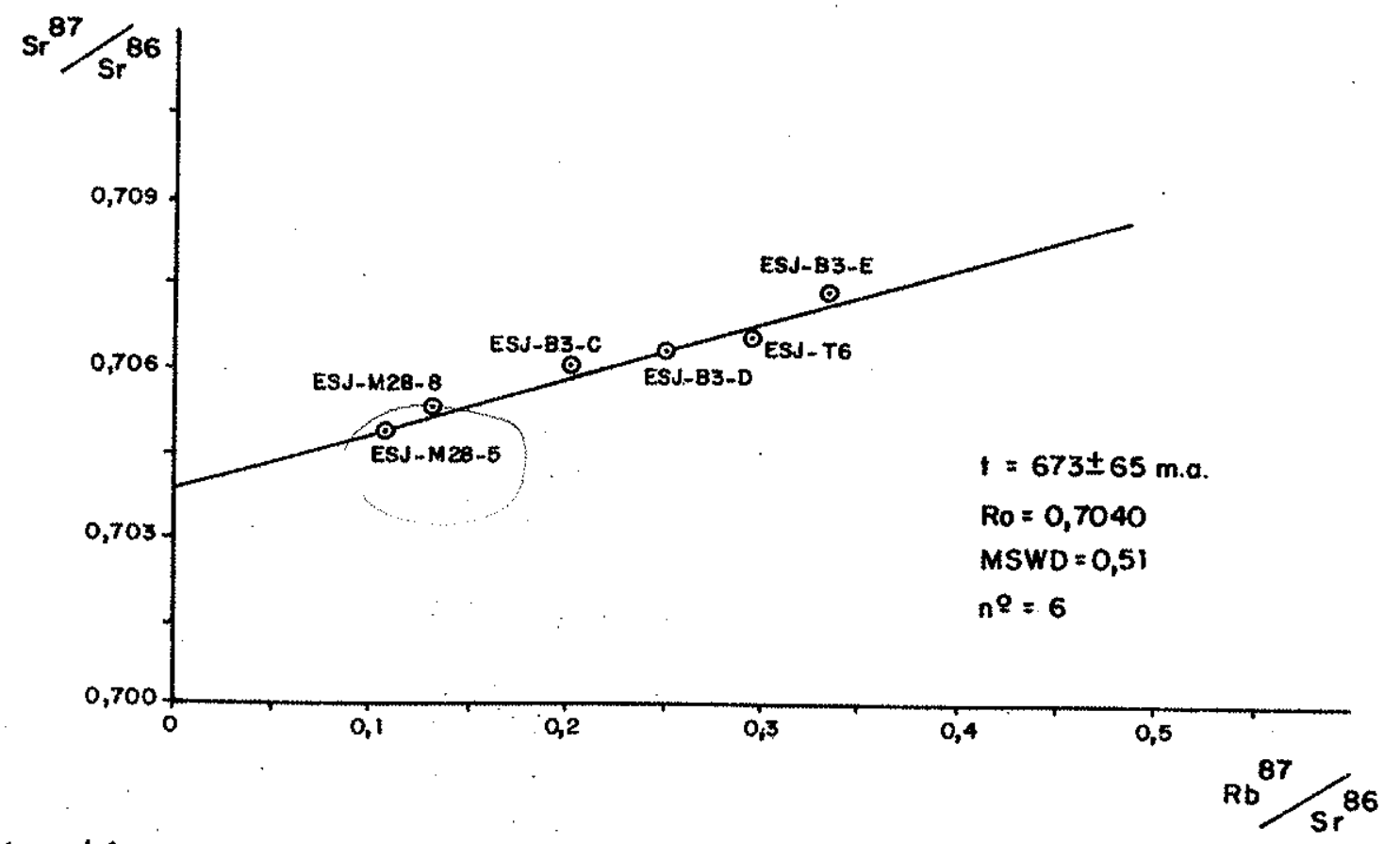

Fig. 46: Diagrama isocrônico Rb-Sr de referência dos tonalitos e trondh jemitos da subärea IV da regiäo de Vila Nova.

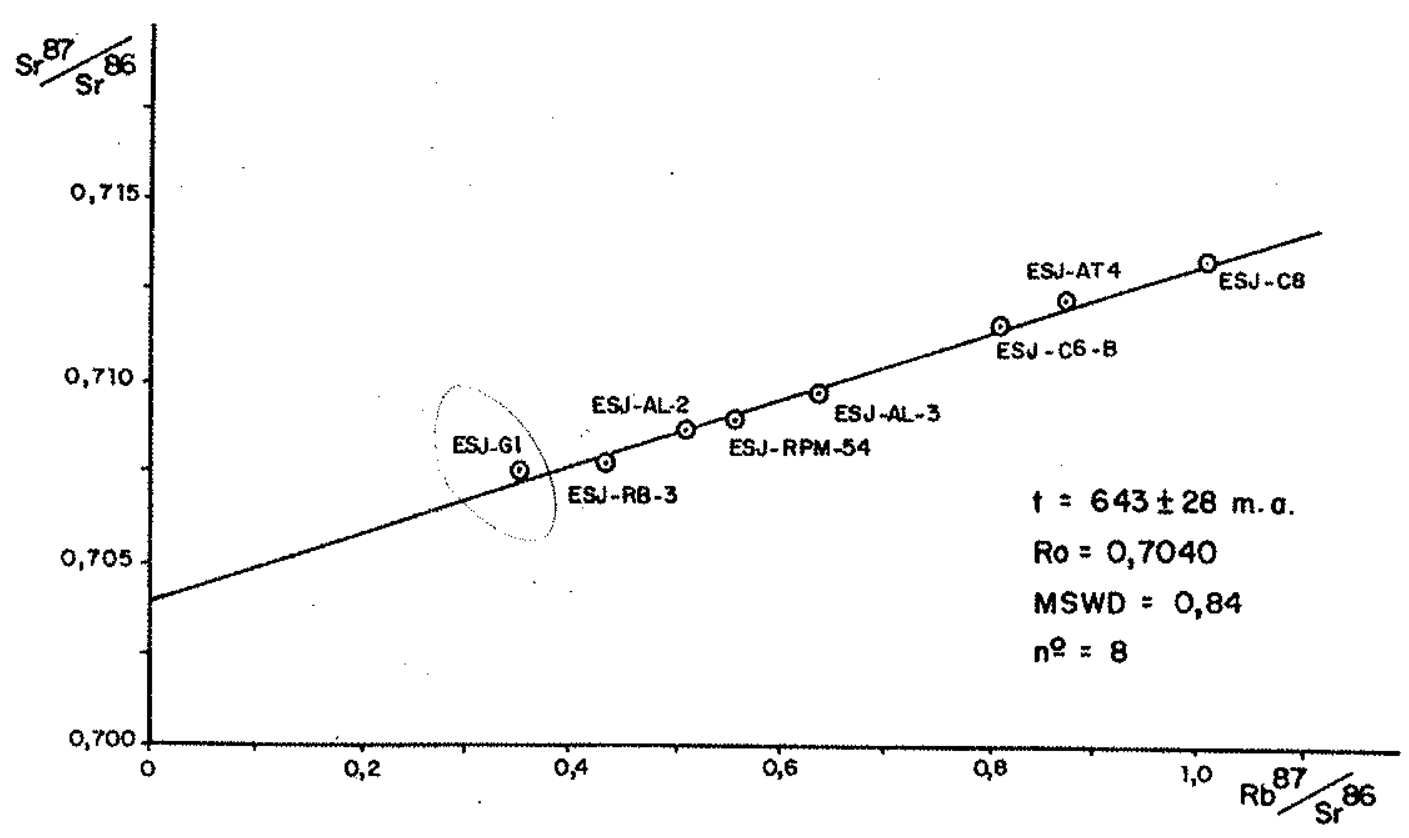

Fig. 47: Diagrama isocrônico $\mathrm{Rb}-\mathrm{Sr}$ de referência dos granodioritos e adamelitos da região de Vila Nova. 


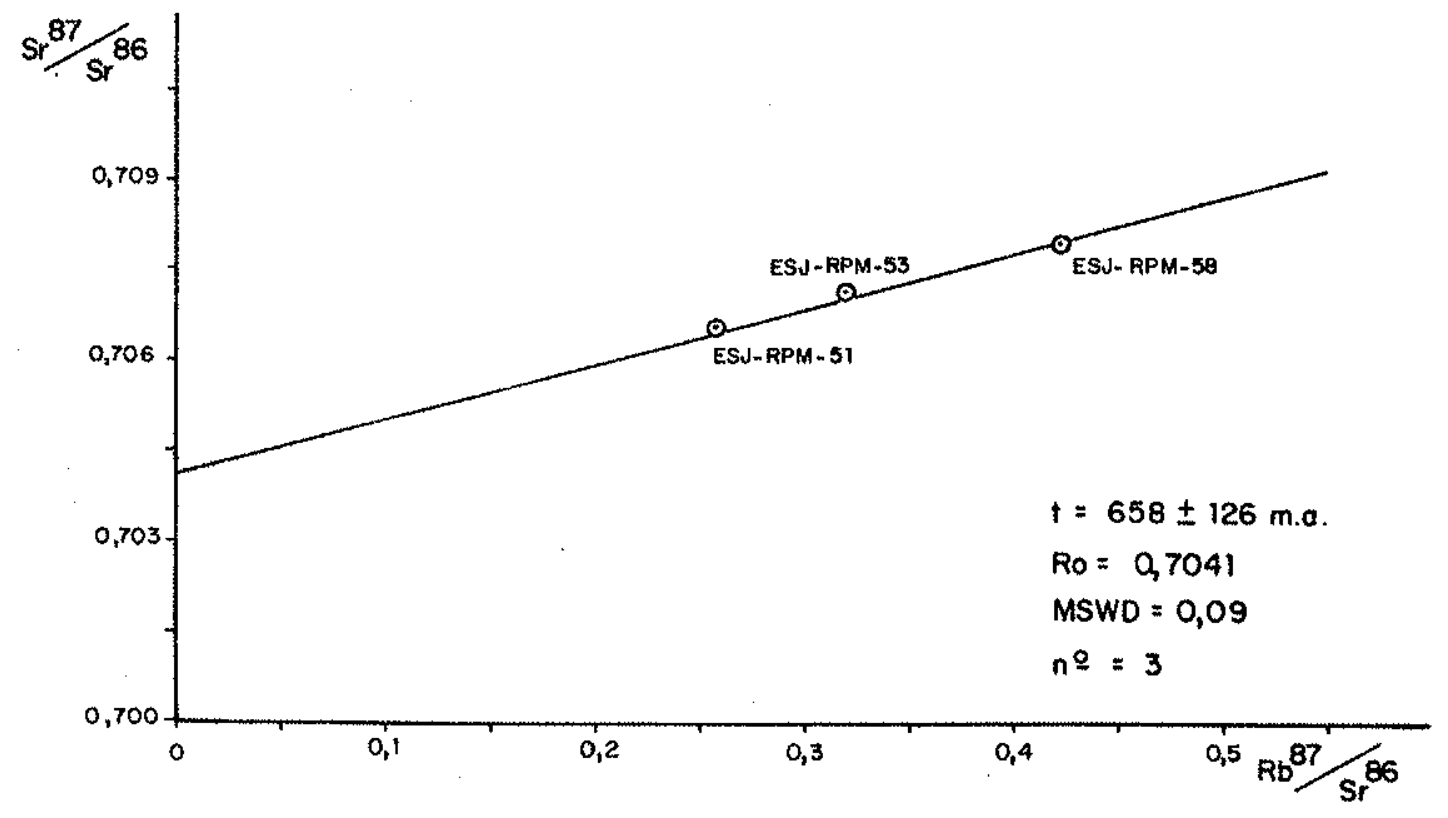

Fig. 48: Isöcrona $\mathrm{Rb}-\mathrm{Sr}$ dos pegmatitos da subärea $\| 1$ da região de Vila Nova. 


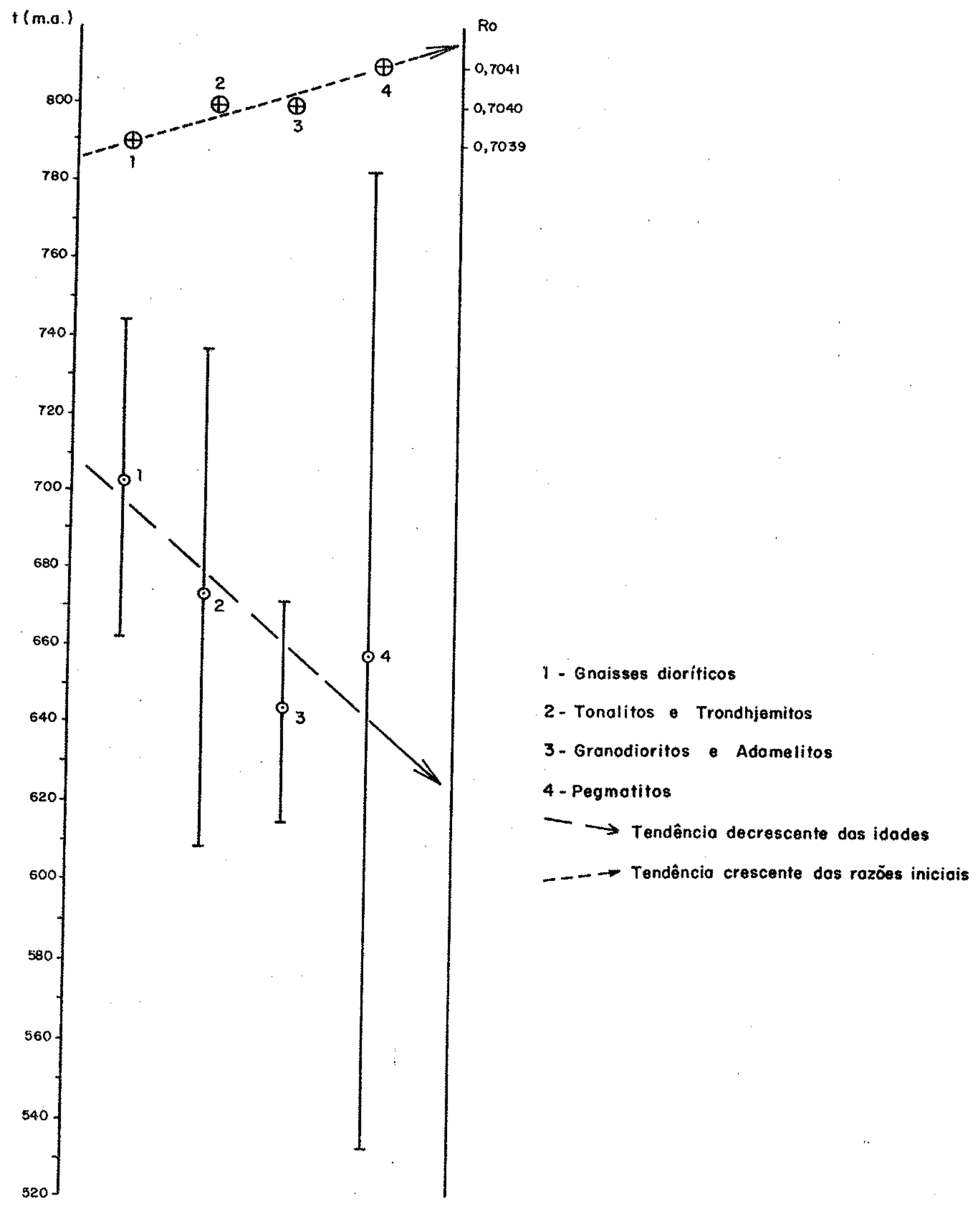

FIG. 49 - TENDENCIAS DECRESCENTE DAS IDADES E CRESCENTE DAS RAZÕES INICIAIS DOS GNAISSES E SUITES INTRUSIVAS DA UNIOADE CAMBAI, NA REGIÃO DE VILA NOVA, DE ACORDO COM A CRONOLOGIA ESTRUTURAL DEFINIDA POR SILVA FILHO (1984). 


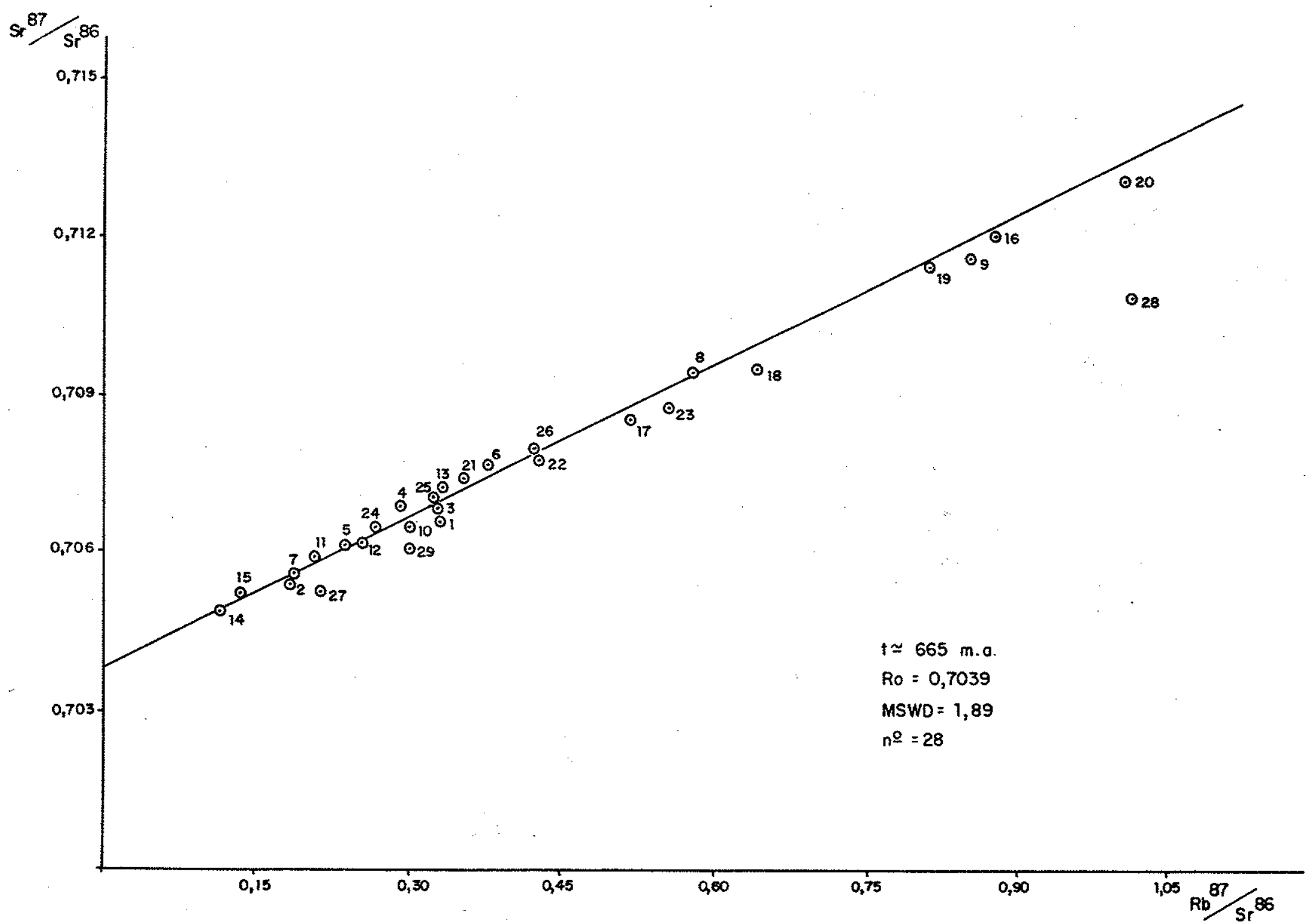

Fig. 50: Diagrama isocrōnico Rb-Sr de referencia dos gnaisses e suítes intrusivas associadas à unidade Cambaí, na região de Vila Nova. 0 ponto 28 não foi utilizado no cálculo dos valores acima fornecidos. 


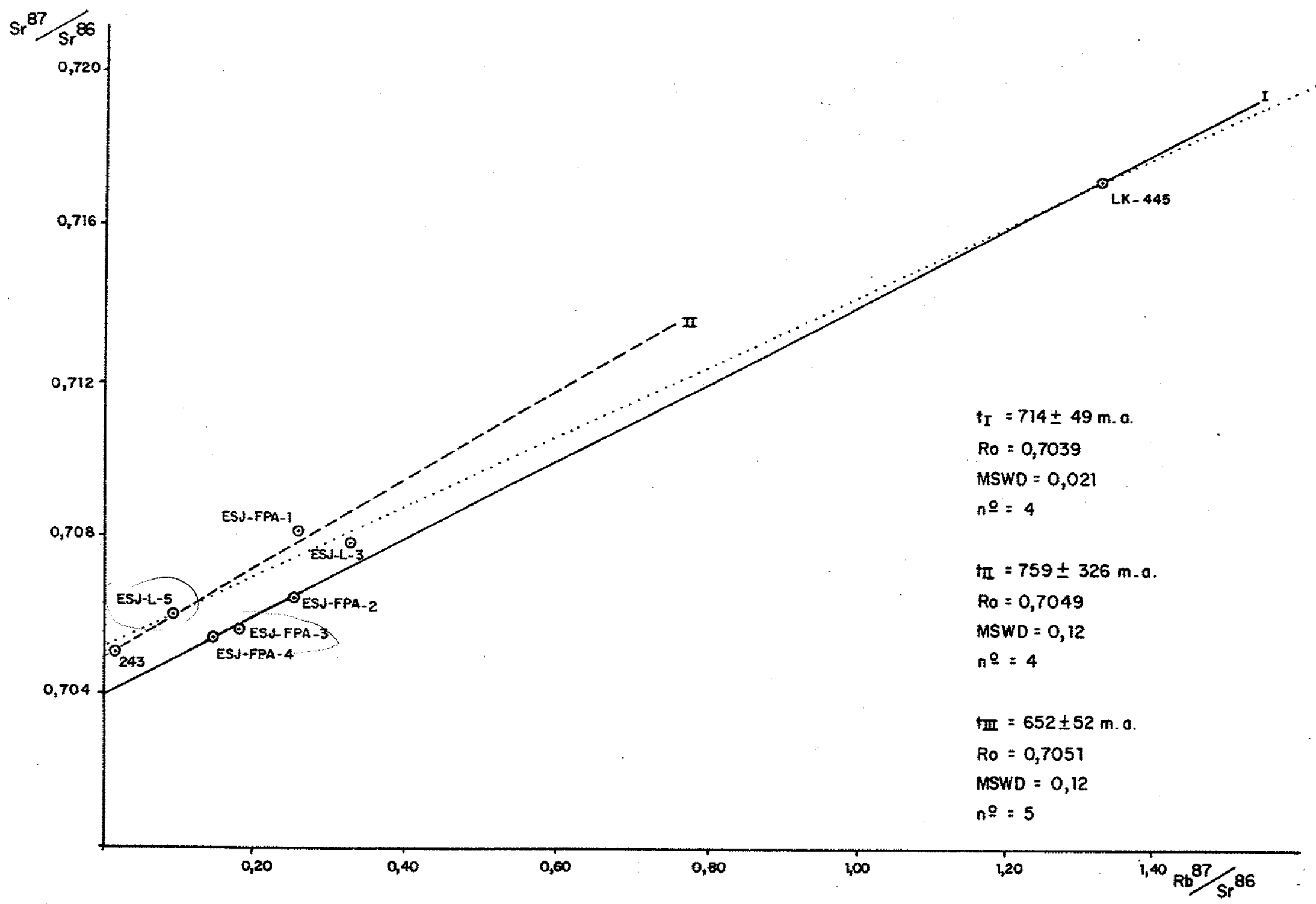

Fig. 51: Tentativas de interpretação geocronolögica dos granitóides Cambaí na região central do Bloco S. Gabriẹl. 


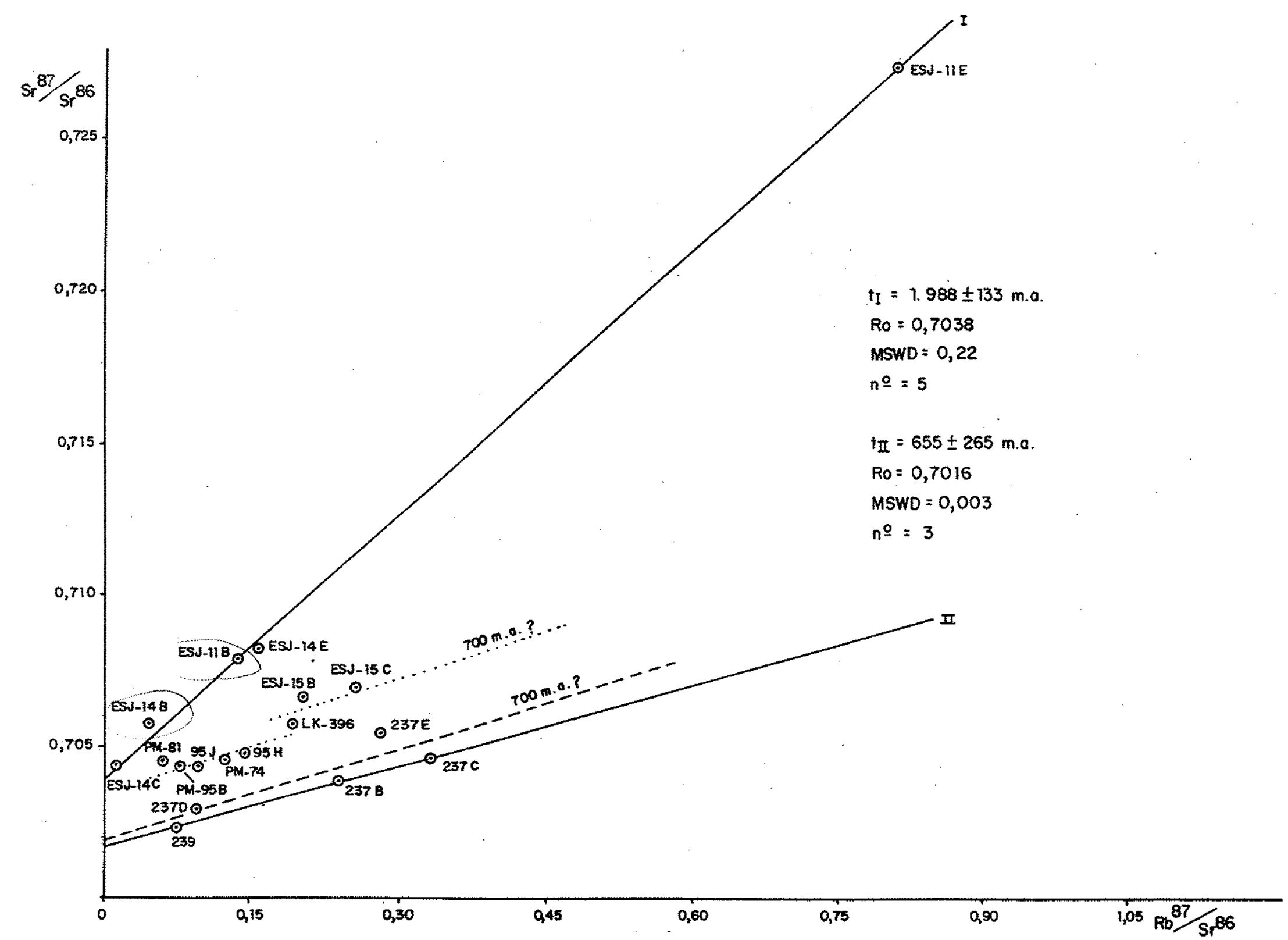

Fig. 52: Tentativas de interpretação geocronolögica dos granitōides Cambaí na região meridional do Blocó S. Gabriel. Os pontos ESJ-1I B e E pertencem ao Bloco Taquarembó. 


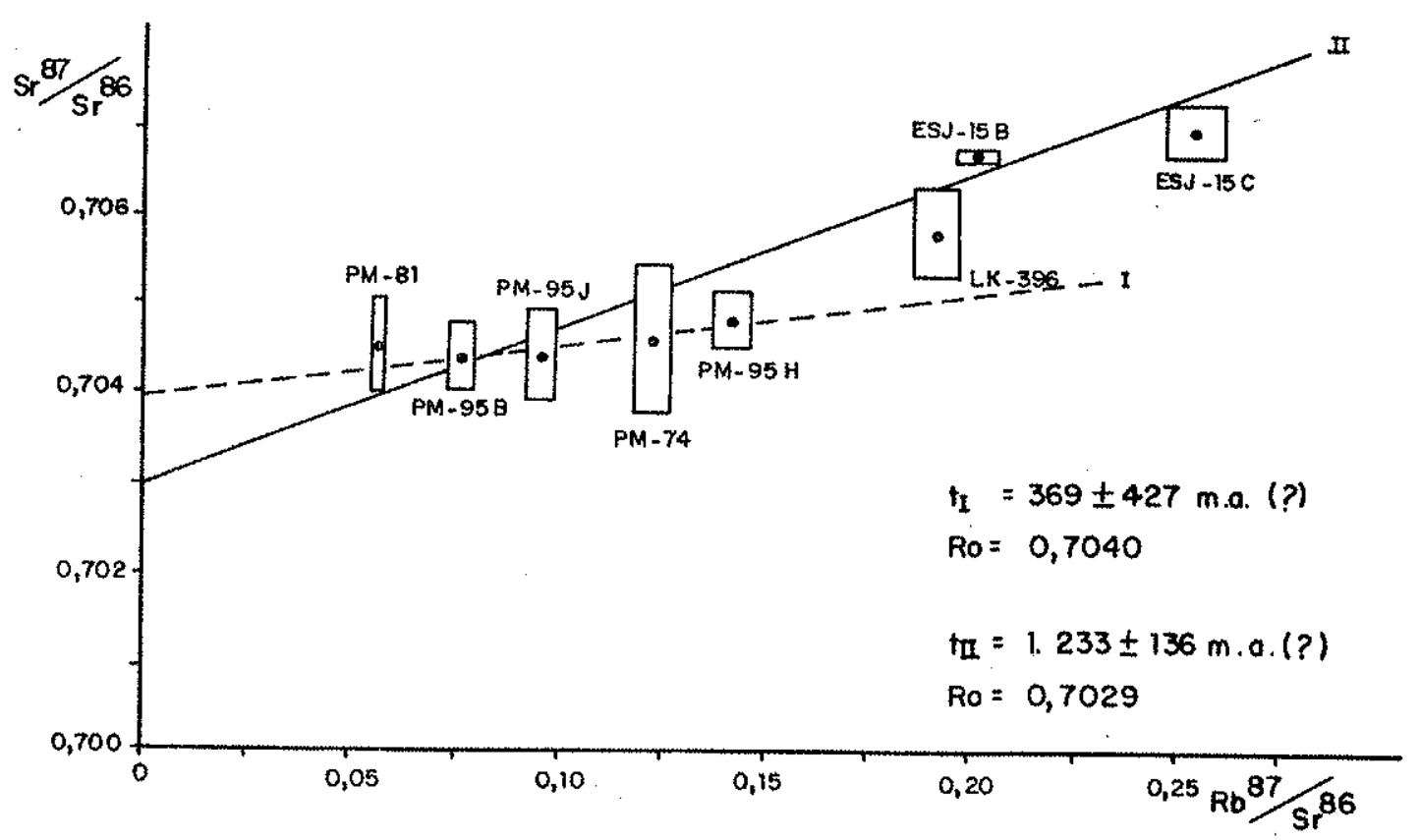

Fig. 53: Diagrama isocrônico $\mathrm{Rb}-\mathrm{Sr}$ de referência dos granitōides da re gião meridional do Bloco São Gabriel, com definição de valor temporal sem significado geolögico conhecido. Os retângulos externos aos pontos correspondem aos erros inerentes às anäl ses isotópicas. 


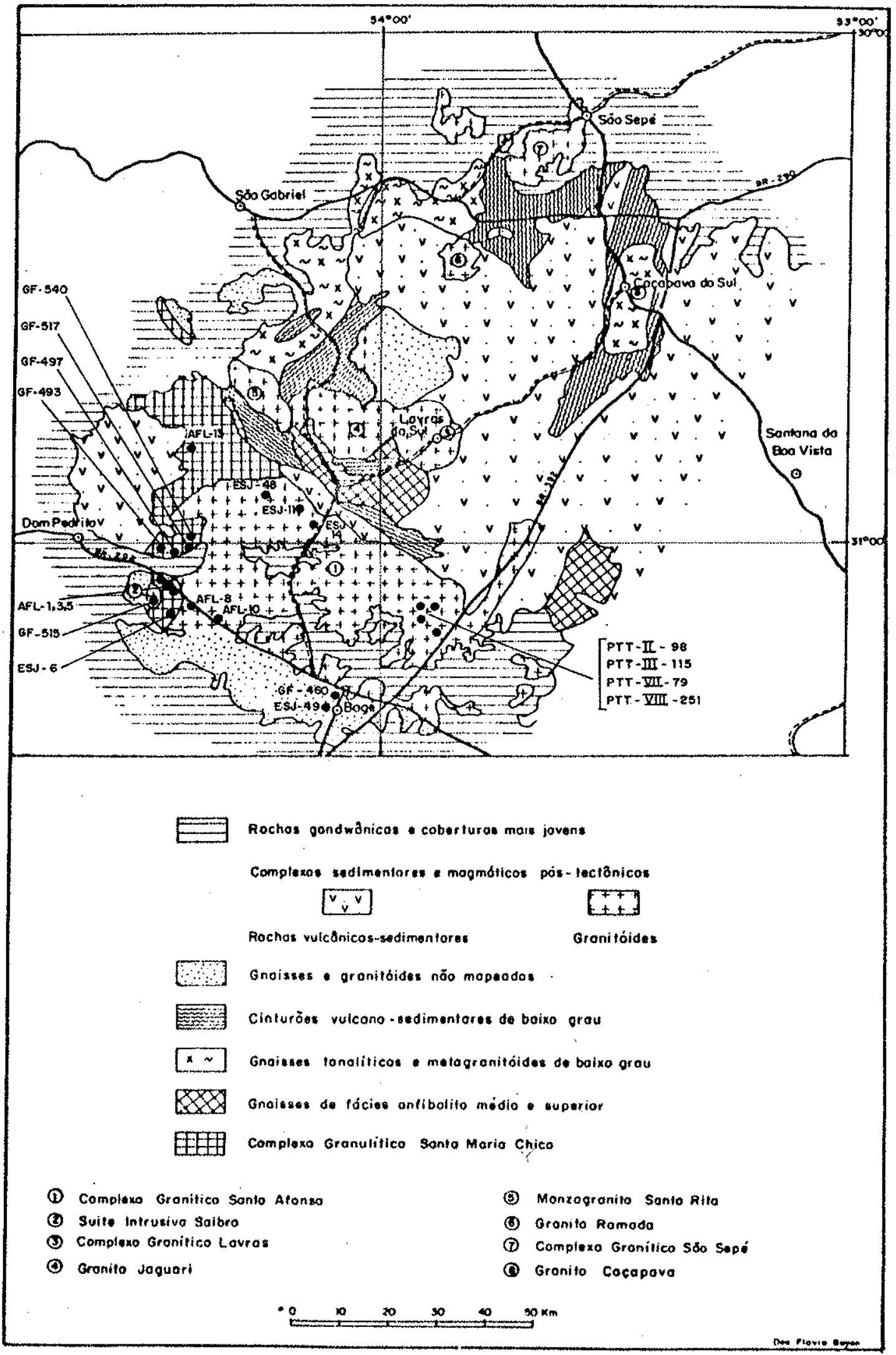

Fig. 54: Distribuição das principais associações litolögicas da região oeste do Escudo Sul-rio-grandense e localização dos pontos amostrados no Bloco Taquarembó. Figura extraída e adaptada de Hartmann e Nardi (1983). 


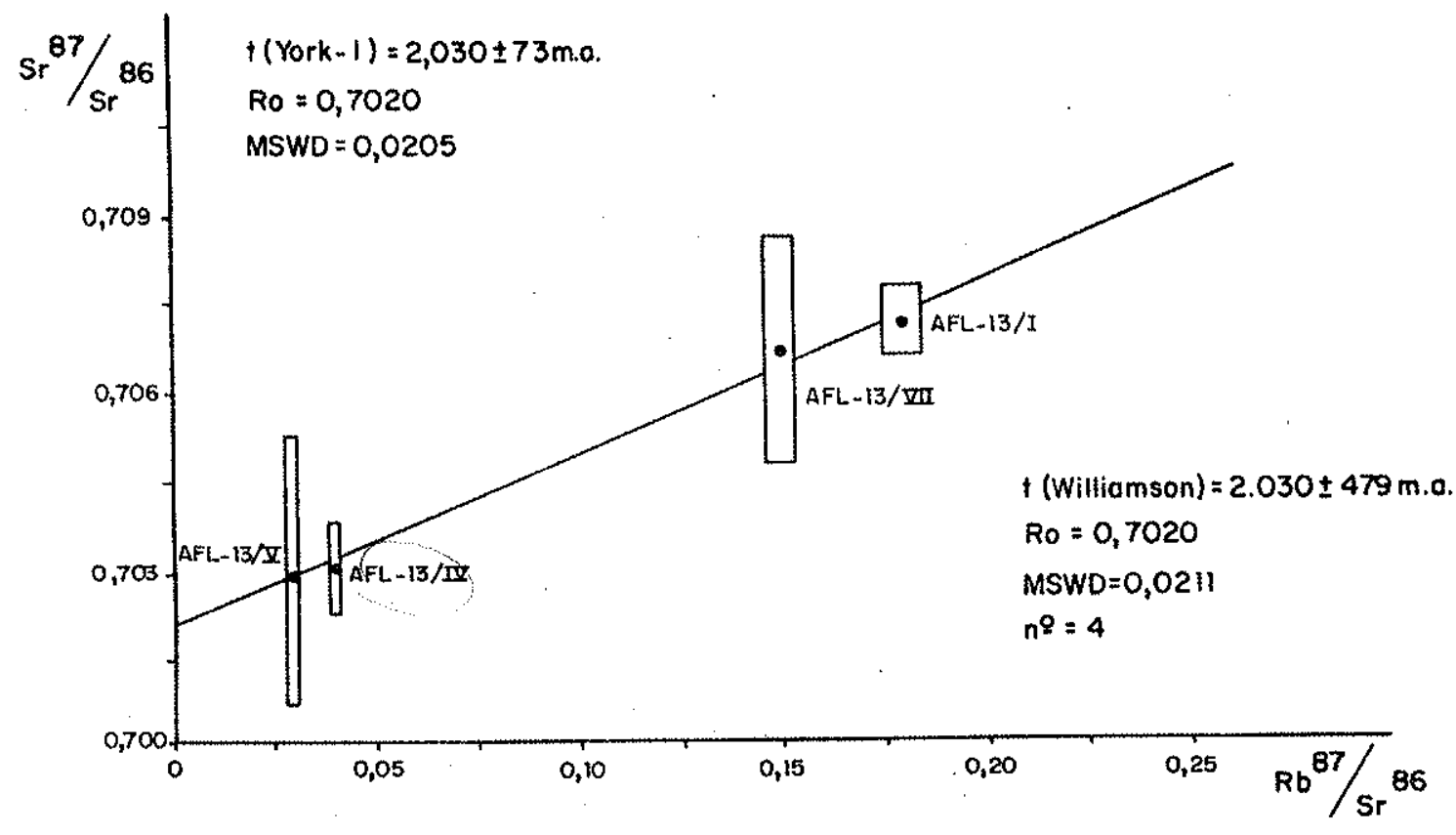

Fig. 55: Isócrona Rb-Sr do Complexo Granulítico Santa Maria Chico, seg: Soliani Jr. et al. (1984). A idade t(Williamson) é a que estä sendo utilizada neste trabalho. Os retángulos externos aos pon tos correspondem aos erros inerentes às anälises isotöpicas. 


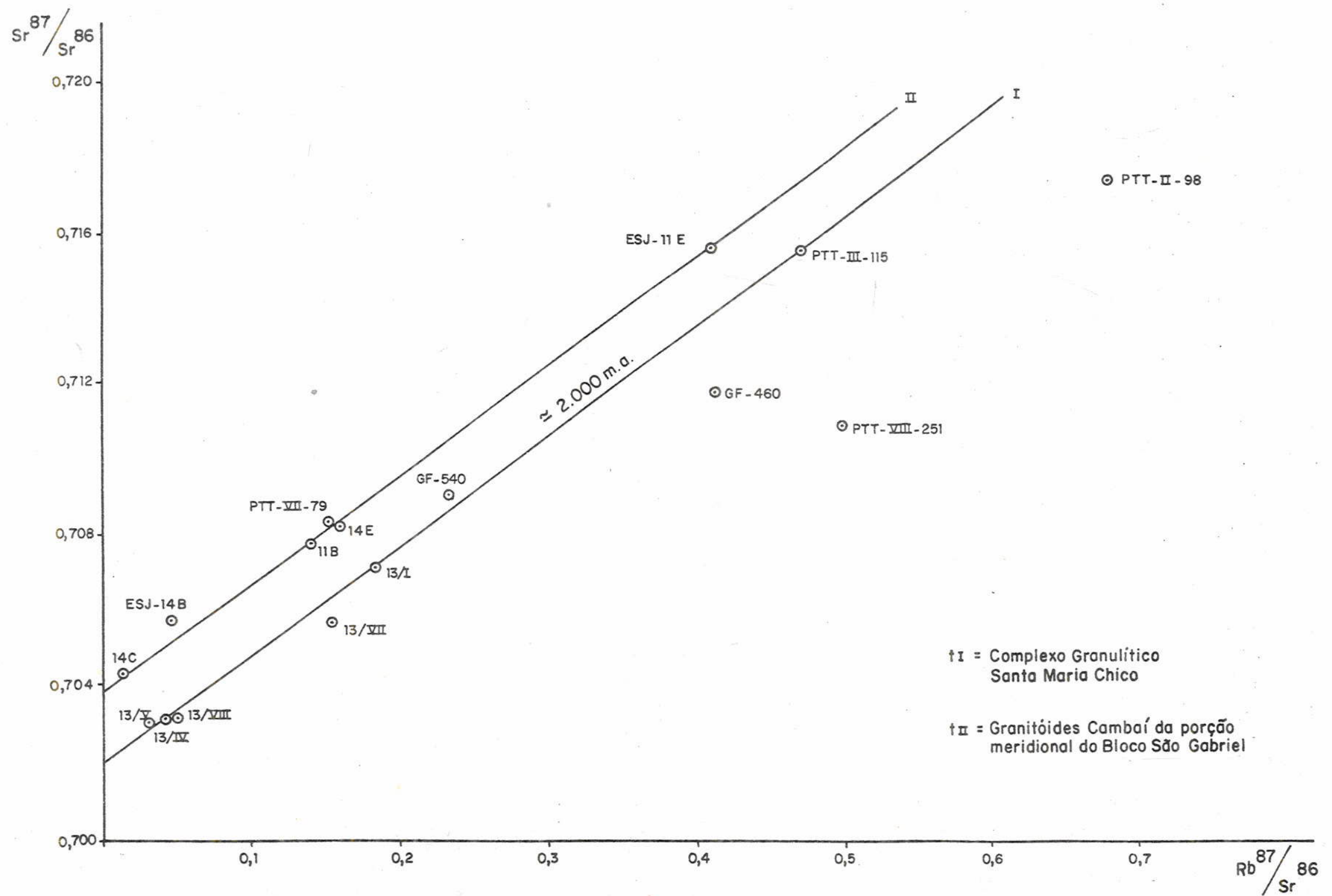

Fig. 56: Diagrama isocrônico Rb-Sr de referência de rochas gnäissicas e migmatíticas da porção meridional do Blo co São Gabriel e do Bloco Taquarembó. Quando não indicado, os pontos 11 e 14 são precedidos pela siglá ESJ e os 13 pela sigla AFL. 


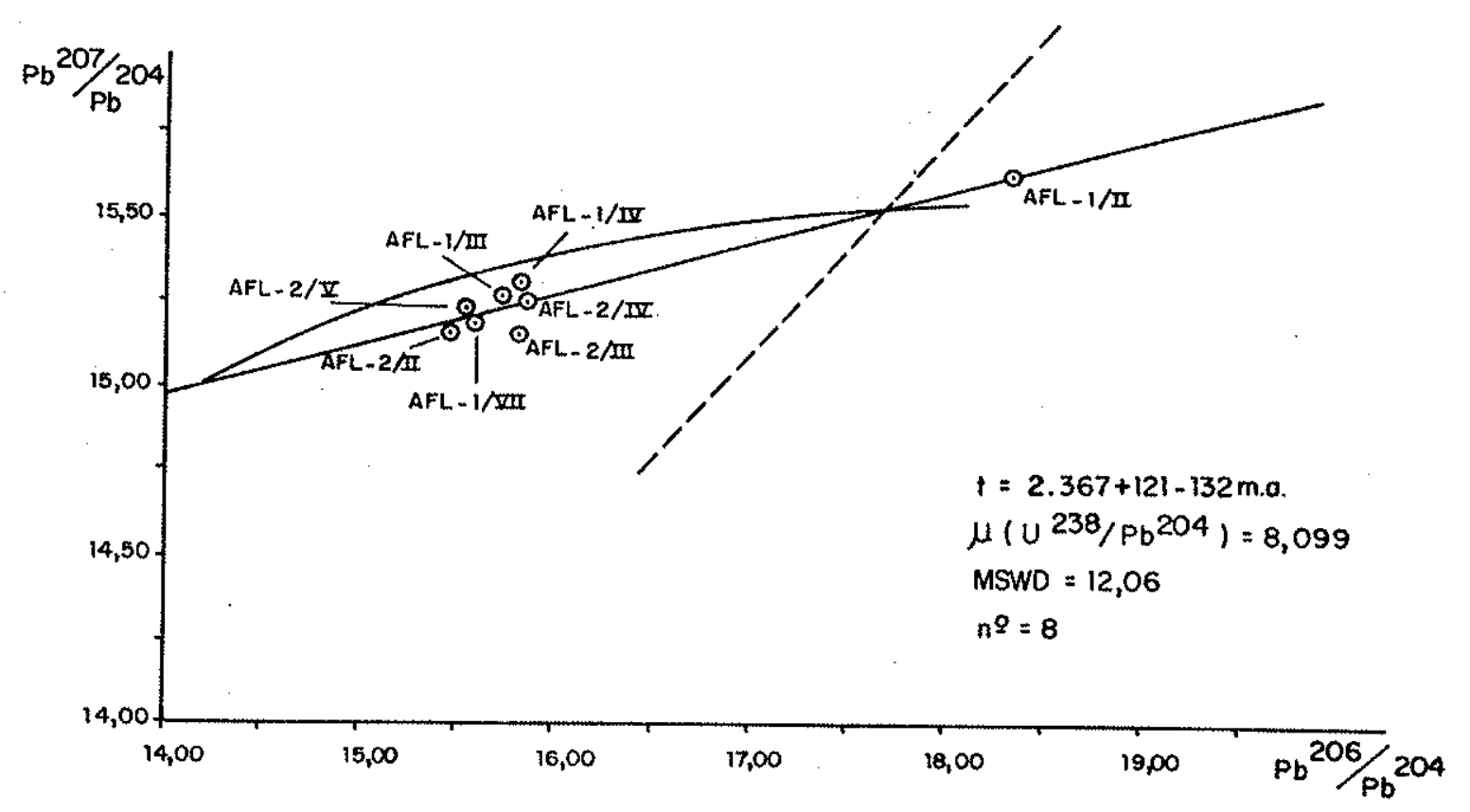

Fig. 57: Diagrama $\mathrm{Pb}-\mathrm{Pb}$ de rochas dos pontos AFL-1 e AFL-2 do Complexo Granulítico Santa Maria Chico.

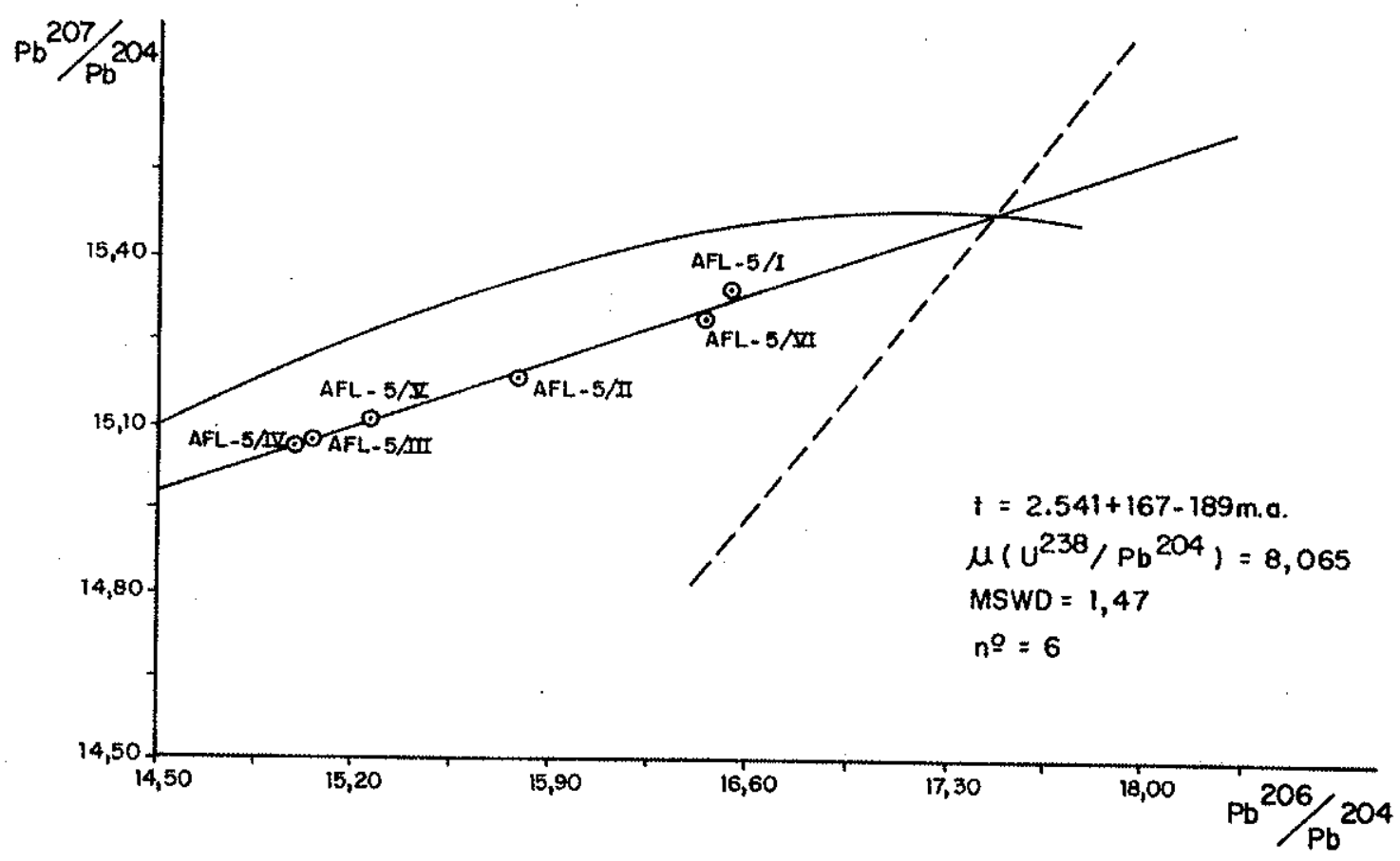

Fig. 58: Diagrama $\mathrm{Pb}-\mathrm{Pb}$ de rochas do ponto AFL-5 do Complexo Granuliti co Santa Maria Chico. 


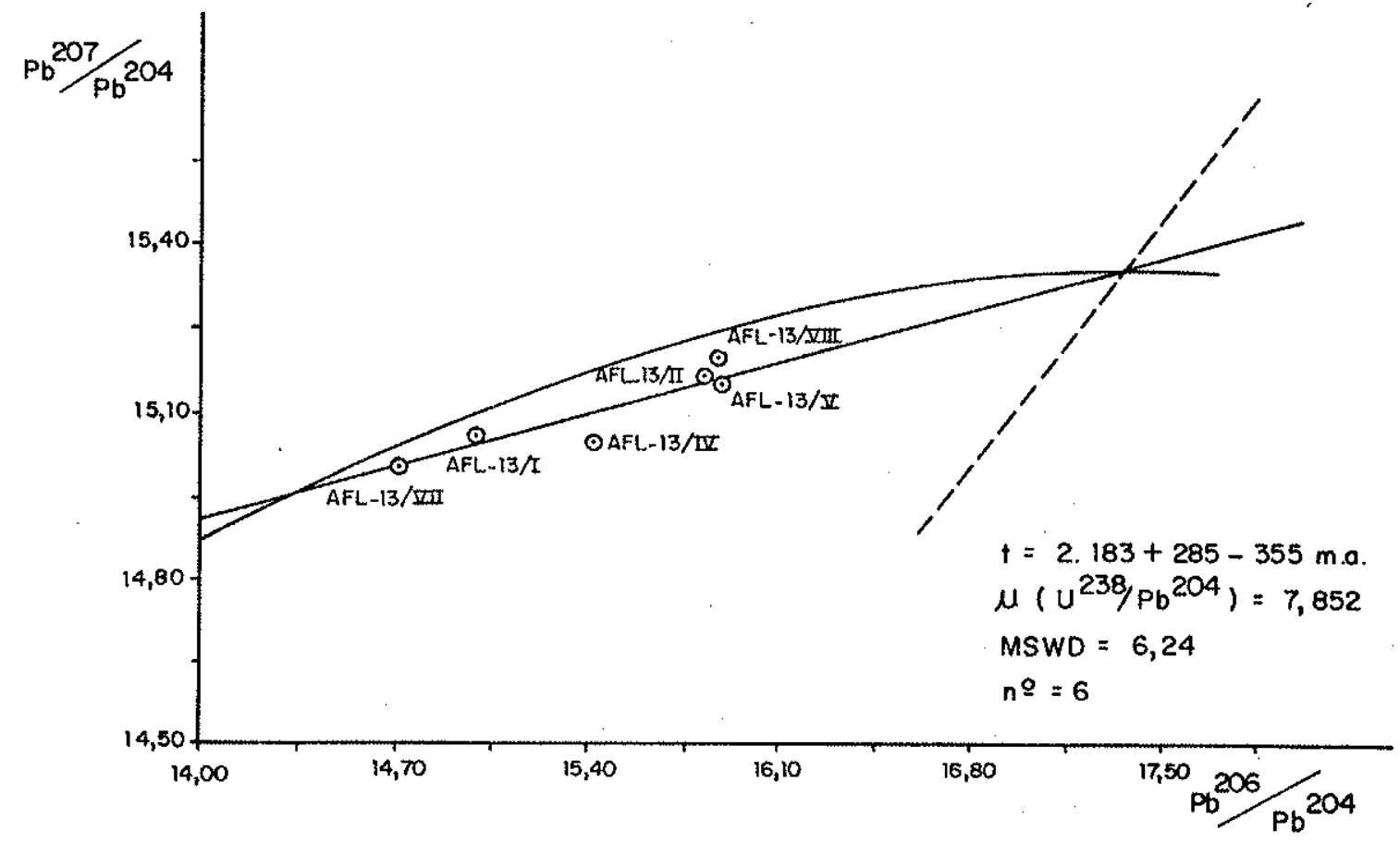

Fig. 59: Diagrama $\mathrm{Pb}-\mathrm{Pb}$ de rochas do ponto AFL-13 do Complexo Granuli tico Santa Maria Chico. 


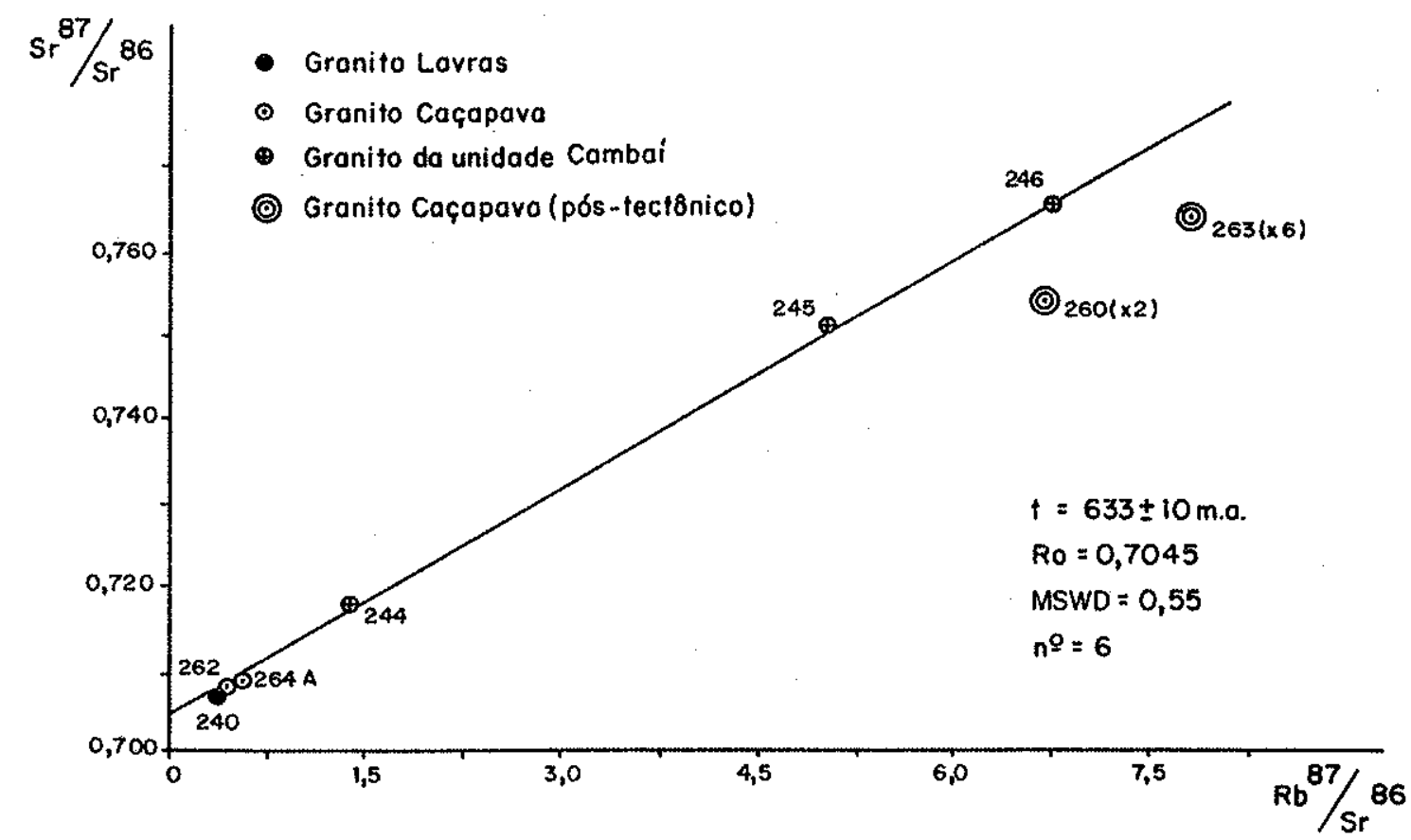

Fig. 60: Diagrama isocrônico Rb-Sr de referência de rochas graniticas das regiões de Caçapava do Sul e Lavras do Sul, seg. Cordani et al. (1974).

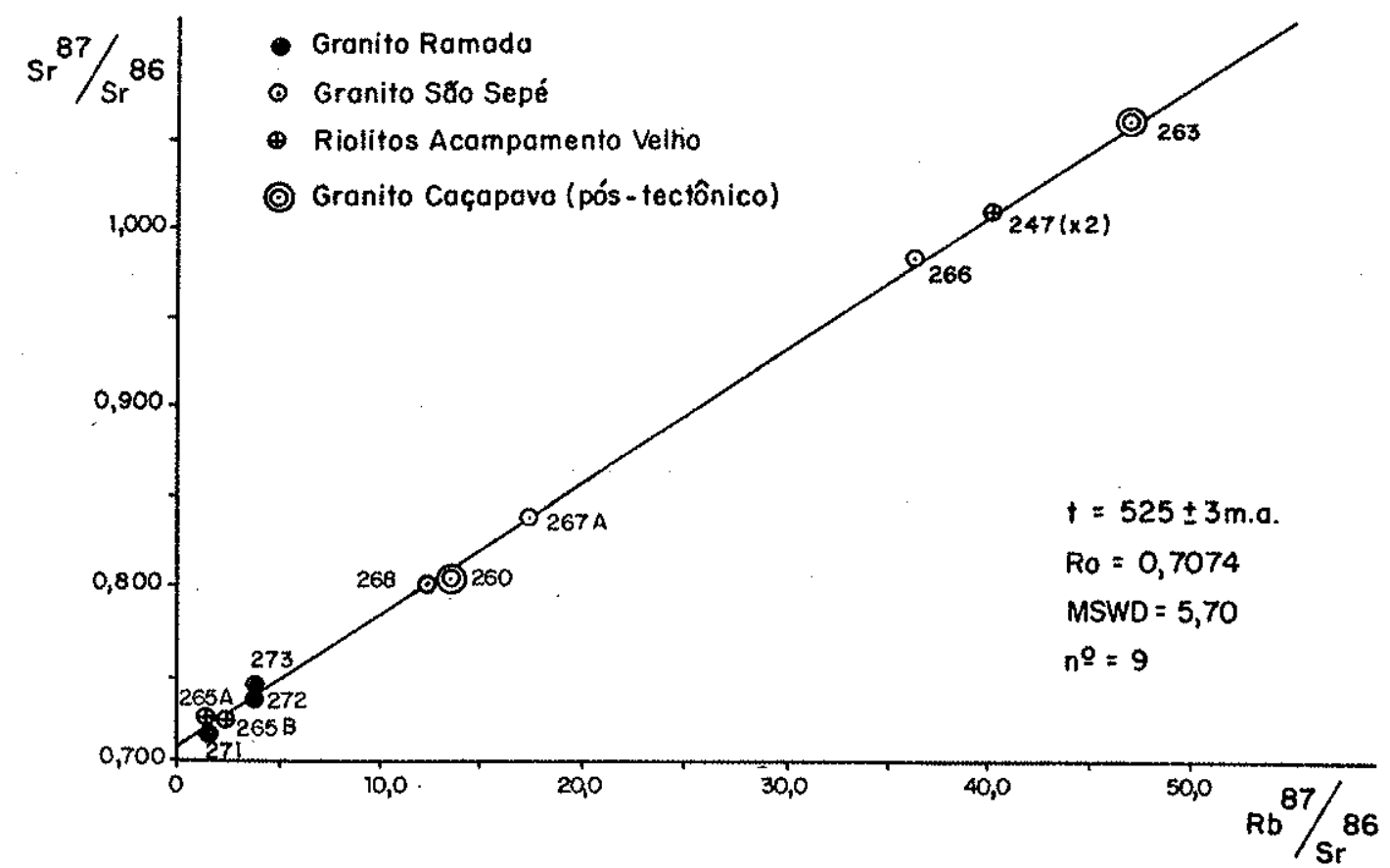

Fig. 61: Diagrama isocrônico Rb-Sr de referência dos granitos São Sepé, Ramada e riolitos Acampamento Velho, seg. Cordani et al.(1974), com a adição dos pontos discordantes da figura anterior relati vos ao Granito de Caçapava do Sul. 


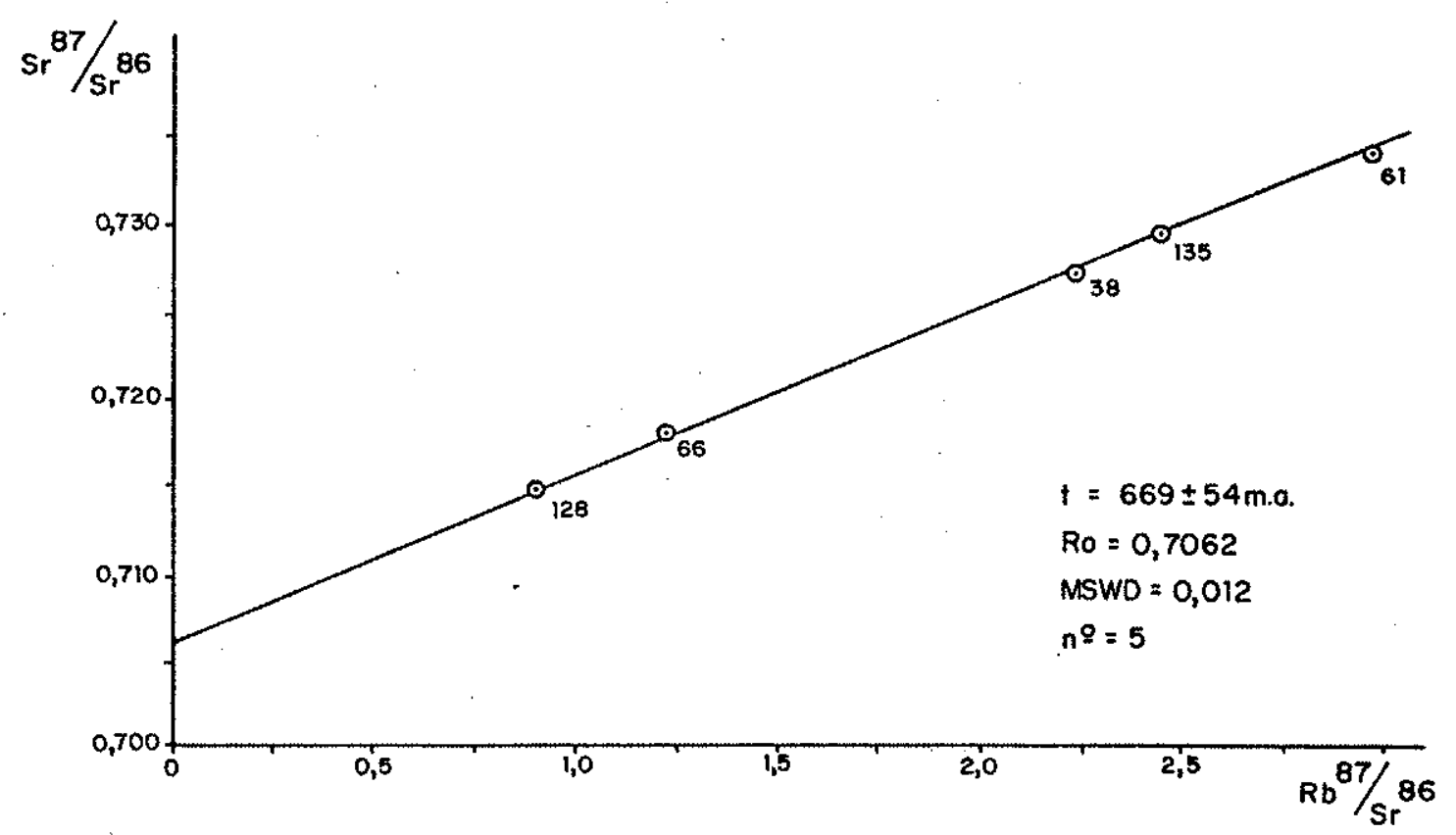

Fig. 62: Diagrama isocrônico $\mathrm{Rb}-\mathrm{Sr}$ de referência de amostras de rochas granito-monzoniticas da parte central do Complexo Granítico de São Sepë, seg. Sartori (1978).

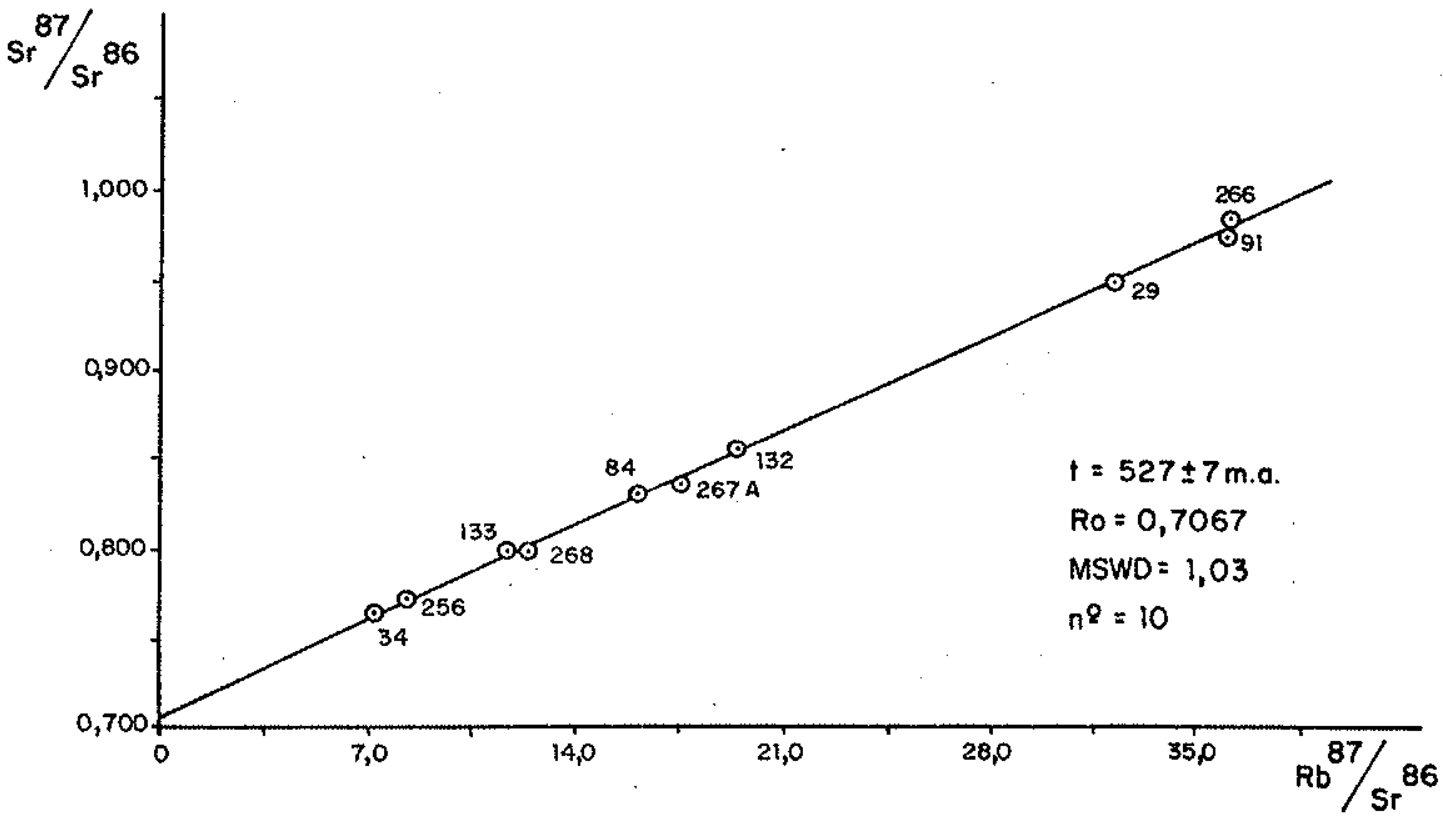

Fig. 63: Diagrama isocrónico Rb-Sr de referência de amostras do granito subalcalino perifërico do Complexo Granítico de São Sepé, seg. Sartori (1978). 


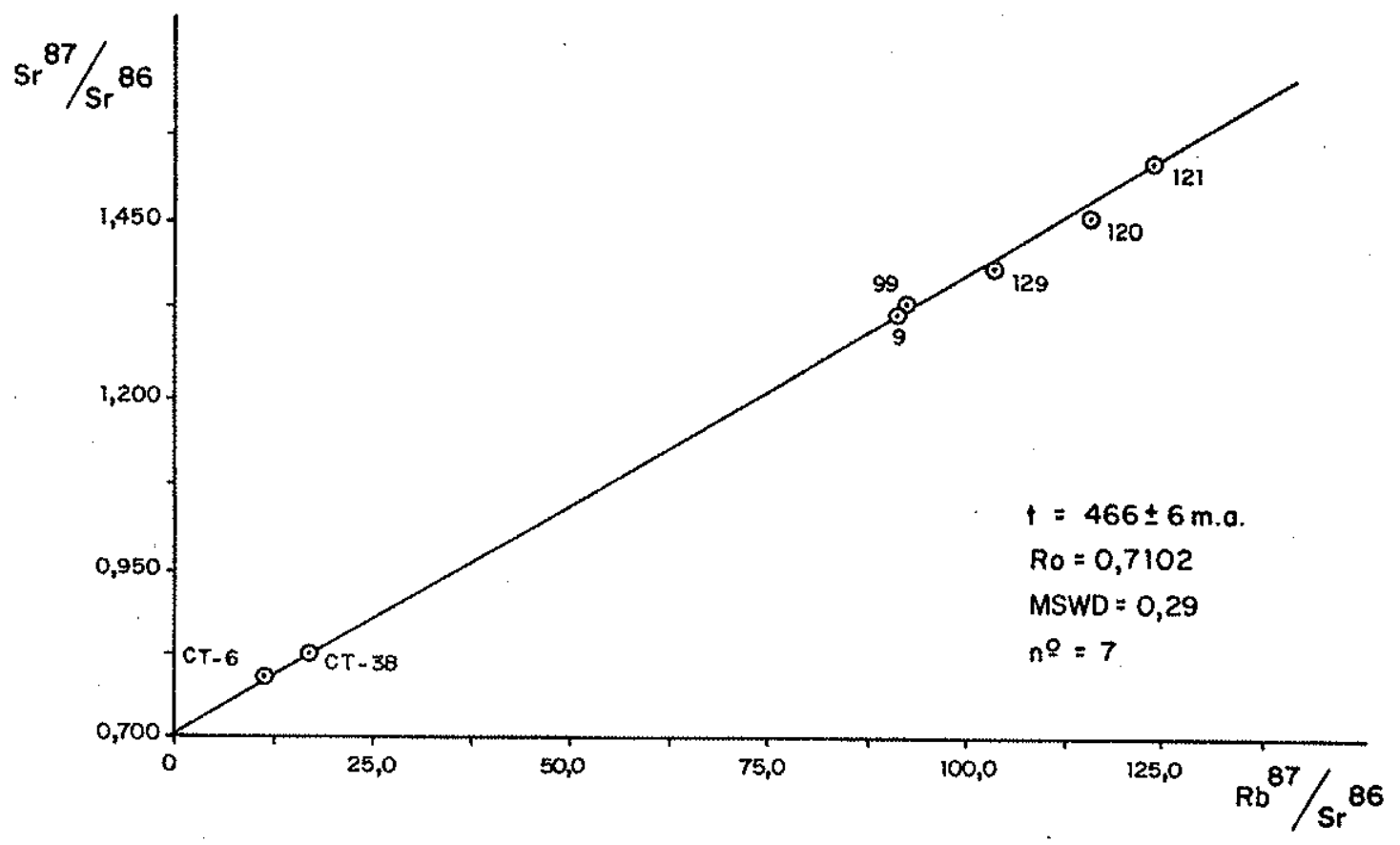

Fìg. 64: Diagrama isocrōnico Rb-Sr de referência reunindo amostras de microgranitos de intrusões menores do Complexo Granitico de $S$. Sepé e de riolitos do Cerro Tupancí, seg. Sartori (1978). 


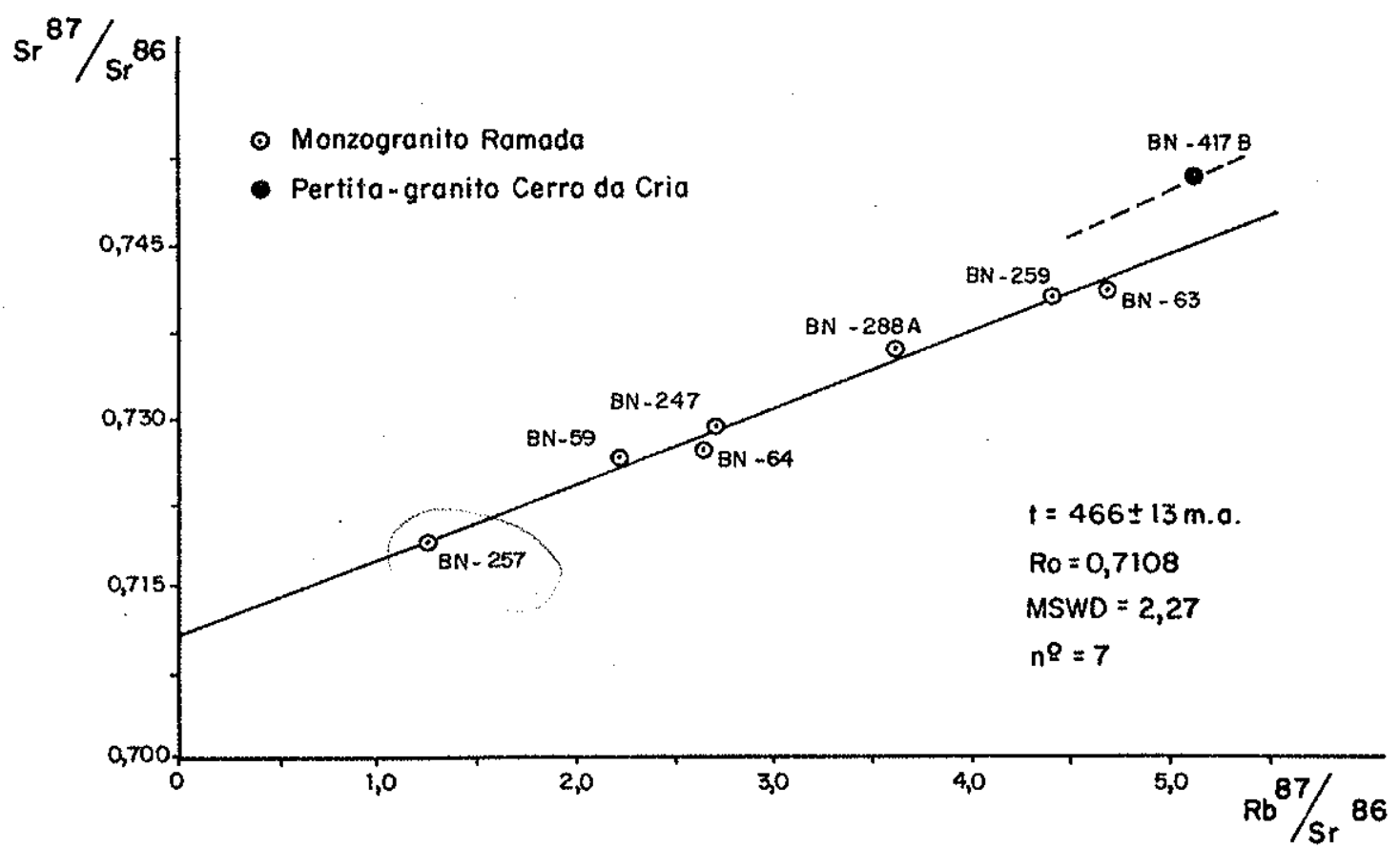

Fig. 66: Diagrama isocrônico Rb-Sr de referência dos monzogranitos Rama da e pertita-granito Cerro da Cria, seg. Naime (em prep.). 


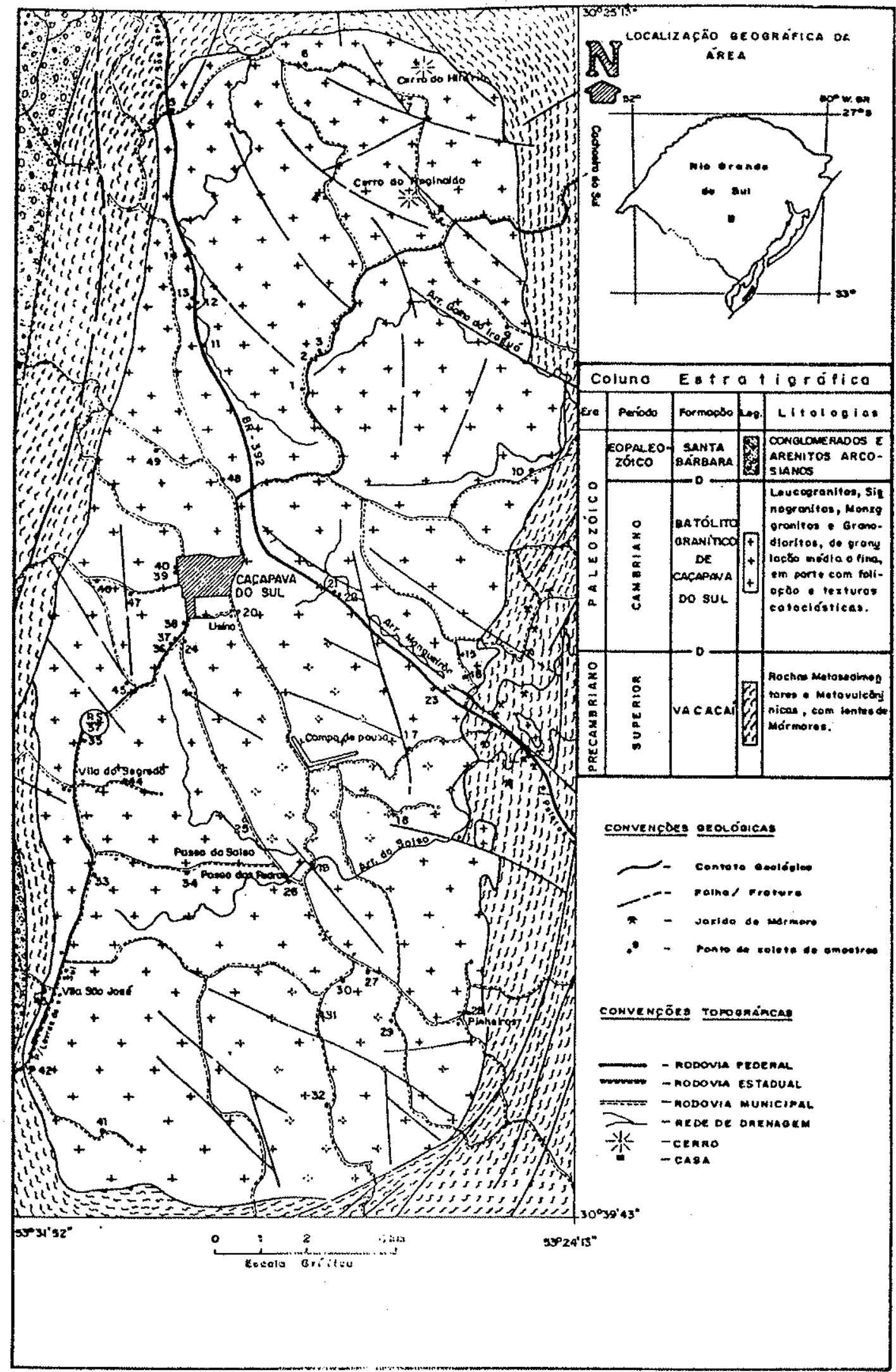

Fig. 67: Mapa geolögico da região de Caçapava do Sul, seg. Sartori e Ka washita (1985), e localização dos pontos amostrados. 


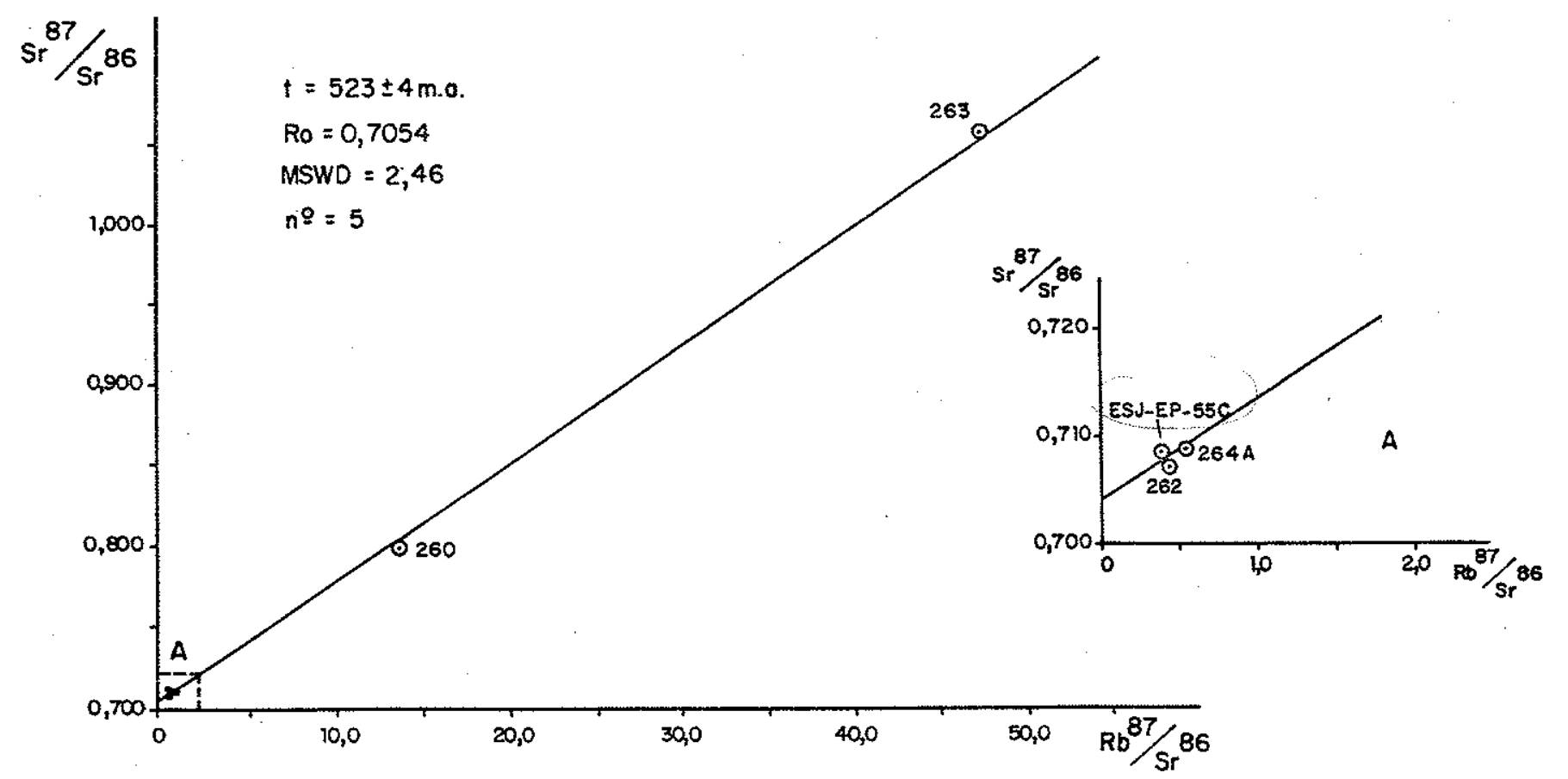

Fig. 68: Diagrama isocrônico Rb-Sr de referência de rochas do Batól ito Granitico de Caçapava do Sul. 


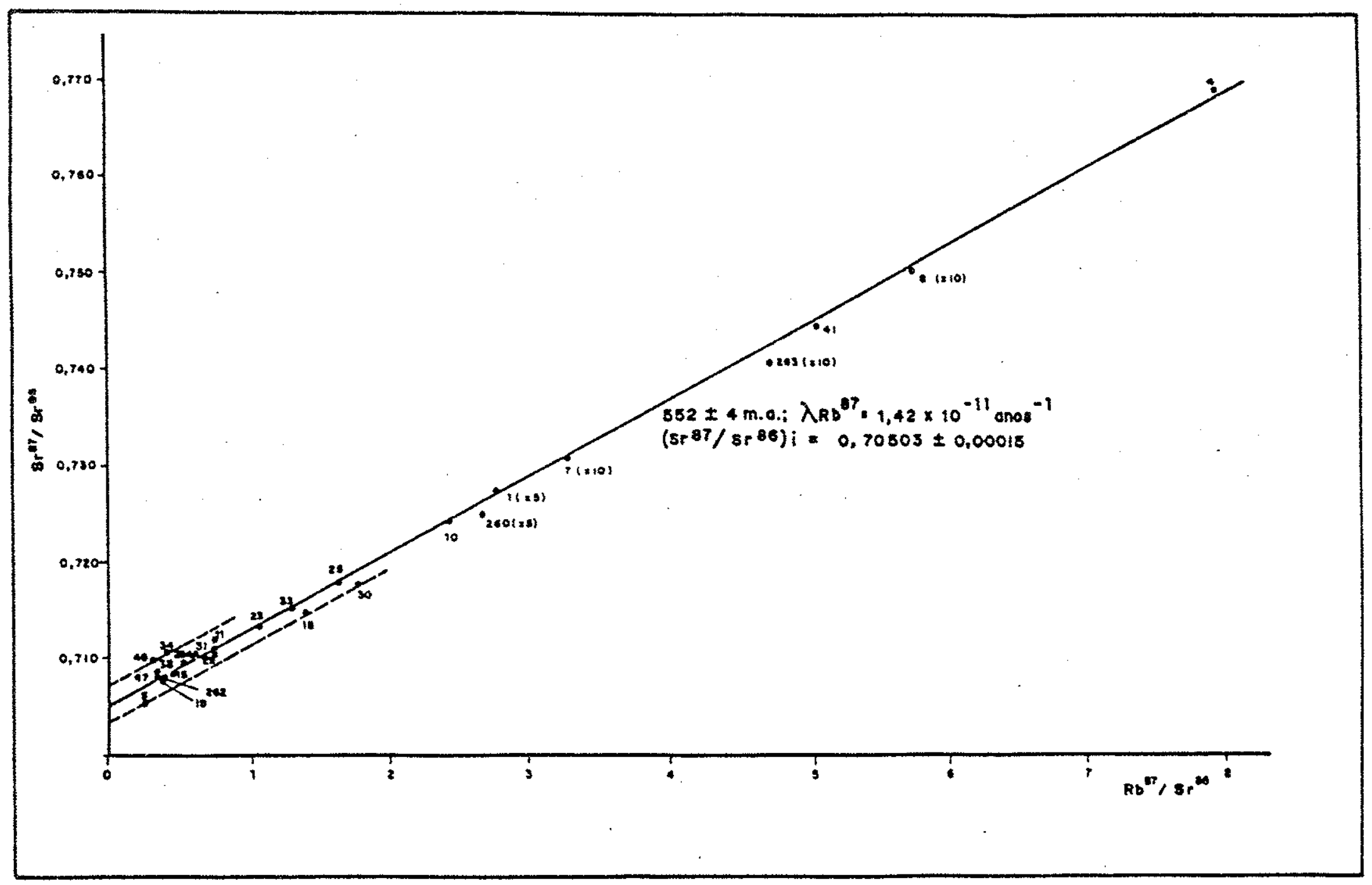

Fig. 69: Diagrama isocrônico Rb-Sr com pontos analfticos de rochas graníticas do Batólito de Caçapava do Sul, seg. Sartori e Kawashita (1985). 


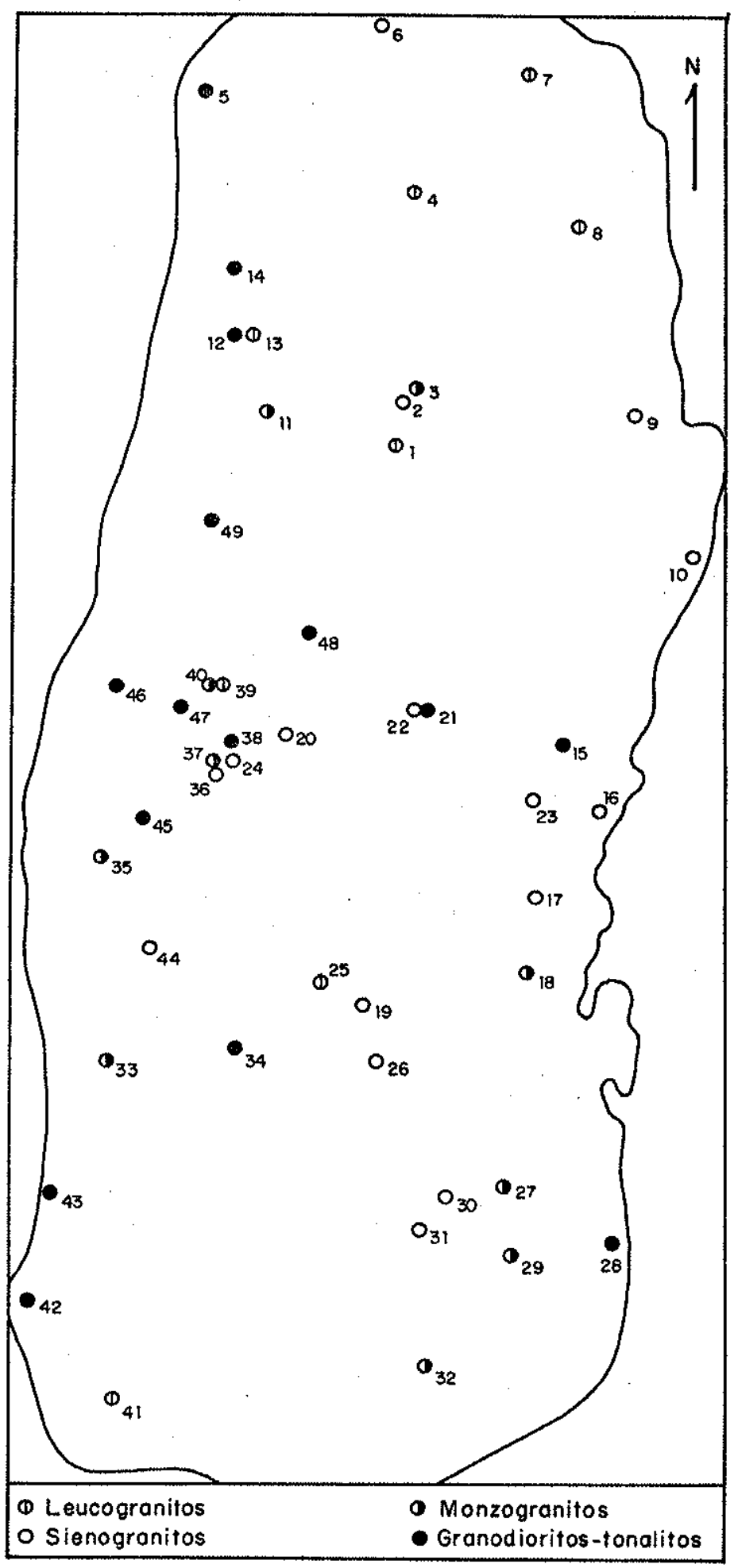

Fi.g. 70: Mapa de localização dos pontos analíticos, com indicação de fa cies petrográficas, do Batōlito Granítico de Caçapava do Sul, seg. Sartori e Kawashita (1985). Os limites da área e o contor no do corpo granitico correspondem, aproximadamente, aos da $f \bar{i}$ gura 67. Os teores de $\mathrm{Rb}, \mathrm{Sr}$ (em $\mathrm{ppm}$ ) e o valor da razão $\mathrm{Rb} / \mathrm{S} \overline{\mathrm{r}}$ podem ser vistos na tabela $25 \mathrm{C}$. 


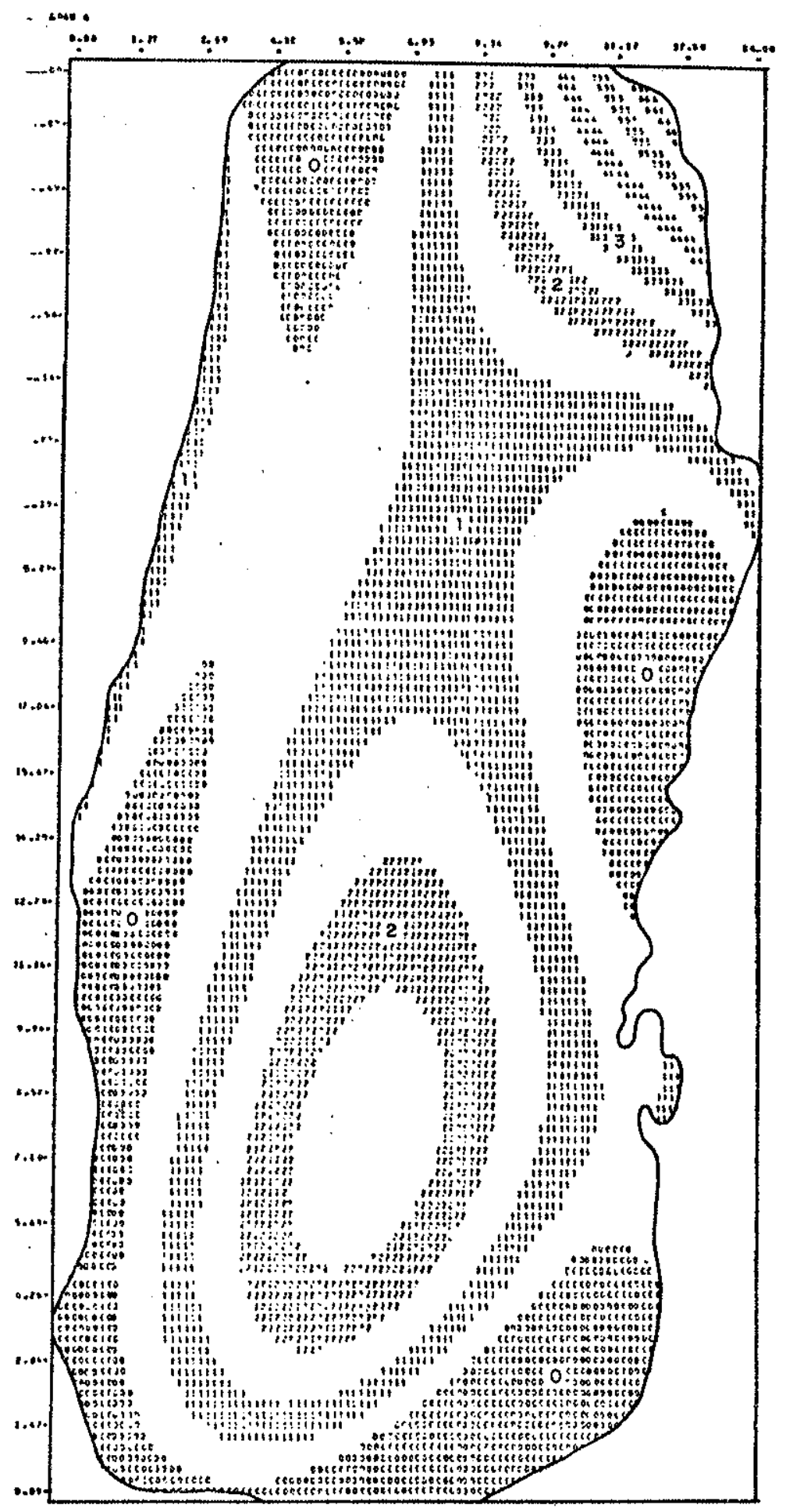

Fig. 71: Superfície de tendência (49. grau). que representa a variação da concentração de Rb no Batōlito Granitico de Caçapava do Sul. Os teores de $\mathrm{Rb}$ são diretamente proporcionais aos nümeros da superfície de tendência (ver tab. $25 \mathrm{C}$ ). 


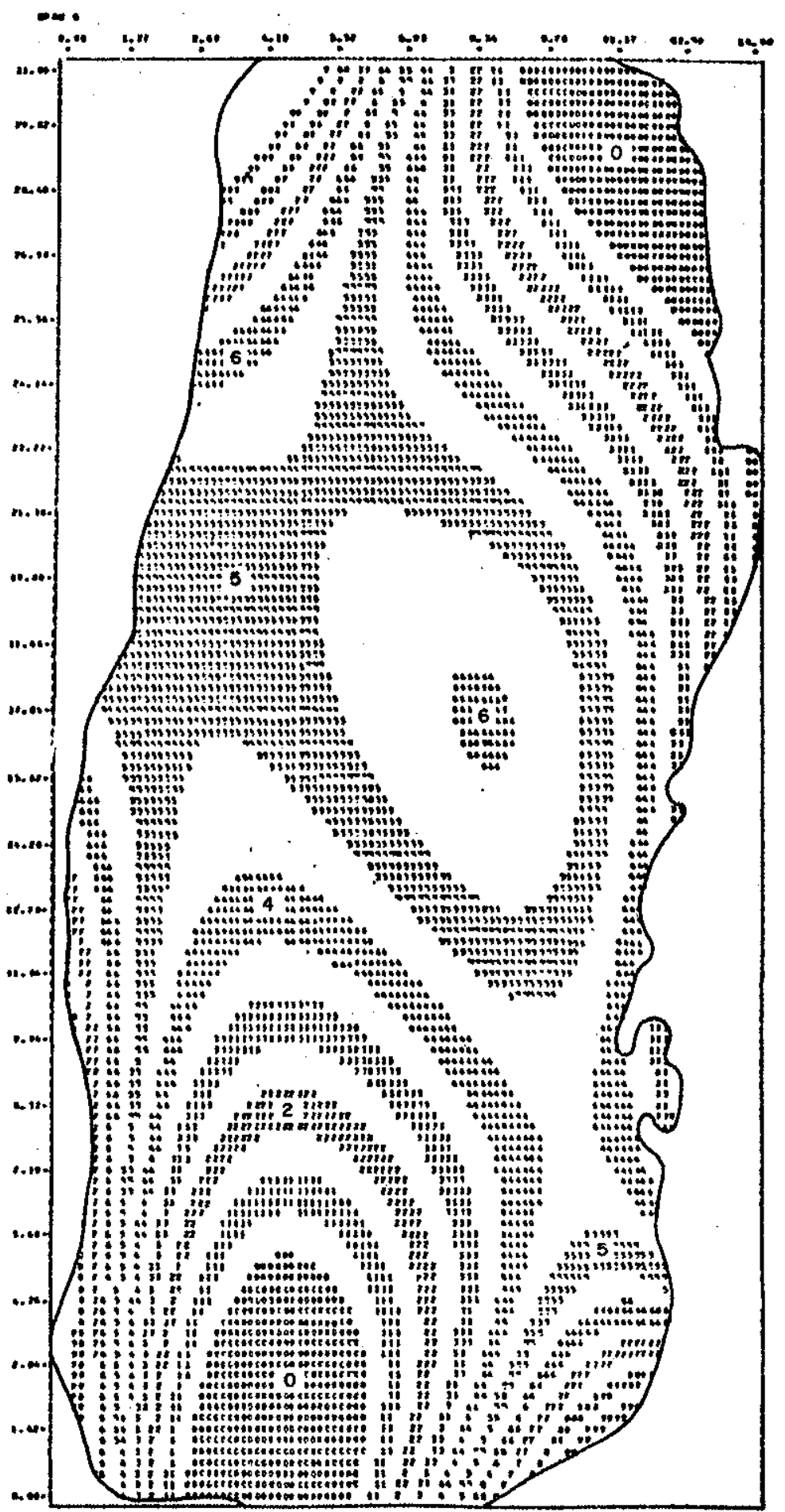

Fig. 72: Superficie de tendência (4\% grau) que representa a variação da concentração de Sr no Batōlito Granítico de Caçapava do Sul. Os teores de $\mathrm{Sr}$ são diretamente proporcionais aos nümeros da superfície de tendência (ver tab. $25 \mathrm{C}$ ). 


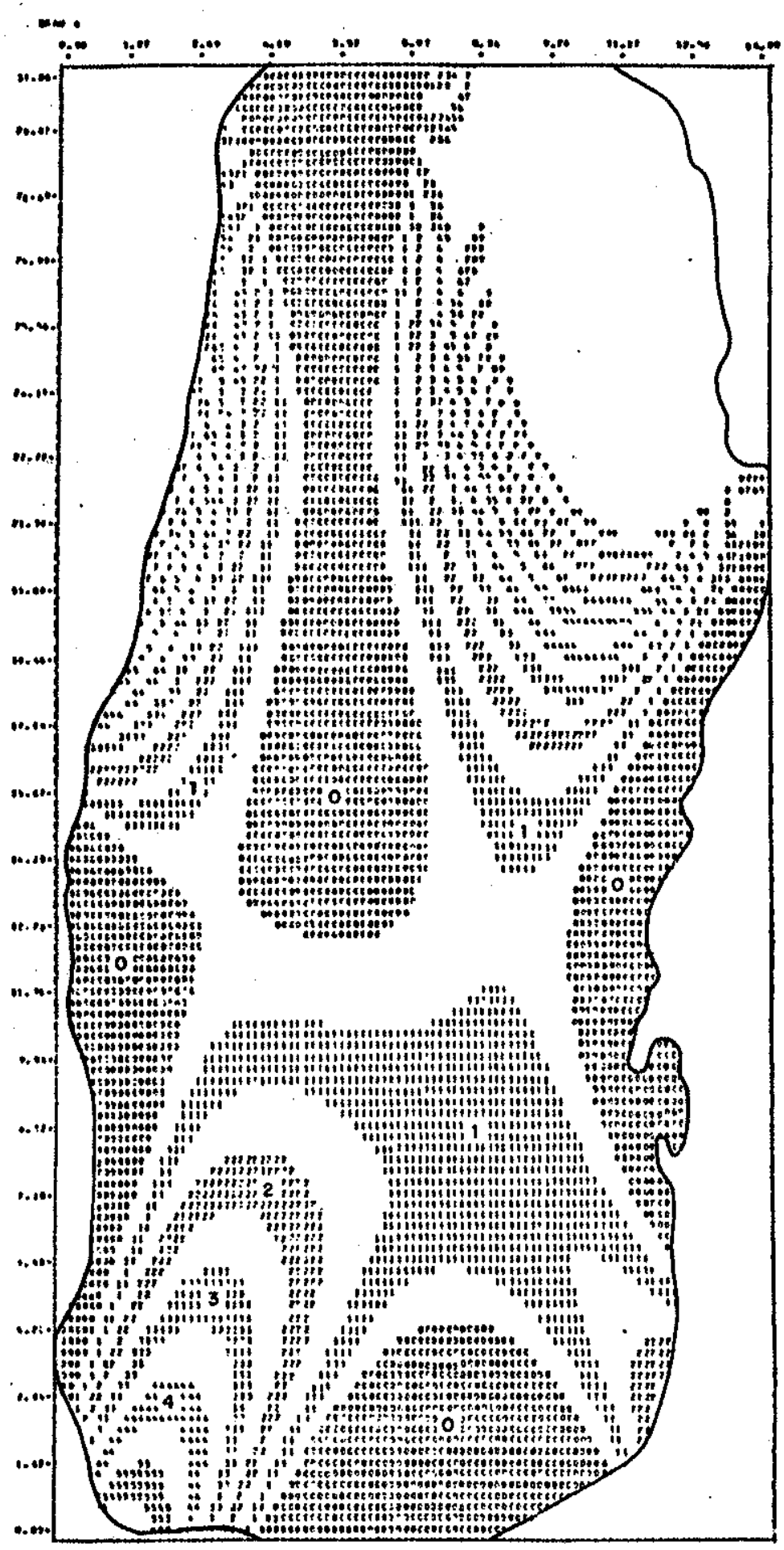

Fig. 73: Superficie de tendência (4\% grau) que representa a variação da razão $\mathrm{Rb} / \mathrm{Sr}$ no Batölito Granítico de Caçapava do Sul. 0s valores da razão $\mathrm{Rb} / \mathrm{Sr}$ são diretamente proporcionais aos nümeros da superfície de tendência (ver tab. $25 \mathrm{C}$ ). 

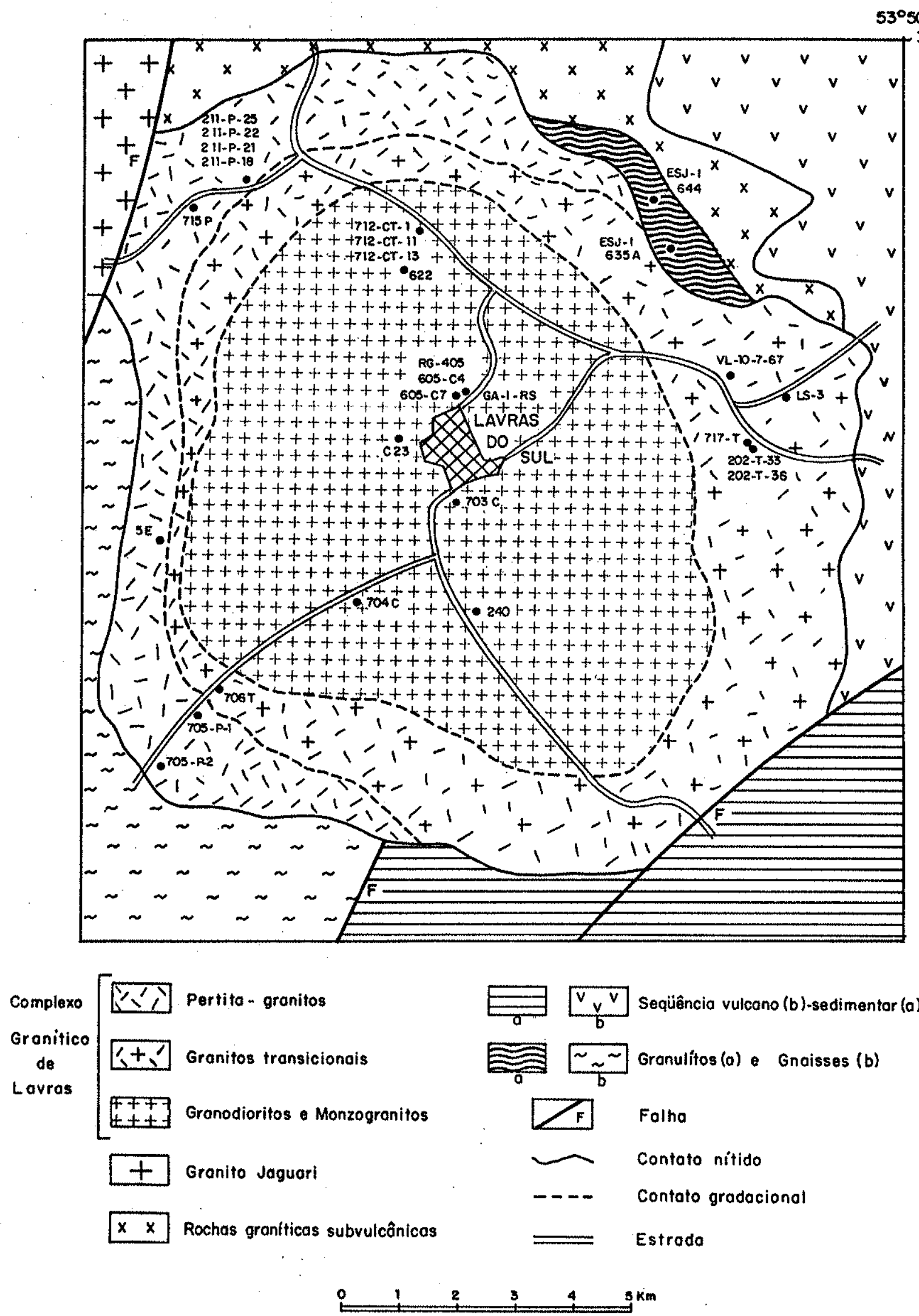

FIG. 74 - MAPA GEOLÓGICO SIMPLIFICADO DA REGIÄO DE LAVRAS DO SUL, SEGUNDO NARDI (1984), COM MODIFICAÇÓES OS PONTOS ASSINALADOS CORRESPONDEM AOS LOCAIS DE COLETA DAS AMOSTRAS ANALISADOS E TODOS SÄO PRECEDIDOS DA SIGLA ESJ-LN, COM EXCECĂO DOS GA, VL O LS. PARA OS CHARNOQUITOS AS SIGLAS ESTÄO COMPLETAS. 


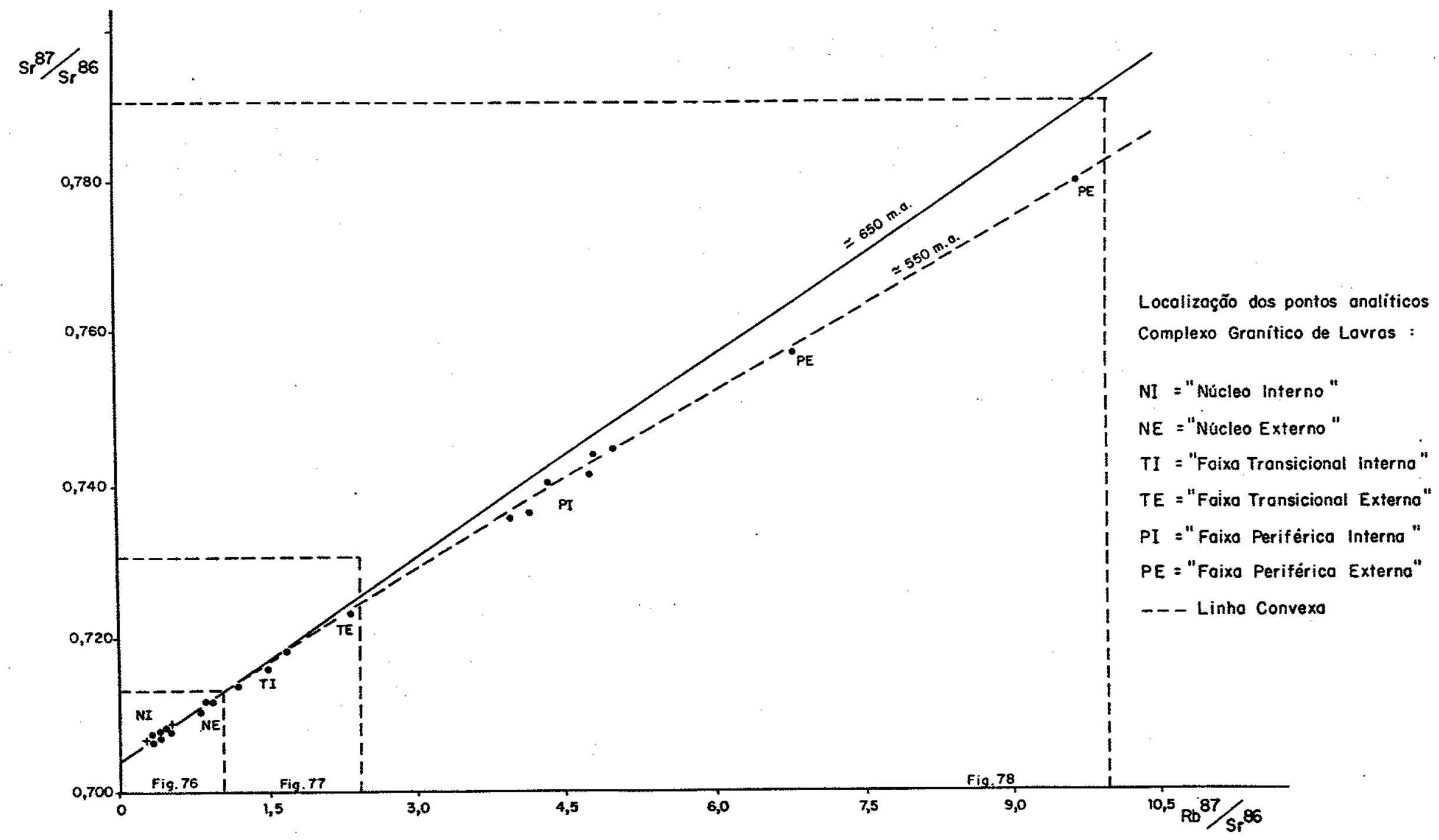

Fig. 75: Diagrama isocrônico Rb-Sr de referencia do Complexo Granítico de Lavras do Sul. A identificação dos pon tos pode ser feita nas figuras seguintes, conforme acima indicado. Os pontos assinalados com uma cruz correspondem a amostras de charnoquitos. 


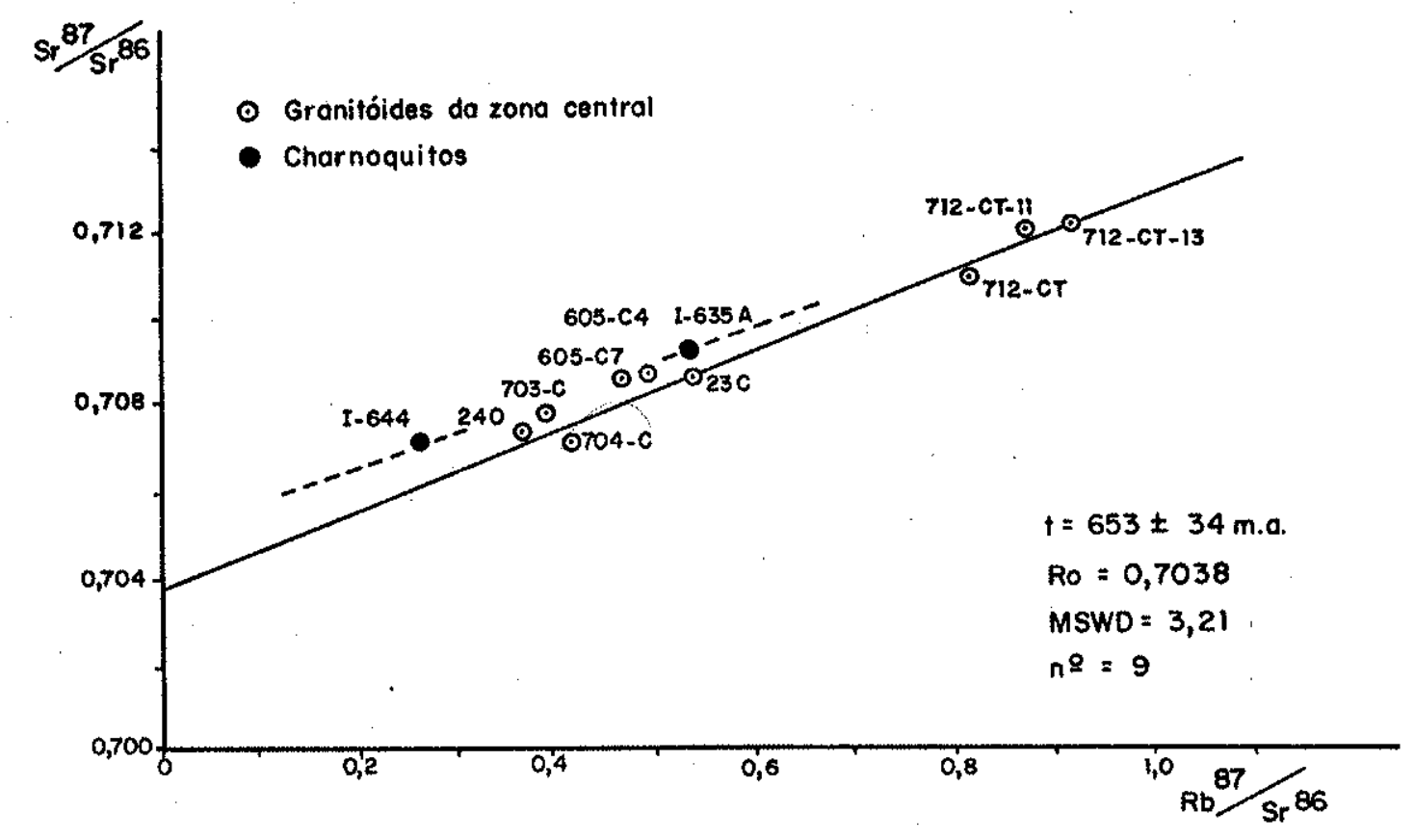

Fig. 76: Diagrama isocrônico Rb-Sr de referência de granodioritos e mon zogranitos da porção central do Complexo Granitico de Lavras do Sul. Os pontos cheios correspondem a rochas charnoquiticas associadas e parecem definir um segmento isocrônico mais jovem. Todos os pontos, com exceção do 240 e daqueles iniciados por 1, são precedidos pela sigla ESJ-LN.

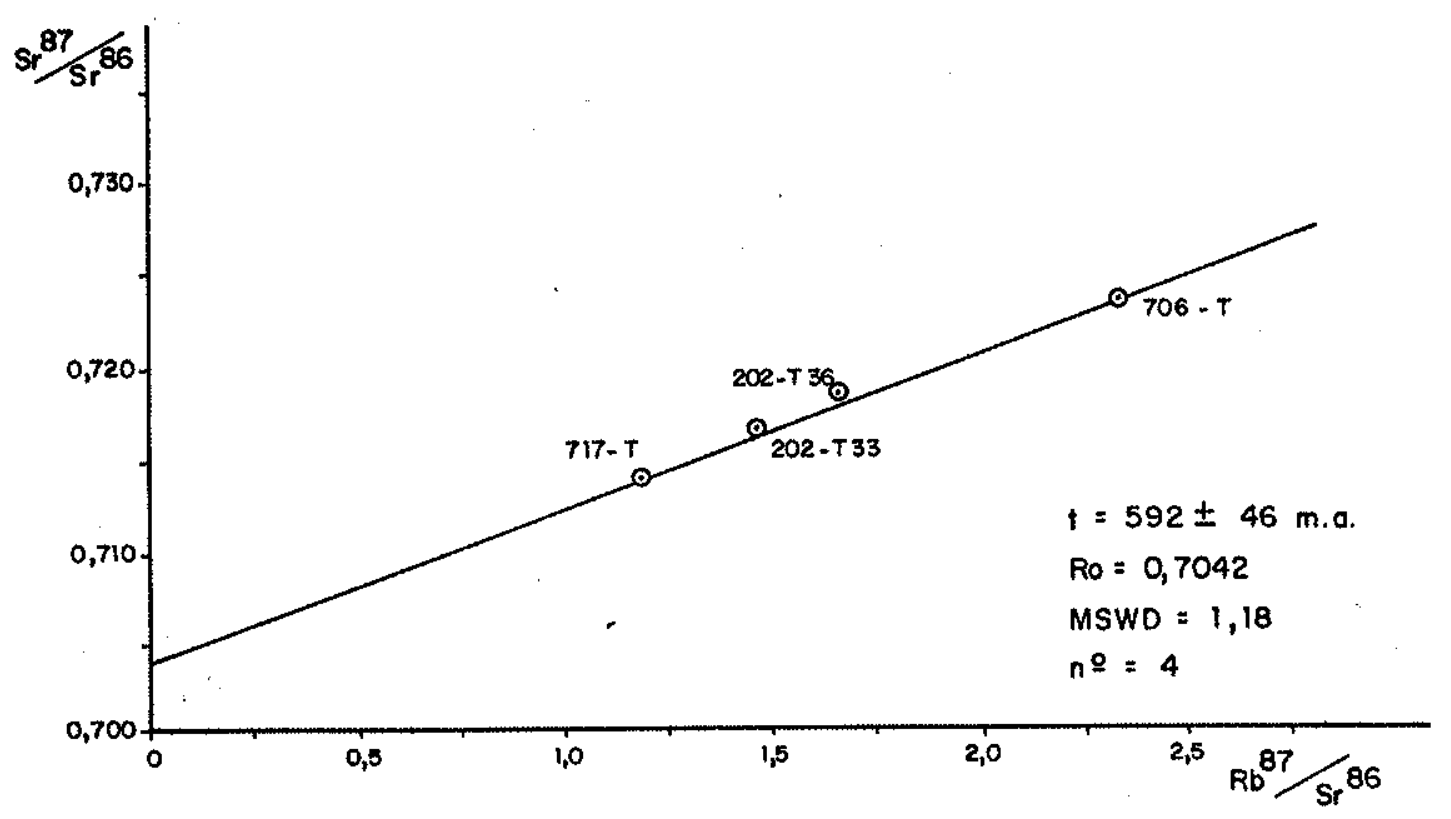

Fig. 77: Diagrama isocrônico Rb-Sr de referência de sienogranitos da faixa transicional do Complexo Granítico de Lavras do Sul. To dos os pontos são precedidos da sigla ESJ-LN. 


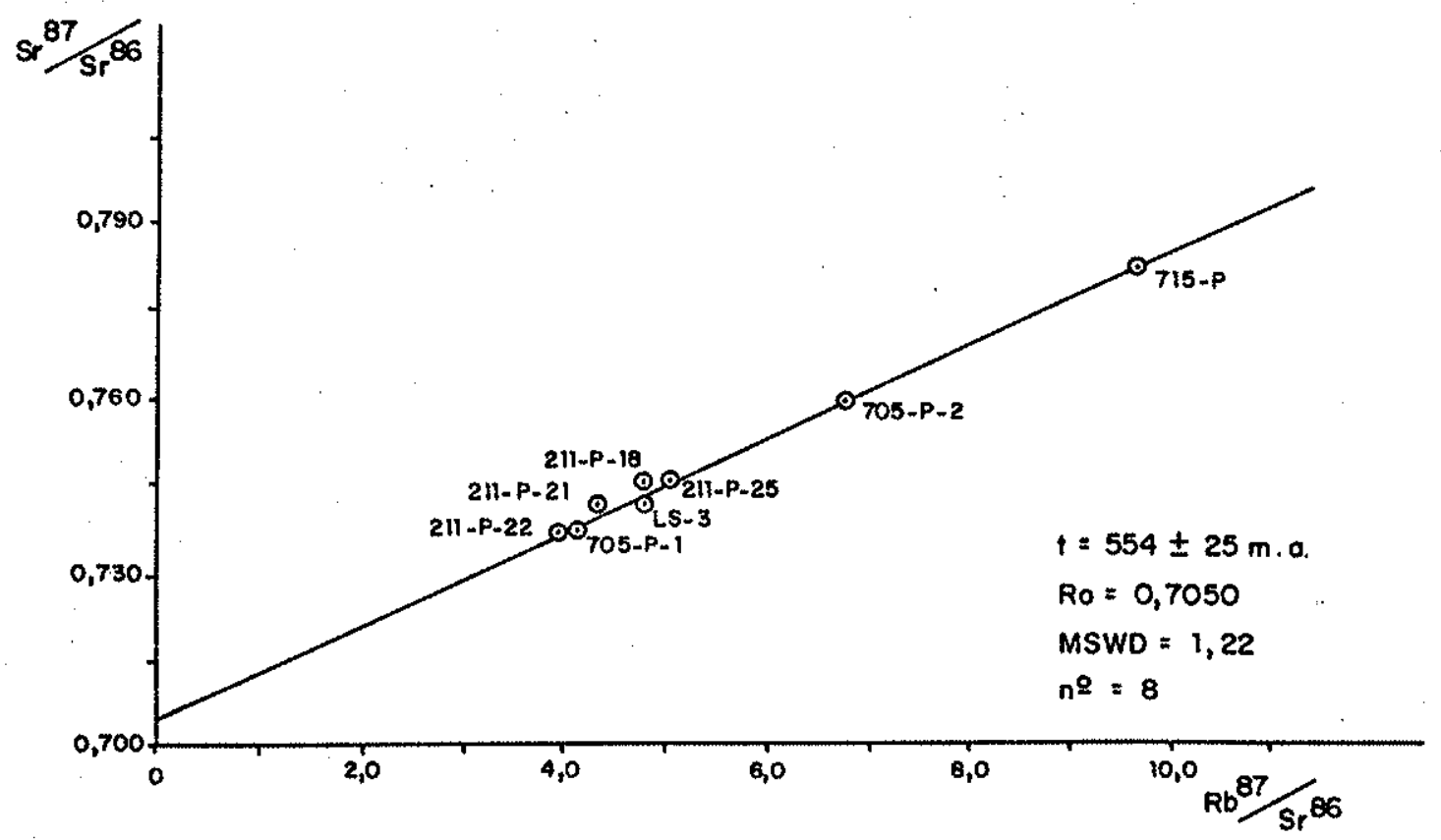

Fig. 78: Diagrama isocrônico $\mathrm{Rb}-\mathrm{Sr}$ de referência de pertita-granitos da porção periférica do Complexo Granitico de Lavras do Sul. Todos os pontos são precedidos da sigla ESJ-LN, com exceção do LS-3. Este, embora coletado na faixa transicional do complexo, por apresentar características isotöpicas dos granitos perifëricos, foi aqui incluido.

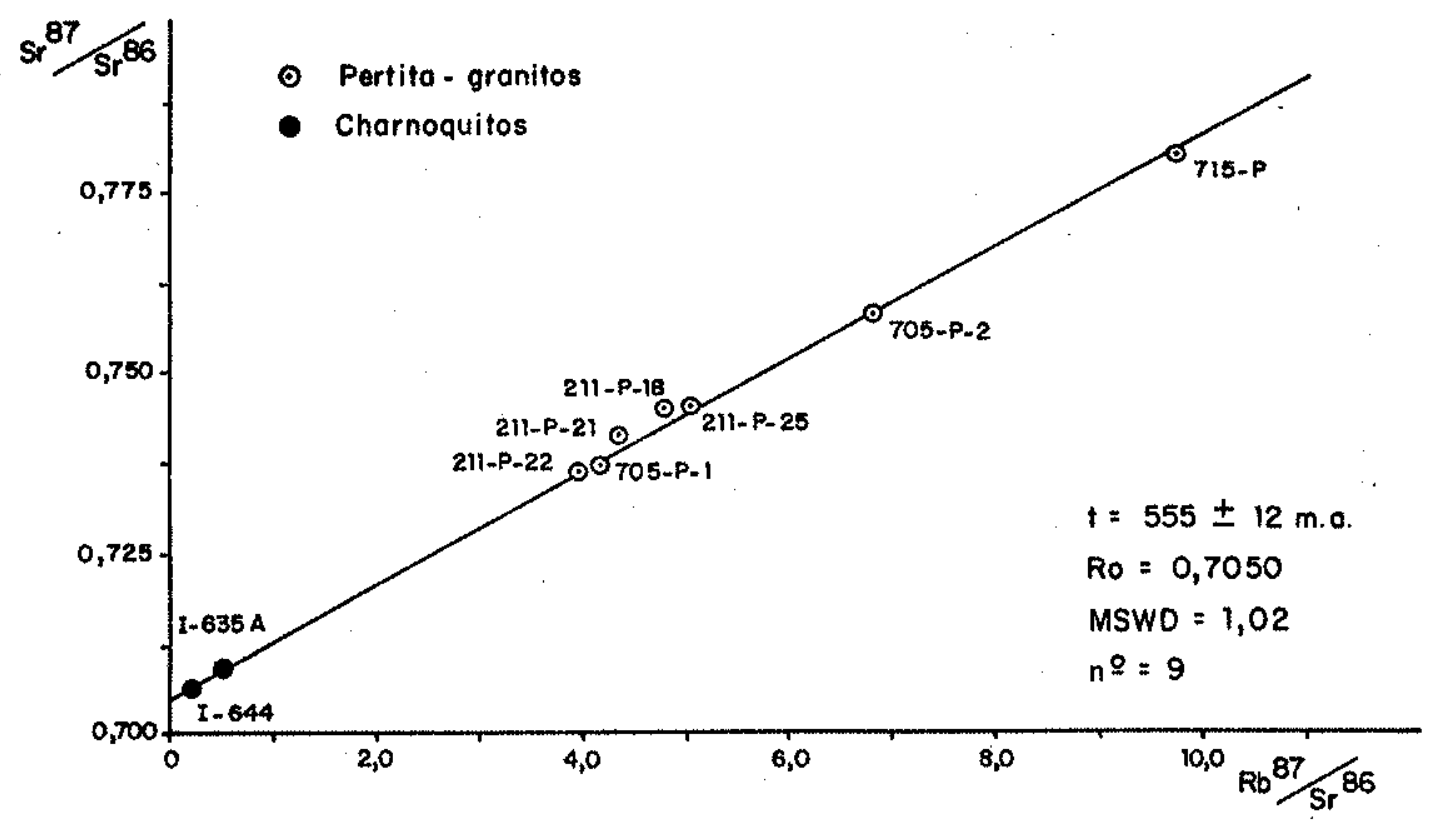

Fig. 79: Diagrama isocrônico Rb-Sr de referência para os pertita-granitos da porção periférica do Complexo Granítico de Lavras do Sul e charnoquitos associados. Todos os pontos, com exceção dos iniciados com 1, são precedidos da sigla ESJ-LN. 


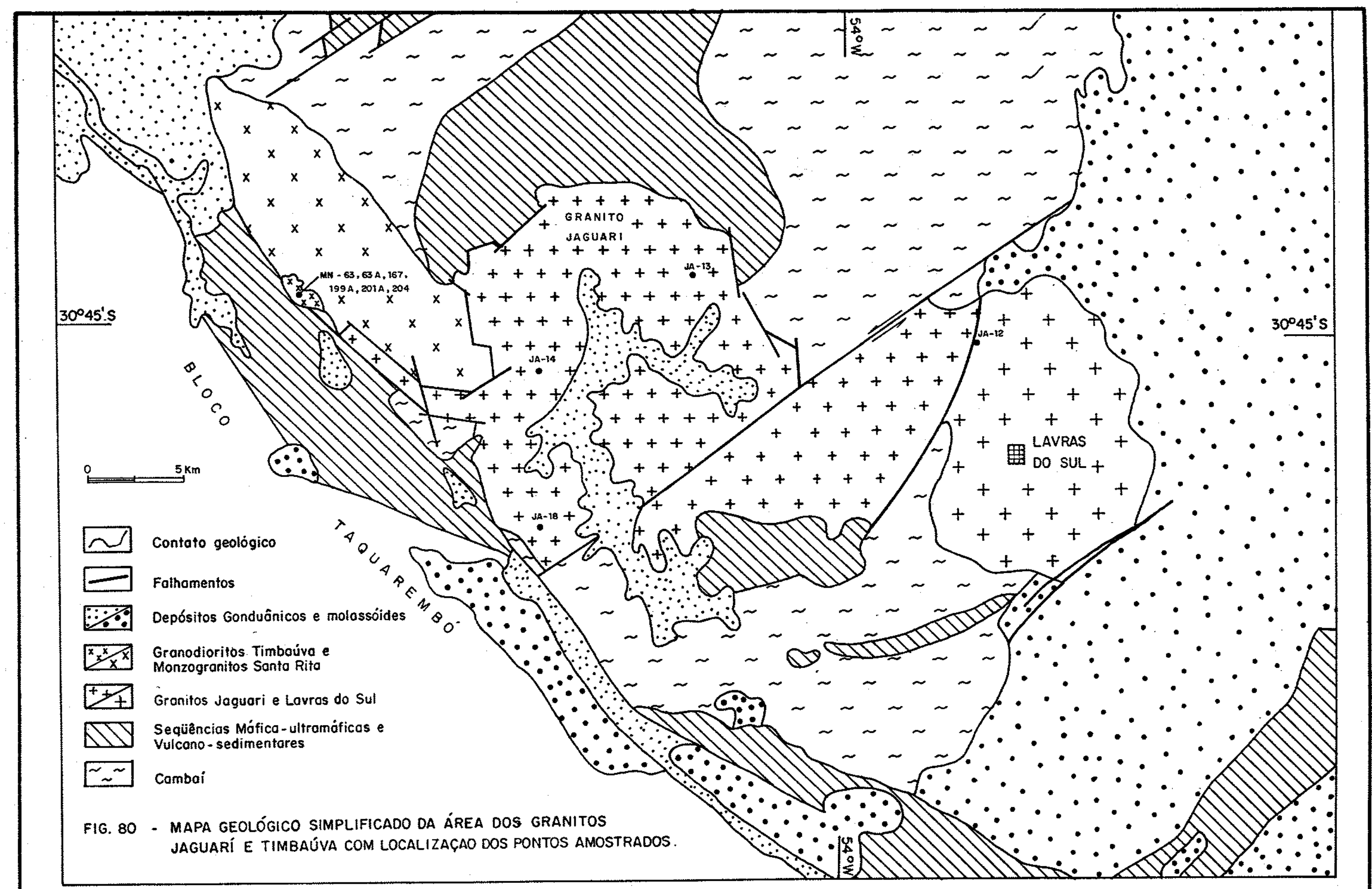




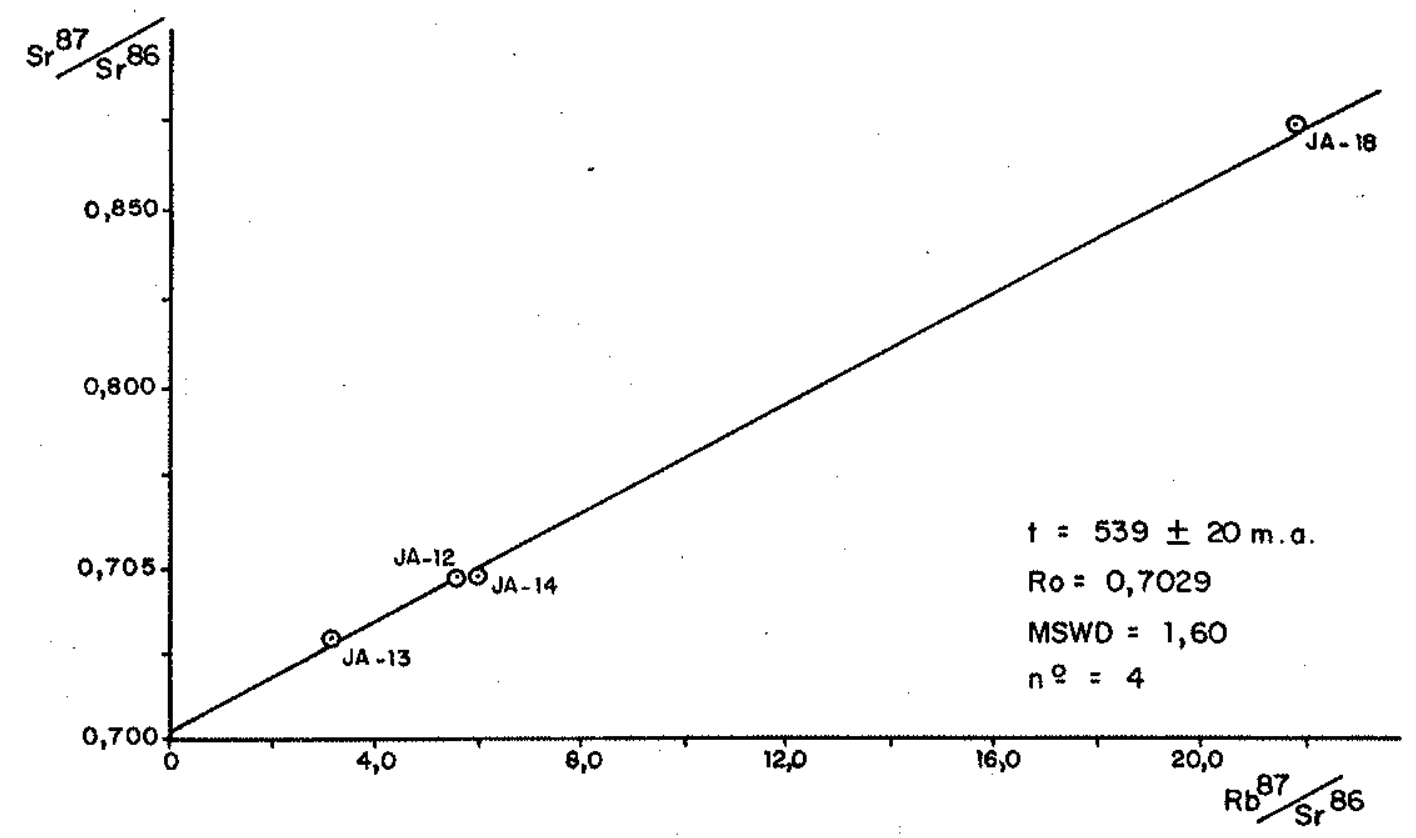

Fig. 81: Diagrama isocrônico Rb-Sr de referência de sienogranitos do Batólito Jaguari.

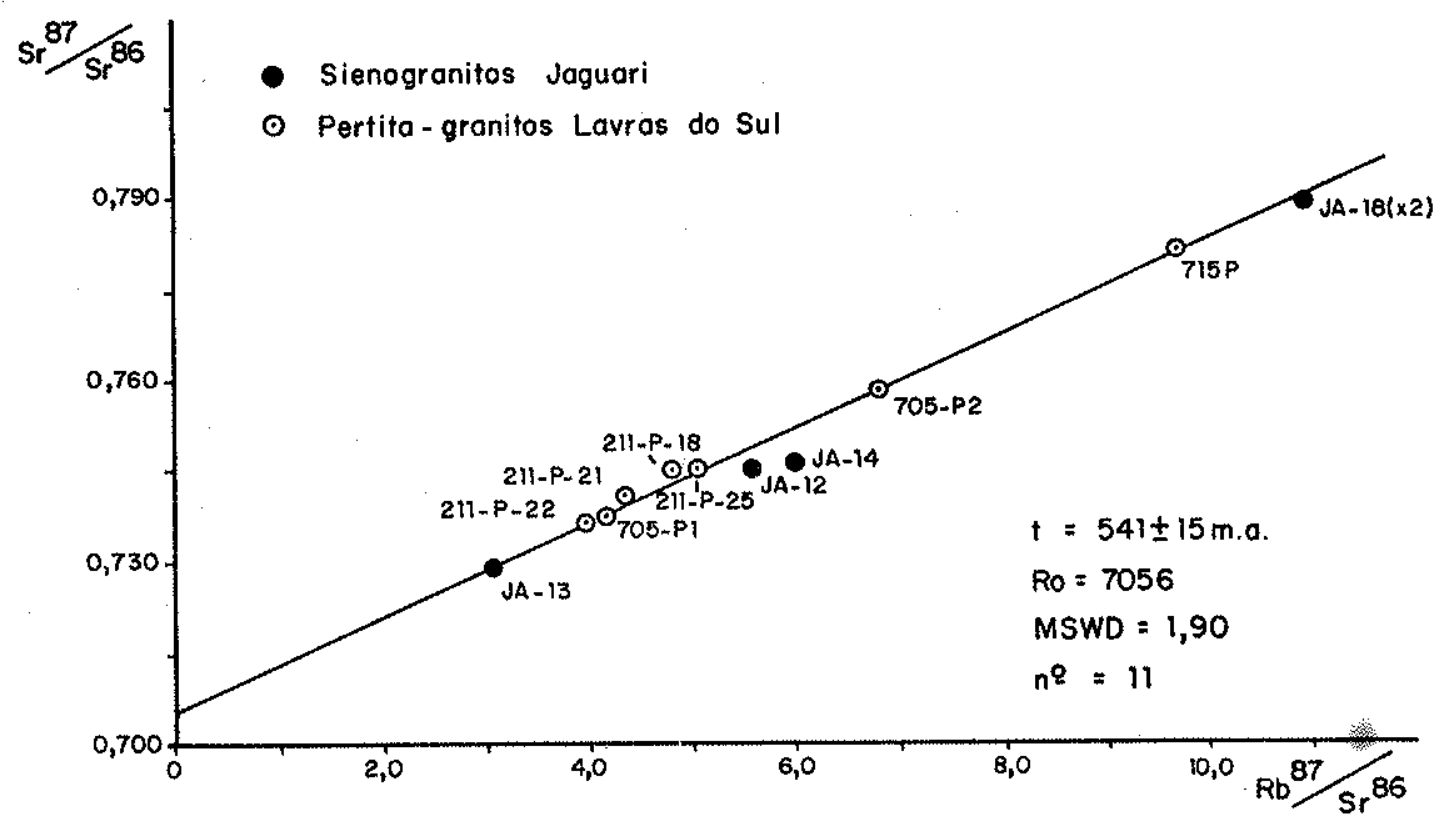

Fig. 82: Diagrama isocrônico Rb-Sr de referência de sienogranitos Jaguari e pertitamgranitos Lavras do Sul. Com exceção dos pontos iniciados por JA, os demais são precedidos por ESJ-LN. 


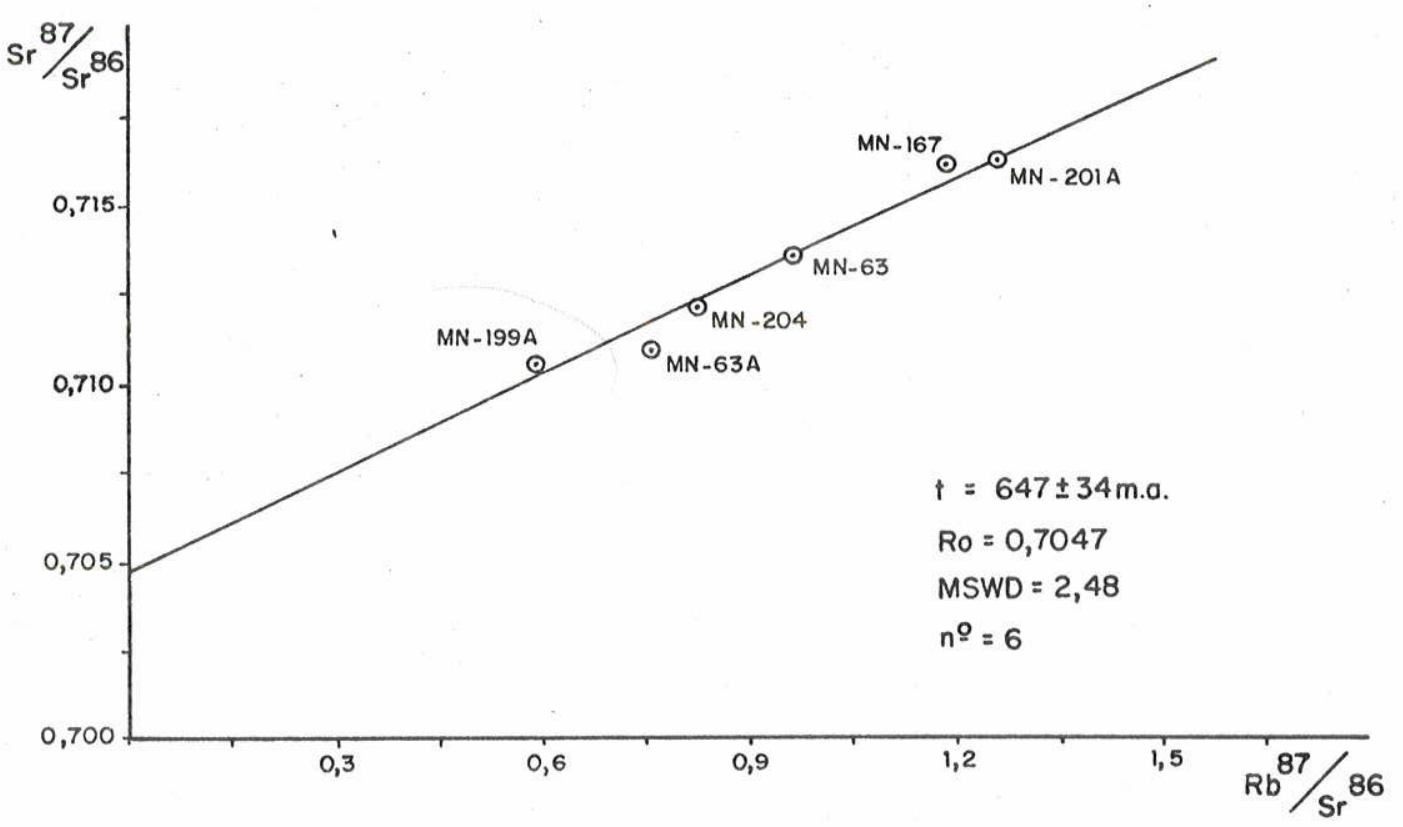

Fig. 83: Diagrama isocrônico Rb-Sr de referência de tonalitos e grano dioritos Timbaúva, seg. Naumann (1984).

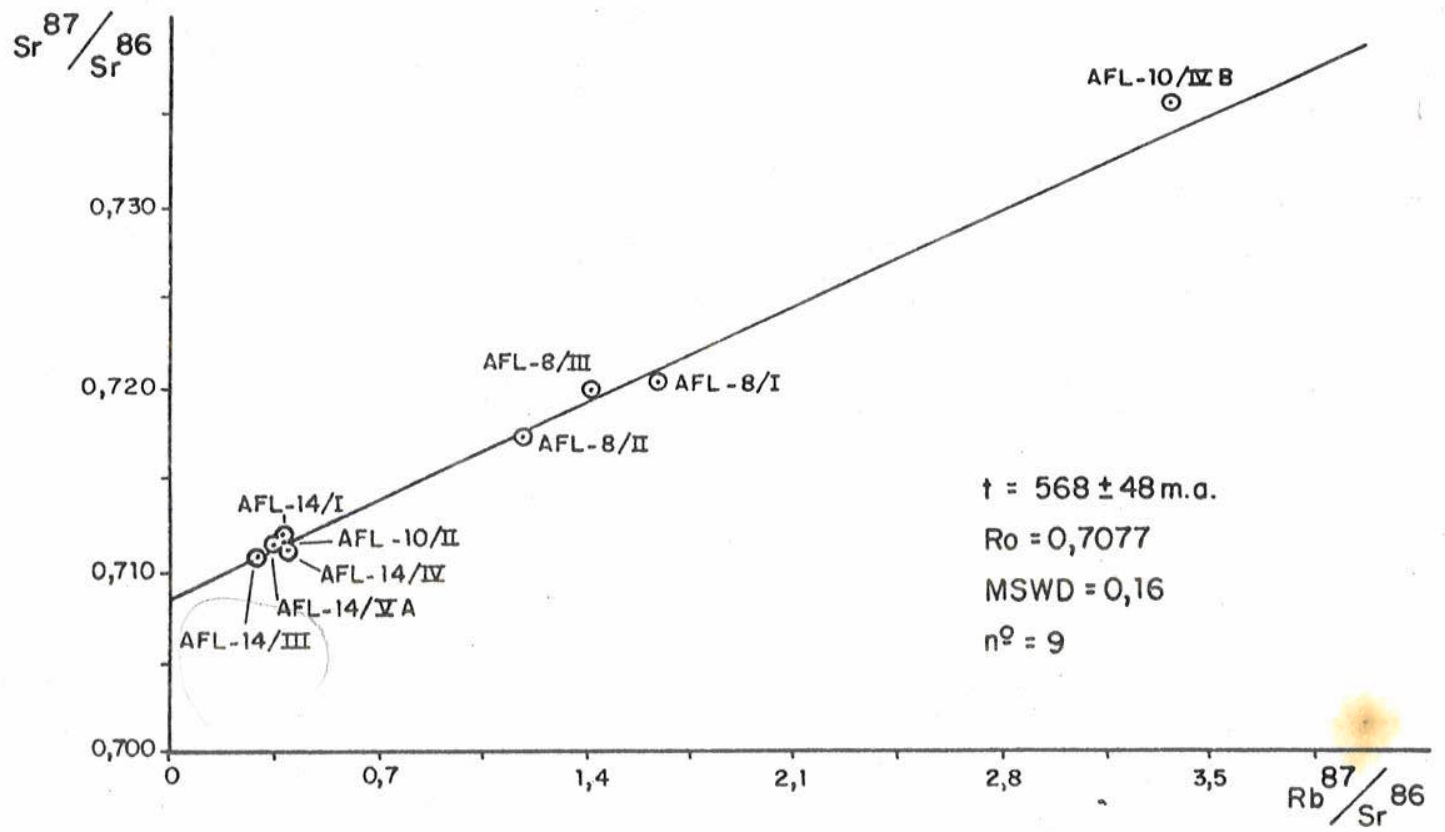

Fig. 84: Diagrama isocrônico Rb-Sr de referência do Complexo Granítico Santo Afonso. 


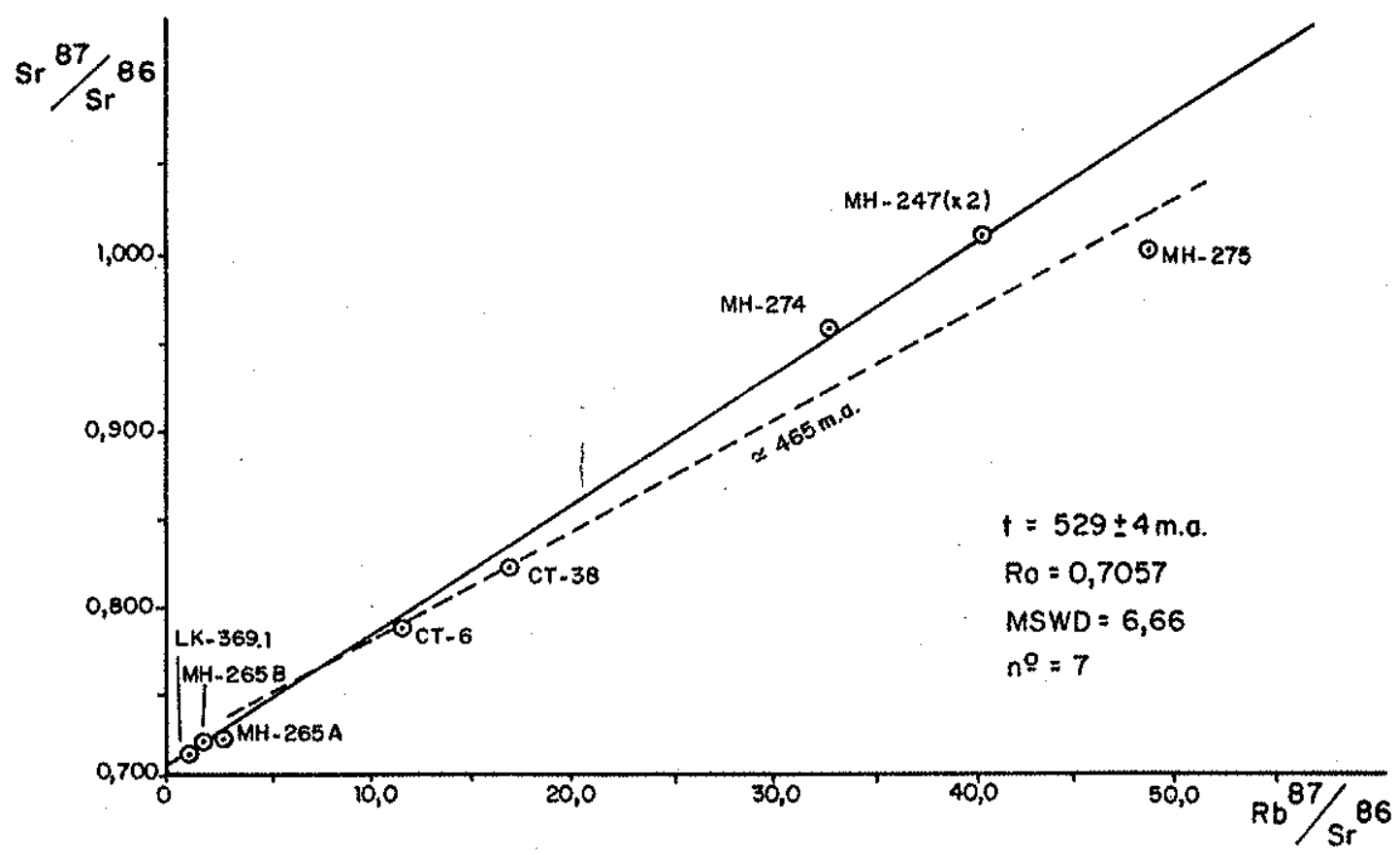

Fig. 85: Diagrama isocrônico Rb-Sr de referência de riolitos da Forma ção Acampamento Velho. Os pontos CT, jä incluidos em segmen= to isocrônico de cerca de $465 \mathrm{~m} . \mathrm{a}$. (Sartori, 1978), foram aqui considerados para o cälculo da idade isocrónica geral da unidade. 0 ponto $\mathrm{MH}-275$ apresentou problemas analíticos como decorrência de diaclasamento. 


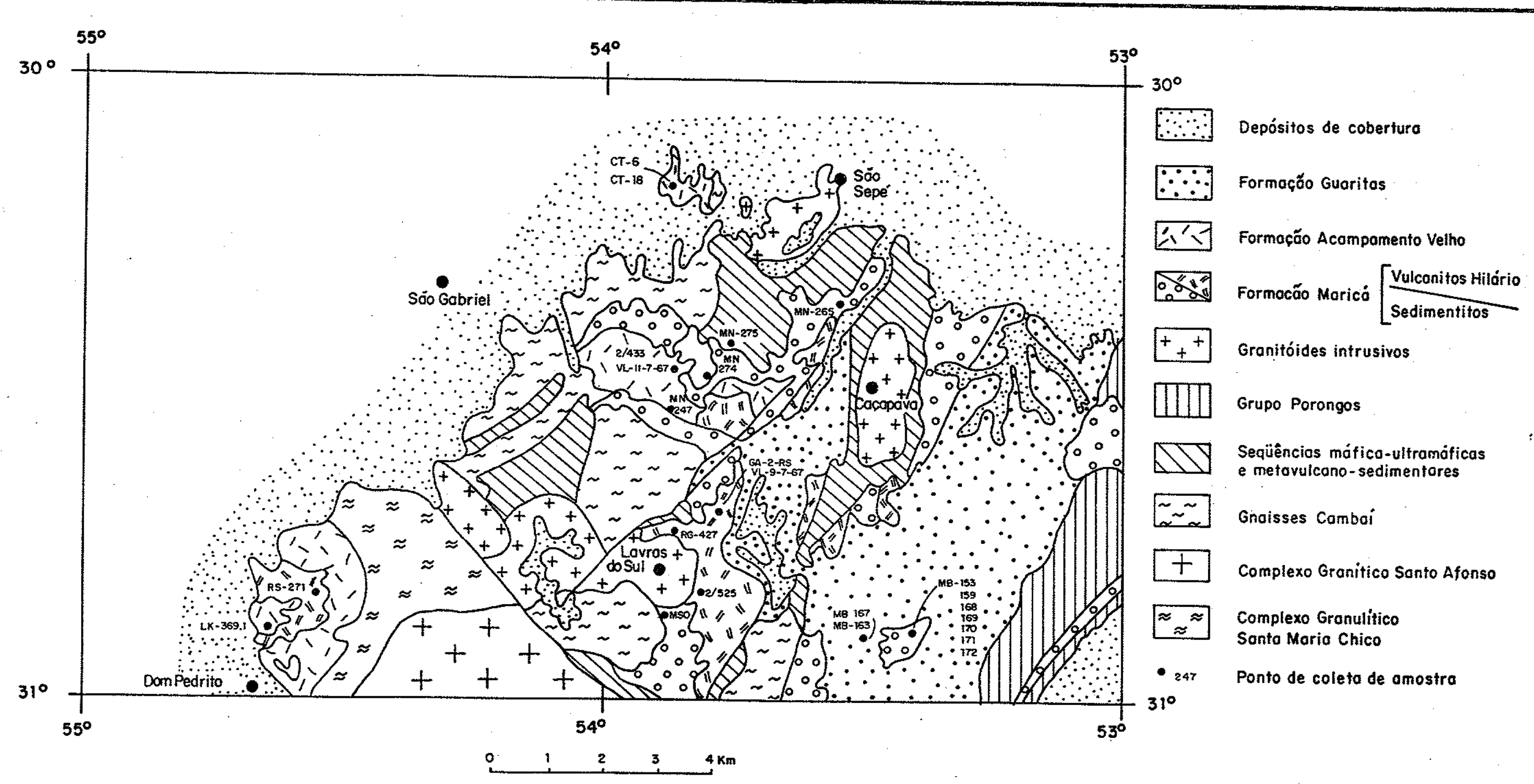

FIG. 86 - MAPA GEOLÓGICO SIMPLIFICADO DE PARTE dOS SEDIMENTITOS E VULCANITOS MOLÁSSICOS DO ESCUDO SUL - RIO - GRANDENSE, COM A LOCALIZAÇAO DOS PONTOS AMOSTRADOS. 


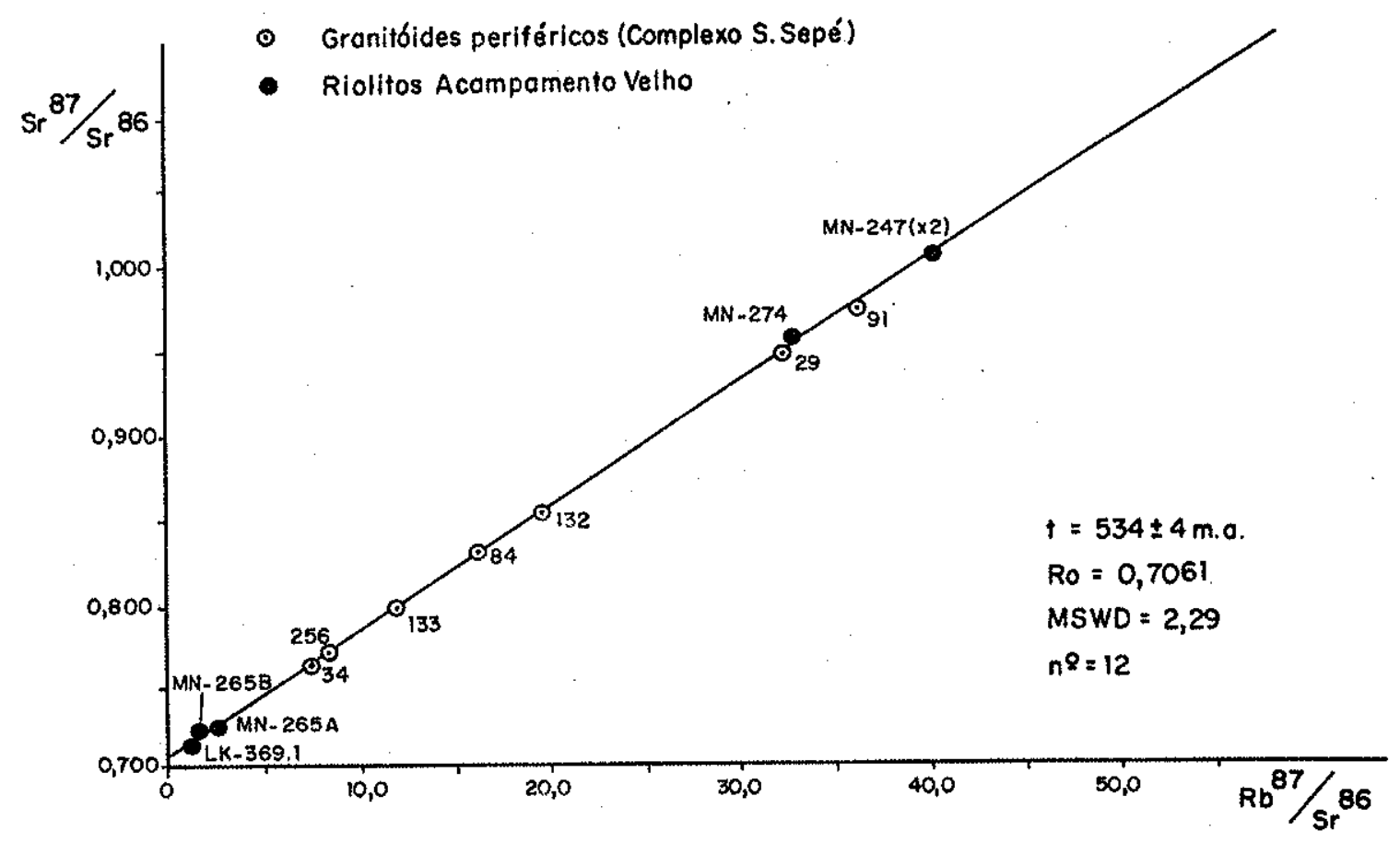

Fig. 87: Diagrama isocrônico $\mathrm{Rb}-\mathrm{Sr}$ de referência de granitos subalcalinos de bordo do Complexo Granítico de São Sepé e riolitos da Formação Acampamento Velho.

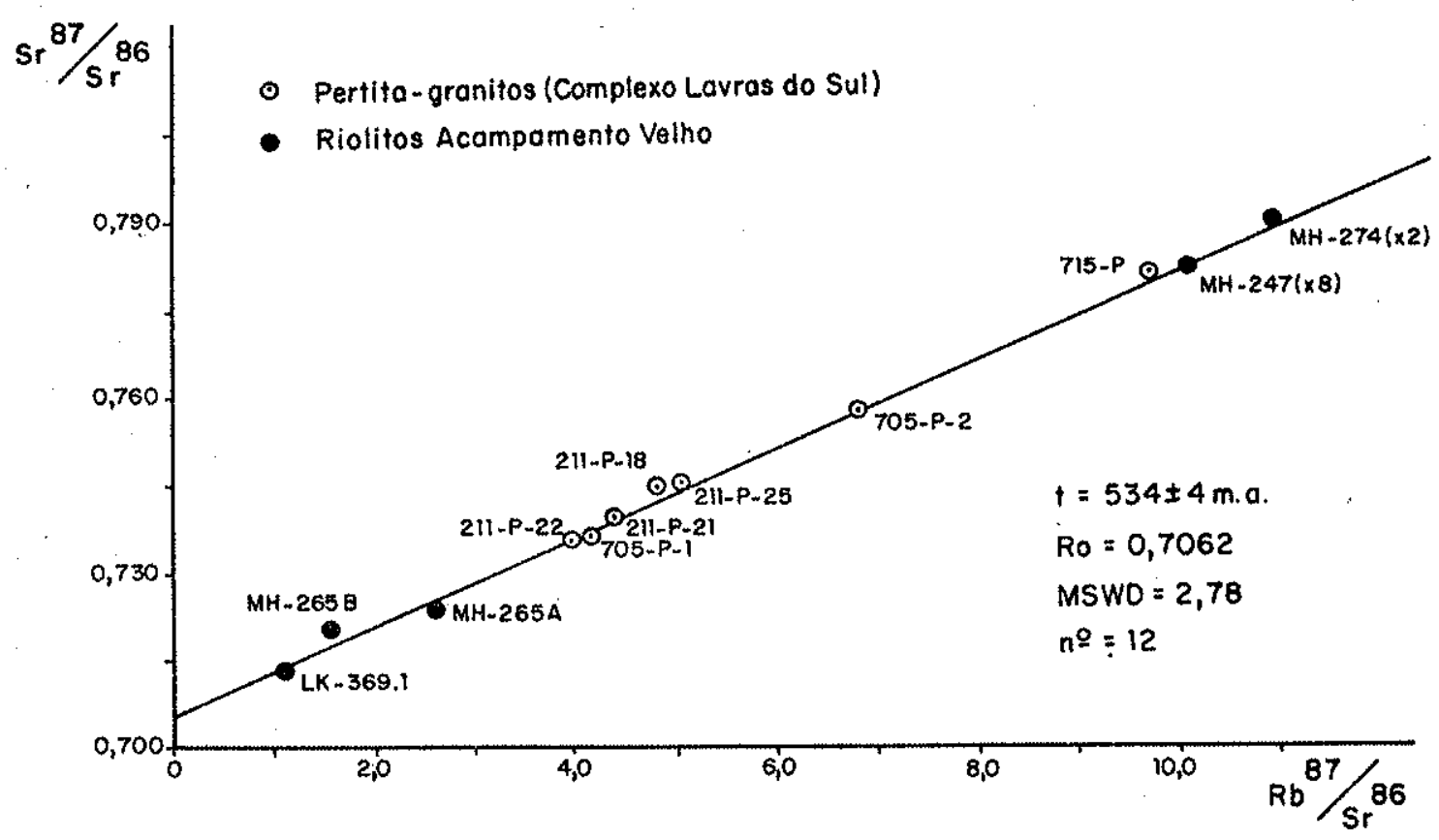

Fig. 88: Diagrama isocrōnico Rb-Sr de referência de pertita-granitos do Complexo Granitico de Lavras do Sul e riolitos da Formação Acampamento Velho. Com exceção dos pontos $L K$ e $M H$, os de mais são precedidos da sigla ESJ-LN. 


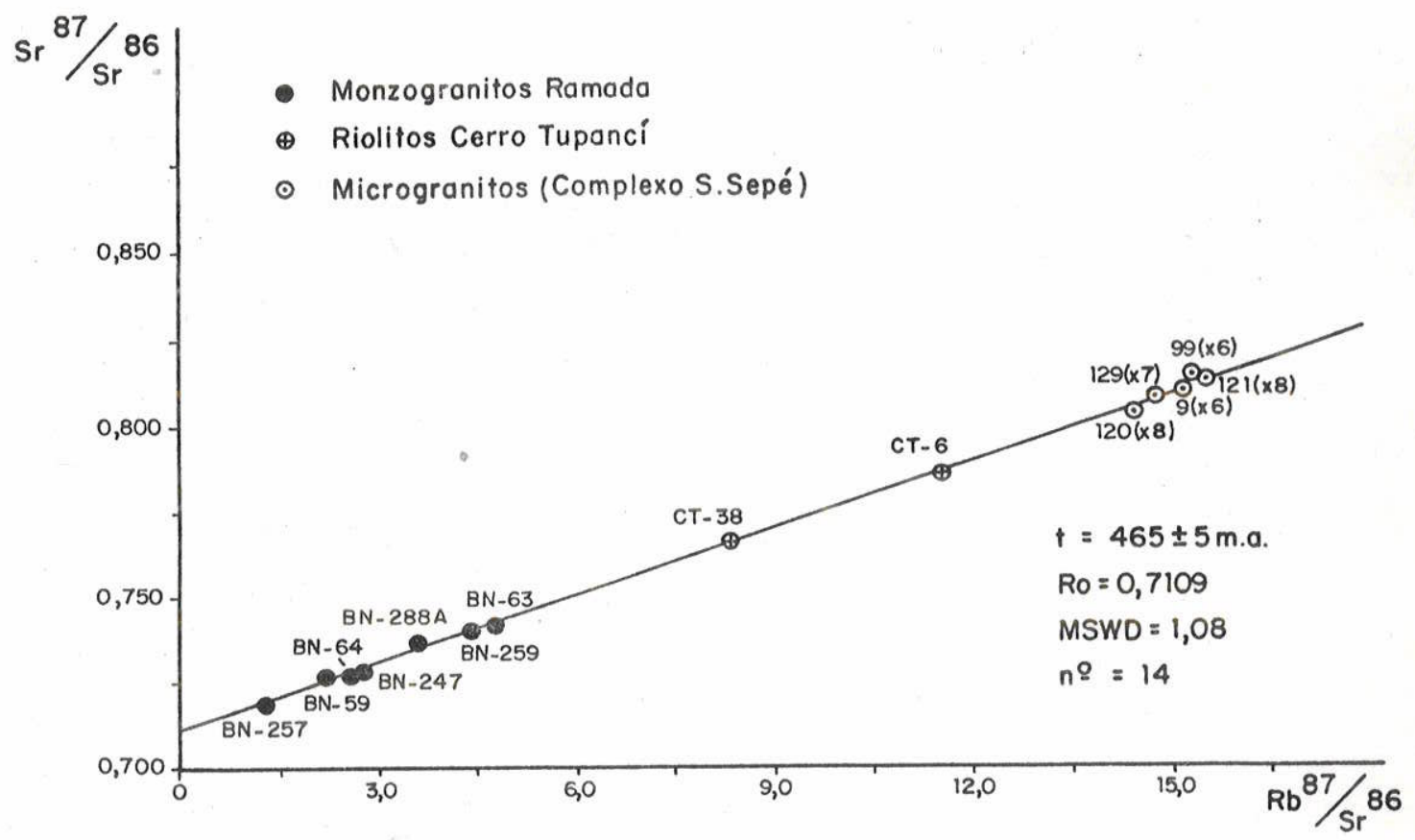

Fig. 89: Diagrama isocrônico Rb-Sr de referência de monzogranitos do Complexo Granítico Ramada, riolitos do Cerro Tupancí e micro granitos intrusivos do Complexo Granítico de São Sepé. 


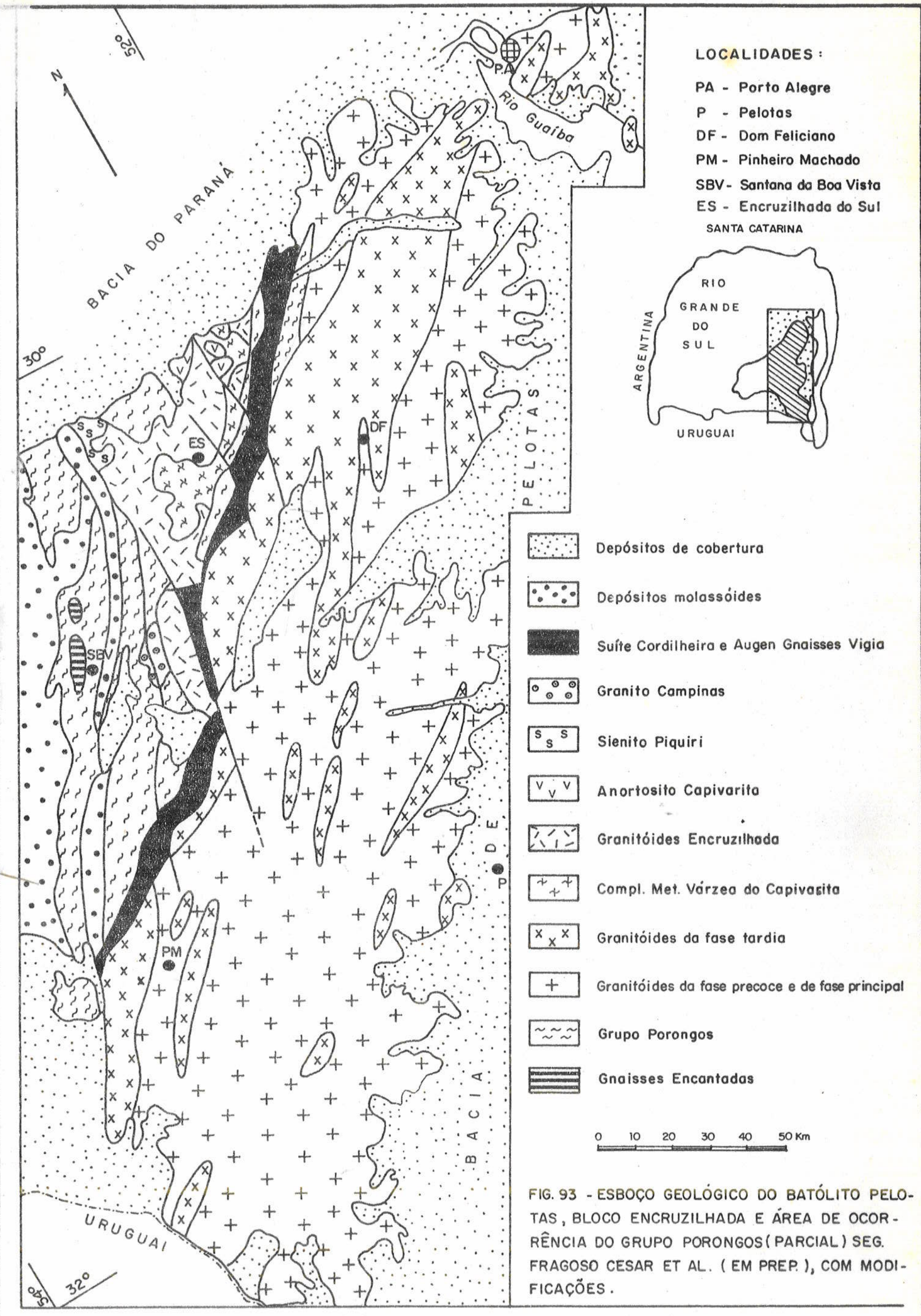


BATÓLITO PELOTAS:

$A=$ Granitóides deformados da fase precoce

$B=$ Granodioritos e monzogranitos da fase principal

$C=$ Gronitos sienogranitos tardios

D = Manifestaçöes magmáticas finais

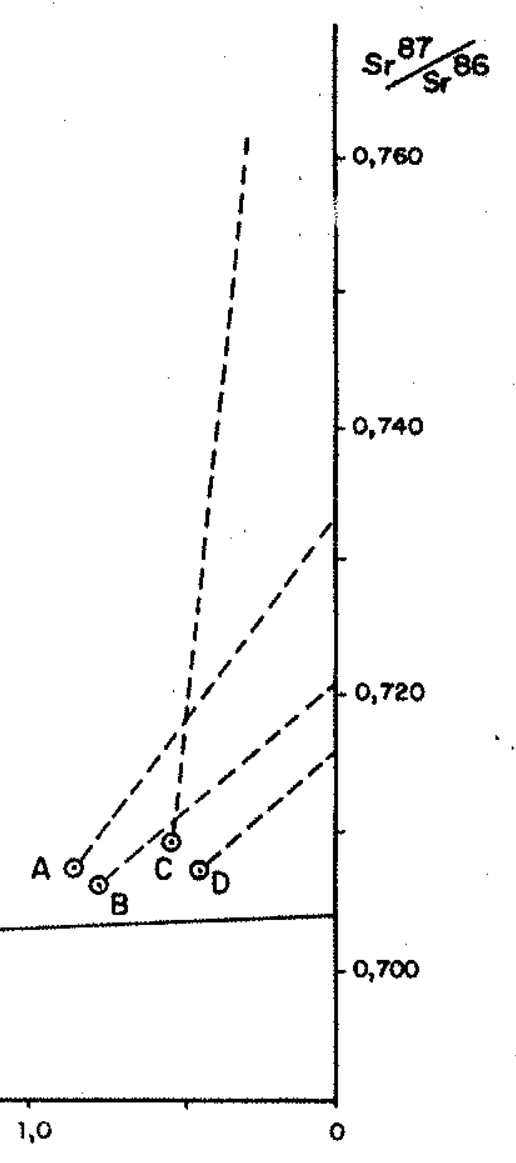

Fig. 94: Diagrama de evolução do Sr de granitōides do Batölito Pelotas. 


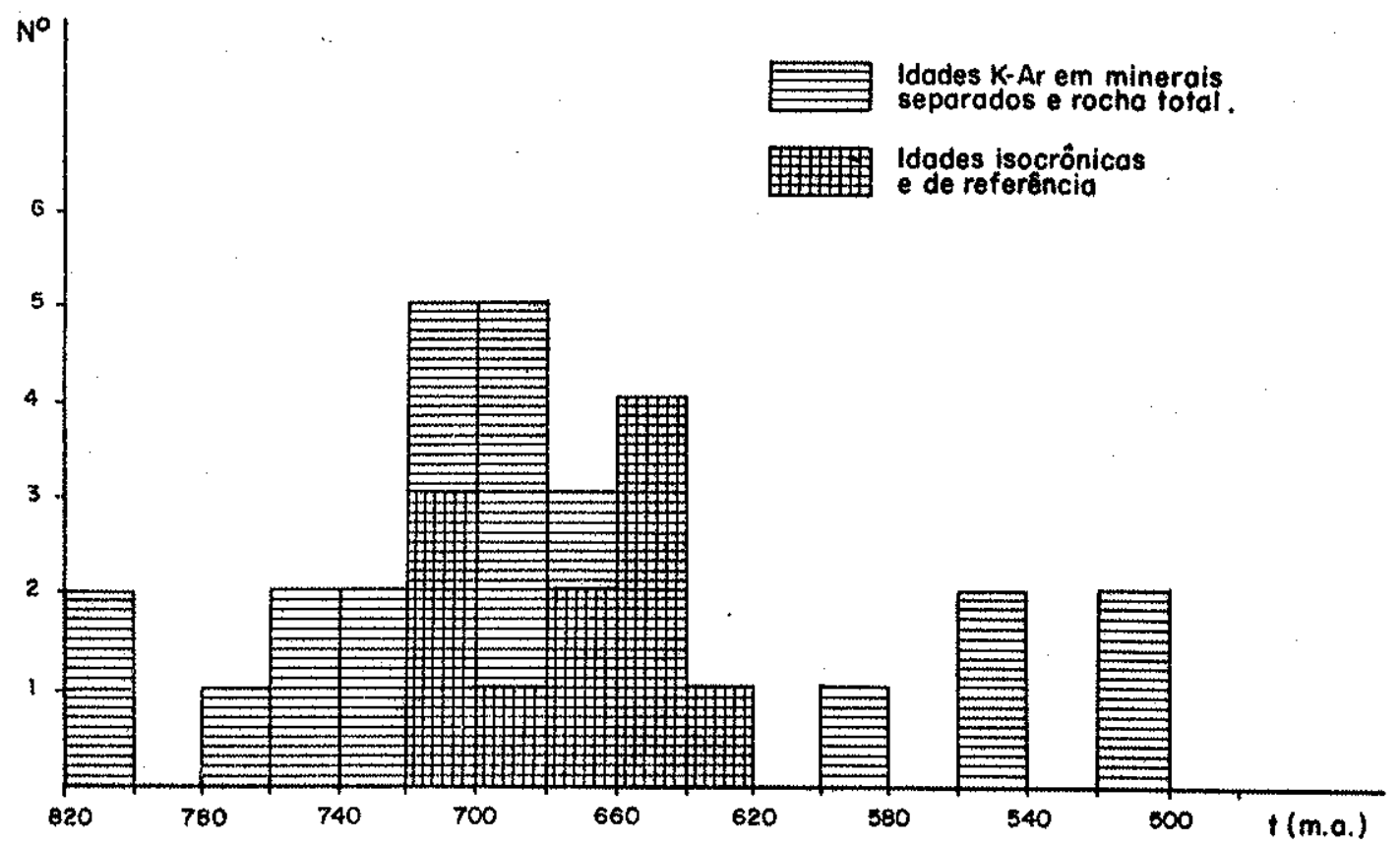

Fig. 95: Histograma de distribuição de idades K-Ar e Rb-Sr no Bloco São Gabriel.

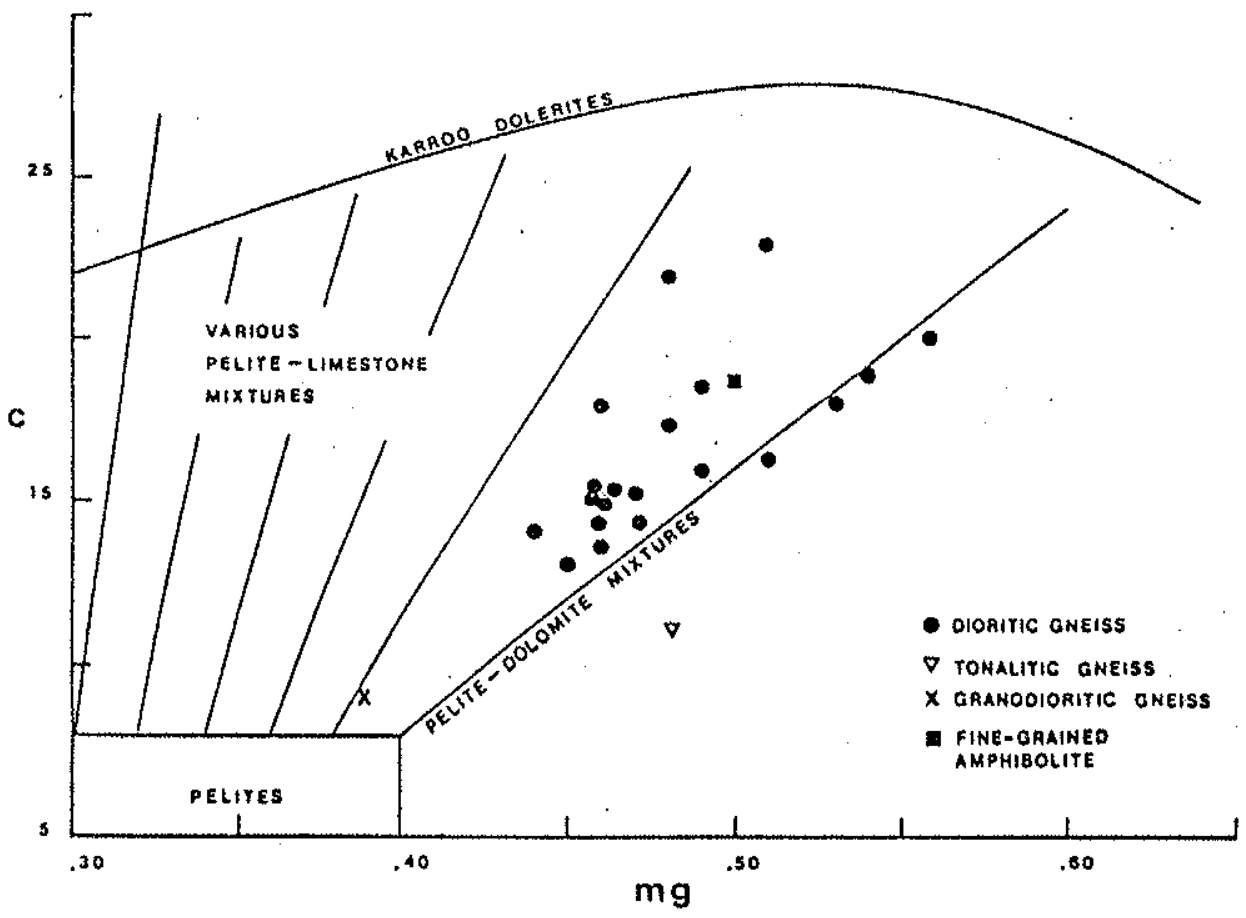

Fig. 96: Diagrama de Niggli $(c \times m g)$ para gnaisses quartzo-feldspāticos do Complexo Vila Nova, seg. Silva Filho (1984). 
BLOCOS SÃO GABRIEL E ENCRUZILHADA:

$A=$ Gnaisses dioríticos de Vila Nova

$B=$ Gnaisses tonalíticos trondhjemíticos de Vila Nova

$C=$ Granodioritos e adamelitos de Vila Nova

$D=$ Granitóides foliados do Bloco Encruzilhada

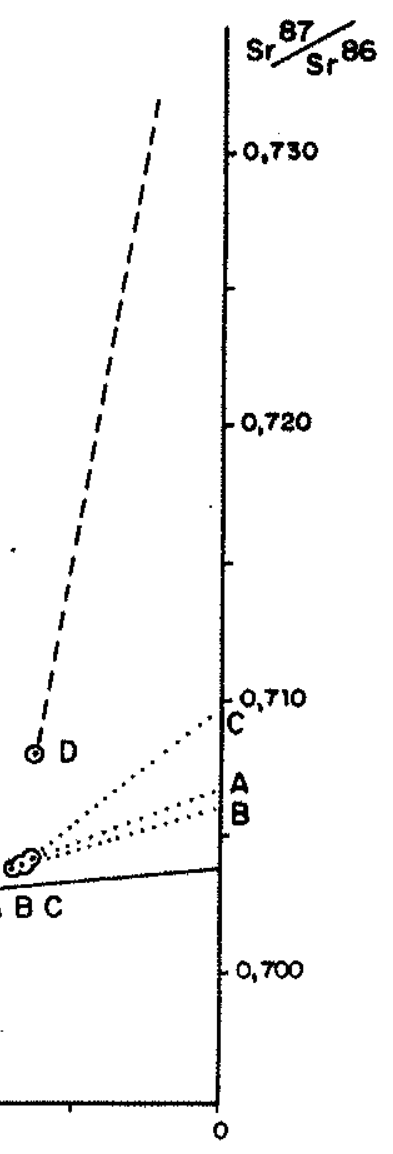

(b.a.)

Fịg. 97: Diagrama de evolução do Sr para granitöides dos blocos São Gabriel e Encruzilhada. 


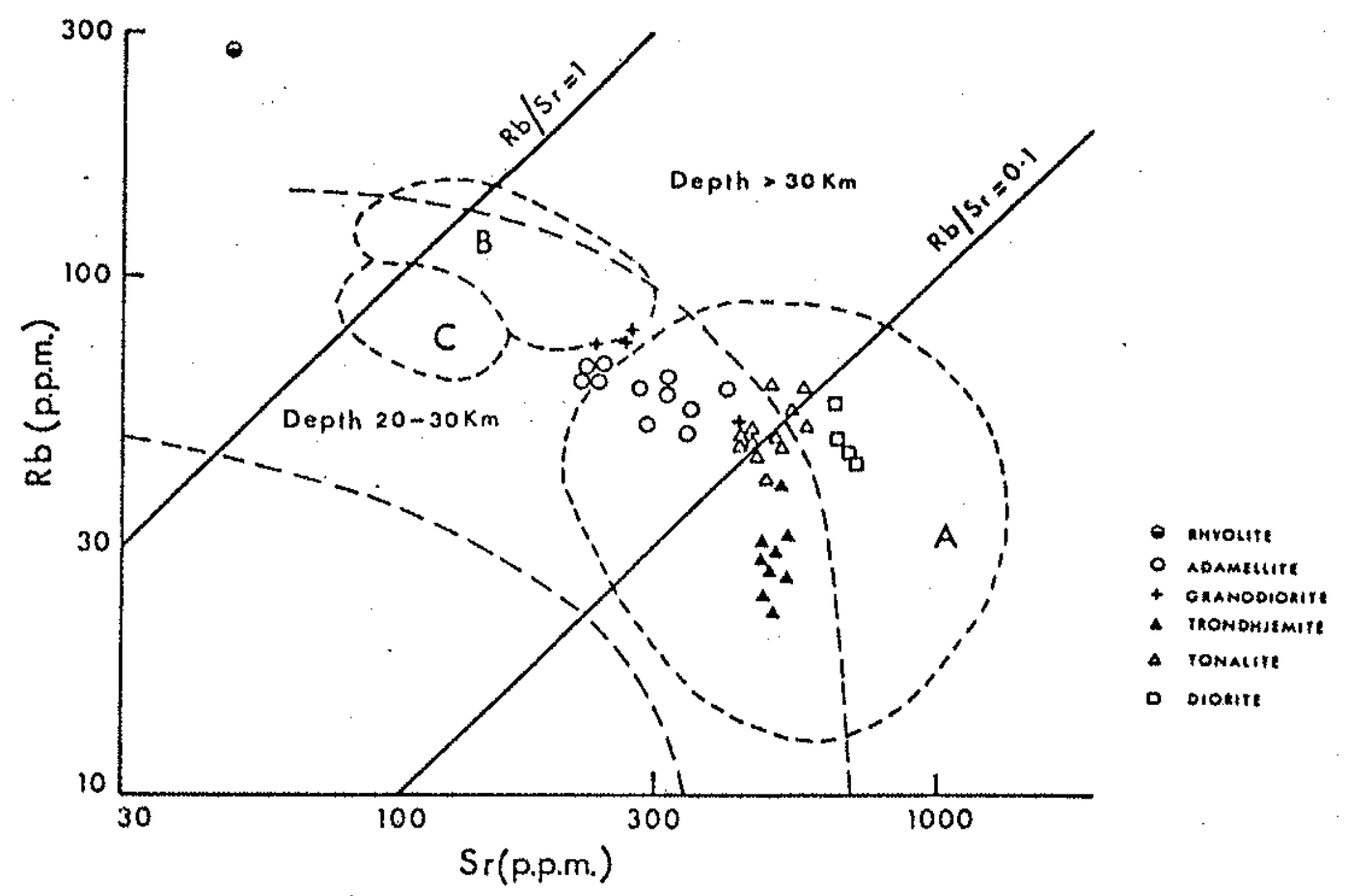

Fig. 98: Diagrama $\mathrm{Rb} \times \mathrm{Sr}$ de rochas intrusivas do Complexo Vila Nova. Os campos assinalados são para (A) trondhjemitos e quartzodioritos, (B) granófiros e riolitos da islândia e (C) granöfiros do Mar Vermelho (Coleman e Peterman, 1975). As linhas tracejadas separam campos distintos de profundidade de geração de magmas (Condie, 1973), seg. Silva Filho (1984).

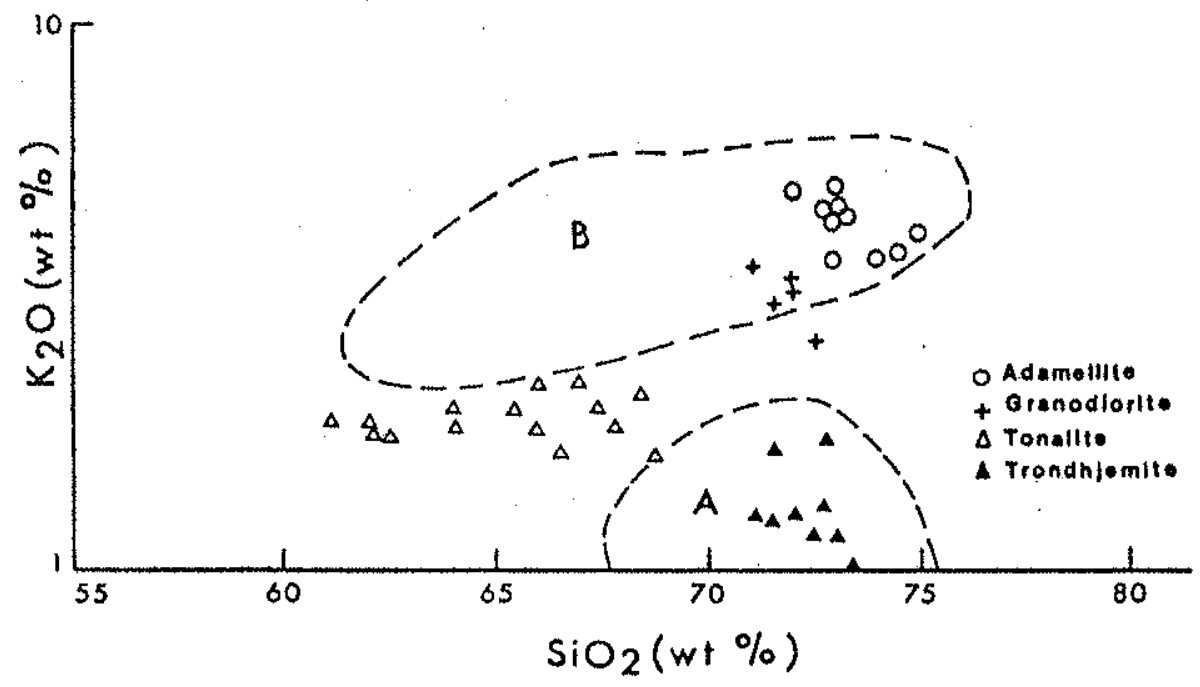

Fig. 99: Diagrama $\mathrm{K}_{2} \mathrm{O} \times \mathrm{SiO}_{2}$ de rochas intrusivas do Complexo Vila No va.comparadas com os campos de Coleman e Paterman (1975). (A) trondhjemitos continentais e (B) granöfiros continentais, seg. Silva Filho (1984). 


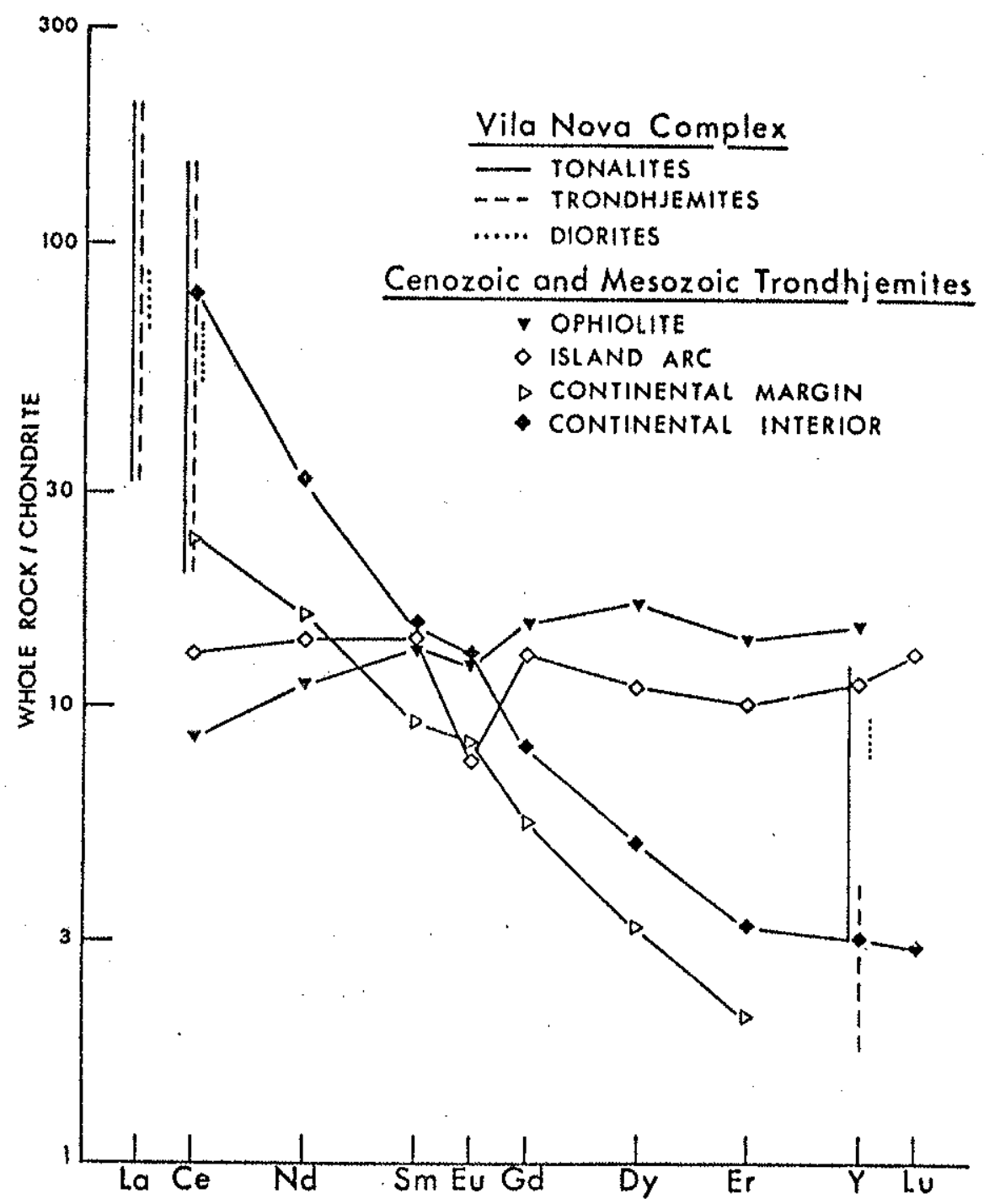

Fig. 100: Distribuição de La, Ce e $Y$ condrito-normalizados para diori tos, tonalitos e trondhjemitos do Complexo Vila Nova compa= rados com terras raras condrito-normalizadas de trondhjemitos de värios contextos tectónicos, seg. Silva Filho (1984). 


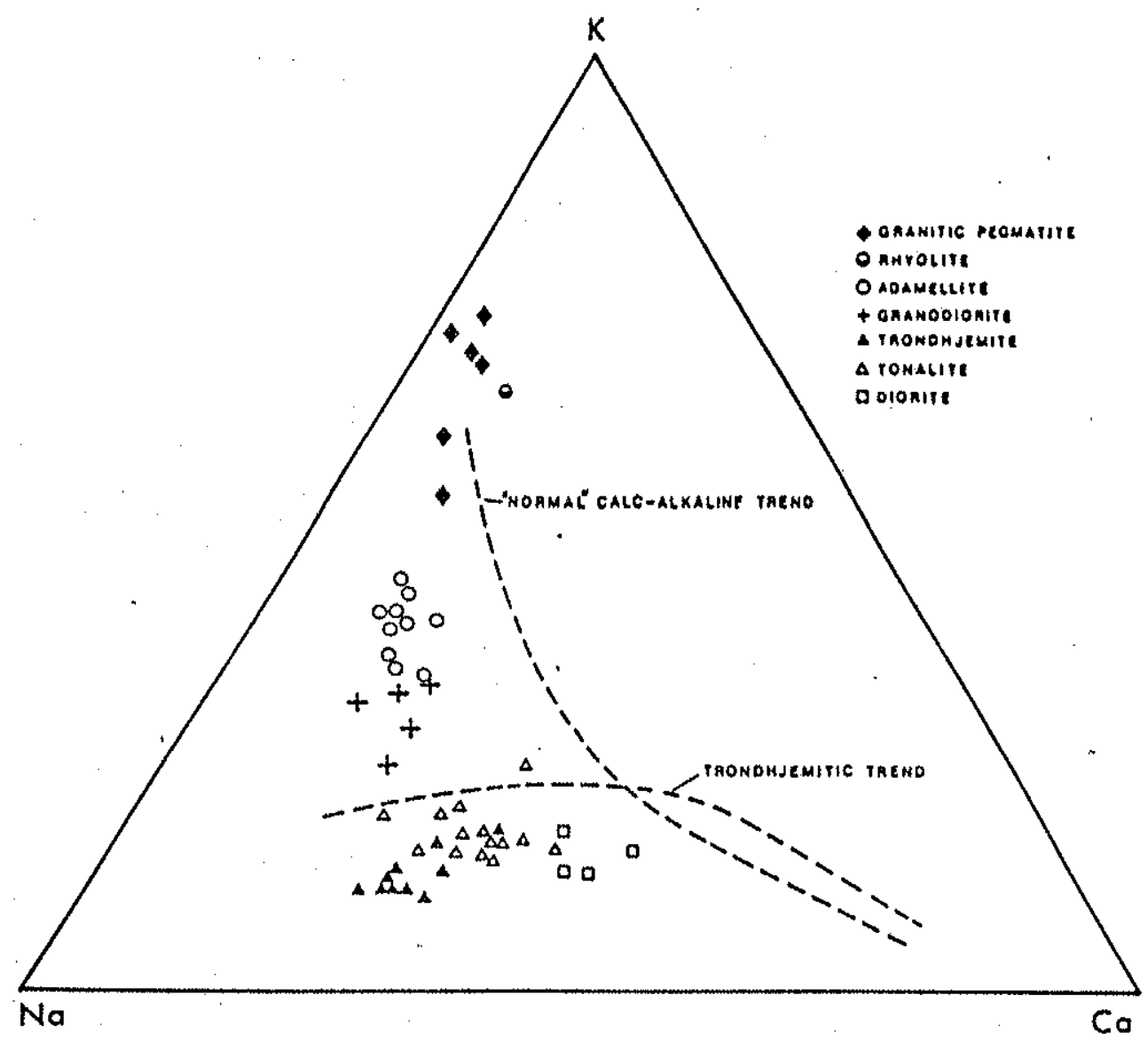

Fig. 101: Diagrama ternärio K-Na-Ca de rochas intrusivas do Complexo Vila Nova. As tendéncias calci-alcalina "normal" e gabro trondhjemitica da sulte do sudoeste da Finlândia (Nockolds e Allen, 1953; Barker e Arth, 1976, respectivamente), foram assinaladas para comparação, seg. Silva Filho (1984). 


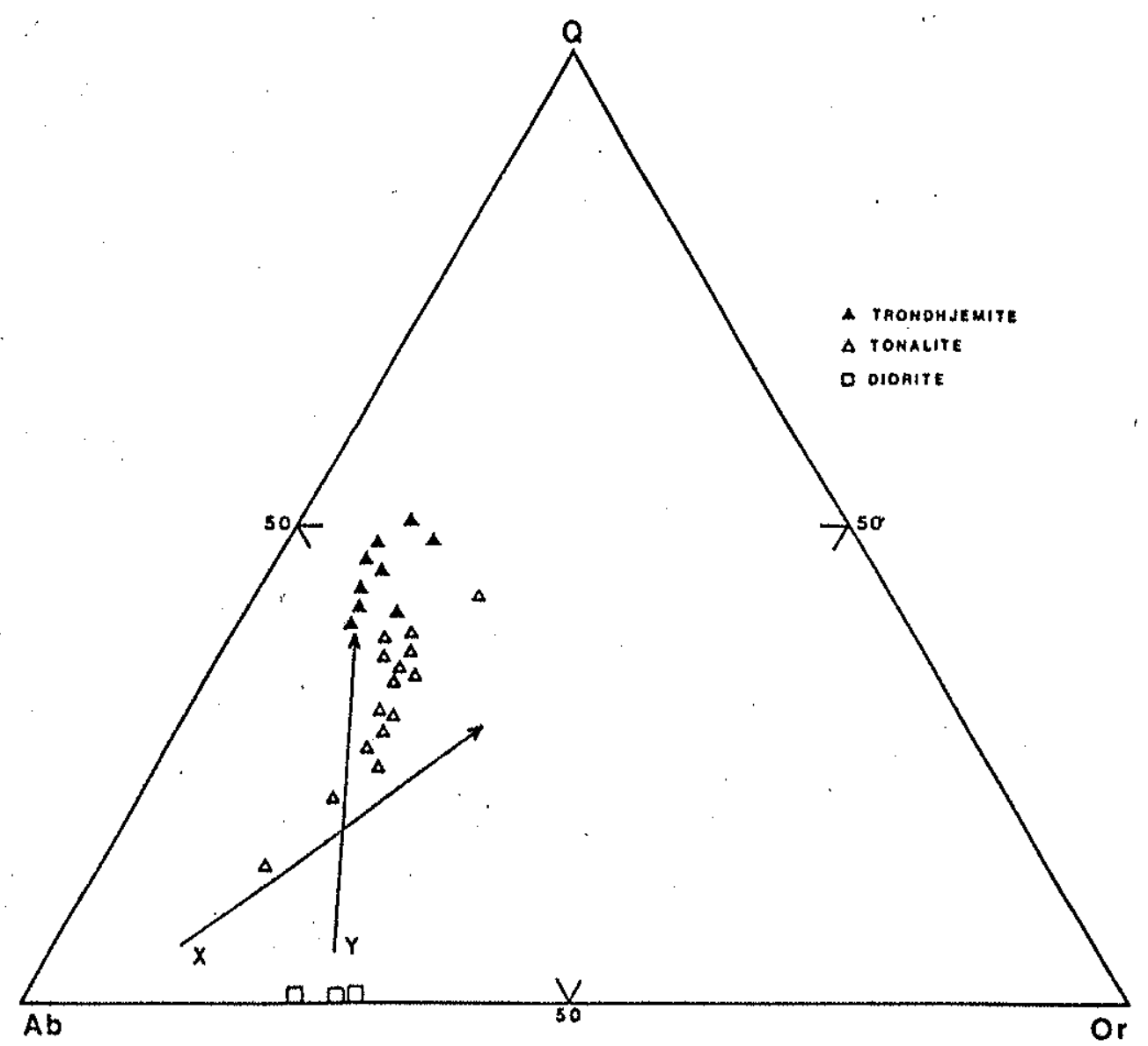

Fig. 102: Diagrama ternärio normativo $Q-A b-0$ r para rochas intrusivas do Complexo Villa Nova. As tendências calci-alcalina $(X)$ e trondhjemitica (Y) säo de Barker e Arth (1976), seg. Silva Fil ho (1984). 

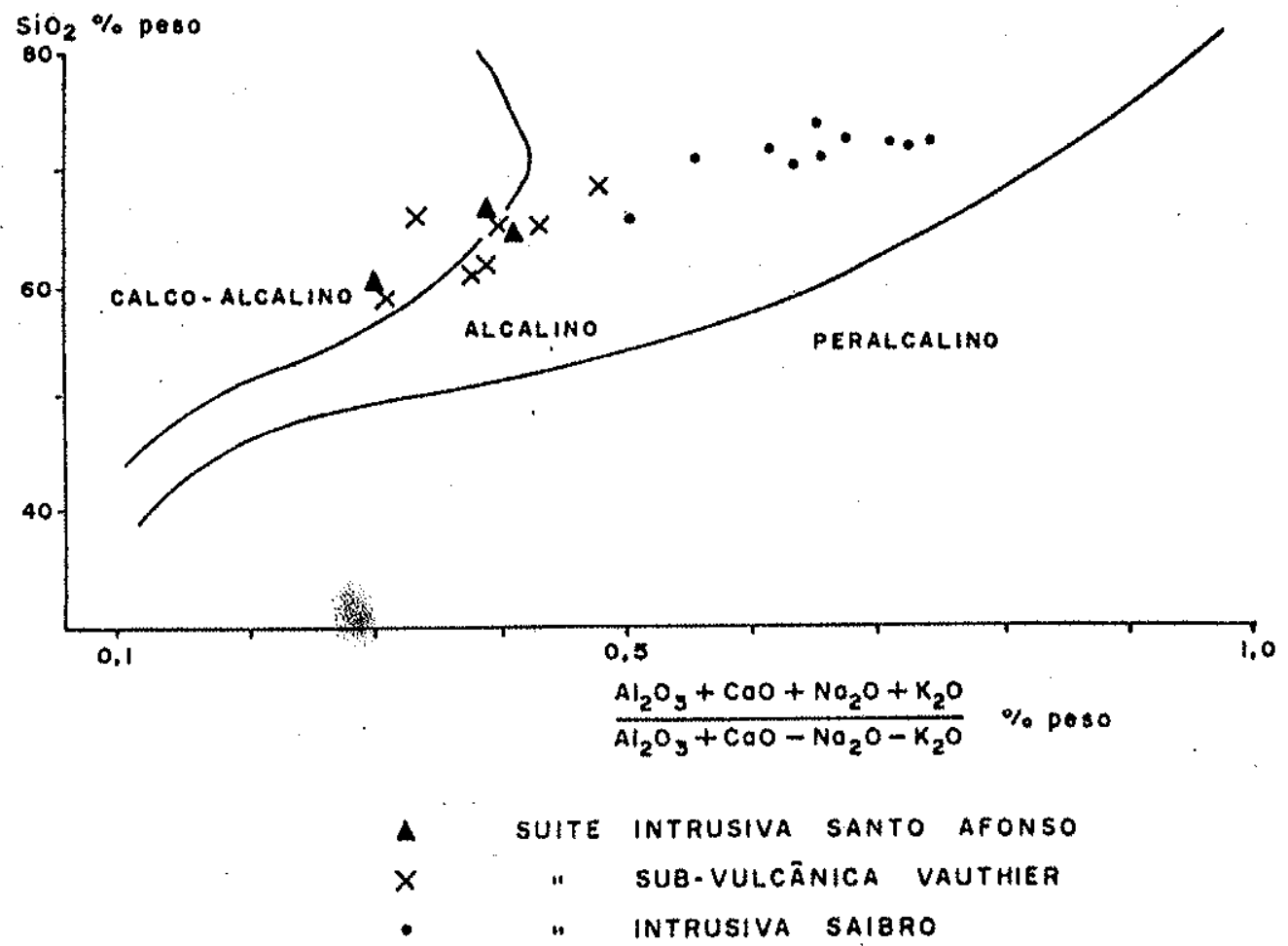

Fig. 103: Diagrama de Wright (1969) para as rochas graníticas do Blo co Taquarembö, seg. Hartmann e Nardi (1982). 


\section{BLOCO TAQUAREMBO}

$A=$ Complexo Gronulítico Santa Morio Chico

$B=$ Gnaisses da regiăo do Arroio do Tigre

$C=$ Complexo Gronitico Santo Afonso

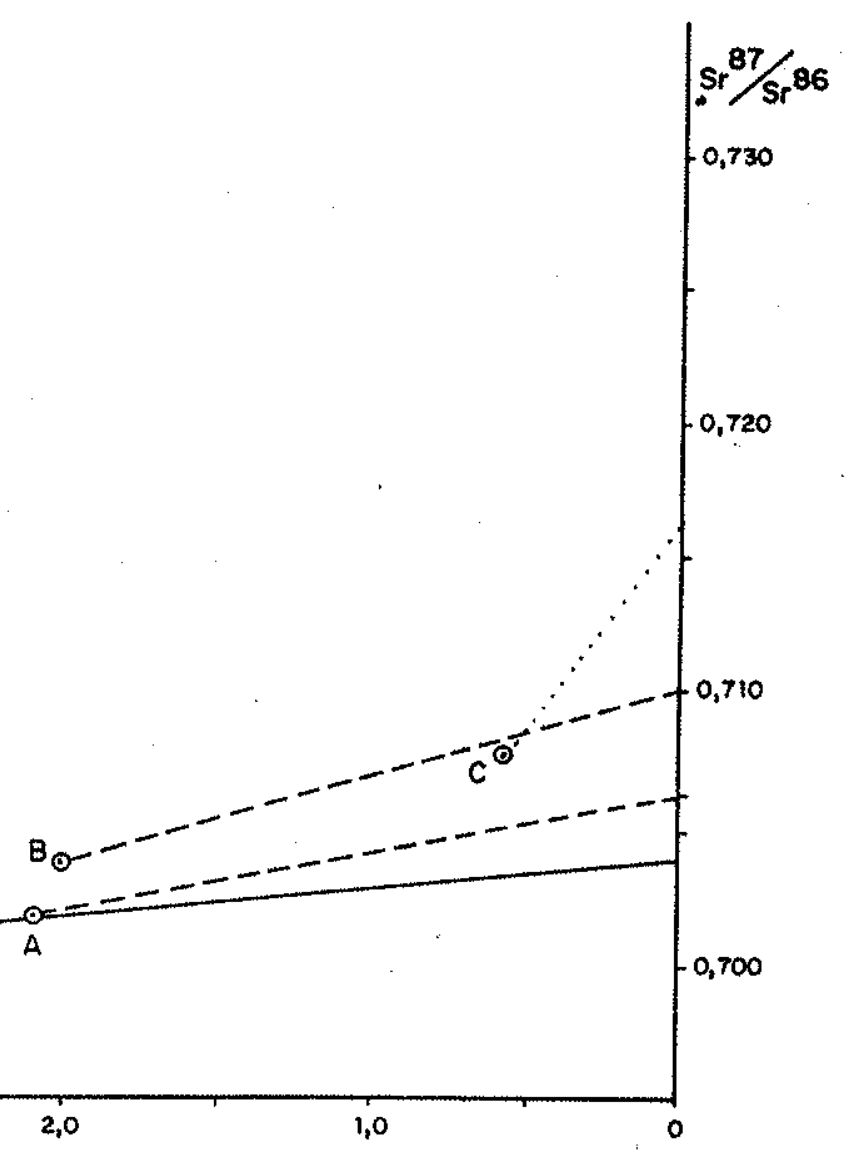

Fig. 104: Diagrama de evolução do Sr de rochas do Bloco Taquarembó. 


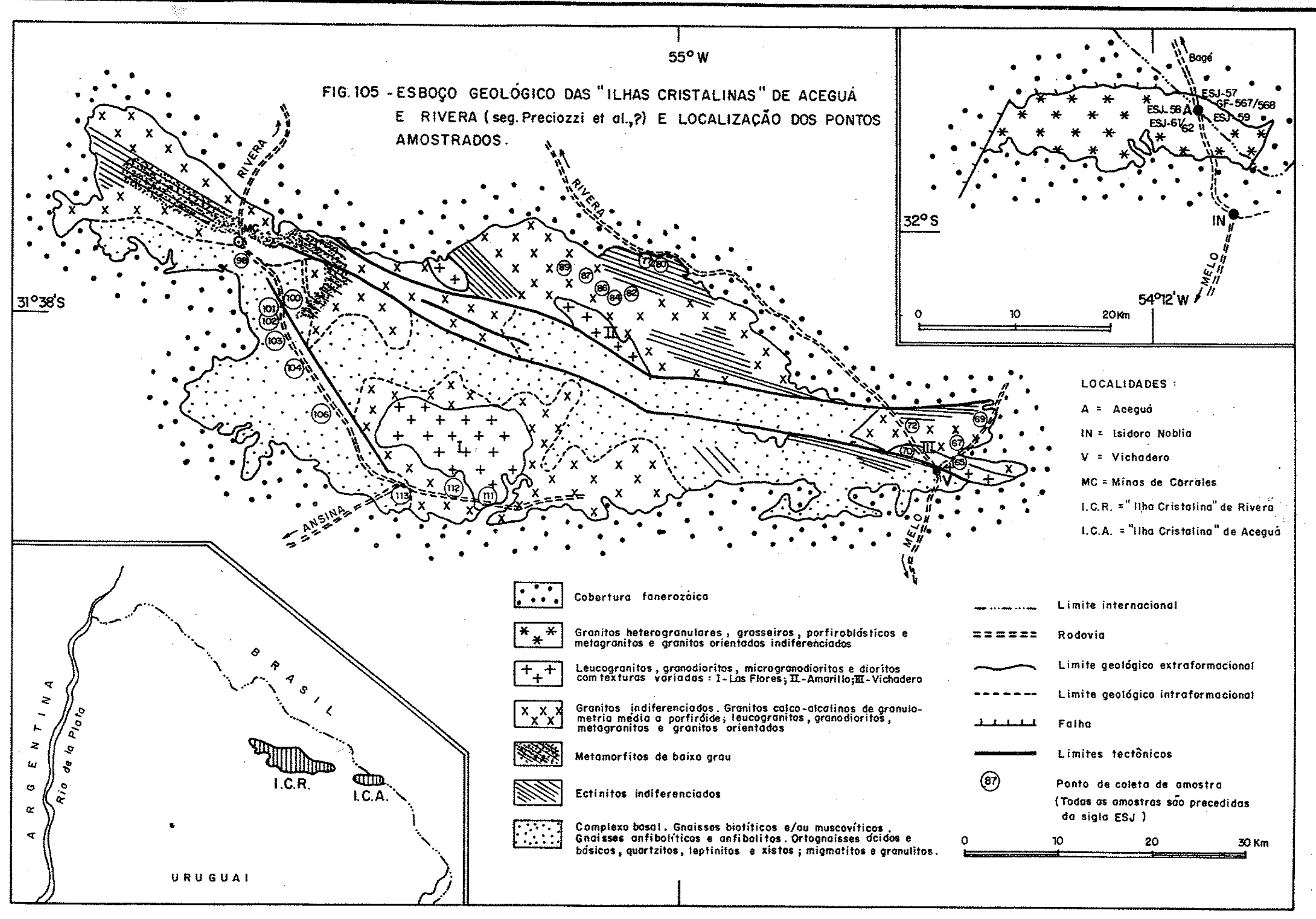




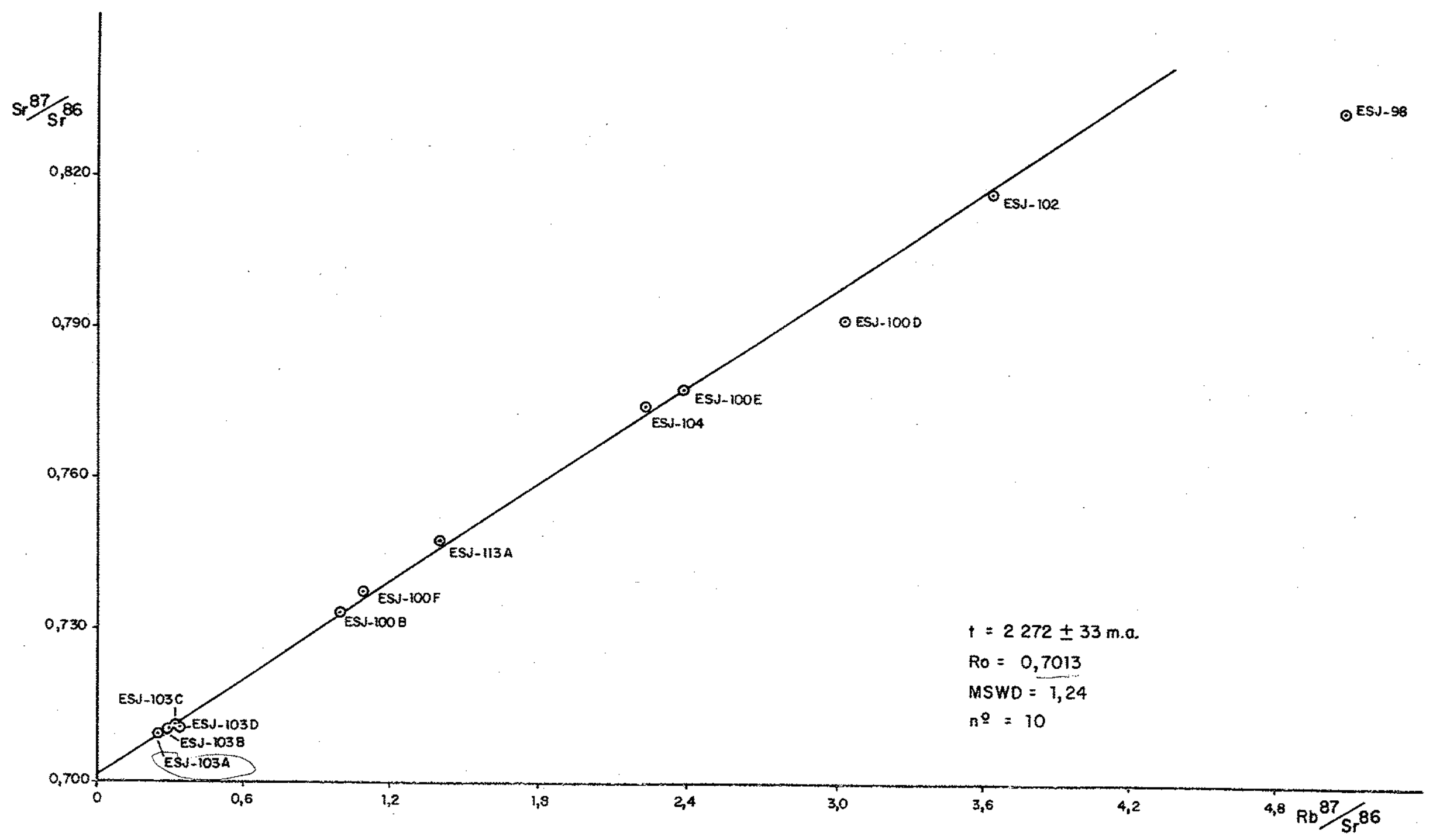

Fig. 106: Diagrama isocrônico Rb-Sr de referência de metagranitōides quartzo-feĺdspäticos das proximidades de Mi nas de Corrales, "ll tha Cristalina" de Rivera, Uruguai. Os pontos ESJ-98 e ESJ-100 D, por revelarem indícios de alterações intempéricas, não foram considerados para o cálculo da idade. 


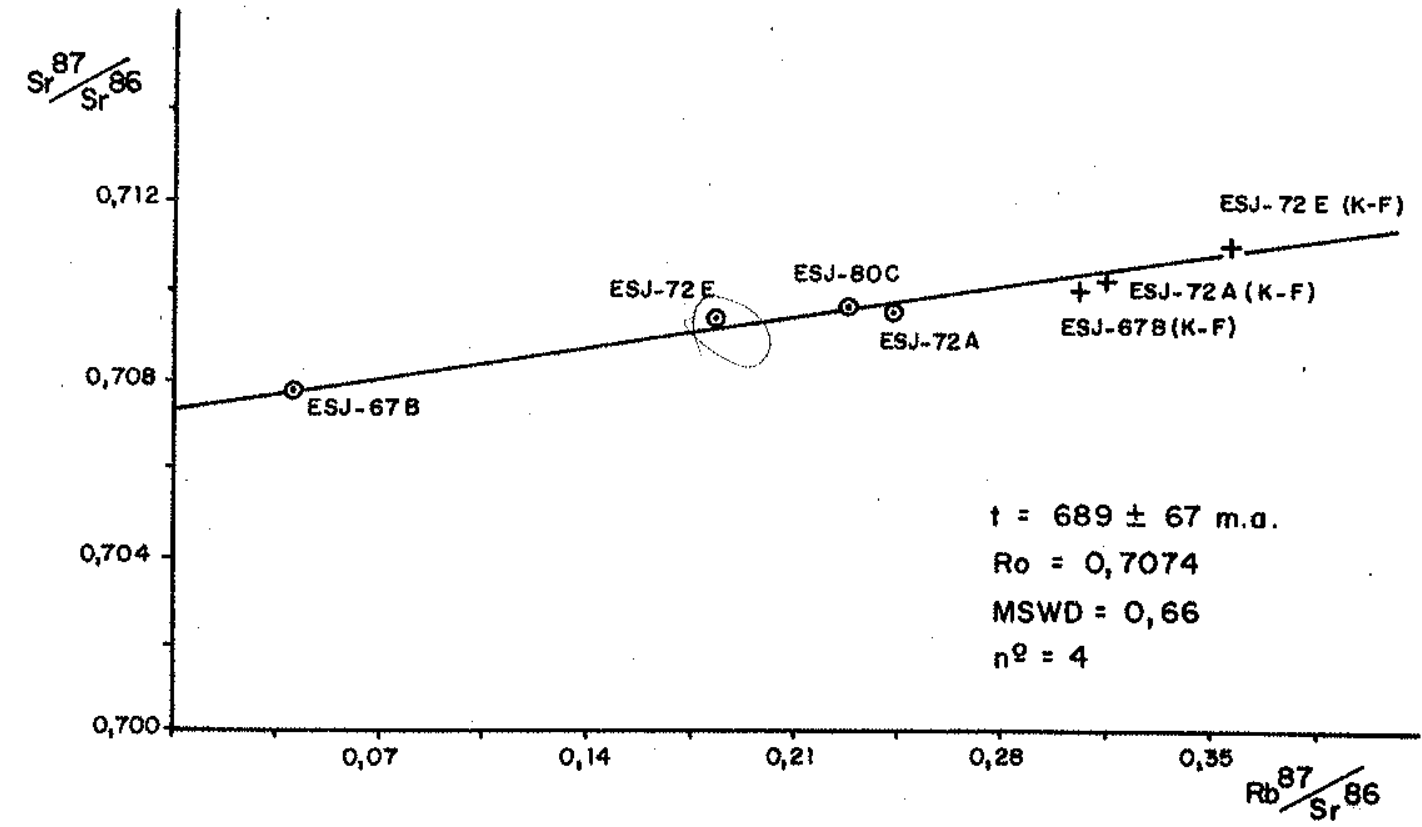

Fig. 107: Diagrama isocrōnico Rb-Sr de referência de granitōides porfirit licos das proximidades de Vichadero e cabeceiras do Arroio Amarillo, "ll ha Cristalina" de Rivera, Uruguai. Os pontos K-F

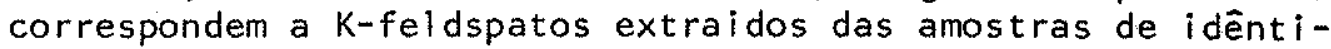
ca nomenclatura.

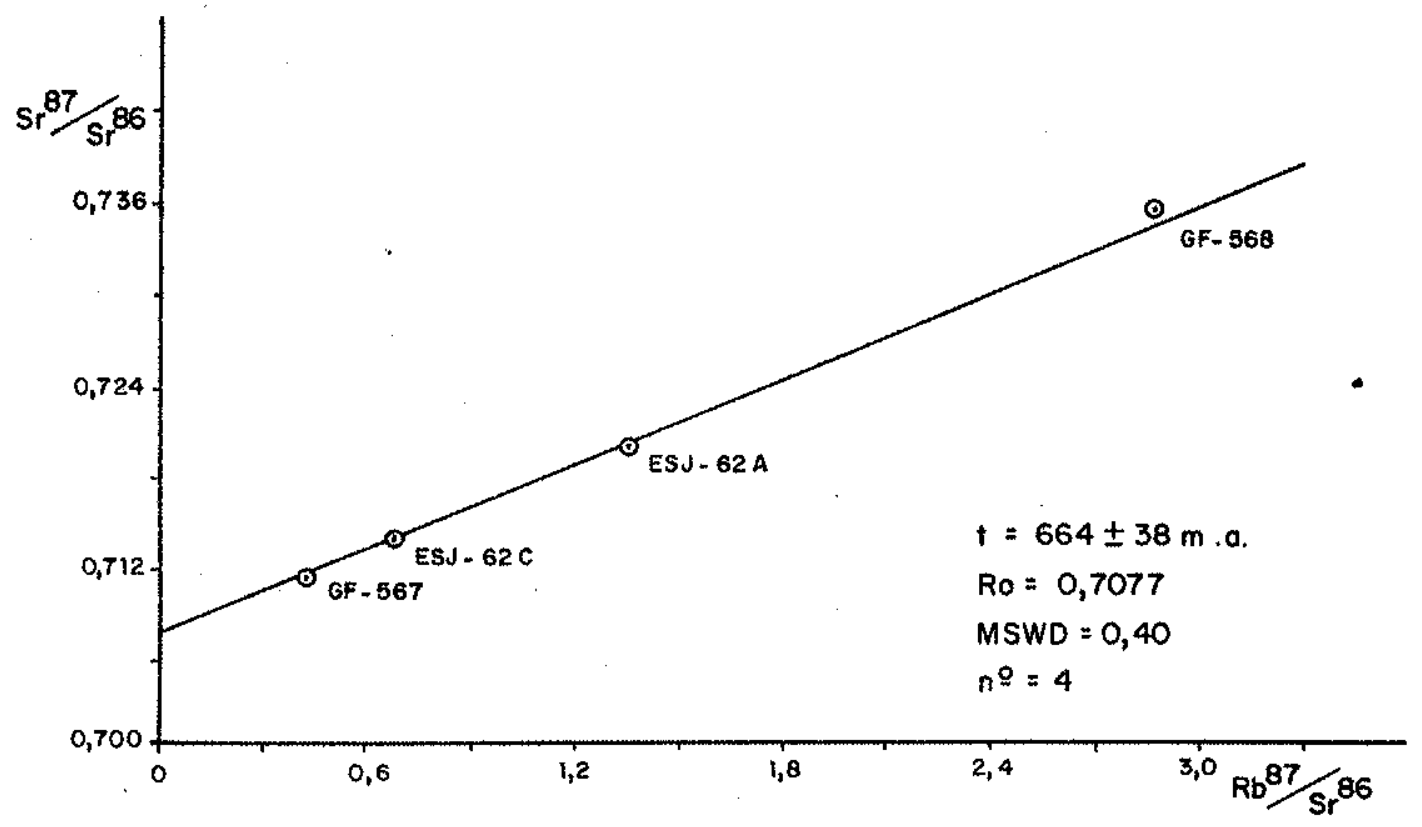

Fig. 108: Diagrama isocrônico Rb-Sr de referência de granodioritos da "ll ha Cristalina" de Aceguá, Brasil/Uruguai. 


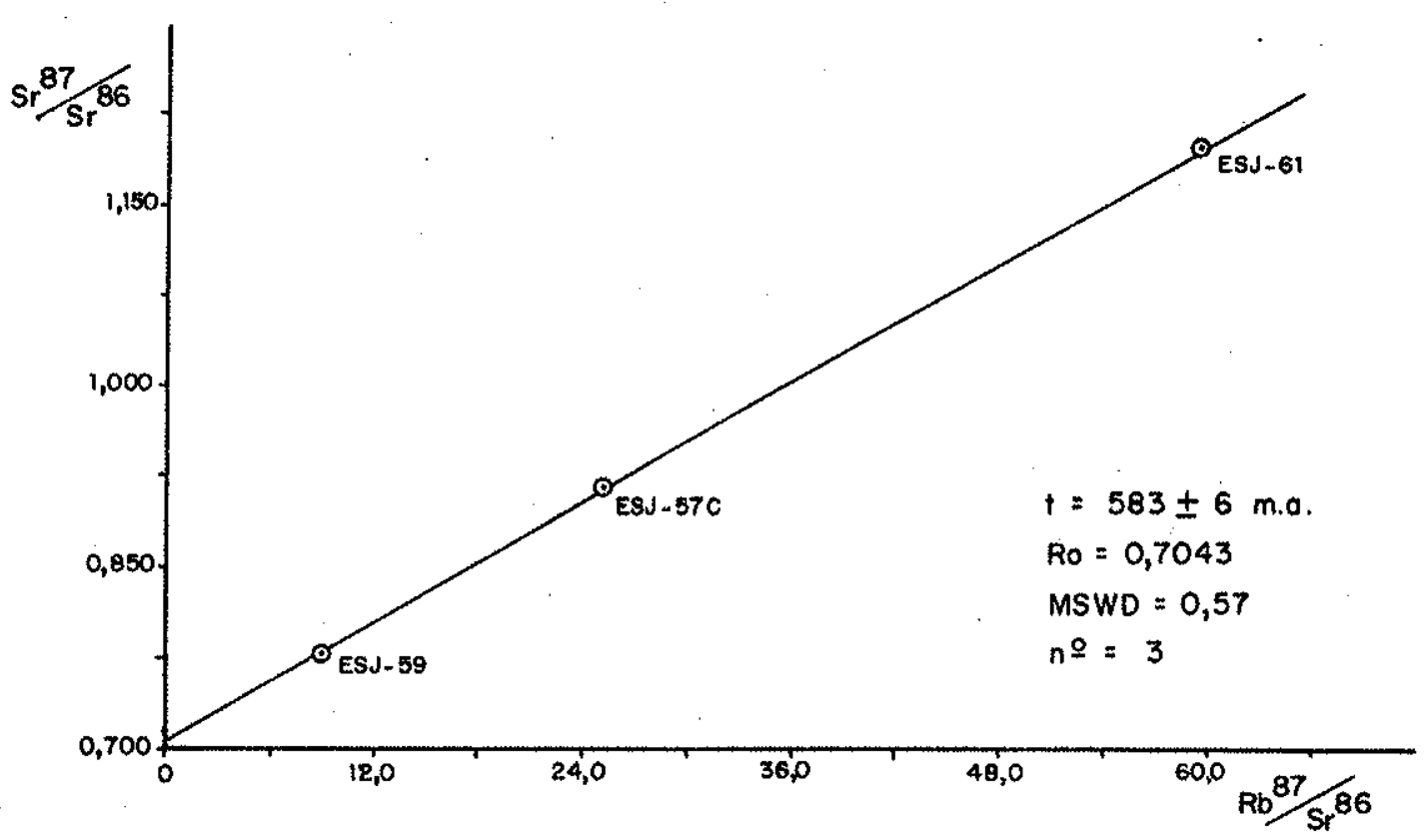

Fig. 109: Diagrama isocrônico Rb-Sr de referência de K-feldspato granitos da "llha Cristalina" de Aceguä, Brasil/Uruguai. 
"IlHAs cRistalinas" oe rivera e aceguá

$A^{\prime}=$ Metagranitóides cataclásticos do Rota 28 (Rivera)

$B=$ Granitóldes porfiríticos de Vichadero e Arroio Amorillo

$C=$ Granodioritos de Aceguá

$D=K$-feldspato granitos de Acegud

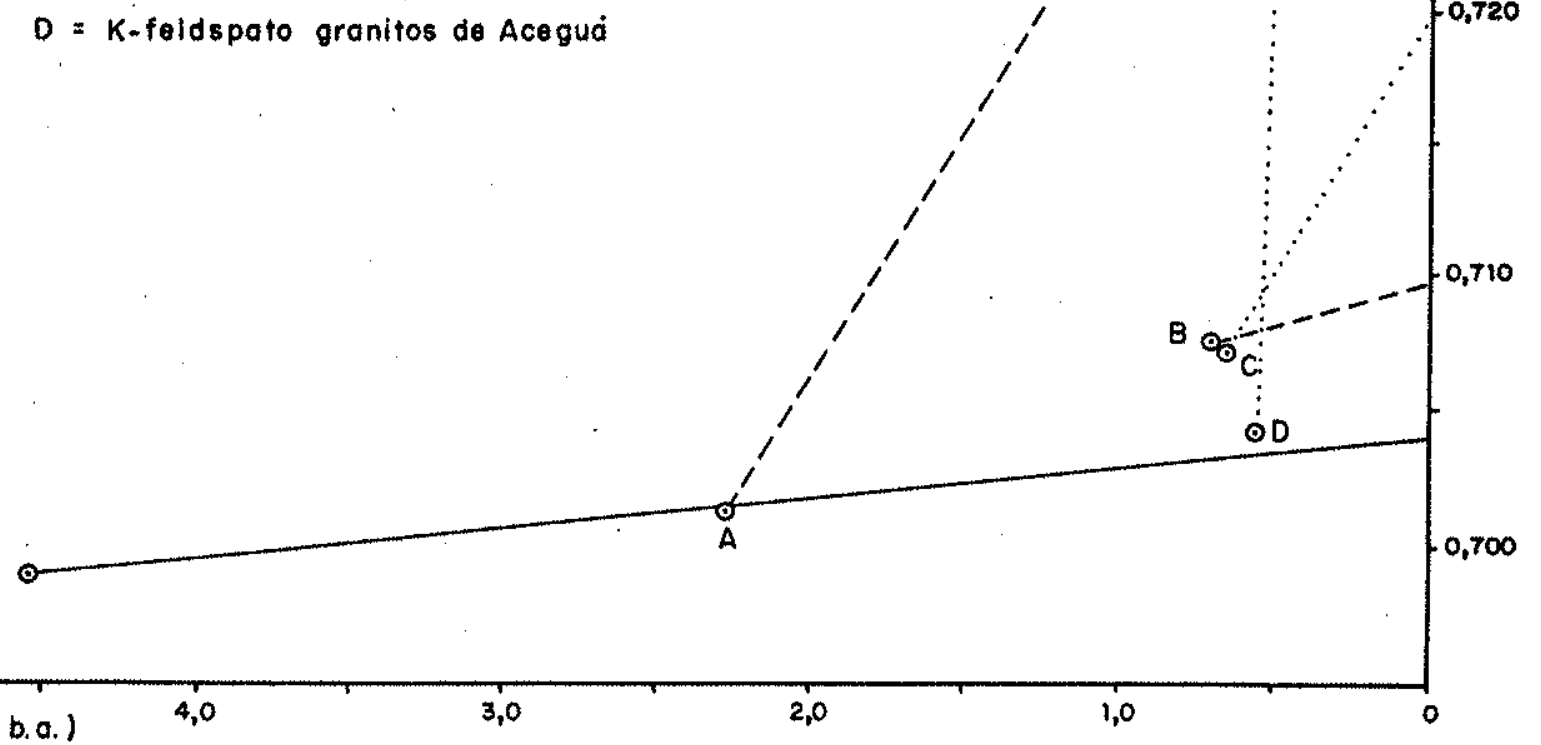

Fig. 110: Diagrama de evolução do Sr de metagranitōides e granitóides das "ilhas cristalinas" de Rivera e Aceguä. 
COMPLEXO DE SÄO SEPÉ :

$A=$ Granito-monzonitos da parte central

$B=$ Granitos subalcolinos periféricos

$C=$ Microgranitos de intrusốes menores

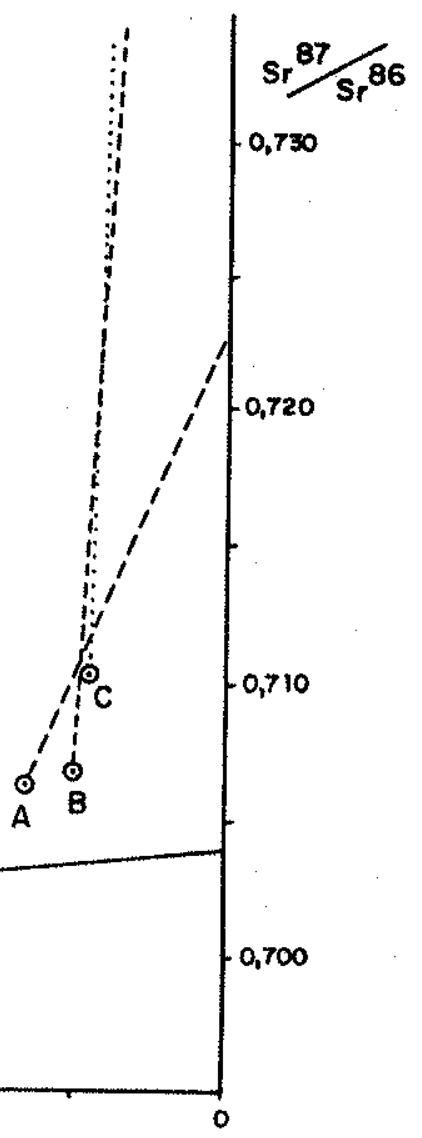

\begin{tabular}{lllll}
\hline (b.a. 4,0 & 3,0 & 2,0 & 1,0 & 0
\end{tabular}

Fig. 111: Diagrama de evolução do Sr de granitöides do Complexó Graniti co de São Sepé. 
COMPLEXO de LAVRAS DO SUL E Jaguarí

$A=$ Granodioritos e monzogranitos da porçăo central

$B=$ Pertita - granitos da porção periférica

$C=$ Sienogranitos Jaguari

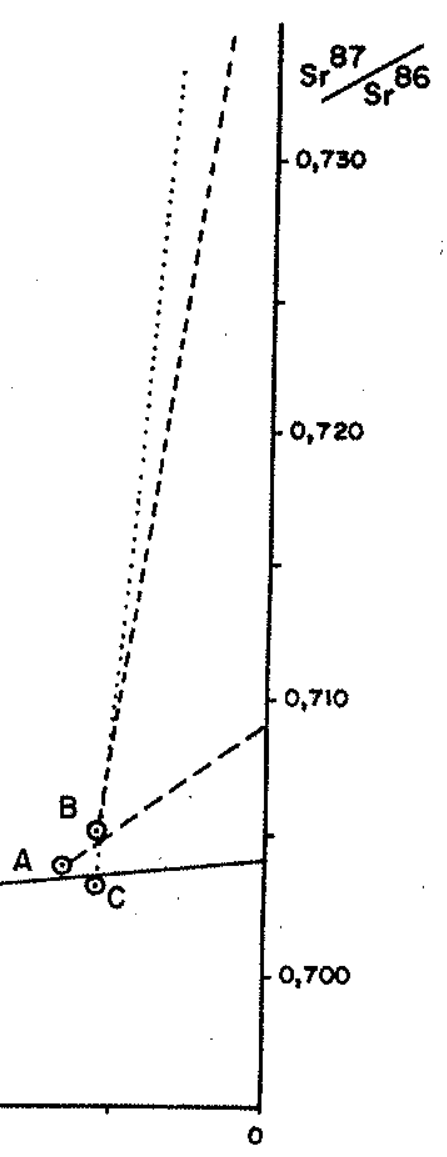

Fig. 112: Diagrama de evolução do Sr de granitöides do Complexo Granítico de Lavras do Sul. 
Fase pré-orogênica

1000-850 m.a.(?)

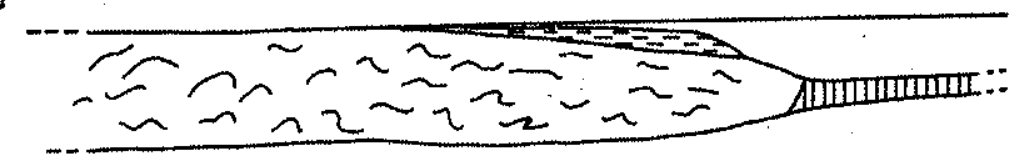

Fase extensiva

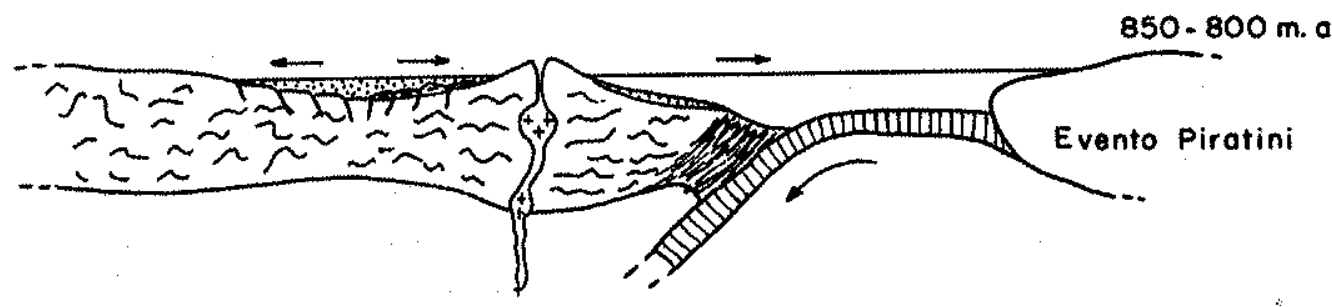

Fase vulcânica e sedimentar

(Inicio da fase colisional)

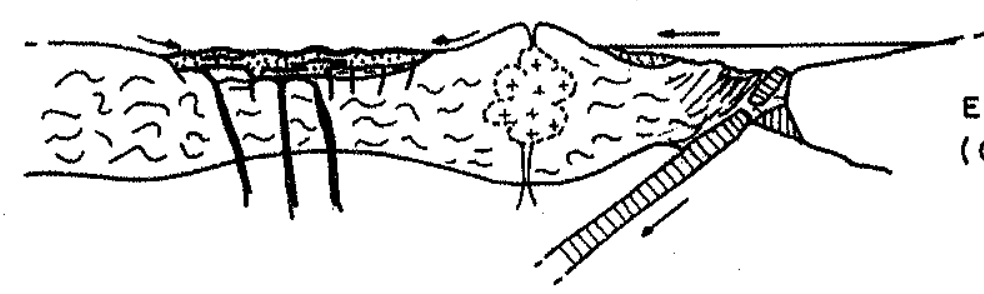

$800-750$ m.a.

Evento Pinheiro Mochado (Granitóides deformados)

Fase colisional e fechomento da bacia (deformaçăo - granitoides sınorogênicos

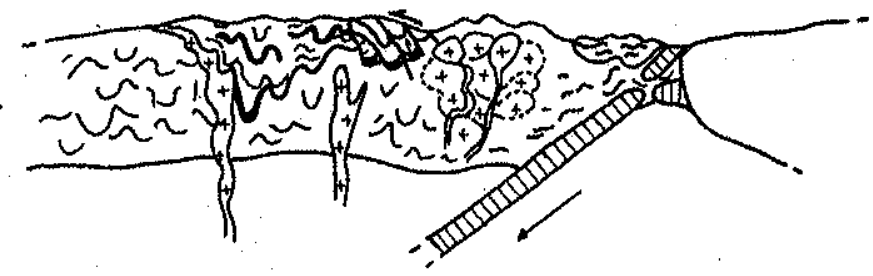

$750-650$ m.a.

Evento Pinheiro Machado (Granitoides isótropos) e Evento Vila Nova

Intrusăo dos granitos potássicos a magmotismo termina!
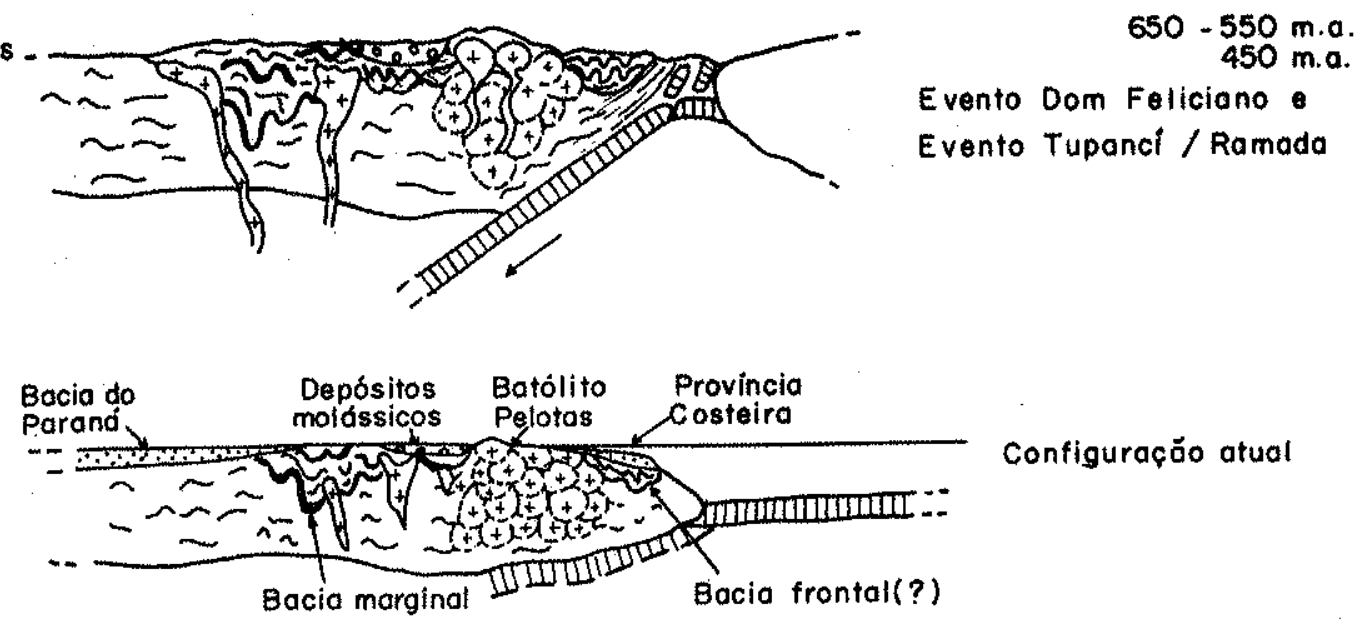

Configuraçóo atual

Fig. 114: Evolução geotectônica esquemática do Cinturão Dom Feliciano no Estado do Rio Grande do Sul. A construção das seções geo lógicas transversais à faixa mövel foram baseadas em Tarney et al. (1976). 


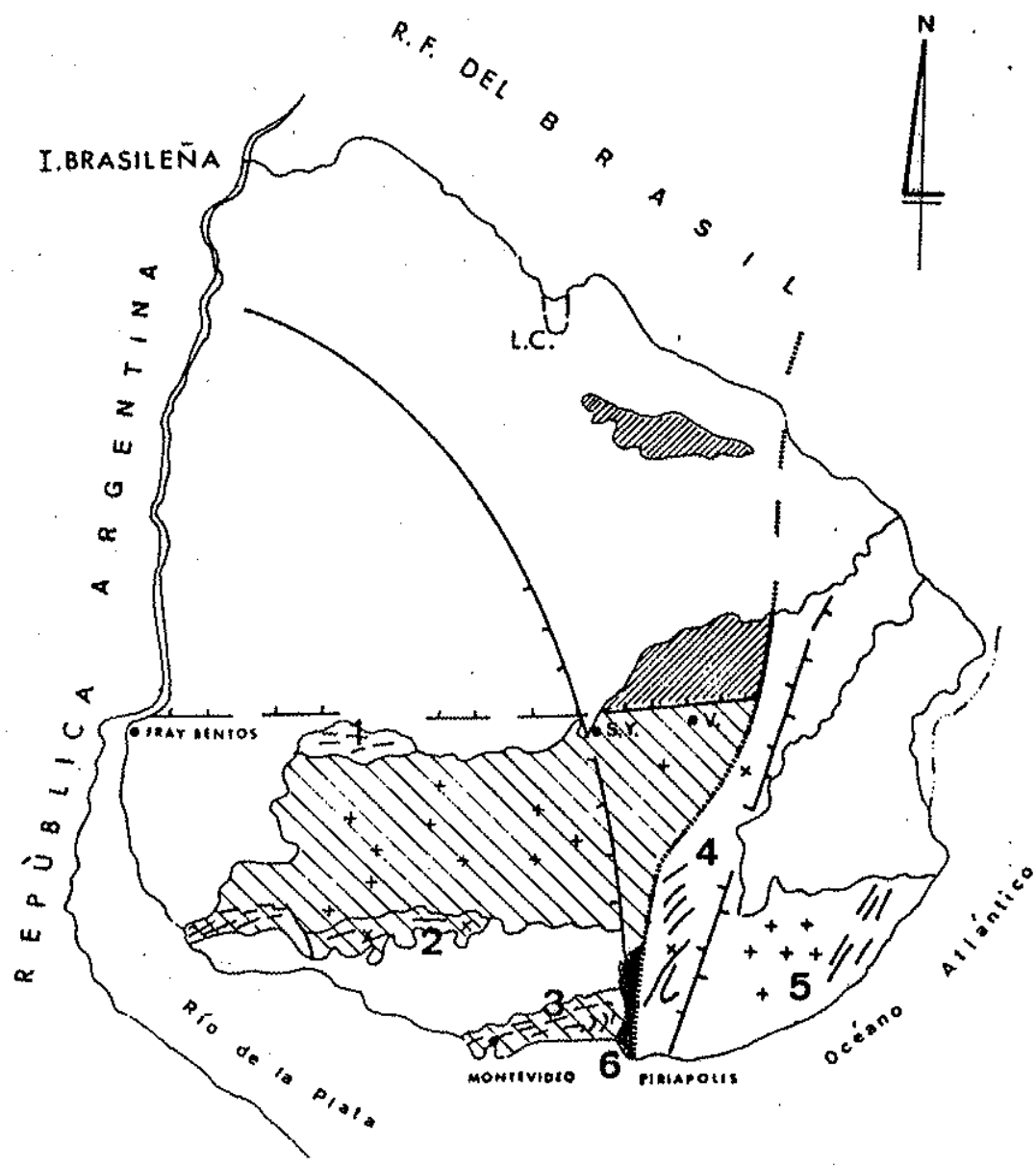

REFERENCIÁS

$\begin{array}{llll}1 . & 4 . & 7 \square+ & 10 \square \square \\ 2 . & 5 . & 8 . \square x & 11 \square \\ 3 . & 6 . & 9 \square \mathbb{B} & 12 \ldots\end{array}$

Referencias: 1 Formación Arroyo Grande 2 Formación Paso Severino - 3 Formación Montevideo - 4 Grupos Lavalleja y Carapé 5 Grupo Rocha - 6 Formación Sierra de Anímas - 7 Granitos sin-orogénicos - 8 Granitos postorogénicos - 9 Núcleo primitivo (tentativo) - 10 Cíclo orogénico antiguo - 11 Ciclo orogénico moderno - 12 Limite orogénico - SY Ciudad de Sarandí del Yi - V Pueblo Valentines. L. C. Límite Contestado. Aprobado por el S.G.M. Res. 8/1983.

Fig. 115: Principais unidades prë-Devonianas do Escudo Uruguaio, seg. Bossi (1983). 


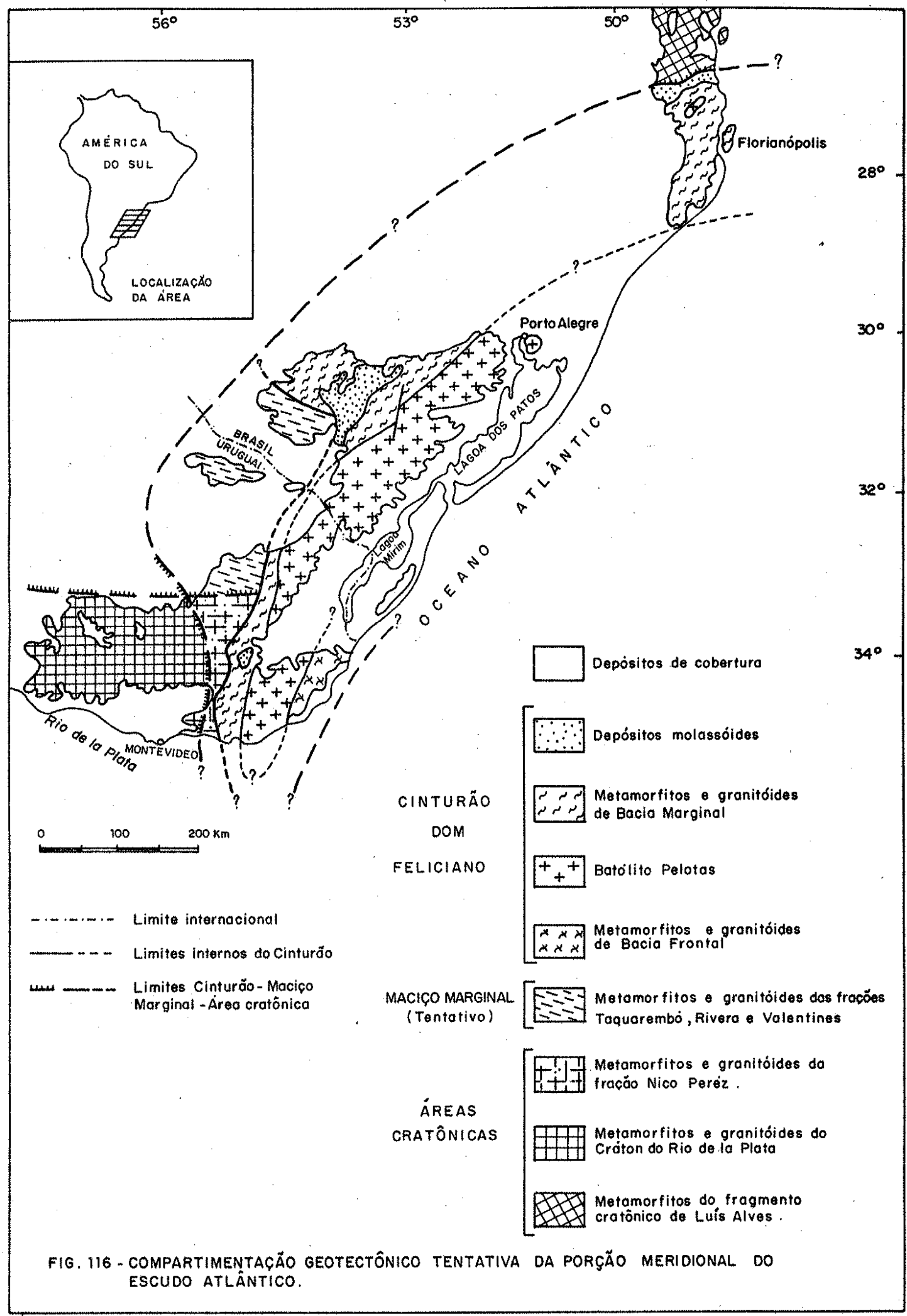



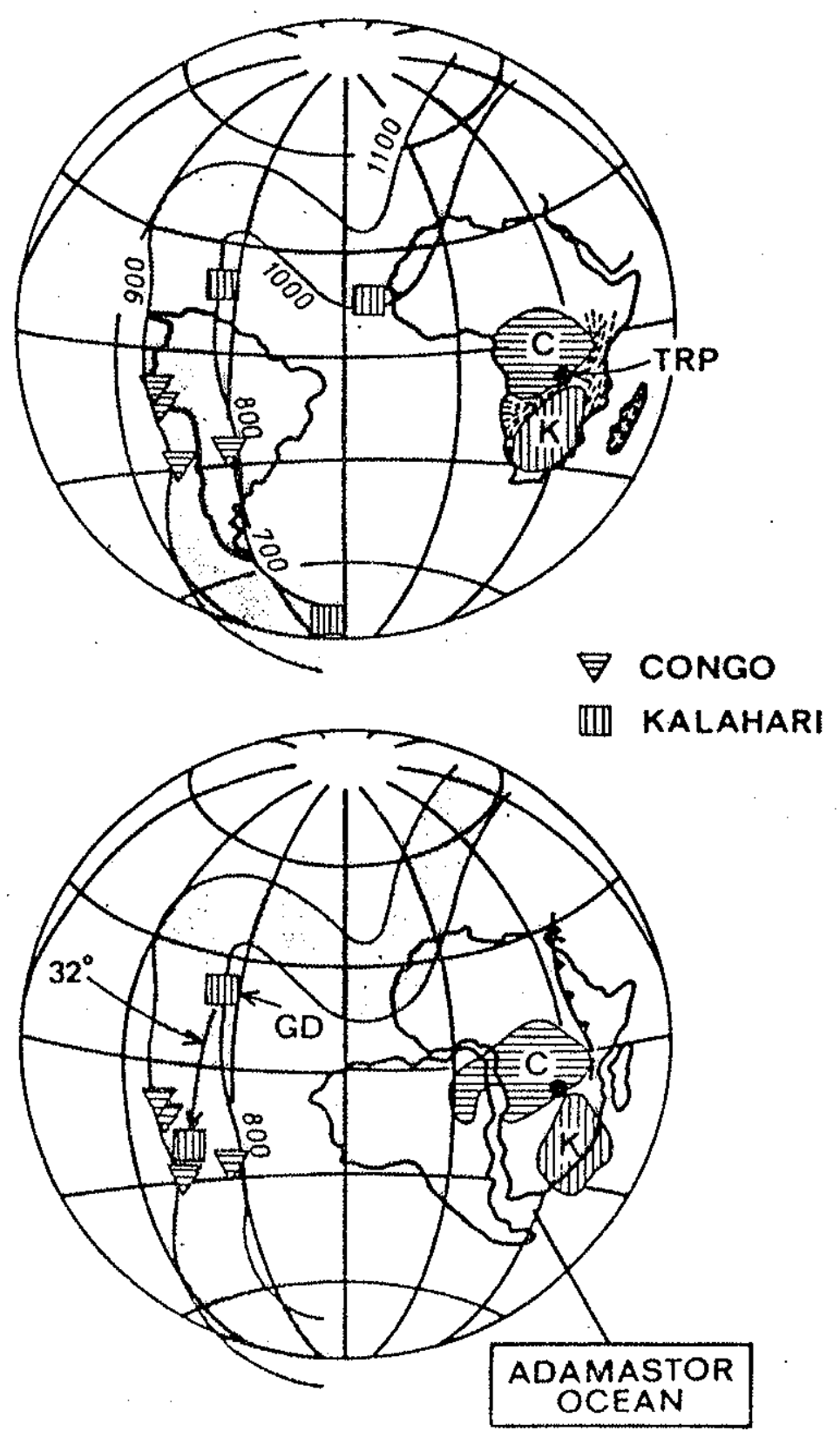

Fig. 117: Evolução geodinâmica da Província Damara por fechamento do oceano Adamastor, seg. Hartnady et al. (1985). TRP é um pö lo de rotação tectônica entre os crätons Kalahari e Congo, do Proterozóico Superior. 


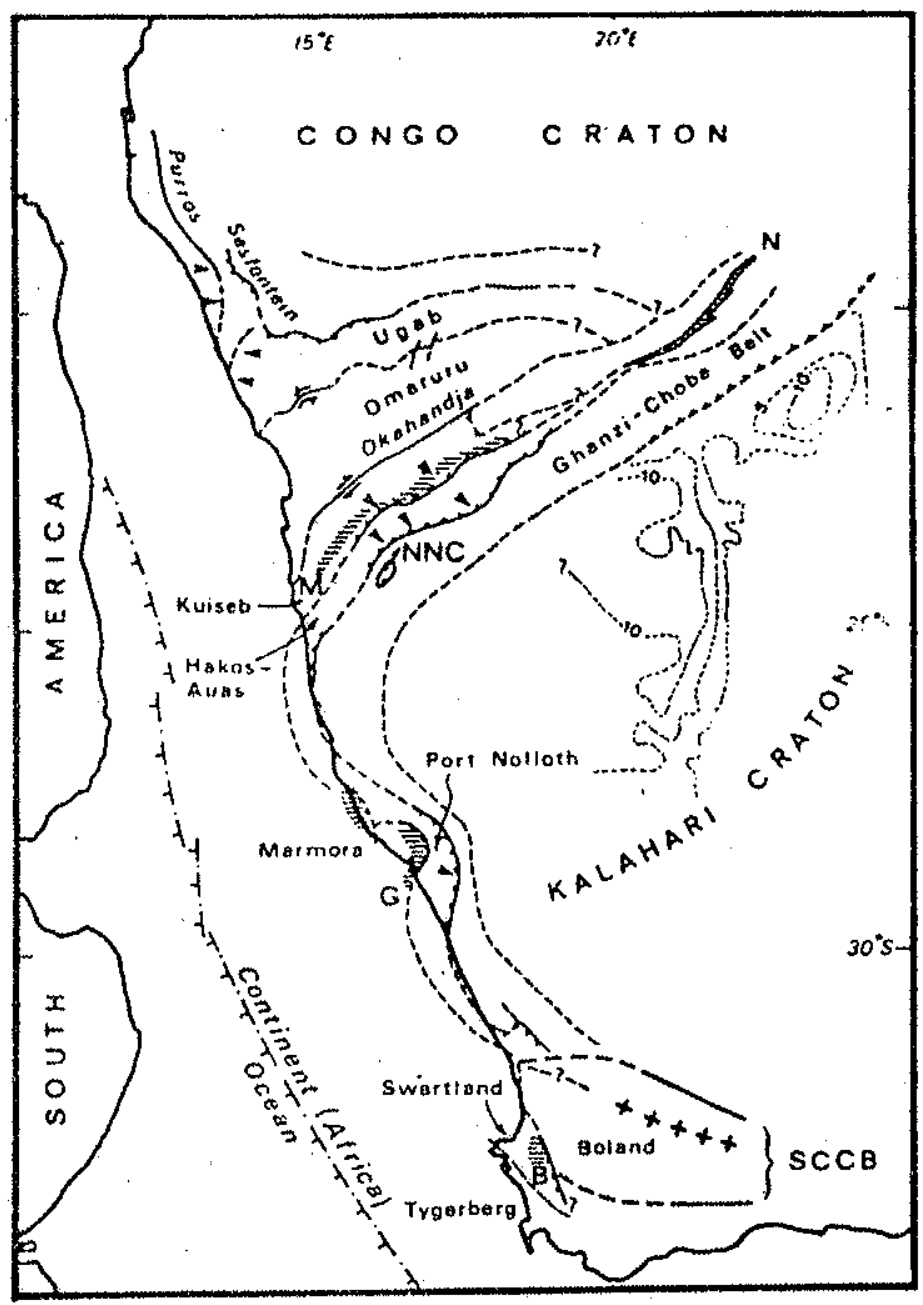

Fig. 118: Configuração tectôncia da Provincia Damara, SW da Africa, seg. Hartnady et al. (1985). SCCB = "Southern Cape Conduc tive Belt". As hachuras horizontais representam relictos oceâni cos da geossutura Adamastor: $N=$ corpo bäsico de No kaneng; $N N C=$ Complexo Naukluft Nappe; $M=$ Anfibolito Mat chless; $G=$ metabasalto, Grootderm; $B=$ metabasal tos Budgetown. $M, G$ e $B$ associam-se a importantes anomalias gravimëtricas na plataforma continental interna (linhas tracejadas). As setas apontam a vergência tectônica. 


\section{LEgENDA PARA AS TABELAS DE PONTOS ANALITICOS K-Ar, Rb-Sr, Pb-Pb E TRACOS DE FISSAYO DE UNIDADES ROCHOSAS DOS ESCUDOS SUL-RIO-GRAN- DENSE E URUGUATO.}

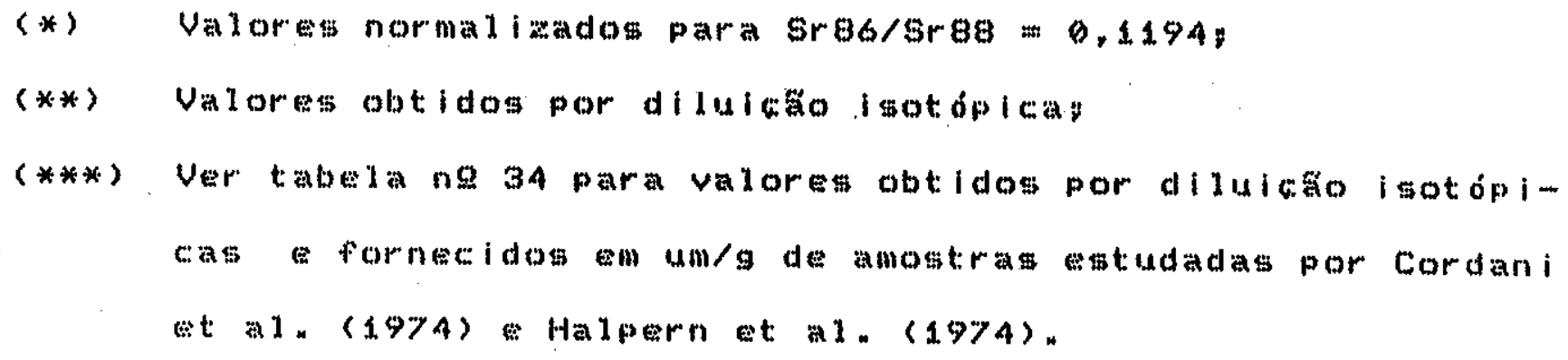

Constantes ut itiondas

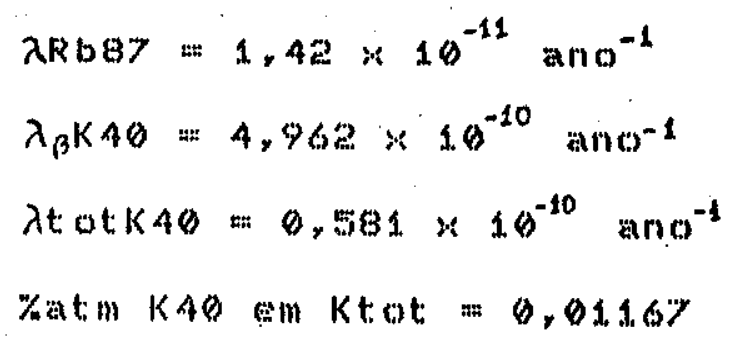


Refer ancian:

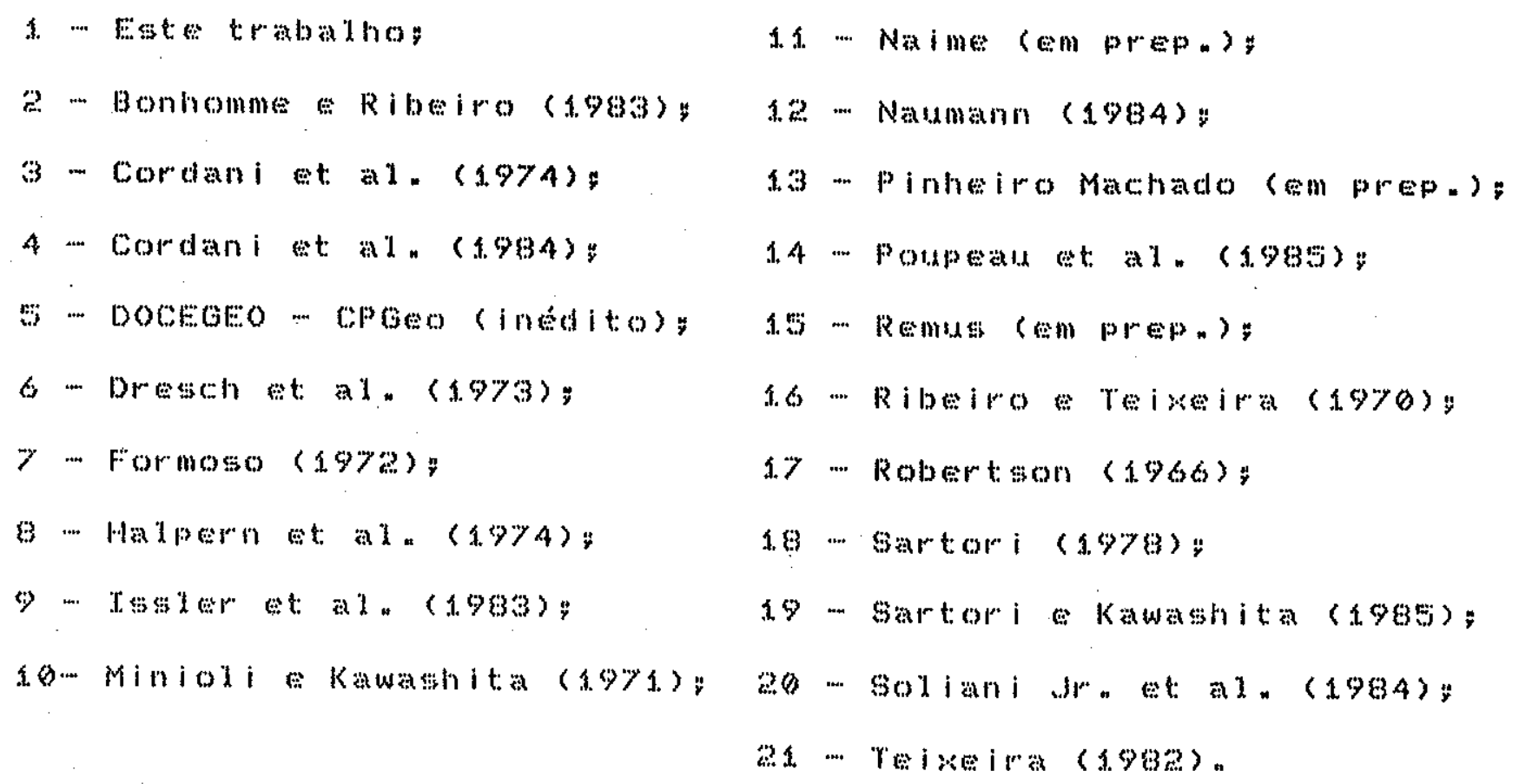

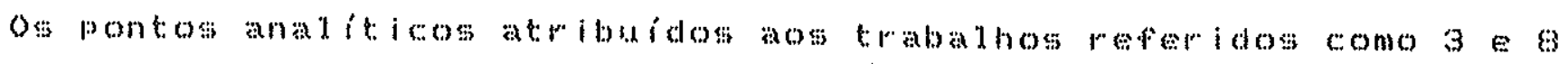
ra 1 ista a sre7/srgo talculatos como um valor medio estatistico fixado, res...

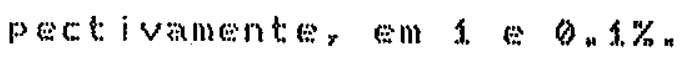




\begin{tabular}{lll}
\hline Int. standard & $\begin{array}{l}\text { Measured values } \\
\text { (errors } 2 \text { sigma) }\end{array}$ & Meun and mean error \\
\hline Eimer and Amend & $0.7074 \pm 0.0011$ & \\
& $0.7080 \pm 0.0011$ & \\
$0.7077 \pm 0.0007$ & $0.7081 \pm 0.00017$ \\
& $0.7091 \pm 0.0014$ & SDM $(0 \overline{\mathrm{x}}) \pm 0.0002$ \\
& $0.7082 \pm 0.0014$ & \\
$0.7069 \pm 0.0011$ & \\
$0.7077 \pm 0.0006$ & \\
& $0.7085 \pm 0.0010$ & \\
& $0.7085 \pm 0.0009$ & \\
& $0.7100 \pm 0.0016$ & \\
NBS-987 & $0.7110 \pm 0.0016$ & \\
& $0.7106 \pm 0.0013$ & $0.71028 \pm 0.000 .10$ \\
& $0.7105 \pm 0.0007$ & SDM $(\circ \overline{\mathrm{x}})=0.00018$ \\
& $0.70963 \pm 0.00043$ & \\
$0.70994 \pm 0.00040$ & \\
\hline
\end{tabular}

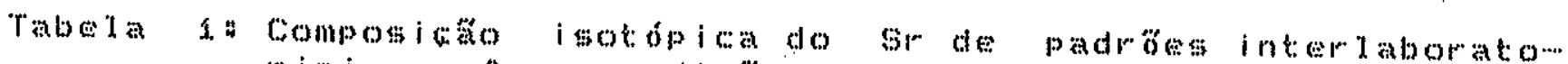
ri 1 i

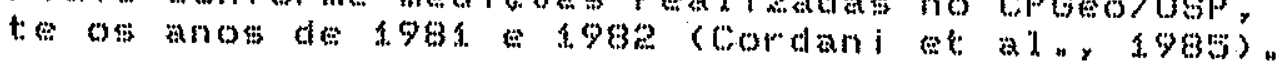


A) Análises $\mathrm{Rb}-\mathrm{Sr}$ en rocha-total:

\begin{tabular}{|c|c|c|c|c|c|c|c|}
\hline N. & N. de Campo & Litologia & N. Laborat ór io & $R b(p p m)$ & Sr(ppm) & $\mathrm{Rb}^{87} / \mathrm{Sr}$ & $\begin{array}{c}87 \\
\operatorname{Sr} / \operatorname{Sr}(*)\end{array}$ \\
\hline 1 & $257 \mathrm{~A}$ & Aplito & --- & 61,5 & 268,6 & 0,663 & 0,7243 \\
\hline 2 & 2570 & Gnaisse & $\cdots$ & 46,0 & 887,1 & 0,130 & 0,7061 \\
\hline 3 & $257 \mathrm{~F}$ & Gnaisse & $\cdots$ & 26,7 & 776,6 & 0,100 & 0,7061 \\
\hline 4 & 248 & Gnaisse & - & 25,7 & 307,3 & 0,242 & 0,7126 \\
\hline 5 & $86-220$ & Gnaisse & 5439 & 55,5 & 694,9 & $0,230+-0,605$ & $0,7694+-0,0065$ \\
\hline-76 & LK-289C. & Graisse & 5595 & $98,53(x *)$ & $837,03(* *)$ & $0,341+0,607$ & $0,7118+-0,0015$ \\
\hline$\longrightarrow 7$ & LK-298C.2 & Gnaisse & 5596 & $54,64(* *)$ & $861,03($ ** $)$ & $0,184+-6,084$ & $0,7104+-0,0013$ \\
\hline$z \leq 0$ & ESJ-115B & Gnaisse & 7698 & 64,7 & 517,5 & $0,362+0,610$ & $0,71486+-6,60023$ \\
\hline 9 & $E 5 J-1156$ & Gnaisse & 7699 & 71,5 & 318,0 & $0,652+-8,618$ & $0,72264+-0,60033$ \\
\hline 10 & ESJ-115F & Gnaisse & 7700 & 61,0 & 660,8 & $0,267+-0,068$ & $0,71481+-0,00015$ \\
\hline is & $E 5 J-1156$ & Gnaisse' & 7701 & 168,2 & 581,8 & $6,625+-0,818$ & $0,72116+-6,00013$ \\
\hline 12 & $E S J-1160$ & Gnaisse & 7702 & 73,8 & 636,9 & $0,336+-0,069$ & $0,71374+0,00013$ \\
\hline$p 13$ & ES.J-116E & Gnaisse & 7703 & 43,9 & 708,0 & $0,179+-0,085$ & $6,76839+-0,60628$ \\
\hline 14 & $E 5]-1178$ & Gnaisse & 7704 & 74,5 & 355,5 & $0,607+-0,017$ & $0,71529+-0,06010$ \\
\hline 15 & ESJ-117C & Gnaisse & 7705 & 61,8 & 795,1 & $0,225+-0,006$ & $8,71690+-0,60020$ \\
\hline
\end{tabular}

B) Anál ises K-Ar :

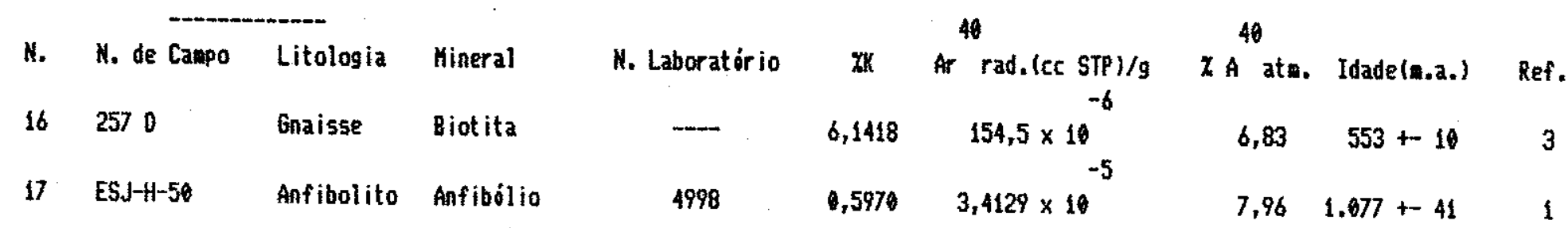


Tabela 3: Deterninacôes radiométricas do Grupo Por ongos.

A) Anál ises $\mathrm{Rb}-\mathrm{Sr}$ en rocha-total:
N. N. de Canpo
Litologia
N. Laboratór io
$R b$ (ppq)
Sr(ppa)
$87 \quad 86$
$87 \quad 86$
Sr / Sr (*) Idade(a.a.) Ref.

(Subgrupo Cerro dos hadeiras, Forsakâo Arroio dos Neves)

$18 \mathrm{RB}-265$

Gnaisse $\quad 5694$

$205,7 \quad 591,8$

$1,01+-0,03 \quad 0,7182+0,011 \quad 915+159 \quad 21$

(Subgrupo Cerro da Arvore, Hetanorfitos Cerro Cambará)

$\begin{array}{llllllllll}19 & \text { ESJ-HH7-10 } & \text { Hetandesito } & 5821 & 186,7 & 78,0 & 6,979+-0,196 & 0,7837+0,6026 & 789+39 & 1 \\ 26 & \text { ESJ-HH7-1E } & \text { hetandesito } & 6159 & 176,6 & 121,6 & 4,247+0,119 & 0,7626+0,0610 & 949+-45 & 1 \\ 21 & \text { ESJ-HH7-2C } & \text { Ketandesito } & 6158 & 137,6 & 180,4 & 2,218+0,062 & 0,7541+0,0611 & 1.542+-83 & 1\end{array}$




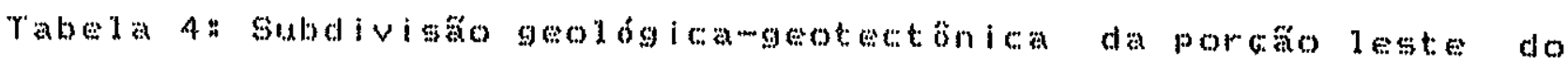

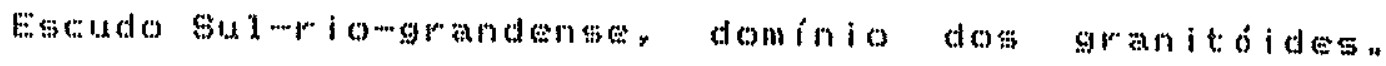

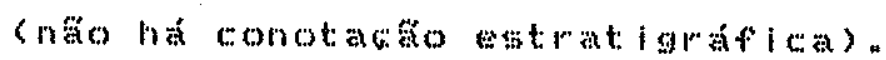

\section{BLOCO DOM FELICIANO=}

Complexo Granitóide de Leste - Oranitóides granitód ges catan

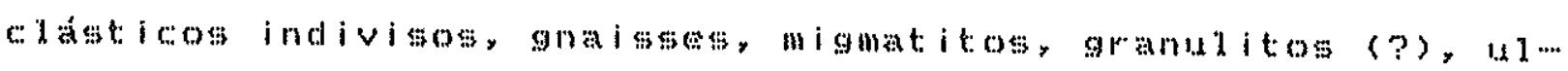

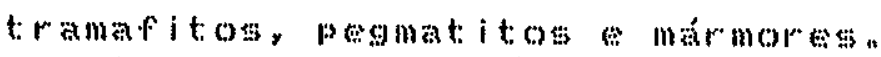

Suite Intrusiva Dom Feliciano ... Granitos Arroio dos Ladróses. Capso do Leño, Cangugu, Fortal a

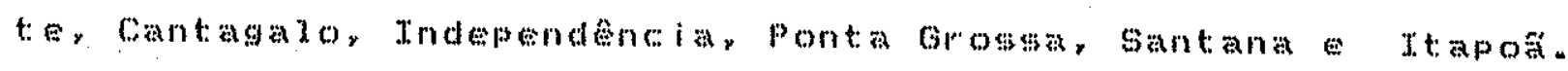
Suite Intrusiva Campinas ".. "Stocks" Cerro Branco, Campina,

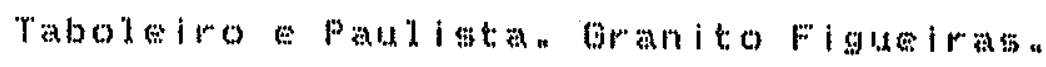

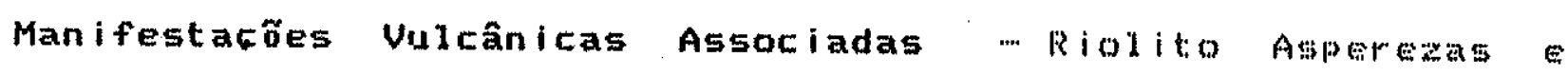
Cerro chation

\section{BLOCO ENCRUZILHADA:}

Complexo Metamórfico Várzea do Capivarita ... Paragnatssos, me-

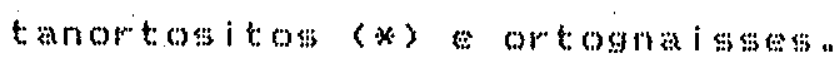

Suite Intrusiva Encruzilhada … Granitó des granodiorit icos a

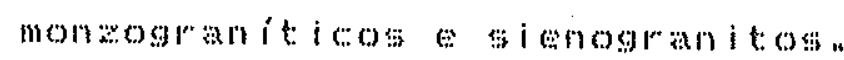

\section{Sienito Piquiri (**) "}

Pegmatitos mármores "

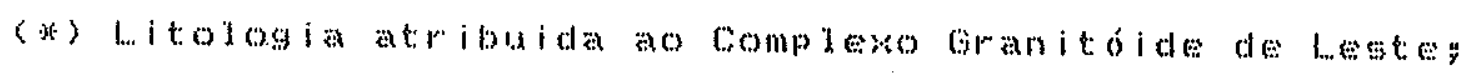

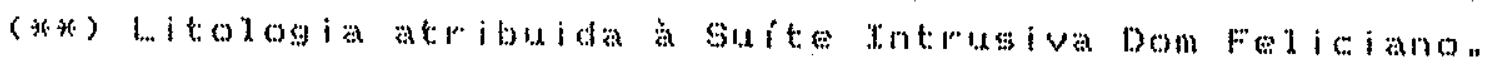


Tabela 5: Deterninacões radionétricas do Complexo Granitóide de Leste.

A) Análises Rb-Sr en rocha-total dos granitóides foliados:
N. N. de Campo N. na fig.20
Litologia
N. Laboratório Rb(ppm) Sr(ppa)
$87 \quad 86$
$87 \quad 86$

\begin{tabular}{rlr}
\hline 22 & $L K-169$ & 1 \\
23 & $L K 258 B$ & 2 \\
24 & $L K-135$ & 3 \\
25 & $E S J-36 A$ & 4 \\
26 & $E S J-36 B$ & 5 \\
27 & $216 A$ & 6 \\
28 & $216 B$ & 7 \\
29 & $218 A$ & 8 \\
30 & $223 B$ & 9 \\
31 & $L K-171 A$ & 10 \\
32 & $226 A$ & 11 \\
33 & $223 A$ & 12 \\
34 & $E S J-290$ & 13 \\
35 & $223 C$ & 14 \\
36 & 2178 & 15 \\
37 & $E S J-29 F$ & 16 \\
38 & $211 B$ & 17 \\
39 & $E S J-298$ & 18 \\
46 & 216 & 19 \\
41 & $215 A$ & 20 \\
42 & $211 A$ & 21 \\
43 & $6 F-331$ & 22 \\
44 & $10-1-8 S$ & - \\
45 & $226 B$ & - \\
46 & $225 A$ & - \\
47 & $226 C$ & -
\end{tabular}

\begin{tabular}{|c|c|c|c|c|c|c|c|}
\hline Granulito & 5594 & $47,54(* x)$ & $768,46(* x)$ & $0,179+-0,004(* x)$ & $0,7096+-0,0006$ & $\cdots$ & 21 \\
\hline Charnoenderb ito & 5497 & 63,6 & 676,2 & $0,272+0,668$ & $0,7699+-0,0011$ & - & 21 \\
\hline Tonalito & $5597=5564$ & $115,54(* *)$ & $443,46(* *)$ & $0,772+-0,617$ & $0,7179+-0,0009$ & -- & 21 \\
\hline higmat ito & 5278 & 144,4 & 438,8 & $0,95+-0,02$ & $0,7195+-0,0010$ & $1.662+-164$ & 4 \\
\hline Hignat ito & 5279 & 155,3 & 489,2 & $0,92+0,02$ & $0,7174+6,6007$ & $943+-162$ & 2 \\
\hline Granito & $\longrightarrow$ & 143,4 & 438,8 & 0,944 & 0,7169 & - & 8 \\
\hline Granito & $\cdots$ & 136,1 & 401,5 & 0,980 & 0,7170 & $\cdots$ & 8 \\
\hline Gaisse & - & 142,8 & 344,3 & 1,20 & 6,7189 & - & 3 \\
\hline Kigat ito & $-\cdots$ & 135,2 & 307,2 & 1,27 & 0,7225 & $-\cdots$ & 3 \\
\hline Granodiorito & 5498 & 173,2 & 359,6 & $1,396+-0,835$ & $0,7210+0,0006$ & & 21 \\
\hline Granito & --- & 183,1 & 357,0 & 1,48 & 0,7221 & $-\infty-$ & 3 \\
\hline Migmatito & - & 162,9 & 297,7 & 1,58 & 0,7232 & . $\quad=$ & 3 \\
\hline Higat ito & 5276 & 157,5 & 278,1 & $1,64+-0,63$ & $0,7264+0,0010$ & $912+97$ & $\mathfrak{1}$ \\
\hline K.felds pege. & - & 190,4 & 295,6 & 1,86 & 0,7269 & - & 3 \\
\hline Gnaisse & $-\infty$ & 22,5 & 338,6 & 1,88 & 0,7289 & $\cdots$ & 3 \\
\hline Higmat ito & 5277 & 218,6 & 288,5 & $2,19+-0,04$ & $0,7329+0,0017$ & $892+87$ & 1 \\
\hline Granito & $--\infty$ & 302,5 & 350,6 & 2,50 & 8,7341 & $-\cdots$ & 8 \\
\hline Migmatito & 5275 & 195,0 & 106,4 & $5,34+-11$ & $0,7714+0,0610$ & $871+-38$ & 1 \\
\hline Granodiorito & $\cdots$ & 61,4 & 935,0 & 0,17 & 0,7064 & $-\cdots$ & 8 \\
\hline Granito & - & 151,0 & 484,1 & 0,961 & 0,7115 & - & B \\
\hline Granito & $-\infty$ & $(* * *)$ & $(* * *)$ & 2,37 & 0,7287 & $-\infty$ & 8 \\
\hline Gnaisse & 5499 & $\{75,4$ & 120,1 & $4,249+-0,0056$ & $0,7628+0,0089$ & $939+45$ & 21 \\
\hline Granodior ito & HIT -7302 & 201,8 & 186,1 & 3,69 & 0,7337 & $640+-57$ & 6 \\
\hline Anfibolito & - & 64,8 & 960,0 & 0,195 & 0,7068 & $-\cdots$ & 8 \\
\hline Anfibolito & $-\cdots$ & 157,5 & 642,0 & 0,708 & 0,7098 & -- & 8 \\
\hline Anfibolito & - & 227,6 & 156,9 & 4,200 & 0,7562 & $850+43$ & 8 \\
\hline
\end{tabular}


Tabela 5: Deterninasônes radionétricas do Complexo Granitóide de Leste.

B) Análises $\mathrm{Rb}-5 \mathrm{r}$ ea rocha-total dos granitóides não fol iados a das efusivas acidas: Granitóides nấo foliados:

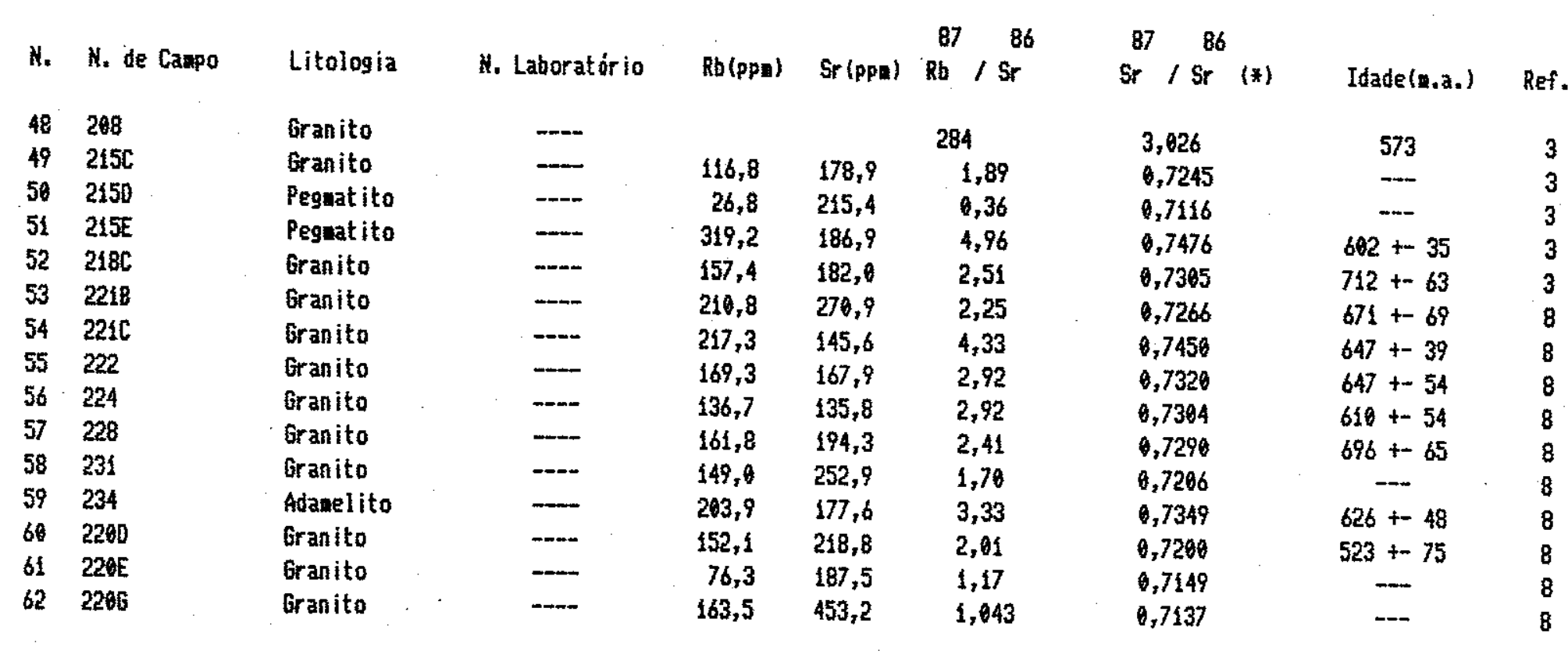

Efusivas Acidas:

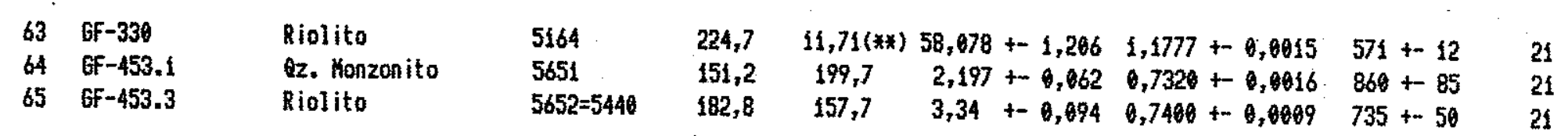


Tabela 5: Deterninacốes radionétricas do Complexo Granitoide de Leste.

C) Anál ises K-Ar:

\begin{tabular}{|c|c|c|c|c|c|c|c|c|c|}
\hline N. & N de Canpo & Litologia & Katerial & N. Labor at ório & $z k$ & $\begin{array}{c}40 \\
\text { Ar }(\operatorname{lec} \text { STP }) / 9 . \\
-5\end{array}$ & $x_{\text {fir }}^{40}$ ats & 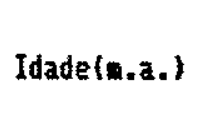 & Ref. \\
\hline 66 & $R S-14$ & Granito & Biotita & 2353 & 4,8486 & $\begin{array}{r}14,32 \times 10 \\
\quad-5\end{array}$ & 2,27 & $635+-27$ & 5 \\
\hline 67 & $220 \mathrm{~B}$ & Anfibolito & Anfibólio & 2850 & 0,2931 & $\begin{array}{r}0,6890 \times 10 \\
-5\end{array}$ & 58,27 & $522+-16$ & 3 \\
\hline 68 & LK-112 & Gabro & Plagioclásio & 4580 & 0,4868 & $\begin{array}{r}2,763 \times 10 \\
-5\end{array}$ & 26,92 & $459+-14$ & 21 \\
\hline 69 & $6 F-371 A$ & Norito' & RT & 4585 & 0,1579 & $\begin{array}{r}0,4503 \times 10 \\
-5\end{array}$ & 38,84 & $611+-18$ & 21 \\
\hline 70 & $6 F-3718$ & Anfibolito & RT & 4578 & 0,2776 & $\begin{array}{r}0,6971 \times 10 \\
-5\end{array}$ & 13,83 & $553+16$ & 21 \\
\hline 71 & $4 K-169$ & Granulito & Biotita & 4586 & 6,7878 & $\begin{array}{r}19,69 \times 10 \\
-3\end{array}$ & 4,56 & $625+-18$ & 21 \\
\hline 72 & $E S J-27$ & Granito & Biotita & 4612 & 5,1950 & $\begin{array}{r}0,1590 \times 10 \\
-3\end{array}$ & 3,62 & $654+11$ & 1 \\
\hline 73 & ESJ-29E & Higmat ito & Biotita & 4638 & 6,9172 & $\begin{array}{r}8,1921 \times 16 \\
-3\end{array}$ & 1,72 & $602+-9$ & 1 \\
\hline 74 & $E S J-31$ & Granito & Biotita & 4590 & 6,5730 & $0,1786 \times 10$ & 4,42 & $592+-14$ & 1 \\
\hline 75 & $E \leqslant 5-32$ & Blastonilon. & Biotita & 4591 & 4,8002 & $\begin{array}{r}0,7658 \times 10 \\
-3\end{array}$ & 22,23 & $370+7$ & $i$ \\
\hline 76. & $E S J-33 A$ & rigmat ito & Biotita & 4645 & 6,2972 & $0,1607 \times 10$ & 2,96 & $560+8$ & $\mathfrak{i}$ \\
\hline 77 & ES.J-34 & fignat ito & Biotita & 4647 & 6,4288 & $\begin{array}{r}0,1577 \times 18 \\
-3\end{array}$ & 1,02 & $542+-13$ & 1 \\
\hline 78 & ESJ-35 & Higatat ito & Biotita & 4694 & 3,9660 & $\begin{array}{r}0,1025 \times 10 \\
-3\end{array}$ & $6,3 i$ & $567+-14$ & 1 \\
\hline 79 & ES.J-37 & Gnaisse & Biotita & 4692 & 6,8682 & $\begin{array}{r}0,1674 \times 10 \\
-5\end{array}$ & 5,79 & $539+-16$ & 1 \\
\hline 80 & ES.J-38 & Granito Catacl. & Biotita & 4696 & 5,5452 & $\begin{array}{r}10,9 \times 10 \\
-3\end{array}$ & 7,60 & $446+-5$ & 1 \\
\hline 81 & ESJ-39 & Granito & Biotita & 4614 & 6,7596 & $0,1669 \times 10$ & 4,93 & $528+6$ & 1 \\
\hline 82 & $T 0-1-R S$ & Granodiorito & Biotita & 1653 & 6,367 & $156,3 \times 10$ & 4,37 & $541+-27$ & 6 \\
\hline
\end{tabular}


Tabela 6: Deterninacôes radioaétricas da Suite Intrusiva Dow Feliciano.

A) Análises $\mathrm{Rb}-\mathrm{Sr}$ en rocha-total:

\begin{tabular}{|c|c|c|c|c|c|c|c|c|c|}
\hline & & & & & & $87 \quad 86$ & $87 \quad 86$ & & \\
\hline N. & N. de Campo & Litologia & N. Laboratório & $R b$ (pp精) & $\operatorname{Sr}(p p n)$ & $\mathrm{Rb} / \mathrm{Sr}$ & Sr / Sr $\quad(*)$ & Idade(a.a.) & Ref. \\
\hline 83 & $L K-1798$ & Granito & $-\cdots$ & 165,3 & 317,2 & $1,51+-0,377$ & $0,7211+0,0065$ & -- & 21 \\
\hline 84 & 212 & Granito & - & 228,0 & 350,0 & 1,88 & $\theta, 7246$ & -- & 3 \\
\hline 85 & 213 & Granito & ---- & $18 i, 5$ & 23,6 & 21,7 & 6,8794 & -- & 3 \\
\hline 86 & 214 & Granito & - & $(* * *)$ & (***) & 1,86 & 0,7221 & - & 8 \\
\hline 87 & 2190 & Granito & --- & (***) & $(* * *)$ & 46,9 & 1,669 & $-\cdots$ & 3 \\
\hline
\end{tabular}


Tabela 7: Deterainacôes radioaétricas de Granitóides do "Bloco Encruzilhada".

A) Anál ises Rb-Sr en rocha-total:

\begin{tabular}{|c|c|c|c|c|c|c|c|c|c|}
\hline$N_{*}$ & N de Campo & Litologia & 1. Laborat ór io & $R$ D $\{$ pp田 $\}$ & $\operatorname{Sr}(p p=)$ & $\mathrm{Rb}^{87} / \mathrm{Sr}^{86}$ & $\mathrm{Sr}^{87} / \mathrm{Sr}^{86}(*)$ & 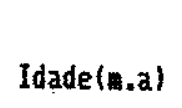 & Ref. \\
\hline 88 & $278 A$ & Granito & $-\cdots$ & 264,2 & 72,8 & 10,6 & 0,8 & $609+-27$ & 3 \\
\hline 89 & 2788 & Granito & $\cdots$ & 209,6 & 20,1 & 28,6 & 0,9378 & $522+17$ & 3 \\
\hline 99 & $278 \varepsilon$ & Granito & $\cdots$ & 225,3 & 14,4 & 40,4 & 1,037 & $494 t-15$ & 3 \\
\hline 91 & 286 & Granodiorito & --- & $(* * *)$ & (***) & 0,798 & 0,7143 & - & 8 \\
\hline$\approx 92$ & $28 i$ & Granito & --- & 296,8 & 92,0 & 9,36 & 0,7998 & $617+29$ & 3 \\
\hline 293 & 282 & Granito & - & 410,4 & 74,6 & 16,1 & 0,8607 & $662+-29$ & 3 \\
\hline 94 & 283 & Granito & --- & 365,8 & 162,8 & 5,46 & 8,7569 & $665+-43$ & 3 \\
\hline$\approx 95$ & 285 & Granito & $\cdots$ & 338,2 & 255,5 & 3,84 & 6,7419 & $594+-51$ & 3 \\
\hline 96 & 286 & Granito & ---- & 343,8 & 29,2 & 33,2 & 0,9878 & ---- & 3 \\
\hline $\begin{array}{r}-97 \\
\end{array}$ & 287 & Granito & -- & 186,8 & 500,0 & 1,08 & 0,7179 & - & 8 \\
\hline 98 & 288 & Kigmat ito & $-\cdots$ & 379,6 & 162,4 & 6,80 & 0,7670 & $640+-36$ & 8 \\
\hline 99 & 289 & Granito & $\cdots$ & 248,8 & $.74,7$ & 9,70 & 0,7862 & $586+-23$ & 8 \\
\hline 200 & $L K-161 B$ & Microgranito & 5561 & 363,2 & 119,5 & $8,863+-0,25$ & $0,7849+-0,0007$ & $610+-24$ & 21 \\
\hline 101 & $L K-\{94$ & Granito Catacl. & 5582 & 316,8 & 92,6 & $9,985+-0,28$ & $0,7933+-0,0008$ & $599+23$ & 21 \\
\hline 162 & $L K-199$ & Granito Catacl. & 5583 & 306,2 & 119,2 & $7,486+-8,21$ & $0,7778+-0,0007$ & $653+-27$ & 21 \\
\hline
\end{tabular}

\section{8) Anállises K-Ar:}

\begin{tabular}{|c|c|c|c|c|c|c|c|c|c|}
\hline & & & & & & 40 & 40 & & \\
\hline$N_{z}$ & N. de Campo & Litologia & Material & N. Laboratório & $z k$ & Ar (ce STP)/g. & ZAF ati & Idade (u.a.) & Ref. \\
\hline 103 & Fornin.1 & Granito & Biot ita & 2234 & 6,404 & $\begin{array}{r}15,31 \times 10 \\
-5\end{array}$ & 6,35 & $533+39$ & 7 \\
\hline 104 & Forn.1 & Granito & Anfibólio & 2233 & 0,9289 & $4,87 \times 10$ & 14,17 & $6.615+13$ & 7 \\
\hline
\end{tabular}

C) Análise K-Ar en rocha carbonática :

105290 Hármore Flogopita $2856 \quad 7,1448 \quad 19,49 \times 10^{-5} \quad 7,16 \quad 606+18 \quad 3$


Tabela 8: Determinacôes radionétricas do Anertosito Capivarita e rochas associadas.

A) Análises Rb-Sr en rocha-total:

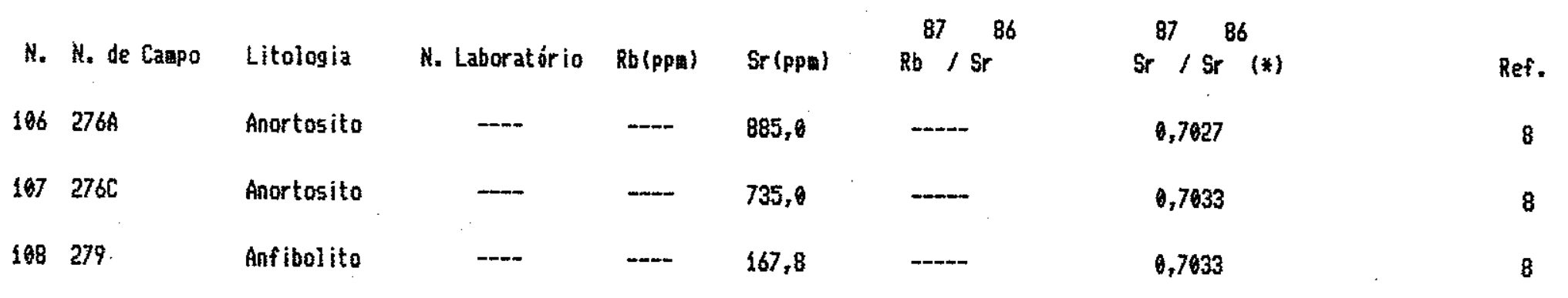

B) And́lises K-Ar:

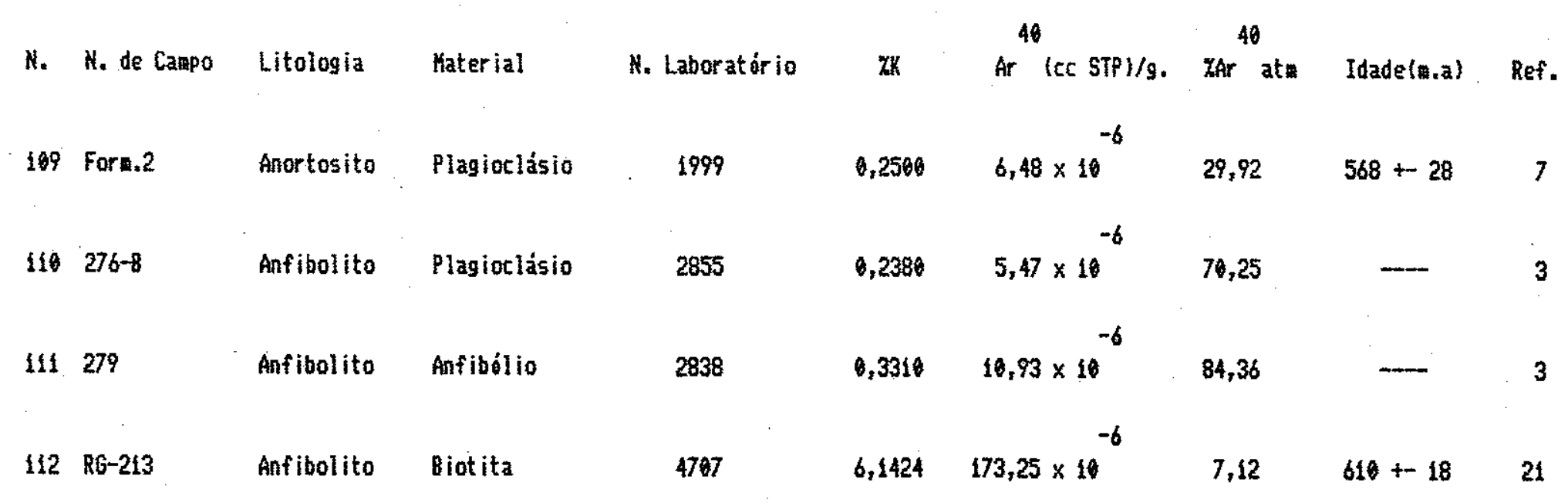


Tabela 9: Deterninacōes radionétricas do Sienito Piquiri e Granito Campinas:

A) Análises $\mathrm{Rb}-\mathrm{Sr}$ ea rocha-total do Sienito Piquiri:

\begin{tabular}{|c|c|c|c|c|c|c|c|c|}
\hline N. & N. de Campo & Litologia & N. Laboratór io & $R b$ (PPR) & Sr (ppa) & $\mathrm{Rb}^{87} / \mathrm{Sr}$ & $\mathrm{Sr}^{87} / \mathrm{Sr}^{86}$ & Ref. \\
\hline 113 & 291 & Sienito & $\cdots$ & 335,0 & $1.200,0$ & 0,813 & 0,7145 & $\theta$ \\
\hline 114 & 292 & Sienito & --- & 434,6 & $1.050,0$ & 1,190 & 0,7164 & 8 \\
\hline 115 & 293 & Sienito & $-\cdots$ & 292,0 & $1.750, \theta$ & 0,481 & 0,7164 & 8 \\
\hline & 294 & Sienito & - & 362,0 & $1.500,0$ & 0,695 & 8,7117 & 8 \\
\hline
\end{tabular}

B) Análises K-Ar do Sienito Piquiri:

\begin{tabular}{|c|c|c|c|c|c|c|c|c|}
\hline \multirow{2}{*}{ N. N. de Campo } & \multirow[b]{2}{*}{ Litologia } & \multirow[b]{2}{*}{ Haterial } & \multirow[b]{2}{*}{ W. Laboratório } & \multirow[b]{2}{*}{ zk } & 40 & 40 & \multirow[b]{2}{*}{ Idade (m.a) } & \multirow[b]{2}{*}{ Ref. } \\
\hline & & & & & Ar $(e C$ STP $) / g$. & zat atm & & \\
\hline & & & & & -5 & & & \\
\hline 293 & Sienito & Anfibólio & 2845 & 0,7080 & $1,878 \times 16$ & 34,38 & $580+-25$ & 3 \\
\hline
\end{tabular}

C) Análises Rb-Sr do Granito Campinas:

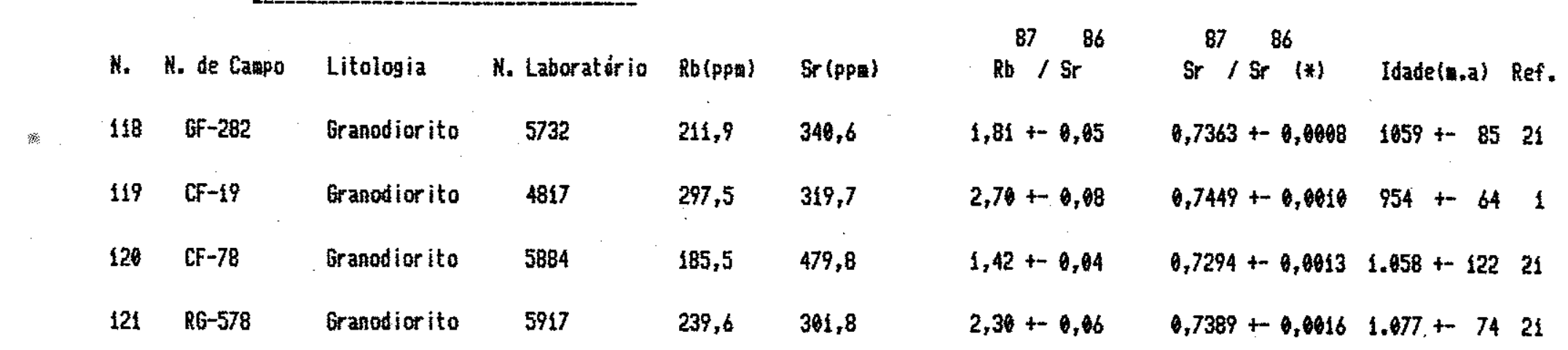


Tabela 16: Deterninacôes radionétricas de granitóides do Complexo Granitoide de Leste por Traços de Fissão.

N. N. de Campo Litologia Material Teaperatura(OC) Observ. Tracos fósseis Tracos induzidos

\begin{tabular}{|c|c|c|c|c|c|c|c|c|c|c|c|c|}
\hline & & & & & & H & $n$ & $\begin{array}{r}52 \\
\text { oft-for }(f \theta / c t)\end{array}$ & H & $n$ & $\begin{array}{r}52 \\
0 i+-f_{\sigma}(1 \theta / c=\end{array}$ & $\begin{array}{l}\text { Idade } \\
\text { (a.a.) }\end{array}$ \\
\hline 122 & ESJ-27 & Granito & Apat ita & $\begin{array}{c}\text { Aabiente } \\
300 \\
310 \\
320\end{array}$ & $\begin{array}{l}A \\
A \\
A \\
A\end{array}$ & $\begin{array}{l}846 \\
702 \\
607 \\
497\end{array}$ & $\begin{array}{l}46 \\
40 \\
40 \\
46\end{array}$ & $\begin{array}{l}20,98+-0,75 \\
17,41+-0,55 \\
15,65+0,42 \\
12,33+-0,72\end{array}$ & $\begin{array}{l}852 \\
701 \\
616 \\
490\end{array}$ & $\begin{array}{l}40 \\
40 \\
49 \\
40\end{array}$ & $\begin{array}{l}21,13+-0,99 \\
17,38+-0,64 \\
15,28+-0,33 \\
12,15+-0,81\end{array}$ & $\begin{array}{l}273+-16 \\
276+-13 \\
271+-10 \\
279+-25\end{array}$ \\
\hline & & & & $\begin{array}{c}\text { Anbiente } \\
309 \\
318 \\
320\end{array}$ & $\begin{array}{l}B \\
B \\
B \\
B\end{array}$ & $\begin{array}{l}693 \\
638 \\
950 \\
853\end{array}$ & $\begin{array}{l}30 \\
30 \\
30 \\
30\end{array}$ & $\begin{array}{l}17,46+0,86 \\
16,68+0,87 \\
17,96+0,86 \\
16,12+0,85\end{array}$ & $\begin{array}{l}784 \\
711 \\
869 \\
819\end{array}$ & $\begin{array}{l}30 \\
30 \\
30 \\
30\end{array}$ & $\begin{array}{l}19,76+-0,97 \\
17,92+-1,10 \\
16,42+-0,72 \\
15,48+-0,71\end{array}$ & $\begin{array}{l}244+17 \\
248+20 \\
300+20 \\
286+-20\end{array}$ \\
\hline 123 & ESJ-29 & Migmat ito & Apat ita & $\begin{array}{l}\text { Ambiente } \\
300 \\
310 \\
320\end{array}$ & $\begin{array}{l}\text { A } \\
\text { A } \\
\text { A } \\
\text { A }\end{array}$ & $\begin{array}{l}992 \\
883 \\
922 \\
768\end{array}$ & $\begin{array}{l}40 \\
40 \\
46 \\
40\end{array}$ & $\begin{array}{l}24,60+1,11 \\
21,90+-0,54 \\
22,87+0,60 \\
19,05 \div-0,60\end{array}$ & $\begin{array}{l}963 \\
842 \\
933 \\
769\end{array}$ & $\begin{array}{l}40 \\
40 \\
40 \\
40\end{array}$ & $\begin{array}{l}23,88+1,10 \\
20,88+-0,61 \\
23,14+0,54 \\
19,67+0,63\end{array}$ & $\begin{array}{l}283+18 \\
288+-11 \\
272+-10 \\
275+-13\end{array}$ \\
\hline & & & & $\begin{array}{l}\text { Anbiante } \\
300 \\
310 \\
320\end{array}$ & $\begin{array}{l}B \\
B \\
B\end{array}$ & $\begin{array}{l}1150 \\
807 \\
960 \\
810\end{array}$ & $\begin{array}{l}48 \\
49 \\
48 \\
48\end{array}$ & $\begin{array}{l}21,74+0,98 \\
15,25+-0,94 \\
18,14+-1,00 \\
15,31+-0,87\end{array}$ & $\begin{array}{l}1.193 \\
929 \\
1.023 \\
834\end{array}$ & $\begin{array}{l}40 \\
40 \\
40 \\
40\end{array}$ & $\begin{array}{l}22,55+-0,97 \\
17,56+-0,92 \\
19,33+-1,03 \\
15,76+-0,71\end{array}$ & $\begin{array}{l}266+-17 \\
240+-19 \\
259+-20 \\
268+19\end{array}$ \\
\hline 124 & ES.J-33 & Higeat ito & Apatita & $\begin{array}{c}\text { Ambiente } \\
309 \\
310 \\
320\end{array}$ & $\begin{array}{l}\text { A } \\
A \\
A \\
A \\
A\end{array}$ & $\begin{array}{l}938 \\
872 \\
827 \\
771\end{array}$ & $\begin{array}{l}40 \\
40 \\
40 \\
40\end{array}$ & $\begin{array}{l}23,26+0,87 \\
21,63+-0,62 \\
20,51+-0,71 \\
19,12+0,61\end{array}$ & $\begin{array}{l}917 \\
837 \\
787 \\
753\end{array}$ & $\begin{array}{l}40 \\
40 \\
40 \\
40\end{array}$ & $\begin{array}{l}22,74+0,79 \\
20,76+-0,61 \\
19,52+-0,64 \\
18,67+-0,55\end{array}$ & $\begin{array}{l}281+14 \\
287+-12 \\
289+-14 \\
282+-12\end{array}$ \\
\hline
\end{tabular}


Tabela 10: Deterninacões radiométricas de granitóides do Complexo Granitóide de Leste por Tracos de Fissão.

N. N. de Campo Litologia Material Temperatura(oc) observ. Tracos fússeis

52 Tracos induzidos

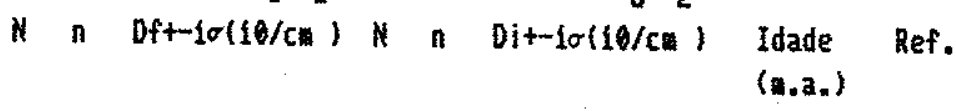

125 ESJ-33 Migatito Apatita Ambiente

$$
300
$$

310

320

$9794018,50+0,811.0124019,13+0,80266+1614$

$810 \quad 40 \quad 15,13+-0,82 \quad 789 \quad 40 \quad 14,31+-0,75 \quad 282+24$

$6414012,11+0,66 \quad 6784012,81+0,65261+19$

$58940 \quad 10,96+-0,62 \quad 616 \quad 46 \quad 11,64+-0,59 \quad 260+-20$

126 ESJ-37 Gnaisse Apatita Ambiente

300

$9434023,39+-0,1099740 \quad 24,73+-0,96 \quad 261+10.14$

316

$8484021,03+-0,44 \quad 898 \quad 40 \quad 22,27+-0,60 \quad 260+-9$

$8144020,19+-0,48 \quad 873 \quad 4021,65+-0,53 \quad 257+-9$

320 A $76840 \quad 19,50+-0,62 \quad 797 \quad 40 \quad 19,77+0,57 \quad 265+-12$

Obs.: O tempo de aquecinento das amostras, confor a a coluna 5 , foi de 1 hora. 
Tabela 11: Correspondência entre as idades-plateau por tracos de fissão en apatitas e idades k-Ar ea biotitas, ao longo do perfil Pinheiro hachado-Pelotas, seg. Poupeau et.al., (1985), con modificacöes (ver fig. 27).

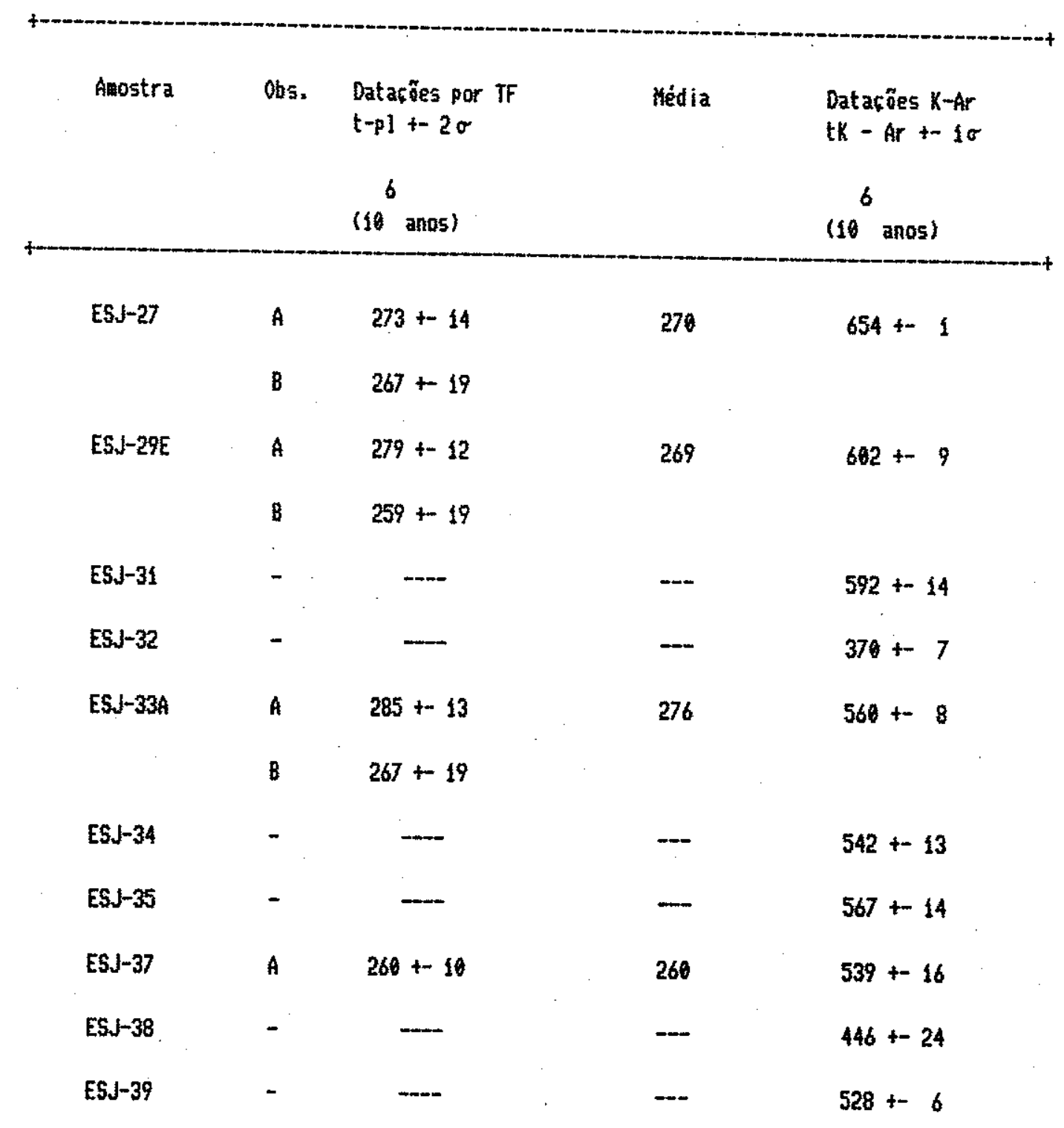


Tabela 12: Determinacîes radiométricas das sequências Káfica-ultramáficas e Vulcano-sediaentares do "Bloco São Gabr iel".

A) Análises K-Ar do Gabro de hata Grande:

\begin{tabular}{|c|c|c|c|c|c|c|c|c|c|c|}
\hline \multirow[b]{2}{*}{$N_{*}$} & & & \multicolumn{8}{|c|}{40} \\
\hline & N. de Canpo & Litologia & Haterial & N. Laborat ór io & $\boldsymbol{z K}$ & Ar & $\operatorname{rad}(e c$ STP/g) & $x_{\text {Ar }}$ at & Idade $\left(m_{1} a_{z}\right)$ & Ref. \\
\hline & & & & & & & -6 & & & \\
\hline 127 & $R S-4 A$ & Gabro & Plag. & 2352 & 0,1426 & 23, & $49 \times 10$ & 9,69 & $2.183+100$ & 9 \\
\hline 128 & $R S-4 B$ & Gabro & Plag. & 2354 & 0,4672 & 50, & $\frac{0}{60}$ & 9,53 & $1.826+55$ & 9 \\
\hline 129 & RG-256 & Gabro & Plag. & 4763 & 0,1236 & 15, & $70 \times 10$ & 18,61 & $1.867+56$ & 21 \\
\hline
\end{tabular}

(8) Análises K-Ar do Complexo Básico-ultrabásico de Pedras Pretas:

$\begin{array}{llllllllll}136 & \text { P-122 } & \text { Anfibolito } & \text { Plag. } & 3843 & 0,1478 & 7,70 \times 10^{-6} & 48,01 & 1,694+55 & 18 \\ 131 & P-123 & \text { Anfibolito } & \text { Plag. } & 3054 & 0,7770 & 4,85 \times 10^{-6} & 36,95 & 839+29 & 18 \\ 132 & \text { PP-118 } & \text { Gabro } & \text { Plag. } & 4400 & 8,6165(* *) & 0,74 \times 10^{-6} & 82,12 & 891+79 & 1 \\ 133 & \text { PP-127 } & \text { Anortosito } & \text { Plag. } & 4393 & 1,1244 & 13,9 \times 10^{-6} & 26,92 & 293+7 & 1 \\ 134 & \text { PP-129 } & \text { Gabro } & \text { Plag. } & 4390 & 0,4116 & 9,501 \times 10^{-6} & 16,34 & 514+17 & 1\end{array}$

C) Análise K-Ar de ketabásica de Palıa:

135 RB-281.2 Hetabásica RT.
D) Análise K-Ar de hetagabro do Arroio do Jaques:

$3,018 \quad 76,83 \times 10^{-6}$

$2,95 \quad 559+17 \quad 21$

136 RG-409C hetagabro Plag.

4792

1,0625

$24,47 \times 10^{-5}$

$10,90 \quad 513+15 \quad 21$ 
Tahela 12: Deterainacôes radiouétricas das sequências Máfica-ultranáficas e Vuicano-sed iaentares do "Bloco São Gabriel".

E) Análise $K$-Ar de Serpent inito do Cerro Matiqueiras:

$137 \quad$ LK-408.2 Serpentinito RT $\quad 4706 \quad 0,0128 \quad 5,195 \times 10^{-7} \quad 71,90 \quad 911+-276 \quad 21$

F) Análises K-Ar de Calci-silicaticas das regiôes de kata Grande e Palaa:

$\begin{array}{lllllll}138 \cdot \text { MG-IV-43 Calci-silicáticas Anfibólio } & 4808 & 0,1098 & 3,517 \times 10^{-6} & 36,63 & 691+44 & 1 \\ 139 \text { ESJ-F-120A Calci-silleáticas Anfibólio } & 4888 & 0,2729 & 10,71 \times 10^{-6} & 11,83 & 895+38 & 1\end{array}$

6) Análise K-Ar de Muscovita-xisto da região de Taboleiro:

148 ESJ-13 huscovita-xisto Huscovita $4846 \quad 7,7179 \quad 0,2616 \times 10^{-3} \quad 2,19 \quad 712+20 \quad 1$

H) Anál ise K-Ar de Gabro de Esaeralda:

141 ES-2-RS Gabro Feldspato $4815 \quad 3,3753 \quad 78,69 \times 10^{-6} \quad 47,5 \quad 518+25 \quad 4$


Tabela 13: Deterainacôes radiométricas das sequêencias Káfica-ultraaáficas do "Bloco São Gabriel".

A) Análise Rb-Sr to Gabro de Hata Grande:

\begin{tabular}{|c|c|c|c|c|c|c|c|c|}
\hline & & & & & & 87 & 87 & \\
\hline N. & N. de Campo & Litologia & N. Laborat ór io & $R b$ (ppm) & SF (pp世) & $\mathrm{Rb} / \mathrm{Sr}$ & $\mathrm{sr}_{r} / \mathrm{sr}_{\mathrm{r}}(*)$ & Ref. \\
\hline 43 & 225 & Gabro & $-\cdots$ & $\{B, 1(* * *)$ & 824,0 & 0,063 & 0,7032 & 8 \\
\hline
\end{tabular}

B) Análises $\mathrm{Rb}-\mathrm{Sr}$ de ultramafitos do Cerro Mantiqueira:

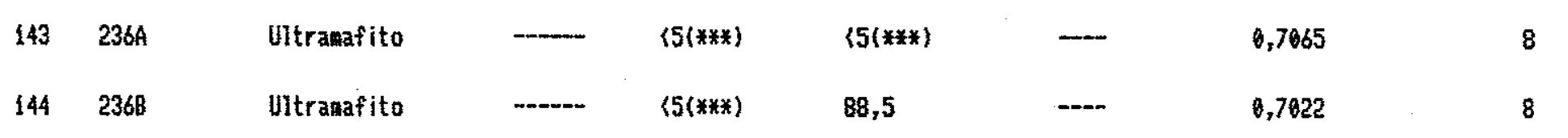

C) Análises Rb-Sr de ultramafitos da Seqiência Lajeadinho, Complexo Bossoroca:

\begin{tabular}{|c|c|c|c|c|c|c|c|}
\hline 145 & HTG -81 & Metaper idot ito & 6668 & $\langle 5$ & 12,2 & -- & $0,70698+-0,06051$ \\
\hline 146 & HTG-62 & Metaultramafito & 6669 & $\langle 5$ & $<5$ & $\cdots$ & $0,70921+-0,00044$ \\
\hline 147 & HTG-03 & Ketaultramaf ito & $667 \%$ & $\langle 5$ & 8,9 & $\cdots$ & $0,70737+6,00641$ \\
\hline 148 & HTG-64 & Hetaultranafito & 6671 & 13,5 & $\{17,7$ & $0,332+-0,009$ & $0,70564+-0,00027$ \\
\hline
\end{tabular}


Tabela 14: Deterninacões radiométricas do Complexo hetamórfico Pąsso Feio ( = Formacão Arroio das Ilhas).

A) Análises K-Ar:

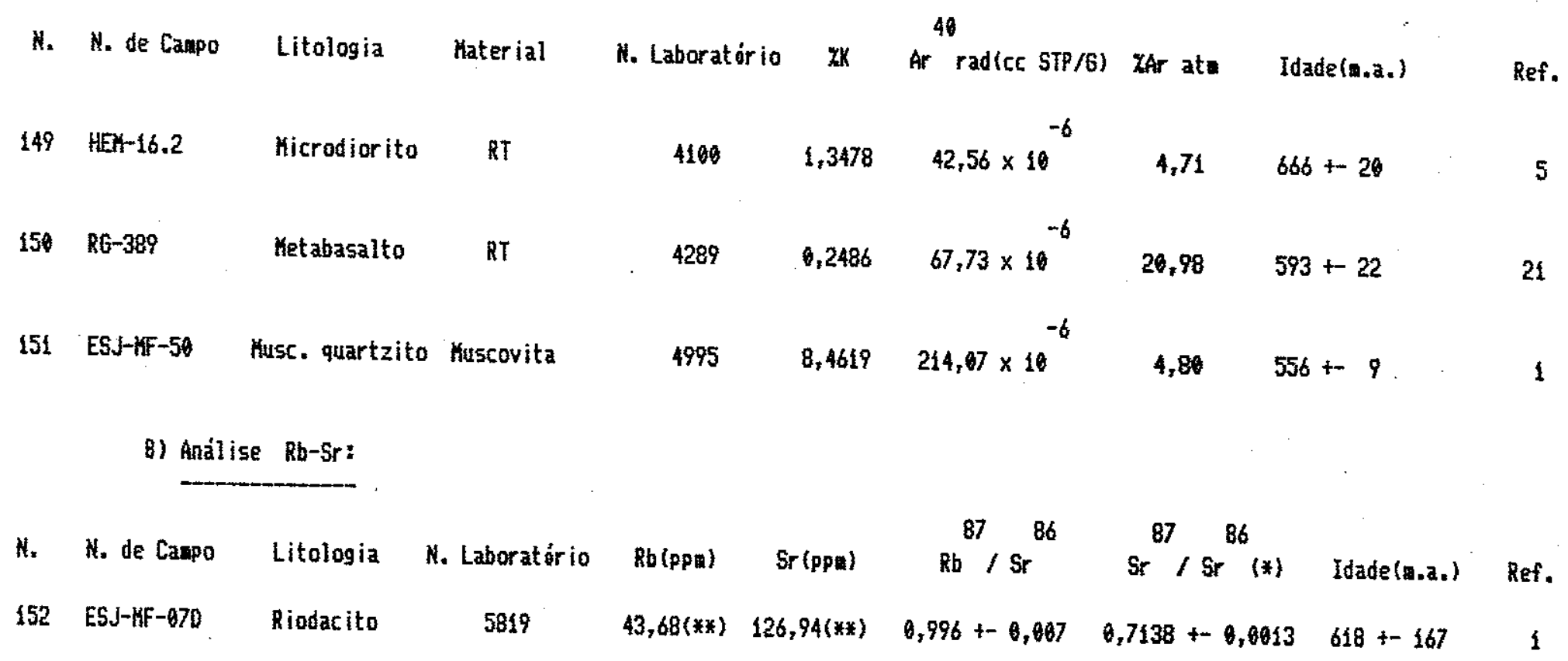


Tabela 15: Determinacões radiométricas dos gnaisses e suites intrusivas associadas à unidade Cambai.

A) Análises k-Ar da região do Cerro Mantiqueiras:

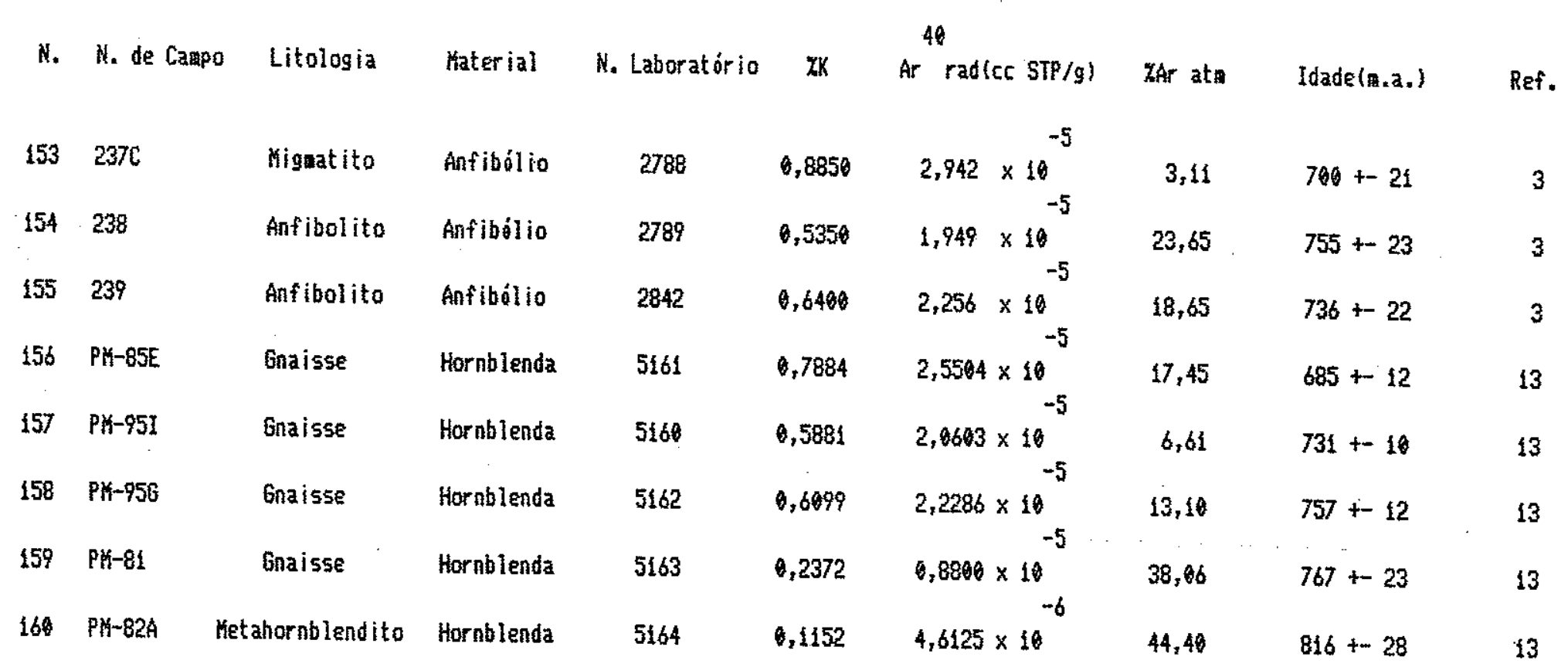

8) Análises K-Ar da porcão setentrional (Vila Nova e Hata Grande):

$\begin{array}{lllllllll}161 & P G-273 B .2 & \text { hetatonalito Biotita } & 4788 & 6,8266 & 21,958 \times 10^{-5} & 2,78 & 682+29 & 21 \\ 162 & \text { AG-UI-99 Anfibolito Anfibálio } & 4847 & 0,7064 & 2,318 \times 18^{-5} & 14,32 & 694+23 & 1\end{array}$

C) Análises K-Ar ea testeaunhos de sondage nos dominios da Bacia do Paraná:

$\begin{array}{llllllllll}163 & \text { RD-1-RS } & \text { Gnaisse } & \text { Muscovita } & 4758 & 7,531 & 14,42 \times 10^{-5} & 10,45 & 436+-6 & 4 \\ 164 & \text { RD-1-RS } & \text { Gnaisse } & \text { Muscovita } & 4775 & 7,531 & 18,70 \times 10^{-5} & 4,4 & 547+7 & 4 \\ 165 & \text { II-1-RS } & \text { Granodiorito } & \text { Feldspato } & 4910 & 0,539 & 10,815 \times 10^{-6} & 41,15 & 455+19 & 4\end{array}$


Tabela 15: Deterainacôes radiowétricas dos gnaisses e suites intrusivas associadas à unidade Canbai.

D) Outras análises K-Ar:

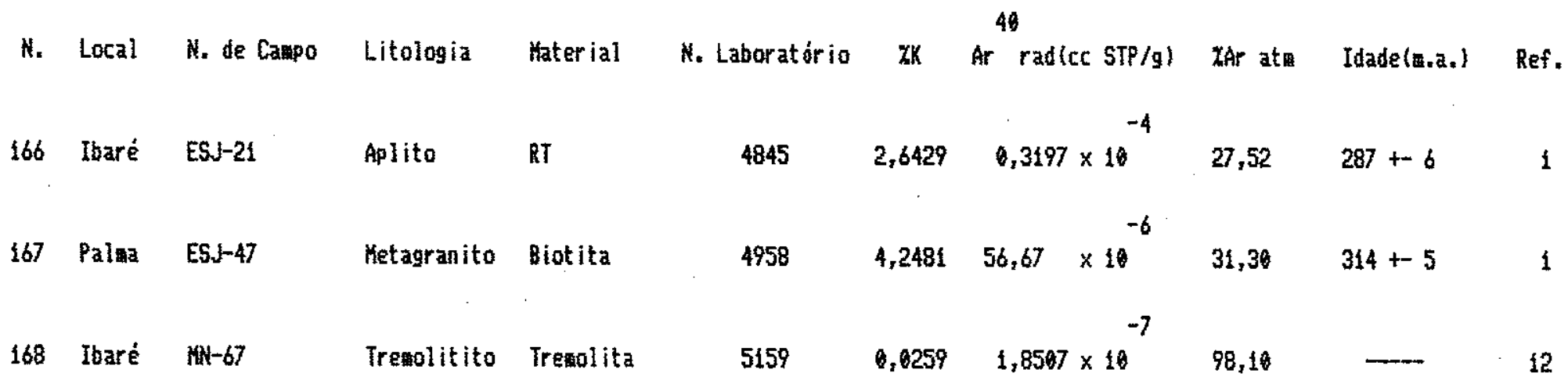


Tabela 16: Deterainacôes radiométricas dos gnaisses e suites intrusivas associadas à unidade Canbai.

A) Análises Rb-Sr de graniticas da zona do Arrolo do Jaques:

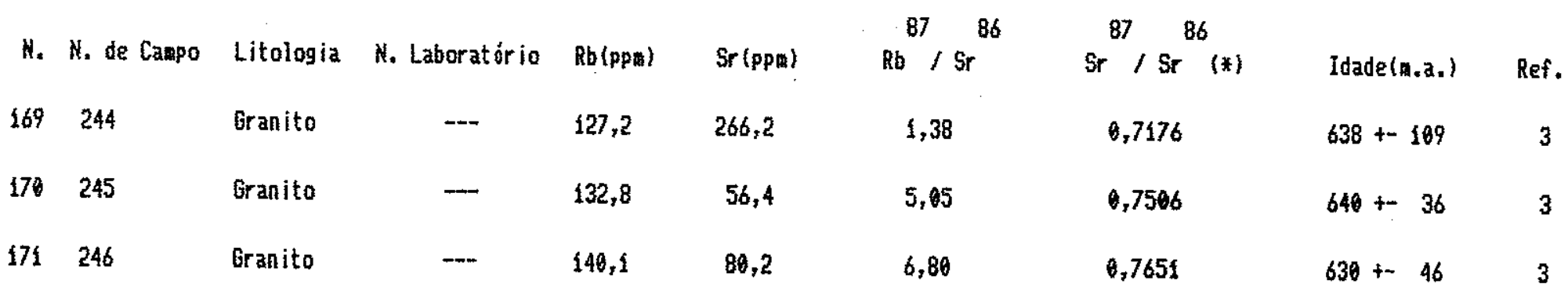

B) Análises ph-Sr de granitóides diversos da área de Vila Nová

\begin{tabular}{|c|c|c|c|c|c|c|c|c|c|}
\hline$\$ 72$ & ESJ-61 & Gnaisse & 4533 & 62,5 & 467,5 & 0,39 & $+-\theta, 01$ & $0,7080+-0,0019$ & --- \\
\hline 173 & $E S J-62$ & Gnaisse & 4534 & 71,6 & 506,2 & $\theta, 41$ & $+-0,91$ & $0,7684+-0,0012$ & $\cdots$ \\
\hline 174 & ESJ-63 & Gnaisse & 4535 & 47,4 & 485,9 & 6,28 & $+-0,01$ & $0,7070+-0,0610$ & --- \\
\hline 175 & ESJ -04 & Gnaisse & 4536 & 37,7 & 456,5 & 9,24 & $+-0,01$ & $0,7086+-0,0018$ & $\cdots$ \\
\hline 176 & ESJ-65 & Gnaisse & 4537 & 42,2 & 438,6 & 0,28 & $+0,01$ & $0,7667+-0,0609$ & - \\
\hline 177 & 252 & Migmat ito & 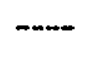 & 84,9 & 206,6 & & , 19 & 0,7145 & $566+-126$ \\
\hline 178 & 2538 & Migmat ito & - & 46,2 & 518,0 & & ,257 & 0,7063 & - \\
\hline$\$ 79$ & $253 C$ & Niguat ito & $\cdots$ & 54,3 & 390,8 & &, 461 & 0,7063 & $\cdots$ \\
\hline 180 & $R G-273.81$ & Gnaisse & 5592 & $44,61(* *)$ & $546,34(* *)$ & 0,236 & $+-8,065$ & $0,7054+0,0012$ & $\cdots$ \\
\hline 181 & $R G-273.82$ & Metatonalito & 5449 & 55,4 & 447,3 & 0,36 & $+-6,01$ & $8,7860+-0,0008$ & $\cdots$ \\
\hline
\end{tabular}


Tabela 16: Determinacões radionétricas dos gnaisses e suétes intrusivas associadas à unidade Canbai.

C) Análises Rb-Sr de granitóides diversos da área da Sanga do Velocindo e kata Grande:

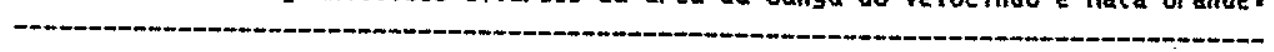

\begin{tabular}{|c|c|c|c|c|c|c|c|c|c|c|}
\hline N. & N. de Campo & Litologia & N. Laborat ório & $R b$ (pp糟) & $\operatorname{sr}(\mathrm{ppa})$ & & $18 r^{86}$ & $\mathrm{Gr}^{87} / \mathrm{Sr} \quad(*)$ & Idade(n.a.) & Ref. \\
\hline 182 & ESJ-40A & Gnaisse & 5822 & $56,29(* *)$ & $423,12(* *)$ & 0,385 & $+-9,803$ & $0,7670+-0,0009$ & $\cdots$ & 1 \\
\hline 183 & $E S J-41 B$ & Gnaisse & 5818 & 87.4 & 232,1 & 1,69 & $\pm-0,83$ & $0,7145+0,0615$ & $609+162$ & 1 \\
\hline 184 & $E S J-8-82$ & Higatito & 5609 & $31,38(* *)$ & $592,83(* x)$ & 0,153 & $+-0,005$ & $0,7052+-0,0012$ & --- & 1 \\
\hline 185 & ESS-B-69 & Higmatito & 5600 & 98,1 & 206,0 & 1,38 & $+0,84$ & $0,7170+0,0016$ & $610+130$ & 1 \\
\hline 186 & $R-4-116$ & Migmat ito & 5610 & $18,85(* *)$ & $433,37(* *)$ & 0,126 & $+-6,064$ & $0,7653+0,0017$ & -- & 1 \\
\hline 187 & $R-V I-43$ & Granodior ito & 5614 & $45,34(* *)$ & $426,26(* *)$ & 0,368 & $+-0,068$ & $0,7080+-0,0607$ & - & 1 \\
\hline 188 & $R-U I-129 A$ & Granodior ito & 5615 & $34,24(* *)$ & $871,67(* *)$ & 0,114 & $+-0,003$ & $0,7655+-0,0012$ & -- & 1 \\
\hline 189 & $254 \mathrm{~A}$ & Granito & - & 20,6 & 926,0 & & 0,865 & 0,7037 & -- & 8 \\
\hline
\end{tabular}


Tabela 16: Determinarốes radiométricas dos gnaisses e suites intrusivas associadas à unidade Canbai.

0) Anál ises Rb-Sr de granitóides diversos da área do Arroio Caubaizinho:

\begin{tabular}{|c|c|c|c|c|c|c|c|c|c|}
\hline \multirow{3}{*}{190} & \multirow{3}{*}{$\begin{array}{l}\text { H. de Campo } \\
\text { MR-64 }\end{array}$} & \multirow{3}{*}{$\begin{array}{l}\text { Litologia } \\
\text { Honzogranito }\end{array}$} & \multirow[b]{2}{*}{ H. Laboratório } & \multirow[b]{2}{*}{ Rb (pp田) } & \multirow[b]{2}{*}{ Sr (pp困) } & \multirow{2}{*}{${ }_{\mathrm{Rb}}^{87} / \mathrm{Sr}^{86}$} & \multirow{2}{*}{$\mathrm{Sr}^{87} \mathrm{Sr}^{86}(*)$} & \multirow[b]{2}{*}{ Idade(n.a.) } & \multirow{3}{*}{$\begin{array}{l}\text { Ref. } \\
15\end{array}$} \\
\hline & & & & & & & & & \\
\hline & & & 7134 & 121,6 & 181,1 & $1,946+-6,655$ & $0,72321+-8,00648$ & $655+-76$ & \\
\hline 191 & r $\operatorname{R} R=05$ & Granodior ito & 7133 & 82,6 & 176,9 & $1,343+\cdots, 038$ & $0,71591+0,06050$ & $570+-109$ & 15 \\
\hline 192 & KR -15 & Granodior ito & 7130 & 59,4 & 334,6 & $0,514+-0,015$ & $0,70829+-8,60032$ & $\cdots$ & 15 \\
\hline 193 & $1 R^{2}-2 \theta C$ & Granodior ito & 7129 & 119,6 & 221,1 & $1,567+-8,644$ & $0,71783+-0,60049$ & $574+93$ & 15 \\
\hline 194 & $4 k^{2}-55$ & Honzogranito & 7128 & 110,5 & $\$ 49,5$ & $2,138+-0,060$ & $0,72377+-B, 60628$ & $616+-68$ & 15 \\
\hline 195 & $8 R-88 A$ & Granodior ito & 7258 & 98,4 & 260,2 & $1,095+-0,031$ & $0,71347+-0,00612$ & $543+-129$ & 15 \\
\hline 196 & $K R-88 C$ & ronzogranito & 7257 & 96,8 & 261,4 & $1,006+-0,028$ & $0,71298+-0,00015$ & $557+-140$ & 15 \\
\hline 197 & Rik $-88 E$ & Granodior ito & 7131 & 82,2 & 313,5 & $0,759+0,021$ & $0,71154+-0,06250$ & -- & 15 \\
\hline 198 & $1 k-98$ & Granodior ito & 7132 & 125,2 & 181,0 & $2,665+-6,657$ & $0,72259+-0,80640$ & $615+-73$ & 15 \\
\hline 199 & 250 & Hignat ito & -7 & 83,5 & 91,9 & 2,63 & 0,7274 & $596+-59$ & 8 \\
\hline 280 & {$[R-487.8$} & Granodior ito & 5449 & 123,3 & 985,6 & $0,36+-0,01$ & $0,7079+-6,0066$ & י & 21 \\
\hline
\end{tabular}


Tabela 16: Deterninarỗes radiométricas dos gnaisses e suites intrusivas associadas à unidade Cambai.

E) Análises Rb-sr dos gnaisses dioriticos de vila Nova:

\section{n. $\mathrm{na}$}

N. N. de Campo Sub-area fig.5 Litologia

N. Laborat. Rb(ppe) Sr(ppa)

$87 \quad 86$

201 ESJ-AI

202 ESJ-A2

203 ESJ-A3

204 ESJ-6R-4 IV

205 ESJ $-6 R-5$ IV

266 ESJ $-6 R-6$ IV

267 ESJ-6R-8 IV

268 ESJ $-6 R-9$ IV

269 ESJ-AL -7
I Gnaisse dioritico 7998

2 Gnaisse dioritico 7999

3 Gnaisse dioritico 8000

4 Gnaisse dioritico 8001

5 Gnaisse dioritico 8902

6 Fnaisse dioritico 8003

7 Enaisse dioritito 8964

8 Gnaisse dioritico 8905

$9 \quad$ Gnaisse granitico 7997
$60,2 \quad 532,4 \quad 0,327+0,609$

$38,8 \quad 625,5 \quad 0,179+-0,005$

$67,5 \quad 601,8 \quad 0,325+-0,669$

$56,4 \quad 570,9 \quad 0,286+0,008$

$38,6 \quad 482,1 \quad 0,232+-0,607$

$62,8 \quad 484,5 \quad 0,375+0,011$

$31,3 \quad 509,1 \quad 0,478+0,005$

$75,0 \quad 377,3 \quad 0,575+0,016$

$99,0 \quad 338,0 \quad 0,848+-0,624$

$$
s r^{87} / s r^{86}
$$

Ref.

$0,70668+0,00024$

$0,70553+-0,00015$

$0,70690+-0,00092$

$0,70691+0,00025$

$0,70618+-0,00022$

$0,70772+0,00015$

$0,70557+0,00634$

$0,70950+0,00011 \quad 1$

$0,71169+-0,00016 \quad 1$

F) Análises Rb-5r dos tonalitos e trondhjemitos de Vila Nova:

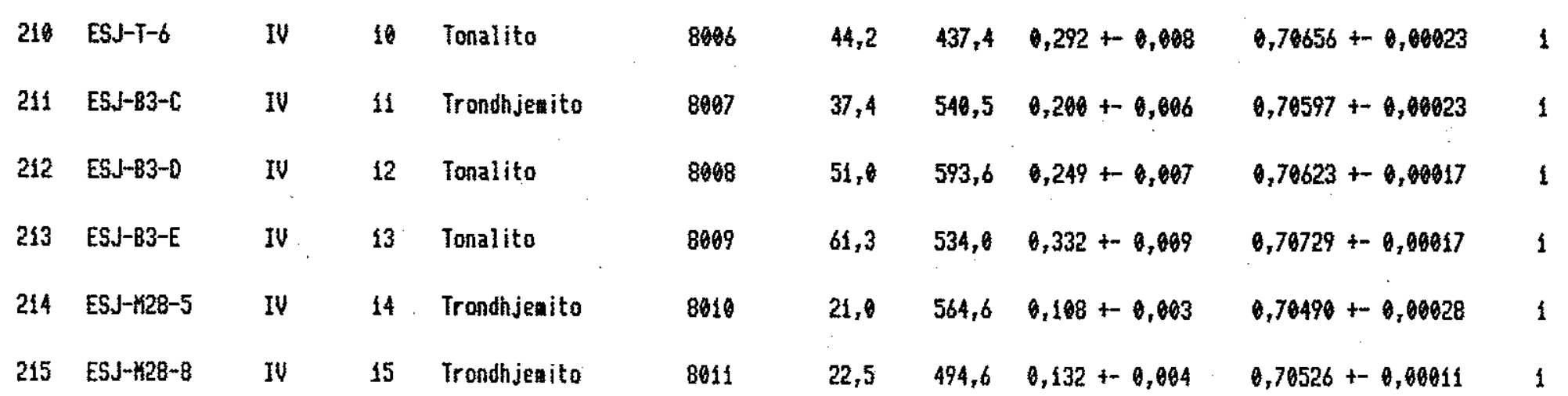


Tabela 16: Detersinaç̃es radiométricas dos gnaisses e suétes intrusivas associadas à unidade Cambai.

G) Análises Rb-Sr dos granodioritos e adamelitos de Vila Nova:

M. N. de Campo Sub-area fig.50

216 ESJ-AT-4 IIIA 16 Adamelito

217 ESJ-AL-2 IIIC 17 Adanelito

218 ESJ-AL-3 IIIC 18 Adamelito 8016

219 ESJ-C6-8 I 19 Granodiorito 8017

220 ESJ-C8 I 20 Granodiorito 8018

221 ESJ-G1 IV

222 ESJ-8D-3 II

223 ESJ-RPH-54 II
N. Laborat. Rb(ppa) $\mathrm{Sr}(\mathrm{ppq}) \quad \mathrm{Rb}^{87} / \mathrm{Sr}$

8786

$\begin{array}{ll} & \text { loade Ref } \\ \left(a_{*} a_{2}\right)\end{array}$

$8014 \quad 70,4 \quad 232,7 \quad 0,876+0,025 \quad 0,71217+0,00020 \quad-\quad 1$

$8015 \quad 53,3 \quad 301,4 \quad 0,512+-0,014 \quad 0,70861+0,00021 \quad \ldots \quad 1$

$62,8 \quad 284,7 \quad 0,639+0,018 \quad 0,70962+0,00021 \quad-\quad 1$

$78,8 \quad 282,3 \quad 0,868+0,023 \quad 0,71156+-0,00034 \quad \cdots \quad 1$

$81,3 \quad 233,8 \quad 1,607+0,628 \quad 0,71326+0,60015 \quad \cdots \quad 1$

$55,1 \quad 457,5 \quad 0,349+0,010 \quad 0,70749+0,00016 \quad \cdots, \quad 1$

$58,0 \quad 389,2 \quad 0,431+0,012 \quad 0,70786+-0,00099-1$

$62,2 \quad 325,7 \quad 0,553+-0,016 \quad 0,70886+-0,00049 \quad \ldots$

H) Análises Rb-Sr dos pegeatitos de Vila Nova:

$\begin{array}{lllllllllll}224 & \text { ESJ-RPH-51 } & \text { II } & 24 & \text { Peguatito } & 8621 & 74,6 & 834,9 & 0,259+0,007 & 0,70652+-0,00017 & -\cdots \\ 225 & \text { ESJ-RPH-53 } & \text { II } & 25 & \text { Pegnatito } & 8022 & 96,9 & 876,3 & 0,320+0,069 & 0,70715+-0,00009 & -0 \\ 226 & \text { ESJ-RPH-59 } & \text { II } & 26 & \text { Peguatito } & 8023 & 124,7 & 852,3 & 0,423+0,012 & 0,70806+0,00020\end{array}$

1) Análises Rb-Sr de outros tipos litológicos de Vila Nova:

\begin{tabular}{|c|c|c|c|c|c|c|c|c|c|c|}
\hline 227 & ESJ-EB-1 & IV & 27 & Anfibolito & 8812 & 53,6 & 743,4 & $0,209+-0,006$ & $0,70532+-0,00011$ & - \\
\hline 228 & ESJ-RT-II & IIIB & 28 & Riolito & 8020 & 300,8 & 50,9 & $\{7,306+-0,484$ & $0,82758+-0,00025$ & $497+-16$ \\
\hline
\end{tabular}


Tabela 17: Deterninąôes radiométricas Rb-Sr dos aetagranitóides Canbai na Região de Palaa e Arroio do Jaques.

\begin{tabular}{|c|c|c|c|c|c|c|c|c|}
\hline & & & & & & $87 \quad 86$ & $87 \quad 86$ & \\
\hline N. & N. de Campo & Litologia & N. Laborat ór io & $R b(p p m)$ & $\operatorname{Sr}(\mathrm{pP})$ & Rb / Sr & $\mathrm{Sr} / \mathrm{Sr} \quad(*)$ & Ref. \\
\hline 236 & LK-445 & Metadior ito & 5448 & 107,8 & 235,1 & $1,33+6,63$ & $0,7174+0,0007$ & 21 \\
\hline 231 & 243 & Graisse & $\cdots$ & 2,5 & 648,6 & $\theta, 011$ & 0,7050 & 8 \\
\hline 232 & ESJ-L-3 & Honzodior ito & 5667 & $71,66(* x)$ & $629,49(* *)$ & $0,327+0,068$ & $0,7679+0,0017$ & 1 \\
\hline 233 & $E S J-L-5$ & Diorito & 5668 & $28,90(* *)$ & $974,34(* x)$ & $0,686+-6,003$ & $0,7060+0,0012$ & 1 \\
\hline 234 & ESJ-FPA-1 & Hetagranito & 5611 & $61,74(* *)$ & $690,77(* *)$ & $0,259+-0,006$ & $0,7082+-0,6014$ & 1 \\
\hline 235 & ES.J-PA-2 & Ketagranito & 6333 & 57,6 & 666,7 & $0,250+0,007$ & $0,76645+-0,06029$ & 1 \\
\hline 236 & ES $3-F P A-3$ & hetagranito & 6334 & 38,9 & 633,8 & $0,178+-0,005$ & $0,76564+-0,00028$ & 1 \\
\hline & ES.J-FPA-4 & Hetagranito & 5612 & $49,27(* x)$ & $1006,12(* *)$ & $0,142+-0,064$ & $0,7054+0,0010$ & 1 \\
\hline
\end{tabular}


Tabela 18: Determinatôes radiozétricas Rb-Sr dos metagranitóides Caabai na Região do Cerro Hant iqueiras.

A) Metagranitóides transamazônicos:

\begin{tabular}{|c|c|c|c|c|c|c|c|c|}
\hline \\
\hline & & & & & & $87 \quad 86$ & $87 \quad 86$ & \\
\hline N. & N. de Campo & Litologia & N. Laboratório & Rb (pp畔) & $\operatorname{Sr}(p p q)$ & $\mathrm{Rb} / \mathrm{sr}$ & $\mathrm{Sr} / \mathrm{Sr} \quad(*)$ & Ref, \\
\hline 238 & $E S J-\{1 B(+)$ & Gnaisse & 5266 & $45,18(* *)$ & $952,47(* *)$ & $0,137+0,004$ & $0,7078+-0,0018$ & 1 \\
\hline 239 & $E S J-\{1 E(t)$ & Gnaisse & 5268 & 107,6 & 384,7 & $0,81+0,82$ & $0,7274+-0,0613$ & 1 \\
\hline 240 & ESJ-14B & Gnaisse & 5269 & $7,17(* *)$ & 467,8 & $0,644+-0,001$ & $0,7057+-0,0010$ & 1 \\
\hline 241 & ESJ-14C. & Gnaisse & 5270 & $1,79(* *)$ & 516,4 & $\theta, 010+0,001$ & $0,7043+-0,0007$ & 1 \\
\hline 242 & ESJ $14 E$ & Gaaisse & 5271 & $11,30(* *)$ & 268,3 & $0,157+6,684$ & $0,7082+-0,0003$ & 1 \\
\hline
\end{tabular}

B) Metagranitóides brasilianos:

\begin{tabular}{|c|c|c|c|c|c|c|c|}
\hline 243 & 2378 & Higmatito & $\cdots$ & 39,5 & 476,6 & 0,239 & 0,7039 \\
\hline 244 & $237 c$ & Migmat ito & - & 67,1 & 587,0 & 0,330 & 0,7047 \\
\hline 245 & 2370 & Higmat ito & .... & $28 x^{2}$ & $8 B \theta, 0$ & 0,093 & 0,7030 \\
\hline 246 & $237 E$ & Higmat ito & $\cdots$ & 41,1 & $428, \theta$ & 0,283 & 0,7075 \\
\hline 247 & 239 & Anfibolito & --- & 22,8 & 915,0 & 0,072 & 0,7023 \\
\hline
\end{tabular}

(t) Amostras do Bloco Taquar eabio. 
Tabela 18: Deterninąốes radiométricas Rb-Sr dos aetagranitóides Cambai na Regiâo do Cerro Mantiqueiras.

C) Ketagranitóides de posicẫo isocrônica indefinida:

\begin{tabular}{|c|c|c|c|c|c|c|c|c|}
\hline & & & & & & $87 \quad B 6$ & $87 \quad 86$ & \\
\hline N. & N. de Campo & Litologia & N. Laboratório & 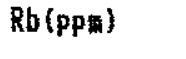 & Sr(ppi) & $R b / S r$ & $\mathrm{Sr} / \mathrm{Sr} \quad$ (*) & Ref. \\
\hline 248 & $L K-396$ & Enaisse & 5593 & $20,65(* *)$ & $301,48(* *)$ & $0,192+-0,006$ & $0,7658+-0,0065$ & 21 \\
\hline 249 & Pris-74 & Gnaisse & 6538 & $\{4,4(* *)$ & 389,4 & $0,123+8,064$ & $0,76460+-0,06887$ & 13 \\
\hline 250 & PH-81 & Gnaisse & 6537 & $9,4(* *)$ & 479,6 & $0,057+-0,002$ & $0,70456+-0,60054$ & 13 \\
\hline 251 & PX-95B & Gnaisse & 6539 & $16,5(* *)$ & 619,4 & $0,677+-0,003$ & $0,70439+-0,60639$ & 13 \\
\hline 252 & PH-95H & Gnaisse & 6540 & $16,1(* *)$ & 324,6 & $0,143+-0,605$ & $0,70483+-0,00033$ & 13 \\
\hline 253 & $P \&-95.5$ & Gnaisse & 6619 & $23, \theta(* *)$ & 694,1 & $0,096+-0,004$ & $0,70446+0,60052$ & 13 \\
\hline 254 & $E S J-15 B$ & Anfibolito & $=5272$ & $17,09(* *)$ & 245,3 & $0,202+-0,006$ & $0,78670+-0,60690$ & 1 \\
\hline 255 & $E S J-15 C$ & Anfibolito & 5273 & $25,99(* *)$ & $294,88(* *)$ & $8,255+-0,088$ & $0,7070+0,0031$ & 1 \\
\hline
\end{tabular}


Tabela 19: Deterninacôes radiométricas Rb-Sr do Complexo Granulitico Santa Maria Chico.

A) Anál ises realizadas no CPGeo-IG/USP e no NCGG-UFPA:

\begin{tabular}{|c|c|c|c|c|c|c|c|c|c|}
\hline & & & & & & & $87 \quad 86$ & 67 & \\
\hline N. & N. de Campo & Litologia & N. Laboratório & $\mathrm{Rb}$ (ppm) & Sr (ppin) & $R \mathbf{b}$ & $/ \mathrm{Sr}$ & $\mathrm{Sr} / \mathrm{Sr}(*)$ & Ref. \\
\hline 256 & $A F L-13 / I$ & Gnais5e & 4085 & 57,7 & 923,3 & 0,181 & $1+-0,005$ & $0,7072+-0,0006$ & 20 \\
\hline 257 & $A F L-13 / I V$ & Gnaisse & 4086 & 12,9 & 995,3 & 0,037 & $7+-0,001$ & $0,7031+0,0008$ & 20 \\
\hline 258 & AFL-13/N & Gnaisse & 4462 & 11,1 & 985,4 & 0,633 & $3+-0,001$ & $0,7030+-0,0023$ & 20 \\
\hline 259 & AFL-13/UII & Gnaisse & 4987 & $49,94(* *)$ & $1.020,27(* *)$ & 0,139 & $9+-0,003$ & $0,7056+-0,0015$ & 1 \\
\hline 260 & AFL- $\{3 /$ VIII & Gna isse & 5311 & $10,16(* x)$ & $1.088,4$ & 0,027 & $7+-0,001$ & $0,7032+-0,0016$ & 1 \\
\hline 261 & AFL-I/I & Granulito & 4982 & $\cdots$ & -- & & - & $0,7020+0,0901$ & 1 \\
\hline 262 & $A F L-1 / I U$ & Granulito & 4983 & -- & $\ldots$ & & -- & $0,7018+-0,0011$ & 1 \\
\hline 263 & AFL-I/NI & $\checkmark$ Granulito & 4984 & - & - & & $-\cdots$ & $0,7622+0,0012$ & 1 \\
\hline 264 & $A F[-3 / 1]$ & Granulito & 4985 &.--- & $\cdots$ & & --- & $0,7629+-0,6069$ & 1 \\
\hline 265 & $A F L-5 / I I$ & Gnaisse & 4986 & - & $-m$ & & - & $0,7040+0,0010$ & 1 \\
\hline 266 & Af $[-5 / H$ & Gnaisse & 4987 & $\cdots$ & $-\infty-\infty$ & & $\cdots$ & $0,7028+-0,0607$ & 1 \\
\hline
\end{tabular}


Tabela 19: Deterwinacöes radionétricas Rb-Sr do Complexo Granulitico Santa haria Chico.

B) Análises realizadas no I6S-Londres:

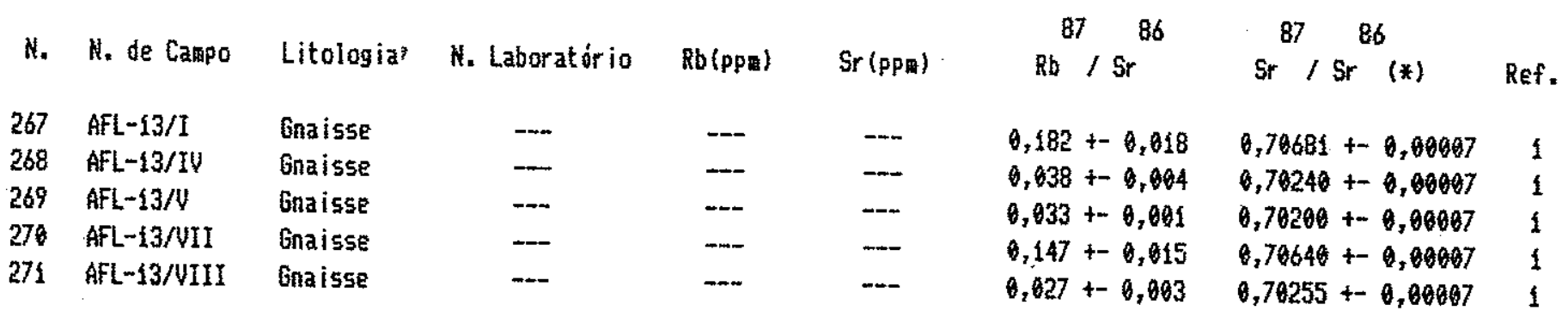

C) Análises Rb-Sr de outros granitóides fol iados do Bloco Taquarestó:

\begin{tabular}{|c|c|c|c|c|c|c|c|c|c|}
\hline 272 & $G F .460 .1$ & Gnaisse & 5450 & 103,5 & 725,2 & 0,41 & $\pm-6,01$ & 6,7118 & $+0,0007$. \\
\hline 273 & GF 540 & Dacito & 5441 & 69,6 & 873,7 & 9,23 & $+-\theta_{2} 01$ & 0,7091 & $+0,0009$ \\
\hline 274 & PTT-VII-79 & Gnaisse & 5824 & 54,7 & $1.650,3$ & 0,15 & $+-0,64$ & 0,7684 & $+0,0009$ \\
\hline 275 & PIT-UIII-251 & Gnaisse & 6335 & 108,4 & 630,4 & 0,498 & $+0,014$ & 6,71103 & $+0,00017$ \\
\hline 276 & PTT-III-115 & Enaisse & 6336 & 77,3 & 478,3 & 0,468 & $+6,013$ & 0,71565 & $+-0,06006$ \\
\hline 277 & PTT-11-99 & Gnaisse & 5823 & 92,7 & 397,0 & 0,68 & $+-8,819$ & 0,7175 & $\pm-0,0014$ \\
\hline 278 & ESJ-1LB(t) & Gnaisse & 5266 & $45,18(* *)$ & $952,47(* *)$ & 0,137 & $+0,004$ & 0,7078 & $+-0,0018$ \\
\hline 279 & $E S,-11 E(t)$ & Gnaisse & 5268 & 107,6 & 384,7 & 0,81 & $+-\theta, 02$ & 0,7274 & $\pm-0,0013$ \\
\hline 280 & $E S J-14 B$ & Gnaisse & 5269 & 7,17 (**) & 467,8 & 0,044 & $+0,041$ & 0,7657 & $+-0,0010$ \\
\hline 281 & $E S J-14 C$ & Gnaisse & 5270 & $1,79(* *)$ & 516,4 & 0,010 & $+-6,001$ & 0,7043 & $\pm-0,0607$ \\
\hline 282 & $E S J-14 E$ & Gna isse & 5271 & $11,36(* *)$ & 268,3 & 0,157 & $+-0,004$ & 0,7082 & $+0,0003$ \\
\hline
\end{tabular}


Tabela 26: Determinacôes radiozétricas K-Ar do Bloca Taquareabó.

\begin{tabular}{|c|c|c|c|c|c|c|c|c|c|}
\hline \multirow{2}{*}{ N. } & \multirow{2}{*}{ N. de Campo } & \multirow[b]{2}{*}{ Litologia } & \multirow[b]{2}{*}{ Haterial } & \multicolumn{3}{|r|}{40} & \multirow[b]{2}{*}{ ZAr at } & \multirow[b]{2}{*}{ Idade(佂.a.) } & \multirow[b]{2}{*}{ Ref. } \\
\hline & & & & N. Laboratório & $\not K$ & Ar $\operatorname{rad}($ ce STP $/ g)$ & & & \\
\hline & & & & & & -5 & & & \\
\hline 20.5 & AtL $-1 / L V$ & Grañllito & Plagioclásio & $428 i$ & 0,1371 & $0,4786 \times 16$ & 46,86 & $730+-27$ & 1 \\
\hline 284 & AFL- $-1 / \mathrm{IN}$ & Granulito & Anfibúlio & 4284 & 0,3266 & $0,3128 \times 10$ & 2,65 & $1.555+-38$ & 1 \\
\hline 285 & AFL-4/I & Granul ito & Anfibólio & 4282 & 0,3227 & $0,3265 \times 10$ & 4,75 & $1.595+-62$ & 1 \\
\hline 286 & AFL $-4 / I$ & Granul ito & Plagioclásio & 4283 & 0,2402 & $\begin{array}{r}0.1293 \times 10 \\
-5\end{array}$ & 8,26 & $1.028+-26$ & 1 \\
\hline 287 & $6 F-493$ & Anfibolito & Anfibólio & 4709 & 0,4179 & $\begin{array}{r}4,995 \times 10 \\
-5\end{array}$ & 0,42 & $1.796+-54$ & 21 \\
\hline 288 & GF-497 & Gabro & Playioclásio & 4704 & 0,3878 & $\begin{array}{r}1,238 \times 10 \\
-5\end{array}$ & 18,44 & $677+36$ & 21 \\
\hline 289 & $6 F-517.1$ & Anortosito & Plagioclásio & 4785 & 0,1468 & $\begin{array}{r}0,4647 \times 10 \\
-4\end{array}$ & 31,11 & $674+-30$ & 21 \\
\hline 290 & $A L-1-R S$ & Granulito & Feldspato & 4911 & 2,664 & $\begin{array}{r}2,3276 \times 10 \\
-5\end{array}$ & 2,1 & $1.731+-41$ & 4 \\
\hline 291 & ESJ-66 & Anortosito & Plagioclásio & 4481 & 0,2077 & $\begin{array}{r}0.5438 \times 10 \\
-4\end{array}$ & 35,27 & $574+21$ & 1 \\
\hline 292 & ESJ-48 & Granodior ito & Biotita & 4957 & 3,3681 & $\begin{array}{r}0,8025 \times 10 \\
-3\end{array}$ & 6,05 & $528+-8$ & 1 \\
\hline 273 & ES, $3-49$ & ranitoide porfir. & Biotita & 4959 & 7,3851 & $0,1962 \times 10$ & 3,20 & $581+-26$ & 1 \\
\hline
\end{tabular}


Tabela 21: Deterainacỗes radionétricas Pb-Pb do Complexo Granulítico Santa har ia Chico.

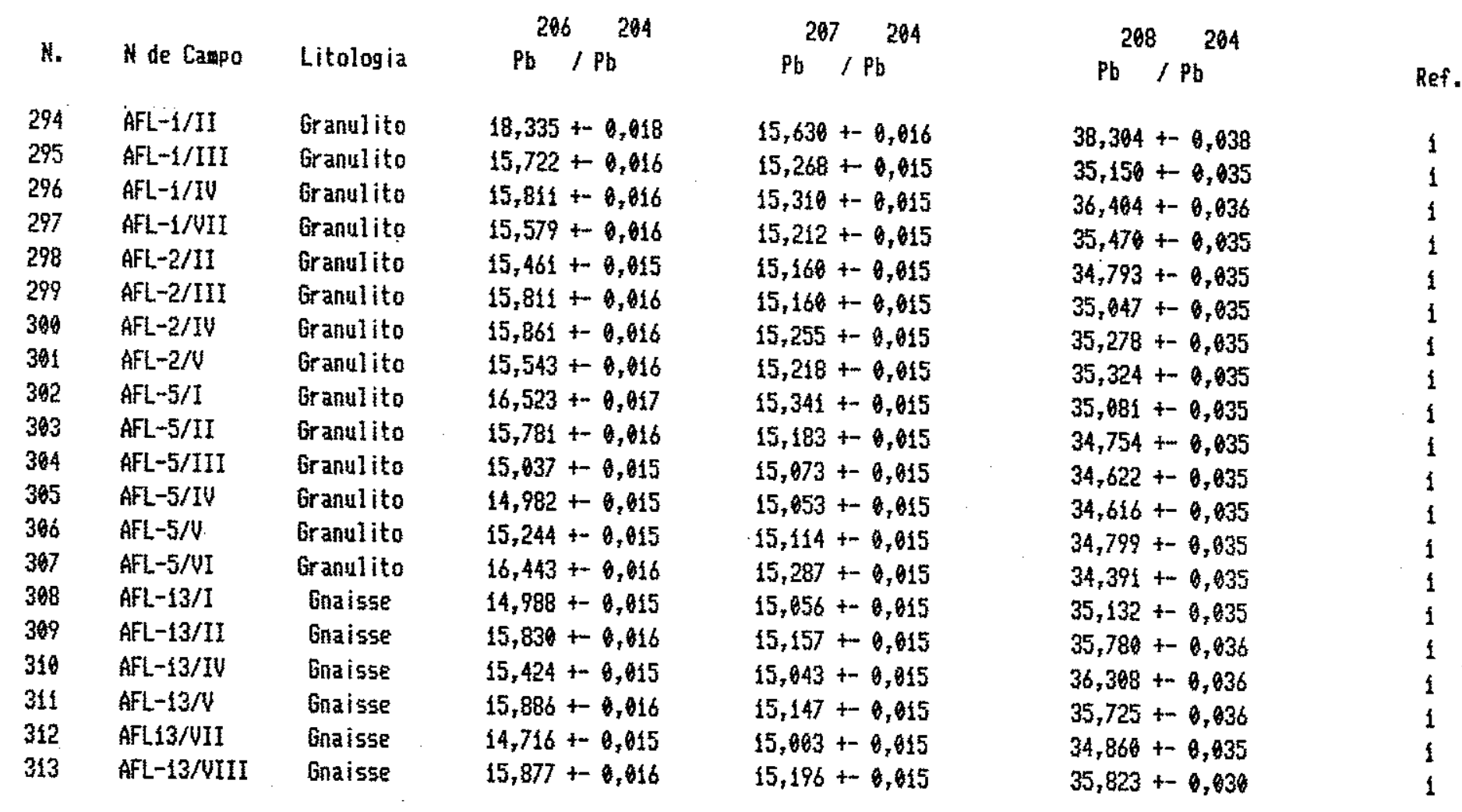


Tabela 22: Deterainacôes radionétricas por Trąos de Fissão do Complexo Granulitico Santa Mar ia Chico:

\begin{tabular}{|c|c|c|c|c|c|c|c|c|c|c|c|}
\hline N. N. de Campo & Litologia & Material & Temperatura(QC) & & $\cos$ & fósseis & Tra & $\cos$ & induzidos & & \\
\hline & & & & & & 52 & & & 52 & & \\
\hline & & & & $N$ & $n$ & $0 f+-10(10 / c)$ & $n$ & $\mathrm{n}$ & Dit-10(10/ca) & Idade(n.a.) & Ref. \\
\hline 314 AFL-2 & Granul ito & Apatita & Alabiente & 265 & 40 & $6,57+-0,37$ & 343 & 40 & $8,51+0,49$ & $214+-17$ & 14 \\
\hline & & & 300 & 226 & 40 & $5,60+-0,26$ & 288 & 40 & $7,14+-0,33$ & $217 \div-14$ & 14 \\
\hline & & & 310 & 190 & 40 & $4,46+-0,24$ & 231 & 40 & $5,73+0,43$ & $215+-20$ & 14 \\
\hline & & & 320 & 138 & 40 & $3,42+-0,32$ & 173 & 40 & $4,29+-0,25$ & $220+-24$ & 14 \\
\hline
\end{tabular}

Obs.: O teapo de aquecinento das amostras, conforme a coluna 5 , foi de 1 hora. 
Tabela 23: Deterninacôes radợioútricas do Conplexo Granitico de São Sepé.

A) Análises Rb-Sr do granitos monzoniticos da parte central:

\begin{tabular}{|c|c|c|c|c|c|}
\hline N. & N. de Campo & Litologiz & N. Laboratório & $R b$ (pps) & $\operatorname{Sr}(p)$ \\
\hline 315 & 38 & Granito & - & 139,4 & 181,9 \\
\hline & 61 & Granito & $\cdots$ & 157,0 & 155, \\
\hline 317 & 66 & Granito & $\cdots$ & 94,4 & 226, \\
\hline 318 & 128 & Granito & $-\infty$ & 78,3 & 256, \\
\hline & 135 & Granito & $-\cdots$ & 151,0 & \$79, \\
\hline
\end{tabular}

\begin{tabular}{|c|c|c|c|}
\hline \multirow{2}{*}{$\mathrm{Rb}^{87} / \mathrm{Sr}$} & \multicolumn{3}{|l|}{$87 \quad 86$} \\
\hline & $\operatorname{Sr} / 5 r \quad(*)$ & Idade(a.a.) & Ref. \\
\hline $223+-0,063$ & $0,72732+-0,00144$ & $704+-80$ & 18 \\
\hline$, 935+0,083$ & $0,73441+-0,00126$ & $703+-60$ & 18 \\
\hline $1,208+-0,033$ & $0,71769+-0,06108$ & --- & 18 \\
\hline $6,885+0,825$ & $0,71480+0,00143$ & - & 18 \\
\hline $2,438+-0,0.69$ & $0,72941+-0,90080$ & $702+-65$ & \\
\hline
\end{tabular}

B) Análises Rb-Sr dos granitos subalcalinos periféricos:

\begin{tabular}{|c|c|c|c|c|c|c|c|c|}
\hline 320 & 29 & Granito & - & 232,6 & 21,4 & $32,208+-8,921$ & $\theta, 94819+-0,00120$ & $530+-16$ \\
\hline 322 & 34 & Granito & $\cdots$ & 251,8 & 84,8 & $7,268+-0,266$ & $0,76199+-0,00114$ & $550+-27$ \\
\hline 322 & 84 & Granito & - & 249,8 & 45,4 & $16,124+0,459$ & $6,83150+-6,60191$ & $551+-20$ \\
\hline 323 & 91 & Granito & $\cdots$ & 184,9 & 15,2 & $36,144+-1,035$ & $0,97641+0,06126$ & $527+-16$ \\
\hline 324 & 132 & Granito & - & 237,0 & 35,7 & $19,493+-0,555$ & $0,85367+-0,06288$ & $535 t-20$ \\
\hline 325 & 133 & Granito & $\cdots$ & 209,9 & 51,7 & $11,694+-0,248$ & $0,79812+-6,60678$ & $551+-20$ \\
\hline 326 & 256 & Granito & - & 183,2 & 64,5 & $8,272+6,234$ & $6,76999+-0,00124$ & $551+-25$ \\
\hline 327 & 266 & Granito & -- & 197,0 & 14,1 & 36,2 & 0,9810 & $-\cdots$ \\
\hline 328 & $267 \mathrm{~A}$ & Granito & - & 239,3 & 39,9 & 17,5 & 0,8359 & $523+17$ \\
\hline 329 & 268 & Granito & -- & 184,9 & 43,6 & 12,4 & 0,7986 & $530+-19$ \\
\hline
\end{tabular}


Tabelā 23: Deterinacốes radioaétricas do Complexo Granitico de São Sepé.

C) Análises Rb-Sr dos microgranitos intrusivos e dos riolitos do Cerro Tupanci:

\begin{tabular}{|c|c|c|c|c|c|c|c|c|c|}
\hline & & & & & & $87 \quad 86$ & $87 \quad 86$ & & \\
\hline$N_{x}$ & N. de Campo & Litologia & N. Laboratór io & $R b(p p M)$ & $\mathrm{Sr}(\mathrm{ppm})$ & $\mathrm{Rb} / \mathrm{Sr}$ & $\operatorname{Sr} / \mathrm{Sr}(*)$ & Idade (a.a.) & Ref: \\
\hline 330 & 9 & Microgranito & --- & 229,5 & 7,7 & $91,561+-2,644$ & $1,32261+-0,8041$ & $474+-14$ & 18 \\
\hline 331 & 99 & Microgranito & $-\cdots$ & 218,5 & 7,3 & $91,981+-2,683$ & $1,33385+-0,06424$ & $480+-14$ & 18 \\
\hline 332 & 120 & Microgranito & $\cdots$ & 244,9 & 6,8 & $115,689+-2,487$ & $1,4642+-0,00259$ & $420+-12$ & 18 \\
\hline 333 & 121 & Microgranito & -- & 296,2 & 7,5 & $123,642+-3,642$ & $1,53560+0,60220$ & $472+-14$ & 18 \\
\hline 334 & 129 & Kicrogranito & $-\cdots$ & 234,8 & 6,4 & $183,447+-2,364$ & $1,39361+-0,06298$ & $432+-13$ & 18 \\
\hline 335 & CT6 & Riolito & -- & 71,0 & 18,0 & $11,565+-1,326$ & $0,78609+-0,60119$ & $495+-20$ & 18 \\
\hline 336 & ci3B & Riolito & $\cdots$ & 81,1 & 14,2 & $16,718+-0,475$ & $0,82189+-0,60185$ & $491+-17$ & 18 \\
\hline
\end{tabular}

D) Análises $\mathrm{K}$-Ar de rochas relacionadas ao Complexo:

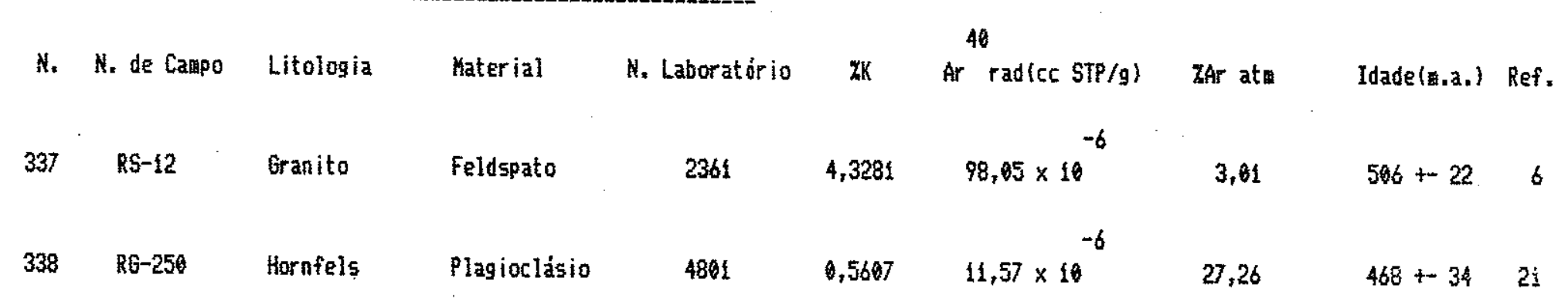


Tabela 24: Determinaçênes radiométricas das suites graniticas Ramada e Cerro da Cria.

A) Análi ses Rb-Sr dos aonzogranitos da porcẫo setentrional do "stock" da Ramada:

\begin{tabular}{|c|c|c|c|c|c|c|c|c|c|c|}
\hline N. & H. de Campo & Litologia & N. Labor at ório & $R b(p P$ 田) & Sr (ppp) & $R b^{8}$ & ${ }^{37} / \mathrm{Sr}^{86}$ & $\mathrm{Sr}^{87} / \mathrm{Sr}^{86}(*)$ & Idade (a.a.) & Ref. \\
\hline 339 & $B N-59$ & Monzogranito & 8635 & 124,3 & 162,3 & 2,221 & $+-\theta, 063$ & $0,72623+-0,00015$ & $670+-66$ & 11 \\
\hline 340 & $B N-63$ & Honzogranito & $8 \geqslant 26$ & 148,4 & 91,7 & 4,699 & $+-0,132$ & $0,74987+-0,00022$ & $536+-34$ & 11 \\
\hline 341 & $B N-64$ & Monzogranito & 8627 & $\{28,6$ & $146, \mathfrak{1}$ & 2,662 & $+-0,675$ & $0,72730+-0,00012$ & $588+-55$ & 11 \\
\hline 342 & $B N-257$ & Honzogranito & 8630 & 103,9 & 243,4 & 1,238 & $+0,035$ & $0,71901+-0,00018$ & $\cdots$ & 11 \\
\hline 343 & $B N-259$ & Honzogranito & 8031 & $\{33,8$ & 87,8 & 4,425 & $+-6,125$ & $0,74626+-0,08026$ & $559+-35$ & 11 \\
\hline 344 & $B N-247$ & Honzogranito & 8636 & 97,1 & 103,9 & 2,710 & $+-0,076$ & $0,72837+-0,00016$ & $605+-54$ & 11 \\
\hline 345 & $B N-260 A$ & Honzogranito & 8033 & 127,3 & 161,8 & 3,629 & $+-0,162$ & $0,73587+0,00010$ & $597+-42$ & 11 \\
\hline 346 & 271 & Granito & -- & 96,3 & 191,7 & & 1,45 & 0,7190 & $\cdots$ & 3 \\
\hline 347 & 272 & Eranito & --- & --- & --- & & 3,88 & 0,7373 & $\cdots$ & 3 \\
\hline 348 & 273 & Granito & - & 126,7 & 92,7 & & 3,96 & 6,7394 & $608+-41$ & 3 \\
\hline
\end{tabular}

B) Análises Rb-Sr do pertita-granito Cerro da Cria:

\begin{tabular}{|c|c|c|c|c|c|c|c|}
\hline 349 & $B N-4178$ & Sienogranito & 8037 & $\{76,87$ (**) 8,46 (**) & $61,2384+0,3949$ & $1,19715+-0 ; 00037$ & $564+-4$ \\
\hline 35 & $B N-417 B$ & Sienogranito & 8037 & $\{72,53(* *) 8,47(* *)$ & $61,7076+1,4611$ & $1,18691+-0,00482$ & $547+-14$ \\
\hline
\end{tabular}


Tabela 25: Determinacôes radiouétricas do Batólito Granitico de Cacapava do Sul.

A) Análises $R b-5 r$ :

N. N. de Campo Litologia

\begin{tabular}{|c|c|c|}
\hline 351 & $26 \theta$ & Granito \\
\hline 352 & 262 & Granito \\
\hline 353 & 263 & Granito \\
\hline 354 & $264 \AA$ & Granito \\
\hline 355 & $E S J-E P-55 C$ & Granito \\
\hline 356 & $\mathrm{C}-1$ & Leucogranito \\
\hline 357 & {$[-4$} & Leucogranito \\
\hline 358 & $c-5$ & Granodiorito \\
\hline 359 & {$[-7$} & Leucogranito \\
\hline 360 & $c-8$ & Leucogranito \\
\hline 361 & $6-18$ & Sienogranito \\
\hline 362 & $c-18$ & Honzogranito \\
\hline 363 & $c-19$ & Sienogranito \\
\hline 364 & $c-23$ & Sienogranito \\
\hline 365 & $6-25$ & Leucogranito \\
\hline 366 & $c-29$ & Honzogranito \\
\hline 367 & $c-36$ & Sienogranito \\
\hline 368 & $c-31$ & Sienogranito \\
\hline 369 & $c-33$ & Honzogranito \\
\hline 370 & $c-34$ & Granodiorito \\
\hline 371 & $c-41$ & Leucogranito \\
\hline 372 & {$[-47$} & Granodiorito \\
\hline 373 & c-11 & Honzogranito \\
\hline 374 & $c-15$ & Granodiorito \\
\hline 375 & {$[-38$} & Granodior ito \\
\hline 376 & {$[-49$} & Granadiorito \\
\hline
\end{tabular}

W. Laboratór io Rb(pps) Sr(ppw)

$\begin{array}{cc}130,6 & 28,3 \\ 70,6 & 515, \theta \\ 164, \theta & 9, \theta \\ 70,7 & 383,9 \\ 61,7 & 472,9 \\ 134,2(* *) & 28,2(* *) \\ 95,6(* *) & 35,1(* *) \\ 51,8 & 594,7 \\ 193,9(* *) & 17,5(* *) \\ 183,1(* *) & 9,6(* *) \\ 86,7(* *) & 95,8(* *) \\ 163,8 & 215,5 \\ 56,5 & 422,8 \\ 91 ; 1 & 242,5 \\ 83,3 & 163,4 \\ 78,2 & 360,3 \\ 97,5 & 158, \theta \\ 75,3 & 292,9 \\ 90,4 & 199,7 \\ 63,1 & 428,3 \\ 83, \theta(* *) & 48,1(* *) \\ 56,4 & 479,3 \\ 86,6 & 331,8 \\ 77,5 & 482,5 \\ 68,2 & 547,3 \\ 55,8 & 86,9\end{array}$

\begin{tabular}{l}
$7--$ \\
\hline-0 \\
\hline 5820 \\
7231 \\
7232 \\
7233 \\
7234 \\
7235 \\
7236 \\
7237 \\
7238 \\
7239 \\
7249 \\
7241 \\
7242 \\
7243 \\
7244 \\
7245 \\
7246 \\
7247 \\
7417 \\
7418 \\
7419 \\
7429
\end{tabular}

$87 \quad 86$

$\mathrm{Rb} / \mathrm{Sr}$
13,4

$$
0,396
$$$$
47,4
$$$$
0,532
$$

$0,38+0,01$

$7,911+0,061$ $0,252+-0,007$

$32,939+0,124$

$57,505+0,417$

$2,442+0,049$

$1,395+6,639$

$0,387+0,011$

$1,088+0,031$

$1,477+0,042$

$0,754+0,021$

$1,788+0,051$

$0,744+-0,021$

$1,311+0,637$

$0,427+0,012$

$5,060+0,020$

$0,341+0,010$

$0,756+-0,621$

$0,465+0,013$

$0,361+-0,010$

$0,332+0,099$
$87 \quad 86$

$\mathrm{Sr} / \mathrm{Sr}(*)$

Idade(m:a.) Ref.

\begin{tabular}{|c|c|}
\hline 0,8034 & $515+-18$ \\
\hline 0,7079 & -- \\
\hline$\{, 0684$ & $\cdots$ \\
\hline 0,7090 & - \\
\hline $0,7097+0,0008$ & - --- \\
\hline $0,81641+0,00052$ & $562+-11$ \\
\hline $0,76922+-0,00046$ & $567+-19$ \\
\hline $0,70528+-0,60633$ & - \\
\hline $0,96328+-8,80028$ & $550+-5$ \\
\hline $1,15583+6,00079$ & $550+-5$ \\
\hline $0,72400+-0,00039$ & $546+-59$ \\
\hline $0,71477+-0,00032$ & - \\
\hline $0,70758+-0,00024$ & ---- \\
\hline $0,71326+-0,06018$ & - \\
\hline $0,71781+-0,60011$ & $-\cdots$ \\
\hline $0,71646+-0,69628$ & $-\cdots$ \\
\hline $0,71751+-0,60024$ & $\cdots$ \\
\hline $0,71682+-0,00028$ & $\cdots$ \\
\hline $0,71452+-0,00913$ & $\cdots$ \\
\hline $0,71066+0,60015$ & --- \\
\hline $0,74445+-0,00012$ & $547+-28$ \\
\hline $0,70806+-0,00023$ & - \\
\hline $0,71191+-0,00010$ & $-\cdots$ \\
\hline $0,70849+0,06008$ & --- \\
\hline $0,70863+-0,66026$ & $\cdots$ \\
\hline $0,70988+0,00005$ & - \\
\hline
\end{tabular}


Tabela 25: Deterninacôes radionétricas do Batólito Granitico de Cacapava do Sul.
B) Análises K-Ar:

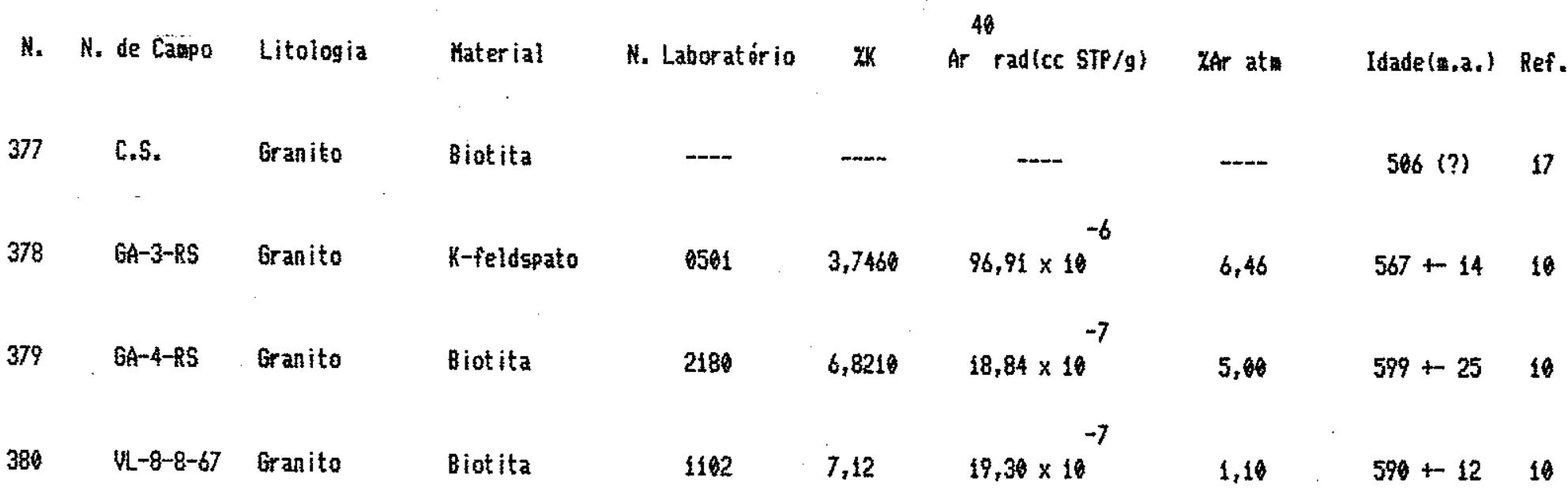


Tabela 25: Deterwinacôes radiométricas do Batólito Granitico de Cacapava do Sul.

C) Teores de Rb-St e razôes Rh/Sr por fluorescência de rajos-X (análises seai-quantitativas):

N. nas figs. Facies Rb $\mathrm{Sr} R \mathrm{Rb} / \mathrm{Sr}$ ! N. nas figs. Facies Rb $\mathrm{Sr}$ Rb/Sr ! N. nas figs. Facies $\mathrm{Rb}$ Sr Rb/Sr 67 e 70 petrográfica (ppa) (ppa) $\quad ! 67$ e 70 petrográfica (ppa) (ppm) $\quad 67$ e 70 petrográfica (ppm) (ppm)

\begin{tabular}{|c|c|c|c|c|c|c|c|}
\hline Leucogranito & $\$ 32$ & 28 & $4,743 ! 18$ & Honzogran ito & 97 & 204 & $0,473 ! 35$ \\
\hline Sienogranito & 83 & 447 & $0,187 ! 19$ & Sienogranito & 55 & 421 & $0,131 \div 36$ \\
\hline nzo-granod ior it & 08 & 473 & $0,169 ! 20$ & Sienogranito & 79 & 281 & $6,286 ! 37$ \\
\hline Leucogranito & 102 & 39 & $2,633 ! 21$ & Honzogranito & 81 & 411 & $0,197 !$ \\
\hline nzo-granod ior it & 054 & 568 & $0,095 ! 22$ & Sienogranito & 61 & 339 & $6,157 !$ \\
\hline Sienogranito & 99 & 284 & $0,349 ! 23$ & Sienogranito & 86 & 208 & $0,412 !$ \\
\hline Leucogranito & 191 & 15 & $12,651 ! 24$ & Sienogranito & 78 & 193 & $0,404 !$ \\
\hline Leucogranito & 176 & & $19,623 ! 25$ & Leucogranito & 81 & 165 & $0,491 !$ \\
\hline Sienogranito & 92 & 118 & $0,781 ! 26$ & Sienogranito & 84 & 303 & $6,277 ! 43$ \\
\hline Sienogranito & s5 & 69 & $9,867 ! 27$ & Monzogranito & 73 & 326 & $0,224 !$ \\
\hline Honzogran ito & 74 & 284 & $6,262 ! 26$ & Honzogranito & 76 & 317 & $0,240 ! 45$ \\
\hline Honzogranito & 78 & 501 & $0,155 ! 29$ & Honzogranito & 76 & 280 & $0,271 ! 46$ \\
\hline Leucogranito & 99 & 125 & $0,790 \div 30$ & Sirnogranito & 92 & 153 & $0,690 \div 47$ \\
\hline Monzogranito & 68 & 434 & $0,156 ! 31$ & Sienogranito & 76 & 280 & $0,248 ! 48$ \\
\hline Monzogranito & 74 & 491 & $0,150 ! 32$ & Honzogranito & 77 & 241 & $8,320 ! 49$ \\
\hline Sienogranito & 65 & 284 & $0,228 ! 33$ & Honzogranito & 87 & 177 & $0,493 !$ \\
\hline Sienogranito & 78 & 236 & $6,327 ! 34$ & Honzogranito & 67 & 394 & $\theta, 17 \theta !$ \\
\hline
\end{tabular}

$\begin{array}{lrrr}\text { Honzogranito } & 77 & 265 & 0,288 \\ \text { Sienogranito } & 146 & 176 & , 797 \\ \text { Monzogranito } & 61 & 251 & 0,245 \\ \text { Honzogranito } & 65 & 527 & 0,123 \\ \text { Leucogranito } & 100 & 144 & 0,695 \\ \text { Monzogranito } & 86 & 348 & 0,248 \\ \text { Leucogranito } & 84 & 43 & 1,936 \\ \text { Honzogranito } & 51 & 540 & 0,695 \\ \text { Honzogranito } & 50 & 427 & 0,118 \\ \text { Sienogranito } & 113 & 187 & 0,683 \\ \text { Honzogranito } & 71 & 396 & 0,236 \\ \text { Honzogranito } & 67 & 253 & , 266 \\ \text { Honzogranito } & 53 & 371 & 0,144 \\ \text { Honzogranito } & 69 & 277 & 0,248 \\ \text { Honzogranito } & 51 & 448 & 0,114\end{array}$


A) Análises Rb-Sr:

\begin{tabular}{|c|c|c|c|c|c|c|c|c|c|}
\hline & & & & & & $87 \quad 86$ & $87 \quad 86$ & & \\
\hline N. & N. de Campo & Litologia & N. Laboratório & $R b(p p m)$ & $\operatorname{Sr}(p p$ t) & 跔 / $\mathrm{sr}$ & Sr / Sr (*) & Idade(ma.) & Ref. \\
\hline 381 & 246 & Granito & $\cdots--$ & $(* * *)$ & $(* * *)$ & 0,360 & 0,7074 & $\cdots$ & 3 \\
\hline 382 & LS-3 & Granito & - & 288,6 & 127,1 & $4,776+0,134$ & $0,74180+-0,00185$ & - & 18 \\
\hline 383 & ES.J-LH-23C & Granito & 6892 & $\{38,0$ & 756,2 & $0,532+-6,615$ & $0,70868+-0,06648$ & $\cdots$ & 1 \\
\hline 384 & ESJ-LN-703C & Granito & 6893 & 122,6 & 926,4 & $0,383+-0,011$ & $0,70768+-0,06025$ & $\cdots$ & 1 \\
\hline 385 & ESJ-LN-605C4 & Granito & 7706 & 133,2 & 789,6 & $0,488+-0,014$ & $0,70879+-0,00015$ & $-\cdots$ & 1 \\
\hline 386 & ES.S-LN-665-C7 & Granito & 7707 & 134,1 & 847,1 & $0,458+0,013$ & $0,70853+0,00018$ & $\cdots$ & $i$ \\
\hline 387 & ESJ-LN-704C & Granito & 6980 & 136,5 & 959,6 & $0,412+-8,012$ & $0,70709+-0,00814$ & $-\cdots$ & 1 \\
\hline 388 & ES.J-LN-712CT & Granito & 7106 & 159,9 & 564,3 & $0,810+-0,023$ & $0,71086+0,00026$ & - & 1 \\
\hline 389 & ESJ-LH-712CT-11 & Granito & 7768 & 160,9 & 539,9 & $0,863+-0,024$ & $0,71280+-\theta, 06030$ & $\cdots$ & 1 \\
\hline 390 & ESJ-LH-712CT-13 & Granito & 7769 & 179,9 & 572,9 & $0,909+-0,026$ & $0,71224+0,00013$ & - & 1 \\
\hline 391 & ESJ-LN-T717 & Granito & 6894 & 195,3 & 474,6 & $1,193+-6,634$ & $0,71396+-0,06025$ & $-\cdots$ & 1 \\
\hline 392 & ESJ-LN-T796 & Granito & 6895 & 197,4 & 244,7 & $2,338+-0,066$ & $0,72339+-8,69224$ & $552+-62$ & 1 \\
\hline 393 & ES.J-LH-202-T33 & Granito & 7710 & 199,1 & 394,1 & $1,463+-6,941$ & $0,71665+-0,06814$ & $\cdots$ & 1 \\
\hline 394 & ESJ-LN-262-T36 & Granito & 7741 & 199,2 & 346,6 & $1,665+-0,047$ & $0,71865+0,00017$ & - & 1 \\
\hline 395 & ES.J-LN-765-PI & Granito & 6896 & 192,0 & 133,8 & $4,165+-0,117$ & $0,73647+-0,08030$ & $530+-37$ & 1 \\
\hline 396 & ES.J-LN-765-P2 & Granito & 6897 & 176,7 & 75,7 & $6,789+0,191$ & $0,75765+-0,00027$ & $544+-26$ & 1 \\
\hline 397 & ESJ-LN-715P & Granito & 6898 & 208,7 & 62,7 & $9,703+-0,272$ & $0,79073+-0,00650$ & $.548+\cdots 22$ & 1 \\
\hline 398 & ESJ-LN-211-P18 & Granito & 7711 & 195,2 & 118,1 & $4,801+-0,135$ & $0,74436+-0,0011$ & $574+-33$ & 1 \\
\hline 399 & ESJ-LH-211-P21 & Granito & 7712 & 489,3 & 126,9 & $4,331+-6,122$ & $0,74067+-0,06012$ & $578+-36$ & 1 \\
\hline 400 & ESJ-LN-211-P22 & Granito & 7713 & 261,5 & 147,5 & $3,965+0,112$ & $0,73569+-0,06030$ & $543+-39$ & 1 \\
\hline 401 & $E S J-L N-211-P 25$ & Granito & 7714 & 261,2 & 116,1 & $5,034+-0,142$ & $0,74565+-0,06014$ & $558+-32$ & 1 \\
\hline
\end{tabular}


Tabela 26: Determinacões radiométricas do Complexo Granitico de Lavras do Sul.

8) Análises K-Ar:

\begin{tabular}{|c|c|c|c|c|c|c|c|c|c|c|}
\hline \multirow{2}{*}{ N. } & \multirow{2}{*}{ N. de Campo } & \multirow[b]{2}{*}{ Litologia } & \multicolumn{8}{|c|}{40} \\
\hline & & & Katerial & $N=$ Laboratório & ZK & Ar $r$ & ad (ec STP/g) & Zar at & Idade (m.a.) & Ref: \\
\hline 402 & (?) & Granito & Biotita & $\cdots$ & --- & & $-\cdots--$ & $-\cdots$ & $570(?)$ & 17 \\
\hline 463 & $G A-1-R S$ & Granito & & & & & -6 & & & \\
\hline & & & telospato & 6522 & 5,1240 & &, $1 \times 10$ & 1,90 & $584+-15$ & 10 \\
\hline 484 & $V L-16-7-67$ & & & & & & -6 & & & \\
\hline & $\sqrt{2}-10-2-51$ & Granito & Biotita & 1069 & 5,2800 & & $0,8 \times 10$ & 1,84 & $582+-45$ & 10 \\
\hline 465 & $R 6-405$ & Granito & & & & & -6 & & & \\
\hline & & of ditiso & Elotita & 4774 & 6,3928 & & $2,1 \times 10$ & 2,32 & $527+17$ & 21 \\
\hline 406 & ESJ-LH-622 & Granito & & & & & -6 & & & \\
\hline & & 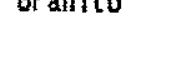 & seficita & 5436 & 8,8332 & & $4,62 \times 19$ & 5,79 & $600+-8$ & 1 \\
\hline 407 & $E S J-L N-5 E$ & Granito & Sericita & 5448 & 8,7181 & & $75 \times 10^{-6}$ & & & \\
\hline
\end{tabular}

C) Análises $86-5 r$ dos charnoquitos associados ao Complexo Granitico de Lavras do Sul:

\begin{tabular}{|c|c|c|c|c|c|c|c|c|c|}
\hline & & & & & & 87 & 87 & & \\
\hline$N=$ & N. de Campo & Litologia & N. Laboratório & $R b(p p q)$ & Sr (ppa) & $\mathrm{Rb} / \mathrm{Sr}$ & $\operatorname{sr} / \operatorname{sr} \quad(*)$ & Idade (m.a.) & Ref. \\
\hline 468 & ESJ-I -635A & Charnoquito & 5599 & 147,5 & $8\{3,4$ & $0,530+-0,015$ & $0,7091+-0,0013$ & $--\cdots$ & 1 \\
\hline & ES $]-I-644$ & Charnoquito & 5613 & 81,8 & 906,7 & $0,260+-0,008$ & $0,7070+0,0010$ & & \\
\hline
\end{tabular}


Tabela 27: Deterainatôes radiouétricas dos Sienogranitos Jaguar $i$.

A) Análi lses Rb-Sr:

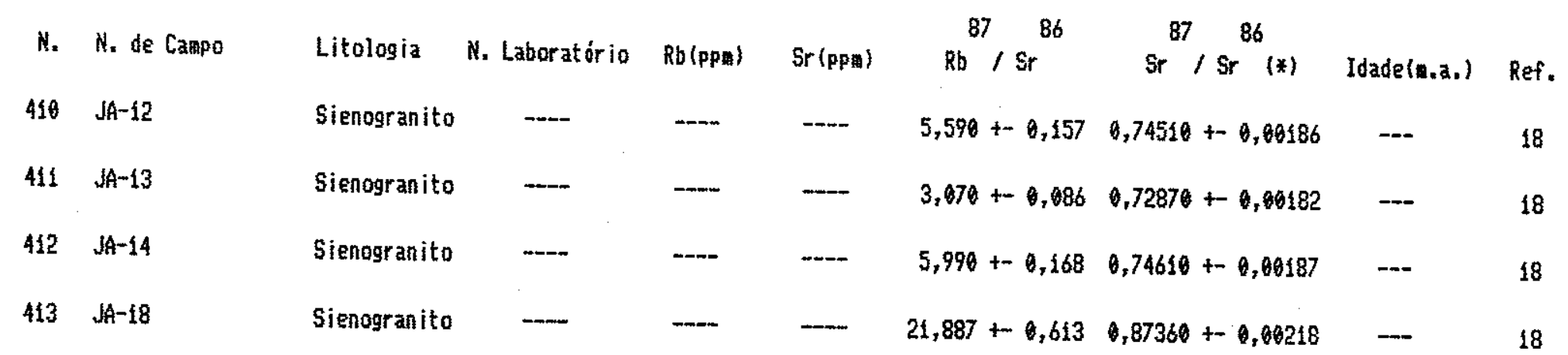

B) Análises K-Ar:

\begin{tabular}{|c|c|c|c|c|c|c|c|c|c|}
\hline & & & \multicolumn{7}{|c|}{40} \\
\hline N. & N. de Campo & Litologia & Material & N. Laboratór io & zK & Ar $\mathrm{rad}(\mathrm{ccc} \mathrm{STP} / \mathrm{g})$ & ZAr at at & Idade (m.a.) & Ref. \\
\hline 414 & $4[-12-7-67$ & Granito & Biotita & 1078 & 6,7426 & $165,4 \times 10^{-6}$ & 2,93 & $541+42$ & 10 \\
\hline 415 & $V L-12-7-67$ & Granito & Biotita & 1354 & 6,7500 & $187,0 \times 10^{-6}$ & 12,21 & $661+27$ & 10 \\
\hline 416 & $U L-13-7-67$ & Granito & Biotita & 1375 & 6,8740 & $197,7 \times 10^{-6}$ & 7,18 & $620+27$ & 6 \\
\hline
\end{tabular}


Tabela 28: Deterninacôes radionétricas da Suite Granitica Timbauva.

A) Análi ises Rb-Sr:

\begin{tabular}{|c|c|c|c|c|c|c|c|c|}
\hline N. & N. de Campo & Litologia & & & & $87 \quad 86$ & $87 \quad 86$ & \\
\hline & & & & KDPPP & $\operatorname{Sr}(\mathrm{PP}$ 畐) & $\mathrm{Rb} / \mathrm{Sr}$ & $\mathrm{Sr} / \mathrm{Sr} \quad(*)$ & Ref. \\
\hline 417 & $6-63$ & Tonalito & 6541 & 99,0 & 296,8 & $0,966+-0,027$ & $0,71344+-0,60006$ & 12 \\
\hline 418 & $4 N-63 A$ & Tonal ito & 6542 & 86,6 & 331,5 & $0,756+-0,021$ & $0,71080+0,00032$ & 12 \\
\hline 419 & $\operatorname{kin}-167$ & Granodiorito & 6543 & 110,6 & 270,6 & $1,184+-6,633$ & $0,71606+-0,00011$ & 12 \\
\hline 420 & $B N-199 A$ & Granodior ito & 6544 & 78,2 & 386,6 & $0,586+0,017$ & $0,71036+-0,00068$ & 12 \\
\hline 421 & $H M-201 A$ & Granodiorito & 6545 & 118,8 & 273,2 & $1,260+-0,036$ & $0,71627+-0,60023$ & 12 \\
\hline 422 & $k m-264$ & Granodiorito & 6546 & 96,2 & 317,7 & $0,822+0,023$ & $0,71209+0,00042$ & 12 \\
\hline
\end{tabular}

B) Anál ises K-Ar:

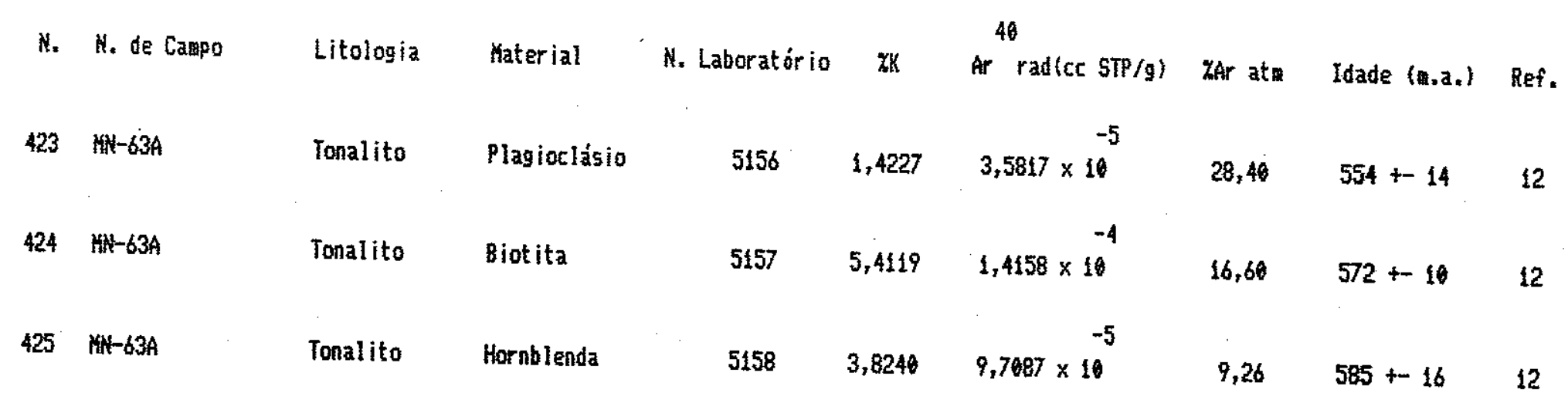


Tabẹla 29: Deterainać̂́es radiométricas das suites graniticas intrusivas no Bloco Taquarembó.

A) Complexo Granitico Santo Afonso:

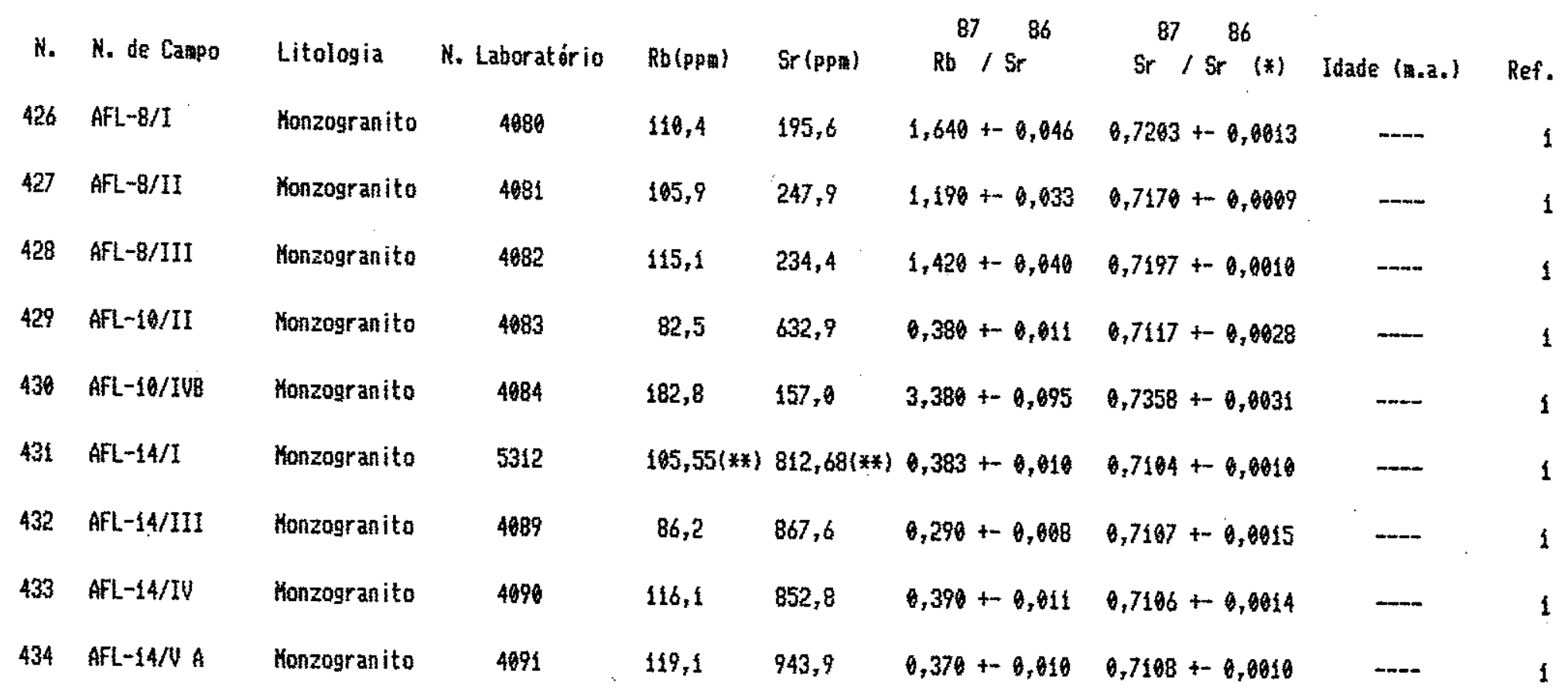

8) Suite Intrusiva Saibro (Granito Santa Juliana): 
Tabela 30: Determinąôes radiouétricas do Membro Hiląr io (For aacâo Maricá).

A) Anál ises $R b-S r$ :

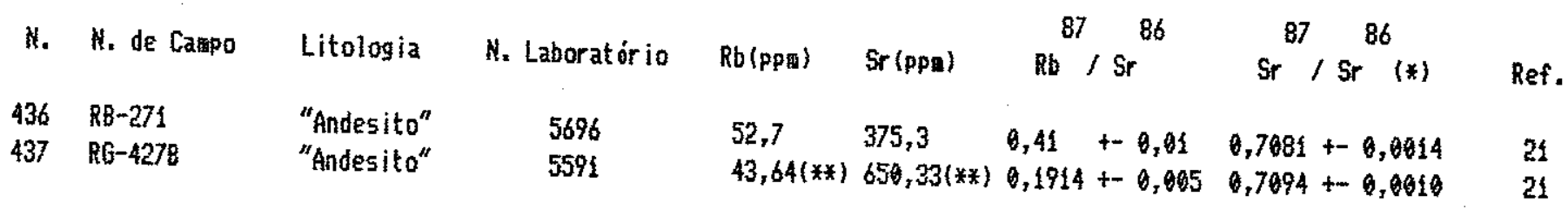

B) Análises $\mathrm{K}-\mathrm{Ar}$ :

\begin{tabular}{|c|c|c|c|c|c|c|c|c|c|}
\hline$N_{*}$ & N. de Ca那o & Litologia & Raterial & N. Laboratório & ZK & Ar $\operatorname{rad}(\mathrm{cc}$ STP/g) & ZAr atm & Idade (n.a. & Ref. \\
\hline 438 & 150 & "Andesito" & RT & 1651 & & $=x^{-6}$ & & & \\
\hline & & & & 2001 & $48+872$ & $\begin{array}{r}30,28 \times 10 \\
-6\end{array}$ & 3,67 & $519+-26$ & 16 \\
\hline 439 & $6 A^{2}-2-R S$ & "Andesito" & RT & 533 & 1,6540 & $\begin{array}{r}39,86 \times 10 \\
-6\end{array}$ & 13,63 & $533+-14$ & 10 \\
\hline 440 & $G A-2-R S$ & "Andesito" & RT & 461 & $2,245 i$ & $51,73 \times 10$ & 8,73 & $513+16$ & 10 \\
\hline 441 & $G A-2-R S$ & "Andesito" & Feldspato & 499 & 1,0440 & $23,87 \times 10$ & 44,60 & $510+-15$ & 10 \\
\hline 442 & VL $-9-7-67$ & "Andesito" & $R T$ & 1350 & 1,6803 & $\begin{array}{r}25,59 \times 10 \\
-6\end{array}$ & 25,13 & $525+-24$ & 10 \\
\hline 443 & $2 / 525$ & Hornfels & RT & 492 & 2,1920 & $\begin{array}{r}57,06 \times 10 \\
-6\end{array}$ & 19,91 & $570+-12$ & 10 \\
\hline 444 & $P-224$ & "Andesito" & Plagioclásio & 3213 & 0,7450 & $17,06 \times 10$ & 15,59 & $510+8$ & 18 \\
\hline 445 & $B L-6$ & Basalto & RT & 3995 & 1,1885 & $\begin{array}{r}13,41 \times 10 \\
-6\end{array}$ & 3,36 & $269+5$ & 5 \\
\hline 446 & RS-17 & Lampr of iro & RT & 2342 & 1,6592 & $21,83 \times 10$ & 3,81 & $465+-20$ & 6 \\
\hline
\end{tabular}


Tabela 31: Deterninarâes radiowétricas da Foraacão Acampamento Velho.

A) Análises Rb-Sr:

\begin{tabular}{|c|c|c|c|c|c|c|c|c|c|}
\hline & & & & & & $87 \quad 86$ & $87 \quad 86$ & & \\
\hline N. & N. de Caspo & Litologia & N. Laborat ór io & Rb(pp喟) & $5 r(\mathrm{PP})$ & $\mathrm{Rb} / \mathrm{Sr}$ & $\mathrm{Sr} / \mathrm{Sr} \quad(*)$ & Idade $\left(a \times a_{n}\right)$ & Ref. \\
\hline 447 & $H H-247$ & Riolito & ---- & 151,4 & 3,9 & 80,60 & 1,3162 & $-\cdots$ & 3 \\
\hline 448 & $\mathrm{HH}-265 \mathrm{~A}$ & Riolito & -- & 84,8 & 94,6 & 2,60 & 0,7234 & $497+59$ & 3 \\
\hline 449 & $\$ H-2658$ & Rinlito & $\cdots$ & 96,7 & 186,7 & 1,55 & 0,7199 & -... & 3 \\
\hline 450 & HH-274 & Riolito & -- & 126,1 & 9,8 & 32,9 & 0,9578 & $-\cdots$ & 3 \\
\hline 451 & $\mathrm{HH}-275$ & Riolito & $\cdots$ & 99,6 & 4,6 & 48,7 & 1,8101 & $\cdots$ & 3 \\
\hline 452 & LK-369.1 & Riolito & 5697 & 69,6 & 186,1 & $1,08+-6,63$ & $0,7134+-0,0017$ & -- & 21 \\
\hline 453 & CT6 (1) & Riolito & --- & 71,0 & 18,0 & $11,565+0,326$ & $0,78609+-0,06119$ & $495+-20$ & 18 \\
\hline 454 & CT38 (1) & Riolito & $\cdots$ & 81,1 & 14,2 & $16,718+0,475$ & $0,82189+0,00105$ & $491+-17$ & 18 \\
\hline
\end{tabular}

B) Análises K-Ar:

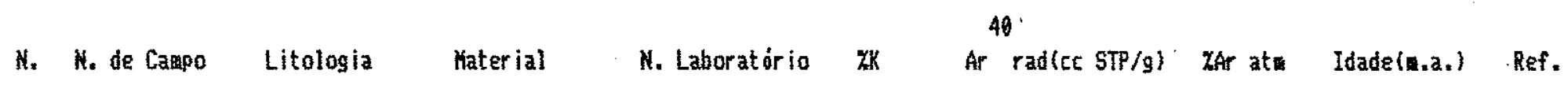

$\begin{array}{llllllllll}455 & 2 / 433 & \text { Ignimbrito } & \text { RT } & 494 & 4,0370 & 92,96 \times 10^{-6} & 7,73 & 512+9 & 10 \\ 456 & \text { RL-11-7-67 } & \text { Ignimbrito } & \text { RT } & 1066 & 4,1460 & 110,6 \times 10^{-6} & 2,94 & 582+11 & 10 \\ 457 & \text { BL-3B (?) } & \text { Riodacito } & \text { RT } & 3993 & 2,7000 & 68,09 \times 10^{-6} & 1,23 & 554+10 & 5 \\ 458 & \text { BL-3B (?) } & \text { Riodacito } & \text { Plagioclásio } & 3994 & 1,5230 & 39,05 \times 10^{-6} & 2,50 & 563+13 & 5\end{array}$,

(1) Pontos ja listados na tabela $23 \mathrm{C}$. 
Tabela 32: Determinacôes radionétricas ea sedimentitos aolássicos do Escudo Sul-rio-grandense.

A) Análises K-Ar e argilas do Meabro Mangueirâo (For maç̃o Maricá):

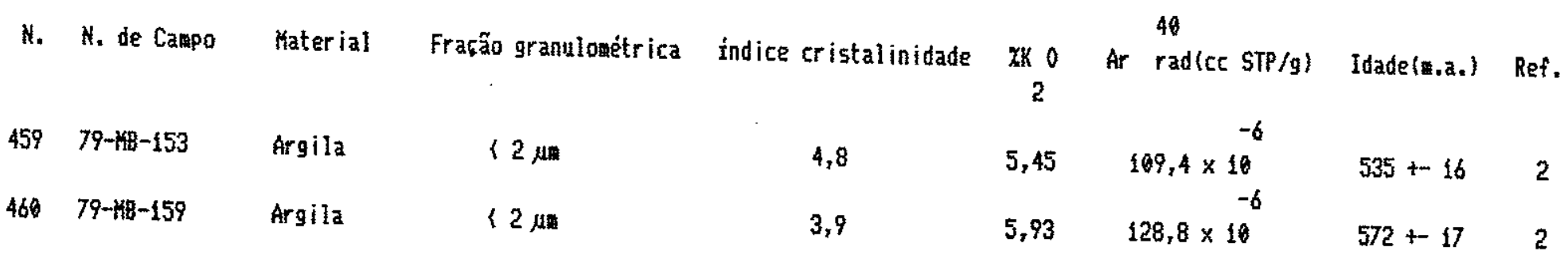

B) Análises K-Ar en argilas da Formação Guaritas:

\begin{tabular}{|c|c|c|c|c|c|c|c|c|}
\hline & & & & & & -6 & & \\
\hline 461 & $79-18-163$ & Argila & (2 2 期 & 8,7 & 5,36 & $186,2 \times 10$ & $529+16$ & 2 \\
\hline 462 & $79-18-167$ & Argila & $\{2$ \} & 8,1 & 6,02 & $117,9 \times 10$ & $524+16$ & 2 \\
\hline
\end{tabular}

C) Anál işes K-Ar em argilas associadas aos fillôes aupriferos da Hina Camaquã:

\begin{tabular}{|c|c|c|c|c|c|c|c|c|}
\hline & & & & & & & & \\
\hline 463 & $79-9 B-168$ & & & & & -6 & & \\
\hline & 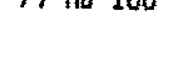 & Argila-zona seca & $r 2 \mu$ & 7,2 & 7,81 & $131,8 \times 10$ & $457+-11$ & 2 \\
\hline 464 & " & $"$ & $\{0,2\}$ 拥 & nẫo determinado & 7,35 & $124,2 \times 10^{\circ}$ & $460+-11$ & 2 \\
\hline 465 & $"$ & " & $0,2-0,8$ in & não deterninado & 8,24 & $140,8 \times 10^{-6}$ & & 3 \\
\hline & $"$ & $\|$ & & & & -6 & $464+11$ & \\
\hline 466 & & $"$ & $0,5-2$, nn & 5,1 & 8,26 & $\{44,7 \times 10$ & $474+11$ & 2 \\
\hline 467 & $79-168-169$ & $"$ & $\{2$ на & 6,1 & 7,93 & $138,8 \times 10^{-6}$ & $474+-11$ & 2 \\
\hline 468 & $79-188-170$ & $"$ & $\{2 \mu$ & & & -6 & & \\
\hline & & & $\gamma 2$ 晒 & 6,6 & 7,82 & $\begin{array}{r}133,7 \times 16 \\
-6\end{array}$ & $464+-11$ & 2 \\
\hline 469 & $79-1+18-17 i$ & $\begin{array}{l}\text { Argila-zona de } \\
\text { circulacâo de HO }\end{array}$ & $\{2$ un & não determinado & 4,99 & $72,4 \times 10$ & $401+-10$ & 2 \\
\hline 470 & $"$ & 2 & & & & -6 & & \\
\hline & & & $\{0,2, \mu$ & nẫo determinado & 4,89 & $\begin{array}{r}72,4 \times 10 \\
-6\end{array}$ & $409+-10$ & 2 \\
\hline 471 & $"$ & $"$ & $0,2-0,5 \mu$ & & 5,49 & $68,4 \times 10$ & $350+8$ & 2 \\
\hline 472 & $n$ & $"$ & $0,5-2 \mu$ & 7,1 & 5,46 & $72,5 \times 10$ & $371+-9$ & 2 \\
\hline
\end{tabular}


Tabela 33: Deterainaçōes radionétricas de granitóides das "ilhas cristalinas" de Aceguá a Rivera.

A) Análises K-Ar de granitóides de Aceguá:

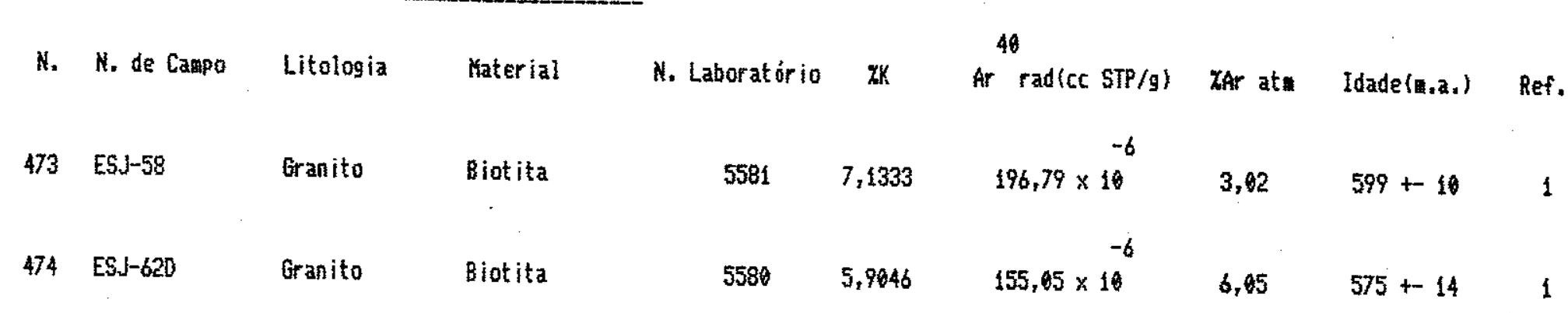

B) Análises Rb-Sr de granitóides de Aceguá:

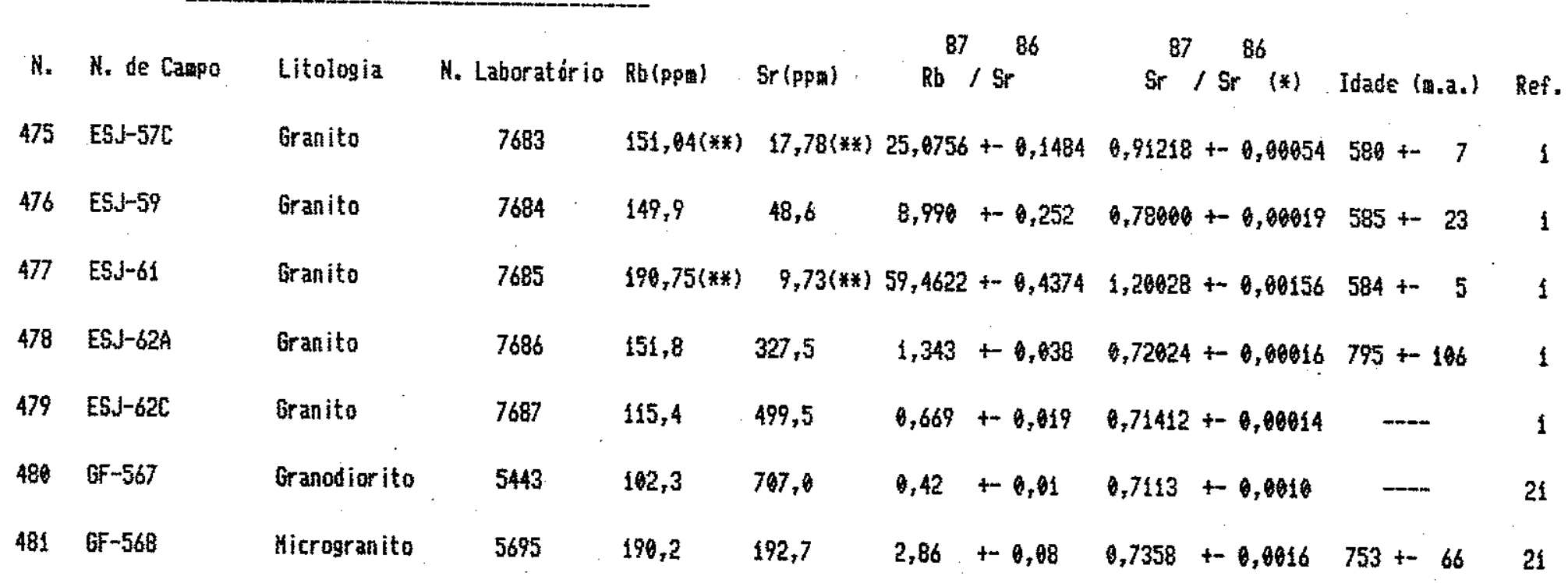


Tabela 33: Determinacões radionétricas de granitúides das "ilhas cristalinas" de Aceguá e Rivera.

C) Análises K-Ar de granitóides de Rivera:

\begin{tabular}{|c|c|c|c|c|c|c|c|c|c|}
\hline \multirow[b]{2}{*}{$N=$} & \multirow[b]{2}{*}{ N. de Campo } & \multirow[b]{2}{*}{ Litologia } & \multirow[b]{2}{*}{ Material } & \multirow[b]{2}{*}{ N. Laborat or io } & \multicolumn{2}{|r|}{40} & \multirow[b]{2}{*}{ zar at } & \multirow[b]{2}{*}{ Idade(a.a.) } & \multirow[b]{2}{*}{ Ref. } \\
\hline & & & & & 张 & Ar $\mathrm{rad}(\mathrm{ccc}$ STP/g) & & & \\
\hline & & & & & & -6 & & & \\
\hline 482 & $E S J+85$ & Granito catacl. & Biotita & 5579 & 0,5712 & $\begin{array}{r}8,92 \times 16 \\
-6\end{array}$ & 58,18 & $366+-31$ & 2 \\
\hline 483 & ESJ-76 & Granito & Biotita & 5578 & 4,7737 & $\begin{array}{r}13,90 \times 10 \\
-6\end{array}$ & 50,99 & $414+29$ & 1 \\
\hline 484 & $E S J-8 B C$ & Granito porfir. & Biotita & 5577 & 2,6727 & $\begin{array}{r}47,94 \times 10 \\
-6\end{array}$ & 9,43 & $515+-11$ & 1 \\
\hline 485 & ES.J-82 & Microgranito & $R T$ & 5683 & 2,8056 & $\begin{array}{r}66,00 \times 10 \\
-6\end{array}$ & 9,87 & $523+-13$ & $\mathfrak{i}$ \\
\hline 486 & $E S\}-84$ & Vulc, básica & $R T$ & 5684 & 2,3101 & $\begin{array}{r}56,83 \times 18 \\
-6\end{array}$ & 9,49 & $537+-15$ & 1 \\
\hline 487 & ESJ -89 & Vule: básica & RT & 5685 & 2,5496 & $\begin{array}{r}61,79 \times 10 \\
-6\end{array}$ & 4,01 & $536+-11$ & 1 \\
\hline 488 & $E S J-1618$ & Hetagranitóide & Plagioclásio & 5582 & 3,8415 & $\begin{array}{r}189,73 \times 10 \\
-6\end{array}$ & 2,91 & $968+-14$ & 1 \\
\hline 489 & ESJ-65 & Hetagranitóide & Plagioclásio & 5575 & 3,7414 & $\begin{array}{r}180,38 \times 10 \\
-6\end{array}$ & 2,74 & $946+-31$ & 1 \\
\hline 490 & ESJ-106B & Tonalito & Plagioclásio & 5583 & 0,6996 & $\begin{array}{r}15,68 \times 10 \\
-6\end{array}$ & 26,98 & $507+-12$ & 1 \\
\hline 491 & $E S J-1068$ & Tonalito & Hornblenda & 5611 & 0,1042 & $2,79 \times 10$ & 51,18 & $586 \div-22$ & 1 \\
\hline 492 & ESJ-111A & Granodior ito & Plagioclásio & 5573 & 0,4881 & $\begin{array}{r}13,68 \times 10 \\
-6\end{array}$ & 19,83 & $584+15$ & 1 \\
\hline 493 & ESJ-IIIA & Granodior ito & Biotita & 5574 & 6,7434 & $\begin{array}{r}179,83 \times 10 \\
-6\end{array}$ & 7,89 & $580+8$ & $i$ \\
\hline 494 & ESJ-\{1IB & Granodiorito & Plagioclásio & 5587 & 2,7650 & $\begin{array}{r}68,27 \times 10 \\
-6\end{array}$ & 14,20 & $499+-12$ & 1 \\
\hline 495 & ESS-111B & Granodior ito & Biotita & 5588 & 5,5716 & $\begin{array}{r}146,84 \times 10 \\
-6\end{array}$ & 8,24 & $576+-10$ & 1 \\
\hline 496 & $E S J-112 A$ & Diorito & Biotita & 5569 & 6,2300 & $\begin{array}{r}165,06 \times 10 \\
-6\end{array}$ & 2,28 & $579+20$ & 1 \\
\hline 497 & ESJ-112B & Diorito & Biotita & 5572 & 1,7273 & $27,57 \times 10$ & 18,35 & $370+7$ & \\
\hline
\end{tabular}


Tabela 33: Deterninąôes radioaétricas de granitóides das "ilhas cristalinas" de Aceguá e Rivera.

D) Análises Rb-Sr de granitóides de Rivera:

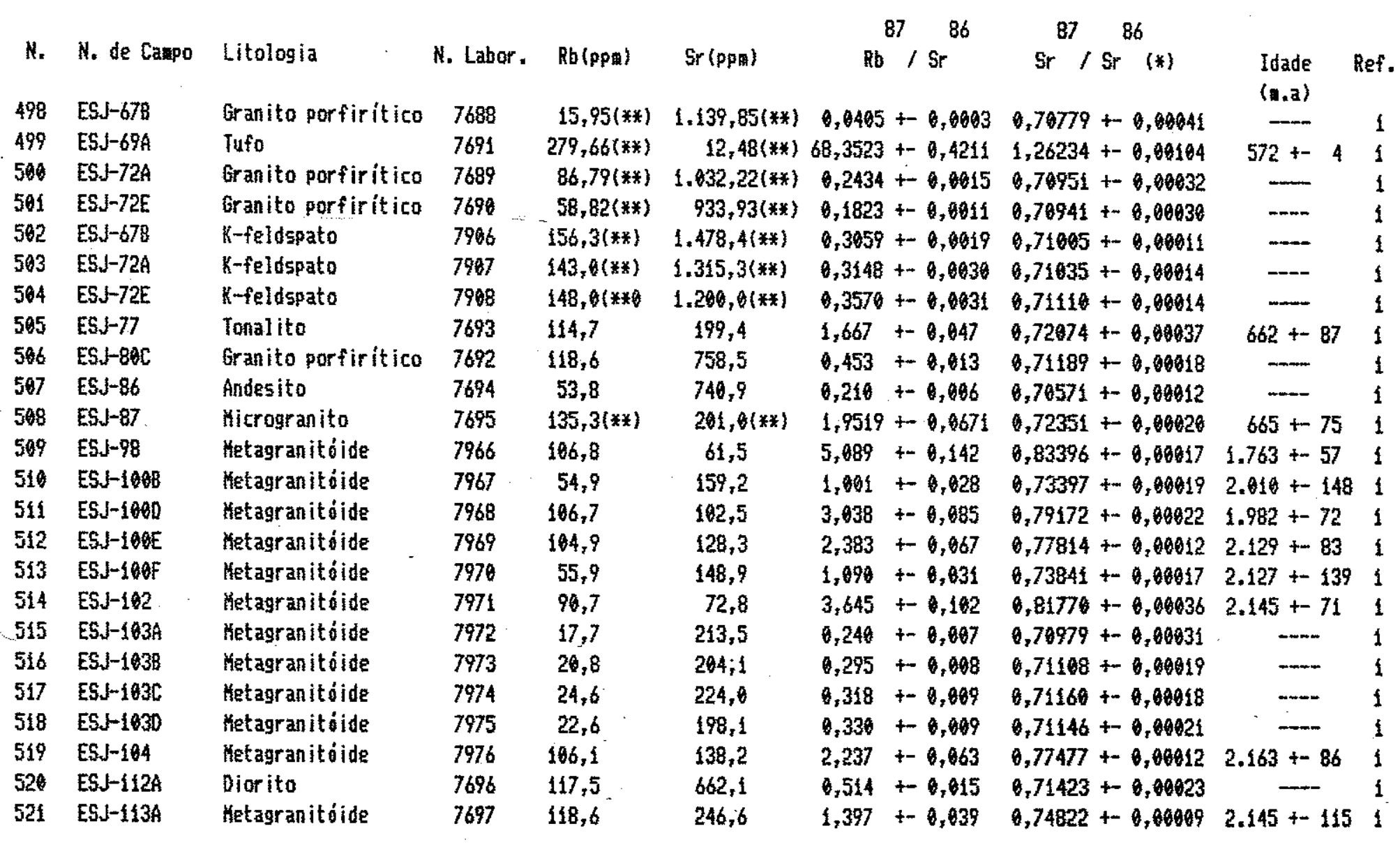


Tabela 34: Deterainacôes dos teores de Rb e de Sr, por fluorescência de raios-X e por diluição isotópica, rẹalizadas, respectivamente, no CPGeo-IG/USP e na Universidade do Texas, em Dallas, ell amostras do Escudo Sul-rio-grandense, conforme Halpern et al. (1974).
H. zmostra
Rb(ppa)
$\operatorname{Sr}(\mathrm{ppE})$
$n s(\mu \mathrm{m} / \mathrm{g})$
$\operatorname{Sr}(\mu \omega / g)$
(Fluor. raios-X* An. Guant.) (diluicåo isotópica)

\begin{tabular}{|c|c|c|c|c|}
\hline 208 & 321,8 & 1,0 & $\{, 051$ & 0,0937 \\
\hline $210 \mathrm{~A}$ & 143,4 & 438,8 & - & - \\
\hline $216 \mathrm{~B}$ & 136,1 & 401,5 & ----- & ---..-- \\
\hline $21 \mathrm{AA}$ & - & --- & 6,871 & 0,368 \\
\hline $211 B$ & 302,5 & 350,6 & $\cdots$ & -..-- \\
\hline 212 & 228,0 & 350,0 & 0,740 & $8,393$. \\
\hline 213 & 181,5 & 23,6 & 0,589 & 0,0272 \\
\hline 214 & $\cdots$ & - & 0,642 & 0,345 \\
\hline $215 \mathrm{~A}$ & 151,0 & $484, \frac{1}{2}$ & 0,490 & 6,544 \\
\hline $215 c$ & 116,8 & 178,9 & 0,379 & 0,201 \\
\hline 2150 & 26,8 & 215,4 & 0,087 & 0,242 \\
\hline 215E & 319,2 & 186,9 & $\{, 84$ & 0,209 \\
\hline 216 & 61,4 & 935,0 & 0,199 & 1,65 \\
\hline $217 \mathrm{~B}$ & 220,5 & 338,3 & 9,716 & 0,380 \\
\hline $218 \mathrm{~A}$ & 142,8 & 344,3 & 0,464 & 6,387 \\
\hline $218 \mathrm{C}$ & 157,4 & $\{82,0$ & 0,511 & 0,204 \\
\hline 2190 & $163 ; 5$ & 9,0 & $\theta, 531$ & 0,6113 \\
\hline 2268 & 64,8 & 960,0 & 0,210 & 1,08 \\
\hline 2200 & 152,1 & 218,8 & 0,494 & 6,246 \\
\hline $226 E$ & 76,3 & 187,5 & 0,248 & 0,211 \\
\hline 2200 & 163,5 & 453,2 & 0,531 & 0,509 \\
\hline 2218 & 216,8 & 270,9 & 6,684 & 0,364 \\
\hline $221 \mathrm{C}$ & 217,3 & 145,6 & 6,706 & 0,163 \\
\hline
\end{tabular}


(Cont inuąão)

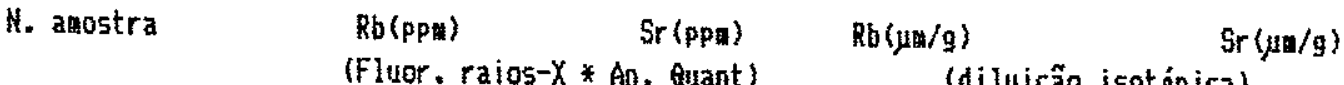

\begin{tabular}{|c|c|c|c|c|}
\hline 222 & 169,3 & 167,9 & 0,550 & 0,188 \\
\hline $223 \mathrm{~A}$ & 162,9 & 297,7 & 0,529 & $\$, 334$ \\
\hline 2238 & ---- & $-\cdots$ & 0,439 & 0,345 \\
\hline $223 C$ & 196,4 & 295,6 & 6,618 & 0,332 \\
\hline 224 & $\{36,7$ & 435,8 & 6,444 & 0,152 . \\
\hline $225 \mathrm{~A}$ & $\{57,5$ & 642,0 & 0,511 & 0,722 \\
\hline $226 \mathrm{~A}$ & $\{83,1$ & 357,0 & 0,594 & 6,404 \\
\hline $226 C$ & 227,6 & 156,9 & 0,739 & 0,176 \\
\hline 228 & 161,8 & 194,3 & 0,525 & 0,218 \\
\hline 231 & 149,0 & 252,9 & 0,484 & 0,284 \\
\hline 234 & 263,9 & 177,6 & 0,662 & 0,199 \\
\hline $236 \mathrm{~A}$ & 1,5 & 2,2 & 0,0008 & 6,6027 \\
\hline $236 \mathrm{~B}$ & $1, \theta$ & 88,5 & $\theta, 063$ & 0,100 \\
\hline $237 B$ & 39,5 & 476,6 & 0,128 & 0,536 \\
\hline $237 \mathrm{C}$ & 67,1 & 587,6 & 0,218 & 0,660 \\
\hline 2370 & 28,2 & 880,0 & 0,692 & 6,990 \\
\hline $237 \mathrm{E}$ & 41,1 & 420,0 & 0,133 & 0,472 \\
\hline 239 & 22,8 & 915,0 & 0,074 & 1,03 \\
\hline 240 & ---- & --.-- & 0,350 & 6,980 \\
\hline 243 & 2,5 & 646,0 & 0,098 & 6,726 \\
\hline 244 & 127,2 & 266,2 & 0,413 & 6,299 \\
\hline 245 & 132,8 & 56,4 & 6,455 & 0,090 \\
\hline 246 & 146,1 & 80,2 & 0,431 & 0,8634 \\
\hline 247 & 151,4 & 3,9 & 0,492 & 0,0061 \\
\hline 256 & 83,5 & 91,9 & 0,271 & 0,103 \\
\hline 252 & 84,9 & 286,6 & 0,276 & 0,232 \\
\hline
\end{tabular}


(Cont inuaxão)

H. anostra

2538

2530

$254 \mathrm{~A}$

255

$257 \mathrm{~A}$

2570

258

260

262

263

$264 \mathrm{~A}$

$265 A$

266

$267 \mathrm{~A}$

268

271

272

273

274

275

$276 \mathrm{C}$

$278 \mathrm{~A}$

$278 B$
Rb $\langle p p a\rangle$

(Fluor raios- $X *$ An

46,2

54,3

20,6

18,1

$\frac{61,5}{26,7}$

25,7
130,9

130,0

76,6
164,6

76,7

84,8

197,6

239,3

184,9

96,3

126,7

126,7

90,6

2,0

1,8

264,2

209,6

$\begin{array}{rl}518,6 & 0,150 \\ 390,8 & 0,176 \\ 920,0 & 0,667 \\ 824,0 & 0,0405 \\ 268,6 & 0,200 \\ -770,0 & 0,130 \\ 397,3 & 0,687 \\ 28,3 & 0,6834 \\ 515,0 & 0,579 \\ 9,0 & 0,229 \\ 383,9 & 0,532 \\ 94,6 & 0,230 \\ 14,1 & 0,275 \\ 39,9 & 0,640 \\ 43,6 & 0,777 \\ 191,7 & 0,600 \\ 20,313 \\ 92,7 & 0,438 \\ 9,8 & 0,414 \\ 4,6 & 0,411 \\ 885,0 & 0,351 \\ 735,6 & 0,0965 \\ 72,8 & 0,0058 \\ 20,1 & 0,681\end{array}$

$\operatorname{sr}(\mu \mathrm{n} / \mathrm{g})$

(diluifáo isotópica)

0.583

0,440

1,034

0,927

0,301

0,998

0,866

0,345

6,8315

0,422

0,8113

0,432

0,106

0,0177

0,0443

0,0486

0,215

0,113

0,104

0,0125

0,0072

0,996

0,827

0,6811

0,0238 (cont inua) 
(Cont inuação)

N. amostra

$278 C$
279
280
281
282
283
285
286
287
288
289
291
292
293
294

$R b$ (PPM)

(Fluor. raios- $X *$ An.

225,3

5,4

296,8

410,4

365,8

338,2

343,8

186,8

379,0

248,8

335,0

434,6

292,6

362,0
$\operatorname{Sr}$ (ppa)

$\mathrm{Rb}(\mu \mathrm{a} / \mathrm{g})$

(diluiç̃o isotópica)

$\begin{array}{ll}0,731 & 0,0181 \\ 0,0175 & 0,189 \\ 0,426 & 0,534 \\ 0,964 & 0,103 \\ 1,332 & 0,0826 \\ 0,993 & 0,182 \\ 1,10 & 0,286 \\ 1,12 & 0,0337 \\ 0,606 & 0,562 \\ 1,23 & 0,181 \\ 0,808 & 0,0833 \\ 1,00 & 1,34 \\ 1,41 & 1,18 \\ 0,948 & 1,97 \\ 1,18 & 1,69\end{array}$

